\title{
UM SISTEMA DE SUPORTE À DECISÃO NA INTERNET PARA O PLANEJAMENTO DA MOBILIDADE URBANA
}

Orientador: Prof. Assoc. Antônio Nélson Rodrigues da Silva

Tese apresentada à Escola de Engenharia de São Carlos da Universidade de São Paulo, como parte dos requisitos para a obtenção do título de Doutor em Engenharia Civil: Transportes. 
AUTORIZO A REPRODUÇÃO E DIVULGAÇÃO TOTAL OU PARCIAL DESTE TRABALHO, POR QUALQUER MEIO CONVENCIONAL OU ELETRÔNICO, PARA FINS DE ESTUDO E PESQUISA, DESDE QUE CITADA A FONTE.

Ficha catalográfica preparada pela seção de Tratamento da Informação do Serviço de Biblioteca - EESC/USP

\footnotetext{
Magagnin, Renata Cardoso

Um Sistema de Suporte à Decisão na internet para o planejamento da Mobilidade Urbana / Renata Cardoso Magagnin; orientador Antônio Nélson Rodrigues da Silva. -- São Carlos, 2008.

Tese (Doutorado) - Programa de Pós-Graduação em Engenharia Civil: Transportes -- Escola de Engenharia de São Carlos da Universidade de São Paulo.
}

1. Mobilidade urbana. 2. Sistema de suporte à decisão. 3. Planejamento. 4. Internet. I. Título. 
Dedico este trabalho a meus pais Wilson e Claudeti pelo incentivo e apoio aos estudos.

A meus irmãos André e Thiago pelo apoio durante o desenvolvimento desta pesquisa. 


\section{AGRADECIMENTOS}

Agradeço primeiramente a Deus pela saúde e força nos momentos de desânimo ao longo desta Tese e por ter colocado no meu caminho algumas pessoas especiais que contribuíram para meu crescimento pessoal e intelectual.

Ao orientador Prof. Associado Antônio Nélson da Silva, pela amizade, compreensão, incentivo e apoio fundamentais para a realização desta pesquisa.

Ao Prof. Dr. Rui António Rodrigues Ramos, pela oportunidade do Estágio na Universidade do Minho (Portugal) e pela amizade.

À Universidade de São Paulo - USP que possibilitou a realização deste Doutorado.

Aos professores do Departamento de Transportes pelos ensinamentos transmitidos.

À Prof $^{\mathrm{a}}$ Dr $^{\mathrm{a}}$. Márcia Helena Macedo pela contribuição para o desenvolvimento desta pesquisa.

Aos amigos de pós-graduação Fabiana, Marcela, Simone, Gustavo, Andréa Júlia, Fabíola, Vanessa e Alexandra pela amizade.

Aos colegas da Universidade do Minho que tornaram minha permanência em Portugal mais agradável, de modo especial Ligia, Daniel, Prof. José Mendes e Vânia Barcelos.

Aos funcionários do Departamento de Transportes, em especial à Heloísa, Bete, Toco e Magali, pela amizade, atenção e pelos inúmeros serviços prestados;

À Universidade Estadual Paulista - UNESP, a Faculdade de Arquitetura, Artes e Comunicação e o Departamento de Arquitetura, Urbanismo e Paisagismo pela disponibilidade para o desenvolvimento desta pesquisa.

Aos colegas do Departamento de Arquitetura, Urbanismo e Paisagismo da Faculdade de Arquitetura, Artes e Comunicação - FAAC, da Universidade Estadual Paulista - UNESP.

As amigas Léa, Mitsue, Silvana, Emília e Solange pelo incentivo e compreensão.

A todos os profissionais e especialistas que participaram do processo de avaliação do sistema proposto neste trabalho, em especial aos profissionais da Prefeitura Municipal de Bauru (SEPLAN - em especial a Arquiteta Maria Helena Carvalho Rigitano, EMDURB), pesquisadores da Universidade Estadual Paulista - UNESP - Campus de Bauru pela paciência, disponibilidade e atenção despendida;

Aos meus familiares que incentivaram direta ou indiretamente para a realização desta pesquisa.

Agradeço a todos aqueles que, de alguma forma direta ou indiretamente contribuíram para o desenvolvimento desta pesquisa. 


\section{SUMÁRIO}

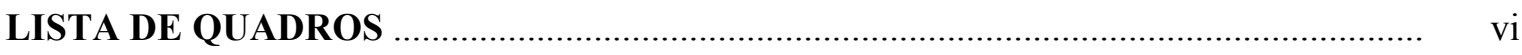

LISTA DE FIGURAS ….............................................................................. ix

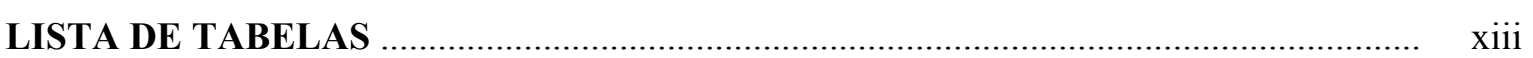

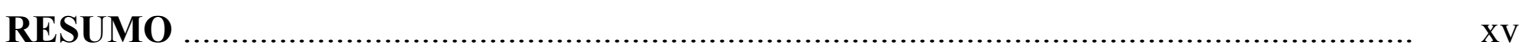

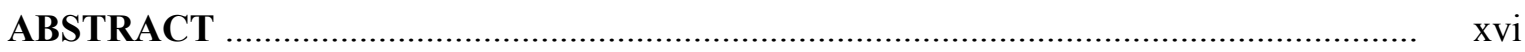

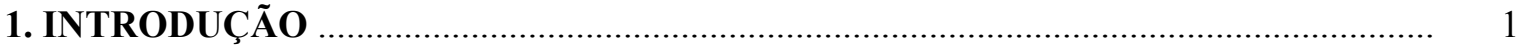

1.1 Caracterização do Problema .......................................................................................... 1

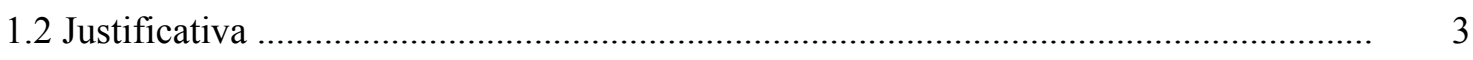

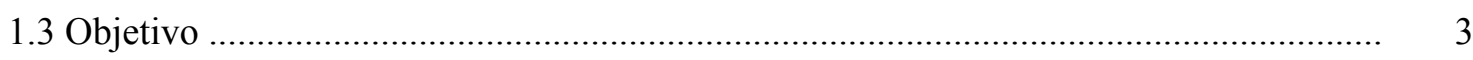

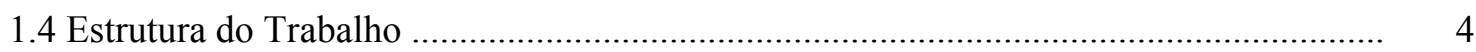

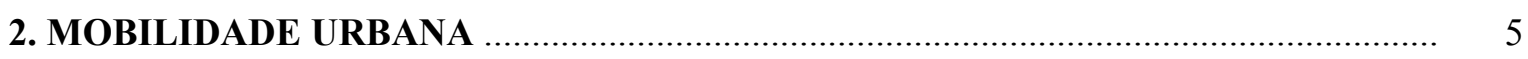

2.1 Mobilidade Urbana ........................................................................................ 5

2.2 Política de Mobilidade Urbana no Brasil .................................................................. 10

2.3 Plano Diretor de Mobilidade Urbana ....................................................................... 13

3. PLANEJAMENTO PARTICIPATIVO _.................................................................. 18

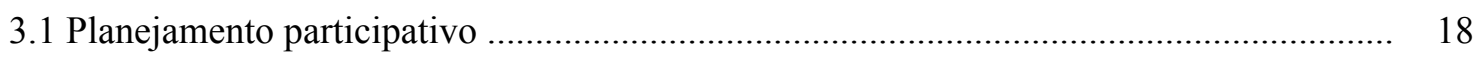

3.2 O planejamento participativo no Brasil ................................................................... 23

3.3 Planejamento participativo na internet ……............................................................. 28

4. SISTEMA DE SUPORTE À DECISÃO E INTERNET …......................................... 33

4.1 A tomada de decisão no processo de planejamento ........................................................ 33

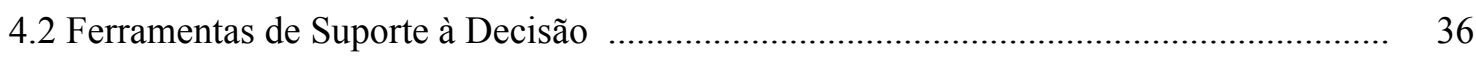

4.2.1 Sistemas de Informações Geográficas - SIG ................................................... 37

4.2.2 Sistemas de Suporte à Decisão - DSS ............................................................. 38

4.2.3 Sistemas de Suporte ao Planejamento - PSS ...................................................... 39

4.2.4 Sistemas de Suporte à Decisão Espacial - SDSS .................................................. 40

4.3 Sistema de Suporte à Decisão Espacial no Planejamento Urbano e de Transportes ...... 43

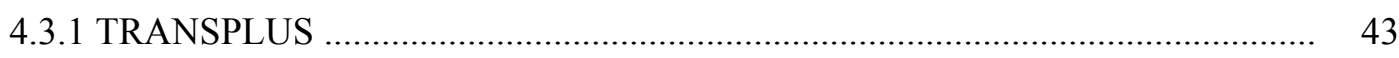

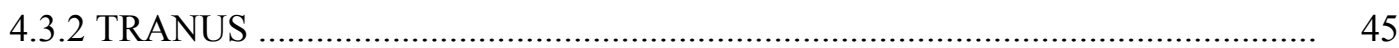


4.4 Principais aplicações de SDSS na internet ………..................................................... 46

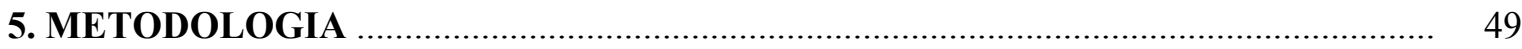

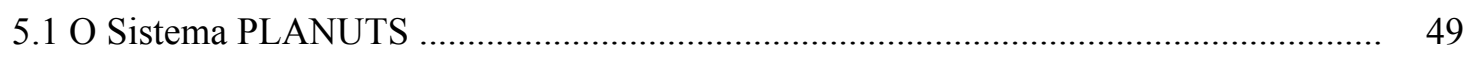

5.1.1 Arquitetura do sistema ........................................................................... $\quad 50$

5.2 A estrutura das informações no PLANUTS ................................................................ 52

5.2.1 Estrutura dos Indicadores ........................................................................... 54

5.2.2. Definição da Fonte e do Formato dos Dados ...................................................... 56

5.3 Métodos para Análise dos Resultados ........................................................................ 57

5.3.1 Avaliação interna do sistema PLANUTS .......................................................... 58

5.3.2 Avaliação dos resultados obtidos em cada módulo ............................................... 61

5.3.3 Avaliação da contribuição do sistema para ampliação do conhecimento sobre a questão da mobilidade urbana

6. PLANUTS - SISTEMA DE SUPORTE À DECISÃO NA INTERNET PARA O PLANEJAMENTO DA MOBILIDADE URBANA ……............................................. 78

6.1 Concepção do sistema PLANUTS ............................................................................. 78

6.2 Princípios do sistema PLANUTS ........................................................................... 79

6.3 Detalhamento do Sistema PLANUTS …………….................................................. 79

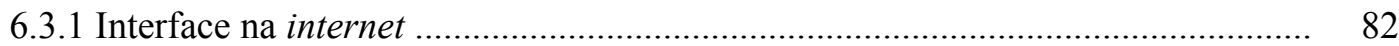

6.3.2 Módulo de Avaliação da Mobilidade Urbana ........................................................ 82

6.3.2.1 Caracterização Geral ...................................................................................... 84

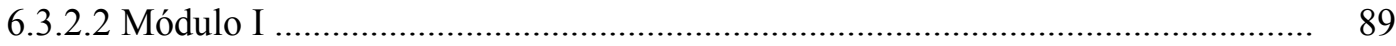

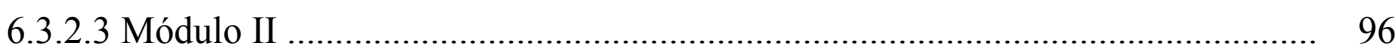

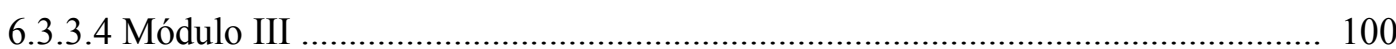

6.3.3.5 Proposta para o Módulo IV .................................................................................. 110

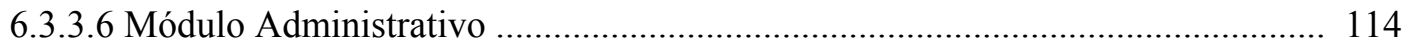

6.4 Utilização do sistema PLANUTS no Plano Diretor de Transportes e Mobilidade ......... 121

6.4.1 O processo participativo no sistema PLANUTS .................................................. 121

7. IMPLEMENTAÇÃO DO SISTEMA PLANUTS ......................................................... 134

7.1 Estudo de caso: o município de Bauru e a questão da Mobilidade Urbana .................... 136

7.2 Implantação do sistema - aplicação no Município de Bauru ........................................... 139

7.2.1 Detalhamento da implantação do sistema PLANUTS ........................................... 143

7.2.2 Resultado da aplicação do Sistema PLANUTS - teste piloto ............................... 151

8. APRESENTAÇÃO E ANÁLISES DOS RESULTADOS …......................................... 154

8.1 Avaliações referentes ao Módulo I .......................................................................... 154

8.2 Avaliações referentes ao Módulo II .................................................................... 165

8.3 Avaliações referentes ao Módulo III ..................................................................... 169

8.3.1 Problemas e soluções referentes a cada indicador ...................................... 169

8.3.2 Análise do Grau de Importância dos Indicadores ..................................... 177

8.3.2.1 Comparação entre a avaliação dos Temas e dos Indicadores ................... 180 
8.3.3 Análise do Grau de Urgência dos Indicadores

8.3.3.1 Comparação entre os resultados do ordenamento da Avaliação do Grau de Importância e Grau de Urgência para as Categorias

8.3.4 Localização dos problemas de Mobilidade por indicador e por região na cidade

8.4 Avaliação dos Questionários ................................................................................ 191

9. CONCLUSÕES E CONSIDERAÇÕES FINAIS ....................................................... 231

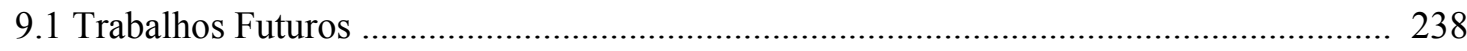

10. REFERÊNCIAS BIBLIOGRÁFICAS _.......................................................... 240

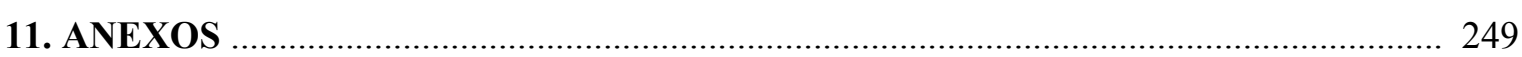

ANEXO 1 - Indicadores de Mobilidade Sustentável propostos por Costa (2003) ..................... 250

ANEXO 2 - Indicadores de Mobilidade Sustentável implantados no PLANUTS ...................... 253

ANEXO 3 - Definição das Categorias e Temas avaliados no Módulo I ....................................... 256

ANEXO 4 - Módulo I - Seqüência de Imagens referente às Categorias .................................... 258

ANEXO 5 - Definição dos Indicadores avaliados no Módulo II ................................................. 259

ANEXO 6 - Proposta de Lei referente à Mobilidade inserida no PDM .................................... 264

ANEXO 7 - Coeficiente de Correlação de Concordância de Kendall para as Categorias -

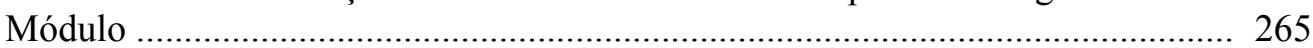

ANEXO 8 - Coeficiente de Correlação de Postos de Kendall para as Categorias ..................... 267

ANEXO 9 - Relação dos Problemas e Soluções avaliados no Módulo III ................................. 269

ANEXO 10 - Análises de Suporte à tomada de decisão em relação aos problemas avaliados

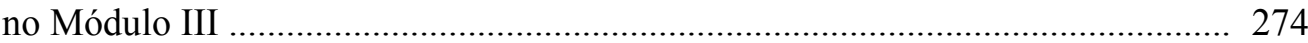

ANEXO 11 - Cálculo dos pesos dos indicadores por avaliador e por indicador - Grau de Importância (MÓDULO III) ................................................................................ 279

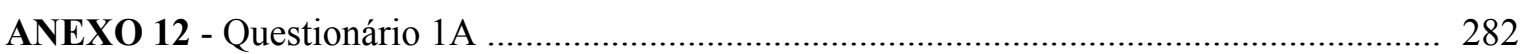

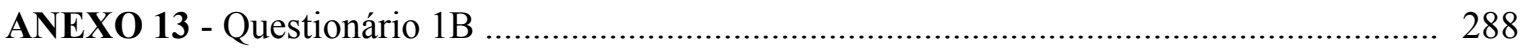

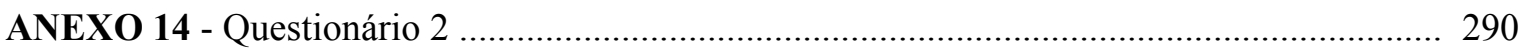




\section{LISTA DE QUADROS}

Quadro 2.1 - Princípios e diretrizes da Política Nacional de Mobilidade Urbana Sustentável .. 12

Quadro 3.1 - Grau de envolvimento popular no Processo de Tomada de Decisão ................... 21

Quadro 3.2 - Classificação dos problemas políticos e os tipos de planejamento ....................... 22

Quadro 4.1 - Combinações de processo de participação através de interferências de localização e horário dos envolvidos

Quadro 4.2 - Possibilidades de implementação de um sistema de participação popular utilizando SIG

Quadro 4.3 - Vantagens e desvantagens dos processos não-participativos e participativos nas políticas de TUS

Quadro 4.4 - SDSS: experiências internacionais

Quadro 5.1 - Definição dos elementos estruturais propostos para o sistema PLANUTS .

Quadro 5.2 - Definição dos elementos que permitiram estruturar o sistema PLANUTS

Quadro 5.3 - Quadro comparativo entre as Categorias e Temas definidos por Costa (2003) e a correspondente nomenclatura definida para o Sistema PLANUTS

Quadro 5.4 - Processo de definição dos Indicadores para o Sistema PLANUTS ..................... 56

Quadro 5.5 - Definição da estrutura dos Indicadores relacionados ao Tema Energia ............... 57

Quadro 5.6 - Avaliação Multicritério: Método da Escala de Pontos ........................................ 60

Quadro 5.7 - Cálculo do Índice de Correlação de Concordância de Kendall ........................... 62

Quadro 5.8 - Cálculo do Índice de Correlação de Postos de Kendall ......................................... 64

Quadro 5.9 - Questionário 1A - avaliação dos participantes especialistas antes da utilização do Sistema PLANUTS

Quadro 5.10 - Questionário 1B - avaliação dos participantes não-especialistas antes da utilização do Sistema PLANUTS

Quadro 5.11 - Questionário 2 - avaliação dos participantes dos participantes especialistas e não-especialistas após a utilização do Sistema PLANUTS

Quadro 6.1 - Descrição das páginas do sistema PLANUTS

Quadro 6.2 - Principais funções dos quatro Módulos de Avaliação da Mobilidade Urbana .....

Quadro 6.3 - Características gerais do Sistema PLANUTS ..................................................... 88

Quadro 6.4 - Características gerais do Módulo I …………...................................................... 95

Quadro 6.5 - Características gerais do Módulo II .................................................................. 100

Quadro 6.6 - Características gerais do Módulo III .................................................................. 109 
Quadro 6.7 - Características gerais do Módulo VI .............................................................. 113

Quadro 6.8 - Cadastro das informações no Módulo III ........................................................... 118

Quadro 6.9 - Etapas a serem cumpridas na elaboração do PlanMob ........................................ 122

Quadro 6.10 - Etapas a serem cumpridas na implantação do sistema PLANUTS .................... 124

Quadro 6.11 - Pesquisas e levantamentos sugeridas pela SeMob para cidades com população entre 250 a 500 mil habitantes

Quadro 6.12 - Levantamentos sobre a Mobilidade no município ………………….................. 129

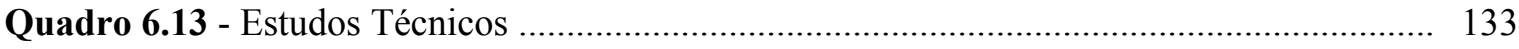

Quadro 7.1 - Principais problemas de mobilidade identificados na etapa de diagnóstico do Plano Diretor Municipal

Quadro 7.2 - Relação das atividades desenvolvidas no Curso de Capacitação

Quadro 7.3 - Etapas adotadas no curso de capacitação para a implantação do Sistema PLANUTS no Município de Bauru

Quadro 7.4 - Descrição das páginas do sistema PLANUTS ..................................................... 144

Quadro 7.5 - Pré-requisitos que podem comprometer o desempenho do Sistema PLANUTS . 152

Quadro 8.1 - Quadro resumo da variação das avaliações por grupo de avaliadores ................... 157

Quadro 8.2 - Quadro resumo das avaliações dos Temas .......................................................... 158

Quadro 8.3 - Ordenamento dos Temas por Grau de Importância - 10 primeiros colocados por grupo de avaliação

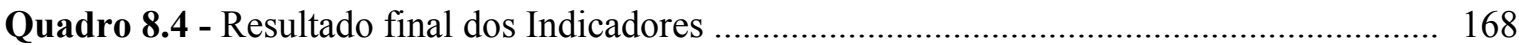

Quadro 8.5 - Quadro resumo dos problemas e soluções identificados pelos avaliadores ....... 170

Quadro 8.6 - Relação dos problemas e soluções apresentados para os Indicadores relacionados ao Tema Energia

Quadro 8.7 - Análises de Suporte à Tomada de Decisão em relação aos Problemas avaliados no Módulo III

Quadro 8.8 - Relação dos 10 primeiros indicadores Mais Importantes por grupo de avaliação 179

Quadro 8.9 - Resultado das avaliações dos Módulos I e III - Ordenamento dos Temas e Indicadores por grupo de avaliação

Quadro 8.10 - Relação dos 10 primeiros indicadores Mais Urgentes por grupo de avaliação .. 186

Quadro 8.11 - Análise da distribuição dos problemas de Mobilidade por Categoria (Região da Cidade com Problema relacionado ao indicador avaliado)

Quadro 8.12 - Questões em branco por avaliador - Questionário 1A

Quadro 8.13 - Questões em branco por avaliador - Questionário 1B

Quadro 8.14 - Comparação entre as avaliações dos Questionários 1A, 1B e 2

Quadro 8.15 - Transcrição e análise das respostas dos especialistas para a questão que trata da definição de Mobilidade Urbana nos Questionários 1A, 1B e $2 .$.

Quadro 8.16 - Transcrição e análise das respostas dos avaliadores para a questão que trata da identificação dos problemas de Mobilidade Urbana nos Questionários 1A e 2 .....

Quadro 8.17 - Transcrição e análise das respostas dos avaliadores para a questão que trata da identificação da existência de medidas para promover a melhoria da Mobilidade Urbana no município nos Questionários 1A e 2 
Quadro 8.18 - Transcrição e análise das respostas dos avaliadores para a questão que trata da identificação das medidas adotadas para promover a melhoria da Mobilidade Urbana no município nos Questionários 1A e 2

Quadro 8.19 - Transcrição e análise das respostas dos avaliadores para a questão que trata da identificação dos setores envolvidos com o Plano de Transporte e Mobilidade no município nos Questionários 1A e 2

Quadro 8.20 - Transcrição e análise das respostas dos avaliadores para a questão que trata da identificação das secretarias envolvidas com o Plano de Transporte e Mobilidade no município nos Questionários 1A e 2

Quadro 8.21 - Transcrição e análise das respostas dos avaliadores para a questão que trata da identificação dos principais Temas relacionados à política de Transporte e Mobilidade no município nos Questionários 1A e 2

Quadro 8.22 - Transcrição e análise das respostas dos avaliadores para a questão que trata da identificação da política municipal de Estacionamentos nos Questionários 1A e 2

Quadro 8.23 - Transcrição e análise das respostas dos avaliadores para a questão que trata da identificação da política municipal de Transporte Público nos Questionários $1 \mathrm{~A}$ e 2

Quadro 8.24 - Transcrição e análise das respostas dos avaliadores para a questão que trata da identificação da política municipal de Circulação nos Questionários 1 A e 2

Quadro 8.25 - Transcrição e análise das respostas dos avaliadores para a questão que trata da identificação da existência de um plano para a diminuição da poluição provocada pelos transportes no município nos Questionários 1A e 2

Quadro 8.26 - Transcrição e análise das respostas dos avaliadores para a questão que trata da identificação da existência de uma política de redução dos Níveis de Poluição nos Questionários 1A e 2

Quadro 8.27 - Transcrição e análise das respostas dos avaliadores para a questão que trata da identificação da existência de um plano para a diminuição dos níveis de ruído provocados pelos transportes no município nos Questionários 1A e 2

Quadro 8.28 - Transcrição e análise das respostas dos avaliadores para a questão que trata da identificação de medidas para a redução dos níveis de Ruído no município nos Questionários $1 \mathrm{~A}$ e 2

Quadro 8.29 - Transcrição e análise das respostas dos avaliadores para a questão que trata da identificação da existência de um plano para a redução dos pontos de Congestionamento no município nos Questionários 1A e 2

Quadro 8.30 - Transcrição e análise das respostas dos avaliadores para a questão que trata da identificação de medidas para a redução dos pontos de Congestionamento no município nos Questionários 1A e 2

Quadro 8.31 - Transcrição e análise das respostas dos avaliadores para a questão que trata da identificação do grau de conhecimento dos participantes sobre a existência de um Plano de Acessibilidade Municipal nos Questionários 1A e 2

Quadro 8.32 - Transcrição e análise das respostas dos avaliadores para a questão que trata da identificação da política de Acessibilidade no município nos Questionários 1A e 2

Quadro 8.33 - Transcrição e análise das respostas dos avaliadores para a questão que trata da adaptação de Pontos de ônibus nos Questionários 1A e 2

Quadro 8.34 - Transcrição e análise das respostas dos avaliadores para a questão que trata do envolvimento das secretarias municipais na política de Acessibilidade nos Questionários 1A e 2228

Quadro 9.1 - Problemas de Mobilidade apresentados nos Questionários 1A e 1B .................. 236

Quadro 9.2 - Problemas de Mobilidade apresentados no Questionário 2 ………….................. 236 


\section{LISTA DE FIGURAS}

Figura 2.1 - Círculo vicioso da degradação do transporte urbano

Figura 2.2 - Diagnóstico dos problemas urbanos que contribuem para a imobilidade das cidades

Figura 3.1 - Diferenças entre o processo de planejamento participativo e o tradicional

Figura 3.2 - Fases de um processo de planejamento participativo

Figura 3.3 - Regra da participação popular no planejamento urbano associado à organização política

Figura 3.4 - Diagnóstico do processo de participação popular nos Planos Diretores Municipais

Figura 4.1 - Utilização de ferramentas computacionais de Suporte à Decisão no processo de planejamento

Figura 4.2 - Protótipo de arquitetura de software para SDSS - com participação pública através de diferentes horários e lugares

Figura 5.1 - Estrutura proposta para o PLANUTS

Figura 5.2 - Processo de definição dos indicadores de mobilidade urbana para o PLANUTS .. 52

Figura 5.3 - Definição dos pesos para os indicadores propostos .............................................. 53

Figura 5.4 - Escala de Avaliação de 7 Pontos ......................................................................... 59

Figura 5.5 - Quadro síntese dos métodos de avaliação adotados para cada módulo ................. 61

Figura 5.6 - Mapa cognitivo (mapa de causa) - Conceito unipolar ......................................... 70

Figura 5.7 - Mapas de Causa: SODA I ............................................................................. 72

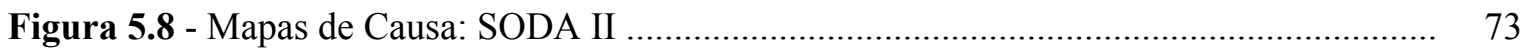

Figura 5.9 - Exemplo de análise temática de um texto ............................................................. 76

Figura 6.1 - Estruturação do Sistema PLANUTS ................................................................. 81

Figura 6.2 - Fluxograma de funcionamento do Sistema PLANUTS ….................................. 83

Figura 6.3 - Fluxograma de funcionamento do Módulo I ......................................................... $\quad 90$

Figura 6.4 - Módulo I - Página de login ………….............................................................. 91

Figura 6.5 - Módulo I - Esqueceu a senha ……….............................................................. 91

Figura 6.6 - Categoria Meio Ambiente e Transportes .............................................................. 92

Figura 6.7 - Tema: Impacto Ambiental - Módulo I …......................................................... 92 
Figuras 6.8 a, b e c - Seqüência de imagens referente à Categoria Meio Ambiente e Transportes

Figura 6.9 - Fluxograma de funcionamento do Módulo II

Figura 6.10 - Módulo II - Páginas de login

Figura 6.11 - Módulo II - Páginas Esqueceu a senha

Figura 6.12 - Categoria Meio Ambiente e Transportes - Tema Energia

Figura 6.13 - Tema Energia - Definição do Indicador .

Figuras 6.14 e 6.15 - Tema Energia - Seleção dos Indicadores ................................................... 99

Figura 6.16 - Fluxograma de funcionamento do Módulo III ................................................... 102

Figuras 6.17 e 6.18 - Módulo III - Páginas de login e Esqueceu a senha ................................. 102

Figura 6.19 - Página de escolha dos Indicadores referente a Categoria Meio Ambiente e Transportes

Figura 6.20 - Tema Energia - Definição do Indicador ..

Figuras 6.21 e 6.22 - Tema Energia - Seleção dos Indicadores .............................................. 104

Figura 6.23 - Definição do Indicador ............................................................................... 105

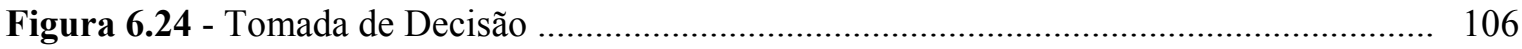

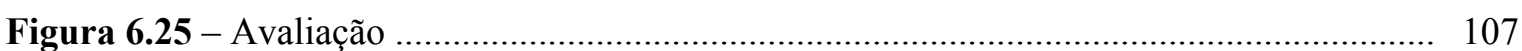

Figura 6.26 - Localização do Problema …........................................................................... 108

Figura 6.27 - Fluxograma com uma proposta inicial para o funcionamento do Módulo IV ..... 111

Figura 6.28 - Acesso a área administrativa do Sistema PLANUTS ....................................... 114

Figura 6.29 - Мenu de navegação - Visualização do Relatório das avaliações e Cadastro das Informações para o Módulo III

Figura 6.30 - Forma de cadastro dos usuários no Sistema PLANUTS …................................. 115

Figura 6.31 - Visualização dos usuários cadastrados ............................................................ 116

Figura 6.32 - Visualização dos relatórios gerados no Módulo I ............................................ 117

Figura 6.33 - Visualização dos relatórios gerados no Módulo II ............................................. 117

Figura 6.34 - Cadastro dos Temas - Módulo III ……............................................................. 119

Figura 6.35 - Cadastro dos Indicadores - Módulo III ................................................................ 119

Figura 6.36 - Cadastro das Mídias - Módulo III ...................................................................... 120

Figura 6.37 - Visualização dos relatórios gerados no Módulo III ............................................ 121

Figura 6.38 - Visualização do relatório do Indicador Eficiência energética do transporte de passageiro e carga

Figura 7.1 - Gráfico comparativo entre a frota total em relação ao número de automóveis do município de Bauru entre o período de janeiro/2001 a agosto/2007

Figura 8.1 - Visualização dos resultados dos pesos das Categorias, com exemplo para a Categoria Aspectos Socioeconomicos do Transportes, da faixa que representa uma menor dispersão (entre um limite inferior e outro superior, definidos pela média menos e mais um desvio padrão, respectivamente)

Figura 8.2 - Categoria Meio Ambiente e Transportes .............................................................. 170

Figura 8.3 - Categoria Gestão dos Transportes .............................................................. 172

Figura 8.4 - Categoria Infra-estrutura dos Transportes ..................................................... 173 
Figura 8.5 - Categoria Planejamento dos Transportes

Figura 8.6 - Categoria Aspectos Socioeconômicos dos Transportes

Figura 8.7 - Gráfico referente aos Indicadores relacionados à Categoria Meio Ambiente e Transportes

Figura 8.8 - Gráfico referente aos Indicadores relacionados à Categoria Gestão dos Transportes

Figura 8.9 - Gráfico referente aos Indicadores relacionados à Categoria Infra-Estrutura dos Transportes

Figura 8.10 - Gráfico referente aos Indicadores relacionados à Categoria Planejamento dos Transportes

Figura 8.11 - Gráfico referente aos Indicadores relacionados à Categoria Aspectos Socioeconômicos dos Transportes

Figura 8.12 - Mapa Cognitivo 1 - Definição de Mobilidade Urbana extraída do Questionário $1 \mathrm{~A}$

Figura 8.13 - Mapa Cognitivo 2 - Definição de Mobilidade Urbana extraída do Questionário $1 \mathrm{~B}$

Figura 8.14 - Mapa Cognitivo 3 - Definição de Mobilidade Urbana extraídas do Questionário 2

Figura 8.15 - Mapa Cognitivo 1 - Identificação dos problemas de Mobilidade Urbana extraídos do Questionário 1A

Figura 8.16 - Mapa Cognitivo 2 - Identificação dos problemas de Mobilidade Urbana extraídos do Questionário 2

Figuras 8.17 e 8.18 - Gráfico comparativo mostrando o grau de conhecimento dos participantes sobre a existência de medidas para melhorar a mobilidade urbana no município .

Figura 8.19 - Mapa Cognitivo 1 - Medidas adotadas no município para incentivar a mobilidade extraídos do Questionário $1 \mathrm{~A}$

Figura 8.20 - Mapa Cognitivo 2 - Medidas adotadas no município para incentivar a mobilidade extraídos do Questionário 2

Figura 8.21 - Gráfico comparativo mostrando os setores municipais estão envolvidos com o com o Plano de Transporte e Mobilidade

Figura 8.22 - Gráfico comparativo mostrando as secretarias municipais envolvidas com o Plano de Transporte e Mobilidade 208

Figura 8.23 - Mapa Cognitivo 1 - Identificação dos Temas de Mobilidade Urbana extraídos do Questionário $1 \mathrm{~A}$

Figura 8.24 - Mapa Cognitivo 2 - Identificação dos Temas de Mobilidade Urbana extraídos do Questionário 2

Figura 8.25 - Mapa Cognitivo 1 - Identificação da política de Estacionamentos extraídos do Questionário $1 \mathrm{~A}$

Figura 8.26 - Mapa Cognitivo 2 - Identificação da política de Estacionamentos extraídos do Questionário 2

Figura 8.27 - Mapa Cognitivo 1 - Identificação da política de Transporte Público extraídos do Questionário 1A

Figura 8.28 - Mapa Cognitivo 2 - Identificação da política de Transporte Público extraídos do Questionário 2 
Figura 8.29 - Mapa Cognitivo 1 - Identificação da política de Circulação extraídos do Questionário 1A

Figura 8.30 - Mapa Cognitivo 2 - Identificação da política de Circulação extraídos do Questionário 2

Figuras 8.31 e 8.32 - Gráfico comparativo mostrando o grau de conhecimento dos participantes sobre a existência de um plano para a diminuição da poluição provocada pelos transportes

Figura 8.33 - Mapa Cognitivo 2 - Identificação da política de redução dos níveis de poluição extraídos do Questionário 2

Figuras 8.34 e 8.35 - Gráfico comparativo mostrando o grau de conhecimento dos participantes sobre a existência de um plano para a redução dos níveis de ruído provocados pelos transportes

Figura 8.36 - Gráfico comparativo mostrando as medidas a serem adotadas para a redução dos Níveis de Ruído

Figuras 8.37 e 8.38 - Gráfico comparativo que permite identificar o grau de conhecimento dos participantes sobre a existência de um plano para a redução dos pontos de congestionamento no município de Bauru

Figura 8.39 - Mapa Cognitivo 1 - Identificação da política de Congestionamentos extraídos do Questionário 1A

Figura 8.40 - Mapa Cognitivo 2 - Identificação da política de Congestionamentos extraídos do Questionário 2

Figuras 8.41 e 8.42 - Gráficos de setores comparando o grau de conhecimento dos participantes com relação a existência de um Plano de Acessibilidade no Município de Bauru

Figura 8.43 - Mapa Cognitivo 1 - Identificação da política de Acessibilidade extraídos do Questionário 1A

Figura 8.44 - Mapa Cognitivo 2 - Identificação da política de Acessibilidade extraídos do Questionário 2

Figuras 8.45 e 8.46 - Gráfico comparativo entre a atual política de adaptação de pontos de ônibus e a necessidade de adaptação apontada pelos participantes do questionário

Figura 8.47 - Gráfico comparativo entre as secretarias envolvidas na atual política de acessibilidade e aquelas que poderiam integrar-se ao atual conjunto de secretarias 


\section{LISTA DE TABELAS}

Tabela 3.1 - Questões Estruturais dos Planos Diretores Participativos

Tabela 3.2 - Percentual das pessoas que utilizaram a internet por finalidade (população de 10 anos ou mais de idade) no período de referência dos últimos três meses por Grandes Regiões .

Tabela 3.3 - Percentual das pessoas que utilizaram a internet em cada local (população de 10 anos ou mais de idade) no período de referência dos últimos três meses por Grandes Regiões .

Tabela 8.1 - Pesos por Categoria e por grupo de avaliação

Tabela 8.2 - Pesos por Tema e por grupo de avaliação

Tabela 8.3 - Ordenamento das Categorias por grupo de avaliadores

Tabela 8.4 - Ordenamento dos Temas por grupo de avaliadores

Tabela 8.5 - Ordenamento dos pesos por avaliador e Coeficiente de Correlação de Concordância de Kendall para as Categorias

Tabela 8.6 - Ordenamento dos pesos por avaliador e Coeficiente de Correlação de Concordância de Kendall para os Temas

Tabela 8.7 - Coeficiente de Correlação de Postos de Kendall para as Categorias Ordenamento das avaliações

Tabela 8.8 - Coeficiente de Correlação de Postos de Kendall para as Temas - Ordenamento das avaliações

Tabela 8.9 - Resultado da avaliação dos Temas por grupo de avaliação

Tabela 8.10 - Cálculo do peso médio por grupo e o respectivo ordenamento na avaliação do Grau de importância dos indicadores

Tabela 8.11 - Cálculo do Coeficiente de Correlação de Kendall (w) para os indicadores através da avaliação do Grau de importância de cada indicador

Tabela 8.12 - Cálculo do Coeficiente de Correlação de Postos de Kendall $(\tau)$ para os indicadores através da avaliação do Grau de Importância de cada indicador

Tabela 8.13 - Avaliação do Grau de Urgência dos Indicadores - Definição dos pesos por avaliador, média global e desvio padrão

Tabela 8.14 - Cálculo do peso médio por grupo e o respectivo ordenamento na avaliação do Grau de Urgência dos indicadores

Tabela 8.15 - Cálculo do Coeficiente de Correlação de Kendall (w) para os indicadores através da avaliação do Grau de Urgência de cada indicador

Tabela 8.16 - Comparação entre o ranking das avaliações referentes ao Grau de Importância e ao Grau de Urgência por Categoria 
Tabela 8.17 - Identificação dos problemas relacionados a cada indicador nas cinco regiões do município de Bauru 


\section{RESUMO}

MAGAGNIN, R.C. (2008) Um Sistema de Suporte à Decisão na internet para o planejamento da mobilidade urbana. Tese (Doutorado) - Escola de Engenharia de São Carlos, Universidade de São Paulo, São Carlos, 2008.

Alguns dos problemas enfrentados pelas cidades que ainda sofrem com um crescimento rápido são, não raro, conseqüência da falta de políticas públicas que possam orientar o crescimento espacial de forma sustentável e com qualidade de vida. Há uma clara necessidade de instrumentos efetivos de controle e monitoramento da mobilidade urbana, bem como de políticas mais sustentáveis destinadas a orientar o crescimento e ordenamento espacial. Neste contexto, a elaboração de um Sistema de Suporte à Decisão através de uma interface on-line pode proporcionar novas perspectivas para um planejamento da mobilidade mais participativo e sustentável. Assim, um dos objetivos desta pesquisa foi desenvolver uma ferramenta computacional destinada a promover um processo integrado e sustentável para elaboração e monitoramento de Planos Diretores de Mobilidade Urbana. A proposta focou no processo de tomada de decisão participativo envolvendo múltiplos segmentos da sociedade, sobretudo em cidades pequenas e médias. Outro objetivo foi verificar se, através da utilização do sistema proposto, os avaliadores (especialistas ou não-especialistas), modificariam significativamente seu nível de percepção com relação à mobilidade urbana. Para atingir a estes objetivos, a pesquisa foi dividida em duas fases. Inicialmente foi desenvolvido o Sistema de Suporte à Decisão para internet, denominado PLANUTS - PLANejamento Urbano e de Transportes integrado e Sustentável. Este sistema é composto por quatro Módulos de Avaliação da Mobilidade Urbana e um Módulo Administrativo. O funcionamento da ferramenta proposta foi demonstrado, na prática, através de sua aplicação junto a um grupo de especialistas e nãoespecialistas em Bauru, cidade média localizada no estado de São Paulo, Brasil. Com a aplicação foi possível simular etapas do desenvolvimento de um Plano Diretor de Transporte e Mobilidade participativo, com a definição de indicadores de mobilidade. A aplicação também foi útil para demonstrar a contribuição do sistema na mudança de percepção dos usuários com relação a questões que envolvem aspectos da mobilidade. Os resultados obtidos conduziram às seguintes conclusões: i) o sistema PLANUTS pode contribuir para a participação de diferentes segmentos da sociedade no processo de avaliação da mobilidade urbana; ii) a utilização do sistema possibilita uma ampliação no conhecimento e definição dos temas que envolvem a mobilidade urbana; e iii) é possível definir um conjunto de indicadores representativos dos problemas mais importantes de mobilidade com vistas a um sistema de indicadores de mobilidade no município.

Palavras Chave: Mobilidade Urbana, Sistema de Suporte à Decisão, Internet, Planejamento. 


\section{ABSTRACT}

MAGAGNIN, R. C. (2008) A web-based Decision Support System for urban mobility planning. Ph.D. Thesis - Escola de Engenharia de São Carlos, Universidade de São Paulo, São Carlos, 2008.

Some of the problems faced by fast growing cities are often a consequence of the lack of public policies able to drive the spatial growth towards sustainable development and a better quality of life. There is a clear need of more effective tools for urban mobility monitoring and control, as well as sustainable policies for guiding urban growth and spatial distribution. In such a context, the construction of a web-based Decision Support System can produce new perspectives for mobility planning in a more participative and sustainable way. Therefore, one of the objectives of this research was to develop a computational tool for promoting an integrated and sustainable process of construction and management of Mobility Master Plans. The focus of the proposal was on a participative decision-making process involving multiple segments of the society, mainly of small and medium-sized cities. Another objective of the research was to test if the use of the proposed system could significantly change the perception level of the participants (experts or non-experts) regarding urban mobility. In order to reach the stated objectives, the research was conducted in two phases. The first step was the development of the internet-based Decision Support System named PLANUTS (which stands for PLANnig Urban and Transportation integrated and Sustainable systems). It comprises four modules for the evaluation of urban mobility and one administrative module. The use of the proposed tool was shown, in practice, through an application with a group of experts and another one of non-experts in Bauru, which is a medium-sized city located in the state of São Paulo, Brazil. The application made possible to simulate some steps of the development of a participative Mobility Master Plan, with the definition of mobility indicators. It was also useful for showing the contribution of the system in changing the users' perception regarding mobility issues. The results obtained led to the following conclusions: i) PLANUTS can be used to allow the participation of distinct segments of the society in the evaluation of urban mobility; ii) the use of the system brings an improvement in the definition of the Themes and to the overall knowledge of urban mobility; and iii) it is possible to define a set of indicators associated to the most important mobility problems in order to build a system of urban mobility indicators to the municipality.

Keywords: Urban Mobility, Decision Support System, Internet, Planning. 


\section{INTRODUÇÃO}

Este capítulo apresenta e discute algumas das principais características que envolvem o planejamento da mobilidade urbana num processo de tomada de decisão participativa. Na seqüência são apresentados a justificativa, o objetivo e a estrutura deste trabalho.

\subsection{Caracterização do Problema}

Atualmente várias cidades do mundo buscam alternativas para resolver seus problemas urbanos. A expansão desordenada provocada pela grande concentração de pessoas nas cidades, associada à falta de infra-estrutura urbana e a dependência do transporte individual motorizado, tem levado a uma deterioração da qualidade de vida da população nos centros urbanos. Em conseqüência destes problemas, pesquisadores, planejadores e tomadores de decisão têm se preocupado cada vez mais em encontrar soluções para minimizar estes diferentes problemas urbanos. A qualidade de vida nos centros urbanos, que está diretamente associada à sustentabilidade urbana, não pode, portanto, ser tratada através de políticas que abordem apenas parcialmente esta questão tão complexa.

Historicamente, as questões que envolvem o planejamento urbano sempre estiveram associadas aos aspectos do planejamento de transportes, ou seja, o crescimento urbano influencia e é influenciado pela demanda e oferta de transportes em uma cidade. Assim, deficiências no planejamento urbano e de transportes interferem diretamente no cotidiano da população. O crescimento urbano desordenado, a dispersão espacial, o aumento no número de automóveis nos centros urbanos, os congestionamentos, o aumento no número de acidentes de trânsito, as deficiências no transporte coletivo, as questões de uso do solo e ordenamento espacial são reflexos da dissociação entre as vertentes do planejamento urbano e de transporte (Litman, 2006b). 
Num passado ainda recente, no caso brasileiro, o planejamento de transportes era realizado de forma dissociada do planejamento urbano ou mesmo de qualquer outro plano. Neste caso, os planejadores de transportes utilizavam modelos matemáticos para produzir planos (desenvolvidos para períodos de vinte anos, permitindo atualizações a cada cinco anos) que visavam solucionar principalmente problemas de demanda e oferta de transportes na cidade, mas que estavam freqüentemente desvinculados do planejamento de uso do solo. Entretanto, estes planos, quase sempre propostos ou financiados pelo Governo Federal, não resolveram os problemas das cidades porque não contemplavam as inter-relações entre as diversas fases do planejamento urbano. Esse quadro melhorou e atualmente, ainda que de forma não totalmente integrada, as questões ambientais e de uso do solo integram os modelos de análise e simulação na área do planejamento de transportes (Ministério das Cidades, 2006a).

$\mathrm{O}$ avanço tecnológico, especialmente de recursos computacionais, tem contribuído para minimizar os impactos causados pela dissociação das diferentes interfaces que estão presentes no processo de planejamento urbano. Nos últimos 40 anos, em função da evolução tecnológica, foram desenvolvidas algumas ferramentas que podem subsidiar o processo de planejamento urbano e de transportes, através inclusive da participação popular direta ou indireta. Além disso, planejadores e decisores podem hoje fazer uso de novas ferramentas e modelos, inclusive com forte componente espacial, para auxiliá-los na escolha de alternativas para minimizar os problemas urbanos.

O planejamento da mobilidade sustentável surge como uma nova alternativa para a investigação dos problemas urbanos complexos, permitindo avaliar alguns dos reflexos (impactos) entre o uso do solo e transportes (Banister, 2007). Alguns grandes centros urbanos, principalmente em países da Europa e América do Norte, têm adotado políticas de planejamento mais integradas através da adoção dos princípios da mobilidade sustentável para minimizar os problemas urbanos em substituição ao tradicional modelo de planejamento de transportes (Richardson, 2005). Entretanto, os problemas urbanos que estão direta ou indiretamente relacionados a esta definição ainda não estão muito claros para a maioria da população.

O processo de planejamento adotado recentemente no Brasil tem envolvido a participação de técnicos e de representantes da sociedade, predominantemente através de reuniões presenciais. A nova política urbana brasileira tem incentivado a participação popular no processo de planejamento das cidades. No entanto, para que o processo leve a 
cidades mais igualitárias é necessário que uma parcela significativa da população possa participar destas discussões.

$\mathrm{Na}$ perspectiva de disponibilizar informações que possam subsidiar planejadores, decisores e pesquisadores no planejamento da mobilidade urbana de cidades brasileiras de pequeno e médio porte, beneficiando-se sobretudo das inovações computacionais, esta pesquisa propõe o desenvolvimento de um Sistema de Suporte à Decisão voltado para a internet, que poderá permitir a ampliação da participação popular no processo de discussão e tomada de decisão no Planejamento da Mobilidade Urbana nas cidades brasileiras de pequeno e médio porte.

\subsection{Justificativa}

A relevância desta pesquisa apóia-se, portanto, exatamente nas possibilidades de ampliação da participação popular no processo de planejamento da mobilidade urbana de cidades de pequeno e médio porte através da utilização da internet como ambiente de participação pública. Assim, a utilização de um Sistema de Suporte à Decisão na internet surge como uma alternativa para o aprimoramento do processo de planejamento urbano e de transportes tradicionalmente utilizado nas cidades médias brasileiras.

Experiências internacionais confirmam que a implantação de estratégias de participação popular utilizando a internet tem aumentado o número de participantes envolvidos no processo de tomada de decisão local. Assim, espera-se que o desenvolvimento desta pesquisa proporcione um avanço nesse processo de tomada de decisão para as cidades de pequeno e médio porte brasileiras, resultando em novas pesquisas que levem à avaliação e ao aprimoramento do sistema, bem como à sua futura aplicação em outros municípios.

\subsection{Objetivo}

Esta pesquisa tem os seguintes objetivos:

- Desenvolver um Sistema de Suporte à Decisão voltado à internet, que possibilite auxiliar planejadores e decisores locais no processo de elaboração de Planos Diretores de Transporte e Mobilidade para cidades brasileiras, sobretudo as de pequeno e médio porte, através de uma maior participação popular no processo de tomada de decisão local. 
- Avaliar se a utilização do sistema proposto pode, através da inserção de recursos computacionais (multimídia e hipermídia) no processo de discussão dos problemas de Mobilidade Urbana, produzir alterações significativas no conhecimento de cada avaliador (especialista ou não-especialista).

- E, através do Sistema de Suporte à Decisão proposto, definir um conjunto de indicadores que possam auxiliar os municípios que implantarem o sistema a diagnosticar e monitorar a mobilidade urbana.

\subsection{Estrutura do Trabalho}

Este trabalho é composto por nove capítulos, apresentados com a seguinte estrutura: após a introdução ao tema desta pesquisa, apresentado no Capítulo 1, nos Capítulos 2, 3 e 4 são apresentados os elementos da fundamentação teórica que possibilitou desenvolver o Sistema de Suporte à Decisão proposto. O Capítulo 2 refere-se à apresentação do conceito de Mobilidade Urbana e da política de mobilidade adotada no Brasil. Na seqüência, o Capítulo 3 aborda a questão do planejamento participativo, as diversas formas de participação, bem como o modelo adotado atualmente no Brasil. Posteriormente, no Capítulo 4, são apresentadas as ferramentas de Suporte à Decisão desenvolvidas para serem utilizadas por planejadores e tomadores de decisão no planejamento urbano e de transportes. No Capítulo 5 é descrita a metodologia adotada para a elaboração do Sistema de Suporte à Decisão concebido para a internet, denominado PLANUTS, bem como os critérios considerados para avaliação do sistema. No Capítulo 6 é apresentado cada componente do sistema proposto. No Capítulo7 é discutido o processo de implantação do sistema na internet, sendo apresentado de forma detalhada cada uma de suas partes. No Capítulo 8 é apresentada a análise dos resultados obtidos para a composição de um Sistema de Indicadores de Mobilidade Urbana Municipal, incluindo o resultado de um estudo de caso aplicado no município de Bauru - SP. Na seqüência, no Capítulo 9, são apresentadas as conclusões e as propostas para futuros trabalhos. Por fim, o Capítulo 10 refere-se às referências bibliográficas utilizadas para dar suporte ao desenvolvimento desta pesquisa. 


\section{MOBILIDADE URBANA}

Este capítulo apresenta uma revisão acerca dos principais elementos que envolvem a questão da mobilidade urbana. Inicialmente é apresentada a definição de mobilidade e sua influência no planejamento das cidades. Posteriormente é discutida a atual política brasileira de mobilidade e as recomendações para a elaboração de um Plano Diretor de Transporte e Mobilidade.

\subsection{Mobilidade Urbana}

Historicamente, questões de planejamento urbano encontram-se associadas de forma intrínseca a aspectos de transporte, isto é, o crescimento das cidades influencia e é influenciado pelos meios de transporte disponíveis à sua população. Mais ainda, a forma como se dá o processo de circulação urbana interfere diretamente na demanda por transportes, nas áreas destinadas a estacionamento, nos congestionamentos, etc. Apesar disso, houve no passado períodos em que o planejamento de transportes foi realizado de forma dissociada do planejamento urbano ou mesmo de qualquer outro plano. Nestes casos, os planejadores de transportes utilizavam modelos matemáticos para produzir planos (desenvolvidos para períodos de 20 anos, permitindo atualizações a cada 5 anos) que visavam solucionar os problemas de demanda e oferta de transportes na cidade, mas que estavam muitas vezes desvinculados do planejamento de uso do solo. Atualmente, por outro lado, o planejamento de transportes (demanda e oferta) utiliza modelos que incluem em sua análise aspectos mais amplos do que aqueles considerados antigamente. Através destes modelos são hoje consideradas, entre outras, questões ambientais e de uso do solo.

Entre os problemas que as cidades herdaram como conseqüência desta dissociação entre o planejamento urbano e o planejamento de transportes destacam-se: a questão do parcelamento periférico de baixa densidade ocupacional; os assentamentos rarefeitos - ocasionando os vazios urbanos; a substituição do uso pela função; a 
deterioração espacial; a estratificação físico-espacial; a má distribuição de infra-estrutura urbana; e a má distribuição de serviços urbanos coletivos. Todos estes aspectos geram estratificação espacial e segregação urbana.

A expansão desordenada tem provocado grandes problemas em várias cidades do mundo. Pesquisadores, planejadores e tomadores de decisão têm se preocupado cada vez mais com os problemas das zonas urbanas, uma vez que estes afetam diretamente a qualidade de vida da população ali residente. Deficiências no planejamento urbano e de transportes interferem diretamente no cotidiano da população, pois a cidade é um sistema que possui várias inter-relações, ou seja, a alteração em uma parte deste sistema pode gerar impactos em outras partes do mesmo.

O crescimento urbano desordenado, provocado pelo espalhamento espacial, o aumento excessivo no uso do automóvel, a falta de infra-estrutura urbana, a poluição do meio ambiente, entre outras, são questões que interferem na qualidade de vida da população. Estes fatores têm contribuído para que pesquisadores, decisores e tomadores de decisão busquem novas formas de minimizar os problemas, e de discutir e encontrar soluções para estas questões urbanas.

O processo de planejamento tradicional, em que cada problema urbano deve ser resolvido separadamente, não pode mais ser utilizado para solucionar os atuais problemas urbanos, uma vez que é hoje de conhecimento de pesquisadores e decisores que há forte inter-relações entre os diversos problemas urbanos.

Para contrapor-se a este sistema de planejamento que não atende mais às necessidades urbanas e da população, disseminou-se mundialmente um processo de planejamento integrado, onde as questões de uso do solo e transporte são entendidas de uma forma mais ampla, como em Loukopoulos e Scholz (2004).

A antiga denominação do planejamento de transportes passa a planejamento da mobilidade urbana e o conceito de planejamento associado aos transportes é ampliado, incorporando as visões de infra-estrutura, circulação, transporte público associados a questões de uso do solo, meio ambiente, entre outros aspectos.

A mobilidade pode ser definida como um atributo relacionado aos deslocamentos realizados por indivíduos nas suas atividades de estudo, trabalho, lazer e outras. Nesse contexto, as cidades desempenham um papel importante nas diversas relações de troca de bens e serviços, cultura e conhecimento entre seus habitantes, mas isso só é possível se houver condições adequadas de mobilidade para as pessoas (Ministério das Cidades, 2006a). 
Outro conceito incorporado ao planejamento dos transportes (ou ao planejamento da mobilidade urbana) refere-se à sustentabilidade. Segundo Steg e Gifford (2005) o desenvolvimento sustentável no planejamento de transportes está associado ao equilíbrio entre os aspectos ambientais, econômicos e sociais, tanto no presente como nas futuras intervenções urbanas. Este conceito foi adotado inicialmente na Europa, América do Norte e Austrália (Richardson, 2005). No Brasil esta visão ainda é recente e o conceito está sendo incorporado gradativamente nas discussões dos Planos Diretores de Transportes e Mobilidade (Silva et al., 2007).

Segundo a definição da ANTP (2003), “Mobilidade Urbana Sustentável é o resultado de um conjunto de políticas de transporte e circulação que visam proporcionar o acesso amplo e democrático ao espaço urbano, através da priorização dos modos de transporte coletivo e não motorizados de maneira efetiva, socialmente inclusiva e ecologicamente sustentável".

Na visão da Mobilidade Urbana Sustentável dá-se prioridade aos modos coletivos e não-motorizados (a pé e bicicleta), incluindo a utilização de veículos não poluentes, visão esta desconsiderada pela maioria dos planejadores que dão prioridade à utilização de automóveis.

Segundo a UITP - International Association of Public Transport ${ }^{1}$, a base para uma mobilidade sustentável está na inter-relação entre os seguintes componentes: o meio ambiente, a economia e a sociedade. O equilíbrio entre estes três componentes proporcionará: a realização das necessidades das pessoas, no que se refere à qualidade de vida e acessibilidade, e o respeito ao habitat, causando o menor impacto pelas atividades humanas. No tocante à economia, ela está relacionada aos recursos disponíveis, ou ao modo como estes recursos possam satisfazer as necessidades de cada cidadão (Black et al., 2002; Steng e Gifford, 2005; Richardson, 2005).

De forma análoga, o desenvolvimento sustentável é aquele que responde às necessidades do presente sem comprometer a capacidade das gerações futuras de responder às suas próprias necessidades. É um processo que associa as três importantes dimensões: ambiental, econômica e social, estabelecendo uma correlação entre esses três pólos, garantindo a eficácia econômica e a proteção do meio ambiente, sem perder de vista as finalidade sociais que são a luta contra a pobreza, as desigualdades, a exclusão e a busca da eqüidade (WCED, 1987).

\footnotetext{
${ }^{1}$ International Association of Public Transport - http://www.uitp.com/ - Ticket to the Future 3 stops to Sustainable Mobility (2004). http://www.uitp.org/Project/pics/susdev/Brochure-EN.pdf
} 
As cidades que consideram as políticas relacionadas à integração entre mobilidade e sustentabilidade urbana garantem maior eficiência e dinamismo das funções urbanas, com maior e melhor circulação de pessoas e mercadorias. Isto se reflete na valorização do espaço público, na sustentabilidade e no desenvolvimento da cidade, conciliando as dimensões ambiental, social e econômica (IBAM e Ministério das Cidades, 2005).

Alguns fatores afetam a mobilidade, como por exemplo: renda, idade, gênero e limitações permanentes ou provisórias na capacidade de locomoção dos indivíduos. No meio urbano, as condições de mobilidade são inerentes às características dos terrenos e ao tratamento físico dado às vias e aos passeios, à existência de redes regulares de transporte urbano, à qualidade dos seus serviços e o seu preço, à sinalização e aos sistemas de controle do uso do sistema viário e à existência ou não de ciclovias. Esses são apenas alguns itens que influenciam a mobilidade (Ministério das Cidades, 2006a e 2007).

Segundo estudos da UITP, em muitas cidades de diversos países podem ser encontrados os seguintes problemas de mobilidade: i) aumento da população em áreas urbanas; ii) desordenamento espacial; iii) falta de especialistas para resolver os problemas de locomoção; iv) acesso limitado ao transporte motorizado; v) pouco investimento em infra-estrutura; vi) poluição do ar; vii) aumento no número de acidentes de trânsito; viii) aumento no congestionamento; ix) crescimento urbano desordenado; $\mathrm{x}$ ) aumento no consumo de energia.

Um dos problemas enfrentados pela maioria das cidades médias brasileiras refere-se à questão da mobilidade urbana. A dependência no uso do automóvel tem causado grande impacto no fluxo de tráfego. Associado a este problema, as atuais políticas de crescimento e desenvolvimento urbano não têm privilegiado a utilização de meios de transportes mais sustentáveis (tais como, a bicicleta, o modo a pé e o transporte público). Como conseqüência do uso indiscriminado do automóvel nas áreas urbanas, tem-se: o aumento dos congestionamentos, do consumo de energia consumida no setor de transportes e o aumento nas emissões de gases tóxicos como o $\mathrm{CO}_{2}$ (ver Figura 2.1). 


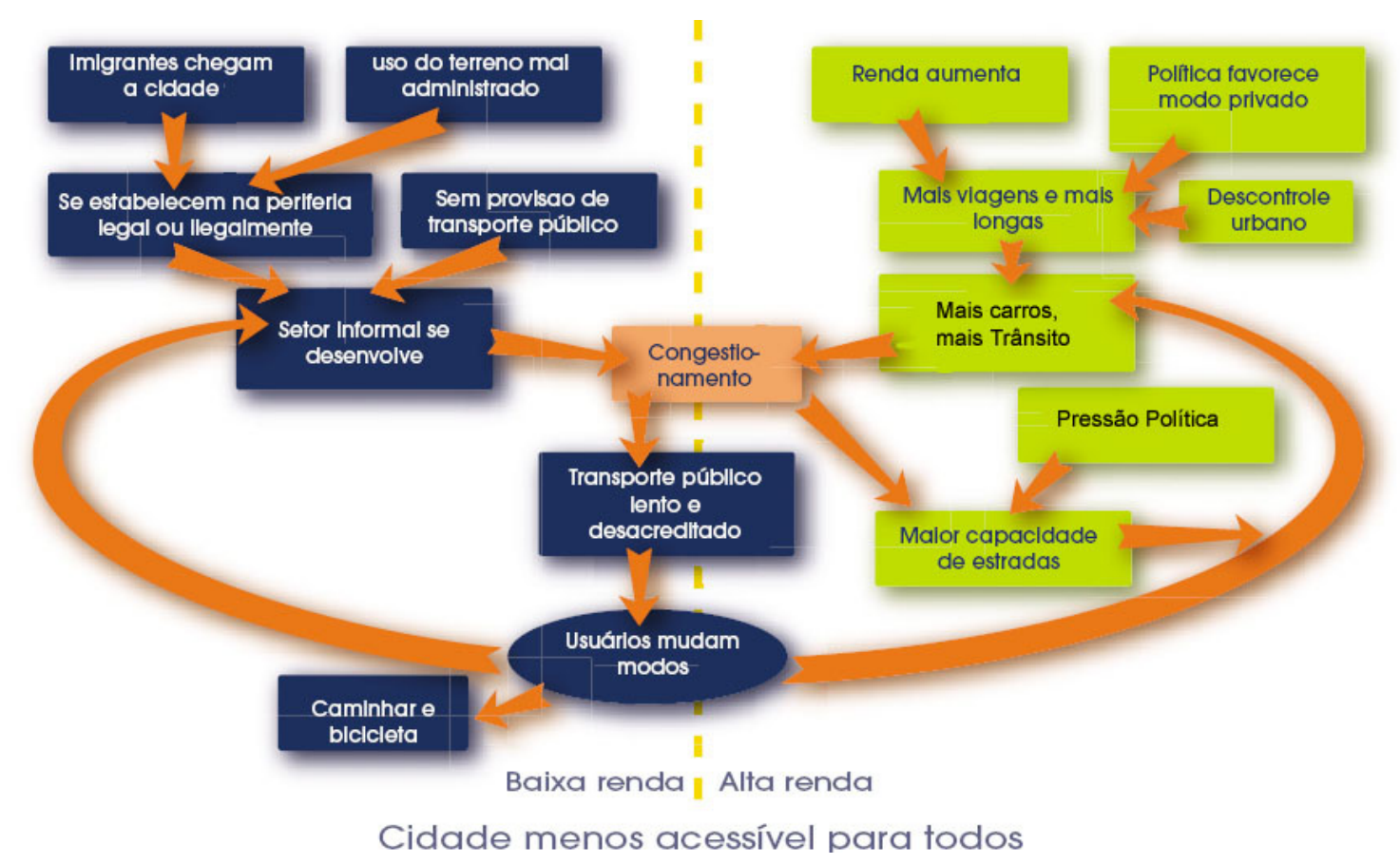

Figura 2.1 - Círculo vicioso da degradação do transporte urbano Fonte: UITP

Outro problema visivelmente identificado nas áreas urbanas e que influencia diretamente no planejamento da mobilidade é a crescente dispersão espacial, observada em muitas cidades, inclusive brasileiras. A localização de novas residências e serviços nas áreas periféricas, localizadas distantes das áreas centrais, está afetando diretamente a mobilidade nestas cidades. As cidades não estão preparadas para oferecer serviços a esta nova demanda. Em alguns casos, é evidente a dissociação que existe entre o planejamento urbano e o de transportes, particularmente na questão do planejamento do uso do solo urbano. Estas questões têm contribuído para aumentar as disparidades nos serviços dos diversos segmentos urbanos, com conseqüência direta sobre a mobilidade urbana.

Segundo o Ministério das Cidades (2004) “A mobilidade urbana é ao mesmo tempo causa e conseqüencia do desenvolvimento econômico-social, da expansão urbana e da distribuição espacial das atividades. Além disso, deve-se considerar a íntima relação entre infra-estrutura, transporte motorizado e a questão ambiental. O deslocamento de pessoas e mercadorias influencia fortemente os aspectos sociais e econômicos do desenvolvimento urbano, sendo a maior ou menor necessidade de deslocamentos definida pela localização das atividades na área urbana".

O modelo de expansão das cidades baseado no espalhamento urbano têm contribuído para agravar a problema da mobilidade urbana; entendendo-se mobilidade 
como o deslocamento de pessoas e serviços de uma região. Ao incorporar a esta definição o conceito de mobilidade urbana sustentável, é necessário levar em consideração os deslocamentos dando prioridade aos modos não-motorizados e coletivos.

A melhoria das condições de mobilidade, com o conseqüente aumento da qualidade de vida urbana, está relacionada com a adoção de medidas para incentivar o transporte público em detrimento ao privado, implantação de legislação que regule a circulação do transporte público e privado, que estabeleça critérios para a construção e manutenção do sistema viário, e que incentive a utilização de modos de transportes mais sustentáveis.

Iniciativas internacionais e nacionais têm contribuído para a melhoria da mobilidade urbana. Um exemplo é a Semana Européia de Mobilidade (European Mobility Week) que em 2007 destinou a semana de 16 a 22 de setembro para atividades relacionadas à melhoria da mobilidade urbana nas cidades participantes. Este evento teve início em 2002, com o objetivo dos participantes utilizarem meios de transportes mais sustentáveis. Este dia (ou semana) é conhecido mundialmente como "na cidade sem meu carro" ("In town without mycar!” ou car-free day) (European Commission's DG Environment).

Segundo a European Commission's DG Environment (s/d), desde o ano de 2002 tem aumentado o número de cidades participantes da semana de mobilidade. Em 2002, participaram deste evento 418 municípios de 23 países. Em 2007, foram 2016 municípios de 35 países participantes. Algumas cidades brasileiras também estão incluídas neste evento; entretanto, o envolvimento das cidades brasileiras ainda é pequeno, se comparado com outros países. Em 2007, 57 municípios brasileiros participaram oficialmente da semana de mobilidade (Rua Viva², 2007; European Commission's DG Environment, s/d).

As autoridades dos paises participantes têm, após estas semanas, lançado medidas permanentes para a melhoria da mobilidade urbana, como a carona compartilhada (car-sharing ou car-pooling), curso de planejamento de viagens, novas rotas para o trânsito local, entre outras medidas.

\subsection{Política de Mobilidade Urbana no Brasil}

A atual Política Nacional de Mobilidade Urbana no Brasil foi iniciada com a aprovação do Estatuto das Cidades (em 2001) e consolidada com a criação do Ministério das Cidades no ano de 2003.

\footnotetext{
${ }^{2}$ Rua Viva - Instituto da Mobilidade Sustentável, cujo site é http://www.ruaviva.org.br
} 
O Estatuto das Cidades, dentre outras questões relevantes para o planejamento das cidades (Capítulo III - referente ao Plano Diretor, no artigo 41, $\S 2^{\circ}$, da lei $\mathrm{n}^{\mathrm{o}} 10.257$, de 10 de julho de 2001), definiu como obrigatória a elaboração de um Plano de Transporte Urbano Integrado para as cidades com população acima de 500 mil habitantes. Este plano deve ser compatível com seu plano diretor ou deve nele estar inserido.

Com a criação da Secretaria Nacional de Transporte e da Mobilidade Urbana - cuja sigla é SeMob (Ministério das Cidades), toda a política referente às questões de transporte, agora denominada de política de Mobilidade Urbana Sustentável, está sob sua responsabilidade. Esta mudança de nomenclatura (denominação) vem ampliar o antigo conceito de Planejamento de Transportes, incorporando as questões da sustentabilidade e da participação popular, além das questões tradicionais de transporte e circulação.

Com a resolução número 34 , de $1^{\circ}$ de julho de 2005 , ampliou-se a obrigação legal estabelecida pelo Estatuto das Cidades para a elaboração do Plano Diretor de Mobilidade. Com esta resolução a SeMob tem incentivado os municípios com população acima de 100 mil habitantes, os situados em regiões metropolitanas e em regiões de desenvolvimento integrado, a realizarem o PlanMob - Plano Diretor de Transporte e Mobilidade.

O objetivo da política de Mobilidade Urbana Sustentável é proporcionar o desenvolvimento dos princípios da Mobilidade Urbana Sustentável através de três eixos principais: i) Desenvolvimento urbano; ii) Sustentabilidade ambiental e iii) Inclusão social.

As ações desenvolvidas pela SeMob para alcançar estes princípios da sustentabilidade envolvem as seguintes questões (Ministério das Cidades, 2004 e 2007):

- Definição de uma política de transporte e circulação (através da integração do transporte ao desenvolvimento urbano e da redução da circulação através da diminuição do número de viagens motorizadas);

- Priorização dos modos de transporte coletivo e não-motorizados (com ampliação da oferta de transporte público com eficiência e qualidade, além de valorizar os deslocamentos de pedestres e ciclistas);

- Apoio ao desenvolvimento institucional, regulatório e de gestão;

- Coordenação de ações para a integração das políticas de mobilidade com as demais políticas urbanas (através desta integração proporcionar uma maior eqüidade do espaço urbano, com melhoria da qualidade de vida para todos os cidadãos, incluindo os portadores de necessidades 
espaciais ou aqueles com restrição de mobilidade);

- Repensar o desenho urbano (através de um novo planejamento urbano

e de uma nova forma para o planejamento do sistema viário, para aumentar a segurança dos pedestres).

A questão da Mobilidade Urbana no Brasil, atualmente, está sendo discutida em um contexto mais abrangente, onde o desenvolvimento urbano está sendo "entendido" de uma forma mais integrada.

O Quadro 2.1 apresenta os princípios e diretrizes da Política Nacional de Mobilidade Urbana Sustentável.

Quadro 2.1 - Princípios e diretrizes da Política Nacional de Mobilidade Urbana Sustentável

PRINCÍPIOS $\quad$ DIRETRIZES

- Direito ao acesso universal, seguro, equânime e democrático ao espaço urbano;

- A participação e controle social sobre a política de mobilidade;

- Direito à informação sobre a mobilidade, de forma a instrumentalizar a participação popular e o exercício do controle social;

- Desenvolvimento das cidades, por meio da mobilidade urbana sustentável;

- Universalização do acesso ao transporte público coletivo;

- Acessibilidade das pessoas com deficiência ou com restrição de mobilidade;

- Políticas públicas de transporte e trânsito, política nacional de mobilidade urbana sustentável, articuladas entre si e com a política de desenvolvimento urbano e a do meio ambiente;

- A Mobilidade Urbana centrada no deslocamento das pessoas;

- O transporte coletivo urbano como um serviço público essencial regulado pelo Estado;

- Paz e educação para cidadania no trânsito como direito de todos.
- Priorizar pedestres, ciclistas, passageiros de transporte coletivo, pessoas com deficiência, portadoras de necessidades especiais e idosos, no uso do espaço urbano de circulação;

- Promover a ampla participação cidadã, de forma a garantir o efetivo controle social das políticas de Mobilidade Urbana;

- Promover o barateamento das tarifas de transporte coletivo, de forma a contribuir para o acesso dos mais pobres e para a distribuição de renda;

- Articular e definir, em conjunto com os Estados, Distrito Federal e Municípios, fontes alternativas de custeio dos serviços de transporte público,

incorporando recursos de beneficiários indiretos no seu financiamento;

- Combater a segregação urbana por intermédio da Política Nacional de Mobilidade Urbana Sustentável;

- Promover o acesso das populações de baixa renda, especialmente dos desempregados e trabalhadores informais, aos serviços de transporte coletivo urbano;

- Promover e difundir sistemas de informações e indicadores da Mobilidade Urbana;

- Estabelecer mecanismos permanentes de financiamento da infra-estrutura, incluindo parcela da CIDE-combustíveis, para os modos coletivos e não-motorizados de circulação urbana;

- Incentivar e apoiar sistemas estruturais, metroferroviários e rodoviários de transporte coletivo, em corredores exclusivos nas cidades médias e nas Regiões Metropolitanas, que contemplem mecanismos de integração intermodal e institucional.

Fonte: Ministério das Cidades (2007). 
Com base nos princípios e diretrizes apresentados no Quadro 2.1, a SeMob tem orientado os municípios na elaboração dos Planos de Transportes e Mobilidade. Esta secretaria elaborou alguns documentos que podem auxiliar os municípios brasileiros na elaboração destes planos, além da criação de um curso de capacitação ${ }^{3}$ para técnicos municipais das capitais brasileiras. Dentre os documentos destacam-se: Guia PlanMob Caderno de Referência para Elaboração de Plano de Mobilidade Urbana; Cartilha "A mobilidade urbana no planejamento da cidade"; Cadernos do Programa Brasil Acessível; Caderno do curso Gestão Integrada da Mobilidade Urbana; e Caderno de Referência para Elaboração de Plano de Mobilidade por Bicicleta nas Cidades.

\subsection{Plano Diretor de Mobilidade Urbana}

Nos últimos 50 anos, no Brasil, o planejamento de transportes era entendido como sendo sinônimo de desenho viário, sendo este o principal elemento estruturador das funções urbanas. As ações deste plano eram fundamentadas na política de desenvolvimento urbano vigente para a época, ou seja, no uso do transporte individual motorizado, na construção de infra-estrutura que atendesse à demanda vigente (processo acelerado de urbanização associado a um crescimento populacional intenso). Questões como uso do solo e meio ambiente não eram abordadas com profundidade.

Neste período os órgãos federais GEIPOT (Empresa Brasileira de Planejamento de Transportes Urbanos) e EBTU (Empresa Brasileira de Transportes Urbanos) foram os responsáveis por divulgar metodologias para o planejamento dos transportes, bem como por formar quadros técnicos para a realização destes planos e, em alguns casos, eram os responsáveis pelo seu desenvolvimento (Ministério das Cidades, 2006a).

Nestes planos outros fatores relevantes não eram considerados, como: i) a questão da acessibilidade, que é dependente do próprio sistema viário e dos meios de transportes disponíveis, e ii) a visão do planejamento como um sistema integrado, e não como um simples conjunto de partes isoladas e independentes.

A combinação de fatores como investimentos em infra-estrutura direcionados para o transporte individual (em função do crescimento de veículos), o crescimento desordenado das cidades associado ao aumento da população, aumento da poluição, aumento no número de acidentes, distribuição desigual das atividades, entre

\footnotetext{
${ }^{3}$ Curso de capacitação Gestão Integrada da Mobilidade Urbana - http://www.cidades.gov.br/cursosemob/
} 
outros problemas urbanos, estão produzindo um ciclo vicioso que tem contribuído para a redução da mobilidade nas cidades (ver Figura 2.2).

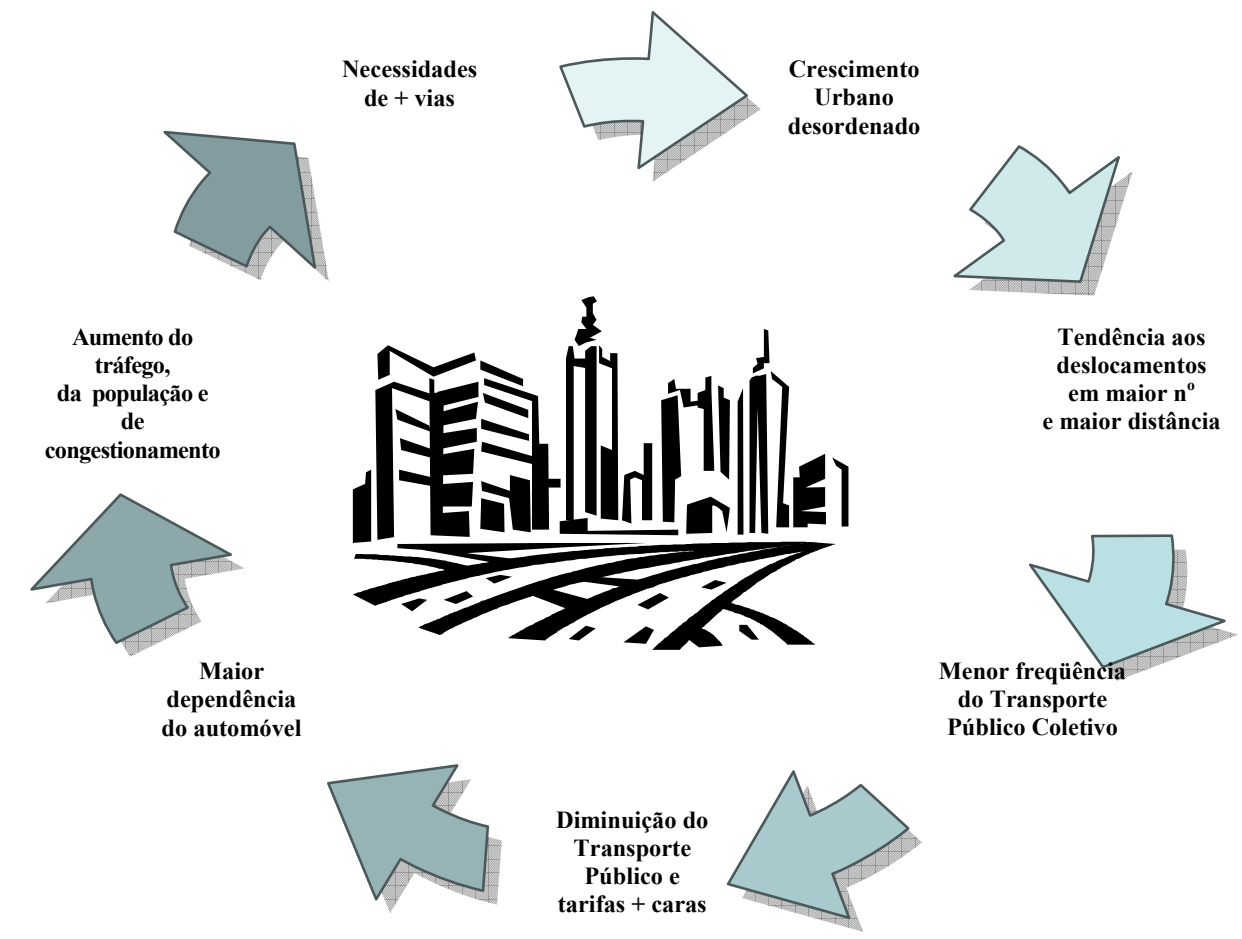

Figura 2.2 - Diagnóstico dos problemas urbanos que contribuem para a imobilidade das cidades.

Fonte: adaptado de Ministério das Cidades (2006a).

Segundo a SeMob, o desafio dos Planos Diretores de Transportes e Mobilidade está pautado na definição de ações que solucionem (ou possam minimizar) os problemas apresentados anteriormente. Para isso é necessária a integração das políticas de transporte, trânsito e planejamento urbano; relacionando a elas instrumentos de controle urbano, de uso do solo, controle ambiental, desenvolvimento econômico e inclusão social (Ministério das Cidades, 2007).

Neste sentido, a elaboração do Plano Diretor de Transportes e Mobilidade deve incorporar a participação da sociedade nas etapas de diagnóstico (discussões dos problemas de mobilidade) e aprovação do plano.

Os planos podem ser realizados sob dois enfoques ou níveis de detalhamento: i) estratégico - quando estabelecem um conjunto de diretrizes gerais, uma relação de ações, programas e projetos que devem ser seguidos pelo poder público; e ii) executivo - quando ampliam o grau de detalhamento das ações, programas e projetos em 
relação às redes de redes de transporte coletivo, sistema viário, infra-estrutura associadas à circulação de modos não motorizados e organização institucional (Ministério das Cidades, 2007).

A Secretaria Nacional de Transporte e da Mobilidade Urbana - SeMob (2006) recomenda aos municípios que os Planos Diretores de Transportes e Mobilidade contenham os seguintes produtos como resultado final:

1. "Hierarquização viária: classificação das vias segundo a sua função urbana e para a mobilidade, incluindo não só as definições tipológicas clássicas (arterial, coletora, local), mas as definições da sua destinação prioritária dentro de um contexto mais amplo da mobilidade, como exemplo, definindo-se vias: (i) para circulação de ônibus; (ii) para priorização da circulação do transporte coletivo; (iii) para priorização da circulação a pé; (iv) para a priorização do tráfego de veículos privados; (v) preferenciais para circulação de cargas; (vi) destinadas à implantação de ciclovias ou ciclofaixas".

2. "Zoneamento da mobilidade: classificação do território urbano, segundo áreas delimitadas, contendo uma destinação especifica no contexto da circulação viária, como exemplo: (i) áreas para preservação dos espaços de circulação a pé, de bicicletas e de tráfego local, onde medidas de moderação de tráfego possam ser implantadas, bem como restrições de circulação, descontinuidades de sentidos de tráfego e outras medidas possam ser tomadas para restrição do tráfego de passagem ou controle de velocidade; (ii) áreas de acesso preferencial, semi-exclusivo ou exclusivo do transporte público (coletivo e táxis) e para modos não motorizados, como regiões comerciais ou no entorno de pólos geradores, onde sejam necessárias medidas de restrição ao transporte individual; (iii) áreas de influência de corredores de tráfego onde se devam disciplinar a circulação a pé, em nome da segurança; (iv) áreas de prioridade para a circulação de veículos de carga (especialmente em cidades com áreas portuárias, em distritos industriais, etc.); (v) áreas especiais no entorno de equipamentos de saúde e de educação onde a circulação viária deva ser orientada em nome da acessibilidade e segurança".

3. Sistema de monitoração da mobilidade: "conjunto de indicadores que expressem a condição do exercício da mobilidade pela população, como exemplo: quantidade de viagens/habitante/dia, relação entre viagens motorizadas e não motorizadas, acidentes de trânsito, vítimas fatais e não fatais, 
multas de trânsito aplicadas, velocidade do transporte coletivo e privado, tempos médios despendidos nos deslocamentos, custos da mobilidade".

4. Base de dados para o planejamento continuado: "conjunto de informações numéricas e geo-referenciadas que deverão ser mantidas no processo de gestão, como exemplo: mapa da rede de transporte coletivo, mapa da hierarquia viária, mapa das condições físicas da infra-estrutura, zoneamento de tráfego, matriz de origem e de destino, tabela com dados cadastrais do serviço de transporte coletivo".

Dos quatro subprodutos do Plano Diretor, definidos pela SeMob, será dada maior ênfase, nesta pesquisa, para o item 3 - "Sistema de monitoração da mobilidade".

Segundo Ministério das Cidades (2006a), Indicadores podem ser definidos como "parâmetros representativos, concisos e fáceis de interpretar para ilustrar as características principais de determinado objeto de análise”.

Segundo Royuela ${ }^{4}$ apud Ministério das Cidades (2006a), "as funções de um indicador são: i) prover informações sobre os problemas enfocados; ii) subsidiar o desenvolvimento de políticas e estabelecimento de prioridades, identificando fatoreschave; iii) contribuir para o acompanhamento das ações definidas, especialmente as de integração; e, iv) ser uma ferramenta de difusão de informações em todos os níveis".

Os indicadores e índices são utilizados para simplificar uma informação sobre fenômenos (problemas) complexos com a finalidade de melhorar seu entendimento por parte dos tomadores de decisão (Direção Geral do Ambiente, 2000).

Alguns países da Europa, os Estados Unidos e o Canadá têm adotado indicadores como um modo de avaliar e monitorar a mobilidade em nível local (Gudmundsson, 2001, Gudmundsson 2004). Em cada um destes países foi utilizado um enfoque diferente para a utilização do conceito de mobilidade sustentável utilizando-se de indicadores (ver Nicolas et al., 2003). Na Europa, por exemplo, são adotadas medidas de integração das questões ambientais com as demais políticas públicas; nos Estados Unidos os indicadores estão sendo utilizados para a elaboração de planos estratégicos em todos os níveis; e no Canadá são utilizados elementos e estruturas advindas das experiências européias e norteamericanas (Gudmundsson, 2001; Gudmundsson, 2004; Silva et al., 2007b).

\footnotetext{
${ }^{4}$ Royuela, M. A. (2001). Los Sistemas de Indicadores Ambientales y su Papel en la Información e Integración del Medio Ambiente. I Congreso de Ingeniería Civil, Territorio y Medio Ambiente, 1231-1256.
} 
No Brasil, a utilização de indicadores faz parte da política de Mobilidade Urbana elaborada pelo governo federal, onde a definição de um Sistema de Indicadores é parte integrante dos produtos a serem definidos na elaboração dos Planos Diretores de Transportes e Mobilidade Municipais. Este sistema de indicadores pode ser utilizado nas etapas de planejamento e monitoração do plano.

Nesta pesquisa, a utilização de um sistema de indicadores será considerada não só como uma ferramenta para a etapa de monitoramento do Plano Diretor de Transportes e Mobilidade, mas a proposta é utilizá-la também na etapa de diagnóstico, como uma ferramenta de apoio a tomada de decisão de forma participativa.

No próximo capítulo são apresentados alguns conceitos relativos às formas de participação num processo de planejamento participativo. 


\section{PLANEJAMENTO PARTICIPATIVO}

Este capítulo apresenta um panorama geral sobre os aspectos que envolvem o processo de planejamento através da participação da sociedade; posteriormente, é abordado o planejamento participativo no Brasil, e na seqüência é discutida a utilização da internet no processo de planejamento participativo.

\subsection{Planejamento Participativo}

$\mathrm{O}$ processo de planejamento participativo disseminou-se mundialmente a partir da década de 60, como oposição ao modelo predominante. Nas últimas décadas, na Europa e Estados Unidos, a participação popular tem crescido muito no processo de discussões dos problemas urbano, principalmente nas questões ambientais, de planejamento urbano e de transportes.

Muitas cidades do mundo inteiro já estão adotando a participação popular como uma forma de minimizar os problemas urbanos, uma vez que, neste processo há o envolvimento da sociedade como um todo.

Uma das diferenças entre o planejamento tradicional e o planejamento participativo está no envolvimento da sociedade nas discussões dos problemas urbanos. No planejamento participativo, cada participante traz uma nova contribuição para o processo de discussão. Neste sentido há uma grande diversidade de idéias, metas, tarefas, habilidades e representações (onde os participantes representam distintos setores da sociedade: público, privado, científico, etc.), o que possibilita que os problemas sejam analisados sob diferentes pontos de vista. Neste sistema podem-se observar as seguintes características: i) diversidade de participantes e interesses; ii) aumento na interação entre os participantes e entre eles e os instrumentos de suporte a decisão; iii) alteração no método e processo de planejamento, já que neste caso o processo de planejamento está intimamente associado ao contexto político da cidade em questão. 
Outra diferença marcante entre o processo de planejamento tradicional e o planejamento participativo refere-se ao tempo de duração de cada etapa de trabalho (ver Figura 3.1). O planejamento participativo exige um tempo maior de duração de cada etapa, se comparado com o tradicional, permitindo que diferentes esferas da comunidade tenham a possibilidade de participar das discussões dos diferentes problemas urbanos. Embora muitas vezes apareçam divergências de interesses entre os diversos atores participantes, o resultado final é um processo mais democrático, resultando num planejamento mais real, auxiliando de fato na resolução dos problemas urbanos e na tomada de decisão (Geertman e Stillwell, 2003).

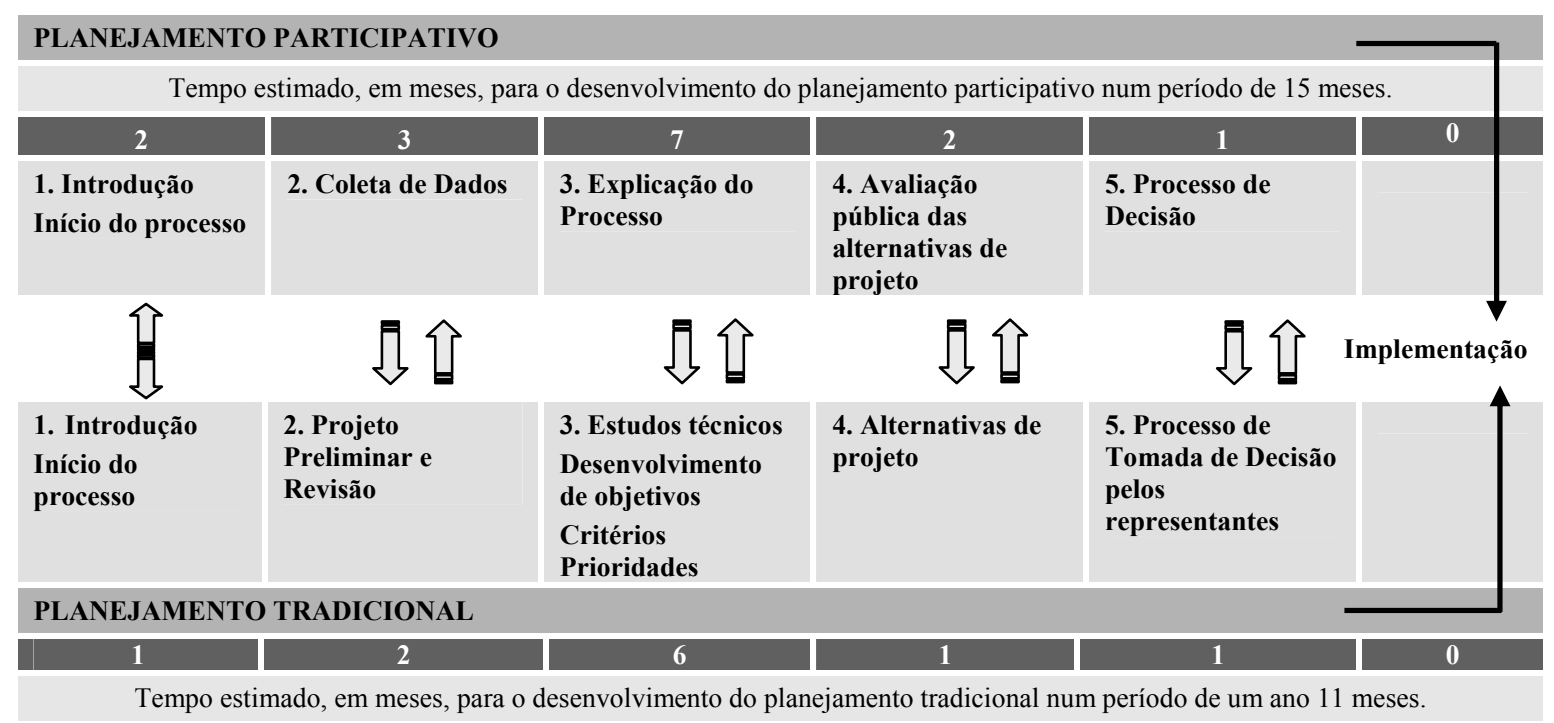

Figura 3.1 - Diferenças entre o processo de planejamento participativo e o tradicional Fonte: adaptado de Connor (s/d)

O processo de planejamento participativo, segundo Allen et al. (2002) pode ser dividido em três fases: i) Início - identificação e envolvimento de diversos segmentos da sociedade. Definição das regras e do processo (método) a ser adotado; ii) planejamento trabalho em conjunto para desenvolver os conhecimentos e ações necessárias para atingir os objetivos no plano; e iii) implementação e monitoramento (ver Figura 3.2).

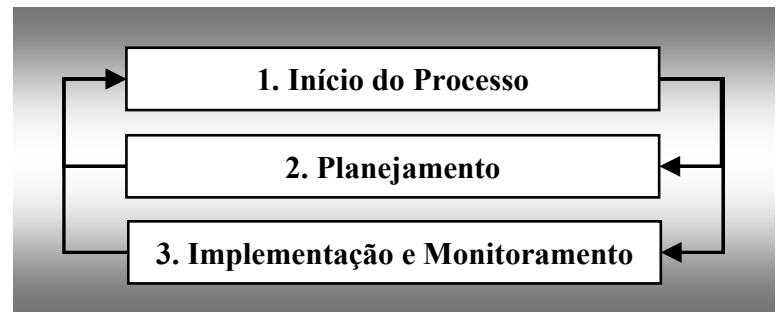

Figura 3.2 - Fases de um processo de planejamento participativo Fonte: adaptado de Allen et al. (2002). 
O envolvimento popular no processo de tomada de decisão está intrinsecamente associado ao processo de gestão governamental local, ou seja, em um processo autocrático/ditatorial, a participação da população ocorrerá através da simples informação sobre a construção do plano para a cidade. A partir do momento que os governos alteram o modo de agir com os cidadãos, ampliam-se os canais de discussão e participação. O contato, que poderia ser apenas de caráter informativo, pode, em um governo participativo, permitir a partilha de decisões (ver Figura 3.3).

A escolha do processo de planejamento a ser adotado pelo município também sofrerá influência do processo de gestão adotado pela esfera governamental, uma vez que este permitirá ou não a participação de representantes da comunidade ou a participação direta da própria população (ver Figura 3.3 e Quadro 3.1) (Yigitcanlar, 2001; Laurini, 2001; Allen et al., 2002).

Desde 1969, alguns pesquisadores, como Arnstein $^{1}$ (1969), Kingston ${ }^{2}$ (1998), Nobre ${ }^{3}$ (1999) e Pretty ${ }^{4}$ (1995), têm proposto métodos para ampliar o envolvimento do público no processo de planejamento das cidades. Todos estes métodos possuem um ponto em comum: a participação popular pode ser passiva ou ativa. Isto dependerá do processo adotado pelos planejadores para a participação dos cidadãos no processo de tomada de decisão.

A Figura 3.3 apresenta o processo de participação popular, através da Regra de Nobre. Nele é possível verificar claramente o nível de participação popular que cada cidade tem adotado em função do processo democrático adotado pelos governos locais.

\begin{tabular}{|c|c|c|c|}
\hline Autoritarismo & Tecnocracia & Democracia & Cidadania \\
\hline Informar & Consultar & Discutir & Participar $\longrightarrow$ \\
\hline Manipulação & Informação & Delegação & Participação \\
\hline
\end{tabular}

Figura 3.3 - Regra da participação popular no planejamento urbano associado à organização política

Fonte: adaptado de Nobre (1999) apud Laurini (2001).

\footnotetext{
${ }^{1}$ Arnstein, S.R. (1969) A ladder for citizen participation. In Journal of the American Institute of Planners. Vol. 35, 7, p. 216-244.

${ }^{2}$ Kingston, R. (1998) Web based GIS for Public Participation Decision Making in the UK. National Center for Geographic Information and Analysis. Proceedings of the Workshop on Empowerment, Marginalization, and Public Participation GIS. Santa Barbara, CA. p. 14-17.

${ }^{3}$ Nobre, J.A. (1999) Improving Community Participation in Urban Planning Decision Making. Private Communication. Public Works Ministry of the Macau Government.

${ }^{4}$ Pretty, J.N. (1995) Participatory Learning for Sustainable Agriculture. World Development 23. p. $1247-$ 1263.
} 
O Quadro 3.1 mostra as formas de participação popular definidas por Pretty (1995) apud Allen et al. (2002), e sua respectiva descrição. As definições de Pretty partem de níveis de participação mais passiva ou manipulada (nível 1) para uma participação mais ativa ou com alto nível de mobilização (nível 7).

Quadro 3.1 - Grau de envolvimento popular no Processo de Tomada de Decisão

\begin{tabular}{|c|c|}
\hline $\begin{array}{l}\text { FORMAS DE } \\
\text { PARTICIPAÇÃO }\end{array}$ & DESCRIÇÃO \\
\hline 1. Participação Simulada & $\begin{array}{l}\text { Neste tipo de participação, embora a comunidade tenha representantes junto aos órgãos } \\
\text { oficiais, elas não possuem o direito a voto. }\end{array}$ \\
\hline 2. Participação Passiva & $\begin{array}{l}\text { Neste caso, o processo de decisão é unilateral. Todas as decisões são tomadas pela } \\
\text { administração (decisores) e a comunidade apenas é informada do que está sendo discutido ou } \\
\text { planejado pelos técnicos. }\end{array}$ \\
\hline 3. Participação por Consulta & $\begin{array}{l}\text { A participação neste caso é realizada através de consultas realizadas junto á população ou } \\
\text { por questionários. A definição dos problemas, o controle de informações e a análise ficam a } \\
\text { cargo dos decisores - técnicos. Neste processo não há participação popular direta no } \\
\text { processo de tomada de decisão. }\end{array}$ \\
\hline $\begin{array}{l}\text { 4. Participação através de } \\
\text { Incentivos Materiais }\end{array}$ & $\begin{array}{l}\text { O processo participativo é estimulado através do recebimento de algum bem (dinheiro ou } \\
\text { alimento) pela contribuição á pesquisa. Entretanto no caso do término do benefício o } \\
\text { processo de participação também sofre perdas. }\end{array}$ \\
\hline 5. Participação Funcional & $\begin{array}{l}\text { O envolvimento popular, neste caso, é realizado com técnicos. Os problemas são discutidos } \\
\text { através de grupos que definirão os objetivos do projeto. Entretanto, a decisão final é } \\
\text { realizada apenas pelos técnicos. }\end{array}$ \\
\hline 6. Participação Interativa & $\begin{array}{l}\text { Este é o processo participativo mais ativo, ou seja, a população interage em todo o processo } \\
\text { de tomada de decisão, desde a fase de análise, desenvolvimento dos planos de ação até a } \\
\text { definição final do projeto. }\end{array}$ \\
\hline $\begin{array}{l}\text { 7. Participação através da } \\
\text { Mobilização da Comunidade }\end{array}$ & $\begin{array}{l}\text { Através da iniciativa da comunidade o processo de discussão sobre os problemas urbanos } \\
\text { pode ser realizado com a parceria de ONGs e órgãos governamentais; mas a característica } \\
\text { deste processo é a iniciativa da comunidade em resolver seus problemas. }\end{array}$ \\
\hline
\end{tabular}

Fonte: adaptado de Pretty (1995) apud Allen et al. (2002).

Em cada processo de planejamento ou tomada de decisão adotado pode haver diferentes graus de participação ou envolvimento do público. Estes fatores podem, por sua vez, influenciar na tecnologia (ou método) a ser utilizada, podendo de certa forma restringir em alguns aspectos a participação popular em todo o processo de planejamento (Geertman e Stillwell, 2003).

Alguns autores afirmam que o planejamento participativo não é necessariamente o melhor método de planejamento para tratar dos problemas da cidade em todas as esferas (instâncias). Segundo Drogendijk e Kuijn ${ }^{5}$ (1999) apud Geertman e Stillwell (2003), o planejamento participativo é apropriado quando os problemas estão claramente definidos, ou seja, existem escalas pré-definidas (problemas sociais e políticos mais complexos). No caso de problemas técnicos mais complexos deve-se adotar um misto entre o planejamento tradicional (convencional) e o participativo.

\footnotetext{
${ }^{5}$ Drogendijk, A. and Kuijn, M. (eds.) (1999) Handreiking voor Interactieve Planvorming, Land Water Milieu Informatietechnologie. LWI/CUR, Gouda.
} 
Drogendijk e Kuijn (1999) apud Geertman e Stillwell (2003) propõem um quadro com combinações entre os problemas e os tipos de planejamento (ver Quadro 3.2).

Quadro 3.2 - Classificação dos problemas políticos e os tipos de planejamento

\begin{tabular}{|c|c|c|}
\hline & $\begin{array}{l}\text { Menor concordância no que diz } \\
\text { respeito aos objetivos e valores }\end{array}$ & $\begin{array}{l}\text { Total concordância no que diz } \\
\text { respeito aos objetivos e valores }\end{array}$ \\
\hline $\begin{array}{l}\text { Menor concordância } \\
\text { no que diz respeito } \\
\text { aos conhecimentos } \\
\text { necessários }\end{array}$ & $\begin{array}{l}\text { Problemas de planejamento não- } \\
\text { estruturados com o processo de } \\
\text { aprendizagem muito adequado ao } \\
\text { planejamento participativo. }\end{array}$ & $\begin{array}{l}\text { Menor estruturação dos problemas de } \\
\text { planejamento com negociações } \\
\text { parcialmente adequadas para o } \\
\text { planejamento participativo. }\end{array}$ \\
\hline $\begin{array}{l}\text { Total concordância } \\
\text { no que diz respeito } \\
\text { aos conhecimentos } \\
\text { necessários }\end{array}$ & $\begin{array}{l}\text { Problemas de planejamento não- } \\
\text { estruturados com apaziguamento } \\
\text { parcialmente adequado ao } \\
\text { planejamento participativo. }\end{array}$ & $\begin{array}{l}\text { Melhor estruturação dos problemas } \\
\text { de planejamento com regulamentos } \\
\text { inadequados ao planejamento } \\
\text { participativo. }\end{array}$ \\
\hline
\end{tabular}

Fonte: Drogendijk e Kuijn (1999) apud Geertman e Stillwell (2003).

Kingston et $a l .^{6}$ (2003) lembram que os moradores e as organizações de classe encontram-se em grande número na abertura das discussões e, à medida que são realizadas novas reuniões, vão diminuindo. Esta diminuição dos componentes deve-se na maioria dos casos ao descomprometimento com o grupo e ao não entendimento das discussões. Este fato está diretamente relacionado à equipe de planejamento, que muitas vezes utiliza termos técnicos que dificultam o debate. Por este motivo, algumas pessoas podem se sentir intimidadas em expor suas opiniões e apresentar dúvidas diante do conhecimento dos demais participantes.

Outro ponto que pode interferir no processo de planejamento refere-se aos planejadores. Segundo Harris ${ }^{7}$ (1998) apud Geertman e Stillwell (2003), os planejadores devem adotar uma postura que leve em consideração as necessidades dos cidadãos, uma vez que eles são os responsáveis por estudar e entender os problemas da cidade e assim decidir o que deverá ser realizado, apresentando aos participantes as soluções para os problemas trazidos pela população.

No que se refere à participação popular é importante ressaltar que o envolvimento da comunidade no processo de planejamento urbano não deve ocorrer apenas na elaboração do plano diretor municipal, mas também no monitoramento deste plano. Após a implementação do plano diretor, este deverá ser avaliado e atualizado para que não

\footnotetext{
${ }^{6}$ Kingston, R.; Evans, A. and Carver, S. (2003) Public Participation via On-line Democracy. Em Planning Support Systems in Practice. Edit. S. Geertman and J. Stillwell, Springer, New York.

7 Harris, B. (1998) Optimization and design. Environment and Planning B: Planning and Design. Anniversary Issue. P. 23-28.
} 
se torne obsoleto, de forma a que sua evolução vá ao encontro das necessidades de cada município.

\subsection{O Planejamento Participativo no Brasil}

No Brasil, nos últimos 50 anos, o processo de planejamento urbano sofreu duas grandes alterações no cenário da tomada de decisão: o primeiro período corresponde à década de 1960, quando se destacou o chamado Planejamento Setorial. No segundo período, que se refere ao final da década de 1980, ganhou destaque o Planejamento Participativo.

O Planejamento Setorial estava embasado numa política de planejamento urbano nacional, ditada pelo governo federal através do SERFHAU - Serviço Federal de Habitação e Urbanismo, cuja responsabilidade era a elaboração de Planos Diretores para a maioria das cidades brasileiras, inúmeras vezes sem um conhecimento específico da realidade local. A ênfase desses planos estava nos aspectos funcionais da cidade - uso e ocupação do solo e sistema viário. Paradoxalmente, entretanto, em muitos destes planos não havia uma conexão entre os aspectos referidos anteriormente. O planejamento de transportes era desvinculado do planejamento de uso do solo e do planejamento de outros aspectos relevantes das cidades. Este era realizado para médio e longo prazo - ou seja, para atender ao município ao longo de um período de 20 anos, sem sofrer nenhuma alteração, embora os problemas da cidade certamente sofressem modificações.

Neste período, o planejamento de transportes era entendido como sendo sinônimo de desenho viário, sendo este o principal elemento estruturador das funções urbanas. No Plano Diretor, no que se refere ao planejamento de transportes, além da análise de demanda e oferta, outros fatores relevantes deveriam ser considerados, tais como: i) a questão da acessibilidade, que é dependente do próprio sistema viário e dos meios de transportes disponíveis, e ii) a visão do planejamento como um sistema integrado, e não como um simples conjunto de partes isoladas e independentes.

A participação popular inseriu-se no contexto urbano apenas na década de 1980, com o movimento político que defendia a volta da democracia no país, uma vez que o país encontrava-se sob regime ditatorial.

O marco da implantação do Planejamento Participativo no Brasil é a promulgação da Constituição de 1988; cujo artigo 182, parágrafo primeiro, refere-se à obrigatoriedade da elaboração de um Plano Diretor para toda cidade brasileira com população acima de 20.000 habitantes. Esta obrigatoriedade poderia ser definida como um 
instrumento básico da política de desenvolvimento urbano. A grande alteração em relação ao passado encontra-se na inclusão dos aspectos físico-espaciais, políticos, sociais, econômicos e ecológicos; além da questão da Participação Popular - característica marcante na discussão dos novos planos, através do estímulo à participação em todas as etapas do processo. Neste contexto, todos os problemas urbanos são então pensados através de uma visão global (holística), cabendo a cada prefeitura a elaboração do respectivo Plano Diretor, através de corpo técnico próprio ou contratado, mas juntamente com a comunidade.

O município de Porto Alegre (RS - Brasil) foi pioneiro na implantação do processo participativo junto à comunidade. Inicialmente, este processo ocorreu com a participação popular nas discussões sobre o Orçamento Participativo - no final da década de 1990. Em um segundo momento, o processo participativo avançou para a elaboração do Plano Diretor da cidade, intitulado de Desenvolvimento Urbano Ambiental (PDDUA). Este foi o primeiro Plano Diretor do Brasil que contou com a participação popular no processo de tomada de decisão, com a proposição de diretrizes urbanísticas inovadoras para a cidade; sendo referência para outras administrações municipais. Nestes dois processos de participação, a comunidade precisava se encontrar em local e horário pré-definido pela comissão técnica para iniciar o processo de discussão.

Outro instrumento que tem contribuído para controlar o crescimento urbano e o espalhamento espacial é o Estatuto da Cidade. Este é composto por um conjunto de leis - instrumentos urbanísticos, que visam subsidiar a elaboração dos Planos Diretores dos Municípios.

A atual política de desenvolvimento urbano adotada pelo Governo Federal baseia-se na democratização dos espaços e serviços urbanos a toda população brasileira, de forma a reduzir as desigualdades urbanas, tendo como ponto central a questão da sustentabilidade urbana. Entretanto, essa política só se efetivará na prática caso haja um envolvimento popular nas discussões sobre seu bairro, município, estado ou país.

Atualmente, o processo participativo tem ocorrido em nível local, ou seja, ele está fundamentado no formato de participação tradicional, onde são necessárias reuniões presenciais com representantes de entidades de classe, técnicos (de diferentes áreas do governo) e representantes da comunidade. Estas reuniões podem ser temáticas e/ou por regiões da cidade, onde a maioria dos participantes nem sempre serão os mesmos, o que pode caracterizar um problema para o planejamento.

De acordo com informações disponibilizadas pelo Ministério das Cidades (2007), de 1683 municípios pesquisados, somente em 23,59\% deles o Plano Diretor foi 
elaborado de forma participativa (embora todos tivessem a obrigatoriedade de adotar esse procedimento). Nos demais casos, ou seja, na maioria dos municípios brasileiros, o processo não ocorreu de forma participativa ou houve divergências na determinação da participação da sociedade (nestes municípios o processo de participação não foi muito claro) (ver Figura 3.4).
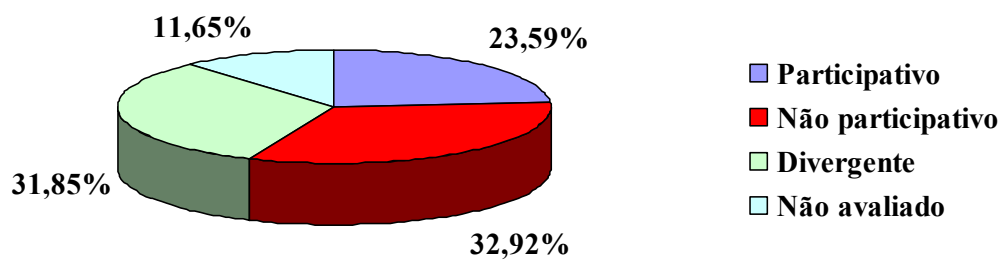

Figura 3.4 - Diagnóstico do processo de participação popular nos Planos Diretores Municipais

Fonte: Ministério das Cidades (junho, 2006).

O Ministério das Cidades realizou uma pesquisa em parceria com o CONFEA (Conselho Federal de Engenharia, Arquitetura e Agronomia) sobre os Planos Diretores Participativos ${ }^{8}$. Esta pesquisa abordou os seguintes temas: i) maiores preocupações municipais com relação ao Plano Diretor, ii) elaboração de estudos específicos, iii) conteúdos e instrumentos dos Planos, iv) terceirização e consultoria, e v) situação dos Planos.

Dentre os cinco temas levantados na pesquisa do Ministério das Cidades, para esta pesquisa o tema Maiores preocupações municipais com relação ao Plano Diretor foi considerado o mais relevante para análise.

A Tabela 3.1 apresenta um elenco das questões estruturais consideradas mais importantes pelos municípios avaliados (por faixa de habitantes e para o país), com seus respectivos ordenamentos. As células em cinza claro apresentam o ordenamento dos Temas e as células na cor cinza escuro mostram os Temas que obtiveram as dez primeiras posições (ranking) para cada grupo de municípios.

\footnotetext{
${ }^{8}$ A pesquisa sobre o processo de elaboração e conteúdo dos Planos Diretores Participativos nos municípios brasileiros foi realizada entre outubro de 2006 a fevereiro de 2007. Esta pesquisa foi aplicada em 1552 municípios, que tinham a obrigatoriedade de elaborar planos até outubro de 2006.
} 
Tabela 3.1 - Questões Estruturais dos Planos Diretores Participativos

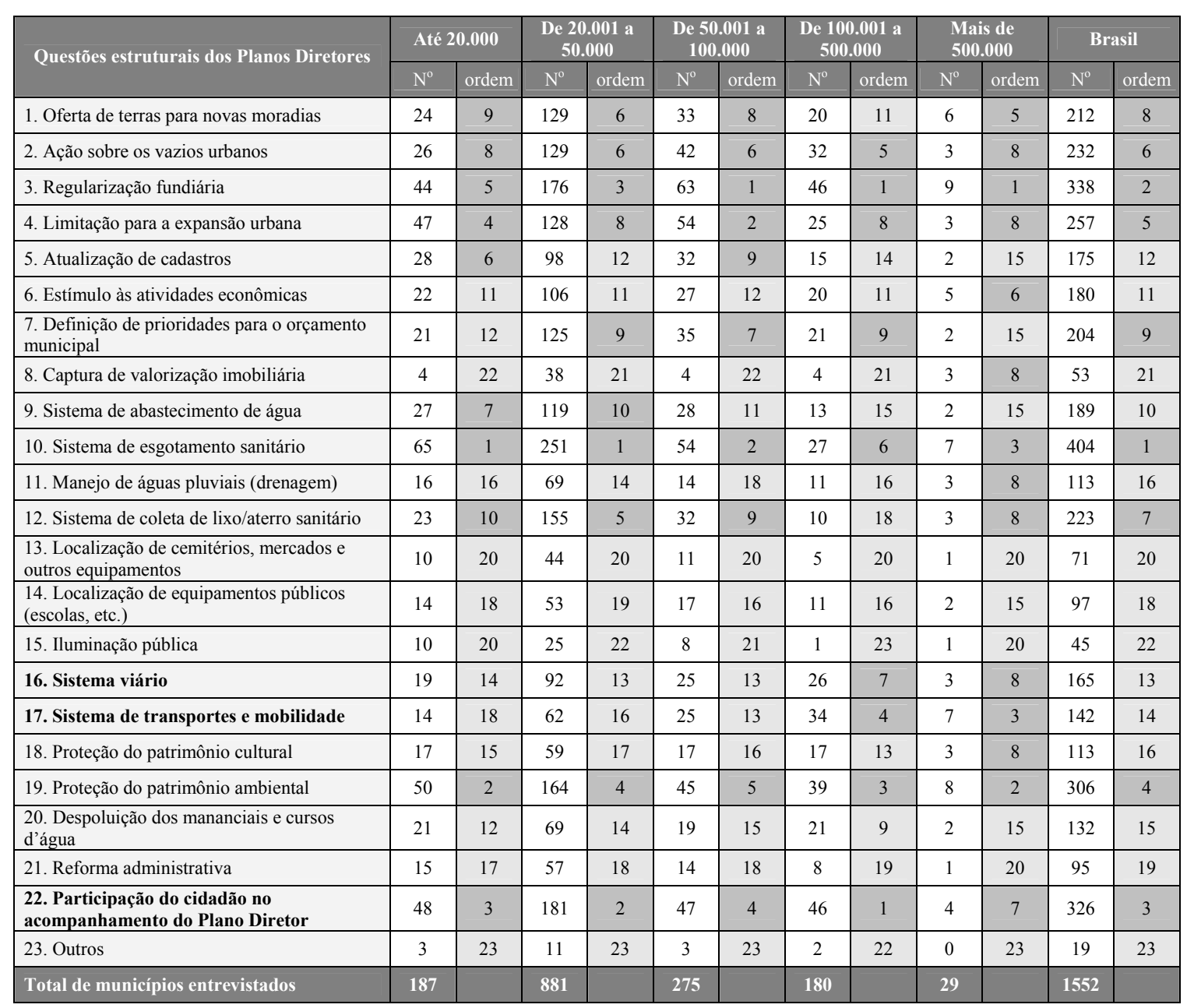

Fonte: Ministério das Cidades (2007)

De acordo com os dados apresentados na Tabela 3.1, dos vinte temas apresentados para avaliação nos municípios brasileiros, os dez Temas considerados mais importantes (no ranking nacional) envolviam questões estruturais das cidades como: Sistema de esgotamento sanitário ( $1^{\mathrm{a}}$ posição); Regularização fundiária ( $2^{\mathrm{a}}$ posição); Participação do cidadão no acompanhamento do Plano Diretor ( $3^{\mathrm{a}}$ posição); Proteção do patrimônio ambiental ( $4^{\mathrm{a}}$ posição); Limitação para a expansão urbana ( $5^{\mathrm{a}}$ posição); Ação sobre os vazios urbanos ( $6^{\mathrm{a}}$ posição); Sistema de coleta de lixo/aterro sanitário ( $7^{\mathrm{a}}$ posição); Oferta de terras para novas moradias ( $8^{\mathrm{a}}$ posição); Definição de prioridades para o orçamento municipal ( $9^{\mathrm{a}}$ posição); e Sistema de abastecimento de água (10 $0^{\mathrm{a}}$ posição).

Um outro ponto que merece destaque na Tabela 3.1 refere-se ao ranking nacional dos temas associados à mobilidade urbana (objeto de estudo da presente pesquisa). Naquela pesquisa as questões Sistema Viário e Sistemas de Transportes e Mobilidade foram pontuadas separadamente, embora sejam temas que, por definição, fazem parte do conceito de Mobilidade, como foi apresentado no capítulo anterior. Estas duas questões 
obtiveram respectivamente a $13^{\mathrm{a}}$ (Sistema Viário) e $14^{\mathrm{a}}$ (Sistemas de Transportes e Mobilidade) posições no ranking brasileiro.

Analisando cada grupo de municípios separadamente, de acordo com os dados apresentados neste levantamento, nos municípios com população de até 20.000 habitantes, nas faixas de 20001 a 50000 habitantes e de 50001 a 100000 habitantes os problemas considerados mais importantes refletem aqueles definidos no ranking nacional, apenas com alteração no ordenamento dos Temas Atualização de cadastro, Definição de prioridades para o orçamento municipal.

As alterações na definição das prioridades (ou na definição dos problemas considerados mais importantes) começam a se tornar significativas, em relação ao ranking nacional, a partir dos levantamentos realizados nas cidades consideradas de médio porte (com população entre 100001 a 500000 habitantes). A partir desta classificação são listados como temas mais importantes a questão do Sistema Viário e Sistemas de transportes e mobilidade, que obtém, respectivamente, a $7^{\mathrm{a}}$ e a $4^{\mathrm{a}}$ posições.

Analisando o ranking referente às cidades de médio porte (compreendidas entre 100.000 a 500.000 habitantes) e aquelas acima de 500000 habitantes, estas questões obtiveram respectivamente a $7^{\mathrm{a}}$ e a $8^{\mathrm{a}}$ posições (para o Tema Sistema Viário) e a $4^{\mathrm{a}}$ e a $3^{\mathrm{a}}$ posições (para o Tema Sistemas de Transportes e Mobilidade). Este resultado aponta para a necessidade destes municípios em implantarem políticas de Mobilidade visando minimizar os problemas decorrentes da falta de planejamento integrado entre as questões de uso do solo e transportes.

Outro elemento que merece destaque na Tabela 3.1, e que também é objeto de estudo desta pesquisa, refere-se ao Tema "Participação do cidadão no acompanhamento do Plano Diretor”. Embora a participação da sociedade tenha sido considerada um aspecto importante para a elaboração do Plano Diretor Participativo, ao se confrontar os dados das duas pesquisas realizadas pelo Ministério das Cidades (Diagnóstico dos Planos Diretores Participativos $x$ Questões Estruturais dos Planos Diretores Participativos) pôde-se observar uma divergência entre elas, uma vez que, na prática a maioria dos municípios não implantou a participação popular de forma efetiva.

Conforme foi apresentado anteriormente, nos últimos anos (2005-2007), a nova política urbana preconizada pelo Governo Federal tem incentivado a participação popular no processo de planejamento das cidades brasileiras através da participação de técnicos e de representantes da sociedade civil, em reuniões predominantemente presenciais. No entanto, para que o processo leve a cidades mais igualitárias é necessário 
que uma parcela significativa da população possa participar destas discussões, fato este que não ocorreu na maioria das cidades brasileiras.

\subsection{Planejamento Participativo e Internet}

Em muitos países, o processo participativo tem sido realizado através da adoção de novas ferramentas computacionais, como forma de ampliar o número de participantes no processo de discussão e tomada de decisão, no âmbito dos problemas urbanos.

No que se refere à utilização das novas tecnologias, a internet já faz parte atualmente do cotidiano de uma parcela significativa da população, permitindo a divulgação de grande quantidade de informações de diferentes áreas e o respectivo acesso, com maior eficiência, a um número maior de pessoas. Ela tem proporcionado uma nova linguagem, bem como um novo modelo de organização das informações, documentações espaciais e visualização destas informações armazenadas, através da utilização de recursos de hipertexto, multimídia e hipermídia; através de websites, portais, sites de busca e quiosques eletrônicos; além de facilitar de certo modo as inter-relações sociais, comerciais e governamentais, quebrando algumas barreiras como a distância física entre os usuários. Ela ainda tem proporcionado um estreitamento entre os usuários e as informações disponíveis neste meio digital - ambiente virtual.

Segundo Kingston et al. (2003), a internet pode ser considerada a ferramenta mais democrática existente em nossa civilização, uma vez que ela permite o livre acesso a uma série de informações através de um clique, desde que o usuário tenha um computador conectado à internet. Entretanto, deve-se lembrar que em muitos países, como é o caso do Brasil, ainda existe um grande número de cidadãos excluídos desta tecnologia.

No âmbito governamental, muitas cidades do Brasil e de outros países têm disponibilizado informações aos cidadãos que contribuíram para facilitar ou estreitar as relações entre o governo e o munícipe. Dentre essas informações, destacam-se: consulta (informações sobre legislação, dados geográficos, etc.), interação (links para e-mail para diferentes setores públicos e áreas para comentários, etc.), além do planejamento participativo.

A participação popular no processo de planejamento urbano tem crescido muito nos últimos anos, principalmente na Europa e nos Estados Unidos, através da utilização da internet como um canal de participação e interação popular. Embora necessite de um tempo maior durante todo o processo de planejamento, se comparado com o 
planejamento tradicional, esta participação tem possibilitado que diferentes esferas da comunidade participem das discussões de distintos problemas urbanos. Embora muitas vezes apareçam divergências de interesses entre os diversos atores participantes, o resultado final é um planejamento mais democrático (Geertman e Stillwell, 2003).

A utilização da internet no processo de planejamento possibilita também que um número maior de usuários possa discutir os problemas urbanos juntamente com os técnicos e decisores, desde que haja divulgação na mídia local. Embora este processo de participação popular já esteja ocorrendo em muitas cidades do mundo inteiro, o principal problema da participação, seja ela na forma tradicional (presencial) ou não, refere-se em geral ao pequeno número de pessoas interessadas em discutir os problemas da cidade. Algumas pesquisas apontam que a baixa taxa de participação popular nestas reuniões é decorrente do local e horário, uma vez que muitos dos participantes são trabalhadores do comércio e indústria, portanto presos a horários de trabalho fixos e rígidos. A internet pode, de certa forma, minorar este problema.

Experiências internacionais mostram o envolvimento popular no processo de tomada de decisão local, através da utilização da internet; acessada no ambiente residencial, de trabalho, escolar ou mesmo através de cybercafés. Na maioria dos casos estudados, o processo de participação pode ocorrer por meio de uma página disponível na internet, através da qual os cidadãos acessam a uma série de informações relacionadas ao município em que residem, independente do local e horário de acesso. Esta consulta pode ser realizada através de processos de interatividade diretos ou indiretos, ou mesmo através de processos não interativos. Dentre os processos de interação e não-interação com a comunidade local, pode-se destacar, como exemplo do segundo tipo, a construção de uma página do município apenas com informações referentes a dados geográficos, censitários, ou referentes à legislação urbana do município.

A participação popular começa a ser interativa a partir do momento que existe a comunicação com o corpo técnico, ou seja, quando na mesma página o usuário pode responder a questionários sobre determinado problema, enviar críticas, sugestões ou realizar consultas recorrendo ao e-mail. No entanto, a participação on-line da comunidade pode se dar através de uma ação direta (embora virtual) nas decisões, em um sistema que proporcione a visualização espacial das intervenções realizadas pelo usuário através de ferramentas de construção de mapas da cidade, fotos do local em questão, além da construção de cenários alternativos. 
As experiências analisadas na literatura confirmam que a implementação do processo de participação popular utilizando a internet tem levado ao crescimento do número de participantes envolvidos em processos de tomada de decisão local. Isto é hoje fundamental para o Brasil, dado que, segundo Magagnin et al. (2004), no caso brasileiro pode-se verificar apenas a disponibilização de e-mail como forma de participação pública junto aos órgãos municipais com recursos da informática.

Segundo Costa et al. (2003) as informações disponibilizadas nos site da maioria das cidades brasileiras de médio porte referem-se apenas a dados geográficos, econômicos e demográficos, sendo que muitos deles têm como origem o IBGE (Instituto Brasileiro de Geografia e Estatística). Outras informações, como índices ou indicadores urbanos ou mesmo informações sobre outras formas de participação popular, utilizando-se da internet ainda não fazem parte da realidade destas cidades.

Por outro lado, segundo dados obtidos junto ao IBGE (2007) o acesso à internet tem crescido muito no Brasil. As Tabelas 3.2 e 3.3 mostram respectivamente o percentual de acesso à internet segundo a finalidade e o percentual de acesso à internet em relação ao local de acesso.

Tabela 3.2 - Percentual das pessoas que utilizaram a internet por finalidade (população de 10 anos ou mais de idade) no período de referência dos últimos três meses por Grandes Regiões

\begin{tabular}{|c|c|c|c|c|c|c|}
\hline \multirow[b]{2}{*}{ Finalidade de acesso à Internet } & \multirow[b]{2}{*}{ Brasil } & \multicolumn{5}{|c|}{ Grandes Regiões } \\
\hline & & Norte & Nordeste & Sudeste & Sul & $\begin{array}{l}\text { Centro- } \\
\text { Oeste }\end{array}$ \\
\hline \multicolumn{7}{|c|}{ Percentual Total } \\
\hline Educação e aprendizado & 71,7 & 77,5 & 75,6 & 69,5 & 72,4 & 74,7 \\
\hline Comunicação com outras pessoas & 68,6 & 57,7 & 65,0 & 70,1 & 71,7 & 64,8 \\
\hline Atividade de lazer & 54,3 & 51,6 & 54,6 & 52,9 & 58,3 & 56,0 \\
\hline Leitura de jornais e revistas & 46,9 & 49,2 & 49,0 & 45,4 & 46,9 & 52,2 \\
\hline $\begin{array}{l}\text { Interação com autoridades públicas ou } \\
\text { órgãos do governo }\end{array}$ & 27,4 & 24,7 & 27,5 & 28,2 & 24,6 & 30,0 \\
\hline $\begin{array}{l}\text { Comprar ou encomendar bens ou } \\
\text { serviços }\end{array}$ & 13,7 & 15,7 & 11,4 & 14,1 & 13,1 & 15,3 \\
\hline Transações bancárias ou financeiras & 19,1 & 13,6 & 14,8 & 20,8 & 18,4 & 20,1 \\
\hline Buscar informações e outros serviços & 24,5 & 19,7 & 23,5 & 25,3 & 23,5 & 25,1 \\
\hline
\end{tabular}

Fonte: IBGE (março, 2007). 
Tabela 3.3 - Percentual das pessoas que utilizaram a internet em cada local (população de 10 anos ou mais de idade) no período de referência dos últimos três meses por Grandes Regiões

\begin{tabular}{|c|c|c|c|c|c|c|}
\hline \multirow{2}{*}{ Local de acesso à Internet } & \multirow{2}{*}{ Brasil } & \multicolumn{5}{|c|}{ Grandes Regiões } \\
\hline & & Norte & Nordeste & Sudeste & Sul & Centro-Oeste \\
\hline \multicolumn{7}{|c|}{ Total } \\
\hline Domicílio em que moravam & 50,0 & 28,6 & 34,7 & 55,7 & 52,9 & 45,1 \\
\hline Local de trabalho & 39,7 & 37,3 & 35,9 & 39,3 & 42,7 & 43,8 \\
\hline Estabelecimento de ensino & 25,7 & 27,2 & 27,1 & 23,7 & 29,6 & 26,5 \\
\hline Centro público de acesso gratuito & 10,0 & 10,9 & 9,6 & 9,8 & 9,8 & 12,0 \\
\hline Centro público de acesso pago & 21,9 & 38,1 & 33,1 & 19,7 & 14,6 & 23,3 \\
\hline Outro local & 31,1 & 28,4 & 31,5 & 30,7 & 32,8 & 30,1 \\
\hline
\end{tabular}

Fonte: IBGE (março, 2007).

Segundo os dados apresentados nas Tabelas 3.2 e 3.3 pode-se afirmar que embora o acesso à internet tenha crescido entre a população brasileira, a população ainda não esta habituada a utilizá-la com a finalidade de interagir com autoridades públicas ou órgãos do governo e/ou buscar informações e outros serviços. A grande maioria dos usuários, ou seja, uma parcela significativa da população ainda tem utilizado a internet para fins educacionais ou para comunicação com outras pessoas (troca de e-mail) ou para atividades de lazer.

Outra informação de destaque refere-se aos locais de acesso: $50 \%$ da população brasileira possui acesso à internet domiciliar. Embora este percentual não esteja distribuído igualitariamente por todas as regiões brasileiras (as regiões sul e sudeste possuem índices acima da média nacional), o país poderia adotar políticas que permitissem a participação da sociedade utilizando-se da internet como um instrumento de participação popular no processo de planejamento das cidades.

Com estes dados pode-se afirmar que o envolvimento popular no Brasil e no exterior ocorreu e ainda ocorre de forma díspar, ou seja, a forma de participação adotada por alguns países já insere as novas tecnologias, como a internet, como um meio de aumentar o número de participantes no processo de tomada de decisão local, enquanto que no Brasil este processo ainda é essencialmente presencial.

No Brasil, a internet poderia ser utilizada como ferramenta para ampliar o processo de planejamento participativo nos municípios. Outro elemento que poderia contribuir para a ampliação do processo participativo está associado à utilização de novas tecnologias. Se as prefeituras recorressem à utilização de novas ferramentas computacionais ao invés da prática atual de reuniões presenciais pré-agendadas, talvez um número maior de participantes contribuísse para o planejamento municipal. Esta mudança permitiria à comunidade escolher o dia e horário mais apropriado para participação no processo de 
discussão. Isto fica evidente em alguns projetos já desenvolvidos em diversos países e voltados ao planejamento urbano e de transporte, que têm utilizado Sistemas de Suporte à Decisão Espacial recorrendo à internet (discutido no próximo capítulo). Na maior parte destes casos, no entanto, a participação popular no processo de tomada de decisão, quando envolve recursos de informática, se dá através da utilização de software comercial. Estes projetos têm ainda como características comuns: financiamento advindo da esfera governamental e envolvimento de universidades para o desenvolvimento e implementação do projeto. Em contrapartida, na maioria das cidades brasileiras, o processo de planejamento urbano e de transportes ocorre em nível local, sem a participação de pesquisadores universitários e com baixo investimento do governo local. Como conseqüência, a proposta de utilização de um sistema que utilize recursos computacionais de baixo custo é essencial para o sucesso do processo, pois a simples adoção de programas comerciais pode inviabilizar toda e qualquer iniciativa.

No próximo capítulo serão apresentadas algumas ferramentas computacionais (sistemas de suporte à decisão) que podem auxiliar no processo de tomada de decisão participativo através da internet. 


\section{SISTEMA DE SUPORTE À DECISÃO E INTERNET}

Este capítulo apresenta uma breve introdução sobre os conceitos que envolvem a tomada de decisão no processo de planejamento. $\mathrm{Na}$ seqüência são apresentados alguns sistemas que dão suporte à tomada de decisão; com destaque ao Sistema de Suporte à Decisão e sua aplicação na internet. Posteriormente são apresentadas algumas experiências de aplicação de sistemas de suporte à decisão que subsidiaram a elaboração do sistema proposto.

\subsection{A Tomada de Decisão no Processo de Planejamento}

O processo de planejamento envolve a tomada de decisão, tanto individual quanto em grupo. Segundo Batty e Densham (1996) o planejamento está baseado no processo para a resolução de problemas urbanos que começa com a definição do problema. Estes são testados através de modelos e simulações, os quais geram cenários alternativos para serem avaliados e escolhidos. Em cada processo de escolha de uma determinada alternativa há um processo de decisão (ou escolha). Este processo por sua vez é cíclico, ou seja, uma decisão tem impacto (direto ou indireto) em outras decisões, e é impossível prever os impactos nas decisões subseqüentes (Kersten et al., 1999).

O problema da "decisão" é muito antigo. Todas as pessoas, a qualquer momento de suas vidas, estão envolvidas de alguma forma no processo de tomada de decisão. As civilizações produziram ao longo do tempo, "especialistas", que tinham como função planejar mecanismos intelectuais para a tomada de decisão (Yigitcanlar, 2001).

A teoria da decisão é uma área do conhecimento que possui técnicas analíticas para auxiliar os decisores a escolher as alternativas em função de suas possíveis conseqüências. Esta teoria pode ser aplicada para as seguintes condições: certeza, risco ou incerteza. A tomada de decisão através da certeza significa que cada alternativa conduz a apenas uma escolha e esta por sua vez equivale a uma conseqüencia, e a escolha entre as 
alternativas geradas é equivalente a uma escolha entre as diversas conseqüências. $\mathrm{Na}$ decisão pelo risco, cada alternativa terá diversas conseqüências, sendo que estas são conhecidas pelo decisor. Na tomada de decisão através da incerteza, cada alternativa está associada com uma conseqüência e a escolha das alternativas está associada com a probabilidade de ocorrência de cada conseqüência (Yigitcanlar, 2001; Kersten et al., 1999; Cybernetica, 2007).

A tomada de decisão pode ser definida como o processo de escolha de alternativas. As decisões referem-se aos seguintes questionamentos: o QUE e QUANDO fazer? (Kersten et al., 1999; Yigitcanlar, 2001; Silva et al., 2004).

A teoria de decisão, segundo Kersten et al. (1999) foi desenvolvida por Herbert Simon em 1947. Segundo esta teoria, o processo de decisão divide-se em 3 fases: i) investigação (ou inteligência) - está associada à etapa de definição (entender e conhecer) do problema, torná-lo mais explícito, determinar as variáveis relevantes e as inter-relações existentes; ii) desenho - está associada à análise dos possíveis cursos de ação (das alternativas), neste momento o decisor realiza as simulações (através de modelos específicos) e analisa as alternativas disponíveis, através do impacto que cada uma delas pode gerar; e iii) escolha - corresponde a escolha de uma alternativa. Posteriormente deve ser realizado um monitoramento após a implementação da alternativa escolhida (Kersten et al., 1999; Saboya, 2000; Yigitcanlar, 2001).

No processo de tomada de decisão o decisor não procura a decisão ótima, mas aquela que atenda a alguns critérios específicos. A melhor decisão é aquela mais satisfatória (ou que trará menor impacto negativo) dentre todas as simulações realizadas. (Kersten et al., 1999).

A tomada de decisão é um processo que envolve múltiplos participantes e múltiplas informações. Em função desta multiplicidade de participantes e informações podem ocorrer alguns problemas para a escolha da(s) alternativa(s), uma vez que os decisores, na maioria das vezes, possuem diferentes pontos de vista e se utilizam de múltiplas interpretações para representar os problemas e assim propor soluções.

O processo de decisão pode ser realizado com o auxílio de vários modelos de decisão. A escolha por um método ou um modelo de decisão, na maioria das vezes, ocorre subjetivamente ou pela preferência ou conhecimento de determinado método. Os modelos podem ser agrupados em quatro Categorias: Modelos Físicos, Abstratos, Simbólicos e Matemáticos. 
Estes modelos (instrumentos de análise) permitem verificar as inter-relações existentes entre os diversos problemas urbanos (por exemplo, nas áreas que envolvem o planejamento da mobilidade urbana) auxiliando na sua representação, análise, solução e avaliação (Kersten et al., 1999).

Algumas ferramentas computacionais, tais como SIG, DSS e SDSS, incorporam em seus sistemas modelos de decisão baseados nos modelos matemáticos. Estas ferramentas constituem-se no objeto de análise da próxima seção deste capítulo. A Figura 4.1 apresenta a utilização de ferramentas computacionais de suporte à decisão no processo de planejamento.

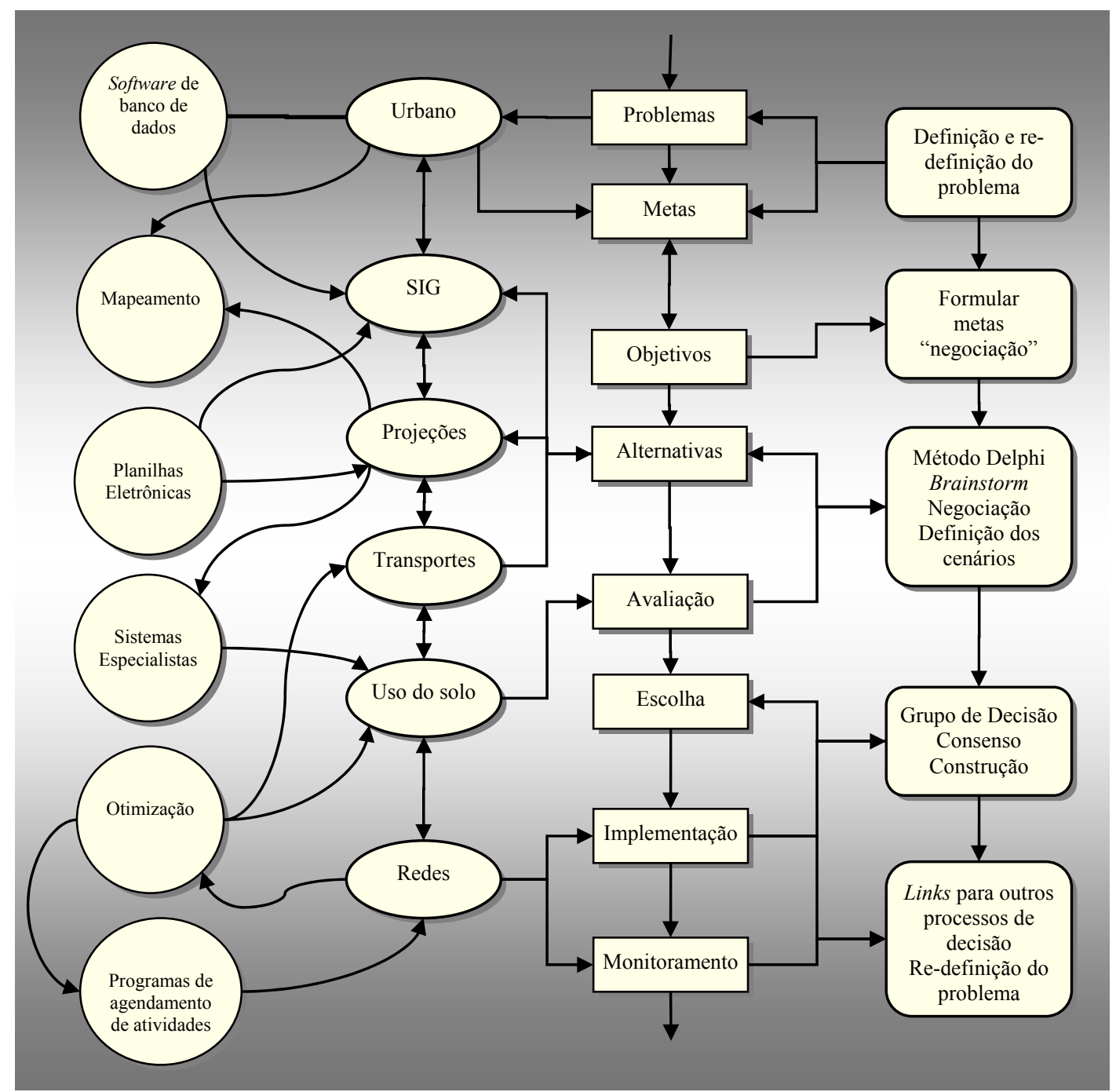

Figura 4.1 - Utilização de ferramentas computacionais de Suporte à Decisão no processo de planejamento

Fonte: adaptado de Batty e Densham (1996).

A Figura 4.1 apresenta, de forma esquemática, como pode se dar a interrelação de um SIG com outras ferramentas computacionais dentro de um processo de 
planejamento. Segundo Batty and Densham (1996) esta estrutura é citada nos estudos de Harris $(1989,1991)$ como sendo um referencial para a utilização de um Sistema de Suporte ao Planejamento (PSS); uma vez que neste esquema são apresentadas as possíveis ligações das ferramentas computacionais aos diferentes estágios de planejamento. Esta figura mostra que é possível realizar uma ligação entre os vários modelos computacionais existentes no mercado com um SIG para resolver determinado problema urbano, seja ele nas áreas de transporte, uso do solo, meio ambiente, etc.

\subsection{Ferramentas de Suporte à Decisão}

Entre 1960 e 1970 foram desenvolvidas ferramentas computacionais que proporcionaram um avanço no processo de planejamento e tomada de decisão. Segundo Batty e Densham (1996) as ferramentas computacionais para análise espacial envolvem qualquer software que contenha um ambiente espacial ou geográfico e um ambiente de descrição de dados. A definição mais tradicional é aquela que integra as funções de armazenamento, manipulação e visualização de dados onde o ambiente (dimensão) espacial é a palavra-chave deste ambiente computacional.

Particularmente, no caso do planejamento urbano e de transportes, destacamse o SIG (Sistema de Informação Geográfica) e o DSS (Decision Support System, ou Sistema de Suporte à Decisão), sendo este último utilizado inicialmente para o gerenciamento de dados, modelagem e suporte ao planejamento estratégico. Nas décadas seguintes (1980 e 1990) houve um grande crescimento tecnológico nas áreas de gerenciamento de Bancos de Dados e visualização gráfica (espacial), incluindo as novas gerações dos SIG. O desenvolvimento de ferramentas mais sofisticadas no final da década de 1990, nas áreas de análise, simulação e modelagem espacial, permitiu o seu uso cada vez mais freqüente para o planejamento das cidades. Mais ainda, as ferramentas com recursos de multimídia e realidade virtual são consideradas ferramentas de modelagem de última geração para o planejamento, uma vez que podem estar associadas à simulação, redes neurais e lógica fuzzy (Huxhold, 1991; Brail e Klosterman, 2001; Yigitcanlar, 2001; Geertman e Stillwell, 2003).

A seguir são apresentadas em mais detalhes estas ferramentas computacionais de suporte à decisão citadas anteriormente. 


\subsubsection{Sistemas de Informações Geográficas - SIG}

$\mathrm{Na}$ linha dos recursos computacionais inovadores, os Sistemas de Informações Geográficas constituem uma ferramenta que possibilita a visualização de informações espaciais em formatos diversos, proporcionando ao planejador uma ampla visão da problemática que está ocorrendo em uma determinada área da cidade, através da interpretação de dados oferecidos pelo próprio sistema (Huxhold, 1991; Brail \& Klosterman, 2001; Shiffer, 1995; Yigitcanlar, 2001). Este ambiente permite o armazenamento, codificação e análise de dados espaciais e alfanuméricos. Ele associa atributos gráficos e não-gráficos, ou seja, ele é composto por um ambiente gráfico associado a um banco de dados alfanumérico, sendo a estrutura de dados baseada em relações topológicas - sua localização espacial relativa está associada a um sistema de coordenadas (Huxhold, 1991).

Os crescentes avanços tecnológicos têm permitido que planejadores urbanos utilizem cada vez mais o SIG, não apenas como suporte para o armazenamento e análise de informações espaciais, mas para a implementação de novas técnicas de planejamento, fazendo dele uma plataforma em que se pode utilizar a simulação de ambientes através de normas e equações advindas do planejamento convencional (Shiffer, 1992).

Segundo Thompson ${ }^{1}$ (1996) apud Yigitcanlar (2001) os SIG trouxeram grandes benefícios para o processo de tomada de decisão, dado que: i) auxiliam no esclarecimento do processo de decisão através da definição de uma estruturação das informações; ii) permitem ampliar a escala de alternativas - o software gera novas alternativas para o problema urbano ampliando-se também as análises; iii) possibilitam uma melhor definição entre os objetivos a serem alcançados em função das alternativas geradas, ou seja, possibilita uma "melhor escolha" dentre as alternativas (cenários) geradas pelo sistema; iv) possibilitam a discussão e alteração dos critérios de decisão; e v) possibilitam explorar os conflitos entre os critérios de decisão e os objetivos.

Um dos maiores impactos na área de planejamento urbano e de transportes, sentido atualmente por pesquisadores e planejadores, foi o desenvolvimento do hardware e software, a partir da década de 1990, voltados à internet. Este "novo" ambiente tem possibilitado a disponibilização, e respectivo acesso, a uma grande quantidade de dados (som, imagens, fotos, vídeo, documentos, mapas - utilizando-se recursos de multimídia e hipermídia) com maior eficiência e a um número maior de pessoas (Klosterman, 2001 apud Brail e Klosterman, 2001; Yigitcanlar, 2001). Este ambiente permite a visualização dos

\footnotetext{
${ }^{1}$ Thompson, D.S.D. (1996) GIS as Social Practice: Consideration for a Developing Country. GIS/LIS 96.
} 
dados gráficos e alfanuméricos através de páginas disponíveis na web, assegurando a consulta, interação e comunicação de multiusuários on-line. No entanto, isto tudo acontece sem que ocorram alterações nas bases de dados originais, após a utilização dos usuários, assegurando a integridade dos bancos de dados.

Para os planejadores, este ambiente proporcionou grandes avanços no desenvolvimento de sistemas que possibilitam o acesso remoto às informações a partir de diferentes locais, através de plataformas heterogêneas, possibilitando um sistema de suporte à decisão interativo, ou seja, o desenvolvimento de ferramentas de participação on-line, com a possibilidade de visualização e modelagem espacial e virtual (Shiffer, 1992; Yigitcanlar, 2001). Nesta linha, a tendência atual refere-se ao desenvolvimento de módulos adicionais ao software de SIG, especialmente desenvolvidos para facilitar a visualização e análise espacial (Klosterman, 2001 apud Brail e Klosterman, 2001).

Com este novo perfil, os Sistemas de Informação Geográfica figuram como ambiente aglutinador para a utilização das técnicas de apoio à decisão, em um processo no qual o Planejamento Participativo se apresenta como uma importante etapa.

\subsubsection{Sistema de Suporte à Decisão - DSS}

Um Sistema de Suporte à Decisão (DSS, do inglês Decision Support System), e as suas variações (SDSS, do inglês Spatial Decision Support Systems; e PSS, do inglês Planning Support Systems), pode ser definido, no caso do planejamento urbano e de transportes, como sendo um sistema computacional que auxilia os planejadores ou tomadores de decisão nas análises e proposição de soluções para os problemas de uma determinada cidade, através da simulação de cenários urbanos. Este sistema inclui: aquisição de informações sobre o próprio estudo de caso, aquisição de informação sobre o próprio software, modelo de sistema de controle da evolução do projeto, modelos de análise de dados e simulação, visualização dos resultados obtidos e planejamento das ações [Turban e Aronson ${ }^{2}$ (1998) apud Laurini (2001)].

Segundo Laurini (2001), um sistema de informações para o planejamento urbano deve conter ferramentas com os quais os diversos atores (técnicos e a comunidade) possam decidir ou negociar a solução dos diversos problemas urbanos. Entretanto, a grande dificuldade que ainda existe não se refere à implementação destas soluções ou planos para a cidade, mas a monitoração cuidadosa das atividades e dos fenômenos urbanos utilizando um sistema de informação.

\footnotetext{
${ }^{2}$ Turban, E. e Aronson, J.E. (1998) Decision Support Systems and Intelligent Systems. Prentice-Hall.
} $5^{\text {th }}$ ed. 
Um Sistema de Suporte à Decisão pode ter, como um de seus objetivos, a criação e visualização de alternativas para o planejamento urbano e de transportes, isto é, permitir o desenvolvimento e visualização de futuros cenários urbanos. É um sistema computacional desenhado para auxiliar os planejadores a resolverem os problemas estruturais urbanos. Ele utiliza a combinação de modelos (físicos, abstratos, simbólicos e matemáticos), técnicas analíticas e recuperação de informações para desenvolver e avaliar problemas urbanos complexos, como por exemplo, a questão da mobilidade urbana.

É importante ressaltar que no processo de tomada de decisão o planejador deve, neste tipo de abordagem, escolher o cenário pretendido levando em consideração as possíveis conseqüências ao meio - análise de risco máximo, intermediário ou mínimo, o que é possível neste ambiente computacional. Os componentes deste processo de decisão são: dados, modelos de decisão, ambiente de decisão (neste caso, a cidade), e as pessoas; sendo que cada um terá uma influência direta na escolha do cenário (Yigitcanlar, 2001; Brail e Klosterman, 2001).

Segundo Klosterman (2001), estes sistemas podem ser compostos também por um SIG, além de ferramentas tradicionais de planejamento urbano e regional, técnicas destinadas a análises econômicas e demográficas, modelos ambientais, técnicas e ferramentas de planejamento de transporte e uso do solo, além de técnicas e recursos tecnológicos diversos e mais recentes, tais como as técnicas de avaliação multicritério e recursos de hipermídia. Por todas estas características, os Sistemas de Suporte a Decisão podem, principalmente se associados aos SIG, auxiliar planejadores e gestores urbanos na tomada de decisões na esfera do planejamento urbano e regional, aumentando desta maneira as chances de sucesso nas intervenções espaciais. Entretanto, neste sistema o SIG é apenas uma ferramenta, pois o objetivo principal não é apenas realizar o mapeamento ou a construção da base gráfica. É necessário ter em mãos elementos de modelagem geográfica e elementos de planejamento. Outro fator de grande importância associado ao uso do SIG refere-se à diminuição do tempo gasto para a realização dessas análises, podendo desta forma levar a reduções no tempo de implantação dos projetos concebidos e selecionados.

\subsubsection{Sistema de Suporte ao Planejamento - PSS}

O Sistema de Suporte ao Planejamento é uma ferramenta computacional que inclui métodos utilizados no planejamento, isto é, é composto por um módulo que reúne informações específicas da área de planejamento. Um sistema de informação para planejamento tem como foco o espaço. Os dados para planejamento referem-se a dados 
espaciais, não espaciais, quantitativos e qualitativos, abordando os aspectos físicos, sociais e econômicos. Uma das características destes dados é que muitos deles não podem ser comparados entre si.

O conceito de PSS foi definido pela primeira vez em 1990, por Briton Harris. Segundo este autor o PSS incorpora as áreas de desenho e simulação no planejamento estratégico. Estes dois módulos são importantes para definir a localização residencial, comercial e industrial em função dos efeitos sobre os níveis de serviço, carência de infra-estrutura, etc. A simulação poderá ser utilizada na interação de modelos de transporte público, áreas de estacionamentos, definição de tarifas, simulação de congestionamentos e impactos do comportamento locacional sobre os usos do solo. Em síntese, os Sistemas de Suporte ao Planejamento permitem a utilização de ferramentas para estudo, manipulação de mapas, modelos, cenários, tabelas multiatributos, planos e realização de cenários, além de também abrir possibilidade para o planejamento participativo (Harris, 2001).

Segundo Geertman e Stillwell (2003), o PSS envolve uma grande diversidade de ferramentas relacionadas a geotecnologias. Ele foi desenvolvido para dar suporte ao planejamento público e privado em qualquer escala (dimensão) espacial. Este sistema está intimamente relacionado com outros dois sistemas: SIG e SDSS (Klosterman, 2001).

\subsubsection{Sistema de Suporte à Decisão Espacial - SDSS}

Os SDSS foram construídos para realizar o suporte à decisão para problemas espaciais complexos. Eles incorporam os componentes essenciais de um DSS, como: banco de dados (espaciais e não espaciais), modelos analíticos e de simulação, e a interface ao usuário utilizando um SIG. Embora os dois sistemas sejam compostos por ferramentas similares para o processo de planejamento urbano, no que se refere à entrada e exibição dos dados coletados, e ambos possuam modelos para simulação urbana, a grande diferença entre eles refere-se a algumas ferramentas especiais que podem compor um Sistema de Suporte à Decisão Espacial: recursos para construção de Cenários Alternativos, para administração de Grupos de Discussões e para gestão da Participação Pública. Desta forma, os SDSS constituem o ambiente ideal para que o planejador ou decisor urbano possa trabalhar com as técnicas de planejamento participativo (Geertman e Stillwell, 2003).

As ferramentas citadas como parte integrante dos SDSS, agora interligadas num ambiente $w w w$ (World Wide Web), proporcionam um novo cenário na área de 
planejamento, no qual é possível congregar diferentes decisores localizados até mesmo em cidades ou países distintos, analisando, discutindo e propondo novas alternativas para um determinado problema da cidade. Esta é uma das razões que levam atualmente diversos grupos de pesquisa à investigação dos impactos advindos da união dos conceitos do Sistema de Suporte à Decisão com o planejamento participativo no ambiente da Internet.

Segundo Jankowski e Nyerges (2001), o processo participativo no Sistema de Suporte à Decisão Espacial pode ocorrer dos seguintes modos: entre participantes que se encontram num mesmo lugar ao mesmo tempo, entre participantes que apesar de estarem numa mesma localidade acessarão o sistema em diferentes períodos, entre participantes localizados em lugares diferenciados, mas conectados ao mesmo tempo, e entre participantes localizados em locais e horários diferentes. Deste modo, a interação humana num Sistema de Suporte à Decisão voltado para o planejamento da mobilidade urbana pode ocorrer através do formato tradicional ou utilizando um ambiente $w w w$. Em ambos os casos o processo de interação é realizado através da interação homem-computador-homem, podendo ainda ser realizado através de uma rede de comunicação intranet ou extranet.

O Quadro 4.1 resume as diferentes combinações de localização e horário referentes ao processo de participação utilizando um computador. Para cada uma das situações apresentadas, pode-se escolher um sistema de interação e/ou participação que vai desde o convencional, face a face, até o de uma arquitetura computacional baseada no conceito cliente-servidor, como mostra a Figura 4.2. Esta primeira definição é importante para a escolha do hardware e software mais indicado para cada caso.

Quadro 4.1 - Combinações de processo de participação através de interferências de localização e horário dos envolvidos.

\begin{tabular}{|c|l|l|}
\multicolumn{1}{c}{ MESMO LOCAL } & \multicolumn{1}{c|}{ MESMO HORÁRIO } & \multicolumn{1}{c|}{ HORÁRIO DIFERENTE } \\
$\begin{array}{c}\text { Ambiente de Rede } \\
\text { Reunião Presencial }\end{array}$ & $\begin{array}{l}\text { Reunião Tradicional } \\
\text { Computadores ligados em rede }\end{array}$ & $\begin{array}{l}\text { Reunião com histórico das } \\
\text { discussões anteriores } \\
\text { Computadores ligados em rede }\end{array}$ \\
\hline $\begin{array}{ll}\text { LOCAL DIFERENTE } \\
\text { Ambiente } w w w\end{array}$ & Videoconferência & $\begin{array}{l}\text { Reunião distribuída } \\
\text { E-mail, rede de banda larga, } \\
\text { ferramentas de multimídia }\end{array}$ \\
\hline
\end{tabular}

Fonte: Adaptado de Jankowski \& Nyerges (2001). 


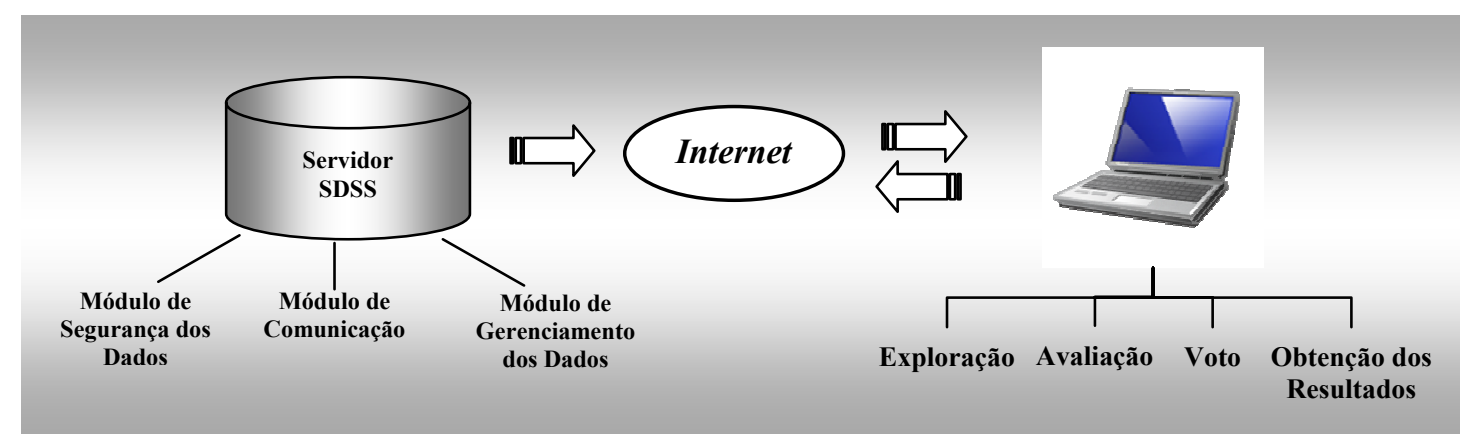

Figura 4.2 - Protótipo de arquitetura de software para SDSS - com participação pública através de diferentes horários e lugares

Fonte: adaptado de Laurini (2001).

No caso do planejamento das cidades, o processo de participação incluído no Sistema de Suporte à Decisão Espacial tornou o processo de tomada de decisão algo inovador. Por poder se dar através da Internet, diferentes grupos podem discutir, argumentar e eleger a solução mais adequada para um determinado problema urbano, mesmo que estas pessoas se encontrem fisicamente separadas uma das outras, até mesmo em países diferentes. Quanto às ferramentas que podem ser usadas em Sistemas de Suporte à Decisão Espacial voltado para Internet, os seguintes aspectos são fundamentais:

- WEB Browser - é um programa que habilita seus usuários a interagirem com documentos HTML (em linguagem de hipertexto) hospedados em um servidor Web, de acesso à Internet, ou seja, é uma aplicação de software que permite aos usuários o acesso a World Wide Web (www);

- Arquitetura do software - ele possui um Módulo de Segurança dos Dados, Módulo de Comunicação, Módulo de Gerenciamento de Dados, Módulo de Exploração, Módulo de Avaliação, Módulo de Voto e Módulo de Obtenção dos Resultados (ver Figura 4.2).

Os estudos de Laurini (2001) mostram que atualmente a participação popular associada a um Sistema de Suporte à Decisão tem-se utilizado das novas tecnologias para facilitar o processo de tomada de decisão tanto dos técnicos quanto da comunidade; permitindo assim que estas ferramentas auxiliem na decisão ou negociação da solução dos diversos problemas urbanos (ver Quadro 4.2). Entretanto, a grande dificuldade que ainda existe não se refere à implementação destas soluções ou planos na cidade, mas na monitoração cuidadosa das atividades e dos fenômenos urbanos. 
Quadro 4.2 - Possibilidades de implementação de um sistema de participação popular utilizando SIG

\begin{tabular}{|c|c|c|}
\hline & Descrição & Ferramentas \\
\hline \multirow{3}{*}{$\begin{array}{l}\text { Nível } 1 \\
\text { Exploração e } \\
\text { Comunicação }\end{array}$} & 1. Comunicação & $\begin{array}{l}\text { Dados, transmissões através de voz, voto eletrônico, grupos de } \\
\text { discussão, videoconferência, computador público (quiosque eletrônico). }\end{array}$ \\
\hline & 2. Gerenciamento da Informação & $\begin{array}{l}\text { Sistema de gerenciamento de banco de dados espacial e alfanumérico - } \\
\text { SIG. }\end{array}$ \\
\hline & 3. Visualização Gráfica & Visualização de mapas, quadros, tabelas, imagens e diagramas. \\
\hline \multirow{3}{*}{$\begin{array}{l}\text { Nível } 2 \\
\text { Análise e Apoio } \\
\text { à Decisão }\end{array}$} & 5. Modelos & $\begin{array}{l}\text { Ferramentas de visualização de modelos em SIG, sistemas especialistas, } \\
\text { bases de conhecimento. }\end{array}$ \\
\hline & 6. Visualização Espacial & Visualização de dados espaciais. \\
\hline & 7. Modelos de Decisão & Técnicas de análise multicritério. \\
\hline
\end{tabular}

Fonte: adaptado de Laurini (2001).

\subsection{Sistema de Suporte à Decisão Espacial no Planejamento Urbano e de Transportes}

No planejamento urbano e de transportes o Sistema de Suporte à Decisão pode auxiliar os planejadores na tomada de decisão junto ao desenvolvimento dos Planos Diretores Municipais, através da simulação integrada das questões de uso do solo e transportes possibilitando ações mais integradas.

Atualmente existem muitas ferramentas computacionais de suporte à decisão; entretanto, a definição de um modelo (sistema) depende da disponibilidade de informação que o município possui, qual é o objeto de estudo e quais os impactos que serão mensurados e a definição de qual (quais) fase(s) será (serão) utilizados neste sistema (TRANSPLUS, 2003).

Não existem muitas cidades que utilizam sistemas integrados de uso do solo e transporte para dar suporte à tomada de decisão no planejamento. Nesta seção são apresentados dois exemplos, TRANSPLUS e TRANUS, de sistemas de suporte à decisão que permitem esta integração de dados.

\subsubsection{TRANSPLUS}

O sistema TRANSPLUS (TRANSport Planning, Land Use and Sustainability, cuja tradução é Planejamento de transporte, uso do solo e sustentabilidade) teve como objetivo identificar as melhores práticas com relação às políticas de transportes e usos do solo para a obtenção de melhoria da mobilidade urbana na Europa. Isso se dá essencialmente através da redução do uso do automóvel, com vistas à promoção de melhorias ambientais, sociais e econômicas (TRANSPLUS, 2003). 
Neste sistema foi desenvolvida uma estrutura que permitiu analisar as experiências européias que tiveram êxito na utilização de políticas integradas de planejamento do uso do solo e transportes. Foram estudados também os indicadores utilizados para o monitoramento dos resultados, identificado-se assim os problemas de mobilidade nas cidades consideradas. Outra questão avaliada foi a participação popular no processo de planejamento, uma vez que este "elemento" é essencial no processo de planejamento.

Resumidamente, este sistema aborda os problemas de mobilidade de forma integrada com as questões de transporte, uso do solo, sob o enfoque da sustentabilidade, incluindo a participação da comunidade neste processo de decisão.

Segundo TRANSPLUS (2003), de acordo com os estudos de caso realizados "o envolvimento dos cidadãos e outros decisores no planejamento de TUS pode ser considerado como um dos principais fatores de sucesso". Através da aplicação do TRANSPLUS pôde-se concluir que:

i. Integração não significa integrar apenas políticas de uso do solo e transporte, mas ferramentas de suporte ao planejamento urbano e de transportes. O estudo mostrou que há pouca integração e desenvolvimento com relação aos modelos, aos indicadores de monitoramento e às estruturas institucionais.

ii. Para limitação da utilização do transporte individual (automóvel) devem ser adotadas medidas para assegurar uma maior acessibilidade aos cidadãos através da melhoria do transporte público.

iii. A participação popular é essencial, pois conduz a melhores resultados parciais, trazendo melhoria ao resultado final do plano.

Os estudos apontaram também alguns prós e contras no tocante à implementação de políticas integradas de uso do solo e transportes, com ou sem a participação popular (ver Quadro 4.3). 
Quadro 4.3 - Vantagens e desvantagens dos processos não-participativos e participativos nas políticas de TUS

\begin{tabular}{|c|c|c|}
\hline & PROCESSO NÃO-PARTICIPATIVO & PROCESSO PARTICIPATIVO \\
\hline 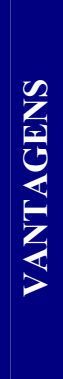 & $\begin{array}{l}\text { - } \quad \text { Baixo custo; } \\
\text { - } \quad \text { Processo relativamente rápido; } \\
\text { - } \quad \text { Liderança no processo é mais clara; } \\
\text { - } \quad \text { Poucos conflitos; } \\
\text { - } \quad \text { Pode ser realizado com procedimentos de } \\
\text { - } \quad \text { Getina; } \\
\text { - } \quad \text { Fácil gestão; } \\
\text { - } \quad \text { Elevada cobertura; entre outros. }\end{array}$ & $\begin{array}{l}\text { - } \quad \text { Forte compreensão; } \\
\text { - } \quad \text { Forte empenho; } \\
\text { - } \quad \text { Maior aceitação; maior credibilidade das } \\
\text { autoridades; } \\
\text { - } \quad \text { Maior transparência; maior justiça; } \\
\text { influência direta dos interessados nas } \\
\text { decisões políticas; } \\
\text { - } \quad \text { Integração no desenvolvimento e } \\
\text { - } \quad \text { Concepção dos utilizadores finais. }\end{array}$ \\
\hline 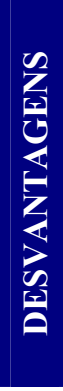 & $\begin{array}{l}\text { - Conhecimento dos objetivos é muito } \\
\text { limitado por parte do público; } \\
\text { - } \quad \text { Pouco empenho na implementação; } \\
\text { - Processo de desenvolvimento é muito } \\
\text { fraco; } \\
\text { - } \quad \text { Falta de elementos importantes; } \\
\text { - Risco de sobrecarga de informação. }\end{array}$ & $\begin{array}{l}\text { - } \quad \text { Custo mais elevado; } \\
\text { - } \quad \text { Processo mais lento; } \\
\text { - } \quad \text { Problemas de liderança; } \\
\text { - } \quad \text { Difícil gestão; } \\
\text { - } \quad \text { Geração de conflitos e dificuldades para } \\
\text { atingir um consenso das opiniões; } \\
\text { - } \quad \text { Fadiga dos agentes; } \\
\text { - } \quad \text { Decréscimo da credibilidade das } \\
\text { autoridades. }\end{array}$ \\
\hline
\end{tabular}

Fonte: adaptado de TRANSPLUS (2003).

\subsubsection{TRANUS}

O sistema TRANUS (Modelo integrado de uso do solo e transportes) é um modelo para a localização de atividades que integra as questões de uso do solo e transporte. Foi construído para ser aplicado nas escalas urbana e regional. Este sistema possui dois objetivos: i) simular os efeitos (impactos) das políticas e projetos relacionados ao uso do solo e transportes, e ii) avaliar estes impacto sob o ponto de vista econômico, social, financeiro e energético. Ele foi desenvolvido em 1982 pela MODELISTICA ${ }^{3}$ e tem sido aplicado para estudos de projetos em diversos países da América Latina, Europa, Estados Unidos e Ásia (Japão) (Modelistica, s/d; Johnston e La Barra, 1998).

Neste sistema é possível avaliar os efeitos das políticas de transporte sobre a localização de atividades e uso do solo; e analisar os efeitos das políticas de uso do solo sobre os transportes e vice-versa. No planejamento integrado, o sistema TRANUS pode ser utilizado para a avaliação de políticas de transporte a curto, médio e longo prazo. No planejamento urbano, este sistema permite a avaliação dos impactos das políticas de transporte em relação à localização e à interação das atividades. No planejamento de transportes ele possibilita o cálculo da demanda através de matrizes de origem-destino, a representação dos movimentos de carga e de passageiros nos transporte público e privado e seu impacto no congestionamento.

\footnotetext{
${ }^{3}$ MODELISTICA é uma empresa (da Venezuela) que tem o propósito de desenvolver serviços de consultoria na área de planejamento urbano, regional e de transportes. http://www.modelistica.com/
} 


\subsection{Principais Aplicações de SDSS na Internet}

Atualmente existem diversas pesquisas que procuram desenvolver o processo de planejamento participativo utilizando Sistemas de Suporte à Decisão Espacial na Internet, conforme pode ser visto na síntese da literatura internacional apresentada no

Quadro 4.4.

\section{Quadro 4.4 - SDSS: experiências internacionais}

\begin{tabular}{|c|c|}
\hline SISTEMA & DESCRIÇÃO \\
\hline \multirow{4}{*}{$\begin{array}{l}\text { 1. GISbPDM- } \\
\text { Geographical } \\
\text { Information } \\
\text { Systems Based } \\
\text { Participatory } \\
\text { Decision Making } \\
\text { Approach } \\
\text { Fonte: Yigitcanlar } \\
\text { (2001). }\end{array}$} & $\begin{array}{l}\text { É um SDSS construído para um ambiente de internet ou de rede que possibilita a } \\
\text { participação da comunidade (público em geral, técnicos e planejadores) através dos } \\
\text { formatos individual ou em grupo, no processo de planejamento urbano da cidade. } \\
\text { Não houve a participação popular efetiva no sistema (houve uma simulação da } \\
\text { participação popular) quando foi aplicado em Saraphane, em Izmir, na Turquia, para } \\
\text { a análise de problemas urbanos referentes à questão do uso do solo naquela região. } \\
\text { O sistema é composto por } 03 \text { componentes básicos: }\end{array}$ \\
\hline & $\begin{array}{l}\text { Collaborative GIS - responsável pelo sistema de suporte à decisão espacial, } \\
\text { representando um novo conceito de SIG, que prioriza a Participação Pública - } \\
\text { realizada pelo público em geral, planejadores urbanos e tomadores de decisão. } \\
\text { Software utilizados: ArcView (ESRI), ARGIS - Smart Places, Smart Places versão } \\
\text { para Internet - Internet Map Server (Grupo CIESIN). }\end{array}$ \\
\hline & $\begin{array}{l}\text { Strategic Choice Approach - é uma técnica sofisticada para tomada de decisão e } \\
\text { desenvolvimento de ações para o planejamento em situações onde existem muitas } \\
\text { opções incertas, através de um modelo que trabalha conectado a plataforma SIG. } \\
\text { Software utilizado: STRAD. }\end{array}$ \\
\hline & $\begin{array}{l}\text { Groupware Plataform - responsável pelo trabalho de interação e participação no } \\
\text { suporte ao desenho no computador. Nesta plataforma, o usuário pode visualizar as } \\
\text { alternativas, submetê-las a outros participantes ou ao tomador de decisão, modificá- } \\
\text { las e criar suas propostas (definir o cenário escolhido). O processo participativo } \\
\text { permite a participação em diferentes níveis: informação, trabalho colaborativo, } \\
\text { participação pública e participação eletiva/restrita. A visualização deste sistema foi } \\
\text { realizada através de um site do projeto. }\end{array}$ \\
\hline $\begin{array}{l}\text { 2. Public } \\
\text { Participation in the } \\
\text { Twin Cities } \\
\text { Fonte: Jankowski \& } \\
\text { Nyerges (2001). }\end{array}$ & $\begin{array}{l}\text { Projeto desenvolvido para auxiliar o processo de planejamento das cidades de } \\
\text { Minneapolis e Saint Paul (conhecidas como Twin Cities - em Minnesota - EUA). } \\
\text { Foram considerados os seguintes aspectos: reorganização espacial da vizinhança, } \\
\text { criação de um senso comunitário, e aumento da participação popular no processo de } \\
\text { planejamento. A utilização da Internet permitiu o acesso ao site do projeto, que } \\
\text { disponibilizou as seguintes informações: Sites contendo regras para os membros, } \\
\text { cópia do plano de Minneapolis com comentários, entre outras informações; } \\
\text { documentos oficiais; E-mail; programa de revitalização detalhado; informações } \\
\text { sobre a vizinhança (dados censitários, etc.); sites sobre o local; links para sites locais } \\
\text { e nacionais (sites governamentais). }\end{array}$ \\
\hline $\begin{array}{l}\text { 3. Virtual } \\
\text { Slaithwaite } \\
\text { Fonte: Carver et al. } \\
\text { (s/d). }\end{array}$ & $\begin{array}{l}\text { Desenvolvido pela Universidade de Leeds (Inglaterra), sob a coordenação de } \\
\text { Richard Kingston, tinha como objetivo realizar um exercício para obter as opiniões } \\
\text { da comunidade local, identificando seus anseios para o futuro, utilizando um } \\
\text { planejamento não-tradicional, através do estímulo a participação popular. Utilizou- } \\
\text { se o ambiente } w w w \text { e o SIG para detectar e analisar o vilarejo de Slaithwaite. A } \\
\text { participação popular na internet proporcionou uma maior integração no processo de } \\
\text { planejamento, se comparado com a participação tradicional, principalmente em } \\
\text { relação ao público mais jovem. As informações dos usuários (comentários e } \\
\text { sugestões) foram armazenadas num banco de dados que possibilitou posteriormente } \\
\text { sua utilização no processo de planejamento local. Como grande parte da população } \\
\text { local não dispunha de computadores com acesso a Internet, foram instalados } \\
\text { computadores pessoais em locais estratégicos para a consulta e interação popular. }\end{array}$ \\
\hline
\end{tabular}




\section{Quadro 4.4 - SDSS: experiências internacionais (continuação)}

\begin{tabular}{|c|c|}
\hline $\begin{array}{l}\text { 4. Transportation } \\
\text { Improvement } \\
\text { Program Decision } \\
\text { Making } \\
\text { Fonte: Nyerges et al. } \\
\text { (2003). }\end{array}$ & $\begin{array}{l}\text { Programa desenvolvido pelo Departamento de Transportes (Washington - EUA), } \\
\text { para o Planejamento Regional de Transportes para as cidades de King, Kitsap, } \\
\text { Pierce e Anohomish. Neste projeto, os especialistas tinham a função de estabelecer } \\
\text { alternativas, os tomadores de decisão definiriam a política e evolução das } \\
\text { alternativas e o público, que era composto por interessados e partes envolvidas, } \\
\text { sofreria os impactos do que seria decidido. Definiu-se em qual parte do processo de } \\
\text { tomada de decisão cada grupo agiria. Foram estabelecidos scores, para os critérios: } \\
\text { acessibilidade e forma urbana. Este projeto foi colocado na Internet para que a } \\
\text { população pudesse comentar sobre a evolução das propostas. Foram } \\
\text { disponibilizados mapas e fotos dos locais do projeto que auxiliaram o público na } \\
\text { identificação e localização dos mesmos. }\end{array}$ \\
\hline \multirow[t]{2}{*}{$\begin{array}{l}\text { 5. PROPOLIS - } \\
\text { Planning and } \\
\text { Research of } \\
\text { Policies for Land } \\
\text { Use and Transport } \\
\text { for Increasing } \\
\text { Urban } \\
\text { Sustainability } \\
\text { Fonte: Lautso et al. } \\
\text { (2002) e Lautso (1998). }\end{array}$} & $\begin{array}{l}\text { Segundo Lautso, Spiekermann e Wegener (2002), o objetivo do projeto PROPOLIS } \\
\text { é definir estratégias urbanas e avaliar seus impactos nas cidades européias. Para } \\
\text { alcançar este objetivo foram desenvolvidas metodologias para modelagem das } \\
\text { seguintes questões: uso do solo, transporte e meio ambiente, bem como indicadores, } \\
\text { sistemas de avaliação e apresentação de dados. Foram definidos } 35 \text { indicadores que } \\
\text { abordam as três dimensões da sustentabilidade (social, econômica e ambiental), } \\
\text { incluindo ainda indicadores relacionados à poluição do ar, consumo dos recursos } \\
\text { naturais, qualidade dos espaços públicos, população exposta à poluição do ar e } \\
\text { sonora, eqüidade das oportunidades e benefícios econômicos do transporte e uso do } \\
\text { solo. Este projeto utilizou-se de técnicas de análise multicritério e métodos de } \\
\text { análise custo-benefício para avaliação dos impactos das decisões para as diferentes } \\
\text { dimensões. As cidades européias utilizadas para testar o sistema foram: Bilbao } \\
\text { (Espanha), Bruxelas (Bélgica), Dortmund (Alemanha), Helsinki (Finlândia), } \\
\text { Inverness (Escócia), Nápoles (Itália) e Vicenza (Itália). }\end{array}$ \\
\hline & $\begin{array}{l}\text { SPARTACUS (System for Planning and Research in Towns and Cities for Urban } \\
\text { Sustainability) - foi um projeto que analisou e testou } 70 \text { combinações de elementos } \\
\text { da política urbana. Destes, } 60 \text { indicadores foram identificados e agrupados em } 6 \\
\text { categorias: Cenário, Uso do Solo, Investimento, Gerenciamento, Novas Tecnologias } \\
\text { e Custo. Esta experiência norteou a seleção e o desenvolvimento de políticas } \\
\text { adicionais para o Projeto PROPOLIS. }\end{array}$ \\
\hline $\begin{array}{l}\text { 6. CommunityViz } \\
\text { Fonte: CommunityViz }\end{array}$ & $\begin{array}{l}\text { É um projeto baseado em SIG-3D - trabalhado num Sistema de Suporte a Decisão, } \\
\text { com aplicações no planejamento urbano comunitário (participação popular). }\end{array}$ \\
\hline $\begin{array}{l}\text { 7. Scatter- } \\
\text { Sprawling Cities } \\
\text { and Transport: } \\
\text { from Evaluation to } \\
\text { Recommendations } \\
\text { Fonte: Gayda et al. } \\
\text { (2003). }\end{array}$ & $\begin{array}{l}\text { Segundo Gayda et al. (2003), foi um projeto apoiado pelo Programa de } \\
\text { Desenvolvimento Energético, Ambiental e Sustentável da Comunidade Européia, } \\
\text { cujo período de vigência foi de } 2002 \text { a } 2004 \text {. O objetivo era desenvolver uma } \\
\text { ferramenta de monitoramento para o crescimento urbano através de diretrizes e } \\
\text { recomendações de projeto para as cidades: Bruxelas, Stuttgart, Bristol, Helsinque, } \\
\text { Rennes e Milão. }\end{array}$ \\
\hline 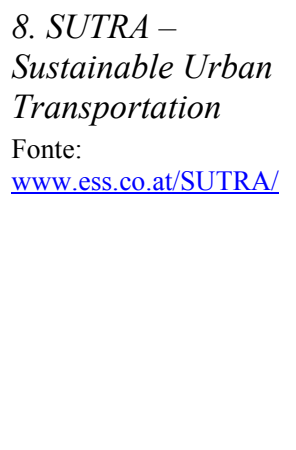 & $\begin{array}{l}\text { Desenvolvido, no período de } 1998 \text { a 2002, pelo Programa de Desenvolvimento } \\
\text { Energético, Ambiental e Sustentável (EESD) da Comunidade Européia, que visa } \\
\text { incentivar pesquisas e o desenvolvimento tecnológico em países da comunidade } \\
\text { européia. As cidades envolvidas foram: Helsinque (Finlândia) Gdansk (Polônia), } \\
\text { Gênova (Itália), Genebra (Suíça), Lisboa (Portugal), Tel Aviv (Israel) e Thessaloniki } \\
\text { (Grécia). O objetivo era desenvolver uma metodologia de planejamento para análise } \\
\text { dos problemas de transportes que permitisse auxiliar na construção de cidades mais } \\
\text { sustentáveis. Trabalhou-se com a combinação de indicadores que permitiram } \\
\text { analisar modelos de simulação e análise de cenários relativos aos aspectos } \\
\text { socioeconômicos e ambientais, associados a um componente de participação } \\
\text { popular. }\end{array}$ \\
\hline
\end{tabular}


Os exemplos apresentados mostram diferentes enfoques da construção de um Sistema de Suporte à Decisão Espacial, alguns com a participação popular, mas no formato presencial, e outros que permitem a participação popular através da Internet. Entretanto, na maioria das experiências apresentadas, o processo de participação popular restringiu-se à troca de informações entre a comunidade e os técnicos através de consultas realizadas num ambiente $w w w$, por questionários ou e-mail, e não pela interação mais efetiva junto a um sistema de apoio a decisão, como a que se pretende com o sistema PLANUTS, aqui proposto. 


\section{METODOLOGIA}

Neste capítulo é descrita a metodologia adotada para a elaboração do Sistema de Suporte à Decisão concebido para a internet, denominado PLANUTS, bem como os critérios considerados para avaliação do sistema, de forma a atender ao objetivo principal da pesquisa.

A metodologia utilizada para o desenvolvimento do sistema PLANUTS pode ser dividida nas seguintes fases: i) definição da arquitetura do sistema - construção dos Módulos de Avaliação da Mobilidade Urbana, e ii) definição da metodologia de análise dos resultados obtidos na aplicação do Sistema PLANUTS.

\subsection{O Sistema PLANUTS}

Foi proposto um Sistema de Suporte à Decisão para internet baseado nos seguintes princípios: i) utilização de um software SIG freeware como elemento estruturador do sistema, incluindo sua versão para a internet, e ii) elaboração de uma interface voltada para a internet que possibilite a participação popular, independente de local e horário de acesso.

O Sistema de Suporte à Decisão proposto poderá ser utilizado para auxiliar no planejamento e monitoramento da mobilidade urbana, principalmente, em cidades brasileiras de pequeno e médio porte; ou seja, deverá trazer subsídios para planejadores e tomadores de decisão, nas áreas de planejamento urbano e de transportes, através de um sistema que contenha modelos e ferramentas que auxiliarão em um processo de tomada de decisão integrado e participativo.

Para o desenvolvimento deste sistema foram estudadas algumas experiências internacionais que utilizam DSS na internet como, por exemplo: GISbPDM - Geographical Information Systems Based Participatory Decision Making Approach; Projeto PROPOLIS - SPARTACUS (System for Planning and Research in Towns and Cities for Urban 
Sustainability); Scatter - Sprawling Cities and Transport: from Evaluation to Recommendations; SUTRA - Sustainable Urban Transportation, entre outros.

O sistema PLANUTS, aqui apresentado, tem a origem de seu nome nos termos PLANejamento Urbano e de Transportes integrado e Sustentável.

\subsubsection{Arquitetura do sistema}

O sistema PLANUTS é formado pelos seguintes componentes: um Módulo de Avaliação da Mobilidade Urbana, uma plataforma SIG e um software SIG para web; conforme mostram a Figura 5.1 e o Quadro 5.1.

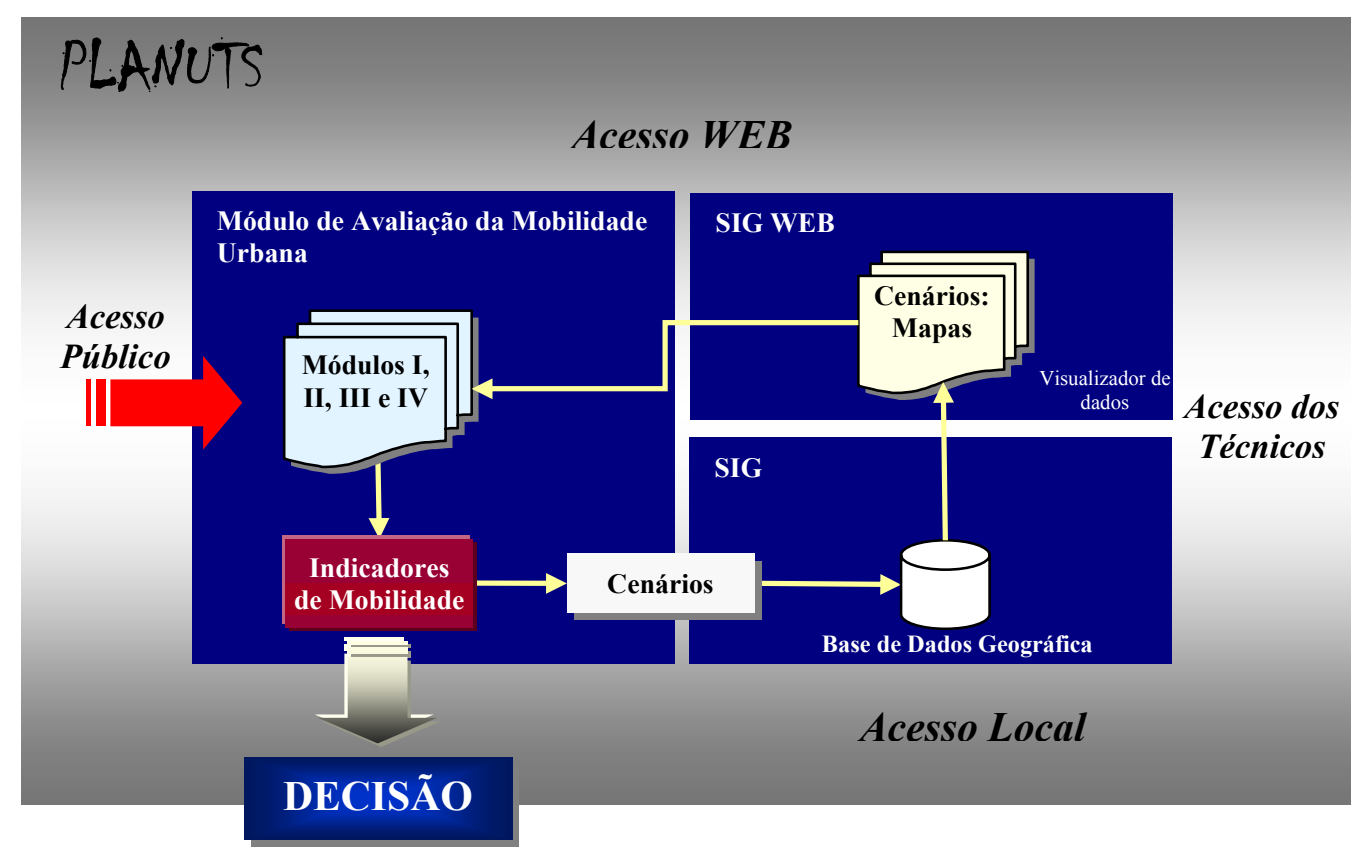

Figura 5.1 - Estrutura proposta para o PLANUTS 
Quadro 5.1 - Definição dos elementos estruturais propostos para o sistema PLANUTS

\begin{tabular}{|c|c|}
\hline AMBIENTES & DESCRIÇÃO \\
\hline \multirow[t]{6}{*}{ Plataforma SIG } & Principais funções \\
\hline & $\begin{array}{l}\text { - Estruturar as informações armazenadas do banco de dados do sistema. } \\
\text { - } \quad \text { Desenvolver e gerenciar as bases de dados espaciais e alfanuméricas. } \\
\text { - } \quad \text { Gerar cenários alternativos para consulta e análises dos decisores. }\end{array}$ \\
\hline & Software SPRING \\
\hline & $\begin{array}{l}\text { 1. Sistema freeware. } \\
\text { 2. Software brasileiro. } \\
\text { 3. Interface para a internet - com ferramentas para comunicação com o público. } \\
\text { 4. Ferramenta de suporte à decisão - Análise Multicritério. } \\
\text { 5. Acesso restrito e local. }\end{array}$ \\
\hline & Banco de Dados \\
\hline & $\begin{array}{l}\text { - Armazenamento das informações cadastrais, de uso do solo e transporte. } \\
\text { - Armazenamento das informações provenientes das avaliações realizadas no } \\
\text { Módulo de Avaliação da Mobilidade Urbana. } \\
\text { Etapas de construção: } \\
\text { i) Implementação dos Dados Espaciais - construção da Base Gráfica Digital. } \\
\text { ii) Alimentação do Banco de Dados - realizada a partir do Módulo de } \\
\text { Avaliação da Mobilidade Urbana. }\end{array}$ \\
\hline \multirow[t]{4}{*}{ SIG Web } & Principais funções \\
\hline & $\begin{array}{l}\text { - Visualizador das informações espaciais e alfanuméricas geradas pelo SPRING. } \\
\text { - Permite a realização de consultas por Agrupamento ou Pesquisa ao Banco de } \\
\text { Dados. } \\
\text { - Responsável pela visualização dos cenários gerados. } \\
\text { - Acesso - através da página do projeto na internet. }\end{array}$ \\
\hline & Software SPRINGWEB \\
\hline & $\begin{array}{l}\text { 1. Sistema freeware. } \\
\text { 2. Software brasileiro. } \\
\text { 3. Interface para a internet - com ferramentas para comunicação com o público. }\end{array}$ \\
\hline \multirow{4}{*}{$\begin{array}{l}\text { Módulo de } \\
\text { Avaliação da } \\
\text { Mobilidade } \\
\text { Urbana }\end{array}$} & Principais funções \\
\hline & $\begin{array}{l}\text { - } \quad \text { Estruturador do sistema PLANUTS. } \\
\text { - Plataforma amigável (internet associada com recursos de multimídia e } \\
\text { hipermídia). } \\
\text { - } \quad \text { Objetivo: incentivar a participação popular no processo de tomada de decisão } \\
\text { nas questões voltadas à Mobilidade Urbana da cidade. }\end{array}$ \\
\hline & Interface voltada para a internet \\
\hline & $\begin{array}{l}\text { i) Página do projeto na internet } \\
\text { - Informações sobre a cidade. } \\
\text { - Informações sobre Mobilidade Urbana. } \\
\text { - Informações sobre o processo de avaliação. } \\
\text { - Ferramenta de comunicação - e-mail. } \\
\text { - Acesso aos Módulos de Avaliação. } \\
\text { ii) Módulos de Avaliação da Mobilidade Urbana } \\
\text { - Quatro módulos interdependentes. } \\
\text { - Responsável pelo gerenciamento das informações, exploração, avaliação e } \\
\text { visualização dos resultados. }\end{array}$ \\
\hline
\end{tabular}


Para a definição do Módulo de Avaliação no Sistema PLANUTS foram adotados os seguintes procedimentos: 1) definição da estrutura das informações (definição dos indicadores a serem implementados no sistema e a definição do método de avaliação a ser utilizado) e 2) construção do modelo. A seguir são apresentadas estas etapas.

\subsection{A estrutura das informações no PLANUTS}

A estruturação das informações para implementação no sistema PLANUTS ocorreu numa fase anterior à definição da interface gráfica do DSS. O processo teve início com a definição de critérios que permitem subsidiar a construção do Módulo de Avaliação da Mobilidade Urbana. A estruturação das informações é apresentada na Figura 5.2 e detalhada no Quadro 5.2.

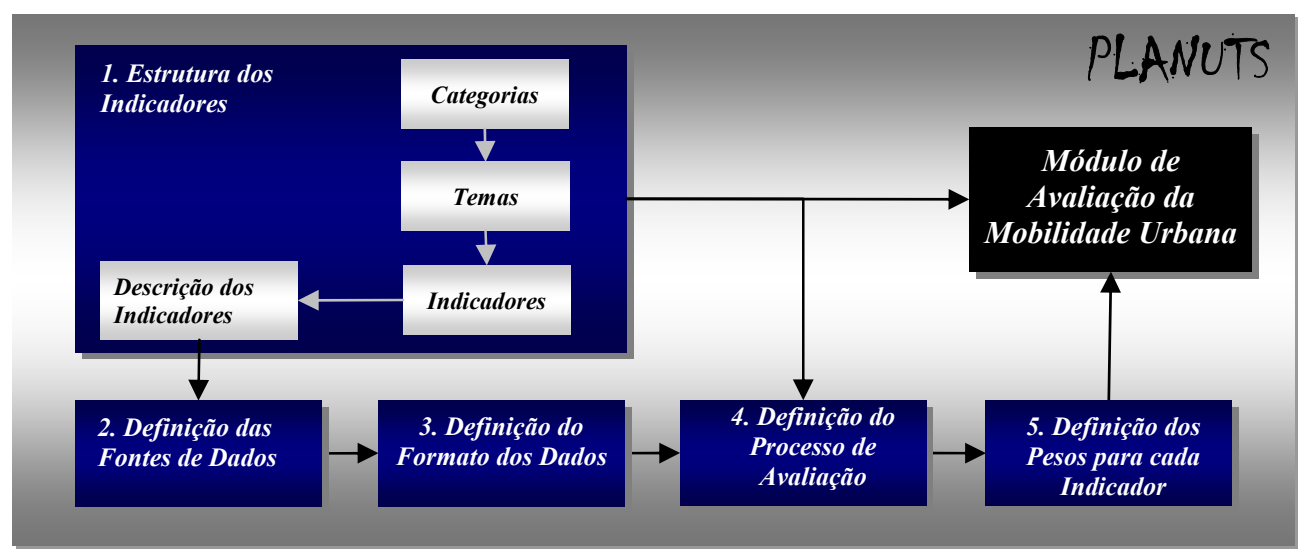

Figura 5.2 - Processo de definição dos indicadores de mobilidade urbana para o PLANUTS 
Quadro 5.2 - Definição dos elementos que permitiram estruturar o sistema PLANUTS

\begin{tabular}{|c|c|}
\hline CRITÉRIOS & DESCRIÇÃO \\
\hline $\begin{array}{l}\text { Estrutura dos } \\
\text { Indicadores }\end{array}$ & $\begin{array}{l}\text { O objetivo desta etapa foi estabelecer todos os elementos (Categorias, Temas e } \\
\text { Indicadores) para o Sistema de Suporte à Decisão. } \\
\text { A definição dos Indicadores de Mobilidade Urbana para o sistema PLANUTS foi } \\
\text { iniciada com o trabalho de Costa (2003), que definiu } 5 \text { Categorias, } 20 \text { Temas e } \\
115 \text { Indicadores associados à Mobilidade Urbana. O Anexo } 1 \text { apresenta estas } \\
\text { divisões e subdivisões. } \\
\text { A partir das Categorias, Temas e Indicadores propostos por Costa (2003) foi } \\
\text { iniciado o processo de verificação dos indicadores que poderiam ser agrupados - } \\
\text { por possuírem uma proximidade de avaliação, e excluidos - por não } \\
\text { representarem a realidade das cidades de pequeno e médio porte brasileiras, ou } \\
\text { por não existirem informações que viabilizassem a sua avaliação no sistema. } \\
\text { Após a realização deste processo, dos } 115 \text { indicadores iniciais, permaneceram no } \\
\text { sistema } 94 \text { indicadores (ver Anexo } 2 \text { ). }\end{array}$ \\
\hline Fonte de Dados & $\begin{array}{l}\text { Para a determinação das fontes de dados foi realizada uma listagem preliminar } \\
\text { dos órgãos municipais, estaduais ou federais que poderiam disponibilizar as } \\
\text { informações sobre cada indicador. A partir desta definição foram determinados } \\
\text { os modos de visualização das informações a serem implementadas no Banco de } \\
\text { Dados. }\end{array}$ \\
\hline Formato dos Dados & $\begin{array}{l}\text { Com a definição do formato dos dados foi definida a forma como cada } \\
\text { Categoria, Tema e Indicador seriam avaliados. }\end{array}$ \\
\hline $\begin{array}{l}\text { Processo de } \\
\text { Avaliação }\end{array}$ & $\begin{array}{l}\text { O sistema PLANUTS foi construído utilizando o Método de Avaliação } \\
\text { Multicritério. Este método permite avaliar diversos critérios através de sua } \\
\text { combinação nos processos de avaliação que envolvem a tomada de decisão. } \\
\text { Existem vários métodos associados à Avaliação Multicritério, tais como: Método } \\
\text { baseado no ordenamento de critérios, Método da escala de pontos, Método da } \\
\text { distribuição de pontos e Método da comparação par a par. } \\
\text { A escolha do Método de Avaliação Multicritério a ser utilizado depende sempre } \\
\text { do enfoque da análise e dos envolvidos no processo de decisão. Neste sentido, } \\
\text { definiu-se pelo Método da Escala de Pontos, porque se trata de um método } \\
\text { simples, e que pode ser facilmente aplicado num processo on-line de } \\
\text { planejamento participativo. }\end{array}$ \\
\hline $\begin{array}{l}\text { Definição dos pesos } \\
\text { para cada indicador }\end{array}$ & $\begin{array}{l}\text { Para a implementação desta técnica, foram estabelecidos inicialmente os limites } \\
\text { aceitáveis e desejáveis (máximos e mínimos) para cada indicador. Foi definida } \\
\text { uma escala de valores com variação de } 1 \text { a } 5 \text {, sendo o valor " } 1 \text { " atribuído ao } \\
\text { resultado que apresentar maior impacto e o valor " } 5 \text { ", ao de menor impacto, ou } \\
\text { uma escala de valores não aceitáveis (1) até aceitáveis (5), conforme mostra a } \\
\text { Figura 5.3. }\end{array}$ \\
\hline
\end{tabular}

\begin{tabular}{|c|c|c|c|c|}
\hline $\mathbf{1}$ & $\mathbf{2}$ & $\mathbf{3}$ & $\mathbf{4}$ & $\mathbf{5}$ \\
\hline Inaceitável & Regular & Bom & Ótimo & Aceitável \\
\hline Maior impacto & \multicolumn{1}{|c|}{} & & Menor impacto \\
\hline
\end{tabular}

Figura 5.3 - Definição dos pesos para os indicadores propostos

$\mathrm{Na}$ seqüência é descrito, em detalhe, cada um dos elementos acima mencionados. 


\subsubsection{Estrutura dos Indicadores}

A estruturação dos elementos que compõe o Sistema de Suporte à Decisão PLANUTS foi iniciada com a definição dos elementos a serem implantados neste sistema; para esta definição adotou-se como referência o trabalho desenvolvido por COSTA (2003).

Costa (2003) classificou 115 indicadores que permitem avaliar a mobilidade urbana da cidade através da avaliação de Categorias, Temas e Indicadores. Eles foram determinados após ampla pesquisa realizada nos seguintes Sistemas: Indicadores da Agenda 21 (UNCED, 1992); Sistema de Indicadores Urbanos propostos pela UNCHS Habitat (UNCHS, 1996); BOSSEL, (1997); LAUTSO, (1998); DICKEY, (2001); EUROPEAN ENVIRONMENT AGENCY (2000); Indicadores para a Integração de Transportes e Meio Ambiente-TERM, da União Européia (EUROPEAN ENVIRONMENT AGENCY, 2000); Indicadores de Seattle, Washington, Estados Unidos (SUSTAINABLE SEATTLE, 1998); Sistema de Indicadores de Desenvolvimento Sustentável - SIDS, de Portugal (DIREÇÃO GERAL DO AMBINTE, 2000); IDS - IBGE (2002); SNIU (2002) e IQVU (s/data). Os indicadores propostos por Costa foram agrupados em Temas e Categorias conforme mostra o Anexo 1.

No sistema PLANUTS a utilização das Categorias, Temas e Indicadores têm por objetivo definir um Sistema de Indicadores de Mobilidade Urbana Municipal, através de um processo de avaliação interativo, onde cada um destes elementos permitirá avaliar e/ou monitorar a mobilidade urbana em cidades brasileiras, sobretudo de pequeno e médio porte.

\section{- Definição dos Indicadores de Mobilidade Urbana para o Sistema PLANUTS}

A partir das Categorias, Temas e Indicadores definidos por Costa (2003) foi iniciado um processo de verificação da nomenclatura e de definição dos termos para cada um dos itens apresentados no Anexo 1. Algumas nomenclaturas e definições foram alteradas para facilitar o entendimento dos avaliadores não-especialistas. Outras definições que apresentavam termos muito técnicos que poderiam dificultar a avaliação também foram alteradas. (ver Quadro 5.3). 
Quadro 5.3 - Quadro comparativo entre as Categorias e Temas definidos por Costa (2003) e a correspondente nomenclatura definida para o Sistema PLANUTS

\begin{tabular}{|c|c|c|c|}
\hline \multicolumn{2}{|c|}{ Definição proposta por COSTA (2003) } & \multicolumn{2}{|c|}{ Definição adotada no Sistema PLANUTS } \\
\hline CATEGORIA & TEMA & CATEGORIA & TEMA \\
\hline \multirow{4}{*}{$\begin{array}{l}\text { TRANSPORTES E MEIO } \\
\text { AMBIENTE }\end{array}$} & Energia/Combustíveis & \multirow{4}{*}{$\begin{array}{l}\text { MEIO AMBIENTE E } \\
\text { TRANSPORTES }\end{array}$} & Energia \\
\hline & Impactos ambientais & & Impacto Ambiental \\
\hline & Qualidade do ar & & Qualidade do Ar \\
\hline & Ruído de tráfego & & Ruído \\
\hline \multirow{4}{*}{$\begin{array}{l}\text { GESTÃO DA MOBILIDADE } \\
\text { URBANA }\end{array}$} & $\begin{array}{l}\text { Despesas/Investimentos/Estratégias } \\
\text { econômicas }\end{array}$ & \multirow{4}{*}{$\begin{array}{l}\text { GESTÃO DOS } \\
\text { TRANSPORTES }\end{array}$} & Estratégias Econômicas \\
\hline & Gerenciamento/Monitoração & & Monitoração \\
\hline & $\begin{array}{l}\text { Medidas para o incremento da } \\
\text { mobilidade urbana }\end{array}$ & & Mobilidade Urbana \\
\hline & Novas tecnologias & & Novas Tecnologias \\
\hline \multirow{4}{*}{$\begin{array}{l}\text { INFRA-ESTRUTURA E } \\
\text { TECNOLOGIAS DE } \\
\text { TRANSPORTE }\end{array}$} & Frota & \multirow{4}{*}{$\begin{array}{l}\text { INFRA-ESTRUTURA DOS } \\
\text { TRANSPORTES }\end{array}$} & Frota \\
\hline & Infra-estrutura/Sistema viário & & Sistema Viário \\
\hline & $\begin{array}{l}\text { Tecnologias e serviços de } \\
\text { transporte }\end{array}$ & & Serviços de Transporte \\
\hline & Tráfego & & Tráfego \\
\hline \multirow{4}{*}{$\begin{array}{l}\text { PLANEJAMENTO } \\
\text { ESPACIAL E DEMANDA } \\
\text { POR TRASPORTES }\end{array}$} & $\begin{array}{l}\text { Acesso aos serviços e atividades } \\
\text { urbanas }\end{array}$ & \multirow{4}{*}{$\begin{array}{l}\text { PLANEJAMENTO DOS } \\
\text { TRANSPORTES }\end{array}$} & Acessibilidade Urbana \\
\hline & $\begin{array}{l}\text { Desenvolvimento urbano/Uso do } \\
\text { solo }\end{array}$ & & Crescimento Urbano \\
\hline & População urbana & & População Urbana \\
\hline & Viagens/Deslocamentos & & Viagens \\
\hline \multirow{4}{*}{$\begin{array}{l}\text { ASPECTOS } \\
\text { SOCIOECONÔMICOS DOS } \\
\text { TRANSPORTES }\end{array}$} & Custos/Preços/Tarifas & \multirow{4}{*}{$\begin{array}{l}\text { ASPECTOS } \\
\text { SOCIOECONÔMICOS DOS } \\
\text { TRANSPORTES }\end{array}$} & Custos \\
\hline & $\begin{array}{l}\text { Impactos socioeconômicos dos } \\
\text { transportes }\end{array}$ & & Impactos Socioeconômicos \\
\hline & Segurança & & Segurança \\
\hline & Transporte público & & Transporte Público \\
\hline
\end{tabular}

Após esta etapa foi necessário realizar a definição dos termos para cada Categoria e Tema, uma vez que isto não havia sido feito por COSTA (2003).

Paralelamente, foi realizada uma verificação os 115 indicadores para definir se alguns deles poderiam ser agrupados (por apresentarem uma proximidade de avaliação) ou excluídos (por não representarem a realidade das cidades de pequeno e médio porte brasileiras) do sistema. Após esta avaliação foi definido um total de 94 Indicadores para compor o Sistema PLANUTS, como apresentado no Anexo 2.

O Quadro 5.4 exemplifica o processo de definição dos Indicadores finais para compor o Sistema PLANUTS. 
Quadro 5.4 - Processo de definição dos Indicadores para o Sistema PLANUTS

\begin{tabular}{|c|c|c|c|c|c|}
\hline \multicolumn{6}{|c|}{ Categoria Meio Ambiente e Transportes - Tema Energia } \\
\hline \multicolumn{3}{|c|}{ Indicadores propostos por Costa (2003) } & \multicolumn{3}{|c|}{ Indicadores definidos para o Sistema PLANUTS } \\
\hline 1 & $\begin{array}{l}\text { Consumo per capita de } \\
\text { combustível fóssil por } \\
\text { transporte em veículo } \\
\text { motorizado. } \\
\text { (Com_Combust_Fos) }\end{array}$ & $\begin{array}{l}\text { Indicador do } \mathrm{n}^{\circ} \text { anual de litros por } \\
\text { pessoa de combustível fóssil } \\
\text { (gasolina, diesel e GLP) consumido } \\
\text { por transporte em veículo } \\
\text { motorizado na área urbana. }\end{array}$ & $\begin{array}{l}1 \\
\text { e } \\
5\end{array}$ & $\begin{array}{l}\text { Consumo per capita de } \\
\text { combustivel fóssil e não-fóssil } \\
\text { por transporte em veículo } \\
\text { motorizado }\end{array}$ & $\begin{array}{l}\text { Indicador que mede o consumo de } \\
\text { combustível fóssil (gasolina, diesel } \\
\text { e GLP), não-fóssil (álcool) e } \\
\text { formas alternativas (eletricidade, } \\
\text { hidrogênio) de combustível } \\
\text { medidos em litros por pessoa } \\
\text { consumido no setor de transporte. }\end{array}$ \\
\hline 2 & $\begin{array}{l}\text { Eficiência energética do } \\
\text { transporte de passageiro e } \\
\text { carga } \\
\text { (Efic_Transp_Carga) } \\
\text { (Efic_Transp_Passag) }\end{array}$ & $\begin{array}{l}\text { Indicador relacionado à redução do } \\
\text { consumo de energia e emissão de } \\
\text { poluentes pelos veículos de } \\
\text { transporte de carga e passageiros. }\end{array}$ & 2 & $\begin{array}{l}\text { Eficiência energética do } \\
\text { transporte de passageiro e } \\
\text { carga }\end{array}$ & $\begin{array}{l}\text { Indicador relacionado à redução do } \\
\text { consumo de energia e emissão de } \\
\text { poluentes pelos veículos de } \\
\text { transporte de carga e passageiros. }\end{array}$ \\
\hline 3 & $\begin{array}{l}\text { Energia final consumida pelo } \\
\text { setor de transporte } \\
\text { (Energ_Final_Transp) }\end{array}$ & $\begin{array}{l}\text { Indicador para medir a contribuição } \\
\text { relativa dos transportes para a } \\
\text { energia final consumida em um } \\
\text { determinado nível. Pode ser obtido } \\
\text { por unidade de Produto Doméstico } \\
\text { Bruto ou per capita. }\end{array}$ & 3 & $\begin{array}{l}\text { Energia final consumida pelo } \\
\text { setor de transporte }\end{array}$ & $\begin{array}{l}\text { Indicador para medir a contribuição } \\
\text { relativa dos transportes para a } \\
\text { energia final consumida. Pode ser } \\
\text { obtido por unidade de Produto } \\
\text { Doméstico Bruto. }\end{array}$ \\
\hline 4 & $\begin{array}{l}\text { Intensidade do Uso de } \\
\text { energia: Transporte } \\
\text { (Intens_Energ_Transp) }\end{array}$ & $\begin{array}{l}\text { Indicador da energia consumida } \\
\text { pelos transportes relativa a } \\
\text { quantidade de carga ou passageiros } \\
\text { transportados e distância viajada. }\end{array}$ & 4 & $\begin{array}{l}\text { Intensidade do Uso de } \\
\text { energia: Transporte }\end{array}$ & $\begin{array}{l}\text { Indicador da energia consumida } \\
\text { pelos transportes relativa a } \\
\text { quantidade de carga ou passageiros } \\
\text { transportados e distância } \\
\text { percorrida. }\end{array}$ \\
\hline 5 & $\begin{array}{l}\text { Porção de energia originada } \\
\text { de fontes de combustível } \\
\text { fóssil e não-fóssil. } \\
\text { (Energ_Fos_NaoFos) }\end{array}$ & $\begin{array}{l}\text { Indicador que mede a participação } \\
\text { e utilização de combustível fóssil, } \\
\text { não-fóssil e formas alternativas no } \\
\text { consumo de combustível no setor } \\
\text { de transportes. }\end{array}$ & & & \\
\hline
\end{tabular}

No Quadro 5.4 pode-se observar que em função da proximidade de avaliação, os Indicadores “1” (Consumo per capita de combustivel fóssil por transporte em veículo motorizado) e "5" (Porção de energia originada de fontes de combustível fóssil e não-fóssil) foram agrupados no Indicador: Consumo per capita de combustível fóssil e não-fóssil por transporte em veículo motorizado.

\subsubsection{Definição da Fonte e do Formato dos Dados}

A segunda e terceira etapas referiram-se a definição das fontes e respectivos formatos dos dados que podem ser utilizados pelos decisores (técnicos) após a definição do Sistema de Indicadores para a avaliação da Mobilidade Urbana no município. Estas informações deverão ser utilizadas na etapa de construção dos cenários comparativos.

$\mathrm{Na}$ definição das Fontes de Informações foram apresentados os Órgãos Públicos (Federal, Estadual ou Municipal) ou Privados que poderiam fornecer os dados para cada um dos 94 Indicadores do sistema.

Paralelamente à definição das Fontes de Informações foi estabelecido o Formato dos Dados para cada um dos 94 Indicadores, ou seja, definiu-se a forma pela qual os dados levantados poderiam ser visualizados pelos técnicos na etapa de Leitura Técnica, como por exemplo: mapas, tabelas, gráficos, texto, etc. (ver Figura 5.2 e Quadro 5.5). 
No Quadro 5.5 é apresentada uma proposta para a definição dos seguintes elementos correspondentes aos Indicadores ligados ao Tema Energia: Forma de avaliação do Indicador, Definição dos Pesos, Forma de visualização dos Dados e a respectiva Fonte dos Dados.

Quadro 5.5 - Definição da estrutura dos Indicadores relacionados ao Tema Energia

\begin{tabular}{|c|c|c|c|c|c|c|c|c|}
\hline Categoria & Tema & $\mathbf{N}$ & Indicador & Definição & Avaliação & Peso & $\begin{array}{l}\text { Formato dos } \\
\text { Dados }\end{array}$ & Fonte de Dados \\
\hline \multirow{4}{*}{ 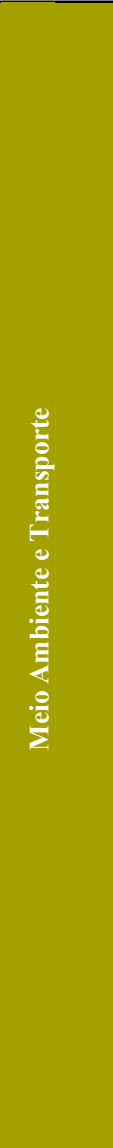 } & \multirow{4}{*}{ 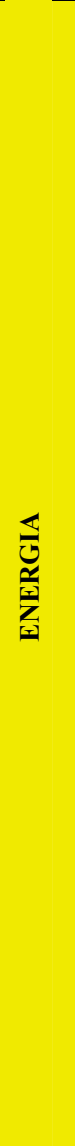 } & 1 & $\begin{array}{l}\text { Consumo per } \\
\text { capita de } \\
\text { combustivel fóssil } \\
\text { e não-fóssil por } \\
\text { transporte em } \\
\text { veículo motorizado }\end{array}$ & $\begin{array}{l}\text { Indicador que mede o } \\
\text { consumo de } \\
\text { combustível fóssil } \\
\text { (gasolina, diesel e } \\
\text { GLP), não-fóssil } \\
\text { (álcool) e formas } \\
\text { alternativas } \\
\text { (eletricidade, } \\
\text { hidrogênio) de } \\
\text { combustível medidos } \\
\text { em litros por pessoa } \\
\text { consumido no setor de } \\
\text { transporte. }\end{array}$ & $\begin{array}{l}\text { - litros_comb_nãofos/pessoa } \\
\text { - litros_comb_nãofos/meio_transp } \\
\text { - litros_comb_fos/pessoa } \\
\text { - litros_comb_fos/meio_transp } \\
\text { - álcool / gasolina / diesel / GLP }\end{array}$ & $*$ & $\begin{array}{l}\text { Gráficos - } \\
\text { comparação } \\
\text { dos dados a } \\
\text { cada } 5 \text { anos. } \\
\text { Idade média } \\
\text { dos veículos } \\
\text { que circulam } \\
\text { na cidade }\end{array}$ & $\begin{array}{l}\text { - Detran } \\
\text { - Pesquisa ao } \\
\text { usuário } \\
\text { - Sind. dos } \\
\text { distrib. de } \\
\text { comb. - Bauru } \\
\text { (consumo na } \\
\text { cidade dos } \\
\text { diferentes. } \\
\text { combustíveis / } \\
\mathrm{n}^{\circ} \text { veículos) }\end{array}$ \\
\hline & & 2 & $\begin{array}{l}\text { Eficiência } \\
\text { energética do } \\
\text { transporte de } \\
\text { passageiro e carga }\end{array}$ & $\begin{array}{l}\text { Indicador relacionado à } \\
\text { redução do consumo de } \\
\text { energia e emissão de } \\
\text { poluentes pelos } \\
\text { veículos de transporte } \\
\text { de carga e passageiros. }\end{array}$ & - \% de veículos/modo/ano & $*$ & $\begin{array}{l}\text { Gráficos - } \\
\text { comparação } \\
\text { dos dados a } \\
\text { cada } 5 \text { anos. } \\
\text { Mapas }\end{array}$ & $\begin{array}{l}\text { - Idade média } \\
\text { dos veículos } \\
\text { que circulam na } \\
\text { cidade } \\
\text { (veículos mais } \\
\text { recentes } \\
\text { possuem } \\
\text { filtros) } \\
\text { - DETRAN }\end{array}$ \\
\hline & & 3 & $\begin{array}{l}\text { Energia final } \\
\text { consumida pelo } \\
\text { setor de transporte }\end{array}$ & $\begin{array}{l}\text { Indicador para medir a } \\
\text { contribuição relativa } \\
\text { dos transportes para a } \\
\text { energia final } \\
\text { consumida. Pode ser } \\
\text { obtido por unidade de } \\
\text { Produto Doméstico } \\
\text { Bruto. }\end{array}$ & - Litros_Comb/modo & * & $\begin{array}{l}\text { Planilhas e } \\
\text { Gráficos } \\
\text { Evolução da } \\
\text { energia } \\
\text { (renovável e } \\
\text { não renovável) } \\
\text { consumida e } \\
\text { do PIB. }\end{array}$ & $\begin{array}{l}\text { - SEADE } \\
\text { - Anuário } \\
\text { Estatístico da } \\
\text { ANTP }\end{array}$ \\
\hline & & 4 & $\begin{array}{l}\text { Intensidade do } \\
\text { Uso de energia: } \\
\text { Transporte }\end{array}$ & $\begin{array}{l}\text { Indicador da energia } \\
\text { consumida pelos } \\
\text { transportes relativa à } \\
\text { quantidade de carga ou } \\
\text { passageiros } \\
\text { transportados e } \\
\text { distância percorrida. }\end{array}$ & $\begin{array}{l}\text { - Litros_Comb } / \mathrm{m}^{3} \text { _carga } / \mathrm{dist} \\
\text { - Litros_Comb } / \mathrm{n}^{\mathrm{o}} \text { passag/dist } \\
\text { - Litros_Comb/modo }\end{array}$ & * & $\begin{array}{l}\text { Mapa linhas } \\
\text { ônibus - } \\
\text { trajeto mais } \\
\text { utilizados. } \\
\text { Comparação } \\
\text { de planilhas de } \\
\text { gasto de } \\
\text { comb. e } \mathrm{n}^{\circ} \\
\text { passageiros } \\
\text { transportados. }\end{array}$ & $\begin{array}{l}\text { - Secretaria } \\
\text { Municipal de } \\
\text { Transportes. }\end{array}$ \\
\hline
\end{tabular}

Após a fase de estruturação das informações partiu-se para a definição dos critérios que possibilitaram avaliar o sistema proposto.

\subsection{Método para Análise dos Resultados}

Após a definição das Categorias, Temas e Indicadores que compõem o Sistema PLANUTS foi iniciada a etapa de escolha do melhor método para: i) avaliação interna do sistema PLANUTS (avaliação dos especialistas e não-especialistas), ii) avaliação dos resultados obtidos em cada módulo, e iii) avaliação da contribuição do sistema para ampliação do conhecimento sobre a questão da mobilidade urbana. 


\subsubsection{Avaliação Interna do Sistema PLANUTS}

Para a definição do método de avaliação do Módulo de Avaliação da Mobilidade Urbana (Categorias, Temas e Indicadores), bem como a avaliação dos resultados destes quatro Módulos buscou-se na literatura uma metodologia que pudesse ser de fácil utilização pelos participantes especialistas e não-especialistas.

A partir destes estudos chegou-se a conclusão que o Método de Avaliação Multicritério era o mais indicado para ser adotado em um processo de tomada de decisão que envolvia múltiplos critérios e participantes. Este método permitiu avaliar diversos critérios, através de sua combinação nos processos de avaliação que envolviam a tomada de decisão.

Segundo Ozernoy ${ }^{1}$ (1991) apud Jankowski e Nyergs (2001) o modelo de tomada de decisão multicritério é, atualmente, um dos métodos mais utilizados para avaliar sistemas que envolvem uma multiplicidade de critérios. Nas últimas décadas alguns destes modelos foram implementados para a tomada de decisão. Entretanto, para a escolha do melhor método deve-se levar em consideração as vantagens e desvantagens de cada um deles.

\section{- O Método de Avaliação Multicritério}

Segundo Malczewski (1999), o problema da tomada de decisão multicritério envolve a escolha de alternativas que serão avaliadas sob a ótica de conflitos e critérios não-mensuráveis. A definição do termo critério engloba: a definição de atributos e objetivos.

A Análise Multicritério é uma ferramenta que permite a estruturação de problemas de decisão complexos. Suas diversas técnicas de avaliação possibilitam a avaliação de problemas que envolvem múltiplos critérios, sendo estes muitas vezes conflitantes, permitindo também o envolvimento de " $n$ " participantes; facilitando assim, o processo de tomada de decisão.

Existem vários métodos associados à Avaliação Multicritério, tais como: Método baseado no ordenamento de critérios, Método da escala de pontos, Método da distribuição de pontos e Método da comparação par a par.

A escolha do Método de Avaliação Multicritério a ser utilizado depende sempre do enfoque da análise e dos envolvidos no processo de decisão. Neste sentido, foi escolhido o Método da Escala de Pontos, pois dentre os métodos existentes, este foi

\footnotetext{
${ }^{1}$ Ozernoy, V.M. (1991) Choosing the best multiple criteria decision-making method. INFO, 30(2).p. 159-
} 171. 
considerado o mais simples para ser aplicado em um processo de planejamento participativo que envolvia pessoas com diferentes graus de apreensão no processo de avaliação.

\section{- Método da Escala de Pontos}

O Método da Escala de Pontos foi desenvolvido por Osgood na década de 1950. Fundamenta-se na determinação de graus de preferência de cada avaliador através da diferenciação das avaliações numa escala compreendida por 7 níveis de importância. A atribuição dos pesos para cada critério avaliado é realizada pela simples escolha de um número numa escala que varia de “1” a “7”, ladeada pelas expressões insignificante e importante, respectivamente, como se pode ver na Figura 5.4 (Silva et al., 2004).

\section{Insignificante}

\begin{tabular}{|l|l|l|l|l|l|l|l|l|}
\hline 1 & 2 & 3 & 4 & 5 & 6 & 7 & Importante \\
\hline
\end{tabular}

Figura 5.4 - Escala de Avaliação de 7 Pontos

Entretanto, outros autores adaptaram este método para outras escalas de pontos, como por exemplo, a escala de 5 pontos (Findlay et al., 1988, Mendes et al., 1999, e Silva et al., 2004).

Para o sistema PLANUTS foi definida a utilização do Método da Escala de Pontos utilizando-se a escala de 5 pontos, uma vez que, dentre as demais escalas, esta foi considerada a mais simples para a avaliação.

O Método da Escala de Pontos pode ser resumido nas seguintes etapas: Definição dos Pesos e Normalização dos critérios. Estas etapas são mostradas no Quadro 5.6. 
Quadro 5.6 - Avaliação Multicritério: Método da Escala de Pontos

RESUMO DAS ETAPAS PARA IMIPLATAÇÃO DO MÉTOTODO DA ESCALA DE PONTOS

\begin{tabular}{|c|c|}
\hline ETA & PROCEDIMENTOS \\
\hline $\begin{array}{l}\text { Definição dos } \\
\text { pesos para cada } \\
\text { critério }\end{array}$ & $\begin{array}{l}\text { A definição dos pesos para cada critério pode ser realizada através do cálculo do Rc e } \\
\text { do Wc, conforme mostrado a seguir. } \\
\text { - Cálculo dos pesos (Rc) } \\
\qquad \mathrm{Rc}=\sum_{j}^{n} R_{c j} \\
\text { Onde: } \\
\text { Rc: soma das notas atribuídas por todos os decisores ao critério } c \\
\mathrm{R}_{\mathrm{cj}}: \text { nota atribuída pelo decisor } j \text { ao critério } c \\
\mathrm{n}: \text { número de decisores } \\
\text { - Cálculo do peso médio ( } \boldsymbol{w}_{\boldsymbol{c}} \text { ) } \\
\text { Onde: } \\
\quad w_{c}=\frac{R_{c}}{\mathrm{w}_{\mathrm{c}}=\text { peso médio do critério entre todos os decisores }} \\
\mathrm{m}=\text { número de critérios }\end{array}$ \\
\hline $\begin{array}{l}\text { Normalização } \\
\text { dos Critérios }\end{array}$ & 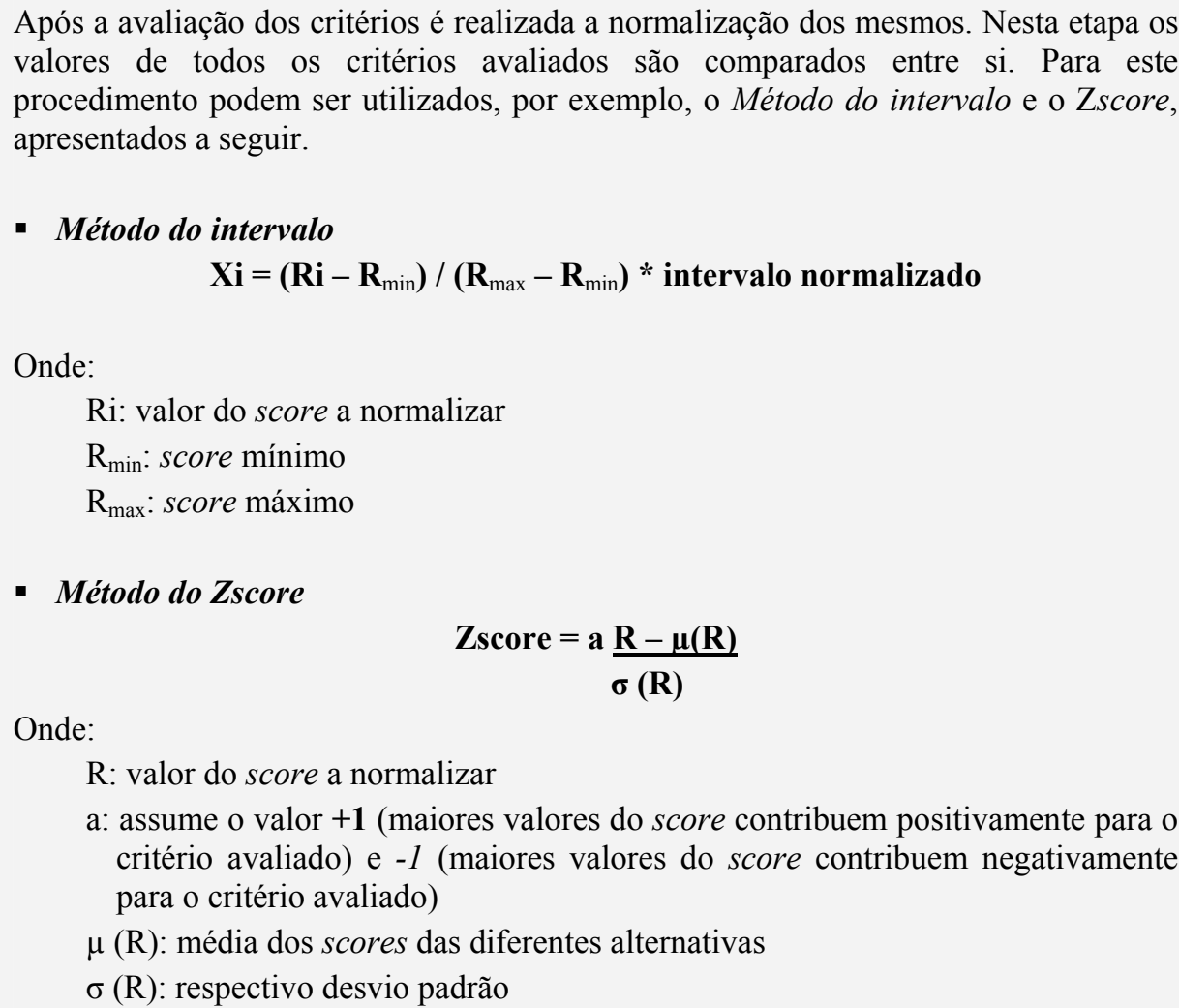 \\
\hline
\end{tabular}


A Figura 5.5 apresenta uma síntese dos métodos de avaliação adotados em cada módulo e o correspondente método de avaliação multicriterial adotado.

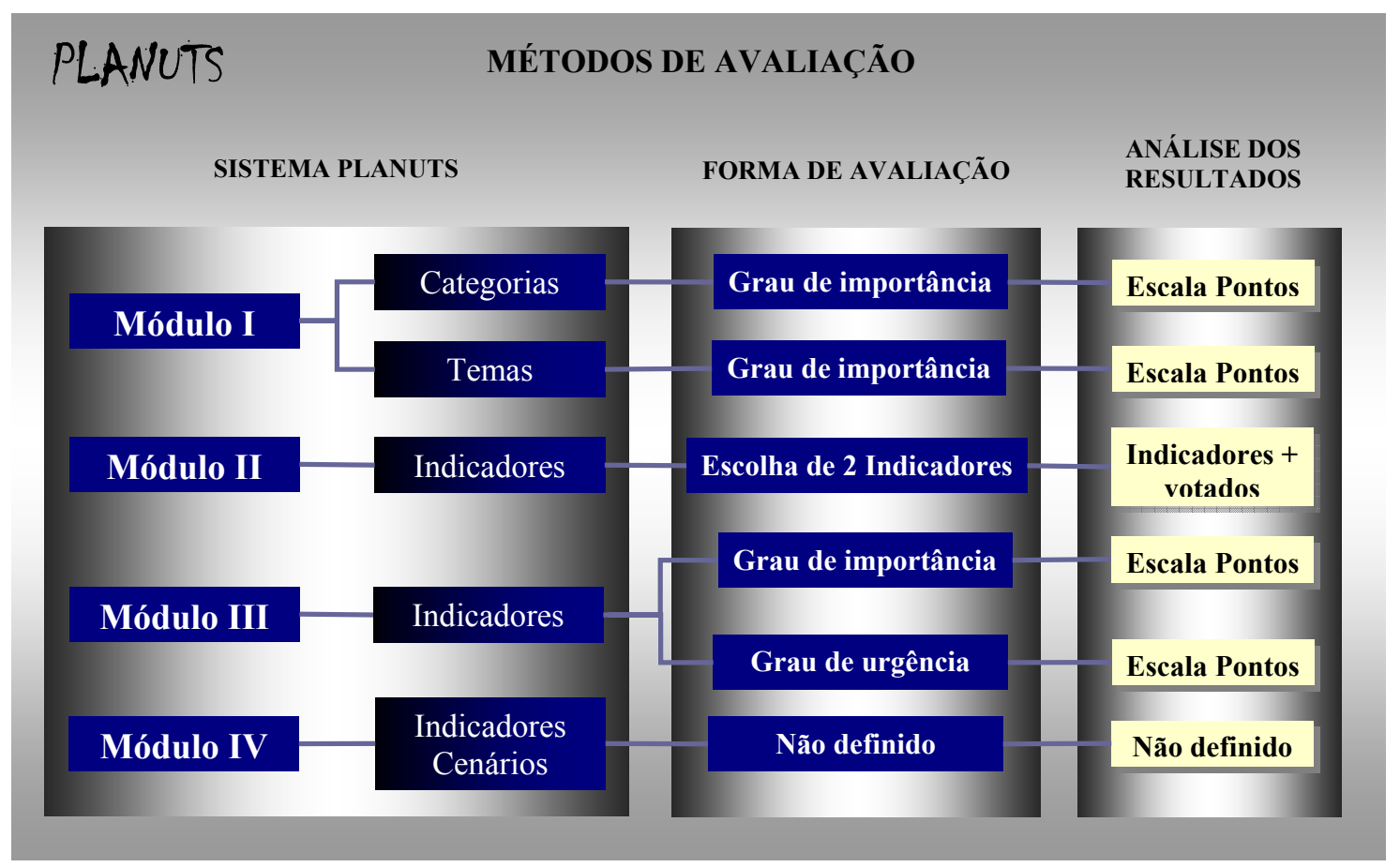

Figura 5.5 - Quadro síntese dos métodos de avaliação adotados para cada módulo

\subsubsection{Avaliação dos resultados obtidos em cada módulo}

A partir das avaliações realizadas em cada um dos três Módulos de Avaliação no sistema PLANUTS foi identificado que método estatístico seria o mais adequado para verificar: i) a existência de uma correlação na avaliação da mobilidade urbana entre os participantes, e ii) uma correspondência no ranking dos pesos dos critérios avaliados.

Dentre as Técnicas Estatísticas analisadas, foram selecionados os Métodos Não-Paramétricos. Estas técnicas permitiram avaliar o nível de concordância das avaliações e a correlação entre os critérios entre os dois grupos de avaliação ${ }^{2}$. Foram adotados: o Método da Correlação de Concordância de Kendall, que permitiu avaliar os resultados obtidos em cada grupo, e o Método da Correlação de Postos de Kendall, que possibilitou verificar uma homogeneidade entre os dois grupos de avaliadores.

\footnotetext{
${ }^{2}$ No processo de avaliação do Sistema PLANUTS, os avaliadores foram divididos em dois grupos de avaliação: Grupo I (especialistas) e Grupo II (não-especialistas).
} 


\section{- Método da Correlação de Concordância de Kendall (w)}

O Método de Correlação de Concordância de Kendall é uma técnica apropriada para avaliar a associação entre múltiplos critérios, verificando se estes mantêm a mesma ordem, ou seja, o Coeficiente de Kendall (w) permite determinar se há uma correspondência no ordenamento de um par de critérios. Nesta técnica é necessário que duas ou mais variáveis (grupos de comparação) estejam na mesma escala e apresentem o mesmo número de critérios para a comparação (Abdi, 2007).

O Coeficiente de Concordância de Kendall (w) corresponde a uma faixa de valores entre 0 e 1 . A interpretação dos valores do coeficiente é direta: o valor zero indica nenhuma correlação, o valor um indica uma correlação total, e os valores entre a escala 0 e 1 mostram a intensidade do relacionamento, ou seja, valores próximo a zero indicam baixa correlação e, próximos a um, forte correlação. A aplicação do método nesta pesquisa permitiu verificar a intensidade da correlação entre os dois grupos de avaliadores: especialistas e não-especialistas (Abdi, 2007).

O Quadro 5.7 apresenta os procedimentos adotados para o cálculo do Índice de Correlação de Concordância de Kendall.

Quadro 5.7 - Cálculo do Índice de Correlação de Concordância de Kendall

\section{RESUMO DAS ETAPAS PARA O CÁLCULO DO ÍNDICE DE CORRELAÇÃO DE CONCORDÂNCIA DE KENDALL}

\begin{tabular}{|c|c|c|c|c|c|}
\hline ETAPAS & \multicolumn{5}{|c|}{ PROCEDIMENTOS } \\
\hline Etapa 1 & \multicolumn{5}{|c|}{ - Cálculo dos pesos por avaliador (ver Método de Escala de Pontos) } \\
\hline Etapa 2 & \multicolumn{5}{|c|}{ - Ordenamento dos pesos por avaliador. } \\
\hline \multirow{7}{*}{$\begin{array}{l}\text { Etapa } 3 \\
\text { Cálculo do } \\
\text { Índice de } \\
\text { Correlação de } \\
\text { Concordância de } \\
\text { Kendall (w). }\end{array}$} & \multicolumn{5}{|c|}{$\begin{array}{l}\text { - Para o cálculo do índice de Correlação de Concordância de Kendall (w) foram } \\
\text { adotados os seguintes procedimentos: } \\
\text { 1. Cálculo da Concordância de Kendall } \\
\text { - Construção de uma matriz de ordenamento dos pesos - Tabela } k \text { x } n \text {; ver Tabela } 1 \text {. } \\
\text { - Onde: " } n \text { ” é o número de objetos ou critérios a serem classificados em postos e } \\
\text { " } k \text { ” é o número de juízes ou avaliadores }\end{array}$} \\
\hline & & n1 & n2 & n3 & n4 \\
\hline & k1 & P1 & P1 & P3 & P4 \\
\hline & $\mathbf{k 2}$ & P5 & P6 & P7 & P8 \\
\hline & k3 & P9 & P10 & P11 & P12 \\
\hline & k4 & P13 & P14 & P15 & P16 \\
\hline & \multicolumn{5}{|c|}{$\begin{array}{l}\text { - Para cada critério, determinar } R j \text {, através da soma dos postos atribuídos àquele } \\
\text { critério pelos avaliadores }(k) \text {. }\end{array}$} \\
\hline
\end{tabular}


Quadro 5.7 - Cálculo do Índice de Correlação de Concordância de Kendall (continuação)

\begin{tabular}{|c|c|}
\hline $\begin{array}{l}\text { Continuação } \\
\text { Etapa } 3 \\
\text { Cálculo do } \\
\text { Índice de } \\
\text { Correlação de } \\
\text { Concordância de } \\
\text { Kendall (w). }\end{array}$ & $\begin{array}{l}\text { - Determinar o valor de } \mathrm{S} \text { : } \\
\qquad \mathrm{S}=\sum_{j=1}^{n}\left(R j-\frac{\sum_{j=1}^{n} R j}{n}\right)^{2} \\
\text { - Calcular o valor de } \mathrm{W}: \quad \mathrm{W}=\frac{S}{\frac{1}{12} k^{2}\left(n^{3}-n\right)}\end{array}$ \\
\hline Etapa 4 & 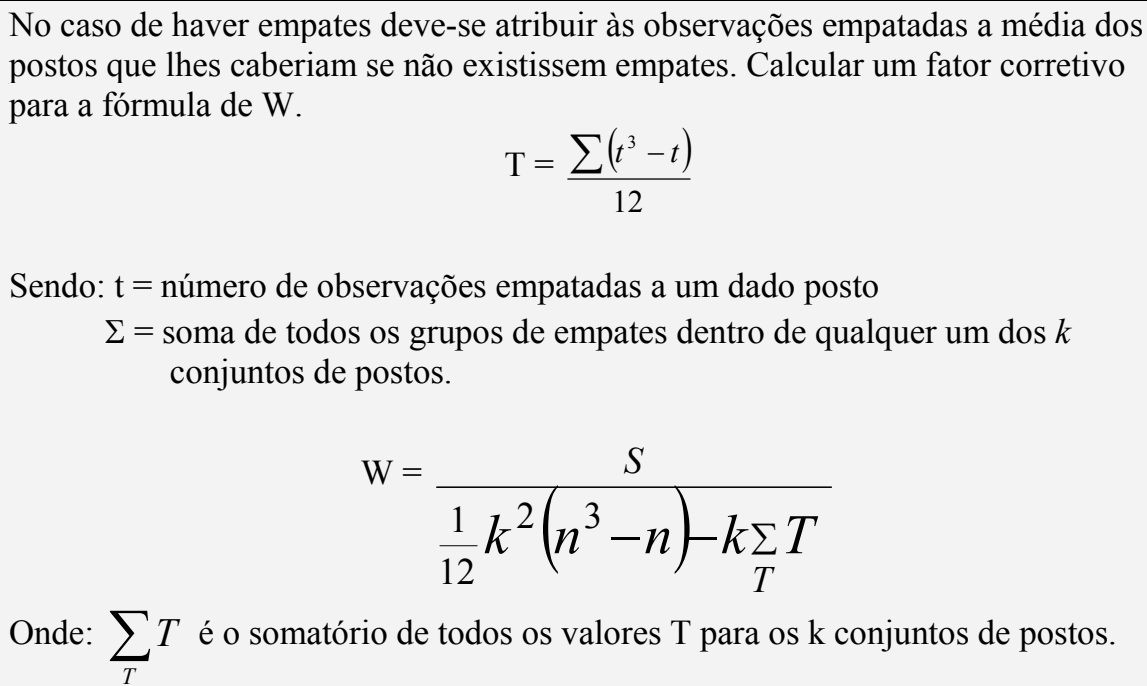 \\
\hline
\end{tabular}

- Método da Correlação de Postos de Kendall ( $\tau$ )

O Método da Correlação de Postos de Kendall é uma técnica que permite avaliar a existência de uma correlação no ordenamento de dois grupos de critérios avaliados. O Coeficiente de Correlação de Postos de Kendall ( $\tau$ ) avalia o grau de semelhança entre dois conjuntos de pares de dados ordenados; sendo que este coeficiente depende do número da inversão dos pares ordenados (Abdi, 2007).

Os valores do Coeficiente de Correlação por Postos de Kendall ( $\tau$ ) encontram-se no intervalo $-1 \leq \tau \leq 1$. A interpretação destes valores é realizada de forma direta, sendo que o valor zero indica uma correlação nula e os valores iguais a um, positivo e negativo, indicam correlação perfeita positiva e negativa, respectivamente. Os valores positivos indicam uma correlação direta enquanto que os valores negativos mostram uma correlação inversa. 
Quadro 5.8 - Cálculo do Índice de Correlação de Postos de Kendall

\begin{tabular}{|c|c|c|c|c|c|c|}
\hline ETAPAS & \multicolumn{6}{|c|}{ PROCEDIMENTOS } \\
\hline Etapa 1 & \multicolumn{6}{|c|}{ - Cálculo dos pesos por avaliador (ver Método de Escala de Pontos) } \\
\hline Etapa 2 & \multicolumn{6}{|c|}{ - Ordenamento dos critérios em função dos pesos finais. } \\
\hline \multirow{18}{*}{$\begin{array}{l}\text { Etapa } 3 \\
\text { Cálculo do } \\
\text { Índice de } \\
\text { Correlação de } \\
\text { Postos de } \\
\text { Kendall }(\tau)\end{array}$} & \multicolumn{6}{|c|}{$\begin{array}{l}\text { - Para o cálculo do Índice de Correlação de Postos de Kendall ( } \tau \text { ) foram adotados } \\
\text { os seguintes procedimentos: } \\
\text { 2. Cálculo dos Postos } \\
\text { - Construção de uma matriz de ordenamento dos pesos (ver Tabela 2). } \\
\text { - Atribuir postos de } 1 \text { a } n \text { à variável X. (ver Tabelas } 2 \text { e 3) } \\
\text { - Atribuir postos de } 1 \text { a } n \text { à variável Y. (ver Tabelas } 2 \text { e } 3 \text { ) } \\
\text { Tabela } 2\end{array}$} \\
\hline & & A & $\mathbf{B}$ & $\mathbf{C}$ & D & $\mathbf{E}$ \\
\hline & $\mathbf{X}$ & 0,193 & 0,192 & 0,199 & $\mathbf{0 , 2 2 8}$ & 0,187 \\
\hline & & 0,194 & 0,186 & 0,184 & 0,207 & 0,229 \\
\hline & \multicolumn{6}{|l|}{ Tabela 3} \\
\hline & & A & B & $\mathbf{C}$ & D & $\mathbf{E}$ \\
\hline & $\mathbf{X}$ & 3 & 4 & 2 & 1 & 5 \\
\hline & $\mathbf{Y}$ & 3 & 4 & 5 & 2 & 1 \\
\hline & \multicolumn{6}{|c|}{$\begin{array}{l}\text { - Ordenar os " } n \text { " indivíduos de maneira que os postos de X estejam apresentados } \\
\text { em sua ordem natural (ver Tabela 4). }\end{array}$} \\
\hline & & A & B & $\mathbf{C}$ & D & $\mathbf{E}$ \\
\hline & $\mathbf{X}$ & 1 & 2 & 3 & 4 & 5 \\
\hline & $\mathbf{Y}$ & 2 & 5 & 3 & 4 & 1 \\
\hline & \multicolumn{6}{|c|}{$\begin{array}{l}\text { - Calcular os pares para cada Grupo segundo as condições a seguir: } \\
\text { - Condição I (X) - se " } \mathrm{A} \text { " for maior que "B" o resultado é negativo (-1), caso } \\
\text { contrário o valor é positivo. } \\
\text { - Condição II (Y) - se "A" for maior que "B" o resultado é negativo (-1), caso } \\
\text { contrário o valor é positivo. } \\
\text { - Cálculo do produto entre os dois grupos }\end{array}$} \\
\hline & & $(\mathrm{A}, \mathrm{C})$ & $(\mathrm{A}, \mathrm{D})$ & $(\mathrm{A}, \mathrm{E})$ & \\
\hline & $x$ & 1 & 1 & 1 & 1 & \\
\hline & $\mathbf{Y}$ & 1 & 1 & 1 & -1 & \\
\hline & Produtos & 1 & 1 & 1 & -1 & $\Sigma S_{A}=2$ \\
\hline & \multicolumn{6}{|c|}{$\begin{array}{l}\text { - Observação: A Tabela } 5 \text { apresenta a combinação somente para os pares de A. } \\
\text { Posteriormente, devem ser realizadas as combinações para os pares: B (B,C; B,D } \\
\text { e B,E), C (C,D;C,E) e D (D,E). } \\
\text { - Observar a ocorrência dos postos de Y quando os postos de X se encontrem na } \\
\text { ordem natural. }\end{array}$} \\
\hline
\end{tabular}


Quadro 5.8 - Cálculo do Índice de Correlação de Postos de Kendall (continuação)

\begin{tabular}{|c|c|}
\hline $\begin{array}{l}\text { Continuação } \\
\text { Etapa } 3 \\
\text { Cálculo do } \\
\text { Índice de } \\
\text { Correlação de } \\
\text { Postos de } \\
\text { Kendall }(\tau)\end{array}$ & 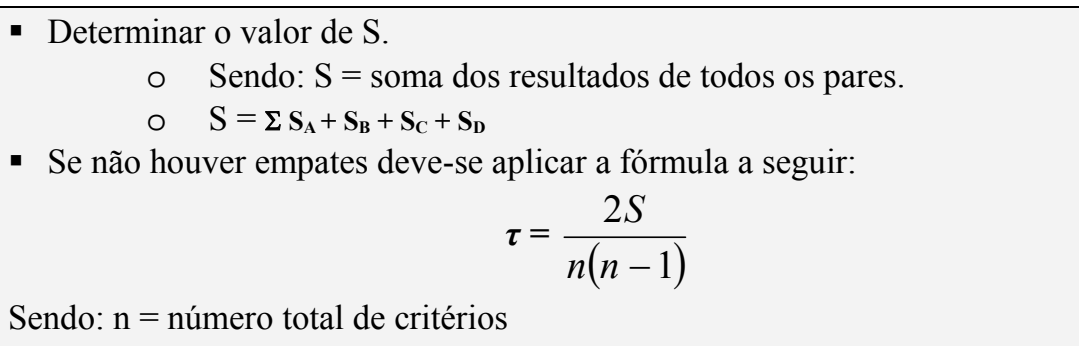 \\
\hline Etapa 4 & $\begin{array}{l}\text { - No caso de haver empates devem ser calculados os empates para Tx e Ty. } \\
\qquad \boldsymbol{\tau}=\frac{S}{\sqrt{\frac{1}{2}} n(n-1)-T_{x} \sqrt{\frac{1}{2} n(n-1)-T_{y}}} \\
\qquad \mathrm{Tx}=\frac{1}{2} \sum t(t-1) \quad \mathrm{Ty}=\frac{1}{2} \sum t(t-1) \\
\text { Sendo: } \mathrm{t}(\mathrm{Tx}) \text { - número de observações empatadas na variável X. } \\
\mathrm{t} \text { (Ty) - número de observações empatadas na variável Y. } \\
\text { OBS: Se não houver empates }=>\mathbf{T} \mathbf{x}=\mathbf{0} \text { e } \mathbf{T y}=\mathbf{0} \text {. }\end{array}$ \\
\hline
\end{tabular}

\subsubsection{Avaliação da contribuição do sistema para ampliação do conhecimento sobre a questão da mobilidade urbana}

Para comprovar que a utilização do Sistema de Suporte à Decisão PLANUTS pôde produzir alterações significativas no conhecimento de cada avaliador (especialista ou não-especialista) com relação às discussões sobre os problemas de Mobilidade Urbana no município foi adotada a aplicação de questionários.

Foram elaborados três questionários: dois para serem aplicados antes da utilização do Sistema PLANUTS (Questionários $1 A$ e $1 B$ ) e um para ser aplicado após a utilização do sistema (Questionário 2).

Foram elaborados dois questionários diferenciados para a primeira fase, em função do processo de avaliação ter públicos diferenciados (técnicos especialistas e nãoespecialistas) e pelo fato de que nem todos os participantes da comunidade conheciam o Tema Mobilidade Urbana com profundidade.

O objetivo do Questionário $1 A$ foi verificar as questões ou temas e ações que o município têm realizado sobre a questão da mobilidade, enquanto que o Questionário $1 B$ teve como objetivo caracterizar o assunto mobilidade no contexto da cidade ou do bairro (ver Quadros 5.9 e 5.10). 
O Questionário 2 foi elaborado para identificar as diferenças ou contribuições do sistema no conhecimento das questões relativas à mobilidade urbana. Como o objetivo principal desta pesquisa era identificar se a utilização da ferramenta computacional alteraria a percepção de cada participante com relação ao tema tratado, este questionário foi aplicado para todos os avaliadores do sistema (ver Quadro 5.11).

Nos três questionários foram elaboradas perguntas abertas, fechadas e/ou de múltipla escolha. As perguntas abertas permitiram identificar o grau de conhecimento de cada participante sobre determinado assunto associado à mobilidade urbana; enquanto que as perguntas fechadas permitiram quantificar alguns dados e assim gerar um diagnóstico da mobilidade na cidade de Bauru.

Os Quadros 5.9, 5.10 e 5.11 apresentam os três questionários propostos para avaliação e o objetivo de cada questão. No Questionário 2, as células com borda em destaque destinam-se a comparação das respostas dos avaliadores antes e após a utilização do sistema PLANUTS.

Quadro 5.9 - Questionário 1A - avaliação dos participantes especialistas antes da utilização do Sistema PLANUTS

\begin{tabular}{|c|c|c|}
\hline \multicolumn{2}{|r|}{ QUESTIONÁRIO 1A } & OBJETIVO \\
\hline 1 & O que você entende por Mobilidade Urbana? & \multirow{2}{*}{$\begin{array}{l}\text { Determinar o grau de conhecimento sobre a } \\
\text { questão da mobilidade e planejamento dos } \\
\text { transportes. }\end{array}$} \\
\hline 2 & O que você entende por Planejamento de Transportes? & \\
\hline 3 & O município possui algum Plano de Transporte? & \multirow{5}{*}{$\begin{array}{l}\text { Verificar se os técnicos municipais têm o } \\
\text { conhecimento da existência de um plano de } \\
\text { transportes para a cidade. }\end{array}$} \\
\hline 4 & Quando ele foi elaborado (ano)? Décadas 1970/1980/1990/após 2000. & \\
\hline 5 & Este Plano foi elaborado para minimizar quais problemas da cidade? & \\
\hline 6 & Quais os problemas da cidade que não estão inseridos neste Plano? & \\
\hline 7 & $\begin{array}{l}\text { O município tem previsão para realizar um novo Plano de Transporte ou } \\
\text { Mobilidade Urbana para a cidade? Qual o prazo (ano)? }\end{array}$ & \\
\hline 8 & $\begin{array}{l}\text { Existe alguma medida para promover (incentivar) a melhoria da mobilidade } \\
\text { urbana no município? }\end{array}$ & \multirow{2}{*}{$\begin{array}{l}\text { Identificar se os técnicos conhecem o } \\
\text { significado do termo "mobilidade" através } \\
\text { da identificação de algumas medidas } \\
\text { adotadas no município. }\end{array}$} \\
\hline 9 & Qual (quais) medida(s) foi (foram) adotada(s)? & \\
\hline 10 & $\begin{array}{l}\text { Qual (quais) o(s) setor(es) que atualmente estão envolvidos numa alteração do } \\
\text { Plano de Transporte para o município? }\end{array}$ & \multirow{2}{*}{$\begin{array}{l}\text { Identificar o grau de conhecimentos dos } \\
\text { técnicos sobre a definição dos setores } \\
\text { municipais que trabalham com a questão da } \\
\text { Mobilidade e Transporte. }\end{array}$} \\
\hline 11 & $\begin{array}{l}\text { Qual (quais) a(s) secretaria(s) que atualmente estão envolvidas quando se } \\
\text { elabora alguma modificação no Plano de Transporte? }\end{array}$ & \\
\hline 12 & Quais são os principais TEMAS da política de transportes do município? & $\begin{array}{l}\text { Verificar o grau de conhecimento dos } \\
\text { técnicos sobre a questão "Política de } \\
\text { Transporte". }\end{array}$ \\
\hline 13 & $\begin{array}{l}\text { Quais os principais objetivos da política de ESTACIONAMENTOS para o } \\
\text { município? }\end{array}$ & \multirow{3}{*}{$\begin{array}{l}\text { Identificar alguns problemas "chave" de } \\
\text { mobilidade relacionados no município. }\end{array}$} \\
\hline 14 & $\begin{array}{l}\text { Quais os principais objetivos da política de TRANSPORTE PÚBLICO para o } \\
\text { município? }\end{array}$ & \\
\hline 15 & Quais os principais objetivos da política de CIRCULAÇÃO para o município? & \\
\hline 16 & $\begin{array}{l}\text { O município tem algum plano para diminuir a POLUIÇÃO causada pelos meios } \\
\text { de transportes na cidade (por ex. o controle da qualidade do ar)? }\end{array}$ & \multirow{4}{*}{$\begin{array}{l}\text { Identificar alguns problemas de mobilidade } \\
\text { relacionados "ao tema meio ambiente" no } \\
\text { município. }\end{array}$} \\
\hline 17 & $\begin{array}{l}\text { Cite as medidas adotadas para reduzir os NÍVEIS DE POLUIÇÃO causados } \\
\text { pelos meios de transportes na cidade. }\end{array}$ & \\
\hline 18 & $\begin{array}{l}\text { O município tem algum plano para diminuir o RUÍDO causado pelos meios de } \\
\text { transportes na cidade? }\end{array}$ & \\
\hline 19 & $\begin{array}{l}\text { Quais das medidas abaixo foram adotadas para reduzir os NÍVEIS DE RUÍDO } \\
\text { causados pelos meios de transportes na cidade? Cite as outras medidas } \\
\text { adotadas? }\end{array}$ & \\
\hline
\end{tabular}


Quadro 5.9 - Questionário 1A - avaliação dos participantes especialistas antes da utilização do Sistema PLANUTS (continuação)

\begin{tabular}{|c|c|c|}
\hline 20 & $\begin{array}{l}\text { O município tem algum plano para reduzir alguns pontos de } \\
\text { CONGESTIONAMENTOS na cidade? }\end{array}$ & \multirow{2}{*}{$\begin{array}{l}\text { Identificar os problemas e medidas } \\
\text { associados ao congestionamento no } \\
\text { município. }\end{array}$} \\
\hline 21 & Cite as medidas adotadas para reduzir os CONGESTIONAMENTOS na cidade. & \\
\hline 22 & O município tem algum plano de ACESSIBILIDADE? & \multirow{5}{*}{$\begin{array}{l}\text { Identificar os problemas associados à } \\
\text { acessibilidade no município. }\end{array}$} \\
\hline 23 & $\begin{array}{l}\text { Quais os principais projetos relacionados com a atual política de } \\
\text { ACESSIBILIDADE do município? }\end{array}$ & \\
\hline 24 & $\begin{array}{l}\text { O atual Plano de Transportes prevê a adaptação dos pontos de ônibus para torná- } \\
\text { los mais acessíveis para todos os cidadãos? }\end{array}$ & \\
\hline 25 & Quais os principais projetos deste Plano? & \\
\hline 26 & $\begin{array}{l}\text { Qual a secretaria, setor ou órgão municipal que trabalha com os temas e políticas } \\
\text { de acessibilidade para as pessoas com deficiência? }\end{array}$ & \\
\hline 27 & $\begin{array}{l}\text { Quais os principais problemas de infra-estrutura de transportes que o município } \\
\text { possui? }\end{array}$ & $\begin{array}{l}\text { Identificar alguns problemas de mobilidade } \\
\text { relacionados ao "tema infra-estrutura" no } \\
\text { município. }\end{array}$ \\
\hline 28 & $\begin{array}{l}\text { Existe alguma política municipal para incentivar as VIAGENS a PÉ ou por } \\
\text { BICICLETA? }\end{array}$ & $\begin{array}{l}\text { Identificar o grau de conhecimentos dos } \\
\text { técnicos sobre a política de incentivo aos } \\
\text { meios de transportes mais sustentáveis. }\end{array}$ \\
\hline 29 & $\begin{array}{l}\text { Existe alguma política municipal para reduzir o NÚMERO DE ACIDENTES } \\
\text { DE TRÂNSITO no município? }\end{array}$ & \multirow{2}{*}{$\begin{array}{l}\text { Identificar o grau de conhecimento dos } \\
\text { técnicos sobre a política de redução de } \\
\text { acidentes e a localização destes acidentes na } \\
\text { cidade. }\end{array}$} \\
\hline 30 & $\begin{array}{l}\text { Quais as regiões da cidade que possuem um maior ÍNDICE DE ACIDENTES } \\
\text { DE TRÂNSITO? }\end{array}$ & \\
\hline
\end{tabular}

Quadro 5.10 - Questionário 1B - avaliação dos participantes não-especialistas antes da utilização do Sistema PLANUTS

\begin{tabular}{|c|c|c|}
\hline \multicolumn{2}{|r|}{ QUESTIONÁRIO 1B } & OBJETIVO \\
\hline 1 & Você tem o conhecimento se em sua cidade existe algum Plano de Transporte? & \multirow{4}{*}{$\begin{array}{l}\text { Determinar o grau de conhecimento sobre a } \\
\text { questão da mobilidade e planejamento dos } \\
\text { transportes. }\end{array}$} \\
\hline 2 & Você sabe para que "serve" um Plano de Transporte? & \\
\hline 3 & Você acha importante a elaboração deste plano para sua cidade? Por quê? & \\
\hline 4 & Você sabe qual é o objetivo de um Plano Diretor de Mobilidade Urbana? & \\
\hline 5 & Quais dos problemas abaixo você encontra em sua CIDADE? & \multirow{9}{*}{$\begin{array}{l}\text { Identificar alguns problemas de mobilidade } \\
\text { que pertencem ao cotidiano da maioria dos } \\
\text { cidadãos. }\end{array}$} \\
\hline 6 & Quais dos problemas abaixo você encontra em seu BAIRRO? & \\
\hline 7 & $\begin{array}{l}\text { Qual o meio de transporte que você utiliza para ir: ao trabalho / à escola / ao } \\
\text { centro da cidade? }\end{array}$ & \\
\hline 8 & $\begin{array}{l}\text { Você tem alguma dificuldade em utilizar o Transporte Coletivo (ônibus) em sua } \\
\text { cidade? }\end{array}$ & \\
\hline 9 & $\begin{array}{l}\text { Assinale com um } \mathbf{X} \text { o(s) problema(s) relacionado(s) à utilização do Transporte } \\
\text { Coletivo (ônibus) que você encontra na cidade? }\end{array}$ & \\
\hline 10 & $\begin{array}{l}\text { Em seu BAIRRO, você tem algum problema com o excesso de barulho } \\
\text { provocado por veículos (carro, moto, ônibus, caminhão)? }\end{array}$ & \\
\hline 11 & $\begin{array}{l}\text { Em seu BAIRRO há muitos veículos que lançam fumaça no ar (presença de } \\
\text { veículos lançando produtos tóxicos)? }\end{array}$ & \\
\hline 12 & Há ligação de ruas - direta, entre seu bairro e os bairros vizinhos? & \\
\hline 13 & $\begin{array}{l}\text { Você já perdeu a concentração ao desenvolver qualquer atividade em sua casa ou } \\
\text { seu trabalho em função do excesso de barulho provocado por qualquer meio de } \\
\text { transporte (ônibus, caminhão, carro, moto, etc.)? }\end{array}$ & \\
\hline
\end{tabular}


Quadro 5.11 - Questionário 2 - avaliação dos participantes dos participantes especialistas e não-especialistas após a utilização do Sistema PLANUTS

\section{QUESTÕES AVALIADAS OBJETIVO}

\begin{tabular}{|c|c|c|}
\hline \multicolumn{2}{|r|}{ QUESTÕES AVALIADAS } & OBJETIVO \\
\hline 1 & O que você entende por Mobilidade Urbana? & \multirow{2}{*}{$\begin{array}{l}\text { Identificar se houve um avanço no grau de } \\
\text { conhecimento dos participantes com relação } \\
\text { a questão da mobilidade e do planejamento } \\
\text { dos transportes. } \\
\text { Questionários 1A e 1B. }\end{array}$} \\
\hline 2 & Cite alguns problemas relacionados à Mobilidade de sua cidade? & \\
\hline 3 & $\begin{array}{l}\text { Existe alguma medida para promover (incentivar) a melhoria da mobilidade } \\
\text { urbana no município? }\end{array}$ & \multirow{2}{*}{$\begin{array}{l}\text { Verificar se os avaliadores conseguem } \\
\text { identificar se existem algumas medidas de } \\
\text { incentivo à mobilidade no município após a } \\
\text { utilização do Sistema PLANUTS. }\end{array}$} \\
\hline 4 & $\begin{array}{l}\text { Cite as medidas que existem em sua cidade que contribuem para a melhoria da } \\
\text { mobilidade urbana. }\end{array}$ & \\
\hline 5 & $\begin{array}{l}\text { Qual (quais) o(s) setor(es) que devem estar envolvido(s) no Plano de } \\
\text { Mobilidade? }\end{array}$ & \multirow{3}{*}{$\begin{array}{l}\text { Identificar se os participantes apontam a } \\
\text { necessidade do envolvimento de outros } \\
\text { técnicos para abordar as questões } \\
\text { apresentadas no sistema, tais como: Meio } \\
\text { Ambiente e Transporte, Gestão dos } \\
\text { Transportes, Infra-estrutura dos Transportes, } \\
\text { Planejamento dos Transportes e Aspectos } \\
\text { Socioeconômicos dos Transportes. }\end{array}$} \\
\hline 6 & $\begin{array}{l}\text { Qual (quais) a(s) secretaria(s) que devem estar envolvido(s) no Plano de } \\
\text { Mobilidade? }\end{array}$ & \\
\hline 7 & $\begin{array}{l}\text { Quais os principais TEMAS que devem fazer parte do Plano de Mobilidade } \\
\text { municipal? }\end{array}$ & \\
\hline 8 & $\begin{array}{l}\text { Quais os principais pontos a serem discutidos no Plano de Mobilidade com } \\
\text { relação à política de ESTACIONAMENTOS para o município? }\end{array}$ & \multirow{8}{*}{$\begin{array}{l}\text { Identificar alguns problemas (chave) de } \\
\text { mobilidade no município a partir das } \\
\text { definições das Categorias, Temas e } \\
\text { Indicadores. }\end{array}$} \\
\hline 9 & $\begin{array}{l}\text { Quais os principais pontos a serem discutidos no Plano de Mobilidade com } \\
\text { relação à política de TRANSPORTE PÚBLICO para o município? }\end{array}$ & \\
\hline 10 & $\begin{array}{l}\text { Quais os principais pontos a serem discutidos no Plano de Mobilidade com } \\
\text { relação à política de CIRCULAÇÃO para o município? }\end{array}$ & \\
\hline 11 & $\begin{array}{l}\text { O município tem algum plano para diminuir a POLUIÇÃO causada pelos meios } \\
\text { de transportes na cidade (por ex., o controle da qualidade do ar)? }\end{array}$ & \\
\hline 12 & $\begin{array}{l}\text { Cite algumas medidas que podem ser adotadas para reduzir os NÍVEIS DE } \\
\text { POLUIÇÃO causados pelos meios de transportes na cidade. }\end{array}$ & \\
\hline 13 & $\begin{array}{l}\text { O município tem algum plano para diminuir o RUÍDO causado pelos meios de } \\
\text { transportes na cidade? }\end{array}$ & \\
\hline 14 & $\begin{array}{l}\text { Quais das medidas abaixo deveriam ser adotadas para reduzir os NÍVEIS DE } \\
\text { RUÍDO causados pelos meios de transportes na cidade? }\end{array}$ & \\
\hline 15 & $\begin{array}{l}\text { O município tem algum plano para reduzir alguns pontos de } \\
\text { CONGESTIONAMENTOS na cidade? }\end{array}$ & \\
\hline 16 & $\begin{array}{l}\text { Cite algumas medidas que podem ser adotadas para reduzir os } \\
\text { CONGESTIONAMENTOS na cidade. }\end{array}$ & \multirow{3}{*}{$\begin{array}{l}\text { Identificar alguns problemas (chave) de } \\
\text { mobilidade no município a partir das } \\
\text { definições das Categorias, Temas e } \\
\text { Indicadores. }\end{array}$} \\
\hline 17 & O município tem algum plano de ACESSIBILIDADE? & \\
\hline 18 & $\begin{array}{l}\text { Quais os principais pontos a serem discutidos no Plano de Mobilidade com } \\
\text { relação a política de ACESSIBILIDADE do município? }\end{array}$ & \\
\hline 19 & $\begin{array}{l}\text { Qual a secretaria, setor ou órgão municipal que deveria trabalhar com os temas e } \\
\text { políticas de acessibilidade? }\end{array}$ & $\begin{array}{l}\text { Verificar o grau de conhecimentos dos } \\
\text { técnicos sobre as inter-relações que devem } \\
\text { existir entre os diversos setores da prefeitura } \\
\text { para a melhoria da mobilidade no município. }\end{array}$ \\
\hline 20 & $\begin{array}{l}\text { Na sua opinião é necessário adaptar os pontos de ônibus para torná-los mais } \\
\text { acessíveis para todos os cidadãos? }\end{array}$ & $\begin{array}{l}\text { Identificar alguns problemas (chave) de } \\
\text { mobilidade no município a partir das } \\
\text { definições das Categorias, Temas e } \\
\text { Indicadores. }\end{array}$ \\
\hline
\end{tabular}

Para avaliar o grau de interferência da utilização do Sistema PLANUTS na percepção de cada avaliador buscou-se na literatura algumas técnicas que pudessem identificar, nas respostas dos questionários, estas diferenças. Dentre as técnicas pesquisadas destacaram-se: a construção de mapas cognitivos e a análise de conteúdo. 


\section{- Método SODA (Strategic Options Development and Analysis)}

A metodologia desenvolvida por Eden $(1989)^{3}$ apud Pidd (2003) tem como objetivo auxiliar grupos no entendimento de problemas complexos, como por exemplo, na questão da tomada de decisão envolvendo múltiplos participantes.

Os métodos SODA I e SODA II (SODA - Strategic Options Develpment and Analysis, cuja tradução é Desenvolvimento e Análise de Ações Estratégicas) têm como objetivo decodificar as informações individuais (método SODA I) ou em grupo (método SODA II) através da construção de Mapas de Causa, também conhecidos como Mapas Cognitivos (ver Figuras 5.6, 5.7 e 5.8). Os dois sistemas são parte da abordagem denominada Making Journey (JOintly Understanding, Reflecting and Negotiating stratEgY) e têm sido utilizados por Eden e outros pesquisadores no planejamento estratégico.

A construção de Mapas Cognitivos ${ }^{4}$ segundo Eden (1989) apud Pidd (2003) é uma forma de capturar os pontos de vista das pessoas através do desenvolvimento de um modelo. A idéia é que o analista (pesquisador) traduza as entrevistas (inquéritos) para um mapa esquemático que represente a síntese dos pensamentos individuais ou de um grupo.

O termo "Mapa Cognitivo" é utilizado por Eden para transmitir conceitos das idéias das pessoas através de representação bidimensional (esquemas gráficos), onde os conceitos (definidos por pessoas ou grupos) são ligados uns aos outros. O objetivo é capturar as idéias dos entrevistados, individualmente ou em grupos, utilizando "palavras" definidas pelos participantes. A intenção deste método é auxiliar os participantes a entender a situação (problema) e definir ações.

Os Mapas Cognitivos são compostos por nós que representam os conceitos. Estes são ligados por arcos (sendo as extremidades compostas por setas, cuja direção pode indicar um link positivo ou negativo). Os conceitos são representados por idéias que possuem algum significado para as pessoas envolvidas; estas idéias são expressas através de palavras. A direção dos arcos mostra a relação de direção dos conceitos (conceito inicial e final) (ver Figura 5.6).

A seguir é descrita a metodologia para a construção dos Mapas Cognitivos Mapas de Causa.

- Conceito - representa uma idéia definida por uma pessoa ou um grupo. Ela deve capturar (expressar) a visão dos participantes. Em alguns casos o conceito pode

\footnotetext{
${ }^{3}$ Eden, C.L. (1989) Using cognitive mapping for strategic options development and analysis (SODA). In J. Rosenhead (ed.) Rational analysis for a problematic world. John Wiley e Sons. Chinchester, Uk.

${ }^{4}$ Os Mapas Cognitivos são métodos que pertencem à área da Psicologia Ambiental; esta por sua vez, é uma disciplina que "procura" entender o pensamento e o sentimento das pessoas através de suas experiências pessoais.
} 
ser definido através de dois pólos separados (denominados de conceitos bipolares); estes dois pólos podem esclarecer a definição do conceito inicial. Segundo Pidd (2003), conceitos similares podem apresentar significados (interpretações) diferentes, por esta razão, não é conveniente desprezá-los. No método SODA II não são definidos muitos conceitos bipolares.

- Arcos - mostram a relação entre um par de conceitos. As setas devem ser posicionadas na direção do conceito inicial para o conceito final. As setas acompanhadas de um sinal negativo mostram uma causalidade negativa entre os dois conceitos. O sinal positivo ou negativo deve ser utilizado para expressar conceitos individuais e não o ponto de vista do consultor (pesquisador interpretador) (ver Figura 5.6).

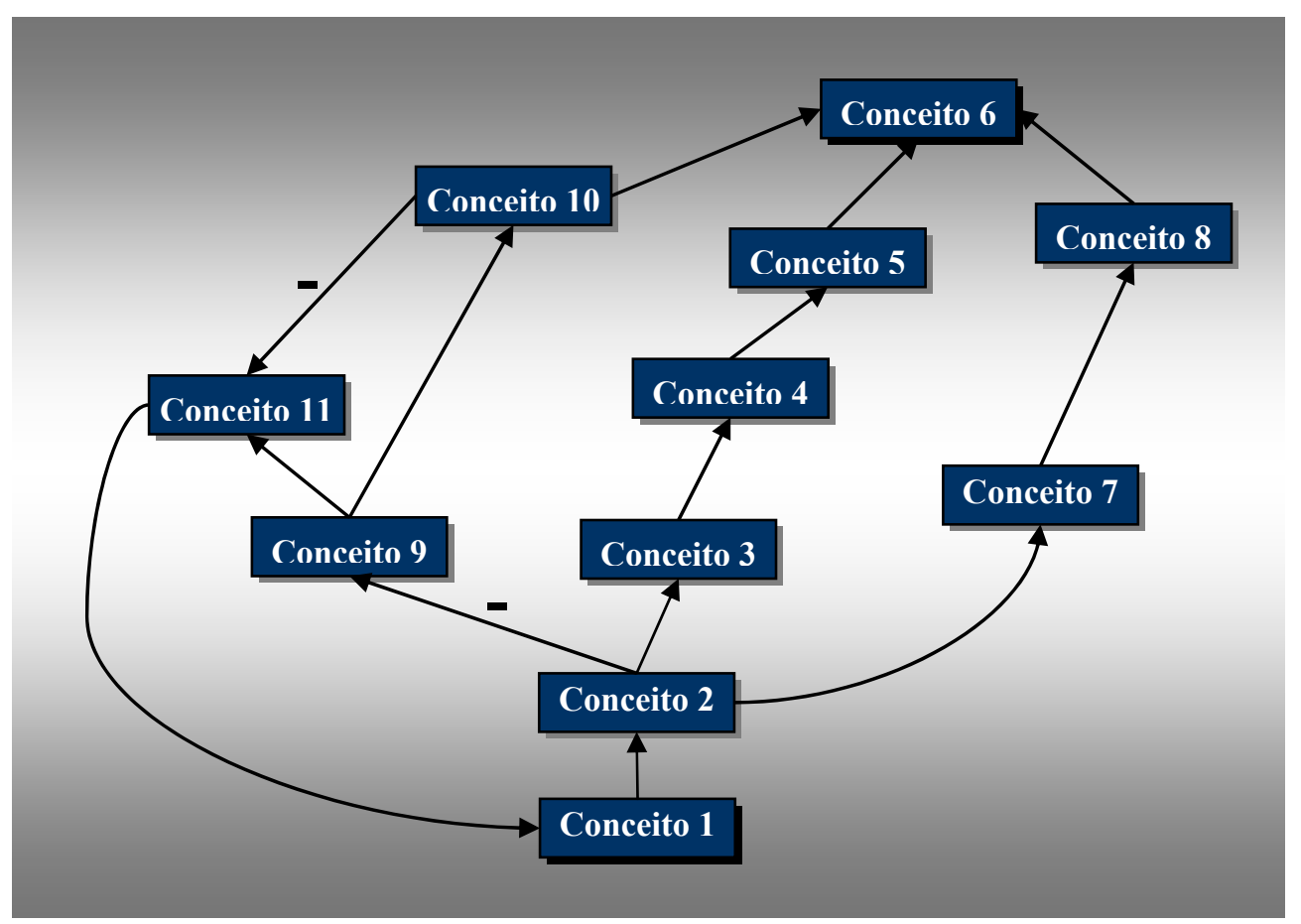

Figura 5.6 - Mapa cognitivo (mapa de causa) - Conceito unipolar Fonte: adaptado de Pidd (2003).

\section{- Construção do Mapa de Causalidade (Mapa Cognitivo)}

Eden et al. ${ }^{5}$ (1995) apud Pidd (2003) apresentam algumas recomendações para a construção dos Mapas Cognitivos:

1. Os objetivos devem ser listados no topo do mapa e devem ser identificados previamente (ver Figura 5.6).

\footnotetext{
${ }^{5}$ Eden C.L.; Ackermann, F. and Cropper, S. (1995) Getting started with Cognitive Mapping, supplied with Decision Explorer. Banxia Software, Glasgow.
} 
2. Colocar os outros conceitos abaixo dos objetivos para determiná-los (conduzílos) ao conceito principal. Os conceitos finais podem ser uma saída estratégica para esta definição.

3. Sempre que possível, deve-se escrever todos os conceitos na forma imperativa ou através do caminho (direção) orientado à ação (action-oriented way).

4. Observar que as setas estejam direcionadas de forma correta (direção da causalidade).

Para a construção do mapa cognitivo, Eden recomenda dispor os conceitos a partir do ponto mais alto para o ponto mais baixo do mapa (top down); sendo que o conceito principal ficará no topo do mapa (ver Figura 5.6).

Segundo Pidd (2003) os mapas cognitivos têm muita influência dos diagramas utilizados nos modelos dinâmicos. Através destes sistemas é possível analisar os mapas cognitivos através de "loops"; onde os conceitos podem ser revistos através da direção dos arcos e setas.

- Método SODA I - Segundo Pidd (2003) este método é utilizado quando um grupo de indivíduos tem seus pontos de vistas, que precisam ser direcionados para a tomada de decisão conjunta. O início do processo é separar os entrevistados de forma que cada membro possa desenvolver seu próprio mapa cognitivo. O mapa deve mostrar como eles expressam seus pensamentos. Cada um destes mapas compõe um mapa estratégico que servirá de base para as discussões e negociações do grupo (ver Figura 5.7). 


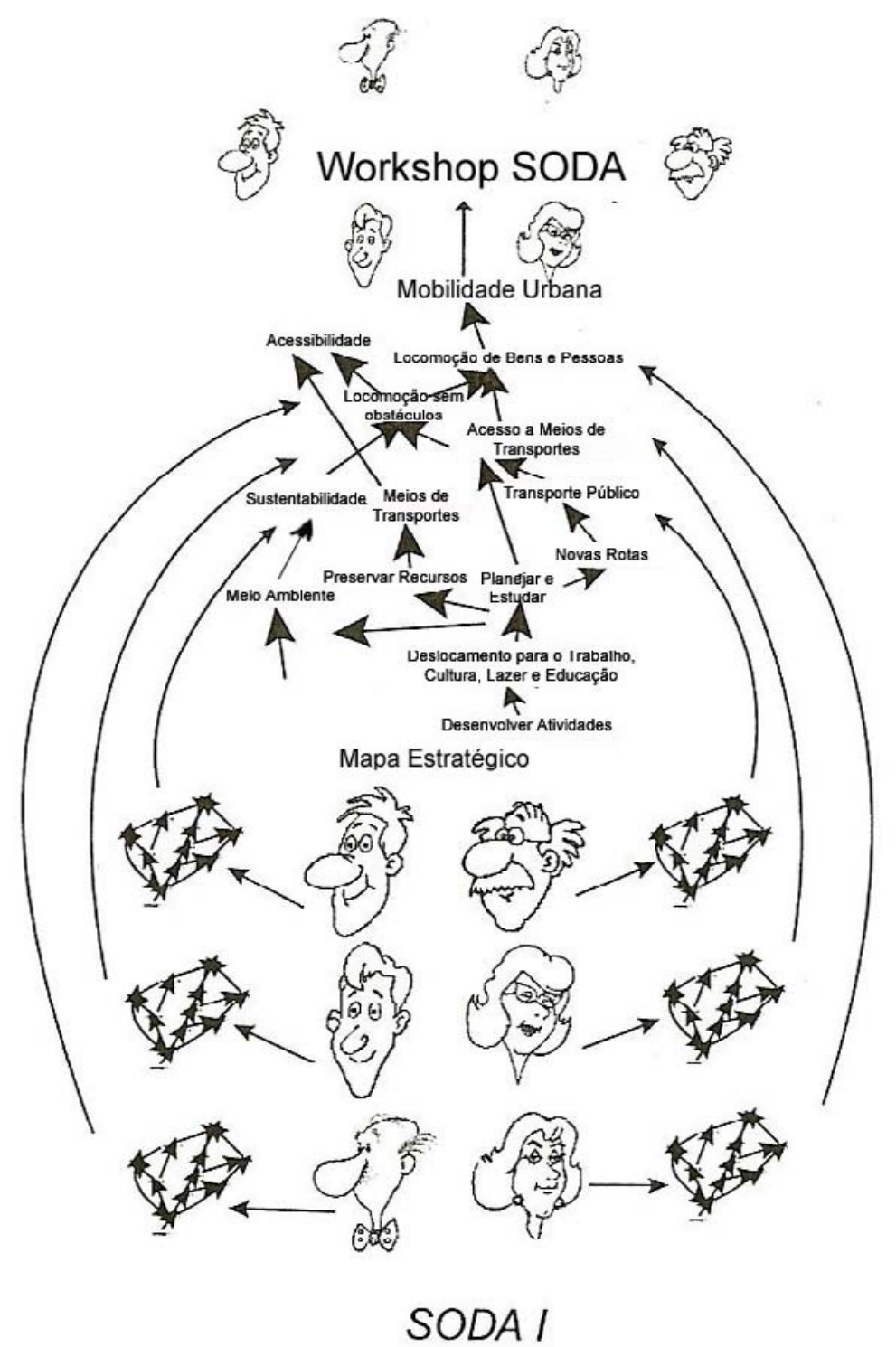

Figura 5.7 - Mapas de Causa: SODA I

Fonte: adaptado de Pidd (2003).

- Método SODA II e Journey Making - Segundo descrições de Eden \& Ackermann $^{6}$ (1998) apud Pidd (2003), deve ser aplicado diretamente com o grupo de decisores. Neste caso pode ser utilizado o software Group Explorer. Este mapa é utilizado pelo facilitador (Coordenador do grupo de decisão) para auxiliar o grupo na concordância da tomada de decisão (ver Figura 5.8).

${ }^{6}$ Eden, C.L. e Ackermann, F. (1998) Making Strategy: The journey of strategic management. Sage Publications. London 


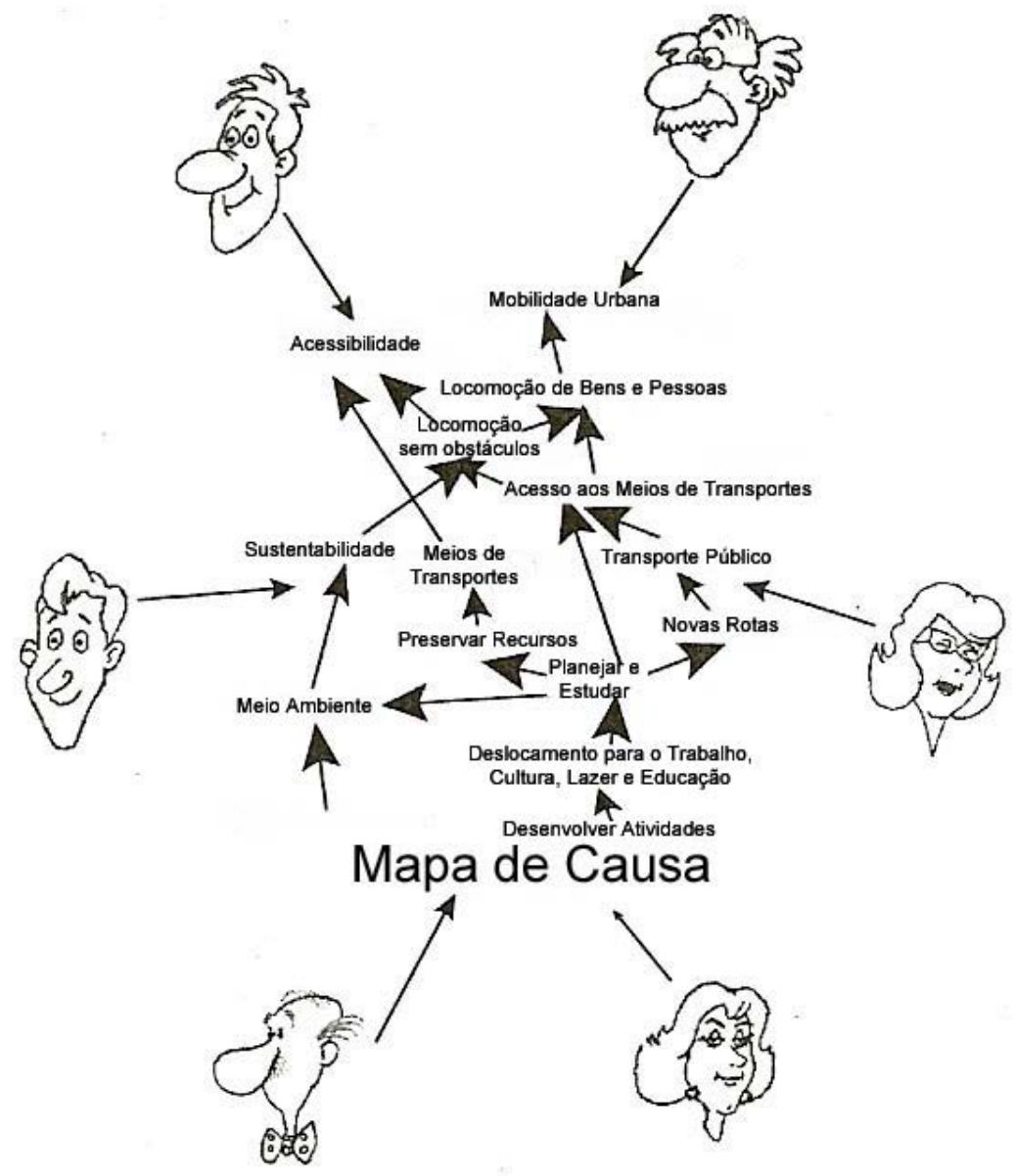

\section{Journey Making (SODA II)}

Figura 5.8 - Mapas de Causa: SODA II

Fonte: adaptado de Pidd (2003).

Eden, juntamente com outros pesquisadores, desenvolveu os software Decision Explore (conhecido anteriormente como Graphics COPE) e Group Explorer para auxiliar na construção dos mapas cognitivos (causa). Este software pode ser utilizado na construção dos mapas cognitivos utilizando-se a metodologia SODA I. O software Group Explorer é um desdobramento do software anterior. Ele é utilizado para a construção de mapas de causa através da internet. Estes software permitem realizar, de forma mais rápida e eficiente, o processo de construção dos Mapas Cognitivos.

$\mathrm{Na}$ área de Gestão da Produção a utilização da metodologia desenvolvida por Eden e Ackermann tem possibilitado validar alguns estudos nos quais as metodologias convencionais não se mostram adequadas (Rieg e Araújo Filho, 2002). Um exemplo desta aplicação pode ser encontrado nos trabalhos de Rieg e Araújo Filho (2002) que utilizaram duas metodologias de planejamento estratégico, o Planejamento Estratégico Situacional 
(PES) e o Mapeamento Cognitivo, para a gestão da Pró-Reitoria de Extensão da UFSCar (1996-2000).

\section{- Método da Análise de Conteúdo}

A análise de conteúdo é um conjunto de técnicas de análise utilizadas principalmente nas Ciências Sociais. Outras áreas de conhecimento também estão se apropriando destas técnicas para decodificarem as mensagens obtidas em entrevistas e questionários.

$\mathrm{Na}$ área de Planejamento dos Transportes, esta técnica foi utilizada por Sant'Anna (2007) para avaliar a percepção de usuários idosos com relação ao sistema viário. Segundo Sant’Anna (2007), a utilização da técnica de análise de conteúdo possibilitou ampliar o enfoque interdisciplinar (fenômenos sociológicos, psicológicos, físicos e técnicos) dos estudos de segurança de trânsito, permitindo assim que pudessem ser compreendidas as causas dos acidentes de trânsito em relação à população idosa.

A análise de conteúdo é um "conjunto de técnicas de análise das comunicações visando obter, por procedimentos, sistemáticos e objetivos de descrição do conteúdo das mensagens, indicadores (quantitativos ou não) que permitam a inferência de conhecimentos às condições de produção/recepção (variáveis inferidas) destas mensagens" (Bardin, 1977). Segundo Henry, P. e Moscovic, S. ${ }^{7}$ apud Bardin (1977) "tudo o que é dito ou escrito é susceptível de ser submetido a uma análise de conteúdo".

São objetos de análise desta técnica: i) documentos naturais, produzidos espontaneamente na realidade, e ii) documentos originados de questionários (respostas de questionários), testes, experiências, etc.

Dentre as técnicas que compõe a metodologia de análise de conteúdo para a análise de respostas para questões abertas destacam-se: Análise Temática, Análise Léxica e Análise de Associação.

\section{- Análise Temática e Análise Léxica}

Estas duas metodologias permitem classificar as respostas de um questionário aberto através de determinados critérios. As respostas abertas podem ser analisadas a partir de uma definição mais geral para uma mais particular. As mensagens podem ser analisadas através do continente e do conteúdo, ou através dos significantes e significados.

\footnotetext{
${ }^{7}$ Henry, P. e Moscovici, S. (1968) Problèms de l'analyse de contenu. Paris: Langage, $2^{\mathrm{a}}$ ed.. n. II.
} 
Segundo Bardin (1977) a análise de conteúdo realizada a partir de uma análise de significados é denominada de Análise Temática, e a realizada através de significantes é denominada de Análise Léxica ou de Procedimentos.

Osgood $^{8}$ (1959) apud Bardin (1977) mostra que as inferências podem ser obtidas a partir de um ou mais índices; estes índices são: unidades léxicas, co-ocorrência léxica, estrutura sintática, outras características formais, pausas, erros, expressões gestuais ou posturais.

A Análise Temática permite descobrir os principais sentidos da comunicação (respostas a questões abertas, entrevistas, etc.), onde a presença ou freqüência de um determinado índice (termo - frase ou palavra) pode ter algum significado no processo de análise.

A Análise Léxica é realizada através da identificação de palavras-chave. Segundo Bardin (1977), para realizar a análise de um texto deve-se levar em consideração todas as "palavras", pois elas podem representar elementos chave (palavras-chave ou palavras-tema) de análise cujo significado pode contribuir para uma determinada análise.

Bardin (1977) mostra que a análise de conteúdo pode ser utilizada para "tirar partido de um material qualitativo". Este material pode ser composto por entrevistas. Neste tipo de análise trabalha-se com a análise temática, freqüencial e quantitativa. A unidade de registro é o objeto (qualquer objeto citado pelo entrevistado). Esta análise deve ser transversal. As entrevistas são recortadas ao redor de cada tema-objeto (ver Figura 5.9).

8 Osgood C.E. 1959 "The Representational Model and Relevant Research Methods" in I.D.S. Pool (ed) Trends in Content Analysis, University of Illinois Press, Urbana, p. 33-88. 


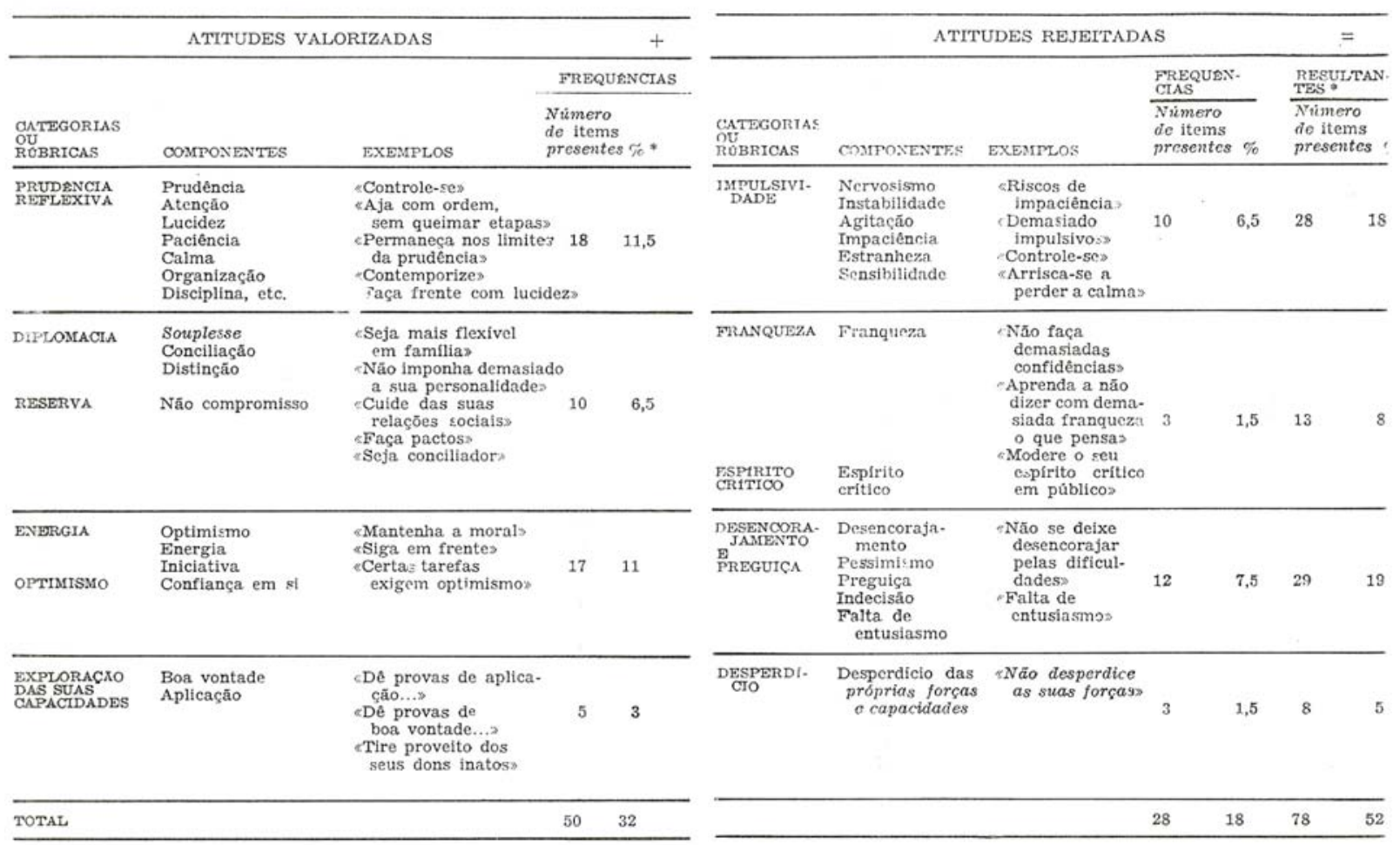

Figura 5.9 - Exemplo de análise temática de um texto Fonte: Bardin (1977).

\section{- Análise de Associação}

A análise de conteúdo também pode ser realizada utilizando-se da Teoria da Associação (análise de associação). Nesta análise, também denominada de co-ocorrências, procura-se extrair do texto as relações entre os elementos da mensagem, ou seja, a relação de associação entre dois ou mais elementos na mesma unidade de contexto. Esta teoria foi esboçada por Baldwin ${ }^{9}$ e defendida por Osgood.

Osgood propõe o seguinte procedimento metodológico para a realização deste tipo de análise:

- Escolher as unidades de registro-palavras-chave, temas.

- Escolher as unidades de contexto e o recorte do texto - numa mensagem descontínua a unidade de contexto pode corresponder: a uma carta, a um artigo, a uma entrevista, etc.

- Codificar - realçar os elementos de cada fragmento para a obtenção de uma matriz que possa mostrar as co-ocorrências ou as associações.

- Calcular as co-ocorrências.

\footnotetext{
${ }^{9}$ Baldwin, A. L. (1942) Personal structure analysis. A statiscal method for investigating the single personality. Journal of Abnormal and Social Psychology, 37. p. 163-183.
} 
- Representar e interpretar os resultados - os resultados podem ser representados através de tabelas de contingência, quadros de redes e de núcleos (clusters analysis).

Nesta pesquisa, para a análise dos questionários foi definida a utilização de uma combinação dos métodos desenvolvidos por Eden e Bardin, ou seja, foram utilizadas como referência as técnicas de construção de Mapas Cognitivos associadas às técnicas de Análise de Conteúdo (Análise Léxica e de Associação).

As respostas dos questionários foram analisadas através da identificação de palavras-chave. Posteriormente foram construídos os Mapas Cognitivos a partir das interrelações de cada palavra-chave para cada questionário avaliado. Na seqüência foram analisados, por comparação de palavras-chave, os Mapas Cognitivos para cada questão. 


\section{PLANUTS - SISTEMA DE SUPORTE À DECISÃO NA INTERNET PARA O PLANEJAMENTO DA MOBILIDADE URBANA}

Neste capítulo é apresentado cada componente do sistema PLANUTS; bem como a concepção de cada um dos quatro Módulos de Avaliação (com exceção da implantação do Módulo 4) e o Módulo Administrativo do sistema.

\subsection{Concepção do sistema PLANUTS}

O Sistema de Suporte à Decisão - PLANUTS foi desenvolvido como uma alternativa que pode ser adotada num processo de planejamento da mobilidade urbana participativa envolvendo múltiplos segmentos da comunidade. O objetivo do sistema é trazer subsídios para as discussões e tomada de decisão nas etapas de planejamento e/ou monitoramento da Mobilidade Urbana, sobretudo em cidades de médio porte.

Durante o processo de utilização do sistema PLANUTS os avaliadores poderão visualizar alguns problemas comuns às cidades de médio porte brasileiras, vinculados à questão da Mobilidade Urbana.

Resumidamente, este sistema foi desenvolvido de forma a permitir:

- Identificação e avaliação de problemas associados à Mobilidade Urbana;

- Exploração (visualização) de informações espaciais sobre a cidade;

- Contribuição ao processo de tomada de decisão participativa;

- Definição de indicadores (para compor um Sistema de Indicadores de Mobilidade que representam os problemas de mobilidade mais importantes para o município) que poderão ser utilizados no processo de avaliação e monitoramento do Plano Diretor de Transportes e Mobilidade Urbana.

Os usuários do sistema PLANUTS podem ser compostos por: especialistas da cidade, especialistas externos ao município (técnicos da área de Mobilidade Urbana - 
pesquisadores brasileiros e estrangeiros) e demais membros representantes dos diversos segmentos da comunidade.

O sistema proposto foi concebido de forma universal, ou seja, ele foi construído de forma modular e flexível; uma vez realizadas as alterações internas necessárias, ele poderá ser implantado em qualquer cidade brasileira de médio porte.

Com base nestes princípios e como uma das premissas para a elaboração do sistema era a utilização de software livre, para diminuir o custo de implantação do sistema em outras cidades de médio porte, o módulo referente à avaliação e participação popular foi desenvolvido sem a utilização de software comerciais; como não há sistemas freeware, optou-se pelo desenvolvimento pleno deste módulo baseado em software existentes.

\subsection{Princípios do sistema PLANUTS}

De acordo com os referenciais teóricos apresentados nos Capítulos 2 e 3 desta pesquisa, onde foram abordadas as questões como Plano Diretor de Transportes e Mobilidade Urbana e Planejamento Participativo, respectivamente, o sistema PLANUTS adotou os seguintes princípios:

- A concepção do sistema PLANUTS fundamenta-se na associação dos princípios e métodos do processo de participação popular tradicional com os recursos que a internet pode proporcionar aos usuários (decisores).

- O modelo de participação adotado é o individual; ou seja, as informações serão armazenadas e disponibilizadas para análise de forma individualizada. O sistema permite a análise das avaliações de cada usuário após a finalização do processo de avaliação do módulo corrente. O processo de decisão ocorrerá através de um consenso geral das decisões parciais resultantes dos diferentes estágios de avaliação e da escolha de alternativas (cenários) definidas pelos diversos agentes participantes.

- O acesso ao sistema será realizado através da internet. Os participantes poderão acessar o sistema em qualquer local (trabalho, casa, terminais públicos - ex. poupa tempo, etc.) e horário desde que o módulo para avaliação esteja ativo.

\subsection{Detalhamento do Sistema PLANUTS}

Após a apresentação da proposta de participação popular no processo de discussão da Mobilidade Urbana utilizando a metodologia participativa presencial e para a internet, são descritos em detalhes, cada um dos componentes do sistema PLANUTS. 
O esquema conceitual do sistema PLANUTS foi elaborado a partir de dois elementos principais:

i) Interface na internet - é representada pela interface do projeto na internet; é composta por páginas $h t m l$ cujos conteúdos estão associados a informações do projeto, do município e sobre mobilidade. Contém ainda uma ferramenta de comunicação entre a comunidade (delegados ou representantes dos diversos segmentos da sociedade que avaliarão o sistema) e os administradores do sistema (equipe que coordena o processo de elaboração do Plano Diretor) possibilitando uma comunicação direta entre os envolvidos (esta comunicação é realizada através de uma conta de e-mail disponível durante todo o processo de avaliação do sistema e desenvolvimento do Plano Diretor de Transportes e Mobilidade).

ii) Módulo de Avaliação da Mobilidade Urbana - é composto por quatro módulos de avaliação interdependentes que possibilitam: o gerenciamento das informações, a exploração, e a avaliação da mobilidade urbana. Outro elemento importante refere-se ao módulo de gerenciamento das avaliações - Módulo Administrativo, ele permite a visualização dos resultados obtidos no processo de avaliação de cada módulo e a "construção" do Módulo III (em função dos resultados obtidos no Módulo II). Este componente representa o sistema propriamente dito, ou seja, é a "essência" do sistema, ele permitirá a definição dos indicadores de mobilidade, a identificação dos problemas e soluções a ele (indicador) relacionadas e sua espacialização no município.

O Sistema PLANUTS ainda possibilita a utilização de outros elementos que auxiliarão no processo de tomada de decisão:

- Base de Dados - As informações armazenadas no Módulo Administrativo poderão ser disponibilizadas para serem visualizadas ou processadas em outros software: SIG e Sistemas de Suporte à Decisão. A base de dados do Sistema PLANUTS é composta pelas seguintes informações: i) Base de dados espaciais - são representadas pelas seguintes informações: mapas, fotografias aéreas, imagens de satélite do município com informações sobre o cadastro urbano, uso do solo, zoneamento, linhas de transporte público, sistema viário, etc., que possibilitarão a elaboração e visualização de mapas de diagnóstico e cenário do município; e ii) Base de dados alfanumérica informações do cadastro técnico multifinalitário municipal, dados do IBGE, de pesquisas de campo como origem-destino, etc., que contribuirão para a avaliação da mobilidade urbana no município. 
- Outros software - A concepção do sistema PLANUTS permite sua interação com qualquer outro SIG. Neste sistema a ferramenta SIG está desvinculada do Módulo de Avaliação da Mobilidade Urbana. Isto permite: uma flexibilidade na escolha do software a ser adotado em função das necessidades locais, do nível de conhecimento e familiaridade dos recursos computacionais da equipe técnica e da população que utilizarão este recurso, bem como da situação econômica e tecnológica do município em que estiver implantando o sistema. Se o software utilizado não incluir um módulo voltado para a internet, as informações (mapas e cenários) poderão ser visualizadas pela população em diferentes formatos [por exemplo: JPG (ou JPEG), TIFF, PDF, etc.] e disponibilizadas no site do projeto.

A Figura 6.1 apresenta o esquema conceitual adotado na construção do Sistema PLANUTS.

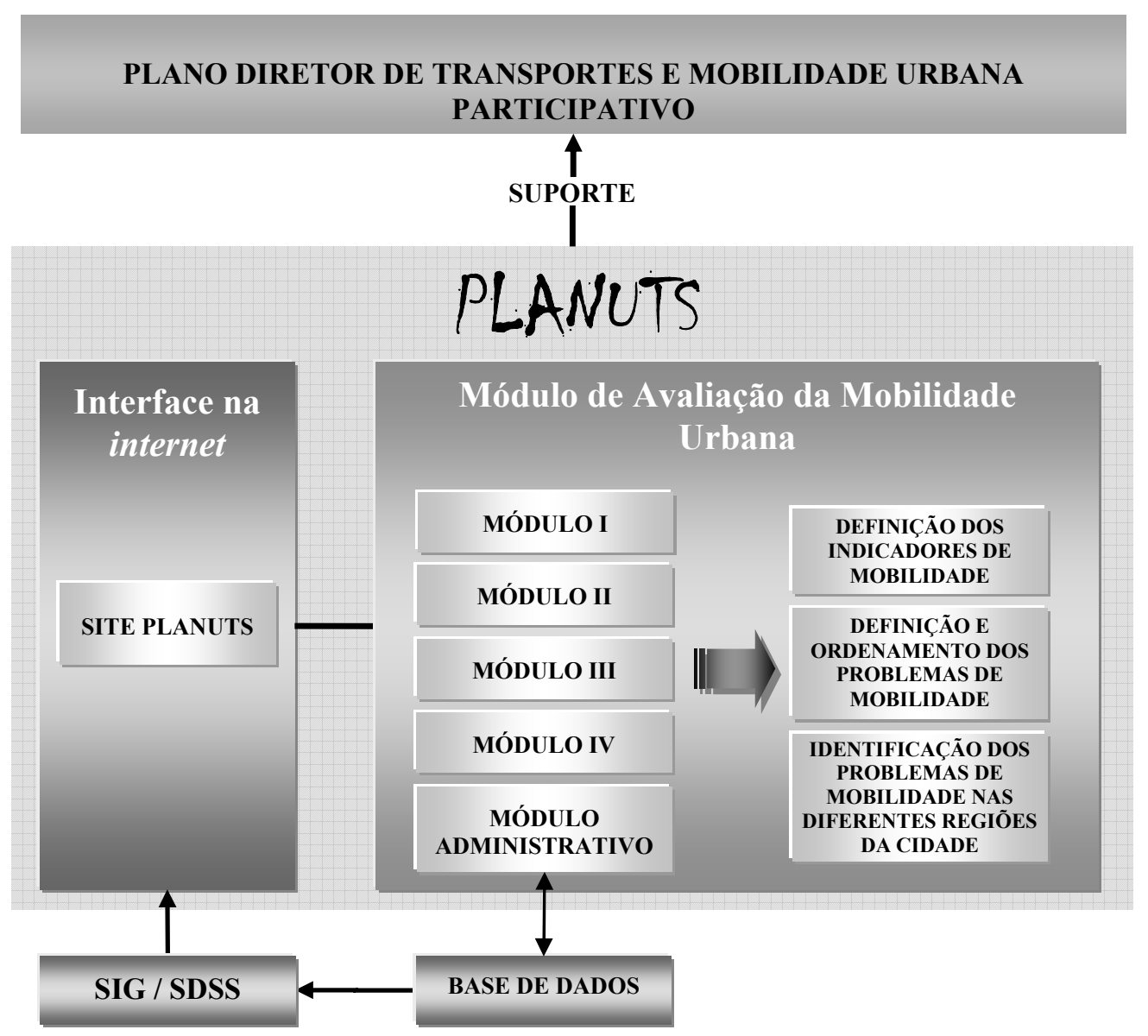

Figura 6.1 - Estruturação do Sistema PLANUTS

A seguir serão detalhados os dois itens principais do sistema PLANUTS: a interface na internet e o Módulo de Avaliação da Mobilidade Urbana. 


\subsubsection{Interface na internet}

A interface na internet é representada pela construção do site do projeto. Este site é o responsável pelo acesso ao Módulo de Avaliação e deverá conter as informações referentes ao município em que está implantando o sistema.

O Quadro 6.1 mostra como deve ser realizada a estruturação das páginas que contêm as informações que subsidiarão as avaliações no sistema.

Quadro 6.1 - Descrição das páginas do sistema PLANUTS

\begin{tabular}{|c|c|}
\hline PÁGINAS & DESCRIÇÃO \\
\hline $\begin{array}{l}\text { PÁGINA } \\
\text { INICIAL }\end{array}$ & $\begin{array}{l}\text { - Apresentação e descrição preliminar do Sistema de Suporte à Decisão - } \\
\text { PLANUTS. } \\
\text { - Informações disponíveis: } i \text { ) mensagem de aviso sobre o Módulo de Avaliação } \\
\text { disponível para acesso, } i i) \text { definição da sigla PLANUTS, iii) definição do } \\
\text { sistema, } i v \text { ) explicação geral de acesso ao Módulo de Avaliação, e } v \text { ) e-mail do } \\
\text { projeto. }\end{array}$ \\
\hline $\begin{array}{l}\text { MOBILIDADE } \\
\text { URBANA }\end{array}$ & $\begin{array}{l}\text { - Deve abordar os seguintes temas: } \\
\text { - Definição de Mobilidade Urbana. } \\
\text { - Medidas para uma política nacional de mobilidade urbana adotada pelo } \\
\text { Ministério das Cidades. } \\
\text { - Diretrizes para o planejamento municipal da mobilidade urbana. } \\
\text { - Diretrizes nacionais para elaboração de planos municipais de acessibilidade. }\end{array}$ \\
\hline $\begin{array}{l}\text { PÁGINA DO } \\
\text { MUNICÍPIO }\end{array}$ & $\begin{array}{l}\text { - Informações sobre o Município. } \\
\text { - Dados sobre o Perfil Municipal, obtido através de consultas ao site do IBGE e } \\
\text { outras fontes de informação. } \\
\text { - Acesso ao SPRINGWEB ou a outro software de visualização de mapas. }\end{array}$ \\
\hline PLANUTS & $\begin{array}{l}\text { - Página principal do sistema. } \\
\text { - Informações disponíveis: definição conceitual do Sistema PLANUTS e os links } \\
\text { para acessar os quatro Módulos de Avaliação da Mobilidade Urbana. }\end{array}$ \\
\hline $\begin{array}{c}\text { FALE } \\
\text { CONOSCO }\end{array}$ & $\begin{array}{l}\text { - Responsável pela troca de informações entre a população e a equipe técnica } \\
\text { responsável pelo PLANUTS. } \\
\text { - As informações devem ser encaminhadas diretamente para o e-mail do projeto. }\end{array}$ \\
\hline SITES & $\begin{array}{l}\text { - Disponibiliza aos usuários do sistema alguns links de órgãos municipais, } \\
\text { estaduais e federais ou não governamentais. } \\
\text { - Contribuição para o processo de avaliação. } \\
\text { - Exemplo de sites: Prefeitura Municipal; DENATRAN; IBGE; etc. }\end{array}$ \\
\hline
\end{tabular}

\subsubsection{Módulo de Avaliação da Mobilidade Urbana}

A construção do Módulo de Avaliação da Mobilidade Urbana partiu dos seguintes princípios: i) possibilitar a participação de multi-usuários no processo de tomada de decisão; ii) auxiliar no processo de conhecimento das questões referentes à Mobilidade Urbana, através da utilização de diversas mídias; e iii) construção de um referencial a partir de um processo de análise e conhecimento hierárquico e gradual do sistema. 
A concepção de cada módulo baseou-se em experiências advindas tanto do planejamento participativo tradicional como daquele que utiliza recursos computacionais. Nos dois processos, a participação popular inicia-se com um processo de conscientização, esclarecimento e/ou conhecimento sobre os principais problemas urbanos associados aos transportes. Estas informações deverão subsidiar as discussões sobre mobilidade no município.

A Figura 6.2 apresenta o fluxograma de funcionamento dos quatro Módulos de Avaliação e do Módulo Administrativo (entrada e saída destes módulos), bem como a interdependência entre eles.

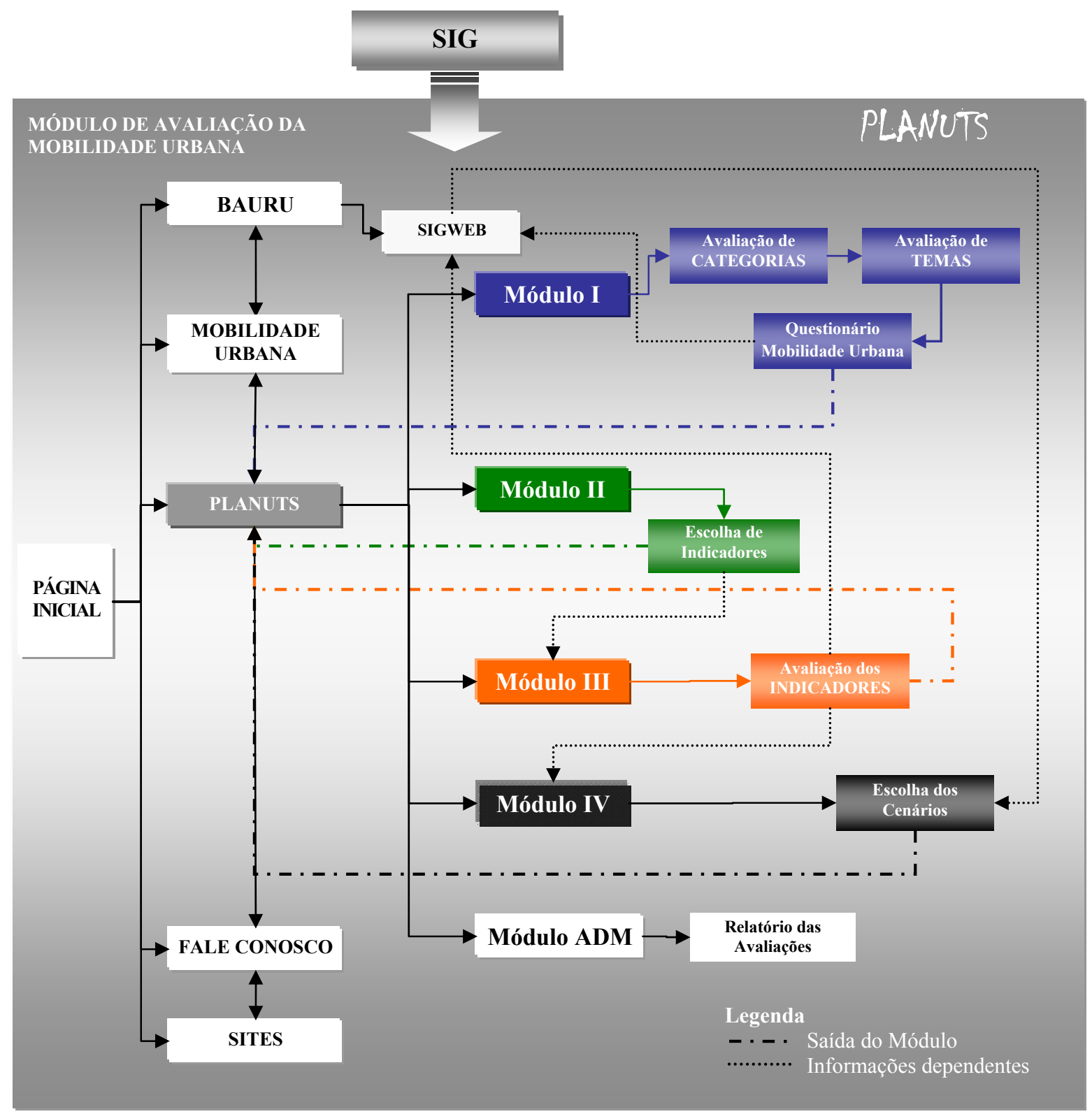

Figura 6.2 - Fluxograma de funcionamento do Sistema PLANUTS 
A seguir são apresentados detalhadamente os quatro Módulos de Avaliação da Mobilidade Urbana que compõem o Sistema PLANUTS.

\subsubsection{Caracterização Geral}

A concepção dos quatros módulos de avaliação baseou-se nos princípios dos Sistemas de Suporte à Decisão voltados para a Internet. Embora o sistema tenha algumas limitações, se comparado com software comercializáveis, uma vez que foi construído utilizando recursos $h t m l$, asp e flash; sua arquitetura foi baseada nas definições de um DSS voltado à internet ${ }^{l}$; ou seja, ele foi construído de forma a possibilitar: a Segurança dos Dados, a Comunicação, o Gerenciamento dos Dados, a Exploração, Avaliação, Voto e Obtenção dos Resultados.

- Segurança dos Dados - é realizada através da Página de Cadastro, localizada na área administrativa do sistema (Módulo Administrativo). Esta página permite realizar a identificação do(s) usuário(s) nos quatro Módulos de Avaliação, através da seguinte classificação: Administrador do sistema, Especialista e População. Através deste cadastro é possível verificar o número de participantes, a duplicidade de votação em cada um dos quatro módulos de avaliação e aqueles usuários que não fazem parte do grupo de avaliadores do sistema.

- Comunicação - a comunicação é realizada por e-mail. Nos Módulos II e III existem áreas que permitem que os usuários insiram seus comentários sobre as questões avaliadas.

- Gerenciamento dos Dados - é realizado no Módulo Administrativo, sendo seu acesso restrito aos administradores do sistema. Este acesso pode ser realizado pela internet; acessando a página ADM (administrativa) no site do sistema PLANUTS. As informações são armazenadas seqüencialmente no sistema, de acordo com o login do usuário em cada um dos módulos de avaliação. A avaliação dos dados deverá ser realizada por um software adequado (um gerenciador de Banco de Dados) para a apresentação dos resultados à população.

- Exploração e Obtenção dos Resultados - a área administrativa do Sistema PLANUTS permite a inclusão no banco de dados de avaliações simultâneas. Os resultados de cada módulo são armazenados numa área restrita.

\footnotetext{
${ }^{1}$ Jankowski, P. and Nyerges, T. (2001) Geographic Information Systems for Group Decision Making. Taylor and Francis. London and New York.
} 
- Avaliação e Voto - o processo de avaliação e voto é realizado em cada módulo individualmente.

O Sistema foi construído adotando-se a estrutura modular, ou seja, buscou-se estruturar as informações de acordo com o grau de conhecimento da população sobre a questão da Mobilidade Urbana e assim possibilitar a participação de múltiplos segmentos da sociedade no processo de avaliação e/ou monitoramento da Mobilidade Urbana.

Além dos fatores acima mencionados, outros elementos foram levados em consideração para a construção dos quatro Módulos de Avaliação da Mobilidade Urbana. A seguir é apresentado cada um destes elementos.

- Processo de diagnóstico participativo - os quatro módulos de avaliação permitem que os usuários possam diagnosticar a mobilidade urbana do município através das definições das categorias, temas e indicadores.

- Problemas de mobilidade em cidades de médio porte - neste sistema a questão da mobilidade urbana é abordada através da definição das Categorias, Temas e Indicadores. Cada uma das informações é apresentada para avaliação partindose de um conceito mais geral (definição da Categoria) para o conceito mais específico (definição do Indicador) mostrando a sua relação com a cidade.

- Identidade Visual - para a diferenciação dos módulos adotou-se o uso de cores primárias. Cada módulo possui uma cor, conforme mostrou a Figura 6.2.

- Estruturação das informações: a estrutura das informações foi concebida para facilitar a identidade visual do sistema. Cada um dos elementos (Categorias, Temas e Indicadores) e mídias (som, texto e imagem) é apresentado de forma mais clara e representativa possível para facilitar o processo de avaliação daqueles usuários que possuem menor familiaridade com as ferramentas computacionais.

- Visualização das Informações - é realizada através da utilização de ferramentas multimídia (áudio, texto e imagem) cujo objetivo foi tornar os conceitos associados à mobilidade mais representativos e simples, de forma a diminuir a diferença de conhecimento entre especialistas e a comunidade.

- Acessibilidade ao público - o sistema proporciona total acessibilidade através de: i) interações junto aos coordenadores do sistema (ocorrerá através de $e$-mail e da inclusão de comentários no próprio sistema), ii) interação na etapa de votação (através da utilização de barra deslizante), e iii) interação nos resultados 
das avaliações [poderão ser observados através de Gráfico de Setores (Módulo I) e Gráfico de Barras (Módulo III)].

- Processo de Avaliação - Os quatro Módulos de Avaliação foram construídos de forma que os usuários possam avaliar a Mobilidade Urbana seqüencialmente. Sugere-se a definição de um período de avaliação de aproximadamente um mês para cada módulo, o que permite uma maior flexibilidade de tempo para a interação com o sistema. Terminado o período de avaliação, o módulo "ativo" torna-se indisponível para acesso externo, permitindo assim que a equipe técnica possa analisar os dados e assim disponibilizar à população o próximo módulo de avaliação. A ordem de avaliação dos módulos é a seguinte: em uma primeira etapa estarão à disposição os Módulos I e II, posteriormente será avaliado o Módulo III e na seqüência o Módulo IV.

- Sistema de Votação - a forma de votação é realizada através da utilização de uma barra deslizante com valores de " 1 " a " 5 ", sendo o valor " 1 " associado à palavra menos importante e o valor "5" a mais importante. Este sistema foi construído baseado no método apresentado por Jankowski e Nyerges (2001), que apresentaram uma forma de votação para a escolha de alternativas através da utilização do software Choice Perspectives, versão 1.2. No Sistema PLANUTS a definição das Categorias ou Temas (Módulo I) ou Indicadores (Módulo III) mais importantes é realizada através do cálculo dos scores (de 1 a 5) para cada um destes critérios. Na etapa de sistematização dos votos são definidos os pesos de cada um destes critérios avaliados, sendo posteriormente realizado um ranking destes pesos.

- Visualização dos votos - Os resultados das avaliações podem ser observados através de Gráfico de Setores (Módulo I) e Gráfico de Barras (Módulo III). Segundo Yigitcanlar (2001), tradicionalmente, os DSS apresentavam a visualização dos resultados através de uma forma sofisticada, onde apenas os especialistas conseguiam entender as informações geradas pelo sistema. A utilização de gráficos mais simples incentiva a participação popular. Este tipo de representação facilita o entendimento, uma vez que pode transformar informações complexas em informações mais simples, possibilitando a compreensão de todos.

- Flexibilidade - uma vez realizadas as alterações internas necessárias, o sistema poderá ser implantado em qualquer cidade brasileira de pequeno e médio porte. 
A partir destes elementos foi possível definir os objetivos e a função de cada um dos quatro Módulos de Avaliação da Mobilidade Urbana, conforme mostra o Quadro 6.2 .

Quadro 6.2 - Principais funções dos quatro Módulos de Avaliação da Mobilidade Urbana

\section{MÓDULOS DE AVALIAÇÃO DA MOBILIDADE URBANA}

- Módulo I - avaliação das Categorias e Temas através da definição do "grau de importância" destes critérios.

- Módulo II - avaliação dos Indicadores através da escolha de dois indicadores por Tema. Estes indicadores são definidos como sendo os "mais importantes" para avaliar a Mobilidade na cidade. O resultado desta avaliação irá definir os indicadores que deverão compor um Sistema de Indicadores de Mobilidade Urbana.

- Módulo III - avaliação dos Indicadores através dos seguintes itens: problemas e soluções associados aos indicadores avaliados, definição dos indicadores "mais importantes" e "mais urgentes", e espacialização dos problemas de mobilidade mais importantes na cidade.

- Módulo IV - avaliação dos cenários comparativos.

Em resumo, o Sistema PLANUTS foi elaborado para possibilitar uma nova visão no processo de tomada de decisão (principalmente dos decisores não-especialistas) nas diversas etapas da elaboração do Plano Diretor de Transportes e Mobilidade, conforme elencado abaixo:

1. Definir um Sistema de Indicadores de Mobilidade para o planejamento e monitoração da Mobilidade Urbana no município;

2. Auxiliar os tomadores de decisão na formulação, definição ou avaliação das situações (cenários) através da identificação dos problemas de mobilidade associados a cada indicador avaliado;

3. Fornecer suporte à tomada de decisão através da análise dos possíveis impactos na adoção de determinada alternativa (Módulo IV).

O Quadro 6.3 apresenta resumidamente as principais características que subsidiaram a construção do Sistema PLANUTS. 


\section{Quadro 6.3 - Características gerais do Sistema PLANUTS}

\section{Construção do Sistema}

- Subdivisão do sistema em quatro Módulos de Avaliação, em função do:

- Grau de especificidade e complexidade na definição dos temas.

- Método de avaliação adotado.

- Os Módulos I e II serão disponibilizados à comunidade no mesmo período para avaliação e os Módulos III e IV serão apresentados em diferentes épocas.

- Esta definição se justifica em função do tempo médio que cada usuário deve gastar para avaliar cada módulo, e sua posterior análise por parte da equipe técnica.

Processo de avaliação participativa

- Inicia-se com definições mais genéricas a respeito das Categorias e Temas a serem avaliados (Módulo I).

- No Módulo II são apresentados conceitos mais específicos que permitem avaliar os Indicadores.

- Nos Módulos III e IV são abordadas, respectivamente, a definição dos principais problemas na cidade e a escolha dos cenários comparativos.

\section{Processo de Voto}

- Está presente nos quatro Módulos de Avaliação.

- Módulos I e III - adotou-se uma barra deslizante que permitirá que o usuário atribua uma pontuação aos critérios avaliados; a escala de valores (grau de importância) varia de 1 a 5 (critério menos importante ao mais importante, respectivamente).

- Módulo II - os indicadores serão definidos pela somatória das escolhas realizadas por todos os participantes.

- Módulo IV - não definido.

Obtenção dos Resultados

- Módulo I - será apresentado através de um gráfico de setores.

- Módulo II - os avaliadores só conhecerão os resultados no Módulo III.

- Módulo III - será apresentado através de gráficos de barra comparativos.

- Módulo IV - não foi definido.

Método de avaliação dos resultados

- Módulos I e III - será utilizada a Avaliação Multicriterial - Método da Escala de Pontos.

- Módulo II - os indicadores serão definidos pela somatória das escolhas.

- Módulo IV - não foi definido, mas sugere-se a adoção do Método de Avaliação Multicriterial.

Flexibilidade (implantação do sistema em outra cidade)

- Estrutura modular:

- Permite sua adaptação ou implementação em outros municípios.

- Algumas etapas (páginas) deverão ser alteradas internamente.

- Módulo I - as alterações referem-se à página do questionário onde os itens a serem alterados são: i) mapa de localização dos bairros, e ii) nome dos bairros nas seguintes questões: bairro onde mora, bairro onde reside, bairro onde trabalha e bairro onde estuda.

- Módulo II - não há necessidade de alteração interna do sistema.

- Módulo III - os aspectos a serem modificados são: alteração dos nomes dos bairros e o mapa de localização dos bairros da cidade.

- Minimização de problemas técnicos na implantação do sistema na internet, ou para realizar a modificação dos módulos.

- Elaboração de material explicativo (tutorial) para a implantação do sistema no servidor e indicação dos elementos internos a serem modificados em cada módulo.

- Observação: O Módulo IV não foi implementado, por isso, algumas características deste quadro não foram definidas. No item 6.3.2.5 são apresentadas apenas algumas sugestões para seu desenvolvimento e construção.

A seguir é apresentado o funcionamento de cada um dos quatro Módulos de Avaliação da Mobilidade Urbana e o Módulo Administrativo. 


\subsubsection{Módulo I}

O Módulo I tem como objetivo avaliar a Mobilidade Urbana, sob o enfoque da sustentabilidade (inclui as dimensões ambiental, social e econômica), através da definição de Categorias e Temas a ela relacionadas. Nesta etapa os participantes (avaliadores especialistas e não-especialistas) irão definir quais são os problemas de mobilidade (associados às Categorias e Temas, apresentados) "mais importantes" para o município que está implantando o sistema. As Categorias e Temas a serem avaliadas são:

- Categorias: Meio Ambiente e Transportes, Gestão dos Transportes, Infraestrutura dos Transportes, Planejamento dos Transportes, Aspectos Socioeconômicos dos Transportes.

- Temas: Energia, Impacto Ambiental, Qualidade do Ar, Ruído, Frota, Sistema Viário, Serviços de Transporte, Tráfego, Acessibilidade Urbana, Crescimento Urbano, População Urbana, Viagens, Custos, Impactos Socioeconômicos, Segurança e Transporte Público.

As definições de cada um destes critérios avaliados encontram-se disponíveis no Anexo 3.

A forma de visualização da definição de cada Categoria ou Tema a ser avaliado neste módulo é realizada através de recursos de Multimídia e Hipermídia (textos, áudio, imagens ou vídeos). A função destes recursos é facilitar o processo de avaliação para os usuários não-especialistas.

O processo de avaliação, conforme mostra a Figura 6.3, inicia-se com o cadastro do usuário no módulo. Posteriormente o usuário acessará a página de demonstração do funcionamento do Módulo I e, na seqüência, tem início o processo de avaliação do sistema com a avaliação das Categorias e Temas. A última etapa refere-se ao preenchimento de um questionário que será utilizado complementarmente às avaliações. Finalizado o processo de avaliação o usuário retornará ao site do PLANUTS (página PLANUTS). 


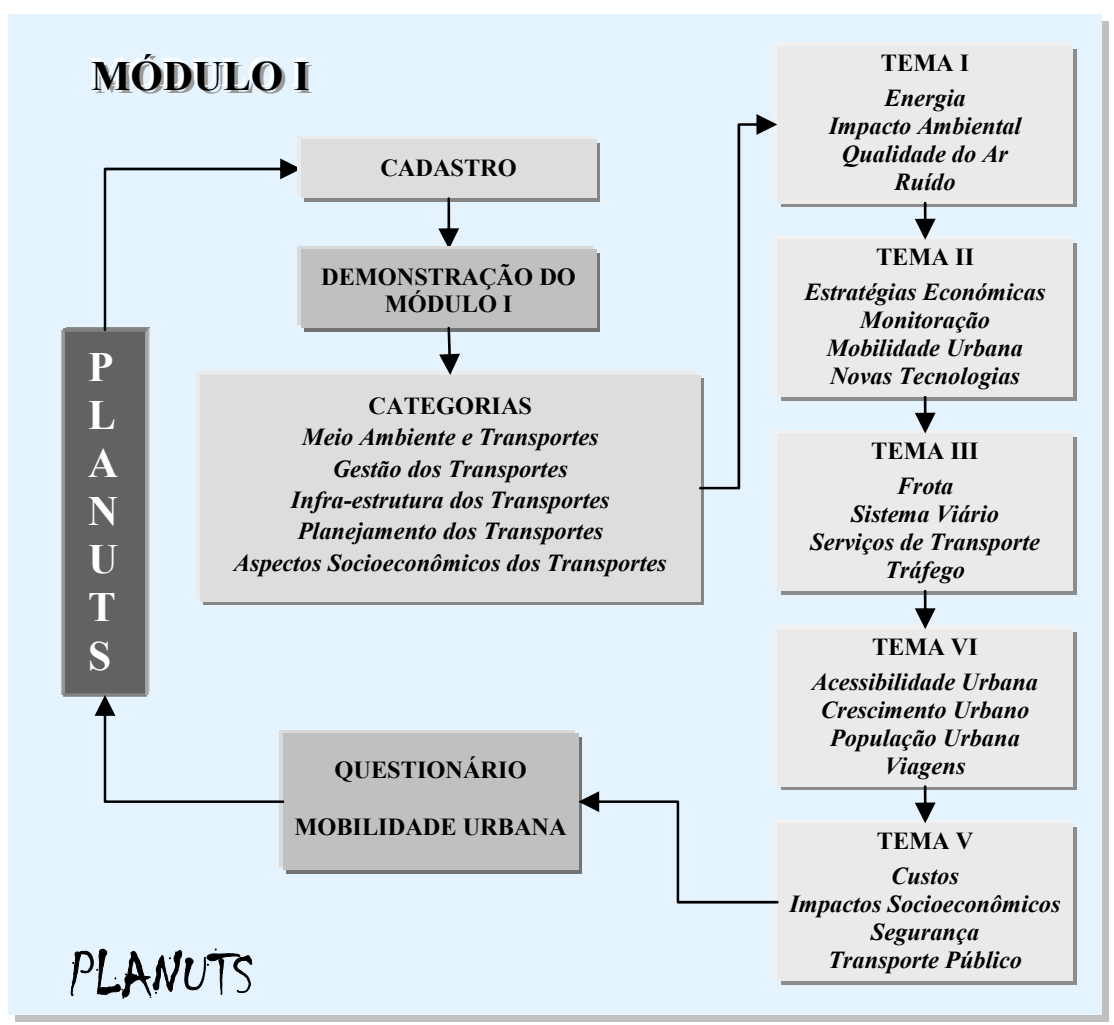

Figura 6.3 - Fluxograma de funcionamento do Módulo I

\section{- Processo de Avaliação das Categorias e Temas}

A página inicial do Módulo I é responsável pelo login de cada usuário cadastrado. O e-mail dos usuários é cadastrado no Módulo Administrativo pelo Administrador do Sistema. A senha deverá ser cadastrada pelo próprio participante na primeira vez que ele acessar o Módulo I. Esta senha deverá ser utilizada para a avaliação dos demais módulos do sistema. Caso o usuário esqueça esta senha, o sistema permite enviá-la automaticamente ao avaliador através da conta de $e$-mail cadastrada, acessando o link Esqueceu a senha (ver Figuras 6.4 e 6.5). 


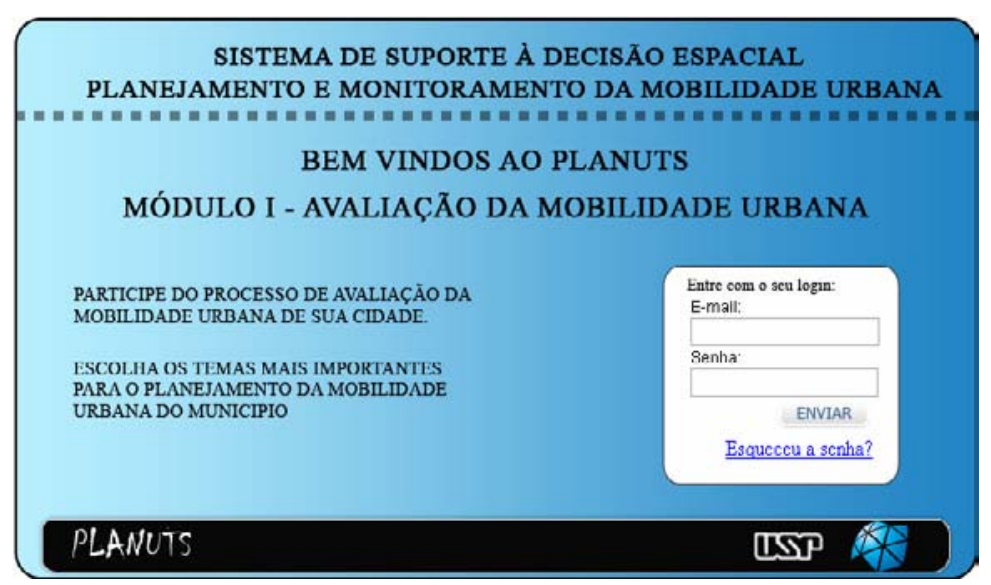

Figura 6.4 - Módulo I - Página de login

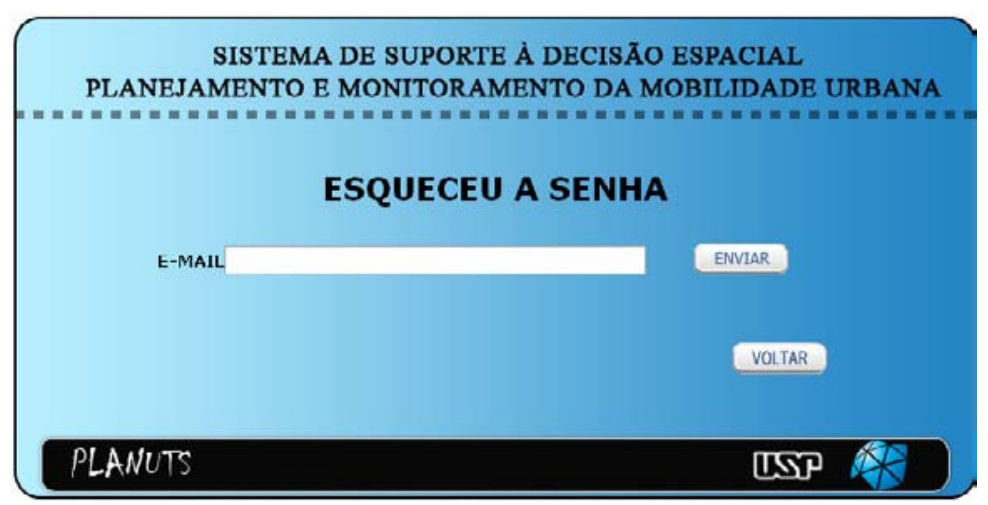

Figura 6.5 - Módulo I - Esqueceu a senha

Após a identificação do usuário na página de cadastro o avaliador acessará a Página de Demonstração ${ }^{2}$ deste módulo. Nesta página os recursos de vídeo e áudio demonstram os procedimentos e recursos disponíveis para auxiliar no processo de avaliação.

$\mathrm{Na}$ seqüência inicia-se o processo de avaliação das Categorias e posteriormente dos Temas. Os procedimentos adotados para a avaliação das Categorias e Temas são idênticos, ou seja, o usuário visualizará as informações e realizará a votação utilizando a mesma metodologia, tanto para as Categorias quanto para os Temas.

As Categorias ou Temas ativos podem ser visualizados através dos botões, localizados na parte superior das páginas de avaliação, destacados pela cor Azul. No caso dos Temas, o primeiro botão indica o nome da Categoria e os demais botões correspondem aos Temas (ver Figuras 6.6 e 6.7).

\footnotetext{
2 A página de demonstração é um recurso disponível nos quatro Módulos de Avaliação da Mobilidade Urbana. A inclusão deste recurso nos quatro módulos tem como objetivo facilitar o entendimento (de especialistas e não-especialistas) do funcionamento de cada módulo. Sua função é permitir a visualização (através de imagem e áudio) dos recursos (texto, áudio e imagem/vídeo) disponíveis e dos procedimentos que podem ser utilizados, pelos avaliadores, no processo de avaliação (voto) do módulo que está sendo utilizado.
} 


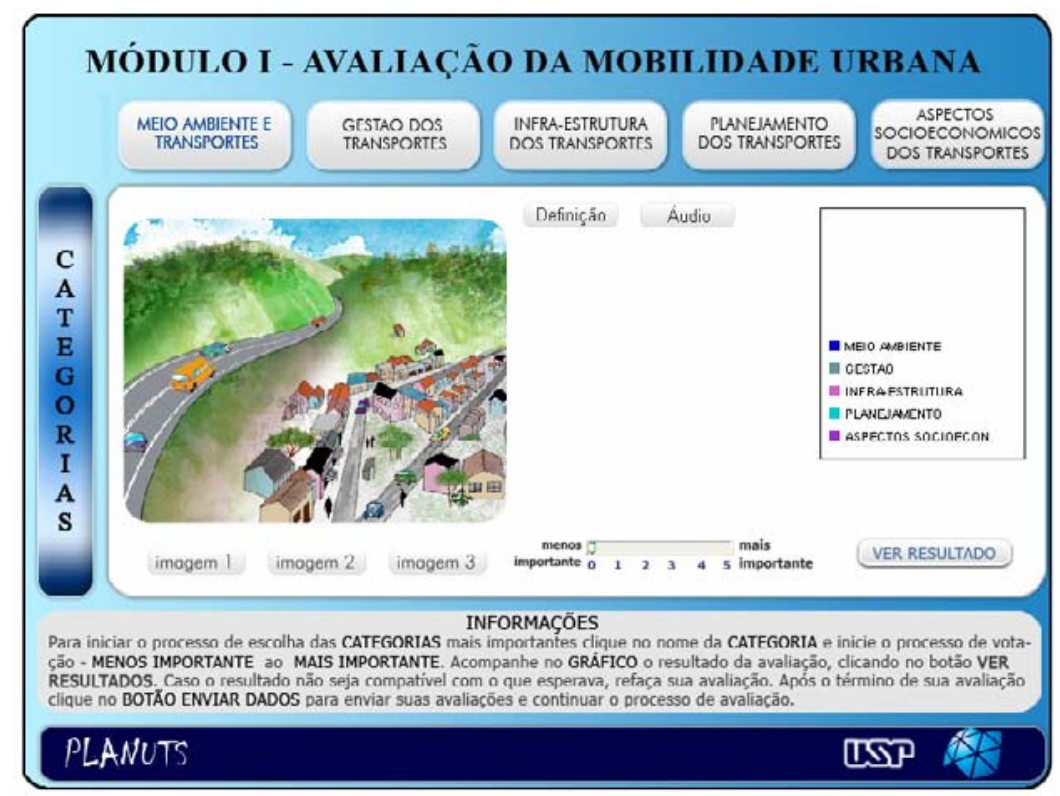

Figura 6.6 - Categoria Meio Ambiente e Transportes

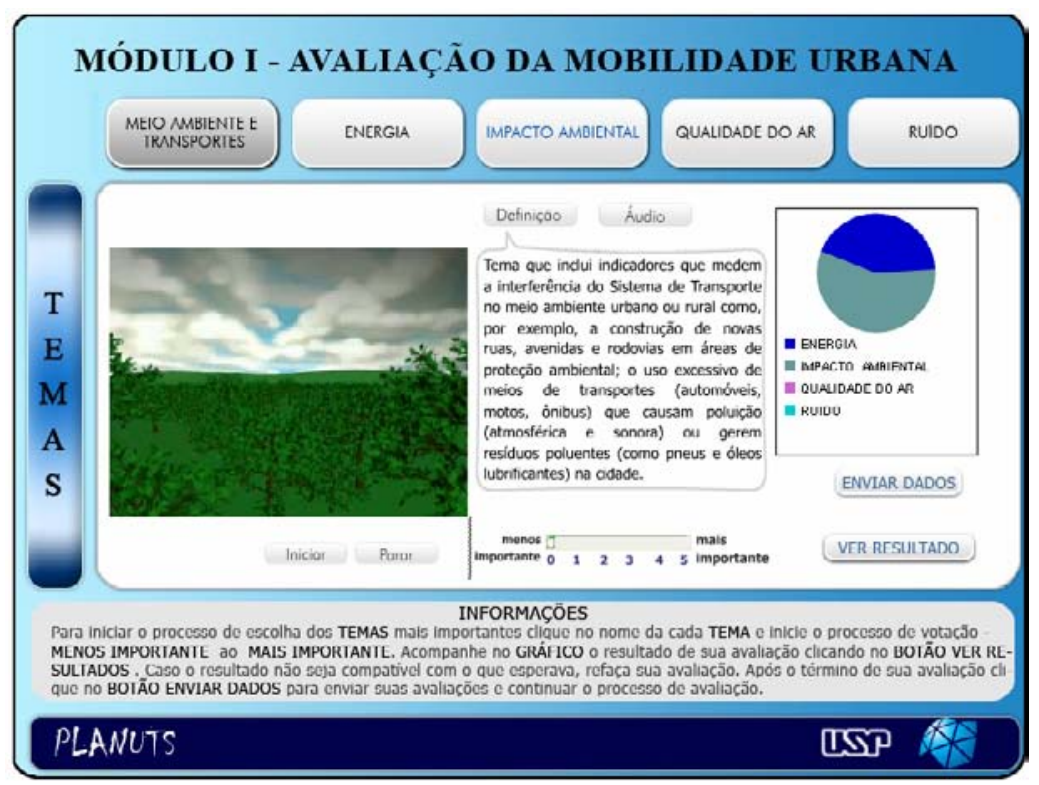

Figura 6.7 - Tema: Impacto Ambiental - Módulo I

As informações disponíveis aos avaliadores para as Categorias ou Temas poderão ser acompanhadas através de três formatos: i) Texto, ii) Áudio e iii) Linguagem Gráfica (seqüência de imagens ou vídeos). Todas as imagens foram construídas utilizando recursos de animação. Estas imagens mostram cenas de uma cidade, onde o avaliador poderá identificar um determinado problema de mobilidade que está sendo considerado (ver Figuras 6.6, 6.7 e 6.8 e Anexo 4). 

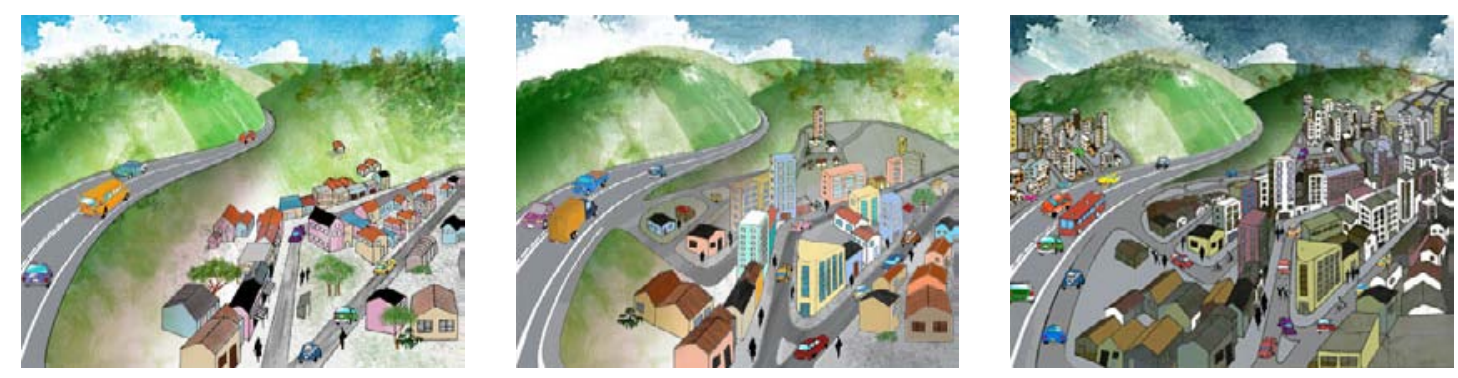

Figuras 6.8 a, b e c - Seqüência de imagens referente à Categoria Meio Ambiente e Transportes

A avaliação de cada Categoria ou Tema será realizada através da atribuição de uma pontuação, através da barra deslizante, cujos valores definem o grau de importância de cada critério avaliado. A escala utilizada corresponde a valores cuja variação está compreendida entre "1" (menos importante) a "5" (mais importante). Embora apresente o valor “0” junto a barra deslizante, o sistema não aceitará este valor e mostrará a seguinte mensagem: É necessário informar o valor. Adotou-se este procedimento para o sistema não armazenar o valor "1" no caso do usuário não votar em um determinado critério e continuar o processo de avaliação (ver Figuras 6.6 e 6.7).

A visualização do voto é realizada no gráfico de setores, após o usuário clicar no botão Ver Resultados. A alteração do voto poderá ser realizada através da escolha de outro valor na barra deslizante. O sistema só armazenará os resultados na área administrativa após a conclusão do processo de votação de cada Categoria ou Tema.

Conforme apresentado no capítulo anterior, os resultados das avaliações das Categorias e Temas serão analisados utilizando a metodologia de Análise Multicritério.

$\mathrm{Na}$ parte inferior das páginas de avaliação das Categorias e Temas, existe à disposição dos avaliadores, um quadro que contém uma síntese das informações necessárias para auxiliá-los no processo de votação (ver Figuras 6.6 e 6.7).

Ainda com relação ao Módulo I, incluiu-se na última etapa do processo de avaliação um Questionário, cujo objetivo é complementar o processo de avaliação da Mobilidade Urbana, através da realização das seguintes análises: i) caracterização dos deslocamentos da população na cidade, ii) identificação do local de acesso ao sistema PLANUTS e iii) caracterização do perfil de cada avaliador.

Os itens abordados neste questionário referem-se a: 1) Local de acesso à internet; 2) Bairro onde mora; 3) Bairro onde trabalha; 4) Idade; 5) Grau de escolaridade; 6) Meio de transporte que utiliza para ir ao trabalho; 7) Meio de transporte que utiliza para ir à 
escola; 8) Bairro onde estuda; 9) Renda familiar; 10) Se possui automóvel e quantos; 11) Se possui alguma deficiência e qual o tipo; e 13) Se a deficiência faz com que o usuário necessite de algum tipo de transporte especial (van, ônibus ou carro adaptado).

Para facilitar a análise das respostas e caracterização do perfil dos avaliadores optou-se por elaborar apenas questões fechadas (múltipla escolha).

Este questionário foi baseado no trabalho de Arruda $(2005)^{3}$ e na Pesquisa Nacional sobre Transporte Acessível ${ }^{4}$, desenvolvida pelo Ministério das Cidades Secretaria Nacional de Transporte e da Mobilidade Urbana.

O Quadro 6.4 apresenta um resumo das principais características do Módulo I.

\footnotetext{
${ }^{3}$ Arruda (2005) realizou uma pesquisa domiciliar em transportes para caracterizar as atividades para análise da relação uso do solo e transportes no contexto brasileiro.

${ }^{4}$ A II Pesquisa nacional sobre acessibilidade para pessoas com deficiência e restrição de mobilidade nos sistemas de transporte público foi realizada pela Secretaria Nacional de Transporte e da Mobilidade Urbana SeMob, em 2005, nas cidades com população igual ou superior a 60 mil habitantes. O objetivo dessa pesquisa, segundo a SeMob, era caracterizar e quantificar os serviços de transporte coletivo e da mobilidade urbana disponíveis no país e as ações para o atendimento e acessibilidade para pessoas com deficiência ou mobilidade reduzida. O questionário abordava as seguintes informações: número de pessoas com deficiência e seus respectivos tipos (física, mental, sensorial, orgânica e múltipla); existência e estruturação da gestão de programas específicos; caracterização do sistema de transporte coletivo, tipos de transporte para pessoas com deficiência (oferta de veículos, serviços, finalidade, demanda, solicitação, disponibilidade, operação, custo), caracterização da infra-estrutura acessível para pessoas com deficiência, sistema de comunicação para pessoas com deficiência, eliminação de barreiras arquitetônicas na cidade e do grau de conhecimento e utilização do programa brasileiro de acessibilidade urbana do Ministério das Cidades.
} 
Quadro 6.4 - Características gerais do Módulo I

\begin{tabular}{|c|c|}
\hline Objetivo & $\begin{array}{l}\text { Definir os aspectos relacionados ao planejamento e monitoramento da } \\
\text { Mobilidade Urbana mais relevantes para a elaboração de um Plano Diretor de } \\
\text { Transportes e Mobilidade Urbana participativo. } \\
\text { - Avaliação das Categorias e Temas associados à Mobilidade Urbana: } \\
\text { 1. Meio Ambiente e Transportes } \\
\text { 2. Gestão dos Transportes } \\
\text { 3. Infra-estrutura dos Transportes } \\
\text { 4. Planejamento dos Transportes } \\
\text { 5. Aspectos Socioeconômicos dos Transportes }\end{array}$ \\
\hline \multirow[t]{9}{*}{ Funcionamento } & Página de cadastro \\
\hline & $\begin{array}{l}\text { - Identificação do usuário no sistema através de Login (endereço de e-mail) e } \\
\text { Senha. } \\
\text { - Objetivo: } \\
\text { - Verificar a duplicidade de informações dos participantes no banco de dados } \\
\text { do sistema. } \\
\text { - Identidade Visual: Cada Módulo foi construído utilizando uma cor primária, } \\
\text { com o objetivo de facilitar a identificação dos módulos já avaliados pelos } \\
\text { usuários. No Módulo I é utilizada a cor azul. }\end{array}$ \\
\hline & Página de demonstração \\
\hline & $\begin{array}{l}\text { - Utilização de recursos de animação. } \\
\text { - Objetivo: } \\
\text { - Demonstrar ao usuário todas as informações disponíveis neste Módulo, } \\
\text { através da utilização de recursos de áudio e vídeo. }\end{array}$ \\
\hline & Páginas referente às Categorias e Temas \\
\hline & $\begin{array}{l}\text { - O processo de avaliação é o mesmo tanto para as Categorias quanto para os } \\
\text { Temas. } \\
\text { - Opções para acompanhamento das definições das Categorias e Temas: } \\
\text { - i) Áudio, ii) Texto e iii) Linguagem Gráfica (Imagens seqüenciais ou } \\
\text { vídeo). Todas as imagens foram construídas utilizando recursos de } \\
\text { animação em 3D. } \\
\text { - Avaliação das Categorias ou Temas } \\
\text { - Atribuição de uma pontuação cujos valores variam de } 1 \text { a } 5 \text {. } \\
\text { - O resultado destas avaliações é apresentado ao avaliador através de um } \\
\text { gráfico de setores. } \\
\text { - O encerramento do processo de avaliação ocorrerá quando o usuário clicar no } \\
\text { botão próximo, que permitirá enviar os dados ao banco de dados e prosseguir no } \\
\text { processo de avaliação. }\end{array}$ \\
\hline & Página de questionário \\
\hline & $\begin{array}{l}\text { - Objetivo: } \\
\text { - Complementar o processo de avaliação da Mobilidade Urbana. } \\
\text { - Analisar algumas informações relacionadas ao deslocamento da população } \\
\text { na cidade, à identificação do local de acesso do sistema PLANUTS, e uma } \\
\text { caracterização do perfil de cada avaliador. }\end{array}$ \\
\hline & $\begin{array}{l}\text { - Ao finalizar o processo de avaliação o usuário retornará ao site do sistema, na } \\
\text { página PLANUTS. }\end{array}$ \\
\hline $\begin{array}{l}\text { Processo de } \\
\text { Avaliação }\end{array}$ & $\begin{array}{l}\text { - Método de Análise Multicritério utilizando o Método da Escala de Pontos. } \\
\text { - A atribuição de pesos a cada critério é realizada pela simples identificação } \\
\text { (escolha) de um número numa escala numérica de } 1 \text { (menos importante) a } 5 \\
\text { (mais importante). }\end{array}$ \\
\hline
\end{tabular}




\subsubsection{Módulo II}

O objetivo do Módulo II é definir os Indicadores “mais importantes” para a avaliação ou monitoramento da Mobilidade no município. Neste módulo o processo de avaliação adotado é realizado pela escolha de dois (2) indicadores (mais representativos para a cidade) por Tema.

A Figura 6.9 apresenta o fluxograma de funcionamento do Módulo II; nela pode-se observar que os procedimentos adotados, neste módulo, são muito semelhantes aos do Módulo I.

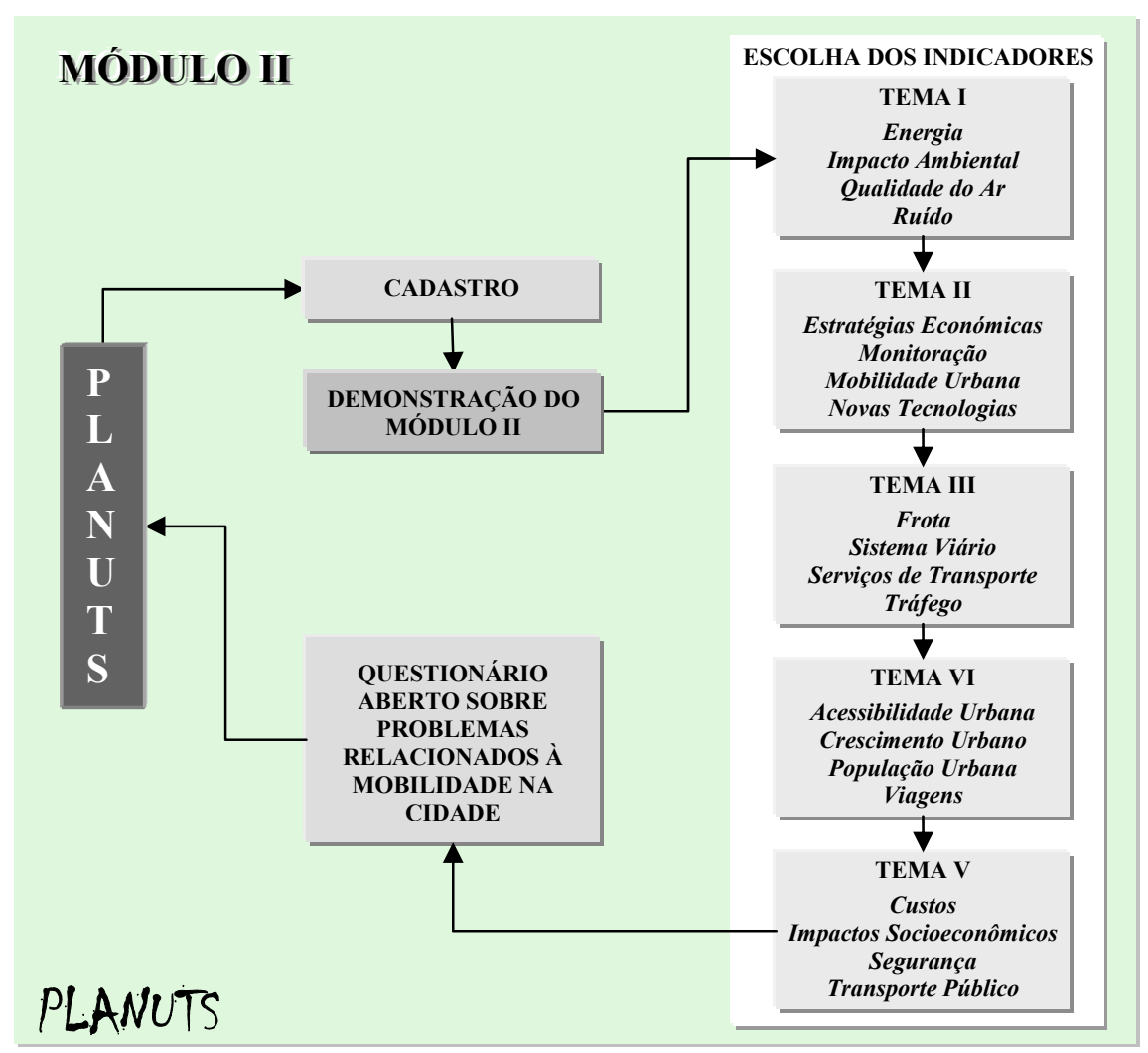

Figura 6.9 - Fluxograma de funcionamento do Módulo II

O funcionamento deste Módulo segue os mesmos princípios do Módulo anterior, ou seja, para iniciar o processo de avaliação é necessário entrar com as informações de e-mail e senha (login e senha) na página inicial. Posteriormente, pode-se assistir a um vídeo demonstrativo que apresenta todos os procedimentos permitidos que podem ser utilizados pelos avaliadores durante o processo de avaliação. Na seqüência, o usuário iniciará o processo de escolha dos Indicadores por Tema. A última etapa refere-se ao preenchimento de um questionário aberto. 


\section{- Processo de Avaliação dos Indicadores}

O processo de avaliação é semelhante ao adotado no Módulo I. Após a identificação do usuário através do login e senha, o participante acessará a página de demonstração. Nesta página são apresentados os procedimentos para a avaliação do Módulo II. Na seqüência é iniciado o processo de escolha dos Indicadores (ver Figuras 6.10 e 6.11). Cada avaliador deverá selecionar 2 Indicadores - considerados mais importantes, relacionados aos Temas apresentados no Módulo I. Os Indicadores disponíveis para voto correspondem àqueles 94 indicadores que foram re-agrupados a partir dos trabalhos de Costa (2003).
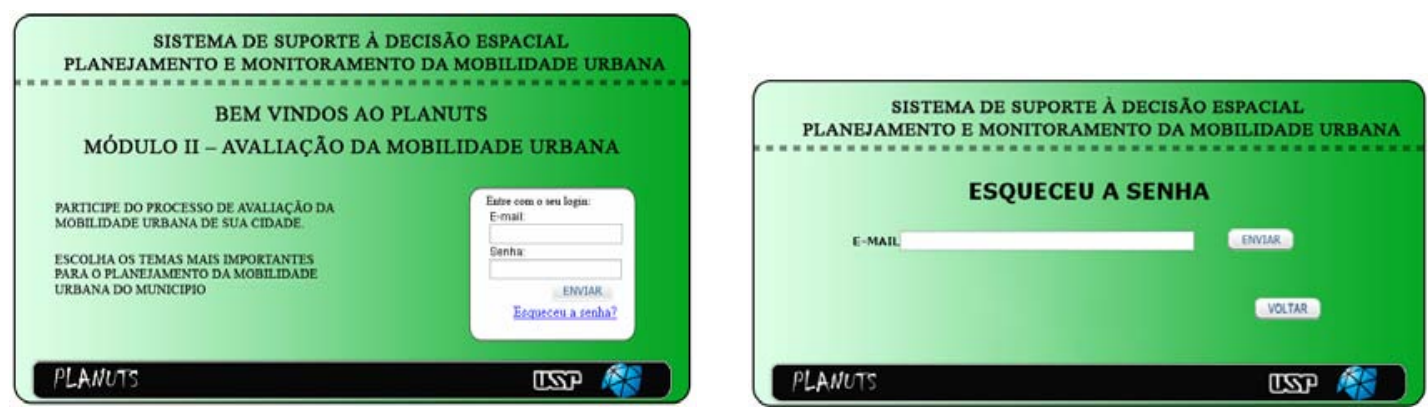

Figuras 6.10 e 6.11 - Módulo II - Páginas de login e Esqueceu a senha

Para auxiliar no processo de escolha dos Indicadores, o usuário tem à disposição as definições do Indicador (apresentadas no formato de texto) e um vídeo representativo ao Tema avaliado. As definições de cada Indicador são apresentadas ao usuário selecionando o nome de cada Indicador (com o mouse), conforme mostram as Figuras 6.12 e 6.13. A lista dos Indicadores, seus respectivos código de identificação e definição encontram-se no Anexo 5. 


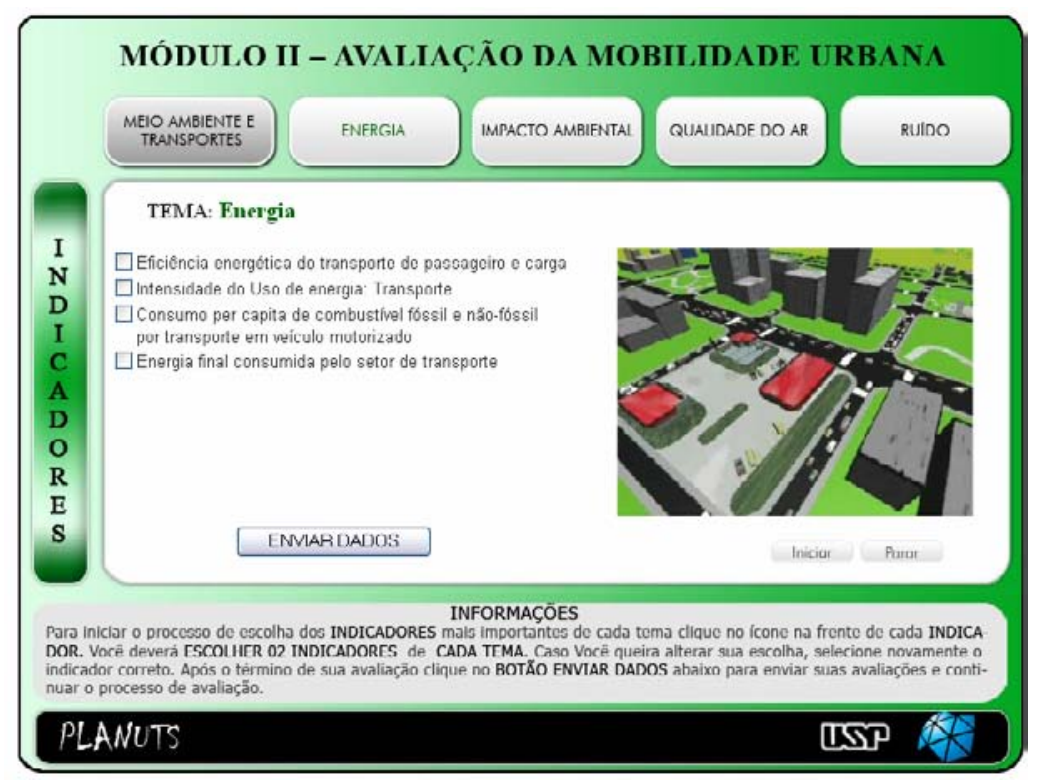

Figura 6.12 - Categoria Meio Ambiente e Transportes - Tema Energia

\section{TEMA: Energia}

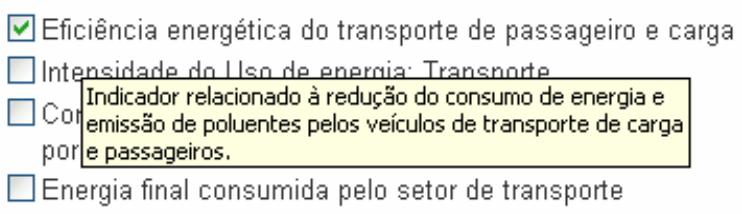

Figura 6.13 - Tema Energia - Definição do Indicador

Foi adotado o modelo de ordenamento randômico ${ }^{5}$ para a visualização dos Indicadores neste módulo. Neste sistema a ordem de visualização dos Indicadores pertencentes a um mesmo Tema é alterada assim que o sistema detecta um novo usuário (novo login). Esta alteração é importante para que não ocorra um "vício" no processo de escolha dos Indicadores, isto é, uma tendência na escolha dos dois primeiros Indicadores de cada Tema.

O sistema foi configurado para aceitar a seleção de apenas 2 Indicadores por Tema. Caso o usuário selecione "1 Indicador", "mais que 2 Indicadores" ou "não selecione qualquer Indicador", o sistema irá apresentar automaticamente uma mensagem de erro, ao usuário, para a revisão de sua(s) escolha(s) (ver Figuras 6.14 e 6.15).

\footnotetext{
${ }^{5}$ No ordenamento randômico os indicadores são mostrados em seqüência alternada a cada novo login.
} 

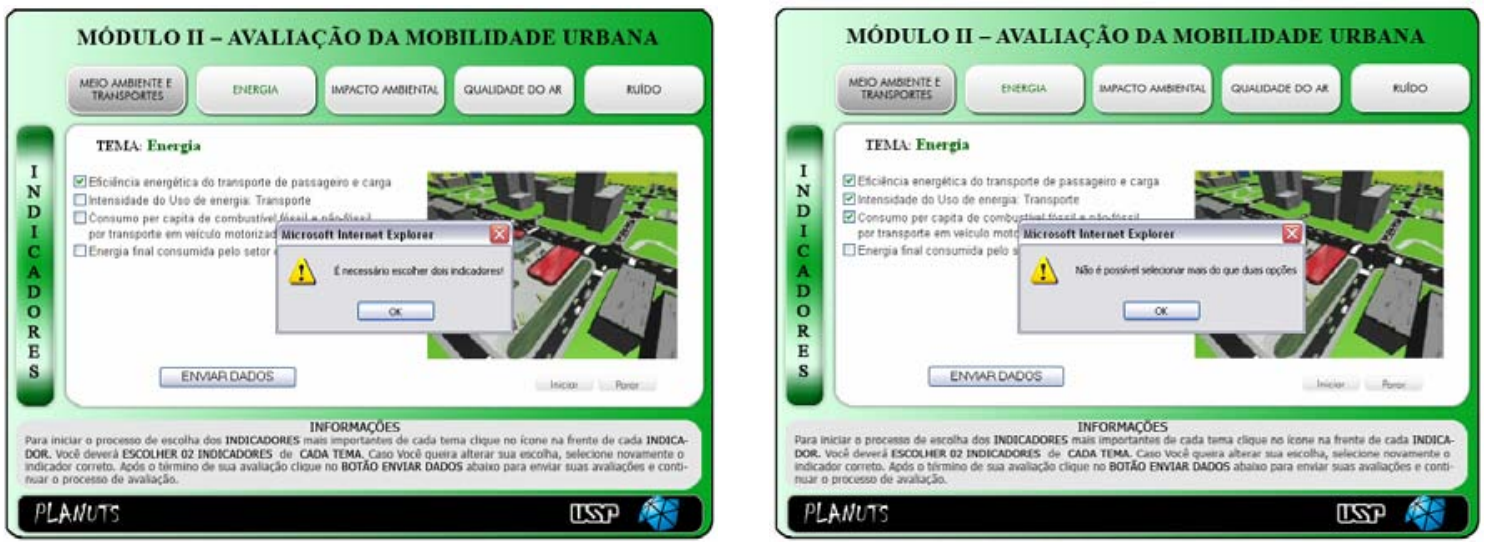

Figuras 6.14 e 6.15 - Tema Energia - Seleção dos Indicadores

Para a obtenção do resultado final deste processo de avaliação deverá ser realizada a somatória das avaliações de todos os participantes; cujo produto é a definição de uma lista contendo aproximadamente 40 indicadores (dos 94 indicadores iniciais) que irão compor o Sistema de Indicadores de Mobilidade ${ }^{6}$ do Município.

A última etapa de avaliação refere-se a um questionário aberto onde os usuários poderão descrever ou listar os principais problemas de mobilidade identificados em sua cidade ${ }^{7}$. Neste item cada avaliador tem à disposição dois espaços para inserir suas respostas. O objetivo deste questionário é verificar se os avaliadores identificam na cidade alguns problemas de mobilidade, a partir das definições apresentadas nos Módulos I e II.

A seguir é apresentado um quadro resumo das características gerais do Módulo II.

\footnotetext{
${ }^{6}$ Sistema de Indicadores de Mobilidade é representado por um conjunto de indicadores que permitirá avaliar ou monitorar a Mobilidade do município, continuamente.

${ }^{7} \mathrm{O}$ tema proposto é: "Descreva duas questões que você considera mais importantes para avaliar a mobilidade urbana de sua cidade".
} 
Quadro 6.5 - Características gerais do Módulo II

\begin{tabular}{|c|c|}
\hline \multicolumn{2}{|r|}{ Módulo II - Avaliação da Mobilidade Urbana } \\
\hline Objetivo & $\begin{array}{l}\text { - Definir } 40 \text { indicadores que farão parte do terceiro Módulo de Avaliação da } \\
\text { Mobilidade Urbana - Módulo III. }\end{array}$ \\
\hline \multirow[t]{9}{*}{ Funcionamento } & Página de cadastro \\
\hline & $\begin{array}{l}\text { - Semelhante ao Módulo I, mas está sendo utilizada a cor verde, como referência } \\
\text { para este Módulo. }\end{array}$ \\
\hline & Pagina de demonstração \\
\hline & $\begin{array}{l}\text { - Utilização de recursos de animação. } \\
\text { - Objetivo: } \\
\text { - Demonstrar ao usuário todas as informações disponíveis neste Módulo } \\
\text { através da utilização de recursos de áudio e vídeo. }\end{array}$ \\
\hline & Páginas de avaliação \\
\hline & $\begin{array}{l}\text { - Processo de escolha dos Indicadores. } \\
\text { - Cada avaliador selecionará } 2 \text { Indicadores - considerados mais importantes -, } \\
\text { relacionados aos Temas apresentados no Módulo I. Os Indicadores disponíveis } \\
\text { para voto correspondem àqueles } 94 \text { indicadores que foram re-agrupados a } \\
\text { partir dos trabalhos de Costa (2003). } \\
\text { - Opções para acompanhamento das definições dos Indicadores: } \\
\text { - i) Texto e ii) Linguagem Gráfica (vídeo). Todas as imagens foram } \\
\text { construídas utilizando recursos de animação em 3D. }\end{array}$ \\
\hline & $\begin{array}{l}\text { OBS: A ordem de visualização dos Indicadores pertencentes a um mesmo Tema } \\
\text { será alterada a cada mudança de avaliador no Módulo. Esta alteração é necessária } \\
\text { para que não ocorra uma seleção "viciada" no processo de escolha dos } \\
\text { Indicadores. }\end{array}$ \\
\hline & Página de comunicação \\
\hline & $\begin{array}{l}\text { - Espaço destinado para o usuário listar os principais problemas associados à } \\
\text { Mobilidade Urbana de sua cidade. } \\
\text { - Ao finalizar o processo de avaliação o usuário retornará ao site do sistema, na } \\
\text { página PLANUTS. }\end{array}$ \\
\hline $\begin{array}{l}\text { Processo de } \\
\text { Avaliação }\end{array}$ & - Indicadores mais votados. \\
\hline
\end{tabular}

Observação: É importante ressaltar que o usuário deverá completar todo o processo de avaliação para que os dados sejam armazenados no banco de dados do sistema (Módulos I e II). No Módulo III as informações são salvas automaticamente a cada inclusão de dados. Após a finalização do processo de avaliação de cada Módulo, o usuário retornará a página PLANUTS.

\subsubsection{Módulo III}

O objetivo principal do Módulo III é subsidiar o processo de tomada de decisão através da definição de ações para os Indicadores mais votados no Módulo II. Este módulo possibilita que as avaliações dos decisores contribuam para a realização de um diagnóstico municipal da mobilidade. Este diagnóstico é realizado através da análise das 
avaliações individuais dos participantes (especialistas e não-especialistas). Com este diagnóstico é possível definir metas para a melhoria da mobilidade urbana no município.

A principal característica deste módulo (e o que o diferencia dos módulos anteriores) refere-se a sua flexibilidade. O sistema foi construído com a possibilidade de poder avaliar qualquer um dos 94 indicadores (apresentados no item anterior). Entretanto, como este módulo é uma seqüência do módulo anterior, aproximadamente 40 indicadores (estes indicadores correspondem àqueles mais votados no Módulo II) estarão disponíveis para avaliação.

Este módulo foi construído com base no modelo de participação popular tradicional e no sistema adotado por Yigitcanlar (2001) que utilizou o software STRAD (STRategic ADviser) no desenvolvimento e implantação do sistema GISPDM.

De uma forma geral, este módulo contribui no processo de tomada de decisão participativa através da identificação dos seguintes elementos:

1. Identificação dos Problemas e Soluções relacionados à mobilidade urbana - definir para cada Indicador quais são os fatores que contribuem para o agravamento (piora) do Indicador no município e listar as possibilidades de ações para cada Indicador.

2. Identificação das Definições de Ação - identificar o grau de conhecimento que os avaliadores possuem quanto à definição dos tipos de soluções que podem ser adotadas para cada Indicador, o período para a solução dos problemas detectados e identificação da esfera governamental responsável pelo financiamento das soluções. Estes elementos são importantes para o desenvolvimento do Plano de Ação Municipal. Para o processo de discussão do Plano Diretor de Transportes e Mobilidade este item é importante para a etapa de negociação (audiência final do PlanMob). Estas definições poderão servir de parâmetro para que os técnicos possam explicar aos demais participantes sobre as definições de ação a serem adotadas [O que fazer? (soluções), Quando? (período) Como? (definição da forma de solução)].

3. Diagnóstico dos indicadores na cidade - identificar em cada região e sub-região os problemas de mobilidade mais importantes.

A Figura 6.16 apresenta o fluxograma de funcionamento do Módulo III. 


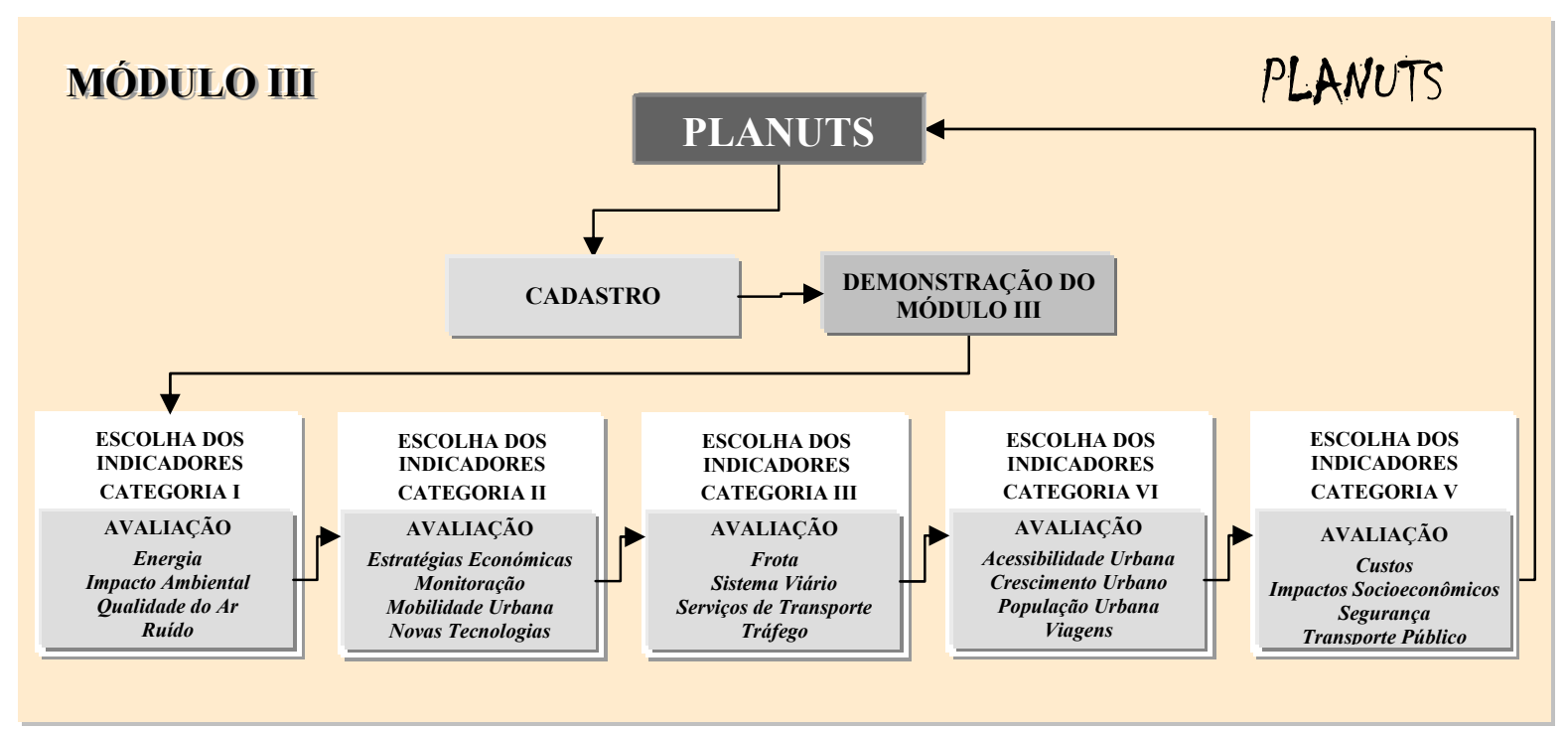

Figura 6.16 - Fluxograma de funcionamento do Módulo III

De acordo com a Figura 6.16, pode-se observar que o funcionamento dos três Módulos de Avaliação da Mobilidade Urbana é semelhante. O acesso ao módulo é realizado através da página inicial (cadastro), na seqüência é apresentado um vídeo exemplificando todas as funções e procedimentos a serem adotados pelos participantes e em seguida inicia-se a avaliação dos Indicadores agrupados por Tema.

\section{- Processo de Avaliação}

Para iniciar o processo de avaliação, o usuário deverá inserir seu Login e Senha na página inicial do Módulo III (ver Figuras 6.17 e 6.18). Posteriormente é apresentado o vídeo demonstrativo deste módulo.
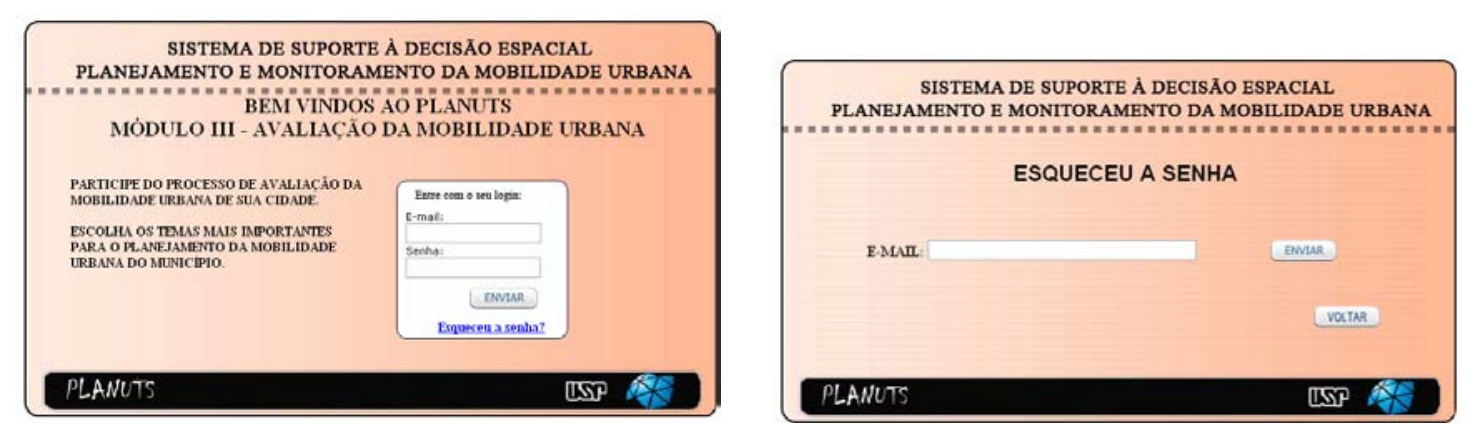

Figuras 6.17 e 6.18 - Módulo III - Páginas de login e Esqueceu a senha

Na seqüência, é apresentada a página de Escolha dos Indicadores. Ela é a responsável pela definição do número de Indicadores a serem avaliados por avaliador; este 
número poderá sofrer uma variação de avaliador para avaliador; uma vez que o sistema permite a escolha de até 2 Indicadores por TEMA (por Categoria), com isto, o número de Indicadores avaliados por decisor poderá variar de 20 a 40 indicadores. Esta escolha deve ser realizada em função do grau de importância do indicador para o Planejamento da Mobilidade Urbana. A definição de cada Indicador é apresentada ao usuário através da seleção no nome do Indicador (ver Figuras 6.19 e 6.20).

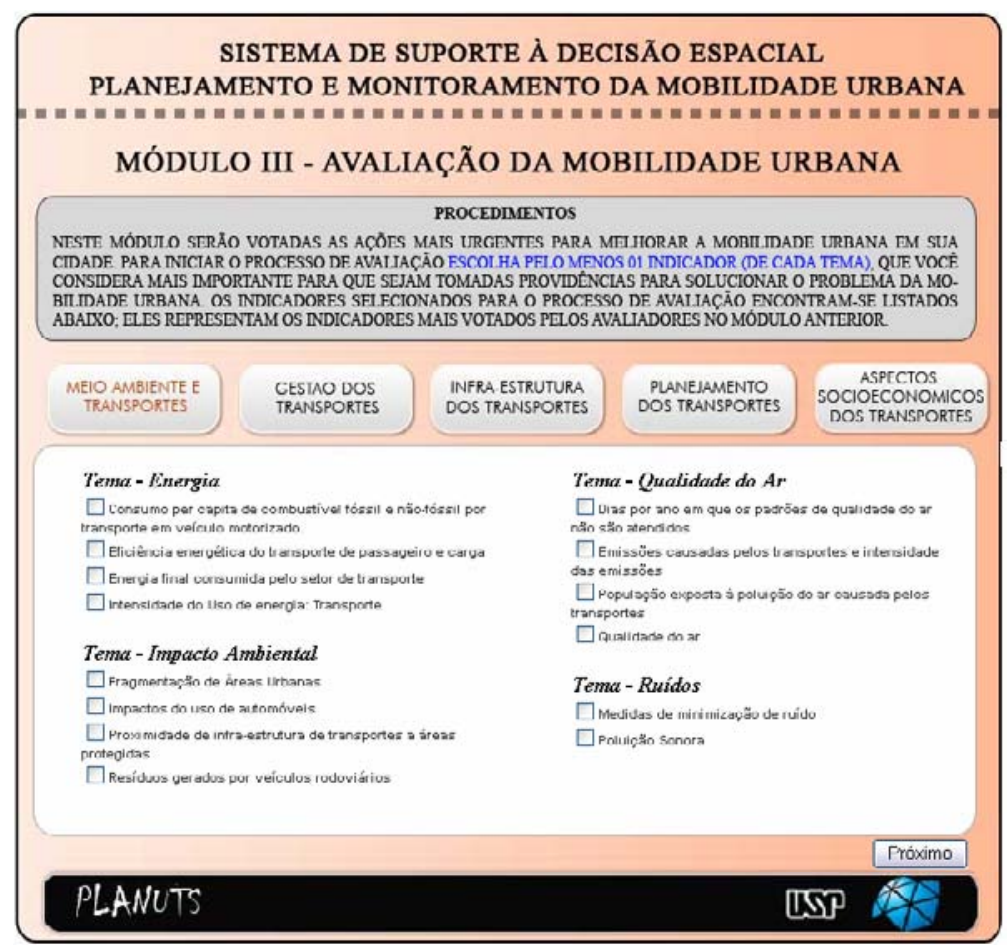

Figura 6.19 - Página de escolha dos Indicadores referente a Categoria Meio Ambiente e Transportes

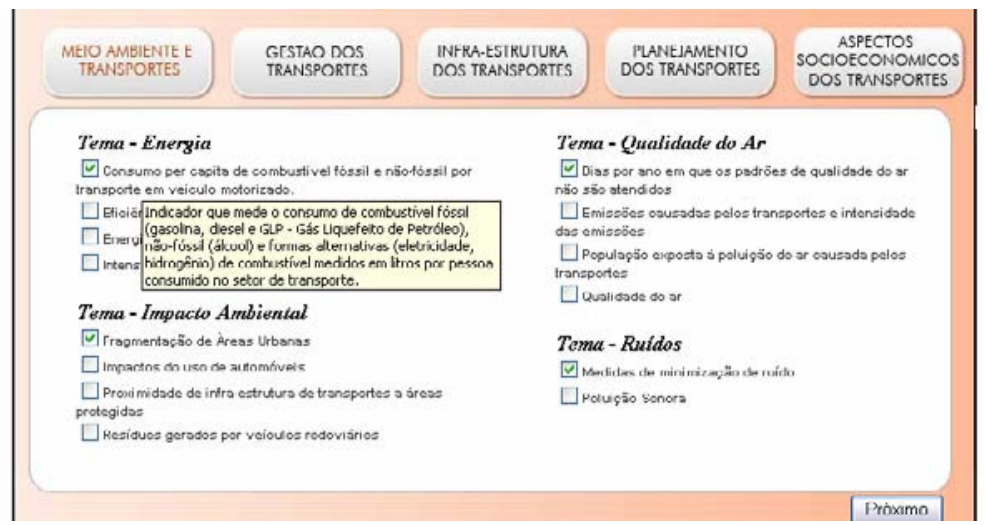

Figura 6.20 - Tema Energia - Definição do Indicador 
O sistema poderá mostrar uma mensagem de erro (nesta página) nas seguintes situações: i) quando o usuário selecionar mais de 2 Indicadores por Tema, e ii) quando o usuário não selecionar alguma opção por Tema (ver Figuras 6.21 e 6.22).
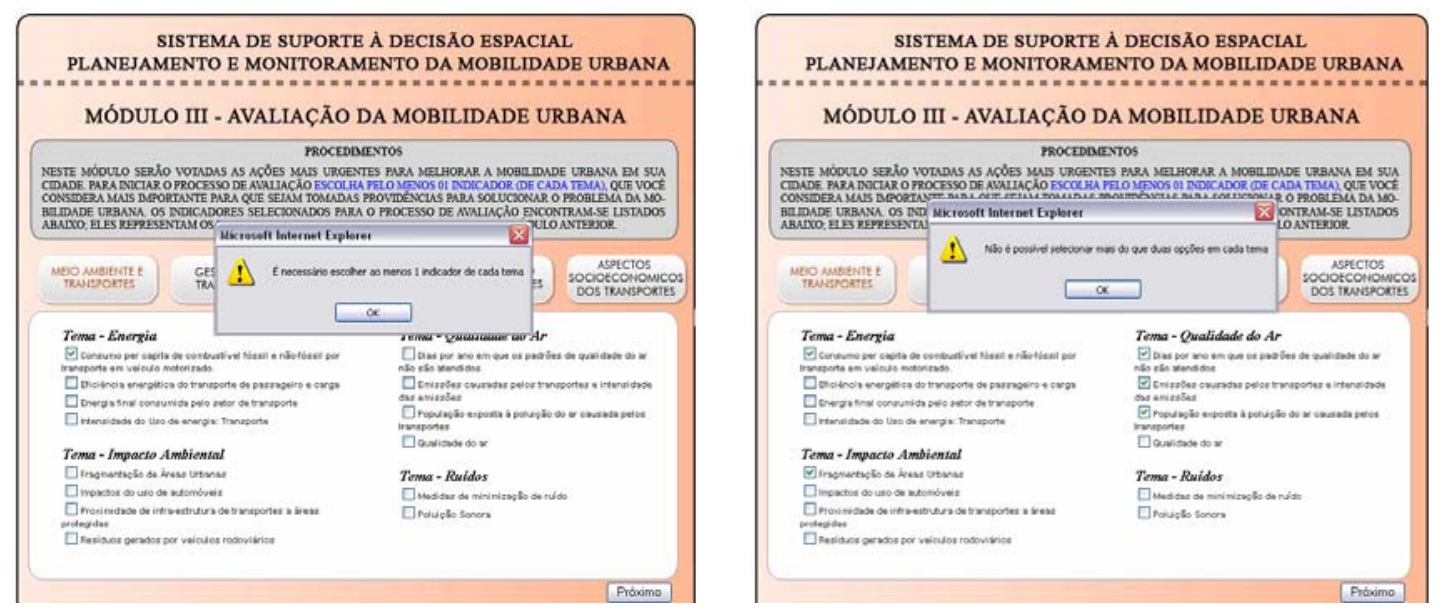

Figuras 6.21 e 6.22 - Tema Energia - Seleção dos Indicadores

No total, este módulo é composto por cinco páginas de Escolha dos Indicadores e cada uma delas está associada a uma Categoria (apresentada no Módulo I). O módulo permite a avaliação destas páginas em períodos distintos (dia e horário diferentes).

A partir da escolha dos Indicadores (por Tema e por Categoria) inicia-se o processo de avaliação dos indicadores escolhidos na página Escolha dos Indicadores. As páginas de avaliação dos Indicadores possuem quatro subdivisões: i) Definição do indicador, ii) Tomada de Decisão, iii) Avaliação do Indicador, e iv) Localização do problema. Cada item auxiliará em uma etapa da tomada de decisão, conforme detalhado a seguir.

- Definição do Indicador - neste item o usuário pode visualizar a definição de cada Indicador através dos seguintes recursos: texto, áudio e vídeo. Os vídeos correspondem aos Temas associados a cada Indicador (ver Figura 6.23). 


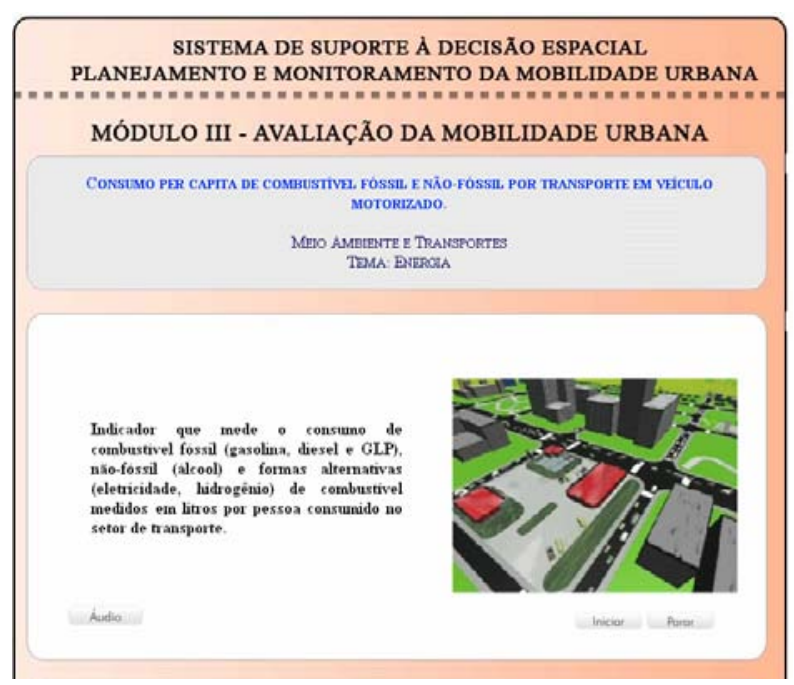

Figura 6.23 - Definição do Indicador

- Tomada de Decisão - setor responsável pela definição das ações para cada Indicador. O objetivo desta etapa é identificar problemas e soluções relacionados ao Indicador avaliado. Este campo é subdividido em 5 itens para avaliação, conforme mostra a Figura 6.24.

- Identificação de Problemas e Soluções - o sistema poderá apresentar aos

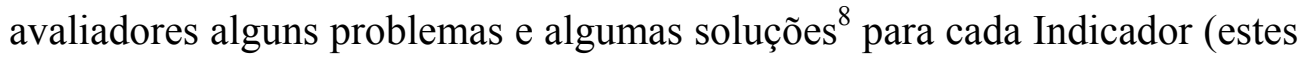
elementos devem ser definidos pelo Grupo Executor) e disponibiliza um campo para que sejam inseridos outros problemas e soluções, pelos avaliadores.

- Prazo médio para solucionar os problemas - na seqüência existe um campo para que os avaliadores identifiquem o prazo que "eles julgam” ser aceitável para a solução dos problemas relacionados anteriormente ao indicador. As opções disponíveis são: não definido, menos de 6 meses, até 1 ano, até 2 anos, mais de 2 anos.

- Responsável pelo financiamento - neste item os avaliadores deverão identificar qual (ou quais) a(s) esfera(s) pública(s) são responsáveis pelo envio de recursos ao município para a solução dos problemas identificados anteriormente. As opções disponíveis são: não definido, governo municipal, governo estadual, governo federal, governo municipal-estadual, governo municipal-estadual-federal.

\footnotetext{
${ }^{8}$ Os problemas e soluções incorporados neste módulo foram listados pela pesquisadora e podem ser inseridos no sistema (através do Módulo Administrativo) como um exemplo para os avaliadores, principalmente para os não-especialistas.
} 
- Tipo de solução - refere-se à identificação, pelos avaliadores, da forma de solução que deve ser adotada para resolver os problemas de mobilidade associados a cada Indicador. As opções disponíveis são: não definido, estudo técnico, construção, estudo técnico-construção, manutenção. Optou-se pela combinação de mais de um tipo para facilitar o entendimento dos avaliadores, pois na maioria dos casos a solução advém de um estudo técnico para posterior construção ou implantação das medidas encontradas.

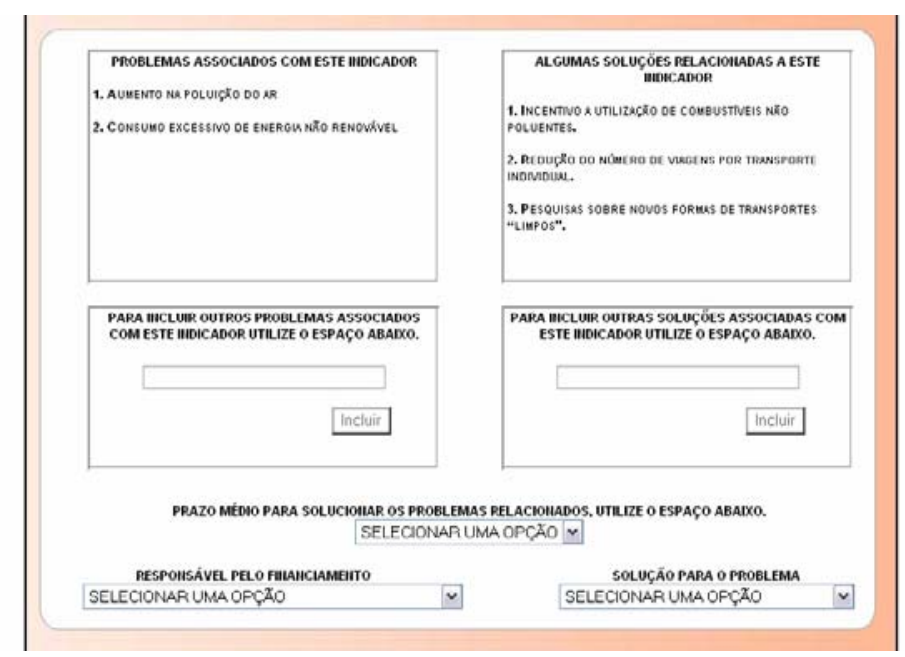

Figura 6.24 - Tomada de Decisão

- Avaliação do Indicador - o objetivo desta etapa é definir o "grau de importância" e "grau de urgência" para o Indicador avaliado. O processo de votação é igual ao adotado no Módulo I, ele é realizado através da seleção de um número (intervalo de 1 a 5 ) através de uma barra deslizante. O valor "1" deverá ser atribuído ao indicador considerado menos importante ou menos urgente e o valor "5" àquele considerado mais importante ou mais urgente. O sistema só aceitará os votos compreendidos entre os valores de 1 a 5 . A visualização dos votos pode ser acompanhada no Gráfico de Barras. Este gráfico permite a visualização e acompanhamento das avaliações dos Indicadores pertencentes a uma determinada Categoria. A alteração no voto só é permitida na página ativa para avaliação (ver Figura 6.25). 


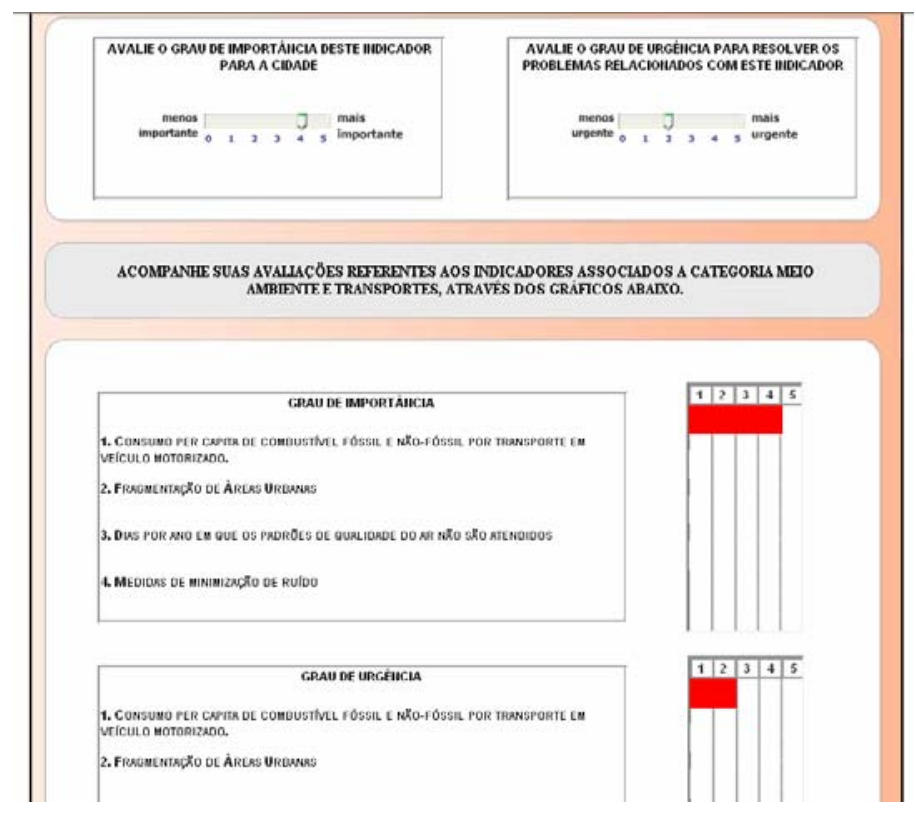

Figura 6.25 - Avaliação

- Observação: Através dos resultados das avaliações das Categorias e Temas (Módulo I) associados à avaliação dos Indicadores (Módulo III) é possível verificar se os avaliadores atribuíram o mesmo grau de importância para Temas e Indicadores. Assim é possível determinar que aqueles Temas que foram comuns às duas avaliações devem ser incluídos do Sistema de Indicadores de Mobilidade Urbana.

- Localização do problema - nesta etapa (última subdivisão) refere-se à identificação, através de localização espacial dos problemas relacionados ao Indicador avaliado nas diversas regiões da cidade. Esta localização é realizada de dois modos: i) por Região (Geral) e ii) por Sub-região(ões $)^{9}$, conforme mostra a Figura 6.26.

- Região - permite verificar a espacialização dos problemas de cada indicador para cinco regiões da cidade (Centro, Norte, Sul, Leste e Oeste).

- Sub-região(ões) - permite identificar, através da seleção (escolha) de uma sub-região, qual o problema de mobilidade mais importante (apresentado ao avaliador ou incluído no Banco de Dados do sistema no item Identificação de Problemas e Soluções).

${ }^{9}$ Uma sub-região é uma divisão da cidade que congrega diversos bairros. Dependendo da cidade ela é denominada com o nome de um bairro. 
- Para facilitar a localização espacial das regiões e sub-regiões do município, neste item é apresentado um mapa da cidade com estas subdivisões. Este mapa deverá ser cadastrado pelo Administrador do Sistema na página administrativa.

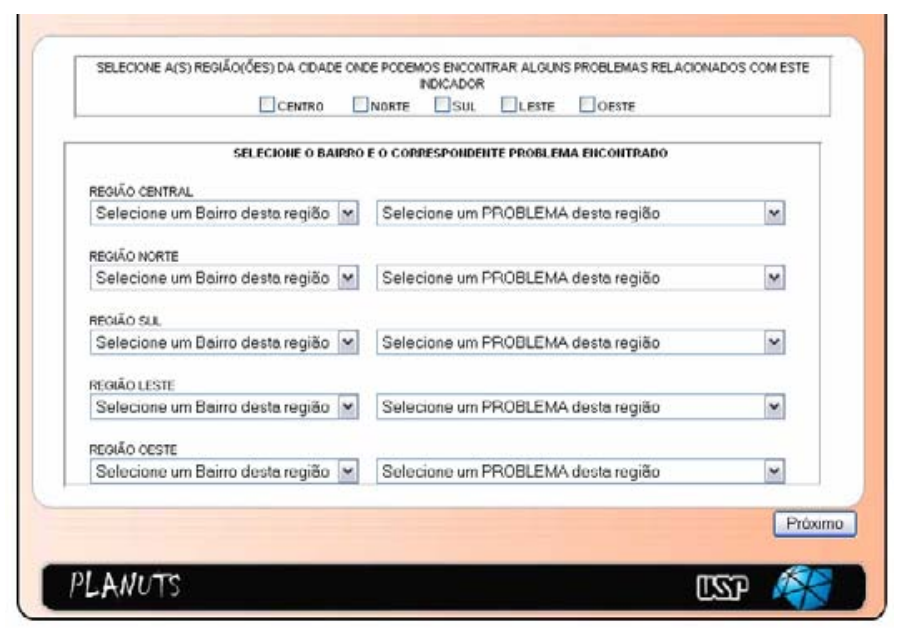

Figura 6.26 - Localização do Problema

O Quadro 6.6 apresenta um resumo das principais características do Módulo III. 
Quadro 6.6 - Características gerais do Módulo III

\section{Módulo III - Avaliação da Mobilidade Urbana}

\section{Objetivo}

- Definir as prioridades de ação na cidade, no que se refere à Mobilidade Urbana, a partir dos Indicadores mais votados pela população no Módulo II.

Funcionamento

Página de cadastro

- Semelhante ao Módulo I, mas foi adotada a cor laranja.

Pagina de demonstração

- Utilização de recursos de animação.

- Objetivo:

- Demonstrar ao usuário todas as informações disponíveis neste Módulo através da utilização de recursos de áudio e vídeo.

Páginas de escolha dos Indicadores

- Responsável pela visualização geral de todos os Indicadores.

- Os Indicadores foram divididos para apresentação ao público separadamente, de acordo com as 5 Categorias apresentadas no Módulo I. No total haverá 5 páginas de escolha de Indicadores que antecedem as páginas de avaliação.

- Definição do número de Indicadores para avaliação:

- O sistema foi construído utilizando os 94 indicadores definidos no Módulo II. Entretanto, somente 40 indicadores serão colocados à disposição do público para avaliação; estes indicadores correspondem àqueles mais votados no Módulo anterior. Para esta etapa, definiu-se que cada usuário poderá escolher de 1 a 2 Indicadores de cada Tema para o processo de avaliação.

- O processo de disponibilização destes Indicadores à população é manual, ou seja, ele pode ser alterado pelo facilitador numa aplicação deste sistema em outra cidade através da ligação às demais páginas de avaliação do sistema.

Páginas de avaliação dos indicadores escolhidos

- Estas páginas precedem à escolha dos Indicadores.

- Cada página de avaliação está dividida em 4 campos distintos, que permitem visualizar as seguintes informações:

\begin{tabular}{|c|c|}
\hline 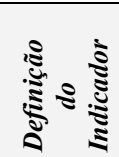 & $\begin{array}{l}\text { - Acompanhamento das definições dos Indicadores: } \\
\text { - i) Áudio, ii) Texto e iii) Linguagem Gráfica (vídeo). Todas as } \\
\text { imagens foram construídas utilizando recursos de animação. }\end{array}$ \\
\hline 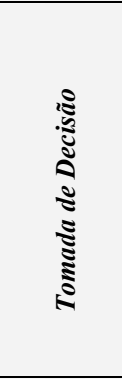 & $\begin{array}{l}\text { - Apresentação de alguns problemas e soluções relacionados ao } \\
\text { Indicador, definidos pelo facilitador, sendo também disponibilizada } \\
\text { uma área para que a população possa incluir outros problemas e } \\
\text { soluções. } \\
\text { - Definição das ações: } \\
\text { - Permite a identificação do grau de conhecimento que a população } \\
\text { tem em relação: ao prazo para a solução dos problemas, a esfera } \\
\text { governamental responsável pelo financiamento das obras e o tipo } \\
\text { de solução para os problemas apontados. }\end{array}$ \\
\hline 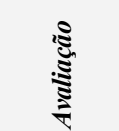 & $\begin{array}{l}\text { - Definição dos graus de importância e urgência para cada Indicador. } \\
\text { - Acompanhamento das avaliações através da leitura dos gráficos de } \\
\text { barras. }\end{array}$ \\
\hline 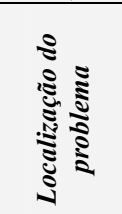 & $\begin{array}{l}\text { - Identificação, através da seleção de cada região ou sub-regiões, na } \\
\text { qual(quais) o(s) problema(s) relacionado(s) à Mobilidade Urbana } \\
\text { pode(m) ser encontrado(s) nestes locais na cidade. } \\
\text { - Em cada página haverá, à disposição do usuário, um mapa da cidade } \\
\text { que poderá ser utilizado para facilitar a localização espacial. }\end{array}$ \\
\hline
\end{tabular}


Quadro 6.6 - Características gerais do Módulo III (continuação)

\begin{tabular}{|c|l|}
\hline $\begin{array}{c}\text { Processo de } \\
\text { Avaliação }\end{array}$ & $\begin{array}{l}\text { - Método de Análise Multicritério utilizando o Método da Escala de Pontos. } \\
\text { - A atribuição de pesos a cada critério é realizada pela simples identificação } \\
\text { (escolha) de um número numa escala numérica de 1 a 5; sendo o valor } \text { um } \\
\text { associado ao critério menos importante (ou mais urgente) e o valor cinco ao } \\
\text { critério mais importante (ou mais urgente). }\end{array}$ \\
\hline $\begin{array}{c}\text { Outras } \\
\text { Informações }\end{array}$ & $\begin{array}{l}\text { Módulo baseado na participação popular tradicional e na experiência de } \\
\text { Yigitcanlar (2001) que utilizou o software STRAD (STRategic ADviser) no } \\
\text { desenvolvimento e implantação do sistema GISPDM. }\end{array}$ \\
\hline
\end{tabular}

- Cadastro das informações

O cadastro das informações deste módulo é realizado no Módulo Administrativo. Todos os procedimentos adotados nesta fase serão apresentados na seção 6.3.2.6, referente ao Módulo Administrativo.

\subsubsection{Proposta para o Módulo IV}

O objetivo do Módulo IV é definir o cenário "ideal” para cada Indicador listado no Módulo III; ou seja, a partir do resultado das avaliações dos Módulos I, II e III serão gerados alguns cenários para cada problema identificado como "mais urgente" para o município. Estes cenários deverão ser escolhidos pelos decisores (especialistas e nãoespecialistas - Delegados do Plano Diretor); e seu objetivo é permitir a definição das ações a serem implementadas no município para a melhoria da Mobilidade Urbana.

Em função do prazo disponível para a finalização desta pesquisa, para este Módulo são apresentadas apenas algumas sugestões para seu desenvolvimento e construção.

Para a elaboração deste Módulo devem ser adotados o mesmo formato e procedimentos para avaliação utilizados nos três módulos anteriores, ou seja, página de login (e-mail e senha), página de demonstração, página de escolha dos Indicadores - para construção dos cenários, páginas para avaliação dos cenários por Indicador.

A Figura 6.27 apresenta uma proposta para o fluxograma de funcionamento do Módulo IV. 


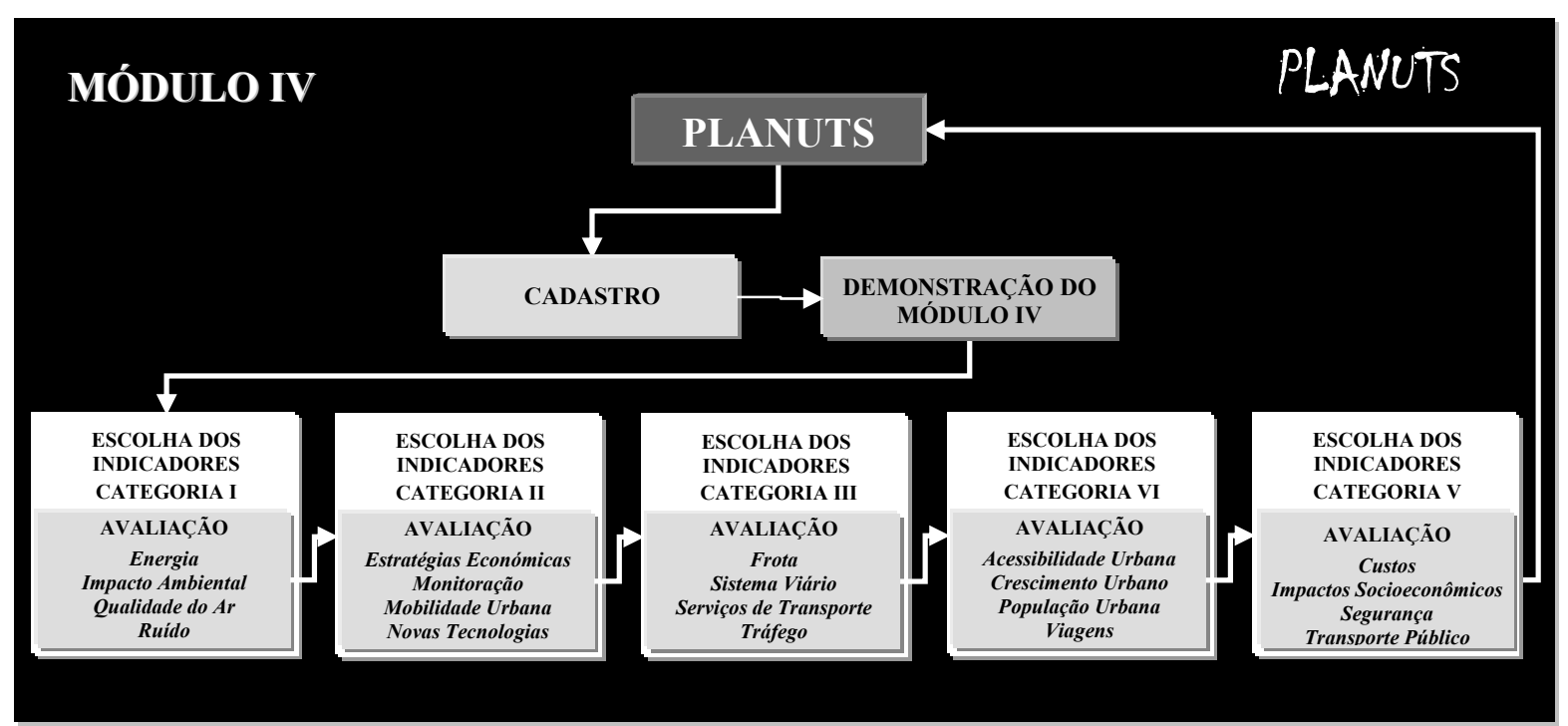

Figura 6.27 - Fluxograma com uma proposta inicial para o funcionamento do Módulo IV

\section{- Proposta para funcionamento do Módulo IV}

O funcionamento deste Módulo deve seguir os mesmos princípios do Módulo anterior. Ele deverá ser construído com a possibilidade de poder avaliar os cenários de qualquer um dos 94 indicadores (apresentados no Módulo II). Entretanto, como este módulo é uma seqüência do Módulo III, aproximadamente 40 indicadores (estes Indicadores correspondem àqueles mais votados no Módulo II) estarão disponíveis para avaliação.

A proposta deste módulo foi baseada no modelo de participação popular tradicional e nos sistemas SUTRA e Própolis, uma vez que estes dois sistemas agregam algumas ferramentas que podem ser facilmente adaptadas na geração dos cenários a partir de Indicadores de Mobilidade. Outro aspecto relevante, que contribuiu para a escolha destes sistemas referiu-se à facilidade no processo de avaliação e visualização dos resultados por participantes não-especialistas.

A seguir são apresentadas algumas propostas iniciais para o Módulo IV.

- Cadastro - O acesso ao módulo deverá ser realizado através da página inicial (cadastro). Esta página deverá ser igual às demais páginas de cadastro dos módulos anteriores. Para facilitar a identificação do Módulo IV pelos avaliadores deverá ser adotada a cor preta de fundo.

- Informações da página: Login, Senha e link - Esqueceu a Senha? 
- Demonstração - nesta página deve ser construído um vídeo exemplificando todas as funções e procedimentos que podem ser adotados pelos participantes para a avaliação e escolha dos cenários.

- Escolha dos Indicadores (cenários) - esta página deverá ser semelhante ao Módulo III. Esta página é responsável pela definição do número de Indicadores ou cenários a serem avaliados por avaliador. Neste módulo a escolha dos Indicadores poderá ser realizada de duas formas: i) a partir dos Indicadores mais votados no Módulo II (neste caso, os avaliadores terão um elenco de aproximadamente 40 indicadores para avaliar os cenários comparativos), ou ii) a partir dos 10 Indicadores considerados “mais importantes" pelos avaliadores no Módulo III (esta definição deverá ser realizada a partir de um ordenamento do resultado dos pesos das avaliações dos Indicadores no Módulo III). O Grupo Executor poderá optar por adotar qualquer um dos dois formatos em função da disponibilidade de dados que o município tiver para gerar os cenários para avaliação.

- Avaliação dos Cenários - esta página é responsável pelo processo de simulação e escolha do cenário por avaliador. Neste módulo o usuário deverá avaliar um Indicador por página. Esta avaliação será realizada exclusivamente por Indicador [através da definição de algumas soluções (efeitos) a ele associadas]. À medida que este Módulo estiver sendo construído será definida uma forma para avaliar os impactos das avaliações de cada Indicador, através do cruzamento de seus efeitos (soluções). Cada página deve conter as informações necessárias para se avaliar o cenário referente ao Indicador avaliado, ou seja, ela deve apresentar os parâmetros necessários para avaliação e simulação do Indicador. Os cenários apresentados para avaliação devem ser construídos utilizando um software SIG (sugere-se a adoção do SPRING).

- Cenários: as simulações devem ser realizadas para os seguintes períodos: i) cenário atual, ii) período de 5 anos, iii) período de 10 anos, iv) período de 15 anos e v) periodo de 20 anos (estes prazos devem estar associados ao período de vigência do Plano Diretor de Transportes e Mobilidade no município). O Intervalo de 5 anos refere-se ao mínimo prazo estabelecido pelo Poder Público para desenvolver os projetos municipais. 
- Sugere-se a adoção do Método de Análise Multicritério para a escolha e avaliação dos cenários.

- Cadastro das informações - em função da flexibilidade deste módulo, as informações que subsidiarão a construção de cada cenário deverão ser cadastradas no Módulo Administrativo.

O Quadro 6.7 apresenta um resumo das principais características propostas para o Módulo IV.

Quadro 6.7 - Características gerais do Módulo VI

\begin{tabular}{|c|c|}
\hline \multicolumn{2}{|r|}{ Módulo IV - Avaliação da Mobilidade Urbana } \\
\hline Proposta & $\begin{array}{l}\text { Pretende-se com a construção deste Módulo que a população possa escolher os } \\
\text { cenários para cada Indicador definidos nos Módulos II e III do PLANUTS. } \\
\text { Este Módulo será implementado na internet utilizando os software SPRING e } \\
\text { SPRINGWEB. As avaliações realizadas pelos decisores no Módulo III serão } \\
\text { importadas do Banco de Dados do sistema PLANUTS para o Banco de Dados do } \\
\text { software SPRING, para que estas informações possam ser processadas gerando } \\
\text { alguns cenários comparativos sobre os indicadores mais votados. }\end{array}$ \\
\hline Objetivo & $\begin{array}{l}\text { A partir dos problemas elencados na fase anterior, permitir que a população possa } \\
\text { escolher, dentre os cenários apresentados, aquele que minimize os problemas de } \\
\text { Mobilidade Urbana na cidade. }\end{array}$ \\
\hline \multirow[t]{9}{*}{ Funcionamento } & Página de Cadastro \\
\hline & - Semelhante aos Módulos I, II e III, mas na cor preta. \\
\hline & Pagina de demonstração \\
\hline & $\begin{array}{l}\text { - Utilização de recursos de animação. } \\
\text { - Objetivo: } \\
\text { - Demonstrar ao usuário todas as informações disponíveis neste Módulo através da } \\
\text { utilização de recursos de áudio e vídeo. }\end{array}$ \\
\hline & Pagina de escolha dos Indicadores (cenários) \\
\hline & $\begin{array}{l}\text { - Deverá ser semelhante ao Módulo III. } \\
\text { - É responsável pela definição do número de Indicadores ou cenários a serem } \\
\text { avaliados por avaliador. }\end{array}$ \\
\hline & Páginas de avaliação \\
\hline & $\begin{array}{l}\text { - Avaliação do Cenário Atual x Cenários desejados para cada indicador. } \\
\text { - Simulações: cenário atual - } 5 \text { anos - } 10 \text { anos - } 15 \text { anos - } 20 \text { anos. }\end{array}$ \\
\hline & OBS: Demais informações ainda precisam ser definidas. \\
\hline $\begin{array}{l}\text { Processo de } \\
\text { Avaliação }\end{array}$ & $\begin{array}{l}\text { A ser definido. } \\
\text { Sugere-se adotar o Método de Avaliação Multicritério. }\end{array}$ \\
\hline $\begin{array}{c}\text { Outras } \\
\text { Informações }\end{array}$ & Módulo baseado nos sistemas SUTRA e Própolis. \\
\hline
\end{tabular}




\subsubsection{Módulo Administrativo}

O Módulo Administrativo é o responsável pelo armazenamento das informações dos quatro Módulos de Avaliação da Mobilidade Urbana (visualização dos Relatórios) e pelo Cadastro das Informações nos Módulos III e IV ${ }^{10}$.

O acesso a esta página é realizado apenas pelos Administradores do Sistema (responsáveis pelo sistema - membros do Grupo Executor). Estes usuários são cadastrados diretamente no software de gerenciamento da Base de Dados do Sistema PLANUTS. Após este cadastro os administradores do sistema poderão acessar através da internet, a página administrativa (ADM) através da inclusão de Login e Senha, conforme mostra a Figura 6.28 .

\begin{tabular}{|l|l|}
\hline \multicolumn{2}{|l|}{ Área administrativa } \\
\hline \multicolumn{2}{|l|}{} \\
\hline E-mail & \\
\hline Senha & \\
\hline & OK \\
\hline
\end{tabular}

Figura 6.28 - Acesso à Área Administrativa do Sistema PLANUTS

Conforme mostra a Figura 6.29, este módulo permite o gerenciamento das avaliações dos Módulos I, II e III, através da visualização dos respectivos relatórios (Categorias, Temas e Indicadores) e o cadastro das informações que irão compor o Módulo III. Como o Módulo IV não foi construído, ele não foi incluído no menu desta página. $\mathrm{O}$ acesso a estas informações é realizado através do menu lateral. A seguir é apresentado, em detalhe, cada um destes tópicos.

${ }^{10} \mathrm{O}$ Módulo IV não foi desenvolvido. Por esta razão não consta da página administrativa. 


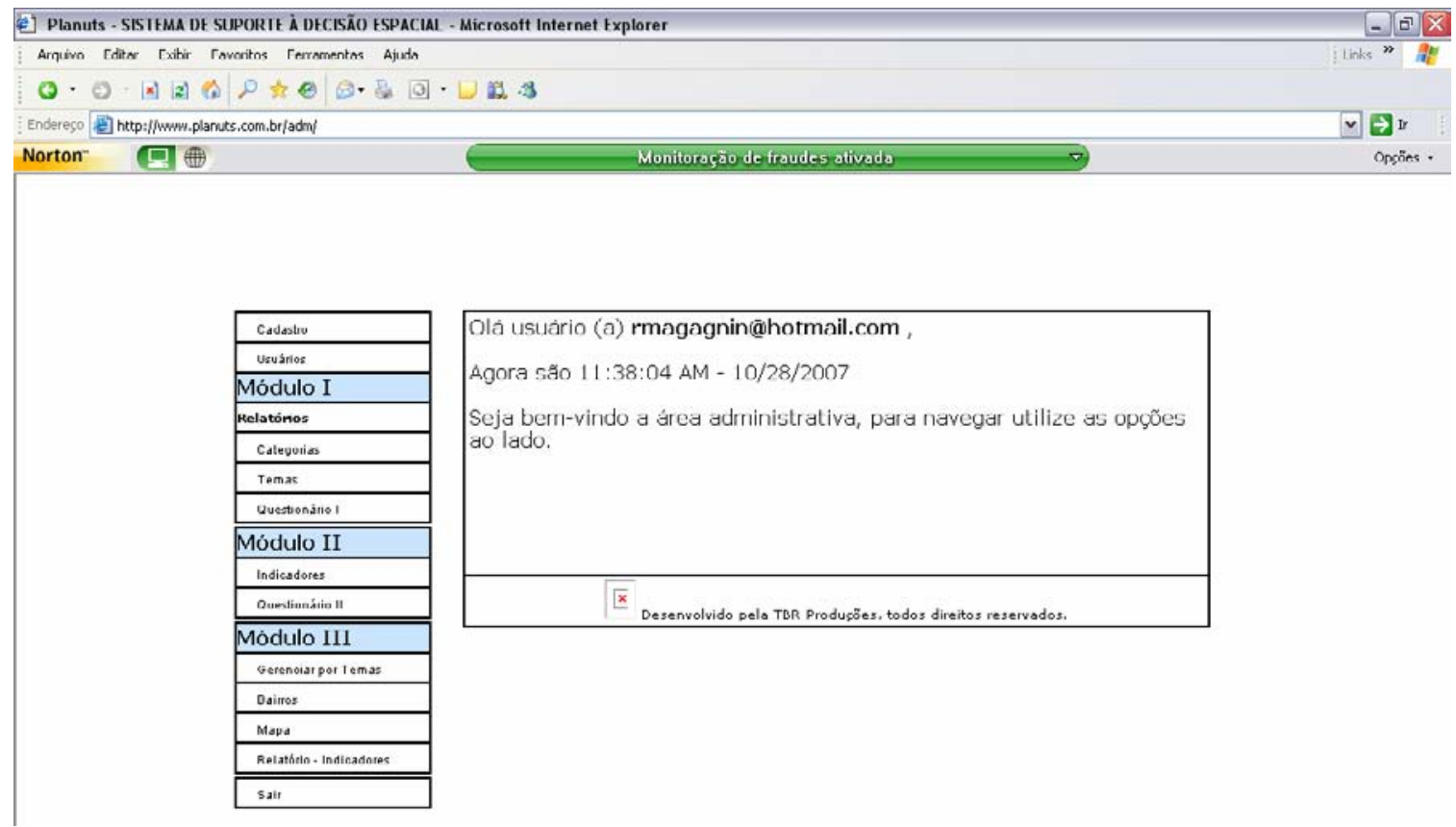

Figura 6.29 - Menu de navegação - Visualização do Relatório das avaliações e Cadastro das Informações para o Módulo III

\section{- Cadastro}

Uma vez implantado o sistema num servidor compatível, pode-se iniciar o cadastramento (no item Cadastro) dos usuários que irão avaliar a Mobilidade Urbana do município, de acordo com sua especialidade: Administrador do sistema (Membros do Grupo Executor); Especialista (técnicos envolvidos no processo de elaboração do Plano Diretor de Transportes e Mobilidade) e População (Delegados representantes de diversos segmentos da sociedade), ver Figuras 6.29 e 6.30.

\section{CADASTRO}

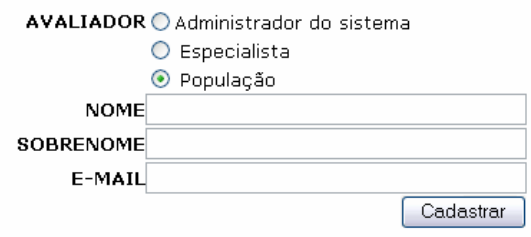

Figura 6.30 - Forma de cadastro dos usuários no Sistema PLANUTS

\section{- Usuários}

A Área Administrativa permite que o administrador do sistema visualize todos os usuários já cadastrados no sistema (inclusive aqueles que fizeram seus cadastros diretamente na página de login de um dos três Módulos de Avaliação); bem como efetue a 
exclusão ou alteração de qualquer usuário cadastrado, conforme mostra a Figura 6.31. As informações disponíveis no item Usuários são:

- Número de cadastro - corresponde a forma de identificação dos usuários nas páginas de relatório dos Módulos I a IV.

- Nome e e-mail - este registro é importante, pois permite a verificação de duplicidade no cadastro dos usuários. Através dos endereços de e-mail é possível realizar um contato com os avaliadores.

- Tipo (especialidade) - permite a identificação do grupo a que cada membro cadastrado pertence.

- Botão Excluir Cadastro - permite excluir as avaliações de um usuário na base de dados, ou seja, exclui as avaliações deste usuário nos relatórios dos três módulos de avaliação.

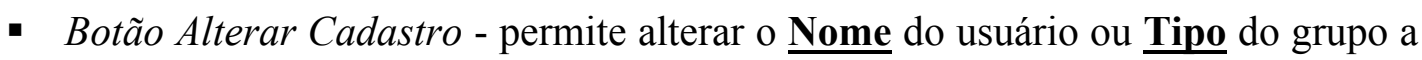
que ele pertence.

\begin{tabular}{|c|c|c|c|c|c|c|}
\hline \multicolumn{7}{|c|}{ USUÁRIOS DO SISTEMA PLANUTS } \\
\hline Usuário & Nome & E-mail & Tipo & $\begin{array}{l}\text { Data do } \\
\text { Registro }\end{array}$ & Alterar & Exclui \\
\hline 15 & Renata & Imagagnin@hotmail.com & $\begin{array}{l}\text { Administrador } \\
\text { do sistema }\end{array}$ & $12 / 5 / 2007$ & Alterar & Excluir \\
\hline 41 & renata & magagnin@afaac.unesp.br & Populaçẫo & & Alterar & Excluir \\
\hline 44 & & Imagagnin@homail.com & Especialista & 14/5/2007 & Alterar & Excluir \\
\hline
\end{tabular}

Figura 6.31 - Visualização dos usuários cadastrados

\section{- Módulo I - Relatórios}

Nesta seção os relatórios referentes ao Módulo I são apresentados separadamente, divididos em três grupos: Relatório de Avaliação das Categorias, dos Temas e do Questionário I.

A identificação da avaliação de cada usuário é realizada através: do código do usuário e endereço de e-mail. Esta referência é importante para posteriormente agrupar as avaliações de acordo com o grupo a que cada usuário pertence (especialista e nãoespecialista) na etapa de análise das avaliações.

O registro das avaliações dos usuários, nestas três seções, é realizado de forma individual, e a ordem de armazenamento das informações é realizada de acordo com a finalização de cada etapa de avaliação. No relatório dos Temas, as avaliações são apresentadas de acordo com a Categoria correspondente (ver Figura 6.32). 


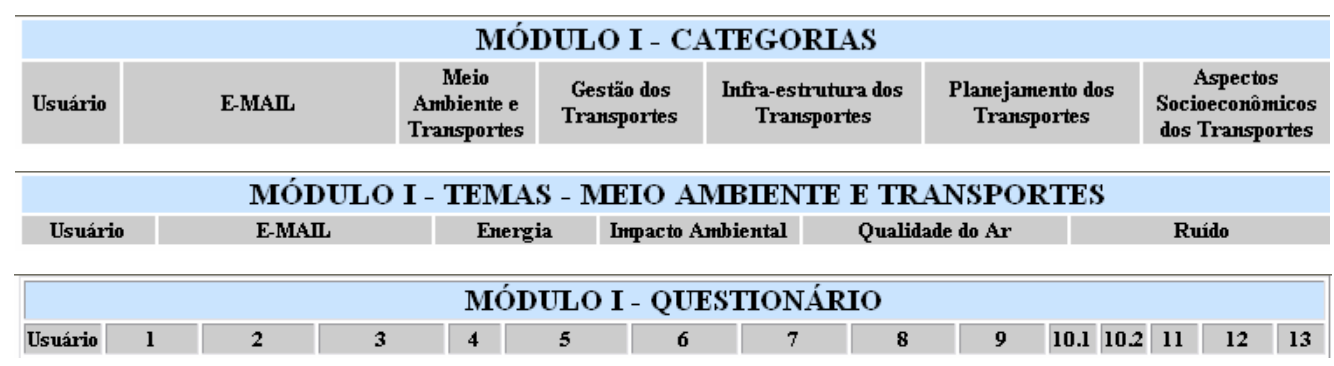

Figura 6.32 - Visualização dos relatórios gerados no Módulo I

- Módulo II - Relatórios

Os relatórios deste Módulo são divididos em 2 seções. A primeira mostra as avaliações dos Indicadores (agrupados por Temas e Categorias) e na segunda seção o Questionário II (ver Figura 6.33).

\begin{tabular}{|c|c|c|c|c|c|c|c|c|c|c|c|c|c|c|c|c|c|}
\hline \multicolumn{18}{|c|}{ EIO AMBIENTE E TRANSPORTES } \\
\hline \multirow{2}{*}{ Usuário } & \multirow{2}{*}{ E-mail } & \multicolumn{4}{|c|}{ ENERGIA } & \multicolumn{4}{|c|}{ IMPACTO AMBIENTAL } & \multicolumn{4}{|c|}{ QUALIDADE DO AR } & \multicolumn{4}{|c|}{ RUÍDO } \\
\hline & & E1 & E2 & E3 & E4 & I1 & 12 & 13 & 14 & Q1 & Q2 & Q3 & Q4 & R1 & R2 & R3 & R4 \\
\hline
\end{tabular}

\begin{tabular}{||c||l||l||l||}
\hline \multicolumn{4}{|c|}{ MÓDULO II - QUESTIONÁRIO } \\
\hline \hline Usuário & \multicolumn{1}{|c|}{ E-mail } & Obs.1 & obs.2 \\
\hline \hline 15 & rmagagnin@hotmail.com & teste & teste 2 \\
\hline \hline
\end{tabular}

Figura 6.33 - Visualização dos relatórios gerados no Módulo II

\section{- Módulo III - Cadastro das Informações}

Na seqüência é apresentada a seção referente ao Módulo III. Nela, as informações são subdivididas em quatro subseções: Gerenciar por Temas, Bairros, Mapa e Relatório - Indicadores. As três seções iniciais correspondem ao cadastro das informações do Módulo III, ou seja, a construção do módulo. O Quadro 6.8 apresenta resumidamente as informações que deverão ser cadastradas neste Módulo. 
Quadro 6.8 - Cadastro das informações no Módulo III

\begin{tabular}{|c|c|}
\hline \multicolumn{2}{|r|}{ Módulo III - Cadastro das Informações } \\
\hline \multirow[t]{4}{*}{$\begin{array}{l}\text { Gerenciar por } \\
\text { Temas }\end{array}$} & $\begin{array}{l}\text { - Cadastrar Tema } \\
\text { - Selecionar uma Categoria - Incluir o Tema. }\end{array}$ \\
\hline & $\begin{array}{l}\text { - Cadastrar Indicador } \\
\text { - Selecionar um Tema - Incluir o Indicador. }\end{array}$ \\
\hline & $\begin{array}{l}\text { - Cadastrar Mídias } \\
\text { - Selecionar um Indicador. } \\
\text { - Cadastrar: Definição de Texto, Áudio e Vídeo. }\end{array}$ \\
\hline & - Cadastrar Problemas e Soluções \\
\hline Bairros & Cadastrar Bairros ou Sub-regiões da cidade. \\
\hline Mapa & Cadastrar Mapa da cidade - extensão JPEG. \\
\hline
\end{tabular}

O cadastro das informações no Módulo III inicia-se com a inclusão dos 20 Temas relativos à Mobilidade Urbana avaliados no Módulo I do Sistema PLANUTS. Posteriormente, são inseridos os Indicadores (aqueles mais votados no Módulo II) de acordo com o Tema a que pertencem. A inclusão dos Indicadores é realizada dentro de cada Tema.

A terceira etapa refere-se ao cadastro das mídias a serem disponibilizadas para cada Indicador. Deverão ser cadastradas as seguintes informações: definição do Indicador (formato texto), áudio do Indicador (arquivo extensão “swf') e vídeo do Indicador (arquivo extensão "swf”). As informações referentes aos áudios e vídeos serão anexadas através da indicação do nome dos arquivos correspondentes, que se encontram disponíveis no servidor.

A quarta etapa refere-se ao cadastro de alguns Problemas e Soluções relacionados a cada Indicador. Os textos referentes a cada um destes itens devem ser inseridos no campo correspondente (na seção interna de cada Indicador). O cadastro das informações relativas a este item poderá facilitar a inserção de outros problemas e solução por parte dos avaliadores, em especial aqueles não-especialistas.

As Figuras 6.34, 6.35 e 6.36 apresentam as etapas de cadastro das informações referentes ao item Gerenciar por Temas. 


\section{Lista de Temas}

Cadastrar nowo tema I Listar Temas

Clique sobre o Tema para ver seus Indicadores.

\begin{tabular}{|l|l|l|l|}
\hline ID & \multicolumn{1}{|c|}{ Tema } & Marcar \\
\hline 16 & $\begin{array}{l}\text { Acessibilidade Urbana } \\
\text { Categoria: Planejamento dos transportes }\end{array}$ & $\square$ \\
\hline 17 & $\begin{array}{l}\text { Crescimento Urbano } \\
\text { Categoria: Planejamento dos transportes }\end{array}$ & Cadastro de Temas \\
\hline 20 & $\begin{array}{l}\text { Custos } \\
\text { Categoria: Aspectos socioeconômicos dos transportes }\end{array}$ & & \\
\hline 3 & $\begin{array}{l}\text { Energia } \\
\text { Categoria: Meio Ambiente e transporte }\end{array}$ & Cadastrar novo tema I Listar Temas \\
\hline \hline
\end{tabular}

\begin{tabular}{|l|l|}
\multicolumn{2}{c|}{ Cadastro de Temas } \\
\hline Categoria: & Meio Ambiente e transporte \\
\hline Nome: & Energia \\
\hline & \\
\hline
\end{tabular}

Figura 6.34 - Cadastro dos Temas - Módulo III

\section{Gerenciar Tema}

Cadastrar novo tema I Listar Temas

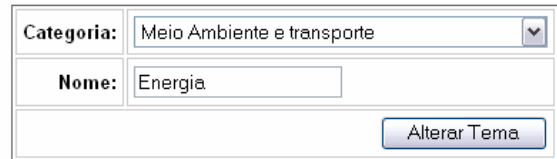

Indicadores deste Tema

Clique sobre o Indicador para ver suas Mídias e/ou Problemas e Soluçöes.

Cadastrar Indicador

\begin{tabular}{|c|l|c|}
\hline ID & \multicolumn{1}{|c|}{ Indicador } & Marcar \\
\hline 2 & $\frac{\text { Consumo per capita de combustível fóssil e năo-fóssil por }}{\text { transporte em veículo motorizado. }}$ & $\square$ \\
\hline 3 & Eficiência energética do transporte de passageiro e carga & $\square$ \\
\hline 4 & Energia final consumida pelo setor de transporte & $\square$ \\
\hline 5 & Intensidade do Uso de energia: Transporte & $\square$ \\
\hline \hline \multicolumn{2}{|c|}{ Excluir Temas Marcados } \\
\hline
\end{tabular}

Cadastro de Indicador

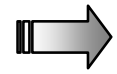

Cadastrar nowo Indicador I Voltar para o Tema

Tema Energia

Nome: Consumo per capita de

Cadastrar

Figura 6.35 - Cadastro dos Indicadores - Módulo III 


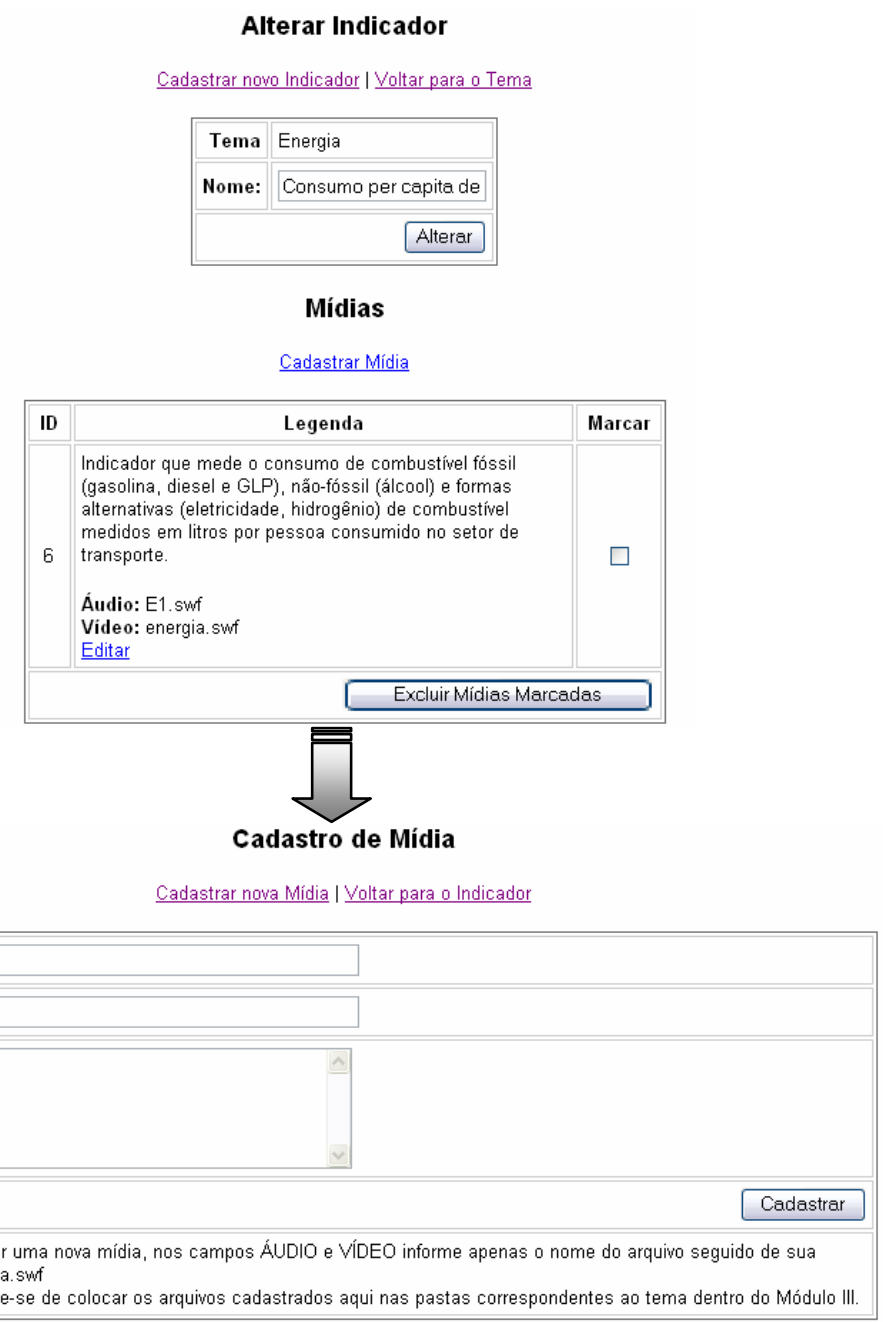

Figura 6.36 - Cadastro das Mídias - Módulo III

Ainda com relação ao cadastro das informações no Módulo III existem dois campos: i) nome dos Bairros ou Sub-regiões da cidade que deverão ser incluídas de acordo com a região a que pertencem e ii) inclusão de um mapa do município (arquivo do tipo imagem - na extensão "jpg") que servirá de referência para a identificação das sub-regiões ou bairros da cidade.

\section{- Módulo III - Relatórios}

O Relatório deste Módulo é apresentado individualmente por Indicador. A primeira página mostra a lista de todos os Indicadores incluídos para avaliação. $\mathrm{O}$ acesso ao relatório de cada Indicador é realizado através da seleção do nome do Indicador correspondente (ver Figuras 6.37 e 6.38). 
CLIQUE SOBRE O INDICADOR PARA VER SEU RELATÓRIO

\begin{tabular}{|l|l|l}
\hline CATEGORIA & TEMA & INDICADOR \\
\hline Meio Ambiente e transporte & Energia & $\begin{array}{l}\text { Consumo per capita de combustivel fóssil e nẫo-fóssil por transp } \\
\text { veículo motorizado. }\end{array}$ \\
\hline Meio Ambiente e transporte & Energia & Eficiência energética do transporte de passageiro e carga \\
\hline Meio Ambiente e transporte & Impacto Ambiental & Fragmentaçẫo de Áreas Urbanas \\
\hline Meio Ambiente e transporte & Impacto Ambiental & Impactos do uso de automóveis \\
\hline Meio Ambiente e transporte & Qualidade do Ar & Emissôes causadas pelos transportes e intensidade das emissổ \\
\hline Meio Ambiente e transporte & Qualidade do Ar & Populaçẫo exposta à poluiçẫo do ar causada pelos transportes \\
\hline Meio Ambiente e transporte & Qualidade do Ar & Qualidade do ar \\
\hline Meio Ambiente e transporte & Ruído & Medidas de minimizaçăo de ruído \\
\hline Meio Ambiente e transporte & Ruído & Poluiçã̃o Sonora \\
\hline
\end{tabular}

Figura 6.37 - Visualização dos relatórios gerados no Módulo III

\begin{tabular}{|c|c|c|c|c|c|c|c|c|c|c|c|c|c|c|}
\hline \multicolumn{15}{|c|}{ INDICADORES } \\
\hline \multicolumn{2}{|c|}{\begin{tabular}{|c|} 
MEIO AMBIENTE E \\
TRANSORTES \\
TEMA: ENERGIA
\end{tabular}} & \multicolumn{13}{|c|}{ INDICADOR: EFICIÊNCIA ENERGÉTICA DO TRANSPORTE DE PASSAGEIRO E CARGA } \\
\hline \multirow{2}{*}{ Usuário } & \multirow{2}{*}{ E-mail } & \multirow{2}{*}{$\begin{array}{c}1 . \\
\text { Problemas }\end{array}$} & \multirow{2}{*}{$\begin{array}{c}2 . \\
\text { Solucọos }\end{array}$} & \multicolumn{3}{|c|}{ 3. Prazos } & \multirow{2}{*}{$\begin{array}{l}\text { 4. Grau } \\
\text { Importancia }\end{array}$} & \multirow{2}{*}{$\begin{array}{l}\text { 5. Grau } \\
\text { Urgenceia }\end{array}$} & \multirow{2}{*}{$\begin{array}{l}\text { 6. Região da } \\
\text { Cidade com } \\
\text { Problemas }\end{array}$} & $\begin{array}{c}\text { 7. Região } \\
\text { Central } \\
\end{array}$ & 8. Região Norte & 9. Região Sul & 10. Região Leste & 11. Região Oeste \\
\hline & & & & $\begin{array}{l}\text { 3.1 Prazo } \\
\text { Médio }\end{array}$ & \begin{tabular}{|c|}
3.2 \\
Responsável
\end{tabular} & \begin{tabular}{|c|}
3.3 \\
Solução
\end{tabular} & & & & \begin{tabular}{|l|l|} 
Bairro & Problema \\
\end{tabular} & $\begin{array}{lll}\text { Bairro } & \text { Problema }\end{array}$ & $\begin{array}{ll}\text { Bairro } & \text { Problema } \\
\end{array}$ & \begin{tabular}{|l|l|} 
Bairro & Problema \\
\end{tabular} & \begin{tabular}{|l|l|} 
Bairro & Problema \\
\end{tabular} \\
\hline
\end{tabular}

Figura 6.38 - Visualização do relatório do Indicador Eficiência energética do transporte de passageiro e carga

Outras informações poderão ser incluídas posteriormente, conforme a necessidade do Módulo de Avaliação da Mobilidade Urbana (Módulos I a IV), para a complementação dos dados atualmente disponíveis no sistema PLANUTS.

\subsection{A utilização do sistema PLANUTS no Plano Diretor de Transportes e Mobilidade}

O sistema PLANUTS foi criado para auxiliar os decisores no processo de tomada de decisão dos assuntos relacionados à Mobilidade Urbana, inserindo-se neste contexto a participação popular.

O sistema permite que o usuário entenda a questão da Mobilidade no município através de elementos mais gerais (denominados no PLANUTS como Categorias e Temas) até o nível mais específico (denominados de Indicadores). Cada um destes elementos pode ser identificado no município através da detecção de problemas a eles relacionados no contexto da cidade como um todo ou particularmente para cada região ou sub-região do município. A metodologia a ser utilizada na etapa de diagnóstico é similar às leituras técnicas realizadas nos Planos Diretores Tradicionais (de forma Presencial).

\subsubsection{O processo participativo no sistema PLANUTS}

Para a definição da fase na qual o sistema PLANUTS pode ser utilizado na elaboração do Plano Diretor de Transportes e Mobilidade Urbana Participativo, utilizou-se como referência as etapas definidas no processo de desenvolvimento dos Planos Diretores Participativos no Brasil e nas recomendações da Secretaria Nacional de Transporte e da 
Mobilidade Urbana - SeMob (vinculada ao Ministério das Cidades) para a elaboração do Plano Diretor de Transportes e Mobilidade Urbana (PlanMob) (ver Quadro 6.9).

Quadro 6.9 - Etapas a serem cumpridas na elaboração do PlanMob

\begin{tabular}{|c|c|}
\hline ETAPAS & DESCRIÇÃO \\
\hline 1. Mobilização & $\begin{array}{l}\text { Preparar os recursos, organizar as equipes de trabalho, organizar a forma } \\
\text { de acompanhamento. }\end{array}$ \\
\hline 2. Identificação e análise prévia & $\begin{array}{l}\text { Discussão inicial das características e problemas da mobilidade, } \\
\text { acessibilidade e circulação no Município - pré-diagnóstico. }\end{array}$ \\
\hline 3. Pesquisas e levantamentos & Execução das pesquisas de acordo com a metodologia definida. \\
\hline 4. Instrumentalização da análise & $\begin{array}{l}\text { Preparação de bases viárias. } \\
\text { Lançamento de dados cadastrais. } \\
\text { Preparação de mapas. } \\
\text { No caso do uso de sistemas informatizados de modelagem - preparação } \\
\text { do modelo e sua calibração. }\end{array}$ \\
\hline 5. Consultas públicas & $\begin{array}{l}\text { Reuniões iniciais com a sociedade tendo como objetivo a apreensão do } \\
\text { conhecimento público sobre as questões envolvidas, expectativas e } \\
\text { problemas. }\end{array}$ \\
\hline $\begin{array}{l}\text { 6. Análise do problema - } \\
\text { diagnóstico }\end{array}$ & $\begin{array}{l}\text { Sistematização das informações colhidas, oferecendo uma síntese de } \\
\text { dados quantitativos e indicadores. }\end{array}$ \\
\hline $\begin{array}{l}\text { 7. Análise dos problemas - } \\
\text { Prognóstico }\end{array}$ & $\begin{array}{l}\text { Antever situações que poderão advir do crescimento urbano em relação à } \\
\text { mobilidade, acessibilidade e circulação, contemplando as diretrizes do } \\
\text { Plano Diretor Urbano. }\end{array}$ \\
\hline 8. Audiências sobre o diagnóstico & $\begin{array}{l}\text { Exposição dos resultados dos levantamentos e análises, incluindo os } \\
\text { resultados da Consulta Pública. Apresentação do diagnóstico com } \\
\text { diretrizes e proposições iniciais de forma a permitir uma avaliação de } \\
\text { receptividade e mapeamento de conflitos. }\end{array}$ \\
\hline 9. Concepção de propostas & $\begin{array}{l}\text { Fixação das diretrizes principais de forma a evitar propostas } \\
\text { concorrentes; } \\
\text { Elaboração de indicativos para os temas obrigatórios; } \\
\text { Elaboração de propostas para os temas particulares, com duas ou mais } \\
\text { propostas para serem avaliadas. }\end{array}$ \\
\hline $\begin{array}{l}\text { 10. Análise de propostas e } \\
\text { simulações }\end{array}$ & $\begin{array}{l}\text { Simulações de alternativas e dimensionamentos, com ou sem o apoio de } \\
\text { modelos de transporte (imprescindível nas cidades de maior porte, acima } \\
\text { de } 250 \text { mil habitantes ou em situações em que o plano apoiará a obtenção } \\
\text { de recursos de fontes de financiamento de infra-estrutura). } \\
\text { Obtenção de estimativas de custos e benefícios, tanto sociais como } \\
\text { econômicos. }\end{array}$ \\
\hline 11. Audiências sobre as propostas & Exposição das propostas com indicadores e dados quantificados. \\
\hline 12. Conclusões sobre as propostas & $\begin{array}{l}\text { Escolha das propostas e alternativas a serem incorporadas na versão final } \\
\text { a partir dos dados sistematizados (indicadores) e do resultado da } \\
\text { audiência sobre as propostas. }\end{array}$ \\
\hline 13. Detalhamento das propostas & $\begin{array}{l}\text { Dependendo do objetivo do Plano o detalhamento das propostas pode ser } \\
\text { realizado enquanto derivação do esforço técnico mobilizado. }\end{array}$ \\
\hline 14. Consolidação do PlanMob & $\begin{array}{l}\text { Organização do conhecimento acumulado Acervo a ser mantido. } \\
\text { Sistematização do material produzido nas demais etapas para compor o } \\
\text { documento final do PlanMob, Sumário Executivo, CD e outras mídias } \\
\text { úteis à divulgação. }\end{array}$ \\
\hline 15. Audiência sobre o PlanMob & Exposição da versão final do PlanMob. \\
\hline 16. Institucionalização do PlanMob & $\begin{array}{l}\text { Preparação da minuta do projeto de lei dispondo sobre as diretrizes da } \\
\text { mobilidade em conformidade com o PlanMob. }\end{array}$ \\
\hline
\end{tabular}

Fonte: Ministério das Cidades (2006). 
A Secretaria Nacional de Transporte e da Mobilidade Urbana - SeMob elaborou um guia, cujo objetivo é orientar as prefeituras na elaboração dos Planos Diretores de Transportes e Mobilidade. Neste material a SeMob divide os procedimentos para a elaboração do Plano Diretor de Transportes e Mobilidade Participativo em 16 etapas. Estes procedimentos são gerais, ou seja, podem ser utilizados para a elaboração de qualquer Plano Diretor.

A partir deste quadro, foi possível identificar em qual (quais) etapa(s) a ferramenta PLANUTS pode ser implementada. O Sistema pode ser utilizado na etapa de diagnóstico, através de consultas públicas presenciais ou através da internet e na simulação de cenários, conforme mostra o Quadro 6.10.

O Quadro 6.10 apresenta de forma sintetizada as etapas a serem cumpridas na adoção do Sistema PLANUTS na elaboração do Plano Diretor de Transportes e Mobilidade, bem como a forma de participação e a definição dos agentes. 
Quadro 6.10 - Etapas a serem cumpridas na implantação do sistema PLANUTS

\begin{tabular}{|c|c|c|}
\hline DESCRIÇÃO DAS ETAPAS & $\overline{A C E S S O}$ & AGENTES \\
\hline $\begin{array}{l}\text { 1. Mobilização } \\
\text { Início do Processo. }\end{array}$ & PRESENCIAL & Grupo Executor e Núcleo Gestor \\
\hline $\begin{array}{l}\text { 2. Identificação e análise prévia } \\
\text { Capacitação Técnica. }\end{array}$ & PRESENCIAL & Grupo Executor e Núcleo Gestor \\
\hline 3. Pesquisas e levantamentos & \multirow[b]{2}{*}{ PRESENCIAL } & \multirow[b]{2}{*}{ Grupo Executor } \\
\hline $\begin{array}{l}\text { 4. Instrumentalização da análise } \\
\text { Implantação dos Dados no SIG. } \\
\text { Construção do Site do Projeto. } \\
\text { Implantação dos dados nos Módulos I e II. }\end{array}$ & & \\
\hline $\begin{array}{l}\text { 5. Consultas públicas } \\
\text { Discussão com os diversos bairros e segmentos da } \\
\text { sociedade. Leitura Comunitária. }\end{array}$ & \multirow[t]{2}{*}{$\begin{array}{l}\text { PRESENCIAL / } \\
\text { INTERNET }\end{array}$} & \multirow[t]{2}{*}{$\begin{array}{l}\text { Grupo Executor, Núcleo Gestor e } \\
\text { Participação Popular }\end{array}$} \\
\hline Módulo I & & \\
\hline 6. Análise do problema - Diagnóstico & PRESENCIAL & Grupo Executor e Núcleo Gestor \\
\hline $\begin{array}{l}\text { 7. Análise dos problemas - Prognóstico } \\
\text { Leitura Técnica. }\end{array}$ & PRESENCIAL & Grupo Executor e Núcleo Gestor \\
\hline $\begin{array}{l}\text { 8. Audiências sobre o diagnóstico } \\
\text { Capacitação dos Delegados do PlanMob. }\end{array}$ & \multirow{4}{*}{$\begin{array}{l}\text { PRESENCIAL / } \\
\text { INTERNET }\end{array}$} & \multirow{4}{*}{$\begin{array}{l}\text { Grupo Executor e Núcleo Gestor } \\
\text { Delegados do PlanMob }\end{array}$} \\
\hline $\begin{array}{l}\text { Módulo I } \\
\text { Avaliação das Categorias e Temas. }\end{array}$ & & \\
\hline $\begin{array}{l}\text { Módulo II } \\
\text { Escolha dos Indicadores. }\end{array}$ & & \\
\hline $\begin{array}{l}\text { Módulo III } \\
\text { Definição das prioridades de ação. }\end{array}$ & & \\
\hline $\begin{array}{l}\text { 9. Concepção de propostas } \\
\text { Implantação dos dados nos Módulos IV }\end{array}$ & \multirow{2}{*}{$\begin{array}{l}\text { PRESENCIAL / } \\
\text { INTERNET }\end{array}$} & \multirow{2}{*}{$\begin{array}{l}\text { Grupo Executor e Núcleo Gestor } \\
\text { Delegados do PlanMob }\end{array}$} \\
\hline $\begin{array}{l}\text { Módulo IV } \\
\text { Definição dos cenários comparativos }\end{array}$ & & \\
\hline 10. Análise de propostas e simulações & PRESENCIAL & Grupo Executor e Núcleo Gestor \\
\hline 11. Audiências sobre as propostas & PRESENCIAL & Grupo Executor e Núcleo Gestor \\
\hline 12. Conclusões sobre as propostas & PRESENCIAL & Grupo Executor e Núcleo Gestor \\
\hline 13. Detalhamento das propostas & PRESENCIAL & Grupo Executor \\
\hline 14. Consolidação do PlanMob & PRESENCIAL & Grupo Executor \\
\hline $\begin{array}{l}\text { 15. Audiência sobre o PlanMob } \\
\text { Projeto de Lei. }\end{array}$ & PRESENCIAL & $\begin{array}{l}\text { Grupo Executor e Núcleo Gestor } \\
\text { Delegados do PlanMob }\end{array}$ \\
\hline 16. Institucionalização do PlanMob & --- & Grupo Executor - Poder Legislativo \\
\hline $\begin{array}{l}\text { 17. Monitoramento do PlanMob } \\
\text { Monitoramento / Re-avaliação do problema }\end{array}$ & --- & $\begin{array}{l}\text { Grupo Executor e Núcleo Gestor } \\
\text { Delegados do PlanMob }\end{array}$ \\
\hline
\end{tabular}

Para o gerenciamento do Plano Diretor de Transportes e Mobilidade é necessário definir, além das etapas, quem são os agentes envolvidos, quais as suas funções no processo de elaboração do plano, e a definição da forma de participação que poderá ser adotada em cada uma das etapas do plano.

Definição dos Agentes - Os agentes do Plano Diretor de Transportes e Mobilidade serão compostos pelos seguintes segmentos: Grupo Executor, Grupo Gestor e Delegados do PlanMob. 
- Grupo Executor - é composto por membros do Poder Público e outros profissionais ${ }^{11}$ (especialistas da área) contratados para auxiliar na condução das atividades necessárias à elaboração do Plano Diretor de Transportes e Mobilidade Participativo. Seu papel é operacionalizar todo o processo de elaboração do plano, como por exemplo, organizar, divulgar as reuniões comunitárias; executar leituras técnicas e a capacitação dos envolvidos na discussão do Plano Diretor de Transportes e Mobilidade, desenvolver estratégias para a discussão da mobilidade no município, etc.

- Grupo Gestor (Núcleo Gestor) - é composto por representantes do Poder Público e da Sociedade (delegados). Os representantes do Poder Público são compostos por especialistas membros das secretarias de planejamento urbano e de transportes ou órgãos equivalentes, envolvidos com a questão da mobilidade. Os representantes da Sociedade Civil são representantes de todos os setores sociais do município. Estes membros deverão ser eleitos de forma direta, por seus pares. Seu objetivo é coordenar, conduzir e monitorar o processo de elaboração do Plano Diretor de Transportes e Mobilidade.

- Delegados - são representantes da sociedade civil eleitos proporcionalmente, de acordo com cada região da cidade e por segmento profissional. Sua função é definir os Temas mais importantes que devem compor o Plano Diretor de Transportes e Mobilidade para o município e aprovar a pré-proposta do PlanMob, ou seja, discutir o conteúdo do Plano (Projeto de Lei).

Forma de Participação - O processo de participação nestas etapas poderá ser realizado através dos seguintes formatos:

- Participação Presencial - a população do município é convidada a participar das discussões sobre os principais problemas de mobilidade na cidade.

- Participação Virtual (internet) - participam desta etapa apenas os Delegados do Plano Diretor de Transportes e Mobilidade. Ela será realizada na etapa de avaliação do Sistema PLANUTS.

De acordo com o Quadro 6.10 o sistema PLANUTS poderá ser utilizado nas Etapas 2, 5, 7 e 10 do Plano Diretor de Transportes e Mobilidade Participativo. A seguir são descritas as atividades que compreendem cada uma destas etapas.

\footnotetext{
${ }^{11} \mathrm{O}$ município pode contratar assessores externos cuja função é capacitar a equipe local e oferecer suporte técnico ao processo de elaboração do Plano Diretor de Transportes e Mobilidade.
} 


\section{- Definição das etapas do Plano Diretor de Transportes e Mobilidade ${ }^{12}$}

- Etapa 1 - Início do Processo (Mobilização) - O processo para a elaboração do Plano Diretor de Transportes e Mobilidade Participativo inicia-se com a definição da equipe técnica que deverá conduzir o Plano Diretor. O Poder Executivo é o responsável por esta definição. Nesta etapa também é definida a participação de especialistas externos que podem auxiliar na condução do Plano Diretor de Transportes e Mobilidade. Estes especialistas podem ser profissionais liberais ou podem estar ligados às Universidades. Nesta etapa os envolvidos deverão definir as diretrizes a serem seguidas, o cronograma de trabalho e os materiais a serem utilizados (mapas, imagens, etc).

- Etapa 2 - Identificação e análise prévia - A segunda etapa refere-se à elaboração de material técnico sobre os problemas de mobilidade no município a serem discutidos nas consultas públicas. Inserem-se nesta fase a coleta de dados para atualização da base de dados gráfica (digital) do município.

- Capacitação da equipe - O objetivo desta capacitação é permitir que todos os membros do Grupo Gestor [especialistas (técnicos que trabalham diariamente nas questões do planejamento urbano e de transportes) e não-especialistas (demais profissionais representantes da sociedade)] possam ter uma visão mais abrangente de todos os aspectos que envolvem a questão da Mobilidade Urbana Sustentável no município. A capacitação deverá ser realizada por especialistas externos. Temas a serem abordados na capacitação: mobilidade urbana, acessibilidade, circulação, mobilidade e sustentabilidade, uso do solo e transportes, etc. Nesta etapa, os técnicos que irão aplicar o Sistema PLANUTS no Plano Diretor de Transportes e Mobilidade devem tomar contato com os quatro Módulos de Avaliação para tirar eventuais dúvidas; pois a partir desta etapa eles serão os intermediários na aplicação do Sistema PLANUTS para com os avaliadores não-especialistas.

- Etapa 3 - Pesquisas e levantamentos - A primeira fase refere-se à coleta de dados sobre todos os Temas, identificados pela equipe técnica, relativos à mobilidade no município.

\footnotetext{
${ }^{12}$ Esta definição foi embasada no material disponibilizado pela SeMob referente a implantação dos Planos Diretores de Transportes e Mobilidade e nas etapas e ações cumpridas pelos municípios brasileiros para a elaboração e desenvolvimento dos Planos Diretores Municipais Participativos.
} 
- Pesquisas e Levantamentos - nesta fase pode-se coletar informações sobre os seguintes Temas: i) descrição e características do sistema viário; ii) circulação de tráfego; iii) sistema de transporte coletivo (linhas); iv) circulação de bicicletas; v) acessibilidade; vi) condição dos passeios (calçadas); vii) circulação de mercadorias; viii) políticas públicas de mobilidade e transporte no município; ix) políticas urbanas e seu reflexo na política de mobilidade, etc. A SeMob, no Guia PlanMob: Construindo uma cidade sustentável (caderno de referência para Elaboração de Plano Diretor de Transportes e Mobilidade Urbana), apresenta os tipos de pesquisas e levantamentos que devem ser realizados em função do número de habitantes do município. No Quadro 6.11, é apresentada esta informação para as cidades de médio porte, objeto desta pesquisa.

Quadro 6.11 - Pesquisas e levantamentos sugeridas pela SeMob para cidades com população entre 250 a 500 mil habitantes

\section{PESQUISAS E LEVANTAMENTOS}

Inventário da infra-estrutura viária, com atenção para as condições das calçadas e travessias;

Inventário das condições de circulação viária, estado da sinalização viária e dimensões das vias, com atenção para a questão semafórica existente e potencial;

Elaboração de um zoneamento de tráfego (regiões) da cidade com características homogêneas de tipo de ocupação, perfil social e econômico da população e adequadas às formas de obtenção dos dados de origem e destino (domiciliar mais origem/destino de transporte coletivo);

Pesquisas de origem e destino de viagens através de pesquisa domiciliar, admitindo-se um zoneamento com aproximadamente 40 a 60 zonas (regiões) e uma amostra de 2.800 a 4.200 domicílios;

Pesquisa de entrevistas com veículos nos pontos de acesso à cidade (pesquisa de linha de contorno);

Pesquisa de ocupação de veículos de transporte coletivo e individual em pontos estratégicos dispostos na malha viária (pesquisa de linha de controle);

Pesquisa de transporte coletivo: operacional, sobe-desce, entrevistas com usuários sobre origem e destino (a bordo dos ônibus ou nos pontos de parada);

Pesquisa de imagem e avaliação do serviço de transporte;

Pesquisas com ciclistas sobre o uso da bicicleta, incluindo origens e destinos, rotas e problemas enfrentados;

Pesquisas de contagem volumétrica de tráfego nos principais locais pré-identificados;

Pesquisa de velocidade e retardamento nas principais rotas, individualizado para o transporte coletivo e individual.

Fonte: SeMob (2006).

- Etapa 4 - Instrumentalização da análise - Após a fase de coleta de dados, estes devem ser sistematizados para serem apresentados e discutidos com a população. Segundo a SeMob devem ser incluídos nesta etapa os trabalhos prévios de preparação dos instrumentos de análise das informações, ou seja, a construção da base de dados gráfica e alfanumérica no formato digital.

- Base de Dados - sugere-se a adoção de um Sistema de Informação Geográfica para facilitar as análises dos dados coletados. Se necessário deve-se capacitar a equipe técnica para a utilização de SIG. Propõe-se a adoção de SIG freeware. Caso o município não tenha especialistas com conhecimento técnico na área de geoprocessamento (para a utilização de software SIG) há a necessidade de 
treinamento específico. Sugere-se adoção de parcerias com Universidades da região para ministrar este curso aos técnicos municipais.

- Utilização do Sistema PLANUTS - nesta fase o município deve construir o site do Plano Diretor de Transportes e Mobilidade Urbana (link na página da Prefeitura para a página do Plano Diretor de Transportes e Mobilidade PlanMob) que dará suporte a implantação e acesso ao Sistema PLANUTS. Insere-se nesta etapa a construção do Mapa do município para ser implantado nos Módulos I e III.

- Materiais a serem elaborados - mapas temáticos, mapa com a atual hierarquia viária, mapa com as linhas de transporte coletivo, mapas de demanda e oferta de transporte coletivo e individual, etc.

- Etapa 5 - Consultas públicas - a primeira etapa consiste na divulgação do Plano Diretor de Transportes e Mobilidade no município. Posteriormente deve-se iniciar o processo de discussão dos problemas que envolvem a mobilidade da cidade com os diversos segmentos da sociedade; através de debates públicos. As reuniões, nesta fase, são presenciais.

- Leitura Comunitária - tem como objetivo a identificação e discussão sobre os problemas de mobilidade do município e/ou de cada região da cidade sob a ótica dos diversos segmentos da sociedade. Para esta leitura podem ser utilizadas diversas metodologias.

- Utilização do Sistema PLANUTS - nas discussões presenciais, pode ser utilizado o Módulo I do Sistema PLANUTS. Nesta etapa, a avaliação do Módulo I poderá ser realizada de forma consensual, ou seja, para cada página apresentada (Categorias e/ou Temas), os participantes devem definir o grau de importância de cada critério para avaliação da mobilidade no município.

- As definições das Categorias e Temas apresentados neste módulo podem subsidiar as discussões sobre a identificação dos problemas de mobilidade no local (onde está sendo realizada a leitura comunitária) ou no município. A utilização das Categorias e Temas pode representar um ponto de referência para o início das discussões sobre a mobilidade (tornando o processo de discussão mais produtivo), uma vez que este tema é desconhecido para a maioria da população. 
- Etapa 6 - Análise do problema (Diagnóstico) - nesta etapa, Grupo Executor e o Núcleo Gestor devem analisar os problemas e as propostas identificadas pela comunidade na fase de Leitura Comunitária. Os resultados destas análises devem ser apresentados à comunidade em audiências públicas (Audiências sobre Diagnóstico).

- Dentre as questões a serem analisadas destacam-se: i) Fatores que interferem na mobilidade - uso e ocupação do solo; mobilidade na área urbana e rural; ii) Características morfológicas - barreiras físicas (naturais) e urbanas; iii) Contexto geopolítico da cidade; iv) Perfil da mobilidade do município; etc.

- Outros levantamentos podem ser realizados para auxiliar nesta etapa, tais como: i) Inventário Físico - levantamentos sobre as condições de infra-estrutura urbana destinada à circulação (sistema viário e as suas benfeitorias, sistemas de controle de tráfego, equipamentos urbanos associados aos serviços de transporte público, pesquisas de comportamento na circulação, pesquisas operacionais de transporte coletivo, etc.); e ii) Análise de estudos e projetos existentes (ver Quadro 6.12).

Quadro 6.12 - Levantamentos sobre a Mobilidade no município

\section{Levantamentos que podem auxiliar nas etapas de Diagnóstico e Prognóstico}

- Identificação das orientações da política urbana estabelecidas no Plano Diretor Urbano;

- Identificação dos vetores de crescimento urbano e das áreas de expansão populacional;

- Identificação de novos parcelamentos de solo urbano em tramitação na Prefeitura ou de áreas de expansão para as quais haja especulação sobre futuro aproveitamento para parcelamento;

- Identificação de novos empreendimentos empresariais, na área de comércio, serviços e indústrias;

- Identificação de projetos existentes, com atenção para projetos de outras instâncias, como o governo estadual;

- Realização de projeção populacional para um horizonte de 10 a 15 anos e sua macro-espacialização de acordo com as diretrizes urbanísticas, ou tendencial com base nos dados obtidos;

- Projeção das viagens de transporte coletivo para o horizonte de estudo utilizando modelos de transporte;

- Análise da malha viária, especialmente sob o ponto de vista da sua capacidade de suporte para o atendimento de demandas futuras de transporte coletivo, de circulação a pé e por bicicletas;

- Análise da regulamentação em vigor sobre os transportes, especialmente sobre o transporte público por modos coletivos e individuais (táxi, escolar, moto-táxi);

- Análise da organização da gestão pública do transporte, em especial prevendo a elevação das demandas e das complexidades inerentes ao crescimento urbano.

Fonte: SeMob (2006).

- Etapa 7 - Análise dos problemas (Prognóstico) - esta etapa refere-se à realização de estudos técnicos (leitura técnica e estudos de projeção) sobre os principais problemas de mobilidade no município.

- Leitura Técnica - realização de estudos técnicos sobre o município, ou seja, identificação da "causa e efeito" sobre cada problema de mobilidade identificado na etapa de diagnóstico. Sugere-se a divisão destes estudos de acordo como as Categorias e Temas propostos por Costa (2003).

- Estudos de projeção - elas visam prever as situações que poderão ocorrer em função do crescimento urbano em relação à mobilidade, acessibilidade e 
circulação. De acordo com a SeMob (2006), estes estudos podem ser estruturados através: i) da construção de cenários (ver Módulo IV - Etapa 9) de evolução urbana, demográfica, econômica e social da localidade e ii) da projeção quantitativa ou qualitativa dos impactos destes cenários na mobilidade, nos serviços de transporte e no sistema viário.

- Etapa 8 - Audiências sobre o Diagnóstico - esta etapa pode ser dividida em 2 fases: i) apresentação dos problemas de mobilidade identificados na etapa de diagnóstico e ii) utilização do Sistema PLANUTS (internet).

1. Apresentação dos Problemas - os problemas identificados na leitura comunitária poderão ser apresentados à população no site do Plano Diretor e nas reuniões presenciais com os diversos segmentos da sociedade. Nestas reuniões deverão ser escolhidos os representantes (Delegados do Plano Diretor de Transportes e Mobilidade) que irão continuar no processo de elaboração do Plano Diretor.

2. Utilização do Sistema PLANUTS - nesta etapa o sistema deverá ser utilizado por todos os Delegados do Plano Diretor de Transportes e Mobilidade (representantes da sociedade civil e do poder público). Inicialmente estes participantes deverão passar por uma etapa de capacitação para conhecer cada um dos Módulos de Avaliação. O objetivo da utilização do sistema nesta fase é definir os Indicadores que irão compor o Sistema de Indicadores de Mobilidade Urbana do município. As avaliações poderão ser realizadas individualmente ou em grupo através da internet.

- Capacitação dos Delegados - após a definição dos Delegados estes deverão participar de um curso de capacitação. O objetivo deste curso é homogeneizar o conhecimento dos participantes (especialistas e não-especialistas) acerca das principais questões que envolvem direta ou indiretamente o tema mobilidade e a apresentar cada um dos Módulos de Avaliação do Sistema PLANUTS.

- Nesta capacitação sugere-se abordar os seguintes temas: Mobilidade Urbana Sustentável, Indicadores de Mobilidade, Plano Diretor de Transportes e Mobilidade, e apresentação e treinamento dos participantes para utilização da ferramenta PLANUTS (Módulos I, II, IIII e IV).

- Embora cada Módulo de Avaliação possua uma página de demonstração que apresenta ao avaliador todos os procedimentos e ferramentas 
disponíveis, a realização deste treinamento (para os Delegados) permitirá que cada participante possa tirar dúvidas sobre alguma etapa do processo de avaliação. Este treinamento deverá ser realizado pelo Núcleo Gestor com acompanhamento do Grupo Executor.

- Administrador do Sistema PLANUTS - dentre os membros do Grupo Executor, deve-se definir quem será o responsável pela Administração do Sistema, ou seja, o responsável pelo cadastro dos participantes e a inclusão das informações nos Módulos III e IV.

- Procedimentos: i) cadastro dos usuários; ii) avaliação dos Módulos I e II; iii) análise dos dados referentes aos Módulo I e II; iv) inclusão das informações no Módulo III; v) avaliação do Módulo III; e vi) análise dos dados referente ao Módulo III.

- Cadastro dos Usuários - todos os membros do Grupo Gestor e Delegados devem ser cadastrados no sistema. Aqueles usuários que avaliarem o sistema sem que estejam cadastrados suas avaliações poderão ser excluídas pelo Administrador do sistema.

- Avaliação do Módulo I

- Avaliação do Módulo II

- Observação: Sugere-se que a avaliação dos Módulos I e II seja realizada em um mesmo período. Sua disponibilidade na internet não deve ultrapassar um prazo de dois meses, caso contrário o processo torna-se muito longo e desestimulante para os avaliadores.

- Etapa intermediária - Grupo Executor e Equipe Técnica irão sistematizar os resultados das avaliações dos dois módulos e inserir os dados no Módulo III para avaliação.

- Análise dos Resultados: para análise dos resultados deve-se adotar os procedimentos metodológicos apresentados no Capítulo 5, ou seja, para a avaliação do Módulo I deve-se aplicar o Método de Análise Multicritério e para a avaliação do Módulo II o resultado é obtido através da somatória dos indicadores mais votados. Os resultados das avaliações do Módulo I e a lista dos Indicadores do Módulo II devem ser disponibilizados na internet. 
- Nesta fase o Grupo Executor deve decidir se adotará pesos diferenciados para a avaliação do Grupo dos Especialistas e Nãoespecialistas.

- Construção do Módulo III - deve ser construído a partir dos resultados obtidos no Módulo II. O responsável por este procedimento é o administrador do sistema, que deverá incluir as seguintes informações: i) cadastrar todos os Temas de acordo com a Categoria a que pertence; ii) cadastrar os Indicadores (mais votados no Módulo II - aproximadamente 40 indicadores); iii) cadastrar as mídias correspondentes a cada indicador [definições (texto), áudios e vídeos] de acordo com o item 6.3.2.6 deste capítulo; iv) cadastrar alguns problemas e soluções associados a cada Indicador; v) cadastrar as sub-regiões do município; e vi) cadastrar o mapa da cidade (dividido em sub-regiões).

\section{- Avaliação do Módulo III}

- Etapa intermediária - Grupo Executor e Equipe Técnica irão analisar os resultados das avaliações do Módulo III.

- Análise dos Resultados: para análise dos resultados deve-se adotar os procedimentos metodológicos apresentados no Capítulo 5. Para a avaliação do Grau de Importância e Grau de Urgência deve-se aplicar o Método de Análise Multicritério. Os demais resultados deverão ser analisados de forma agregada, pois subsidiarão as etapas 9 e 10.

- Etapa 9 - Concepção de propostas - a partir do diagnóstico (realizado através das leituras comunitárias e das leituras técnicas) e dos produtos obtidos das avaliações do Sistema PLANUTS, deve-se definir as diretrizes gerais e específicas do Plano Diretor de Transportes e Mobilidade. Ainda nesta fase devem ser analisadas as propostas apresentadas no módulo anterior e realizadas algumas simulações.

- Diretrizes e Estudos Técnicos - estas diretrizes podem se basear na definição dos Temas e Indicadores determinados na avaliação do Sistema PLANUTS (nas soluções apresentadas no Módulo III) e nas diretrizes elaboradas pela Secretaria 
Nacional de Mobilidade Urbana ${ }^{13}$. O Quadro 6.13 apresenta a definição de alguns estudos técnicos e propostas definidos pela SeMob (2006) para os municípios com população entre 250 a 500 mil habitantes.

\section{Quadro 6.13 - Estudos Técnicos}

\section{Estudos e proposições - Municípios 250 a $\mathbf{5 0 0}$ mil habitantes}

- Identificação dos conflitos de tráfego de passagem porventura existentes, em especial com rodovias e ferrovias;

- Identificação das necessidades de estacionamento nas áreas de atração de viagens;

- Identificação dos pontos de descontinuidade viária entre bairros ou regiões, incluindo barreiras de transposição naturais ou artificiais;

- Identificação de áreas de tráfego local a serem preservadas mediante projetos de trânsito calmo ou restrições de circulação.

- Formulação de proposta de rede de transporte coletivo integrada;

- Análise do modelo tarifário do transporte coletivo;

- Identificação do sistema viário de interesse para a circulação do transporte coletivo e, em especial, dos corredores de tráfego no qual deverão ser previstas diretrizes para a priorização de sua circulação, incluindo a identificação das soluções propostas;

- Identificação de locais para instalação de terminais ou estações de integração ou de conexão da rede de serviços de transporte coletivo, em bairros e/ou na área central;

- Análise do transporte de cargas, em especial em relação à circulação de caminhões com peso bruto elevado e de cargas perigosas;

- Análise pormenorizada da situação da área central ou de corredores viários comerciais, principalmente em relação ao uso das calçadas.

- Representação das alternativas de reorganização das redes de transporte coletivo e sistema viário, incluindo medidas de priorização do transporte coletivo e não motorizado e simulação de seu desempenho frente a indicadores econômicos e sociais;

- Realização de estudos de viabilidade econômico-financeira das soluções estruturais propostas.

\section{Fonte: SeMob (2006)}

- Sistema PLANUTS - a partir das análises e dos estudos técnicos deve-se definir e construir os cenários comparativos (mostram a situação atual e uma projeção do atual problema em diferentes períodos) para serem avaliados no Módulo IV.

- Procedimentos: i) inclusão das informações no Módulo IV; ii) avaliação do Módulo IV; e iii) análise dos resultados.

- Etapa 10 - Análise de propostas e simulações - além dos cenários gerados pelo Módulo IV, outras simulações podem ser realizadas com o intuito de auxiliar no processo de tomada de decisão. Como por exemplo: simulações sobre alternativas para o transporte coletivo, simulações sobre obras viárias, simulações sobre ampliação da capacidade de determinadas vias do sistema viário, simulações sobre o atendimento (freqüência) do transporte coletivo por região da cidade, etc.

- Etapa 11 - Audiências sobre as propostas - após a realização das análises dos cenários e das simulações realizadas, deve-se realizar algumas audiências públicas para a

\footnotetext{
${ }^{13}$ A SeMob definiu temas obrigatórios e particulares de acordo com a faixa populacional que podem facilitar a definição das diretrizes a serem adotadas pelos município.
} 
apresentação das propostas que deverão fazer parte da Minuta do Projeto de Lei de Mobilidade Urbana para o Município.

- Nestas audiências são apresentadas algumas pré-propostas que podem compor o projeto de lei do Plano Diretor de Transportes e Mobilidade. Dentre estas propostas destacam-se: i) Hierarquização viária; ii) Zoneamento da mobilidade; iii) Sistema de monitoração da mobilidade (apresentação dos Indicadores escolhidos); iv) Cenários escolhidos; v) Plano de Ação; vi) Plano de Investimento, entre outros.

- Etapas 12 - Conclusões sobre as propostas - o Grupo Executor irá definir os Temas que irão compor o Plano Diretor de Transportes e Mobilidade levando-se em consideração os resultados obtidos das avaliações e das audiências públicas.

- Etapa 13 - Detalhamento das propostas - o detalhamento das propostas deverá ser realizado em função dos objetivos ${ }^{14}$ do plano diretor adotado. Entretanto, estes trabalhos de detalhamento podem, em função de suas especificidades, assumir uma proporção de esforços e gastos que não é compatível com esta etapa. Recomenda-se que a equipe técnica (Grupo Executor) separe estes projetos mais complexos para serem desenvolvidos após a aprovação do Plano.

- Etapa 14 - Consolidação do Plano - nesta etapa, o Grupo Executor deverá organizar as informações (os diagnósticos, as análises, as alternativas, os cenários e propostas) coletadas ao longo do processo de discussão do Plano Diretor de Transportes e Mobilidade, para comporem o documento final. Este documento deve incorporar a visão dos especialistas e não-especialistas.

- Outros documentos complementares podem ser elaborados, como por exemplo: mapas (cenários escolhidos, etc.) e textos (definição dos Indicadores que irão compor o Sistema de Indicadores de Mobilidade do município).

- Etapa 15 - Audiência sobre o Plano - realização de uma audiência final para a exposição e discussão do conteúdo do Plano de Transportes e da Mobilidade. Devem

\footnotetext{
${ }^{14}$ O Plano Diretor pode ter um caráter estratégico ou executivo. No primeiro caso, o plano limita-se a definição de um conjunto de diretrizes gerais definindo ações, programas e projetos que devem ser executados pelo poder público. No segundo caso, há a necessidade de um detalhamento maior do plano; é necessário detalhar os seguintes aspectos: operacional, tecnológico, de infra-estrutura, institucional e o financiamento.
} 
participar desta audiência: Grupo Executor, Núcleo Gestor e Delegados do Plano Diretor. Nesta etapa são apresentadas as diretrizes gerais e as propostas para a organização do sistema de mobilidade da cidade.

- Apresentação do Projeto de Lei referente ao Plano Diretor de Transportes e Mobilidade.

- Etapa 16 - Institucionalização do Plano - nesta etapa o Grupo Executor deverá produzir a minuta de projeto de lei com as inclusões das deliberações realizadas na fase anterior (Audiência pública para apresentação do Plano Diretor de Transportes e Mobilidade).

- Na seqüência a Minuta do Projeto de Lei deve ser encaminhada à Câmara de Vereadores para aprovação final do Plano Diretor de Transportes e Mobilidade do município.

- Etapa 17 - Monitoramento do Plano - recomenda-se realizar a monitoração do Plano Diretor de Transportes e Mobilidade num prazo de 5 anos a partir de sua aprovação na Câmara Municipal. Esta re-avaliação é necessária para verificar se as metas e os objetivos foram alcançados e para a definição de novas metas e objetivos.

- Utilização do Sistema PLANUTS - os quatro Módulos de Avaliação da Mobilidade Urbana podem ser utilizados para monitorar a aplicação do plano no município. Nesta nova aplicação do sistema outros Indicadores poderão compor o Sistema de Indicadores de Mobilidade do Município, caso as metas iniciais tenham sido atingidas.

No próximo capítulo será apresentado todo o processo de implantação da ferramenta PLANUTS, num município brasileiro de porte médio. Serão apresentadas as etapas necessárias para o desenvolvimento de um Plano Diretor de Transportes e Mobilidade participativo utilizando a ferramenta proposta como elemento de avaliação da mobilidade e definição de um elenco de Indicadores de Mobilidade para o município. 


\section{IMPLEMENTAÇÃO DO SISTEMA PLANUTS}

Após o detalhamento do sistema PLANUTS no capítulo anterior, é apresentado, neste capítulo, o processo de implantação desta ferramenta. A demonstração da aplicação dos Módulos (I, II e III) em uma cidade de médio porte permitiu explicar o processo de implantação de cada parte do sistema de forma detalhada; bem como o processo de análise dos resultados obtidos no sistema para a composição de um Sistema de Indicadores de Mobilidade Urbana Municipal.

Este capítulo apresenta o resultado de um estudo de caso referente à aplicação do Sistema PLANUTS em um município piloto, com base no que foi descrito no capítulo anterior. Posteriormente, são apresentados os resultados e análises desta aplicação.

\subsection{Estudo de Caso: O município de Bauru e a questão da Mobilidade Urbana}

O Município de Bauru foi escolhido para a implantação do sistema pelos seguintes motivos: i) pela facilidade na obtenção das informações e aplicação do sistema, ii) por seus problemas relacionados com a mobilidade, iii) por ter passado recentemente por um processo de elaboração do Plano Diretor Municipal de forma participativa e iv) por sua proposta de Plano Diretor Municipal conter itens específicos referentes à questão da Mobilidade Urbana e Rural e por definir um prazo para a elaboração do Plano Diretor de Transportes e Mobilidade Participativo.

Bauru é uma cidade de médio porte, localizada no interior do estado de São Paulo. Segundo projeções do IBGE (Instituto Brasileiro de Geografia e Estatística) a população em 2007 está estimada em 347.601 habitantes $^{1}$ (IBGE, 2007).

O município apresenta uma alta taxa de população urbana - 98,58\% (ano base 2006), segundo dados fornecidos pelo SEADE (2007), se comparada com a média

\footnotetext{
${ }^{1}$ Estimativa de população para 2007 publicada no Diário Oficial da União em 05/10/2007. O IBGE ainda não disponibilizou os dados do Censo 2007 para o município de Bauru. No último censo, realizado em 2000, a população de Bauru era de 316.064 habitantes.
} 
estadual, que é de 93,7\%. A taxa de crescimento populacional do município é de 1,65\% ao ano, ficando um pouco acima da taxa estadual, que é de 1,52\% (SEADE, 2007). A densidade demográfica municipal (estabelecida para o ano de 2005) é de 509,97 habitantes $/ \mathrm{km}^{2}$. Esta taxa é mais de três vezes maior que a estadual $(160,70$ habitantes $/ \mathrm{km}^{2}$ ), o que representa uma grande concentração de pessoas na zona urbana (SEADE, 2007). Entretanto, este índice, não reflete a realidade do município de Bauru por inteiro. Em função da atual política de uso do solo, esta densidade pode variar consideravelmente de acordo com o bairro estudado. Em algumas regiões da cidade este índice é maior em função do adensamento urbano; entretanto, ao se analisar regiões mais periféricas da cidade encontra-se uma situação oposta. Estas duas realidades são conseqüência dos vazios urbanos e da especulação imobiliária encontrada no município.

Atualmente, a frota municipal é de 156.808 veículos (DENATRAN; novembro, 2007), sendo que, deste total, 64\% são automóveis (ver Figura 7.1). Somente no ano de 2006, cerca de 10000 novos veículos foram colocados em circulação na cidade (DENATRAN, 2007). Deste total, 42\%, ou seja, 4230 veículos eram automóveis. Através destes valores obteve-se um índice de 2,35 habitantes/veículo para o ano de 2006. Para o ano de 2007, o índice calculado até agosto deste ano foi de 2,22 habitantes/veículo. Este resultado mostra um alto grau de dependência do transporte motorizado individual, o que indica a falta de políticas no que se refere a mobilidade sustentável no município.

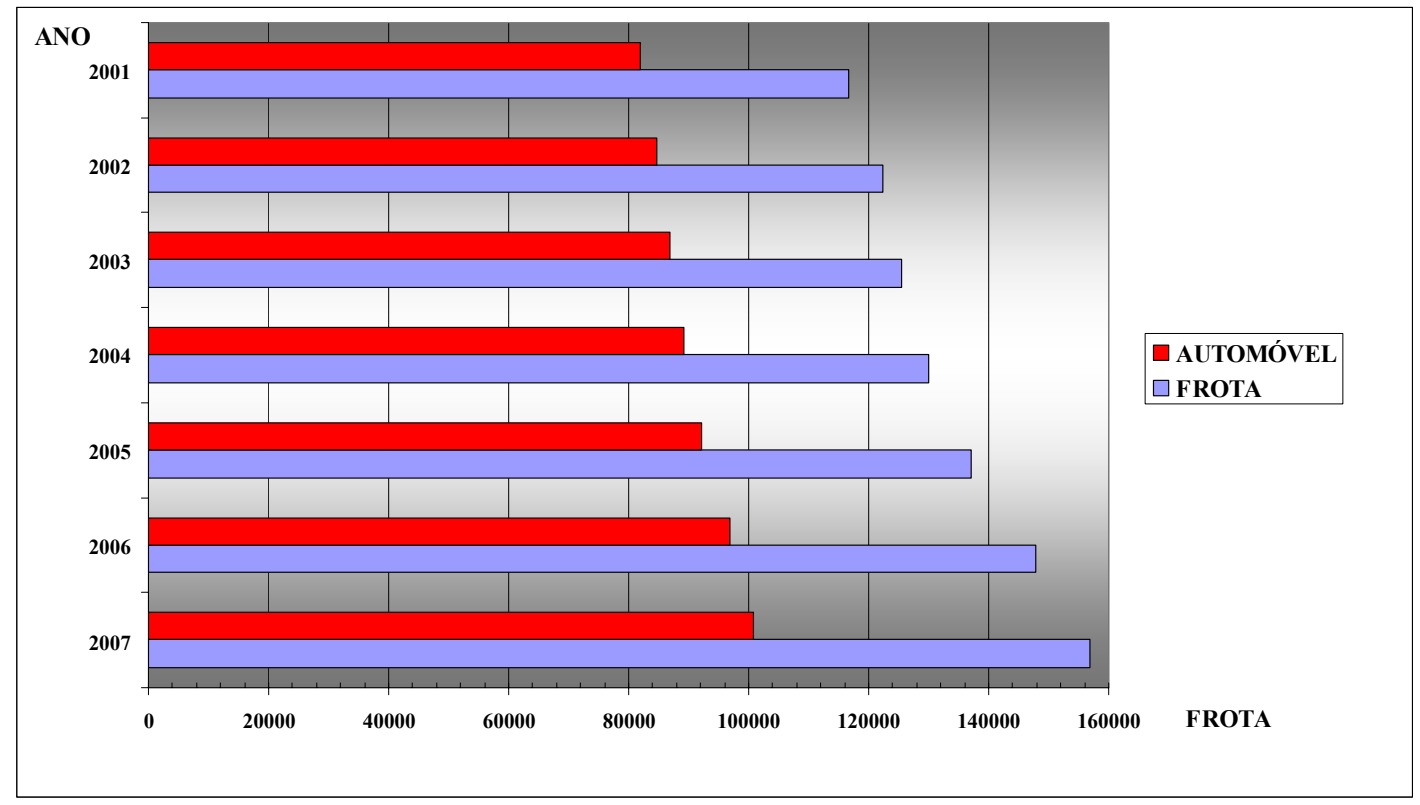

Figura 7.1 - Gráfico comparativo entre a frota total em relação ao número de automóveis do município de Bauru entre o período de janeiro/2001 a agosto/2007

Fonte: DENATRAN (2007). 
O problema de mobilidade do município, como ocorre na maioria das cidades brasileiras, é reflexo, entre outros fatores, da falta de um processo de planejamento que incorpore as questões de uso do solo e transportes de forma integrada. A falta de políticas públicas para orientar este crescimento urbano ordenado e integrado é reflexo da forma tradicional de planejamento adotado pelo município, onde questões como uso e ocupação do solo e sistema viário são tratadas de forma independente.

Algumas conseqüências da adoção deste formato de planejamento para o município são: parcelamento de áreas periféricas da cidade com baixa densidade; presença de grandes vazios urbanos; estratificação físico-espacial (advinda da política de uso e ocupação do solo tradicional); má distribuição de infra-estrutura urbana e de serviços urbanos coletivos; problemas de mobilidade e acessibilidade; degradação do meio ambiente; acidentes de trânsito concentrados de forma mais intensa em determinadas regiões da cidade; alto índice de motorização, entre outras.

Segundo o diagnóstico realizado no município na fase de elaboração do Plano Diretor Municipal Participativo, algumas questões referentes à mobilidade foram identificadas pela população para as áreas urbana e rural do município de Bauru. O Quadro 7.1 apresenta de forma sintética este levantamento, onde as informações foram agrupadas segundo a categoria a que pertencem: i) questões relacionadas ao planejamento e ii) questões relacionadas à infra-estrutura.

Quadro 7.1 - Principais problemas de mobilidade identificados na etapa de diagnóstico do Plano Diretor Municipal

\section{PRINCIPAIS PROBLEMAS}

\begin{tabular}{|l|l|}
\hline \multirow{2}{*}{ Área Rural } & i) Planejamento - Deficiência no Transporte Coletivo. \\
\hline & $\begin{array}{l}\text { i) Infra-estrutura - Problemas de pavimentação no sistema viário; Deficiência no sistema de } \\
\text { drenagem de águas pluviais; Problemas no sistema viário de acesso a determinados bairros do } \\
\text { município; Falta de identificação de determinadas ruas; Problemas em algumas pontes; Falta de } \\
\text { recuperação da Estrada de Ferro (atualmente em estado de degradação); e Falta de recuperação e } \\
\text { manutenção das estradas vicinais. }\end{array}$ \\
\hline Área Urbana & $\begin{array}{l}\text { i) Planejamento - Deficiência no Transporte Coletivo (intervalo entre viagens); e Implantação de } \\
\text { novas linhas. }\end{array}$ \\
\cline { 2 - 2 } & $\begin{array}{l}\text { ii) Infra-estrutura - Problemas de pavimentação das ruas; Falta de interligação entre bairros } \\
\text { (sistema viário); Falta ou deficiência no sistema de drenagem de águas pluviais em determinados } \\
\text { bairros da cidade; Necessidade de implantação e manutenção de vias de acesso em determinados } \\
\text { bairros; Falta de calçadas; Falta de manutenção de calçadas; Falta de identificação de ruas e vias } \\
\text { de acesso; Falta de pontes entre bairros, Falta manutenção de alguns viadutos; Falta de } \\
\text { recuperação da Estrada de Ferro; Problemas de manutenção das estradas; Falta ciclovias; Falta } \\
\text { calçadas para caminhada; Falta cobertura em alguns pontos de ônibus; Falta de abrigos de } \\
\text { onibus; Falta de passarelas para interligação de bairros; Falta de sistema viário marginal à } \\
\text { Rodovia Marechal Rondon; Falta de baias para parada de ônibus; Falta de alças de acesso a } \\
\text { determinados viadutos do município; e Necessidade de construção de ligaços viárias para } \\
\text { desafogar o trânsito da área central. }\end{array}$ \\
\hline
\end{tabular}

$$
\text { Fonte: Prefeitura Municipal de Bauru (2006). }
$$


O Quadro 7.1 contém uma síntese dos principais aspectos relacionados a problemas de mobilidade do município. Estes problemas são identificados tanto na área urbana quanto na rural. $\mathrm{Na}$ área urbana estes problemas são decorrentes: dos inúmeros vazios urbanos advindos da especulação imobiliária, da grande concentração de núcleos habitacionais localizados na periferia da cidade, da falta um plano de transportes para a reorganização do transporte público (atualmente realizado apenas por ônibus), e da freqüência deste meio de transporte em determinados bairros da cidade. Outro aspecto identificado neste diagnóstico está relacionado com deficiências de construção e manutenção do sistema viário (ruas, calçadas, ciclovias, etc.).

Diante deste quadro inicial, espera-se que a implantação do sistema PLANUTS possa, além de definir os indicadores de mobilidade mais importantes para o município neste momento, apontar outras questões relevantes para o planejamento da sua mobilidade.

\subsection{Implantação do sistema - Aplicação no Município de Bauru}

Para avaliar o desempenho de cada módulo do sistema proposto, bem como a capacidade do sistema em incorporar a visão e a participação de múltiplos agentes, sejam eles especialistas ou não, foi realizado um teste piloto no município de Bauru.

O objetivo desta aplicação foi demonstrar, na prática, a ferramenta computacional PLANUTS, simulando as etapas adotadas para a elaboração do Plano Diretor de Transportes e Mobilidade Participativo com a utilização do sistema proposto. Conseqüentemente, foram apresentados os seguintes resultados gerados pelo sistema a partir da aplicação de cada Módulo de Avaliação da Mobilidade Urbana: Definição de uma lista contendo os indicadores mais importantes, Ordenamento dos Temas e Indicadores mais importantes - que irão compor um Sistema de Indicadores de Mobilidade para o município, Definição dos indicadores mais urgentes para o município, Identificação de problemas e soluções para os Indicadores, e Identificação dos problemas de mobilidade por região e por bairro (sub-regiões) do município.

Conforme foi apresentado no Capítulo 2, a definição de um sistema de indicadores de mobilidade é um dos itens que deve estar presente no Plano Diretor de Transportes e Mobilidade, sendo o responsável pela monitoração da mobilidade no município. Segundo a atual Política nacional de mobilidade urbana sustentável, elaborada pela Secretaria Nacional de Transporte e da Mobilidade Urbana - SeMob, as ações que deverão compor este plano são: i) Plano de Ações Estratégicas; ii) Plano de 
Investimentos; iii) Instrumentos para a gestão - Hierarquização viária, Zoneamento da mobilidade, Sistema de monitoração da mobilidade (Sistema de Indicadores) e Base de dados para o planejamento continuado.

Para a realização deste teste piloto foi realizado um Curso de Capacitação intitulado Capacitação técnica para a elaboração de plano diretor de mobilidade urbana: definição de indicadores de mobilidade urbana. $O$ objetivo deste curso foi apresentar aos participantes a ferramenta proposta, bem como o método desenvolvido para definir os indicadores de mobilidade visando a sua posterior inserção no Plano Diretor de Transportes e Mobilidade ${ }^{2}$ municipal que deverá ser executado pela prefeitura local em um futuro próximo.

Participaram deste curso técnicos ligados a área de Planejamento de Transportes e Planejamento Urbano do município, Membros do Núcleo Gestor do Plano Diretor e Delegados, representantes da sociedade, que também participaram do desenvolvimento e aprovação do Plano Diretor Participativo do Município de Bauru. Estes participantes foram escolhidos para atender às seguintes questões: i) representantes técnicos - foram escolhidos aqueles que poderão conduzir a elaboração do Plano Diretor de Transportes e Mobilidade Participativo do município, e ii) representantes da sociedade sua escolha ocorreu em função do conhecimento que cada membro possui referente ao processo de discussão de um Plano Diretor.

Este curso foi realizado, de 28 de julho a 17 de setembro de 2007, na Universidade Estadual Paulista (UNESP - Campus de Bauru). As universidades envolvidas na sua realização foram a UNESP - Faculdade de Arquitetura, Artes e Comunicação FAAC - Departamento de Arquitetura, Urbanismo e Paisagismo e a Universidade de São Paulo - Escola de Engenharia de São Carlos - EESC - Departamento de Transportes, e contou com apoio da Secretaria Nacional de Transporte e da Mobilidade Urbana - SEMOB (Ministério das Cidades). Os responsáveis pelo curso foram: os desenvolvedores deste sistema (a pesquisadora e o professor orientador desta tese). Os participantes utilizaram o Laboratório de Informática do Curso de Arquitetura e Urbanismo do Campus de Bauru, para realizarem suas avaliações.

Para facilitar a avaliação do sistema, os participantes foram agrupados em duas categorias: especialistas (Grupo I) e não-especialistas (Grupo II). O Grupo I contou com a participação de sete especialistas representados por técnicos da Prefeitura Municipal

\footnotetext{
${ }^{2}$ Segundo a proposta de Lei do Plano Diretor Participativo do Município de Bauru, a cidade deverá elaborar o Plano Diretor de Transporte e Mobilidade em um prazo de um ano a partir de sua aprovação, de forma participativa. (Art. 253; $\S 1^{\circ}$ e $2^{\circ}$ do PDM - Anexo 6).
} 
de Bauru, que atuam nos seguintes órgãos: EMDURB (Empresa Municipal de Desenvolvimento Urbano - responsável pelas áreas de transportes, sistema viário e limpeza pública) e SEPLAN (Secretaria de Planejamento - responsável pela área de planejamento urbano).

O Grupo II foi composto por oito pessoas, representantes da sociedade civil, eleitos como Delegados do Plano Diretor Participativo Municipal. Este segmento foi representado por membros do poder público municipal (representantes de outros órgãos municipais), associação de moradores e entidades de classe e uma universidade. É importante destacar que com relação ao segmento - associação de moradores (que pertenceriam também ao Grupo II), foram convidadas 25 pessoas escolhidas ao acaso, desde que representassem as cinco regiões da cidade; entretanto, apenas 3 atenderam ao convite. Uma das hipóteses para esta baixa participação pode ser o atual momento político que a população da cidade vivencia, em função da demora na aprovação do Plano Diretor Municipal pelo Poder Legislativo. Outro fator para a não participação pode ter sido a escolha do sábado de manhã para a realização do curso. Este horário, associado à relativa distância da Universidade em relação à região central e a falta de transporte público promovendo a ligação dos bairros ao centro e à Universidade (principalmente aos sábados) pode ter contribuído para o baixo índice de participação da comunidade.

O Quadro 7.2 apresenta a relação das atividades desenvolvidas no curso por semana e seu correspondente objetivo.

Quadro 7.2 - Relação das atividades desenvolvidas no Curso de Capacitação

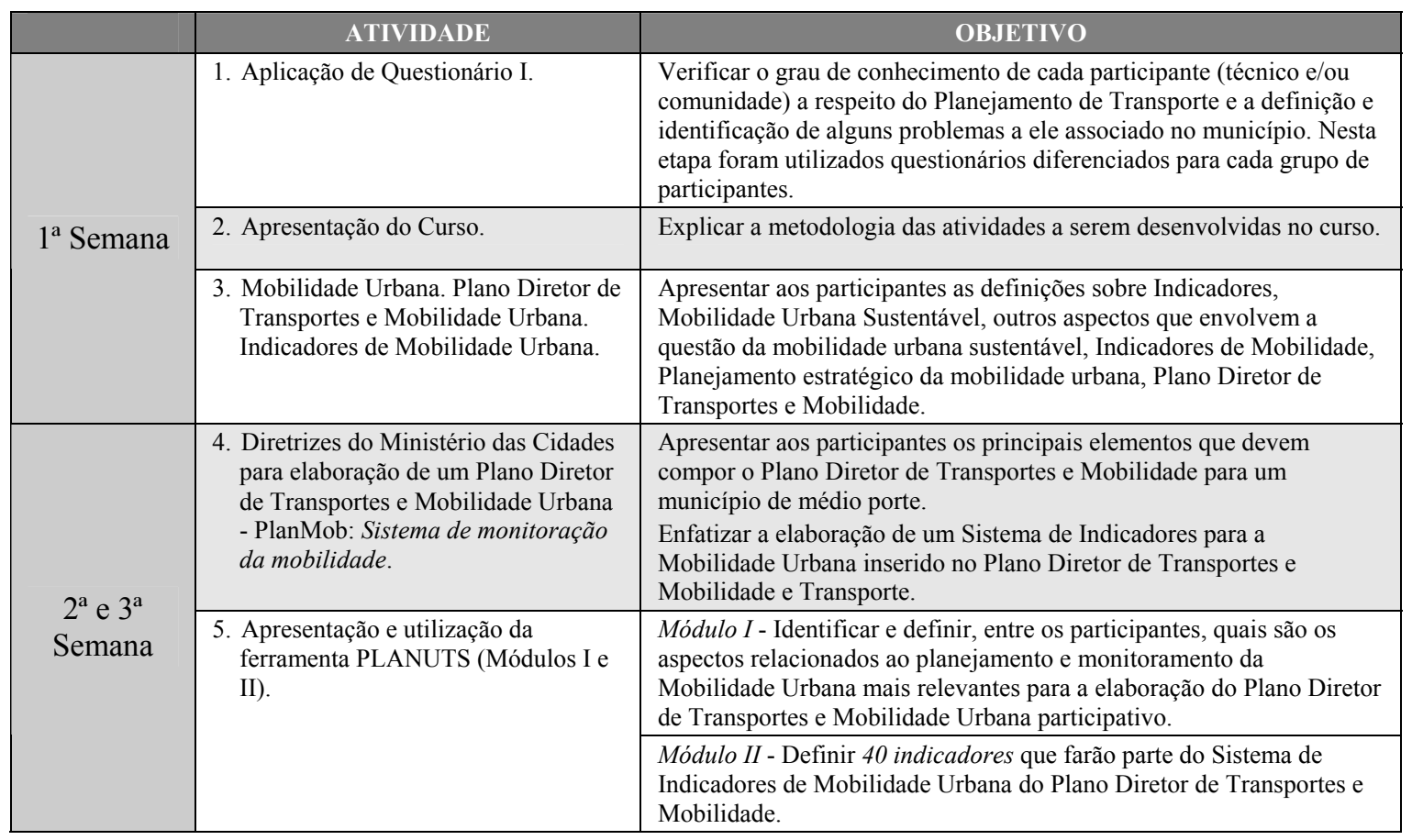


Quadro 7.2 - Relação das atividades desenvolvidas no Curso de Capacitação (continuação)

\begin{tabular}{|c|l|l|}
\hline \multirow{2}{*}{$4^{\text {a Semana }}$} & $\begin{array}{l}\text { 6. Apresentação e utilização da } \\
\text { ferramenta PLANUTS (Módulo III). }\end{array}$ & $\begin{array}{l}\text { Módulo III - Definir as prioridades de ação na cidade através da } \\
\text { definição de problemas e soluções referentes a cada indicador } \\
\text { avaliado, para posteriormente, realizar um diagnóstico por região da } \\
\text { cidade. }\end{array}$ \\
\hline \multirow{5}{*}{$5^{\text {a Semana }}$} & $\begin{array}{l}\text { 7. Aplicação de Questionário II. } \\
\text { 8. Apresentaçãa dos resultados obtidos } \\
\text { na utilização da ferramenta à questão mudança de comportamento dos participantes em } \\
\text { PLANUTS (referentes aos Módulos } \\
\text { I. II e III). }\end{array}$ & $\begin{array}{l}\text { Apresentar aos participantes os resultados da aplicação dos três } \\
\text { módulos por grupo de avaliadores e a definição do Sistema de } \\
\text { Indicadores definidos pelos participantes. }\end{array}$ \\
\cline { 2 - 3 } & 9. Encerramento do Curso. & \\
\hline
\end{tabular}

As etapas adotadas para a utilização do Sistema PLANUTS no Curso de Capacitação foram definidas de acordo com o Quadro 6.10 (apresentado no capítulo anterior). Este quadro define as etapas em que o sistema PLANUTS pode ser utilizado dentro do processo planejamento da mobilidade urbana participativa. Neste curso foram aplicadas as etapas 1, 3, 4, 8 e 10, conforme mostra o Quadro 7.3. Cada uma das etapas é detalhada posteriormente.

Quadro 7.3 - Etapas adotadas no curso de capacitação para a implantação do Sistema PLANUTS no Município de Bauru

\begin{tabular}{|c|c|c|c|}
\hline DESCRIÇÃOO & $\begin{array}{c}\text { Procedimento adotado no } \\
\text { Teste Piloto }\end{array}$ & $\begin{array}{l}\text { Ferramenta de } \\
\text { participação }\end{array}$ & Agentes \\
\hline $\begin{array}{l}\text { 1. Mobilização } \\
\text { Início do Processo }\end{array}$ & $\begin{array}{l}\text { Definição da Cidade para } \\
\text { implantar o sistema. }\end{array}$ & ----- & Coordenadores \\
\hline $\begin{array}{l}\text { 2. Identificação e análise prévia } \\
\text { Capacitação Técnica }\end{array}$ & \multicolumn{3}{|c|}{ Etapa não implementada. } \\
\hline 3. Pesquisas e levantamentos & \multirow[b]{2}{*}{$\begin{array}{l}\text { Construção do Site do Projeto. } \\
\text { Implantação dos dados nos } \\
\text { Módulos I e II. }\end{array}$} & \multirow[b]{2}{*}{ PRESENCIAL } & \multirow[b]{2}{*}{----} \\
\hline $\begin{array}{l}\text { 4. Instrumentalização da análise } \\
\text { Implantação dos Dados no SIG } \\
\text { Construção do Site do Projeto } \\
\text { Implantação dos Dados (Módulos I e II) }\end{array}$ & & & \\
\hline $\begin{array}{l}\text { 5. Consultas públicas } \\
\text { Discussão com os diversos bairros e segmentos da } \\
\text { sociedade }\end{array}$ & \multicolumn{3}{|c|}{ Etapa não implementada. } \\
\hline 6. Análise do problema - diagnóstico & \multicolumn{3}{|c|}{ Etapa não implementada. } \\
\hline 7. Análise dos problemas - Prognóstico & \multicolumn{3}{|c|}{ Etapa não implementada. } \\
\hline $\begin{array}{l}\text { 8. Audiências sobre o diagnóstico } \\
\text { Capacitação dos Delegados }\end{array}$ & \multirow{4}{*}{$\begin{array}{l}\text { Capacitação dos Delegados. } \\
\text { Avaliação dos Módulos I, II e III. }\end{array}$} & \multirow{4}{*}{ INTERNET } & \multirow{4}{*}{$\begin{array}{l}\text { Coordenadores } \\
\text { Especialistas e } \\
\text { não-especialistas }\end{array}$} \\
\hline Módulo I - Avaliação das Categorias e Temas & & & \\
\hline Módulo II - Escolha dos Indicadores & & & \\
\hline Módulo III - Definição das prioridades de ação & & & \\
\hline 9. Concepção de propostas & Avaliação dos dados & $\begin{array}{c}---- \\
\end{array}$ & ----- \\
\hline $\begin{array}{l}\text { 10. Análise de propostas e simulações } \\
\text { Implantação dos dados nos Módulos IV }\end{array}$ & \multicolumn{3}{|c|}{ Etapa não implementada. } \\
\hline 11. Audiências sobre as propostas & $\begin{array}{l}\text { Apresentação dos resultados do } \\
\text { Curso de Capacitação. }\end{array}$ & \multirow{2}{*}{ PRESENCIAL } & \multirow{2}{*}{$\begin{array}{l}\text { Coordenadores / } \\
\text { Especialistas e } \\
\text { não-especialistas }\end{array}$} \\
\hline Módulo IV - Definição dos cenários comparativos & $\begin{array}{l}\text { O módulo IV não foi } \\
\text { implementado }\end{array}$ & & \\
\hline 12. Conclusões sobre as propostas & \multicolumn{3}{|c|}{ Etapa não implementada. } \\
\hline 13. Detalhamento das propostas & \multicolumn{3}{|c|}{ Etapa não implementada. } \\
\hline 14. Consolidação do PlanMob & \multicolumn{3}{|c|}{ Etapa não implementada. } \\
\hline 15. Audiência sobre o PlanMob & \multicolumn{3}{|c|}{ Etapa não implementada. } \\
\hline 16. Institucionalização do PlanMob & \multicolumn{3}{|c|}{ Etapa não implementada. } \\
\hline $\begin{array}{l}\text { 17. Monitoramento do PlanMob } \\
\text { Monitoramento / Re-avaliação do problema }\end{array}$ & \multicolumn{3}{|c|}{ Etapa não implementada. } \\
\hline
\end{tabular}




\subsubsection{Detalhamento da implantação do sistema PLANUTS}

A seguir são descritas todas as etapas implementadas no curso de capacitação a partir das informações apresentadas no Quadro 7.3.

- Etapa 1 - Início do Processo (Mobilização) - Esta etapa iniciou-se com a definição do programa de atividades a ser desenvolvido no curso de capacitação pelos coordenadores, e na definição do público alvo.

- Os coordenadores foram representados pelos desenvolvedores do sistema: a pesquisadora e o orientador (desta pesquisa).

- Etapa 2 - Identificação e análise prévia - Capacitação Técnica da equipe que irá conduzir o Plano Diretor de Transportes e Mobilidade. Esta etapa não foi implementada, uma vez que os coordenadores responsáveis pela condução do processo de avaliação do sistema PLANUTS junto aos participantes foram os desenvolvedores do sistema.

- Etapas 3 e 4 - Pesquisas e levantamentos e Instrumentalização da análise - Dividiuse em duas fases distintas: i) representou a etapa de coleta de dados para a atualização da base de dados geográfica do município, e ii) construção do site do projeto e a inserção (alteração) dos dados do município no Módulo I.

- Construção da base geográfica digital - Representou a primeira etapa desta pesquisa, foi realizada em uma etapa anterior ao desenvolvimento do sistema PLANUTS.

- Construção do site do projeto - O site foi construído em linguagem "html" e "asp" para que as avaliações realizadas na internet pudessem ser armazenadas em um Banco de Dados que posteriormente pudesse compor o banco de dados do SIG.

- Conforme mostra o Quadro 7.4, a partir da página inicial do sistema o usuário pode acessar as seguintes informações: Bauru, Mobilidade Urbana, PLANUTS - os quatro Módulos de Avaliação da Mobilidade Urbana, Fale Conosco e Sites; sem restrição ou hierarquia de navegação. 
Quadro 7.4 - Descrição das páginas do sistema PLANUTS

\begin{tabular}{|c|c|}
\hline$\overline{\text { PÁGINAS }}$ & $\overline{\text { DESCRIÇÃO }}$ \\
\hline $\begin{array}{l}\text { PÁGINA } \\
\text { INICIAL }\end{array}$ & $\begin{array}{l}\text { - Apresentação e descrição preliminar do Sistema de Suporte à Decisão - PLANUTS. } \\
\text { - Informações disponíveis: } i \text { ) mensagem de aviso sobre o Módulo de Avaliação } \\
\text { disponível para acesso, } i i \text { ) definição da sigla PLANUTS, iii) definição do sistema, } i v \text { ) } \\
\text { explicação geral de acesso ao Módulo de Avaliação, e v) e-mail do projeto. } \\
\text { - O e-mail do projeto está implantado no servidor da Faculdade de Arquitetura, Artes e } \\
\text { Comunicação no Campus de Bauru da UNESP pela facilidade no armazenamento e } \\
\text { posterior análise das informações enviadas pela população. }\end{array}$ \\
\hline $\begin{array}{l}\text { MOBILIDADE } \\
\text { URBANA }\end{array}$ & $\begin{array}{l}\text { - Aborda os seguintes temas: } \\
\text { - Definição de Mobilidade Urbana. } \\
\text { - Medidas para uma política nacional de mobilidade urbana adotada pelo } \\
\text { Ministério das Cidades. } \\
\text { - Diretrizes para o planejamento municipal da mobilidade urbana. } \\
\text { - Diretrizes nacionais para elaboração de planos municipais de acessibilidade. }\end{array}$ \\
\hline BAURU & $\begin{array}{l}\text { - Informações sobre o Município de Bauru. } \\
\text { - Dados sobre o Perfil Municipal obtido através de consultas ao site do IBGE entre } \\
\text { outras fontes de informação. }\end{array}$ \\
\hline PLANUTS & $\begin{array}{l}\text { - Página principal do sistema. } \\
\text { - Informações disponíveis: definição conceitual do Sistema PLANUTS e os links para } \\
\text { acessar os quatro Módulos de Avaliação da Mobilidade Urbana. }\end{array}$ \\
\hline $\begin{array}{c}\text { FALE } \\
\text { CONOSCO }\end{array}$ & $\begin{array}{l}\text { - Responsável pela troca de informações entre a população e a equipe técnica } \\
\text { responsável pelo PLANUTS. } \\
\text { - As informações serão encaminhadas diretamente para o e-mail do PLANUTS. }\end{array}$ \\
\hline SITES & $\begin{array}{l}\text { - Disponibiliza aos usuários do sistema alguns links de órgãos municipais, estaduais e } \\
\text { federais ou não governamentais. } \\
\text { - Endereços: Prefeitura Municipal de Bauru; EMDURB; DENATRAN; IBGE; etc. }\end{array}$ \\
\hline
\end{tabular}

- O acesso ao site do sistema PLANUTS pode ser realizado de duas formas: através de domínio próprio do sistema PLANUTS http://www.planuts.com.br, ou através de um link disponível na página principal da Faculdade de Arquitetura, Artes e Comunicação da UNESP ${ }^{3}$. O sistema também está disponível através do site do Departamento de Transportes da Escola de Engenharia de São Carlos da USP ${ }^{4}$. O sistema está hospedado em um servidor particular em função da exigência de armazenamento dos dados requerida pelo sistema.

- Como o sistema PLANUTS foi construído para o município de Bauru, não houve a necessidade de alteração do Módulo I.

- Etapa 5 - Consultas públicas - Esta etapa não foi implementada no Curso de Capacitação.

- Etapa 6 - Análise do problema - diagnóstico - Esta etapa não foi implementada no Curso de Capacitação, pois não havia tempo suficiente para este tipo de análise, uma

\footnotetext{
${ }^{3}$ http://www.faac.unesp.br - link randômico.

${ }^{4} \underline{\mathrm{http}: / / \text { www.stt.eesc.usp.br/renata/httpdocs/layout/ModuloI/home.htm }}$
} 
vez que o objetivo central era a utilização da ferramenta computacional proposta. Ainda assim, com base nas respostas dos questionários aplicados na fase anterior, foi possível realizar um breve diagnóstico sobre a questão da mobilidade no município de Bauru. Os resultados destes questionários são apresentados no item 7.3 deste capítulo.

- Etapa 7 - Análise dos problemas - Prognóstico - Esta etapa não foi implementada no Curso de Capacitação.

- Etapa 8 - Audiências sobre o diagnóstico - Nesta etapa deu-se início ao curso de capacitação. O processo iniciou com a divulgação do curso para o grupo de participantes definidos na Etapa 1. Os convites aos participantes foram realizados através de e-mail e telefone (para os especialistas e membros do Grupo Gestor) e através de cartas (para o grupo dos não-especialistas).

\section{- Atividades desenvolvidas na $1^{a}$ Semana do Curso de Capacitação:}

- Aplicação de Questionário - Inicialmente foi aplicado um questionário que permitiu verificar o grau de conhecimento de cada participante (técnico e/ou comunidade) a respeito dos seguintes temas: Mobilidade e Planejamento de Transporte, e a definição e identificação de alguns problemas a eles associados no município de Bauru. Nesta etapa foram utilizados questionários diferenciados para cada grupo de participantes.

- Apresentação do Curso - Posteriormente foi realizada uma explicação das atividades e da metodologia a serem desenvolvidas durante o curso.

- Mobilidade Urbana. Plano Diretor de Transportes e Mobilidade Urbana. Indicadores de Mobilidade Urbana - A última atividade deste dia referiu-se a uma palestra [proferida pelo Prof. Dr. Antônio Nélson Rodrigues da Silva (Departamento de Transportes da Escola de Engenharia de São Carlos - ESSC - USP)], cujo objetivo era homogeneizar o conhecimento dos participantes (especialistas e não especialistas) acerca das principais questões que envolvem direta ou indiretamente o tema mobilidade. Foram apresentados aos participantes algumas definições sobre: Indicadores, Mobilidade Urbana Sustentável, Indicadores de Mobilidade, Planejamento Estratégico da Mobilidade Urbana e Plano Diretor de Transportes e Mobilidade. 
- Atividades desenvolvidas nas $2^{\mathrm{a}}$ e $3^{\mathrm{a}}$ Semanas do Curso de Capacitação:

- Observação: Com o objetivo de facilitar a utilização do Laboratório de Informática, esta etapa foi realizada em dias alternados para o grupo dos técnicos e para o grupo dos delegados representantes do Plano Diretor.

- Diretrizes do Ministério das Cidades para elaboração de um Plano Diretor de Transportes e Mobilidade Urbana - PlanMob: Sistema de monitoração da mobilidade - Foi apresentada uma palestra aos participantes sobre os principais elementos que devem estar presentes na elaboração do Plano Diretor de Transportes e Mobilidade para um município de médio porte. Foi dada ênfase à importância da elaboração de um Sistema de Indicadores para a melhoria da Mobilidade Urbana para os municípios, bem como aos problemas urbanos resultantes da falta de um Plano Diretor de Transportes e Mobilidade.

- Apresentação e utilização da ferramenta PLANUTS (Módulos I e II) - Posteriormente foi realizada uma apresentação do funcionamento do sistema proposto, Módulos I e II, e suas respectivas importâncias no processo de definição dos indicadores de mobilidade para o município.

- O processo de avaliação foi realizado adotando-se o seguinte procedimento: i) Cadastro dos usuários no sistema, através da utilização do Módulo Administrativo; ii) Avaliação do Módulo I; e iii) Avaliação do Módulo II. Uma vez realizado o cadastro de cada usuário no sistema, foi solicitado que cada participante iniciasse o processo de votação. $\mathrm{O}$ processo de avaliação nos Módulos I e II foi realizado de forma individual. Durante o processo de votação foi solicitado aos participantes para não se comunicarem, para que o processo ocorresse de forma individual. Em função das avaliações estarem ocorrendo em um mesmo horário (período), foi possível verificar possíveis problemas, talvez pelo acesso de múltiplos usuários ao mesmo tempo no sistema.

- Avaliação do Módulo I - esta avaliação permitiu definir quais são as Categorias e Temas mais importantes para o planejamento da mobilidade no município.

- Após o término da avaliação do Módulo I, os participantes realizaram a avaliação do Módulo II. 
- Avaliação do Módulo II - o resultado desta avaliação permitiu definir os indicadores que poderão compor um Sistema de Indicadores de Mobilidade para a cidade de Bauru.

- Os resultados de cada avaliador foram armazenados individualmente na parte administrativa do sistema. Estas informações ficaram disponíveis, podendo ser acessadas através da internet pelos administradores do sistema para o acompanhamento das avaliações, como será apresentado no item 7.3 deste capítulo.

- Dificuldades encontradas pelos participantes:

- Alguns dos participantes sugeriram a realização de um treinamento anterior só para manipulação de cada um dos módulos avaliados, para maior familiaridade com a ferramenta e com as definições que envolvem o Sistema PLANUTS. Esta sugestão referiu-se principalmente ao Módulo I.

- Em função da configuração dos computadores utilizados, alguns participantes tiveram problemas para visualizar as imagens (vídeos) nos Módulos I e II. Este problema ocorreu em função da falta de um aplicativo, em alguns computadores, que permite a visualização de imagens.

- Outro problema que prejudicou a visualização das animações está associado à configuração dos computadores. É necessária a utilização de um equipamento com uma melhor configuração de hardware, o que irá melhorar o desempenho do sistema.

- Etapa intermediária I - Sistematização das avaliações realizadas pelos especialistas e não-especialistas nos Módulos I e II - Esta fase foi realizada pelos coordenadores, sendo dividida nas seguintes etapas: i) aplicação da Análise Multicritério (resultados do Módulo I); ii) somatória dos indicadores mais votados no Módulo II; e iii) construção do Módulo III a partir dos resultados obtidos do Módulo II.

- Os resultados da aplicação da Análise Multicritério no Módulo I e a lista dos indicadores do Módulo II são apresentados no item 7.3 deste capítulo. 
- A construção do Módulo III foi realizada em função dos Indicadores mais votados no Módulo II. Esta etapa é o que efetivamente diferencia a aplicação do Sistema PLANUTS em cidades distintas, uma vez que os indicadores mais votados no módulo anterior poderão ser diferentes para cada cidade que se valer desta ferramenta.

- No Módulo III foram inseridas as seguintes informações: os indicadores mais votados e seus respectivos Temas; as definições, os áudios e os vídeos correspondentes a cada indicador; a inclusão de alguns problemas e soluções associados a cada indicador listado; a inclusão do nome dos bairros da cidade divididos por região - neste item, foram incluídos bairros que congregam uma micro-região da cidade, ou seja, são conhecidos por comporem a reunião de 3 a 4 bairros - esta definição permitiu definir um problema de forma mais abrangente do que apenas identificá-lo em um único bairro. Estes dados foram inseridos na área administrativa do sistema (Módulo ADM - através da internet) pelo administrador do sistema (ver Capítulo 6).

- Observação: Os resultados das avaliações, dos Módulos I e II, foram sistematizados sob duas formas: por grupo e geral. Para facilitar a análise dos dados, os participantes foram agrupados em função de suas atividades profissionais: o Grupo I correspondeu aos participantes que trabalham nos seguinte órgãos municipais: SEPLAN e EMDURB, e o Grupo II correspondeu aos demais participantes. As análises dos resultados referentes aos Módulos I e II encontram-se detalhadas na Seção 7.3 desta pesquisa.

\section{- Atividades desenvolvidas na $4^{\text {a }}$ Semana do Curso de Capacitação -} Continuação da etapa de capacitação dos participantes do Curso - Avaliação da Mobilidade no Sistema PLANUTS. A responsável pelo desenvolvimento desta etapa no curso foi a pesquisadora.

- Observação: Como o número total de participantes foi menor que o esperado, todos os participantes (técnicos e os delegados representantes do Plano Diretor) foram convidados para realizarem as avaliações no mesmo dia e horário no Laboratório de Informática. 
- Apresentação e utilização da ferramenta PLANUTS (Módulo III) -. Inicialmente foi apresentado o objetivo da avaliação deste módulo, a etapa na qual estes resultados podem ser aplicados em um processo de elaboração do Plano Diretor de Transportes e Mobilidade, sendo posteriormente apresentado o funcionamento do Módulo III.

- Avaliação do Módulo III - o resultado desta avaliação permitiu definir para cada indicador uma lista de prováveis problemas e soluções, bem como a localização dos problemas mais importantes por região da cidade.

- A análise dos resultados referentes a este Módulo é apresentada na Seção 7.3 .

- Dificuldades encontradas pelos participantes:

- Um dos problemas detectados na avaliação do Módulo III está relacionado com a definição de um horário para as avaliações - alguns avaliadores ficaram "cansados" para finalizar todo o processo de avaliação em um único período. Isto pode ter prejudicado nas respostas (foram verificadas muitas respostas em branco) de alguns itens. Como o processo de avaliação deste módulo é muito extenso, a possibilidade de flexibilidade de horário no processo de avaliação poderá melhorar os resultados finais em outras situações.

- Em função da configuração dos computadores utilizados, alguns participantes tiveram problemas para visualizar as imagens ou som.

- $\quad$ Sugestão: Alguns participantes sugeriram a realização de um treinamento anterior só para manipulação deste módulo.

- Embora todos os participantes (especialistas e não-especialistas) tenham realizado a avaliação deste módulo, sugere-se que, para a aplicação desta ferramenta em um processo mais ampliado - com um número maior de participantes, seja realizado um debate sobre cada etapa de avaliação do módulo, principalmente com relação à definição de propostas e soluções para cada indicador. Talvez, em alguns casos, seja necessário realizar um estudo sobre a possibilidade de restringir a utilização deste módulo, utilizando-o de forma consensual e não individual, pois alguns delegados 
representantes da população podem vir a ter maiores dificuldades em um processo de avaliação individual do módulo.

- Etapa 9 - Concepção de propostas - Nesta fase, realizada pelos coordenadores, os dados coletados no Módulo anterior foram sistematizados, utilizando-se de Técnicas de Análise Multicritério. Pôde-se definir quais problemas relacionados à mobilidade do município são mais importantes e mais urgentes (ver seção 7.3). Em um processo de elaboração do Plano Diretor de Transportes e Mobilidade, após estas análises, deverão ser definidas diretrizes que permitirão solucionar alguns dos problemas identificados na fase de diagnóstico.

- Etapa 10 - Análise de propostas e simulações - Etapa não implementada no curso de capacitação. Nesta fase deveriam ser analisadas as propostas apresentadas no módulo anterior e realizadas algumas simulações.

- Avaliação do Módulo IV - O Módulo IV não foi desenvolvido.

- Etapa 11 - Audiências sobre as propostas - última etapa do Curso de Capacitação Avaliação da Mobilidade no Sistema PLANUTS.

- Atividades desenvolvidas na $5^{\text {a }}$ Semana do Curso de Capacitação Encerramento do Curso.

- Aplicação de Questionário - foi realizada a aplicação de um segundo questionário para tentar identificar se, com o processo de avaliação do sistema PLANUTS, houve alguma mudança na forma de entender a questão da mobilidade urbana e seus problemas na cidade. Os questionários foram iguais para os dois grupos de avaliadores.

- A política de capacitação da Secretaria Nacional de Mobilidade SeMob (Ministério das Cidades) e Plano Diretor de Transportes e Mobilidade Urbana - Palestra proferida pela Profa. Dra. Márcia Helena Macedo, que é Gerente de Desenvolvimento da Gestão, da Secretaria Nacional de Transporte e Mobilidade Urbana (SeMob), do Ministério das Cidades, com o objetivo de apresentar a política de capacitação do Ministério e as diretrizes da SeMob para a elaboração do Plano Diretor de Transportes e Mobilidade. 


\section{- Apresentação dos resultados obtidos na utilização da ferramenta} PLANUTS (Módulos I, II e III) - Foram apresentados os resultados finais da aplicação dos três Módulos de Avaliação da Mobilidade Urbana e o Sistema de Indicadores definidos no Curso de Capacitação.

- Etapas 12 a 17 - não foram operacionalizadas no curso, uma vez que envolvem outros aspectos do Plano Diretor de Transportes e Mobilidade.

\subsubsection{Resultado da Aplicação do Sistema PLANUTS - Teste Piloto}

A implantação do sistema mostrou que é possível construir uma ferramenta computacional (que aqui recebeu o nome PLANUTS) que possa auxiliar no planejamento da mobilidade urbana e que seja capaz de incorporar a visão e a participação de múltiplos agentes, sejam eles especialistas ou não. Os participantes, técnicos que trabalham diariamente com as questões de planejamento urbano e de transportes, professores universitários e demais profissionais representantes da sociedade, puderam ter uma visão mais abrangente dos aspectos que envolvem a questão da Mobilidade Urbana sob a ótica da sustentabilidade em um município de médio porte.

A interface construída para o Sistema PLANUTS possibilitou que os avaliadores não tivessem dificuldade para votar e visualizar os resultados em cada módulo de avaliação. Este sistema foi considerado de fácil utilização, embora muitos participantes tenham apontado a necessidade da realização de um curso de capacitação para sanar eventuais dúvidas que os participantes possam apresentar.

A aplicação do sistema permitiu comprovar os resultados esperados na avaliação de cada Módulo de Avaliação da Mobilidade Urbana; ou seja, os resultados obtidos atingiram o objetivo principal do sistema, que era definir um elenco de indicadores de mobilidade urbana que poderão compor um Sistema de Indicadores de Mobilidade para o Plano Diretor de Transporte e Mobilidade Municipal. Outros resultados importantes para este processo foram obtidos: i) ampliação do conhecimento dos participantes sobre o tema Mobilidade Urbana, ii) capacitação dos participantes para a utilização de uma ferramenta computacional que permite a definição de indicadores de mobilidade urbana, indicando seus respectivos problemas e soluções de forma participativa e não presencial - Sistema PLANUTS (Módulos de Avaliação da Mobilidade Urbana I, II e III), iii) definição de um sistema de indicadores (dos 94 indicadores que compõe o Módulo II, segundo a avaliação dos especialistas e não-especialistas, foram definidos 43 Indicadores finais que poderão 
fazer parte de um Sistema de Indicadores para Avaliação e Monitoramento da Mobilidade Urbana no Plano Diretor de Transportes e Mobilidade do município), iv) definição dos indicadores que atualmente são considerados mais importantes para o município de Bauru e v) definição dos indicadores mais urgentes, ou seja, problemas que necessitam de um menor prazo para a sua solução.

Além destes resultados, a aplicação do sistema também permitiu identificar o grau de homogeneidade observado no resultado final do processo de avaliação da mobilidade entre o grupo dos especialistas e não-especialistas nos três módulos de avaliação.

Mediante os resultados obtidos com a aplicação do sistema PLANUTS e os problemas encontrados durante este processo pode-se afirmar que o resultado final obtido na avaliação de cada módulo, bem como a melhoria no desempenho do sistema no processo de definição de Indicadores depende das seguintes condições: i) computacional; ii) organizacional e iii) conhecimento pessoal (Yigitcanlar, 2001).

O Quadro 7.5 apresenta cada um dos possíveis problemas associados a estas três condições que podem contribuir para a melhoria dos resultados obtidos da ferramenta PLANUTS.

Quadro 7.5 - Pré-requisitos que podem comprometer o desempenho do Sistema

\begin{tabular}{|l|l|}
\hline \multicolumn{1}{|c|}{ PRÉ-REQUISITO } & \multicolumn{1}{c|}{ PLANUTS } \\
\hline TÉCNICO - COMPUTACIONAL & \\
\hline $\begin{array}{l}\text { Equipamento } \\
\text { - Equipamento computacional adequado }\end{array}$ & $\begin{array}{l}\text { Quanto aos pré-requisitos computacionais há a necessidade de } \\
\text { um computador (que poderá ter o status de servidor) que } \\
\text { suporte as informações coletadas e que esteja conectado à } \\
\text { internet. }\end{array}$ \\
\hline $\begin{array}{l}\text { Dados } \\
\text { - Disponibilidade dos dados }\end{array}$ & $\begin{array}{l}\text { Com relação à equipe técnica, esta deverá ser treinada para a } \\
\text { coleta das informações a serem implantadas no sistema, bem } \\
\text { como para extrair e manipular os dados das avaliações } \\
\text { realizadas pela comunidade. } \\
\text { Como o sistema prevê a utilização de software SIG, há a } \\
\text { necessidade que a equipe técnica tenha conhecimento nesta } \\
\text { área para manipulação das informações no software; caso } \\
\text { contrário sugere-se que o município firme parcerias com } \\
\text { Universidades da região para a capacitação dos técnicos locais. }\end{array}$ \\
\hline $\begin{array}{l}\text { ORGANIZACIONAL } \\
\text { - Coordenação e planejamento adequados } \\
\text { a cada etapa e público alvo. }\end{array}$ & $\begin{array}{l}\text { Treinamento da equipe técnica. } \\
\text { - Gerenciamento e treinamento da equipe } \\
\text { técnica. }\end{array}$ \\
$\begin{array}{l}\text { Desenvolvimento da base de dados } \\
\text { local. }\end{array}$ & $\begin{array}{l}\text { Treinamento da equipe técnica que trabalhará no } \\
\text { gerenciamento das informações. } \\
\text { (dados) coletadas. }\end{array}$ \\
\hline
\end{tabular}


Quadro 7.5 - Pré-requisitos que podem comprometer o desempenho do Sistema PLANUTS (continuação)

\begin{tabular}{|l|l|}
\hline PESSOAL & \\
\hline $\begin{array}{l}\text { Conhecimento computacional } \\
\text { - Conhecimento sobre a utilização do } \\
\text { computador. }\end{array}$ & $\begin{array}{l}\text { Grau de familiaridade dos usuários com a ferramenta } \\
\text { computacional; uma vez que a população brasileira ainda é } \\
\text { muito heterogênea quanto à manipulação de hardware e } \\
\text { software. }\end{array}$ \\
\hline $\begin{array}{l}\text { Outros conhecimentos } \\
\text { - Entender as informações (dados). }\end{array}$ & $\begin{array}{l}\text { Grau de familiaridade dos usuários com relação às questões } \\
\text { - Cone envolvem o Tema Mobilidade Urbana (Plano Diretor de } \\
\text { Transportes e Mobilidade). }\end{array}$ \\
\hline
\end{tabular}

Fonte: adaptado de Kellogg (1999) apud Yigitcanlar (2001).

No próximo capítulo serão apresentados os resultados e as análises da aplicação do sistema PLANUTS no município de Bauru com base na metodologia apresentada no Capítulo 5.

${ }^{5}$ Kellogg, W. (1999) Community-Based Organizations and Neighborhood Environmental Problem Solving: A Framework for Adoption of Information Technologies. Journal of Environmental Planning and Management 42(4). p. 445-469. 


\section{APRESENTAÇÃO E ANÁLISE DOS RESULTADOS}

Neste capítulo são descritos e analisados os resultados obtidos na implantação do sistema PLANUTS junto a um grupo de especialistas e não-especialistas pertencentes ao município de Bauru. Inicialmente são analisados os dados coletados através das avaliações individuais obtidos a partir da aplicação dos três Módulos de Avaliação da Mobilidade Urbana (Módulos I, II e III). Posteriormente, foram analisados os questionários que permitiram verificar se houve uma mudança (ou ampliação) na percepção de cada avaliador com relação ao tema Mobilidade Urbana. Nesta seção também é apresentada a lista final de indicadores, definidos pelos avaliadores, para compor um Sistema de Indicadores de Mobilidade Urbana junto ao Plano Diretor de Transportes e Mobilidade para o município de Bauru.

\subsection{Avaliações referentes ao Módulo I}

Como foi apresentado na segunda parte do capítulo anterior (item 7.2) os dados referentes as avaliações do grupo dos especialistas e não-especialistas foram armazenados na área administrativa do sistema PLANUTS.

A análise dos resultados foi realizada de forma individual e agregada, ou seja, por grupo de avaliação e entre os dois grupos. Estas avaliações permitiram verificar se há divergências entre os técnicos e os demais participantes.

O processo de análise dos resultados obtidos a partir dos dois grupos de avaliação iniciou-se com o cálculo dos pesos médios de cada critério, por avaliador, para as Categorias e Temas relacionados à Mobilidade Urbana. As Tabelas 8.1 e 8.2 apresentam, respectivamente, os resultados dos pesos médios individuais, a média global e o desvio padrão para as Categorias e Temas avaliados.

As informações presentes nas Tabelas 8.1 e 8.2 permitem identificar os resultados obtidos nas avaliações de cada participante através de seu respectivo peso para as 
categorias e temas avaliados, bem como a definição dos pesos que se encontram dentro de um intervalo onde os valores encontram-se próximos a média (há menor dispersão dos pesos).

Tabela 8.1 - Pesos por Categoria e por grupo de avaliação

\begin{tabular}{|c|c|c|c|c|c|c|}
\hline \multicolumn{7}{|c|}{ CATEGORIAS } \\
\hline \multicolumn{2}{|c|}{ AVALIADORES } & $\begin{array}{l}\text { Meio ambiente e } \\
\text { Transportes }\end{array}$ & $\begin{array}{c}\text { Gestão dos } \\
\text { Transportes }\end{array}$ & $\begin{array}{l}\text { Infra-estrutura } \\
\text { dos Transportes }\end{array}$ & $\begin{array}{l}\text { Planejamento dos } \\
\text { Transportes }\end{array}$ & $\begin{array}{c}\text { Aspectos } \\
\text { Socioeconômicos }\end{array}$ \\
\hline \multirow{7}{*}{ GRUPO I } & 1 & 0,190 & 0,190 & 0,238 & 0,190 & 0,190 \\
\hline & 2 & 0,200 & 0,150 & 0,150 & 0,250 & $\mathbf{0 , 2 5 0}$ \\
\hline & 3 & 0,211 & 0,158 & $\mathbf{0 , 1 5 8}$ & 0,263 & 0,211 \\
\hline & 4 & 0,190 & 0,190 & $\mathbf{0 , 2 3 8}$ & 0,238 & 0,143 \\
\hline & 5 & 0,217 & 0,217 & 0,174 & 0,217 & 0,174 \\
\hline & 6 & 0,200 & 0,200 & $\mathbf{0 , 2 0 0}$ & $\mathbf{0 , 2 0 0}$ & $\mathbf{0 , 2 0 0}$ \\
\hline & 7 & 0,143 & $\mathbf{0 , 2 3 8}$ & $\mathbf{0 , 2 3 8}$ & $\mathbf{0 , 2 3 8}$ & 0,143 \\
\hline \multirow{8}{*}{ GRUPO II } & 8 & 0,208 & 0,208 & 0,167 & 0,208 & 0,208 \\
\hline & 9 & $\mathbf{0 , 2 0 0}$ & $\mathbf{0 , 2 0 0}$ & $\mathbf{0 , 2 0 0}$ & 0,200 & $\mathbf{0 , 2 0 0}$ \\
\hline & 10 & $\mathbf{0 , 2 1 7}$ & 0,174 & 0,174 & $\mathbf{0 , 2 1 7}$ & $\mathbf{0 , 2 1 7}$ \\
\hline & 11 & 0,238 & 0,143 & 0,143 & 0,238 & 0,238 \\
\hline & 12 & 0,158 & 0,211 & 0,158 & 0,211 & 0,263 \\
\hline & 13 & 0,174 & 0,174 & $\mathbf{0 , 2 1 7}$ & 0,217 & $\mathbf{0 , 2 1 7}$ \\
\hline & 14 & $\mathbf{0 , 2 3 8}$ & 0,143 & $\mathbf{0 , 2 3 8}$ & 0,190 & 0,190 \\
\hline & 15 & 0,118 & 0,235 & 0,176 & 0,176 & 0,294 \\
\hline \multicolumn{2}{|l|}{ MÉDIA } & 0,194 & 0,189 & 0,191 & $\mathbf{0 , 2 1 7}$ & $\mathbf{0 , 2 0 9}$ \\
\hline \multicolumn{2}{|c|}{ DESVIO PADRÃO } & 0,034 & 0,031 & $\mathbf{0 , 0 3 5}$ & 0,024 & 0,041 \\
\hline
\end{tabular}

Este intervalo corresponde a uma faixa de desvio padrão cujo limite inferior representa a média dos pesos por categoria menos o desvio padrão e o limite superior corresponde a média dos pesos mais o desvio padrão. As células em vermelho representam os critérios que estão abaixo deste limite e os valores em amarelo àqueles que se encontram acima deste limite; os demais valores se encontram dentro do intervalo calculado.

Através dos resultados apresentados na Tabela 8.1, pode-se verificar um equilíbrio entre as respostas dos avaliadores especialistas e não-especialistas. No Grupo I $74,3 \%$ dos critérios encontra-se na faixa onde há pouca dispersão dos valores referentes as categorias calculadas e $25,7 \%$ estão fora desta faixa (sendo que destes $14,3 \%$ estão abaixo do limite inferior e 11,4\% acima do limite superior). O segundo Grupo apresenta $80 \%$ dos critérios dentro do intervalo entre o limite superior e inferior, enquanto que $20 \%$ das respostas estão fora deste intervalo (sendo o mesmo percentual para os critérios acima do limite superior e abaixo do limite inferior; $10 \%$, respectivamente). Tanto no grupo dos especialistas quanto dos não-especialistas pode-se observar que para os participantes [avaliadores identificados pelos números 5, 6, 8, 9, e 10] todos os resultados encontram-se dentro do intervalo entre o limite superior e inferior. Isto reflete uma coesão de definição do grau de importância destes critérios para os dois grupos. Entretanto, ao analisar especificamente os critérios que se encontram acima e abaixo dessa faixa não é possível 
afirmar que há uma correspondência na definição do grau de importância destes critérios entre os demais avaliadores destes grupos.

A Figura 8.1 exemplifica a faixa calculada para a categoria Aspectos Socioeconômicos dos Transportes para cada avaliador.

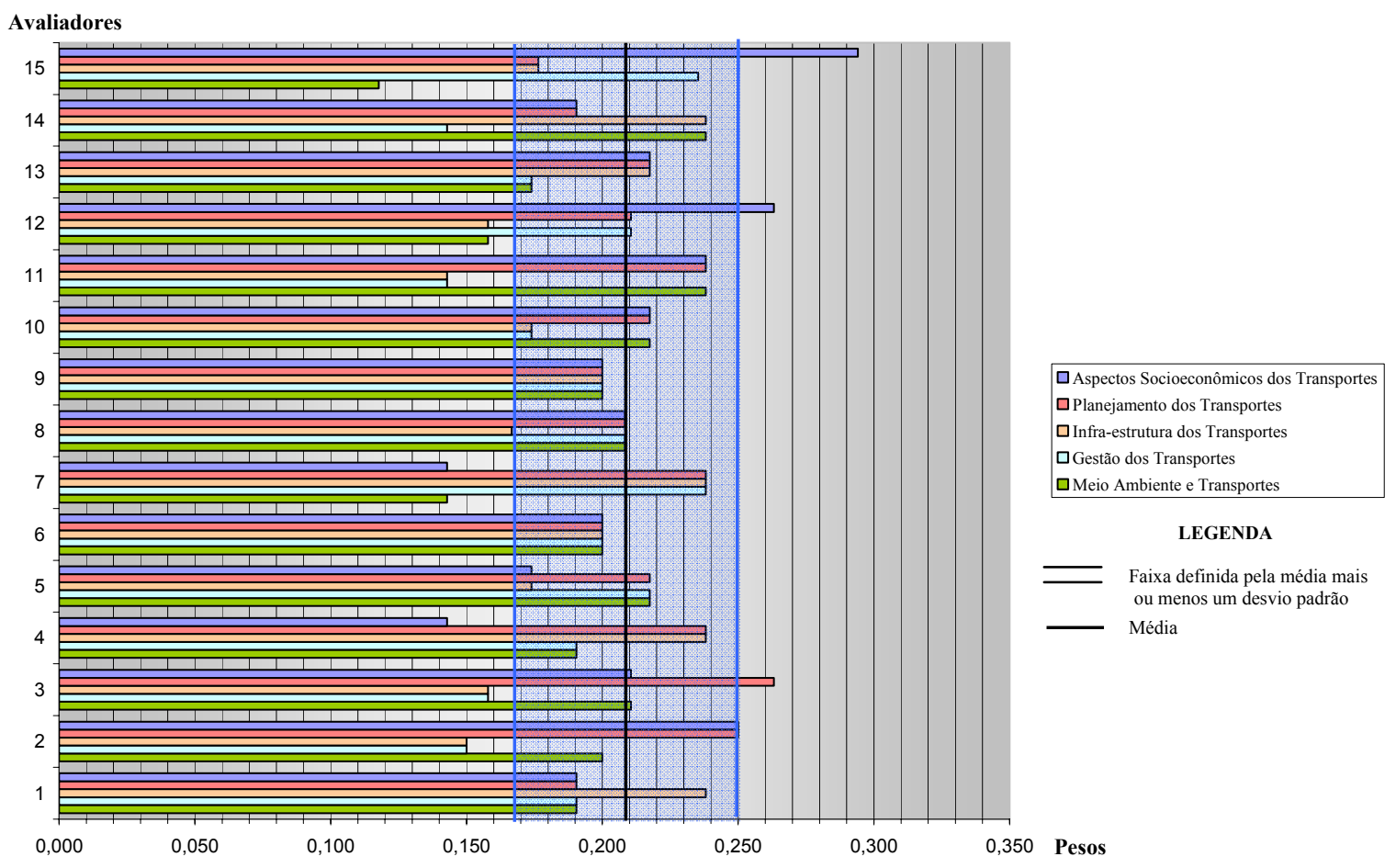

Figura 8.1 - Visualização dos resultados dos pesos das Categorias, com exemplo para a Categoria Aspectos Socioeconomicos do Transportes, da faixa que representa uma menor dispersão (entre um limite inferior e outro superior, definidos pela média menos e mais um desvio padrão, respectivamente) 
Tabela 8.2 - Pesos por Tema e por grupo de avaliação

\begin{tabular}{|c|c|c|c|c|c|c|c|c|c|c|c|c|c|c|c|c|c|c|c|c|c|}
\hline \multicolumn{22}{|c|}{ TEMAS } \\
\hline & & T1 & T2 & T3 & T4 & T5 & T6 & $\mathrm{T7}$ & T8 & T9 & T10 & T11 & T12 & T13 & T14 & T15 & T16 & T17 & T18 & T19 & T20 \\
\hline \multirow{6}{*}{ 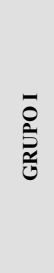 } & 1 & 0,231 & 0,231 & 0,308 & 0,231 & 0,313 & 0,188 & 0,313 & 0,188 & 0,231 & 0,308 & 0,231 & 0,231 & 0,250 & 0,250 & 0,250 & 0,250 & 0,313 & 0,188 & 0,250 & 0,250 \\
\hline & 2 & 0,133 & 0,333 & 0,267 & 0,267 & 0,176 & 0,294 & 0,294 & 0,235 & 0,176 & 0,235 & 0,294 & 0,294 & 0,250 & 0,250 & 0,313 & 0,188 & 0,235 & 0,294 & 0,235 & 0,235 \\
\hline & 4 & 0,231 & 0,308 & 0,231 & 0,231 & 0,250 & 0,250 & 0,313 & 0,188 & 0,222 & 0,278 & 0,222 & 0,278 & 0,278 & 0,278 & 0,222 & 0,222 & 0,250 & 0,250 & 0,250 & 0,250 \\
\hline & 5 & 0,286 & 0,357 & 0,214 & 0,143 & 0,250 & 0,313 & 0,313 & 0,125 & 0,263 & 0,263 & 0,211 & 0,263 & 0,250 & 0,250 & 0,250 & 0,250 & 0,250 & 0,313 & 0,250 & 0,188 \\
\hline & 6 & 0,385 & 0,385 & 0,154 & 0,077 & 0,357 & 0,143 & 0,357 & 0,143 & 0,091 & 0,273 & 0,364 & 0,273 & 0,294 & 0,294 & 0,235 & 0,176 & 0,182 & 0,182 & 0,273 & 0,364 \\
\hline & 7 & 231 & 0,308 & 0,231 & 0,231 & 0,222 & 0,278 & 0,278 & 0,222 & 0,211 & 0,263 & 0,263 & 0,263 & 0,313 & 0,188 & 0,250 & 0,250 & 0,133 & 0,200 & 0,333 & 0,333 \\
\hline \multirow{5}{*}{ 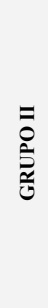 } & 8 & 0,556 & 0,222 & 0,111 & 0,111 & 0,250 & 0,250 & 0,250 & 0,250 & 0,250 & 0,250 & 0,250 & 0,250 & 0,250 & 0,250 & 0,250 & 0,250 & 0,143 & 0,214 & 0,286 & 0,357 \\
\hline & 12 & 0,214 & 0,286 & 0,357 & 0,143 & 0,333 & 0,167 & 0,417 & 0,083 & 0,083 & 0,417 & 0,167 & 0,333 & 0,133 & 0,333 & 0,267 & 0,267 & 0,313 & 0,313 & 0,063 & 0,313 \\
\hline & 13 & 0,250 & 0,250 & 0,250 & 0,250 & 0,278 & 0,167 & 0,278 & 0,278 & 0,214 & 0,286 & 0,286 & 0,214 & 0,313 & 0,313 & 0,188 & 0,188 & 0,200 & 0,267 & 0,200 & 0,333 \\
\hline & 14 & 0,235 & 0,294 & 0,294 & 0,176 & 0,267 & 0,133 & 0,333 & 0,267 & 0,211 & 0,263 & 0,263 & 0,263 & 0,294 & 0,294 & 0,176 & 0,235 & 0,263 & 0,211 & 0,263 & 0,263 \\
\hline & 15 & 0,200 & 0,267 & 0,267 & 0,267 & 0,308 & 0,154 & 0,385 & 0,154 & 0,133 & 0,333 & 0,2 & 0,267 & 0,313 & 0,313 & 0,188 & 0,188 & 0,250 & 0,188 & 0,250 & 0,313 \\
\hline \multicolumn{2}{|c|}{ MÉDIA } & 0,274 & 0,298 & 0,234 & 0,194 & 0,271 & 0,228 & 0,313 & 189 & 0,194 & 0,284 & 0,255 & 0,268 & 0,279 & 0,254 & 0,241 & 226 & 0,249 & 0,234 & 0,233 & 0,283 \\
\hline \multicolumn{2}{|c|}{$\begin{array}{l}\text { DESVIO } \\
\text { PADRÃO }\end{array}$} & 0,099 & 0,053 & 0,072 & 0,062 & 0,053 & 0,066 & 0,068 & 0,066 & 0,058 & 0,047 & 0,058 & 0,033 & 0,053 & 0,049 & 0,037 & 0,036 & 0,063 & 0,048 & 0,064 & 0,050 \\
\hline
\end{tabular}

Quadro 8.1 - Quadro resumo da variação das avaliações por grupo de avaliadores

\begin{tabular}{|c|c|c|c|c|c|c|c|c|c|c|c|c|c|c|c|c|c|c|c|c|}
\hline \multicolumn{21}{|c|}{ TEMAS } \\
\hline AVALIAD. & T1 & T2 & T3 & T4 & T5 & T6 & $\mathrm{T7}$ & T8 & T9 & T10 & T11 & T12 & T13 & T14 & T15 & T16 & T17 & T18 & T19 & T20 \\
\hline GRUPO I & & & & $\square$ & & & & $\square$ & & & & & & & & & & & & \\
\hline Legenda: & & & nite & feri & & Lin & e $\mathrm{S}$ & eriol & & nter & $\mathrm{N}$ & io 1 & is ou & nen & um & svi & Padrã & & & \\
\hline
\end{tabular}

$\mathrm{Na}$ avaliação dos Temas, de acordo com as informações apresentadas na Tabela 8.2 e no Quadro 8.1, observou-se uma heterogeneidade nos resultados obtidos entre os Grupos I e II. Em uma análise comparativa entre os grupos pôde-se observar: i) no Grupo I, 74,3\% dos resultados encontram-se próximos a média calculada, portanto a dispersão é menor e 25,7\% das avaliações encontram-se acima ou abaixo do limite inferior ou superior (12,85\% estão abaixo do limite inferior e $12,85 \%$ acima do limite superior) e ii) no Grupo II 60,6\% dos critérios encontram-se entre o limite superior e inferior, ficando $19,4 \%$ abaixo desta faixa e 20,0\% acima do limite superior (total 30,4\%).

De acordo com os resultados apresentados na Tabela 8.2 e no Quadro 8.1, foi construído um quadro resumo que permite analisar os resultados das avaliações por grupo e por categoria (ver Quadro 8.2). 


\section{Quadro 8.2 - Quadro resumo das avaliações dos Temas}

\begin{tabular}{|c|c|c|c|}
\hline & CATEGORIA & TEMAS & RESULTADOS \\
\hline \multirow[b]{2}{*}{$\frac{1}{0}$} & $\begin{array}{c}\text { Meio Ambiente e } \\
\text { Transportes }\end{array}$ & $\begin{array}{c}\text { Energia, Impacto } \\
\text { Ambiental, } \\
\text { Qualidade do ar e } \\
\text { Ruido }\end{array}$ & $\begin{array}{l}\text { A análise dos dados referentes a esta categoria permite afirmar que } 4 \text { especialistas } \\
\text { possuem pelo menos um de seus pesos finais acima ou abaixo dos limites inferior e } \\
\text { superior calculados a partir dos respectivos desvios padrões. } \\
\text { Em uma análise geral entre os membros deste grupo pode-se afirmar que não há um } \\
\text { consenso nos julgamentos destes temas. Não foi encontrada uma supervalorização } \\
\text { ou sub-valorização dos temas em questão. }\end{array}$ \\
\hline & $\begin{array}{l}\text { Gestão dos } \\
\text { Transportes }\end{array}$ & $\begin{array}{l}\text { Estratégias } \\
\text { Econômicas, } \\
\text { Monitoramento, } \\
\text { Mobilidade } \\
\text { Urbana e Novas } \\
\text { Tecnologias }\end{array}$ & $\begin{array}{l}\text { Os Temas Estratégias Econômicas e Monitoramento obtiveram uma discrepância } \\
\text { nos julgamentos individuais, ou seja, alguns especialistas atribuíram valores (pesos) } \\
\text { a estes temas acima ou abaixo da média calculada. De acordo com a Tabela } 8.2 \text { estes } \\
\text { especialistas foram: } 2 \text { e } 6 \text { ( } 25 \% \text { acima e abaixo dos limites superior e inferior) e } 5 \\
\text { (25\% acima dos limites superior e inferior), para os demais (especialistas } 1,3,4 \text { e } 7) \\
\text { todos seus resultados encontram-se dentro deste limite estabelecido. } \\
\text { Para os Temas Mobilidade Urbana e Novas Tecnologias verificou-se um consenso } \\
\text { na avaliação dos especialistas; todos os resultados encontram-se no intervalo } \\
\text { próximo a média dos pesos calculados. }\end{array}$ \\
\hline & $\begin{array}{l}\text { Infra-estrutura } \\
\text { dos Transportes }\end{array}$ & $\begin{array}{c}\text { Frota, Sistema } \\
\text { Viário, Serviços de } \\
\text { Transporte e } \\
\text { Tráfego }\end{array}$ & $\begin{array}{l}\text { De acordo com as avaliações referentes aos Temas Frota, Sistema Viário, Serviços } \\
\text { de Transportes e Tráfego não foi verificada uma correspondência entre as } \\
\text { avaliações dos especialistas. Entretanto, dos quatro temas avaliados, os temas } \\
\text { Sistema Viário e Serviços de Transportes obtiveram um maior número de } \\
\text { avaliações próximas a média da categoria, ou seja, a maioria dos resultados } \\
\text { encontra-se entre o limite superior e inferior definido para cada tema. }\end{array}$ \\
\hline & $\begin{array}{c}\text { Planejamento } \\
\text { dos Transportes }\end{array}$ & \begin{tabular}{l|} 
Acessibilidade \\
Urbana, \\
Crescimento \\
Urbano, \\
População \\
Urbana e Viagens \\
\end{tabular} & $\begin{array}{l}\text { Para a categoria Planejamento dos Transportes, no que se refere à avaliação dos temas: } \\
\text { Crescimento Urbano e Viagens foram encontradas correspondências de resultados } \\
\text { entre os especialistas (3-7) e (2-6), respectivamente. Com relação a avaliação dos } \\
\text { temas Acessibilidade Urbana e População Urbana, em função dos resultados obtidos } \\
\text { neste grupo de especialistas, pode-se afirmar que estes temas são relevantes e devem } \\
\text { estar presentes na discussões da mobilidade urbana no município de Bauru. }\end{array}$ \\
\hline & $\begin{array}{c}\text { Aspectos } \\
\text { Socioeconômicos } \\
\text { dos Transportes }\end{array}$ & $\begin{array}{l}\text { Custos, Impactos } \\
\text { Socioeconômicos, } \\
\text { Segurança Viária } \\
\text { e Transporte } \\
\quad \text { Público }\end{array}$ & $\begin{array}{l}\text { Dentre os quatro temas avaliados (Custos, Impactos Socioeconômicos, Segurança } \\
\text { Viária e Transporte Público), apenas o tema Segurança Viária não obteve uma } \\
\text { avaliação abaixo do limite inferior (definido pela média do tema somado ao } \\
\text { respectivo desvio padrão), este resultado pode apontar para um consenso na } \\
\text { definição do grau de importância deste tema, entre os especialistas, para a avaliação } \\
\text { da mobilidade urbana no município. }\end{array}$ \\
\hline \multirow{5}{*}{ 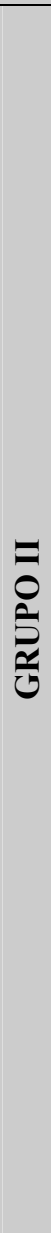 } & $\begin{array}{c}\text { Meio Ambiente e } \\
\text { Transportes }\end{array}$ & $\begin{array}{c}\text { Energia, Impacto } \\
\text { Ambiental, } \\
\text { Qualidade do ar e } \\
\text { Ruido }\end{array}$ & $\begin{array}{l}\text { Em uma análise geral entre os membros deste grupo pode-se afirmar que não há um } \\
\text { consenso nos julgamentos destes temas. Não foi encontrada uma supervalorização } \\
\text { ou sub-valorização dos temas em questão. } \\
\text { Quanto a análise de cada tema, o Tema Energia obteve um maior consenso na } \\
\text { avaliação dos participantes, pois } 87,5 \% \text { das avaliações encontram-se próximos a } \\
\text { média calculada. }\end{array}$ \\
\hline & $\begin{array}{l}\text { Gestão dos } \\
\text { Transportes }\end{array}$ & $\begin{array}{c}\text { Estratégias } \\
\text { Econômicas, } \\
\text { Monitoramento, } \\
\text { Mobilidade } \\
\text { Urbana e Novas } \\
\text { Tecnologias }\end{array}$ & $\begin{array}{l}\text { Ao analisar cada um dos temas, por especialistas, pode-se notar que o Tema Novas } \\
\text { Tecnologias foi o que obteve uma maior diferença nas avaliações: } 25 \% \text { das } \\
\text { avaliações estão abaixo do limite inferior, enquanto que } 37,5 \% \text { encontram-se acima } \\
\text { do limite superior. No Tema Monitoramento, } 25 \% \text { das avaliações encontram-se } \\
\text { abaixo do limite inferior e } 12,5 \% \text { acima do limite superior. Para o Tema } \\
\text { Mobilidade, os resultados foram os seguintes: } 12,5 \% \text { das avaliações estão abaixo do } \\
\text { limite inferior e } 37,5 \% \text { acima do limite superior. E na avaliação do Tema } \\
\text { Estratégias Econômicas encontrou-se os seguintes resultados: } 12,5 \% \text { das avaliações } \\
\text { encontram-se abaixo ou acima da média somada ao respectivo desvio padrão. }\end{array}$ \\
\hline & $\begin{array}{l}\text { Infra-estrutura } \\
\text { dos Transportes }\end{array}$ & $\begin{array}{c}\text { Frota, Sistema } \\
\text { Viário, Serviços de } \\
\text { Transporte e } \\
\text { Tráfego }\end{array}$ & $\begin{array}{l}\text { Entre as avaliações dos especialistas deste grupo pode-se verificar que entre os quatro } \\
\text { temas avaliados (Frota, Sistema Viário, Serviços de Transportes e Tráfego), o Tema } \\
\text { Serviços de Transportes foi aquele onde houve um maior número de avaliações } \\
\text { (37,5\%) abaixo do limite inferior estabelecido para este tema; enquanto que } 37,5 \% \text { das } \\
\text { avaliações estão próximas a média. Para o Tema Frota este limite inferior foi de } 25 \% \text { e } \\
\text { para os Temas Sistema Viário e Tráfego o percentual das avaliações abaixo do limite } \\
\text { inferior corresponderam a 12,5\%. Estes valores indicam uma heterogeneidade na } \\
\text { definição de quais temas são mais importantes para este grupo de avaliadores. Os } \\
\text { temas cujos valores estão abaixo do limite inferior correspondem a aqueles temas } \\
\text { menos importantes para discussão da Mobilidade Urbana em um processo de } \\
\text { elaboração do Plano Diretor de Transportes e Mobilidade. }\end{array}$ \\
\hline & $\begin{array}{c}\text { Planejamento } \\
\text { dos Transportes }\end{array}$ & \begin{tabular}{|c|} 
Acessibilidade \\
Urbana, \\
Crescimento \\
Urbano, \\
População \\
Urbana e Viagens \\
\end{tabular} & $\begin{array}{l}\text { Para a categoria Planejamento dos Transportes, no que se refere a avaliação dos } \\
\text { Temas: População Urbana e Viagens } 37,5 \% \text { das avaliações encontram-se abaixo do } \\
\text { limite inferior estabelecido para estes temas. Enquanto que para os Temas } \\
\text { Crescimento Urbano e Acessibilidade, 25\% e 12,5\% das avaliações, } \\
\text { respectivamente, estão abaixo do limite inferior calculado. }\end{array}$ \\
\hline & $\begin{array}{c}\text { Aspectos } \\
\text { Socioeconômicos } \\
\text { dos Transportes }\end{array}$ & $\begin{array}{l}\text { Custos, Impactos } \\
\text { Socioeconômicos, } \\
\text { Segurança Viária } \\
\text { e Transporte } \\
\text { Público }\end{array}$ & $\begin{array}{l}\text { Ao analisar os quatro temas observa-se que apenas o Tema Transporte Público não } \\
\text { obteve pontuação fora do limite inferior e superior. Este resultado, além de mostrar } \\
\text { que há um consenso entre os avaliadores, pode apontar como sendo um tema } \\
\text { relevante para integrar um sistema de avaliação da mobilidade urbana para este } \\
\text { grupo de avaliadores. }\end{array}$ \\
\hline
\end{tabular}


A próxima etapa consistiu no cálculo dos valores médios dos pesos encontrados por grupo (especialistas e não-especialistas) para as categorias e temas, de seus respectivos ranking (ordenamento), Tabelas 8.3 e 8.4 .

A Tabela 8.3 apresenta os pesos médio e o respectivo ranking para cada grupo de avaliação (especialistas e não-especialistas) para as categorias: meio ambiente e transportes, gestão dos transportes, infra-estrutura dos transportes e aspectos socioeconômicos dos transportes. O cálculo dos ranking foi realizado levando-se em consideração os pesos de cada categoria, ou seja, para as categorias, a primeira posição foi associada ao maior peso de cada grupo e a quinta posição (neste caso) correspondeu ao peso mais baixo. As células com borda em destaque mostram os indicadores que obtiveram o mesmo ordenamento nos Grupos I e II.

Tabela 8.3 - Ordenamento das Categorias por grupo de avaliadores

\begin{tabular}{|l|c|c||c|c|}
\hline \multirow{2}{*}{\multicolumn{2}{|c|}{ CATEGORIAS }} & \multicolumn{2}{c|}{$\begin{array}{c}\text { PESOS } \\
\text { (peso médio por grupo) }\end{array}$} & \multicolumn{2}{c|}{\begin{tabular}{c} 
Ordenamento \\
\cline { 2 - 5 }
\end{tabular}} & GRUPO I & GRUPO II & GRUPO I & GRUPO II \\
\cline { 2 - 5 } & $\mathbf{0 , 1 9 3}$ & $\mathbf{0 , 1 9 4}$ & $\mathbf{3}$ & $\mathbf{3}$ \\
\hline Meio ambiente e Transportes & $\mathbf{0 , 1 9 2}$ & $\mathbf{0 , 1 8 6}$ & $\mathbf{4}$ & $\mathbf{4}$ \\
\hline Gestão dos Transportes & $\mathbf{0 , 1 9 9}$ & $\mathbf{0 , 1 8 4}$ & $\mathbf{2}$ & $\mathbf{5}$ \\
\hline Infra-estrutura dos Transportes & $\mathbf{0 , 2 2 8}$ & $\mathbf{0 , 2 0 7}$ & $\mathbf{1}$ & $\mathbf{2}$ \\
\hline Planejamento dos Transportes & $\mathbf{0 , 1 8 7}$ & $\mathbf{0 , 2 2 9}$ & $\mathbf{5}$ & $\mathbf{1}$ \\
\hline Aspectos Socioeconômicos dos Transportes & & & & \\
\hline
\end{tabular}

De acordo com esta tabela apenas as categorias Meio ambiente e Transportes e Gestão dos Transportes possuem a mesma ordem nos dois grupos de avaliadores, enquanto que os demais critérios ocuparam diferentes posições nos dois grupos.

A Tabela 8.4 apresenta os pesos médios por temas, seu respectivo peso final e o correspondente ranking. No caso dos Temas, o ordenamento está compreendido entre o valor um (o valor mais elevado) e vinte (o valor mais baixo). O cálculo dos pesos finais, para cada grupo de avaliadores, foi realizado a partir do produto entre o peso médio de cada tema pelo correspondente peso obtido na avaliação de cada categoria. As células coloridas mostram os indicadores que obtiveram as dez primeiras colocações (no ordenamento final) para cada um dos grupos. 
Tabela 8.4 - Ordenamento dos Temas por grupo de avaliadores

\begin{tabular}{|c|c|c|c|c|c|c|c|}
\hline \multirow{2}{*}{\multicolumn{2}{|c|}{ CATEGORIAS E TEMAS }} & \multicolumn{2}{|c|}{ Pesos por Tema } & \multicolumn{2}{|c|}{ Peso Final } & \multicolumn{2}{|c|}{$\overline{\text { Ranking Final }}$} \\
\hline & & GRUPO I & GRUPO II & GRUPO I & GRUPO II & GRUPO I & GRUPO II \\
\hline \multirow{4}{*}{$\begin{array}{c}\text { Meio Ambiente e } \\
\text { Transportes }\end{array}$} & Energia & 0,247 & 0,298 & 0,048 & 0,058 & 13 & 4 \\
\hline & Impacto Ambiental & 0,316 & 0,283 & 0,061 & 0,055 & 2 & 6 \\
\hline & Qualidade do Ar & 0,243 & 0,226 & 0,047 & 0,044 & 14 & 16 \\
\hline & Ruído & 0,194 & 0,194 & 0,037 & 0,038 & 19 & 18 \\
\hline \multirow{4}{*}{$\begin{array}{l}\text { Gestão dos } \\
\text { Transportes }\end{array}$} & Estratégias Econômicas & 0,268 & 0,273 & 0,051 & 0,051 & 9 & 10 \\
\hline & Monitoramento & 0,242 & 0,216 & 0,047 & 0,040 & 15 & 17 \\
\hline & Mobilidade Urbana & 0,311 & 0,315 & 0,060 & 0,058 & 3 & 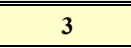 \\
\hline & Novas Tecnologias & 0,179 & 0,197 & 0,034 & 0,037 & 20 & 19 \\
\hline \multirow{4}{*}{$\begin{array}{l}\text { Infra-Estrutura } \\
\text { dos Transportes }\end{array}$} & Frota & 0,201 & 0,187 & 0,040 & 0,034 & 18 & 20 \\
\hline & Sistema Viário & 0,272 & 0,294 & 0,054 & 0,054 & 6 & 8 \\
\hline & Serviços de Transportes & 0,267 & 0,245 & 0,053 & 0,045 & 7 & 15 \\
\hline & Tráfego & 0,259 & 0,275 & 0,052 & 0,051 & 8 & 11 \\
\hline \multirow{4}{*}{$\begin{array}{l}\text { Planejamento } \\
\text { dos Transportes }\end{array}$} & Acessibilidade Urbana & 0,281 & 0,276 & 0,064 & 0,057 & 1 & 5 \\
\hline & Crescimento Urbano & 0,244 & 0,263 & 0,056 & 0,055 & 5 & 7 \\
\hline & População Urbana & 0,255 & 0,229 & 0,058 & 0,047 & 4 & 13 \\
\hline & Viagens & 0,219 & 0,232 & 0,050 & 0,048 & 10 & 12 \\
\hline \multirow{4}{*}{$\begin{array}{l}\text { Aspectos } \\
\text { Socioeconômicos } \\
\text { dos Transportes }\end{array}$} & Custos & $\mathbf{0 , 2 3 0}$ & 0,265 & 0,043 & 0,061 & 17 & 2 \\
\hline & Impactos Socioeconômicos & 0,239 & 0,230 & 0,045 & 0,053 & 16 & 9 \\
\hline & Segurança Viária & 0,263 & 0,207 & 0,049 & 0,047 & 12 & 14 \\
\hline & Transporte Público & 0,267 & 0,298 & 0,050 & 0,068 & 11 & 1 \\
\hline
\end{tabular}

Observando-se o ordenamento final, apresentado na Tabela 8.4, pode-se verificar que apenas o Tema Mobilidade Urbana (células em destaque) possui a mesma ordem no grupo dos especialistas e no grupo dos não-especialistas. Com relação aos demais Temas, não é possível identificar uma correspondência direta.

Embora não seja possível identificar visualmente uma correlação direta no ordenamento dos temas entre os dois grupos, com este ordenamento foi possível definir quais são os Temas "mais importantes" para cada grupo, conforme mostra o Quadro 8.3. Este quadro permite analisar, para cada grupo, quais são os Temas "mais importantes", ou seja, representados por aqueles que pertencem as dez primeiras colocações. Este quadro foi construído a partir das informações presentes na Tabela 8.4.

Quadro 8.3 - Ordenamento dos Temas por Grau de Importância - 10 primeiros colocados por grupo de avaliação

\begin{tabular}{|l|l|c|}
\hline \multicolumn{1}{|c|}{ GRUPO I } & \multicolumn{1}{c|}{ GRUPO II } & ORDEM \\
\hline Acessibilidade Urbana & Transporte Público & $\mathbf{1}$ \\
\hline Impacto Ambiental & Custos & $\mathbf{2}$ \\
\hline Mobilidade Urbana & Mobilidade Urbana & $\mathbf{3}$ \\
\hline \hline População Urbana & Energia & 4 \\
\hline Crescimento Urbano & Acessibilidade Urbana & $\mathbf{5}$ \\
\hline Sistema Viário & Impacto Ambiental & $\mathbf{6}$ \\
\hline \hline Serviços de Transportes & Crescimento Urbano & 7 \\
\hline \hline Tráfego & Sistema Viário & $\mathbf{8}$ \\
\hline \hline Estratégias Econômicas & Impactos Socioeconômicos & $\mathbf{9}$ \\
\hline \hline Viagens & Estratégias Econômicas & $\mathbf{1 0}$ \\
\hline
\end{tabular}


Ao analisar o Quadro 8.3 pode-se observar que $40 \%$ dos Temas não estão presentes nos Grupos I e II (células em destaque). No Grupo I (especialistas) esta diferença pode ser observada pela presença exclusiva dos seguintes Temas: População Urbana, Serviços de Transportes, Tráfego e Viagens. Enquanto que no Grupo II (nãoespecialistas) há uma outra definição dos Temas "mais importantes" para a Mobilidade Urbana que pode ser diferenciada pela presença dos seguintes Temas: Transporte Público,

\section{Custos, Energia e Impactos Socioeconômicos.}

A análise deste ranking permitiu verificar que há um consenso na escolha dos $60 \%$ dos Temas relativos à Mobilidade Urbana. Embora os dois grupos sejam muito heterogêneos, com participantes de diversas formações, pôde-se perceber que ambos possuem a mesma preocupação com relação a definição dos problemas mais importantes para o município de Bauru.

Um dos problemas que mais afeta a mobilidade no município de Bauru, como na maioria das cidades de médio porte brasileiras, refere-se ao crescimento espacial desordenado gerando grandes vazios urbanos. Outro fator que contribui para este problema é a falta de uma política de planejamento integrado onde as questões de uso do solo devem estar associadas ao planejamento do transporte. Estes problemas estão representados nas avaliações destes dois grupos através dos seguintes temas: Crescimento Urbano, Sistema Viário, Acessibilidade Urbana, Impacto Ambiental, Mobilidade Urbana e Estratégias Econômicas.

A última etapa deste Módulo referiu-se a verificação da correspondência (correlação) nos resultados das Categorias e Temas por grupo e entre os resultados dos dois grupos. Para isto, buscou-se a identificação de um método estatístico que permitisse verificar: i) a existência de uma correlação na avaliação da mobilidade urbana entre os dois grupos, e ii) uma correspondência no ranking dos pesos dos critérios avaliados.

Dentre as Técnicas Estatísticas existentes, optou-se pela utilização de Métodos Não-Paramétricos. Para avaliar o nível de concordância das avaliações e a correlação entre os critérios entre os dois grupos, adotou-se respectivamente: o Método da Correlação de Concordância de Kendall para avaliar os resultados obtidos em cada grupo e o Método da Correlação de Postos de Kendall para verificar os resultados entre os dois grupos de avaliadores. 


\section{- Método da Correlação de Concordância de Kendall (w)}

A aplicação do Método de Correlação de Concordância Kendall para as Categorias e Temas permitiu verificar o grau de concordância entre os dois grupos de avaliadores.

A Tabela 8.5 apresenta o ordenamento dos pesos por avaliador e o índice de Kendall (w) calculado para cada grupo. Os procedimentos realizados para aplicação deste método encontram-se detalhados no Anexo 7.

Tabela 8.5 - Ordenamento dos pesos por avaliador e Coeficiente de Correlação de Concordância de Kendall para as Categorias

\begin{tabular}{|c|c|c|c|c|c|c|}
\hline \multicolumn{7}{|c|}{ CATEGORIAS } \\
\hline & & $\begin{array}{l}\text { Meio ambiente e } \\
\text { Transportes }\end{array}$ & Gestão dos Transportes & $\begin{array}{c}\text { Infra-estrutura dos } \\
\text { Transportes }\end{array}$ & $\begin{array}{l}\text { Planejamento dos } \\
\text { Transportes }\end{array}$ & $\begin{array}{c}\text { Aspectos } \\
\text { Socioeconômicos dos } \\
\text { Transportes }\end{array}$ \\
\hline \multirow{7}{*}{\begin{tabular}{l}
$\overline{0}$ \\
\multirow{3}{0}{} \\
Jै
\end{tabular}} & 1 & 1 & 1 & 5 & 1 & 1 \\
\hline & 2 & 3 & 1 & 1 & 4 & 4 \\
\hline & 3 & 3 & 2 & 1 & 5 & 3 \\
\hline & 4 & 2 & 2 & 4 & 4 & 1 \\
\hline & 5 & 3 & 4 & 1 & 4 & 1 \\
\hline & 6 & 1 & 1 & 1 & 1 & 1 \\
\hline & 7 & 1 & 3 & 3 & 3 & 1 \\
\hline \multirow{8}{*}{ 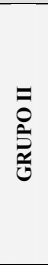 } & 8 & 2 & 2 & 1 & 2 & 2 \\
\hline & 9 & 1 & 1 & 1 & 1 & 1 \\
\hline & 10 & 3 & 1 & 1 & 3 & 3 \\
\hline & 11 & 3 & 1 & 1 & 3 & 3 \\
\hline & 12 & 1 & 3 & 1 & 3 & 5 \\
\hline & 13 & 1 & 1 & 3 & 3 & 3 \\
\hline & 14 & 4 & 1 & 4 & 2 & 2 \\
\hline & 15 & 1 & 4 & 2 & 2 & 5 \\
\hline \multicolumn{7}{|c|}{ Coeficiente de Correlação de Concordância de Kendall (w) } \\
\hline & & $\begin{array}{c}\text { Meio ambiente e } \\
\text { Transportes }\end{array}$ & Gestão dos Transportes & $\begin{array}{c}\text { Infra-estrutura dos } \\
\text { Transportes } \\
\end{array}$ & $\begin{array}{c}\text { Planejamento dos } \\
\text { Transportes } \\
\end{array}$ & $\begin{array}{c}\begin{array}{c}\text { Aspectos Socioeconômicos } \\
\text { dos Transportes }\end{array} \\
\end{array}$ \\
\hline \multicolumn{2}{|c|}{ GRUPO I } & \multicolumn{5}{|c|}{$\mathbf{0 , 2 0 3}$} \\
\hline \multicolumn{2}{|c|}{ GRUPO II } & \multicolumn{5}{|c|}{0,264} \\
\hline
\end{tabular}

De acordo com os resultados apresentados na Tabela 8.5, pode-se verificar uma baixa correlação entre as avaliações realizadas, tanto pelo grupo dos especialistas (Grupo I - w =0,203), quanto para o Grupo II ( $\mathrm{w}=0,264)$. Os baixos índices de correlação encontrados nos dois grupos são decorrentes do cálculo dos pesos individuais atribuídos por avaliador (especialista e não-especialista) para cada critério (ver Anexo 7). Estes resultados foram muito diferentes, conforme mostra o ordenamento de cada categoria (ver Tabela 8.3).

A Tabela 8.6 apresenta os Índices de Correlação de Kendall (w) para os Temas, para os Grupos I e II. Os resultados obtidos na aplicação deste método vem comprovar a baixa correlação direta entre os temas, conforme apresentou a Tabela 8.4. As células em destaque mostram os maiores e menores índices encontrados por grupo de avaliação. 
Tabela 8.6 - Ordenamento dos pesos por avaliador e Coeficiente de Correlação de Concordância de Kendall para os Temas

\begin{tabular}{|c|c|c|c|c|c|c|c|c|c|c|c|c|c|c|c|c|c|c|c|c|c|}
\hline \multicolumn{22}{|c|}{ TEMAS } \\
\hline & & \multicolumn{4}{|c|}{$\begin{array}{l}\text { Meio ambiente e } \\
\text { Transportes }\end{array}$} & \multicolumn{4}{|c|}{$\begin{array}{l}\text { Gestão dos } \\
\text { Transportes }\end{array}$} & \multicolumn{4}{|c|}{$\begin{array}{l}\text { Infra-estrutura dos } \\
\text { Transportes }\end{array}$} & \multicolumn{4}{|c|}{$\begin{array}{l}\text { Planejamento dos } \\
\text { Transportes }\end{array}$} & \multicolumn{4}{|c|}{$\begin{array}{c}\text { Aspectos } \\
\text { Socioeconômicos dos } \\
\text { Transportes }\end{array}$} \\
\hline \multirow{6}{*}{ 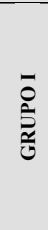 } & 1 & 1 & 1 & 4 & 1 & 3 & 1 & 3 & 1 & 1 & 4 & 1 & 1 & 1 & 1 & 1 & 1 & 4 & 1 & 2 & 2 \\
\hline & 2 & 1 & 4 & 2 & 2 & 1 & 3 & 3 & 2 & 1 & 2 & 3 & 3 & 2 & 2 & 4 & 1 & 1 & 4 & 1 & 1 \\
\hline & 3 & 2 & 3 & 3 & 1 & 3 & 2 & 3 & 1 & 1 & 3 & 3 & 1 & 4 & 1 & 3 & 1 & 1 & 1 & 1 & 1 \\
\hline & 5 & 3 & 4 & 2 & 1 & 2 & 3 & 3 & 1 & 2 & 2 & 1 & 2 & 1 & 1 & 1 & 1 & 2 & 4 & 2 & 1 \\
\hline & 6 & 3 & 3 & 2 & 1 & 3 & 1 & 3 & 1 & 1 & 2 & 4 & 2 & 3 & 3 & 2 & 1 & 1 & 1 & 3 & 4 \\
\hline & 7 & 1 & 4 & 1 & 1 & 1 & 3 & 3 & 1 & 1 & 2 & 2 & 2 & 4 & 1 & 2 & 2 & 1 & 2 & 3 & 3 \\
\hline \multirow{4}{*}{ 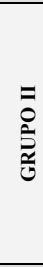 } & 8 & 4 & 3 & 1 & 1 & 1 & 1 & 1 & 1 & 1 & 1 & 1 & 1 & 1 & 1 & 1 & 1 & 1 & 2 & 3 & 4 \\
\hline & 9 & 3 & 1 & 1 & 3 & 3 & 2 & 3 & 1 & 1 & 3 & 1 & 3 & 3 & 1 & 1 & 3 & 4 & 2 & 1 & 2 \\
\hline & 10 & 3 & 4 & 2 & 1 & 2 & 2 & 1 & 2 & 2 & 2 & 1 & 2 & 4 & 1 & 3 & 1 & 4 & 1 & 2 & 2 \\
\hline & 15 & 1 & 2 & 2 & 2 & 3 & 1 & 4 & 1 & 1 & 4 & 2 & 2 & 3 & 3 & 1 & 1 & 2 & 1 & 2 & 4 \\
\hline \multicolumn{22}{|c|}{ Coeficiente de Correlação de Concordância de Kendall (w) } \\
\hline & & \multicolumn{4}{|c|}{ Meio ambiente e Transportes } & \multicolumn{4}{|c|}{ Gestão dos Transportes } & \multicolumn{4}{|c|}{$\begin{array}{l}\text { Infra-estrutura dos } \\
\text { Transportes }\end{array}$} & \multicolumn{4}{|c|}{$\begin{array}{l}\text { Planejamento dos } \\
\text { Transportes }\end{array}$} & \multicolumn{4}{|c|}{$\begin{array}{c}\text { Aspectos Socioeconômicos } \\
\text { dos Transportes }\end{array}$} \\
\hline & & T1 & T2 & T3 & T4 & T5 & T6 & $\mathrm{T} 7$ & T8 & T9 & T10 & T11 & T12 & T13 & T14 & T15 & T16 & T17 & T18 & T19 & $\mathbf{T 2 0}$ \\
\hline \multicolumn{2}{|c|}{ GRUPO I } & \multicolumn{4}{|c|}{$\mathbf{0 , 5 0 1}$} & \multicolumn{4}{|c|}{0,574} & \multicolumn{4}{|c|}{0,325} & \multicolumn{4}{|c|}{0,328} & \multicolumn{4}{|c|}{0,024} \\
\hline \multicolumn{2}{|c|}{ GRUPO II } & \multicolumn{4}{|c|}{0,162} & \multicolumn{4}{|c|}{0,333} & \multicolumn{4}{|c|}{0,397} & \multicolumn{4}{|c|}{0,157} & \multicolumn{4}{|c|}{0,339} \\
\hline
\end{tabular}

Ao analisar os índices de correlação obtidos entre os dois grupos, observa-se que o Tema que obteve o maior índice de concordância foi o relacionado à categoria Gestão dos Transportes ( $\mathrm{w}=0,574$ - Grupo I) e o menor índice de concordância foi Aspectos Socioeconômicos dos Transportes ( $\mathrm{w}=0,024$ - Grupo I) estes valores permitem afirmar que não existe correlação entre os critérios avaliados. $O$ baixo índice de correlação encontrado nos dois grupos indica que cada avaliador possui um critério diferente, que permite avaliar o grau de importância do Tema considerado como sendo mais ou menos importante para a avaliação da Mobilidade Urbana do município.

Em uma análise por grupo observa-se que há uma maior variação nos resultados dos índices de correlação. No Grupo I a variação foi de w $=0,574 \mathrm{a} \mathrm{w}=0,024$ (cuja ordem é a seguinte: Gestão dos Transportes, Meio ambiente e Transportes, Planejamento dos Transportes, Infra-estrutura dos Transportes e Aspectos Socioeconômicos dos Transportes). Com relação ao Grupo II o índice de correlação variou de $\mathrm{w}=0,397 \mathrm{a} \mathrm{w}=0,157$, cuja ordem é Infra-estrutura dos Transportes, Aspectos Socioeconômicos dos Transportes, Gestão dos Transportes, Meio ambiente e Transportes e Planejamento dos Transportes. 


\section{- Método da Correlação de Postos de Kendall ( $\tau)$}

A aplicação desta técnica permitiu verificar o grau de semelhança dos pares de critérios (categorias e temas) entre os dois grupos de avaliação (especialistas e nãoespecialistas).

A Tabela 8.7 apresenta as informações que permitiram calcular o Índice de Correlação de Postos de Kendall $(\tau)$, através das seguintes dados: peso médio por grupo, o respectivo ordenamento e o índice encontrado. As células com borda em destaque mostram os Temas que obtiveram o mesmo ordenamento nos grupos I e II. Os procedimentos realizados para aplicação deste método encontram-se detalhados no Anexo 8.

Tabela 8.7 - Coeficiente de Correlação de Postos de Kendall para as Categorias -

Ordenamento das avaliações

\begin{tabular}{|c|c|c|c|c|c|}
\hline \multirow[t]{2}{*}{ CATEGORIAS } & \multicolumn{2}{|c|}{$\begin{array}{c}\text { PESOS } \\
\text { (peso médio) }\end{array}$} & \multicolumn{2}{|c|}{$\begin{array}{l}\text { RANKING } \\
\text { (Ordenamento) }\end{array}$} & \multirow{2}{*}{$\begin{array}{l}\text { COEFICIENTE DE } \\
\text { KENDALL }(\tau)\end{array}$} \\
\hline & GRUPO I & GRUPO II & GRUPO I & GRUPO II & \\
\hline Meio ambiente e Transportes & 0,193 & 0,194 & 3 & 3 & \multirow{5}{*}{$-0,200$} \\
\hline Gestão dos Transportes & 0,192 & 0,186 & 4 & 4 & \\
\hline Infra-estrutura dos Transportes & 0,199 & 0,184 & 2 & 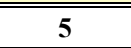 & \\
\hline Planejamento dos Transportes & $\mathbf{0 , 2 2 8}$ & $\mathbf{0 , 2 0 7}$ & 1 & 2 & \\
\hline Aspectos Socioeconômicos dos Transportes & 0,187 & 0,229 & 5 & 1 & \\
\hline
\end{tabular}

Na análise da Tabela 8.7, referente ao cálculo do coeficiente de correlação de postos para as categorias, o resultado final encontrado foi $\tau=-0,200$, o que significa uma Correlação Negativa; ou seja, para a maioria dos critérios avaliados não foi encontrada uma correspondência no ordenamento dos critérios entre os Grupos I e II. Apenas as categorias Meio Ambiente e Transportes e Gestão dos Transportes obtiveram um ordenamento correspondente entre os dois grupos de avaliação.

A Tabela 8.8 apresenta o peso médio de cada tema por grupo de avaliação, seu correspondente ranking e o Coeficiente de Correlação de Postos de Kendall. As células com borda em destaque mostram os temas que obtiveram o mesmo ordenamento nos Grupos I e II. 
Tabela 8.8 - Coeficiente de Correlação de Postos de Kendall para as Temas - Ordenamento das avaliações

\begin{tabular}{|c|c|c|c|c|c|c|}
\hline \multicolumn{2}{|c|}{ CATEGORIAS } & \multicolumn{2}{|c|}{$\begin{array}{c}\text { PESOS } \\
\text { (peso médio) }\end{array}$} & \multicolumn{2}{|c|}{$\begin{array}{c}\text { RANKING } \\
\text { (Ordenamento) }\end{array}$} & \multirow{2}{*}{$\begin{array}{l}\text { COEFICIENTE } \\
\text { DE KENDALL } \\
(\tau)\end{array}$} \\
\hline & & GRUPO I & GRUPO II & GRUPO I & GRUPO II & \\
\hline \multirow{4}{*}{$\begin{array}{c}\text { Meio Ambiente e } \\
\text { Transportes }\end{array}$} & Energia & 0,048 & 0,058 & 13 & 4 & \multirow{20}{*}{0,400} \\
\hline & Impacto Ambiental & 0,061 & 0,055 & 2 & 6 & \\
\hline & Qualidade do Ar & 0,047 & 0,044 & 14 & 16 & \\
\hline & Ruído & $\mathbf{0 , 0 3 7}$ & 0,038 & 19 & 18 & \\
\hline \multirow{4}{*}{$\begin{array}{l}\text { Gestão dos } \\
\text { Transportes }\end{array}$} & Estratégias Econômicas & 0,051 & 0,051 & 9 & 10 & \\
\hline & Monitoramento & 0,047 & 0,040 & 15 & 17 & \\
\hline & Mobilidade Urbana & 0,060 & 0,058 & 3 & 3 & \\
\hline & Novas Tecnologias & 0,034 & $\mathbf{0 , 0 3 7}$ & 20 & 19 & \\
\hline \multirow{4}{*}{$\begin{array}{l}\text { Infra-Estrutura } \\
\text { dos Transportes }\end{array}$} & Frota & 0,040 & 0,034 & 18 & 20 & \\
\hline & Sistema Viário & 0,054 & 0,054 & 6 & 8 & \\
\hline & Serviços de Transportes & 0,053 & 0,045 & 7 & 15 & \\
\hline & Tráfego & 0,052 & 0,051 & 8 & 11 & \\
\hline \multirow{4}{*}{$\begin{array}{c}\text { Planejamento dos } \\
\text { Transportes }\end{array}$} & Acessibilidade Urbana & 0,064 & $\mathbf{0 , 0 5 7}$ & 1 & 5 & \\
\hline & Crescimento Urbano & 0,056 & 0,055 & 5 & 7 & \\
\hline & População Urbana & 0,058 & 0,047 & 4 & 13 & \\
\hline & Viagens & 0,050 & 0,048 & 10 & 12 & \\
\hline \multirow{4}{*}{$\begin{array}{l}\text { Aspectos } \\
\text { Socioeconômicos } \\
\text { dos Transportes }\end{array}$} & Custos & 0,043 & 0,061 & 17 & 2 & \\
\hline & Impactos Socioeconômicos & 0,045 & 0,053 & 16 & 9 & \\
\hline & Segurança Viária & 0,049 & 0,047 & 12 & 14 & \\
\hline & Transporte Público & 0,050 & 0,068 & 11 & 1 & \\
\hline
\end{tabular}

$\mathrm{Na}$ avaliação da Tabela 8.8 o índice de Kendall obtido foi $\tau=0,400$. Este resultado indica uma baixa correlação positiva entre os temas; pois o valor zero indica uma correlação nula e os valores positivo e negativo indicam uma correlação perfeita positiva e negativa, respectivamente. Este índice reflete o resultado das avaliações e o respectivo ordenamento dos Temas; ou seja, nesta avaliação, dos vinte temas avaliados, apenas o Tema Mobilidade Urbana obteve o mesmo ordenamento entre os dois grupos de avaliadores, enquanto que para os demais critérios não foi verificada nenhuma coincidência na correspondência de ordenamento. Apenas em alguns critérios pode-se observar uma proximidade no ordenamento dos dois grupos.

Os resultados obtidos através do cálculo do Índice de Correlação de Concordância de Kendall e do Índice de Correlação de Postos de Kendall, comprovaram que cada avaliador, independente do grupo a que pertence, seja ele especialista ou nãoespecialista, classificou (avaliou) as Categorias e Temas de acordo com seu referencial (repertório). Em alguns casos, isso pode estar associado a uma experiência particular de cada avaliador com relação a cada critério avaliado; seja pelo conhecimento técnico na área, ou por um problema, referente ao tema avaliado, vivenciado por ele.

\subsection{Avaliações referentes ao Módulo II}

O processo de avaliação adotado para a definição dos indicadores (finais) que poderão fazer parte do Plano Diretor de Transportes e Mobilidade Urbana; podendo ser 
utilizados nas etapas de avaliação e monitoramento da Mobilidade Urbana do município, consistiu na somatória dos indicadores mais votados pelos dois grupos de avaliadores, conforme descrito no Capítulo 6.

A Tabela 8.9 apresenta o resultado das escolhas dos indicadores por Tema, para cada grupo de avaliadores, com seu respectivo ordenamento e o resultado final com a composição dos resultados anteriores através do ordenamento final. As células na cor laranja mostram as duas primeiras posições por indicador em relação ao Grupo I e as células na cor verde representam as duas primeiras posições para o Grupo II. As células na cor cinza claro mostram o resultado final do ordenamento.

Tabela 8.9 - Resultado da avaliação dos Temas por grupo de avaliação

\begin{tabular}{|c|c|c|c|c|c|c|c|c|}
\hline \multicolumn{9}{|c|}{ AVALIAÇÕES - MÓDULO II } \\
\hline \multirow{2}{*}{ CATEGORIA } & \multirow{2}{*}{ TEMA } & \multirow{2}{*}{ INDICADOR } & \multicolumn{2}{|c|}{ GRUPO I } & \multicolumn{2}{|c|}{ GRUPO II } & \multirow{2}{*}{$\begin{array}{l}\text { TOTAL } \\
\text { GERAL }\end{array}$} & \multirow{2}{*}{$\begin{array}{l}\text { ORDEM } \\
\text { FINAL }\end{array}$} \\
\hline & & & TOTAL & ORDEM & TOTAL & ORDEM & & \\
\hline \multirow{14}{*}{ 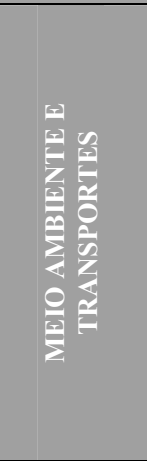 } & \multirow{4}{*}{ Energia } & E1 & 6 & 1 & 4 & 1 & 10 & 1 \\
\hline & & E2 & 5 & 2 & 4 & 1 & 9 & 2 \\
\hline & & E3 & 1 & 4 & 4 & 1 & 5 & 4 \\
\hline & & E4 & 2 & 3 & 4 & 1 & 6 & 3 \\
\hline & \multirow{4}{*}{ Impacto Ambiental } & I1 & 6 & 1 & 5 & 2 & 11 & 1 \\
\hline & & 12 & 4 & 2 & 7 & 1 & 11 & 1 \\
\hline & & $\mathbf{I 3}$ & 2 & 3 & 2 & 3 & 4 & 3 \\
\hline & & I4 & 2 & 3 & 2 & 3 & 4 & 3 \\
\hline & \multirow{4}{*}{ Qualidade do Ar } & Q1 & 2 & 4 & 1 & 4 & 3 & 4 \\
\hline & & Q2 & 3 & 2 & 5 & 1 & 8 & 2 \\
\hline & & Q3 & 3 & 2 & 5 & 1 & 8 & 2 \\
\hline & & Q4 & 6 & 1 & 5 & 1 & 11 & 1 \\
\hline & \multirow{2}{*}{ Ruído } & $\mathbf{R} 1$ & 7 & 1 & 8 & 1 & 15 & 1 \\
\hline & & R2 & 7 & 1 & 8 & 1 & 15 & 1 \\
\hline \multirow{17}{*}{ 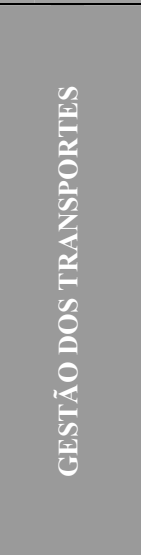 } & \multirow{6}{*}{$\begin{array}{l}\text { Estratégias } \\
\text { Econômicas }\end{array}$} & EE1 & 2 & 3 & 1 & 4 & 3 & 4 \\
\hline & & EE2 & 2 & 3 & 2 & 3 & 4 & 3 \\
\hline & & EE3 & 4 & 2 & 5 & 2 & 9 & 2 \\
\hline & & EE4 & 6 & 1 & 6 & 1 & 12 & 1 \\
\hline & & EE5 & $\mathbf{0}$ & 5 & 1 & 4 & 1 & 5 \\
\hline & & EE6 & $\mathbf{0}$ & 5 & 1 & 4 & 1 & 5 \\
\hline & \multirow{2}{*}{ Monitoramento } & M1 & 7 & 1 & 8 & 1 & 15 & 1 \\
\hline & & M2 & 7 & 1 & 8 & 1 & 15 & 1 \\
\hline & \multirow{6}{*}{ Mobilidade Urbana } & MU1 & 7 & 1 & 6 & 1 & 13 & 1 \\
\hline & & MU2 & 1 & 4 & $\mathbf{0}$ & 6 & 1 & 6 \\
\hline & & MU3 & 2 & 2 & 3 & 3 & 5 & 3 \\
\hline & & MU4 & 1 & 4 & 1 & 4 & 2 & 4 \\
\hline & & MU5 & 1 & 4 & 1 & 4 & 2 & 4 \\
\hline & & MU6 & 2 & 2 & 5 & 2 & 7 & 2 \\
\hline & \multirow{3}{*}{ Novas Tecnologias } & N1 & 6 & 1 & 6 & 2 & 12 & 2 \\
\hline & & N2 & 6 & 1 & 7 & 1 & 13 & 1 \\
\hline & & N3 & 2 & 3 & 3 & 3 & 5 & 3 \\
\hline
\end{tabular}


Tabela 8.9 - Resultado da avaliação dos Temas por grupo de avaliação (continuação)

\begin{tabular}{|c|c|c|c|c|c|c|c|c|}
\hline \multirow{22}{*}{ 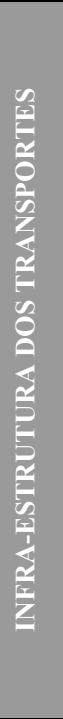 } & \multirow{5}{*}{ Frota } & F1 & 3 & 2 & 3 & 3 & 6 & 3 \\
\hline & & F2 & 1 & 5 & 2 & 4 & 3 & 5 \\
\hline & & F3 & 4 & 1 & 5 & 1 & 9 & 1 \\
\hline & & F4 & 3 & 2 & 5 & 1 & 8 & 2 \\
\hline & & F5 & 3 & 2 & 1 & 5 & 4 & 4 \\
\hline & \multirow{8}{*}{ Sistema Viário } & S1 & 2 & 3 & 2 & 4 & 4 & 4 \\
\hline & & S2 & 0 & 7 & $\mathbf{0}$ & 6 & 0 & 8 \\
\hline & & S3 & 2 & 3 & 3 & 2 & 5 & 3 \\
\hline & & 54 & 0 & 7 & 2 & 4 & 2 & 5 \\
\hline & & S5 & 1 & 5 & $\mathbf{0}$ & 6 & 1 & 6 \\
\hline & & S6 & 1 & 5 & $\mathbf{0}$ & 6 & 1 & 6 \\
\hline & & S7 & 3 & 2 & 6 & 1 & 9 & 1 \\
\hline & & S8 & 5 & 1 & 3 & 2 & 8 & 2 \\
\hline & \multirow{4}{*}{$\begin{array}{l}\text { Serviços de } \\
\text { Transportes }\end{array}$} & ST1 & 2 & 4 & 5 & 2 & 7 & 2 \\
\hline & & ST2 & 3 & 2 & 2 & 3 & 5 & 3 \\
\hline & & ST3 & 3 & 2 & 2 & 3 & 5 & 3 \\
\hline & & ST4 & 6 & 1 & 7 & 1 & 13 & 1 \\
\hline & \multirow{5}{*}{ Tráfego } & T1 & 3 & 3 & 6 & 1 & 9 & 1 \\
\hline & & T2 & 4 & 1 & 1 & 5 & 5 & 4 \\
\hline & & T3 & 3 & 3 & 4 & 2 & 7 & 2 \\
\hline & & T4 & 4 & 1 & 3 & 3 & 7 & 2 \\
\hline & & T5 & 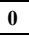 & 5 & 2 & 4 & 2 & 5 \\
\hline \multirow{25}{*}{ 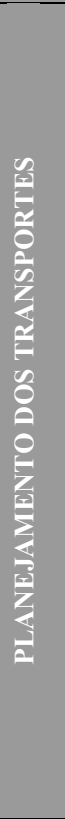 } & \multirow{5}{*}{$\begin{array}{l}\text { Acessibilidade } \\
\text { Urbana }\end{array}$} & A1 & 5 & 1 & 2 & 3 & 7 & 3 \\
\hline & & A2 & 3 & 2 & 1 & 5 & 4 & 4 \\
\hline & & A3 & 1 & 5 & 2 & 3 & 3 & 5 \\
\hline & & A4 & 3 & 2 & 5 & 2 & 8 & 1 \\
\hline & & A5 & 2 & 4 & 6 & 1 & 8 & 1 \\
\hline & \multirow{8}{*}{$\begin{array}{l}\text { Crescimento } \\
\text { Urbano }\end{array}$} & C1 & 0 & 7 & 1 & 6 & 1 & 7 \\
\hline & & $\mathrm{C} 2$ & 0 & 7 & 2 & 3 & 2 & 6 \\
\hline & & $\mathrm{C3}$ & 2 & 2 & 3 & 2 & 5 & 2 \\
\hline & & C4 & 1 & 5 & 0 & 8 & 1 & 7 \\
\hline & & C5 & 2 & 2 & 1 & 6 & 3 & 4 \\
\hline & & C6 & 1 & 5 & 2 & 3 & 3 & 4 \\
\hline & & C7 & 6 & 1 & 5 & 1 & 11 & 1 \\
\hline & & C8 & 2 & 2 & 2 & 3 & 4 & 3 \\
\hline & \multirow{5}{*}{ População Urbana } & P1 & 3 & 1 & 3 & 3 & 6 & 3 \\
\hline & & P2 & 3 & 1 & 5 & 1 & 8 & 1 \\
\hline & & P3 & 3 & 1 & 1 & 5 & 4 & 5 \\
\hline & & P4 & 2 & 5 & 3 & 3 & 5 & 4 \\
\hline & & P5 & 3 & 1 & 4 & 2 & 7 & 2 \\
\hline & \multirow{7}{*}{ Viagens } & V1 & 1 & 5 & $\mathbf{0}$ & 6 & 1 & 6 \\
\hline & & V2 & 5 & 1 & 5 & 1 & 10 & 1 \\
\hline & & V3 & 1 & 5 & $\mathbf{0}$ & 6 & 1 & 6 \\
\hline & & $\mathrm{V4}$ & 2 & 2 & 2 & 5 & 4 & 4 \\
\hline & & V5 & 2 & 2 & 3 & 2 & 5 & 2 \\
\hline & & V6 & 1 & 5 & 3 & 2 & 4 & 4 \\
\hline & & V7 & 2 & 2 & 3 & 2 & 5 & 2 \\
\hline \multirow{16}{*}{ 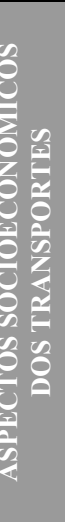 } & \multirow{3}{*}{ Custos } & CT1 & 6 & 1 & 7 & 1 & 13 & 1 \\
\hline & & CT2 & 4 & 2 & 4 & 3 & 8 & 3 \\
\hline & & CT3 & 4 & 2 & 5 & 2 & 9 & 2 \\
\hline & \multirow{4}{*}{$\begin{array}{c}\text { Impactos } \\
\text { Socioeconômicos }\end{array}$} & IS1 & 6 & 2 & 6 & 2 & 12 & 2 \\
\hline & & IS2 & 1 & 3 & 3 & 3 & 4 & 3 \\
\hline & & IS3 & 7 & 1 & 7 & 1 & 14 & 1 \\
\hline & & IS4 & $\mathbf{0}$ & 4 & $\mathbf{0}$ & 4 & $\mathbf{0}$ & 4 \\
\hline & Seouranca Viária & SV1 & 7 & 1 & 8 & 1 & 15 & 1 \\
\hline & segurança viarıa & SV2 & 7 & 1 & 8 & 1 & 15 & 1 \\
\hline & & TP1 & 3 & 2 & 3 & 1 & 6 & 2 \\
\hline & & TP2 & 4 & 1 & 3 & 1 & 7 & 1 \\
\hline & & TP3 & 1 & 5 & 3 & 1 & 4 & 5 \\
\hline & Transporte Público & TP4 & $\mathbf{0}$ & 7 & 1 & 6 & 1 & 7 \\
\hline & & TP5 & 3 & 2 & 2 & 5 & 5 & 3 \\
\hline & & TP6 & 1 & 5 & 1 & 6 & 2 & 6 \\
\hline & & TP7 & 2 & 4 & 3 & 1 & 5 & 3 \\
\hline
\end{tabular}

O resultado final das escolhas dos indicadores foi realizado através do ordenamento dos indicadores que receberam um número maior de votos entre os Grupos I e II. Pertencerão ao Sistema de Indicadores de Mobilidade Urbana aqueles indicadores que obtiveram os $1^{\text {os }}$ e $2^{\text {os }}$ lugares no ranking entre cada grupo (tema) avaliado. 
O Módulo II permitiu a escolha de apenas 2 indicadores por Tema avaliado, embora em alguns casos tenham restado 3 indicadores por Tema, como decorrência de avaliações "empatadas".

Assim, dos 94 indicadores iniciais que compõem o Módulo II, segundo a avaliação dos especialistas e não-especialistas foram definidos 43 Indicadores que refletem as questões mais importantes para o planejamento da mobilidade urbana no município de Bauru. Esta lista de indicadores poderá compor um Sistema de Indicadores para Avaliação e Monitoramento da Mobilidade Urbana junto ao Plano Diretor de Transportes e Mobilidade Participativo do município. O Quadro 8.4 apresenta o resultado final dos indicadores.

Quadro 8.4 - Resultado final dos Indicadores

\begin{tabular}{|c|c|c|c|c|}
\hline \multicolumn{5}{|c|}{ AVALIAÇÕES - MÓDULO II } \\
\hline \multirow{2}{*}{ CATEGORIA } & \multirow{2}{*}{ TEMA } & \multicolumn{2}{|r|}{ INDICADOR } & \multirow{2}{*}{$\begin{array}{l}\text { ORDEM } \\
\text { FINAL }\end{array}$} \\
\hline & & SIGLA & $\overline{\text { DESCRIÇÃO }}$ & \\
\hline \multirow{9}{*}{ 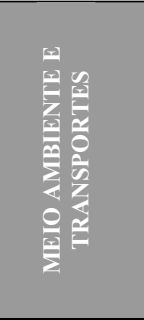 } & \multirow{2}{*}{ Energia } & E1 & $\begin{array}{l}\text { Consumo per capita de combustível fóssil e não-fóssil por transporte em veículo } \\
\text { motorizado }\end{array}$ & 1 \\
\hline & & $\mathbf{E 2}$ & Eficiência energética do transporte de passageiro e carga & 2 \\
\hline & \multirow{2}{*}{ Impacto Ambiental } & I1 & Fragmentação de Áreas Urbanas & 1 \\
\hline & & 12 & Impactos do uso de automóveis & 1 \\
\hline & \multirow{3}{*}{ Qualidade do Ar } & Q2 & Emissões causadas pelos transportes e intensidade das emissões & 2 \\
\hline & & Q3 & População exposta à poluição do ar causada pelos transportes & 2 \\
\hline & & Q4 & Qualidade do ar & 1 \\
\hline & \multirow{2}{*}{ Ruído } & R1 & Medidas de minimização de ruído & 1 \\
\hline & & $\mathbf{R 2}$ & Poluição Sonora & 1 \\
\hline \multirow{8}{*}{ 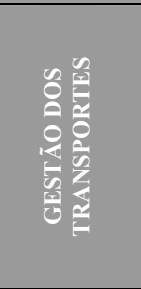 } & \multirow{2}{*}{$\begin{array}{l}\text { Estratégias } \\
\text { Econômicas }\end{array}$} & EE3 & Despesas públicas com transporte público & 2 \\
\hline & & EE4 & Investimentos em infra-estrutura de transportes & 1 \\
\hline & \multirow{2}{*}{ Monitoramento } & M1 & Avaliação de impacto ambiental & 1 \\
\hline & & M2 & Gerenciamento efetivo do tráfego / fiscalização & 1 \\
\hline & \multirow{2}{*}{ Mobilidade Urbana } & MU1 & Desenvolvimento de planos municipais para a redução das viagens & 1 \\
\hline & & MU6 & Priorizar viagens eficientes (a pé ou por bicicleta) & 2 \\
\hline & \multirow{2}{*}{ Novas Tecnologias } & N1 & $\begin{array}{l}\text { Desenvolvimento de combustíveis limpos e número de veículos que utilizam } \\
\text { combustíveis alternativos }\end{array}$ & 2 \\
\hline & & N2 & Novas formas de transporte & 1 \\
\hline \multirow{9}{*}{ 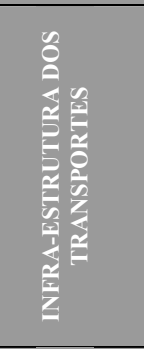 } & \multirow[b]{2}{*}{ Frota } & F3 & Percentagem da frota municipal convertida para reduzir a emissão de poluentes & 1 \\
\hline & & F4 & $\begin{array}{l}\text { Relação entre veículos com consumo eficiente de combustível / veículos com } \\
\text { consumo ineficiente de combustível }\end{array}$ & 2 \\
\hline & \multirow[b]{2}{*}{ Sistema Viário } & S7 & Possibilidade de acesso de transporte coletivo (pavimentação) & 1 \\
\hline & & S8 & $\begin{array}{l}\text { Provisão de infra-estrutura para moderação de tráfego e vias para bicicletas e } \\
\text { pedestres }\end{array}$ & 2 \\
\hline & \multirow{2}{*}{$\begin{array}{l}\text { Serviços de } \\
\text { Transportes }\end{array}$} & ST1 & Mudanças nos modos de transporte & 2 \\
\hline & & ST4 & Transporte de passageiros por modo de transporte & 1 \\
\hline & \multirow{3}{*}{ Tráfego } & T1 & Densidade de tráfego & 1 \\
\hline & & T3 & Taxa de ocupação dos veículos de passageiros & 2 \\
\hline & & T4 & Tempo total gasto no tráfego & 2 \\
\hline \multirow{9}{*}{ 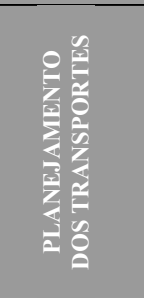 } & \multirow{2}{*}{$\begin{array}{c}\text { Acessibilidade } \\
\text { Urbana }\end{array}$} & $\mathbf{A 4}$ & Percentagem de empregos situados a até $3 \mathrm{~km}$ de distância das residências & 1 \\
\hline & & A5 & Percentagem de pessoas que vivem a até $3 \mathrm{~km}$ de distância das facilidades de lazer & 1 \\
\hline & \multirow{2}{*}{ Crescimento Urbano } & C3 & Desconcentração das atividades & 2 \\
\hline & & C7 & Planejamento do uso do solo urbano & 1 \\
\hline & \multirow{2}{*}{ População Urbana } & $\mathbf{P 2}$ & Densidade populacional & 1 \\
\hline & & P5 & Taxa de crescimento da população & 2 \\
\hline & & V2 & Distância aos serviços básicos & 1 \\
\hline & Viagens & V5 & Número de pessoas vivendo e trabalhando no local & 2 \\
\hline & & V7 & Tempo de viagem & 2 \\
\hline & Custos & CT1 & Custo por passageiro transportado corrigido pela inflação & 1 \\
\hline 을 & Custos & CT3 & Preço dos combustíveis e taxas & 2 \\
\hline द. & & IS1 & Benefícios dos usuários de transportes & 2 \\
\hline 분 & Socioeconômicos & IS3 & Custos sociais dos transportes & 1 \\
\hline 青它交 & Seouranca Viária & SV1 & Acidentes fatais de transporte & 1 \\
\hline 车罟前 & Segurança Viaria & SV2 & Feridos por acidentes de tráfego & 1 \\
\hline 등 & Transnorte Público & TP1 & Demanda por transporte de passageiros & 2 \\
\hline & 1Tansporte ravico & TP2 & Disponibilidade de transporte público & 1 \\
\hline
\end{tabular}




\subsection{Avaliações referentes ao Módulo III}

Em função das possibilidades de análise que este módulo permite realizar, estas foram divididas em quatro etapas: i) análise dos problemas e soluções de cada indicador, ii) análise do Grau de Importância do indicador, iii) análise do Grau de Urgência do Indicador e iv) localização espacial dos problemas relacionados a cada indicador.

Cabe destacar que alguns avaliadores dos Grupos I e II não participaram da avaliação deste módulo, embora tenham sido convidados a fazê-lo, uma vez esta etapa fazia parte do Curso de Capacitação. Por este motivo, houve uma diminuição no número total de participantes, que passou de um total de 15 avaliadores para 8 avaliadores: 5 avaliadores no Grupo I (especialistas) e 3 avaliadores no Grupo II (não-especialistas).

Para a avaliação deste módulo, conforme descrição apresentada no item 7.2 do capítulo anterior, foi solicitado a cada participante a escolha de apenas 1 Indicador para avaliação (embora o sistema permita a escolha de até 2 Indicadores).

\subsubsection{Problemas e soluções referentes a cada indicador}

A primeira etapa de avaliação das informações coletadas neste módulo refere-se a identificação de problemas e/ou soluções referentes a cada indicador. Neste item, os dados foram analisados de forma agregada entre o grupo dos especialistas e nãoespecialistas.

O Quadro 8.5 apresenta um resumo dos indicadores escolhidos para avaliação por cada avaliador, identificados pela célula em amarelo, e sua respectiva identificação: i) definição de problema(s) (letra P) e/ou solução(ões) (letra S). As células em branco mostram os indicadores que não foram escolhidos; as células na cor laranja indicam que o avaliador apresentou algum problema na avaliação deste conjunto de indicadores, o que não permitiu seu registro no banco de dados do sistema. As células em cinza mostram os avaliadores que não participaram da avaliação deste módulo. 
Quadro 8.5 - Quadro resumo dos problemas e soluções identificados pelos avaliadores

\begin{tabular}{|c|c|c|c|c|c|c|c|c|c|c|c|c|c|c|c|c|c|}
\hline \multicolumn{18}{|c|}{ PROBLEMAS E SOLUÇÕES } \\
\hline \multirow[b]{2}{*}{ CATEG. } & \multirow{2}{*}{ TEMA } & \multirow{2}{*}{ IND } & \multicolumn{7}{|c|}{ GRUPO I } & \multicolumn{8}{|c|}{ GRUPO II } \\
\hline & & & 1 & 2 & 3 & 4 & 5 & 6 & 7 & 8 & 9 & 10 & 11 & 12 & 13 & 14 & 15 \\
\hline \multirow{9}{*}{ 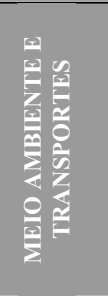 } & \multirow{2}{*}{ Energia } & E1 & -- & $\mathbf{P} / \mathbf{S}$ & & -- & --- & $\mathbf{S}$ & -- & -- & & -- & $\mathbf{P} / \mathbf{S}$ & -- & -- & -- & -- \\
\hline & & E2 & -- & & $\mathbf{P} / \mathbf{S}$ & & & & - & -- & -- & & & -- & -- & -- & -- \\
\hline & \multirow{2}{*}{ Impacto Ambiental } & I1 & -- & $\mathbf{S}$ & & $\mathbf{S}$ & & -- & - & -- & -- & & -- & -- & -- & -- & -- \\
\hline & & 12 & -- & & $\mathbf{P} / \mathbf{S}$ & & --- & & -- & -- & -- & -- & & -- & -- & -- & -- \\
\hline & \multirow{3}{*}{ Qualidade do Ar } & Q2 & -- & & & & & $\mathbf{S}$ & -- & -- & & -- & & -- & -- & -- & -- \\
\hline & & Q3 & -- & & & & & & - & -- & -- & & & -- & -- & -- & -- \\
\hline & & Q4 & -- & $\mathbf{P} / \mathbf{S}$ & -- & $\mathbf{S}$ & --- & & -- & -- & & & $\mathbf{P}$ & -- & -- & -- & -- \\
\hline & \multirow{2}{*}{ Ruído } & R1 & -- & -- & $\mathbf{S}$ & & & & -- & -- & -- & -- & & -- & -- & -- & -- \\
\hline & & $\mathbf{R 2}$ & -- & & & --- & --- & -- & -- & -- & & & $\mathbf{P}$ & -- & -- & -- & -- \\
\hline \multirow{8}{*}{$\begin{array}{l}0 \\
8 \\
8 \\
0 \\
0 \\
0 \\
0 \\
0 \\
0 \\
0 \\
0 \\
0 \\
0\end{array}$} & \multirow{2}{*}{ Estratégias Econômicas } & EE3 & -- & $\mathbf{P} / \mathbf{S}$ & $\mathbf{P} / \mathbf{S}$ & & & & -- & -- & & & & --- & -- & -- & -- \\
\hline & & EE4 & -- & & & $\mathbf{S}$ & -- & $\mathbf{S}$ & -- & -- & -- & -- & $\mathbf{S}$ & -- & -- & -- & -- \\
\hline & \multirow{2}{*}{ Monitoramento } & M1 & -- & & -- & --- & --- & $\mathbf{S}$ & -- & -- & & -- & & -- & -- & --- & -- \\
\hline & & M2 & -- & -- & & & & & - & -- & -- & & $\mathbf{P}$ & -- & -- & -- & -- \\
\hline & \multirow{2}{*}{ Mobilidade Urbana } & MU1 & -- & -- & & $\mathbf{S}$ & --- & $\mathbf{S}$ & -- & --- & -- & -- & -- & -- & -- & -- & -- \\
\hline & & MU6 & -- & $\mathbf{S}$ & $\mathbf{S}$ & & & & -- & -- & & & & -- & -- & -- & -- \\
\hline & \multirow{2}{*}{ Novas Tecnologias } & N1 & -- & $\mathbf{P} / \mathbf{S}$ & -- & & & & - & -- & -- & & & -- & -- & -- & -- \\
\hline & & N2 & -- & -- & & & --- & $\mathbf{P} / \mathbf{S}$ & -- & -- & & -- & $\mathbf{P} / \mathbf{S}$ & -- & -- & -- & -- \\
\hline \multirow{9}{*}{ 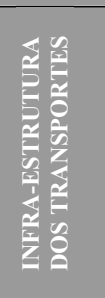 } & Frota & F3 & -- & $\mathbf{S}$ & & --- & & $\mathbf{S}$ & -- & -- & & -- & & -- & -- & -- & -- \\
\hline & Frota & F4 & -- & & $\mathbf{P}$ & & --- & & -- & -- & -- & & $\mathbf{P} / \mathbf{S}$ & -- & -- & -- & -- \\
\hline & & S7 & -- & $\mathbf{S}$ & $\mathbf{P} / \mathbf{S}$ & --- & & $\mathbf{S}$ & -- & -- & $\mathbf{S}$ & -- & & -- & -- & -- & -- \\
\hline & Sistema Viário & 58 & -- & & & & --- & & -- & -- & & & $\mathbf{P}$ & -- & -- & --- & --- \\
\hline & Servicos de Transnortes & ST1 & -- & & $\mathbf{P} / \mathbf{S}$ & & --- & $\mathbf{S}$ & -- & -- & & -- & $\mathrm{S}$ & -- & -- & -- & -- \\
\hline & Serviços de Transportes & ST4 & -- & $\mathbf{P} / \mathbf{S}$ & & $\mathbf{P} / \mathbf{S}$ & & & -- & -- & -- & & & -- & -- & -- & -- \\
\hline & & T1 & -- & & & & & & - & -- & & -- & & -- & -- & -- & -- \\
\hline & Tráfego & T3 & -- & -- & & & & & -- & -- & & & & -- & -- & -- & -- \\
\hline & & T4 & -- & & $\mathbf{P} / \mathbf{S}$ & --- & --- & $\mathbf{S}$ & -- & -- & -- & & $\mathbf{P}$ & -- & -- & -- & -- \\
\hline & & A4 & -- & & $\mathbf{P} / \mathbf{S}$ & $\mathbf{P} / \mathbf{S}$ & -- & -- & -- & -- & & -- & -- & -- & -- & -- & -- \\
\hline & Acessibilidade Urbana & A5 & -- & $\mathbf{P} / \mathbf{S}$ & & & & & -- & -- & --- & & & -- & -- & -- & -- \\
\hline $\bar{z} \overline{ }$ & Crescimento Urbano & C3 & -- & & & --- & & & -- & -- & & & & -- & -- & -- & -- \\
\hline 돌을 & Crescimento Urbano & C7 & -- & $\mathbf{S}$ & $\mathbf{P} / \mathbf{S}$ & & -- & $\mathbf{P}$ & -- & -- & -- & -- & -- & -- & -- & -- & -- \\
\hline$\leqq \frac{2}{3}$ & Ponulacão Urbana & P2 & -- & $\mathbf{S}$ & $\mathbf{P} / \mathbf{S}$ & $\mathbf{S}$ & --- & -- & - & -- & -- & -- & -- & -- & -- & -- & -- \\
\hline$\frac{1}{2} \cong$ & Populaçao Urbana & P5 & -- & & & & & & -- & -- & & & & -- & -- & -- & -- \\
\hline 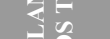 & & V2 & -- & & & & --- & & -- & -- & & & -- & -- & -- & -- & -- \\
\hline 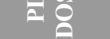 & Viagens & V5 & -- & & -- & & & -- & - & -- & & -- & & -- & -- & -- & -- \\
\hline & & V7 & -- & $\mathbf{S}$ & & --- & & & -- & -- & -- & & & -- & -- & -- & -- \\
\hline & Custos & CT1 & -- & $\mathbf{S}$ & $\mathbf{P} / \mathbf{S}$ & --- & -- & -- & -- & -- & & & & -- & -- & -- & -- \\
\hline 约 & Custos & CT3 & -- & & & & & & -- & -- & -- & -- & -- & -- & -- & -- & -- \\
\hline $8 \sum_{0} \frac{\pi}{0}$ & Imnactos Socioconômicos & IS1 & -- & & $\mathbf{P} / \mathbf{S}$ & --- & & & -- & -- & & -- & & -- & -- & -- & -- \\
\hline 는 & Impactos Socioeconomicos & IS3 & -- & -- & & & --- & -- & -- & -- & -- & & -- & -- & -- & -- & -- \\
\hline 잉 & Seouranca Viária & SV1 & -- & $\mathbf{S}$ & & & & -- & -- & -- & -- & & & -- & -- & -- & -- \\
\hline 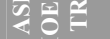 & Segurança Viaria & SV2 & -- & & $\mathbf{P} / \mathbf{S}$ & $\mathbf{S}$ & --- & & - & -- & & -- & -- & -- & -- & -- & -- \\
\hline 둥 & Transnorte Póblice & TP1 & -- & & & --- & & & -- & -- & & & -- & -- & -- & -- & -- \\
\hline 5 & I ransporte Pubico & TP2 & -- & $\mathbf{P} / \mathbf{S}$ & $\mathbf{P} / \mathbf{S}$ & & --- & -- & -- & -- & & -- & & -- & -- & -- & -- \\
\hline
\end{tabular}

Analisando as informações do Quadro 8.5 pode-se verificar que a maioria dos problemas e soluções apresentados foi definida pelo grupo dos especialistas (Grupo I), com exceção de um avaliador que pertence ao segundo grupo (com formação técnica na área).

Dos 43 indicadores definidos para avaliação deste módulo, para 20,93\% destes indicadores (9 indicadores), os avaliadores não apresentaram qualquer problema e/ou solução. Estes indicadores foram: Q3 - População exposta à poluição do ar causada pelos transportes, T1 - Densidade de tráfego, T3 - Taxa de ocupação dos veículos de passageiros, C3 - Desconcentração das atividades, P5 - Taxa de crescimento da população, V2 Distância aos serviços básicos, V5 - Número de pessoas vivendo e trabalhando no local, 
CT3 - Preço dos combustíveis e taxas, IS3 - Custos sociais dos transportes, TP1 Demanda por transporte de passageiros.

Ao analisar as escolhas dos indicadores, por avaliador, pôde-se observar que a grande maioria dos participantes não inseriu no sistema outras sugestões para os problemas e soluções relacionados aos indicadores escolhidos.

Com estas informações foram levantadas algumas hipóteses que permitem justificar este baixo índice de avaliação por parte dos participantes: i) Falta de conhecimento técnico - Como este tipo de informação (definição), para a maioria dos indicadores, requer algum tipo de conhecimento técnico, este pode ser um dos motivos para o baixo índice de respostas referentes à identificação de problemas e soluções por parte da maioria dos avaliadores. ii) Pré-definição de alguns dos problemas e soluções pelo sistema - Um outro fator pode estar associado à própria definição deste módulo, uma vez que foram listados previamente, pelo desenvolvedor do sistema, uma série de problemas e soluções, para que cada avaliador obtivesse uma noção geral de alguns problemas e soluções relacionados a cada indicador. iii) Tempo de avaliação do sistema - Um terceiro fator que pode ter contribuído para a não avaliação deste item pode estar relacionado com o tempo de avaliação deste módulo. Embora o sistema tenha sido concebido para que as avaliações possam ocorrer de forma descontínua (ou seja, o usuário pode realizar a avaliação de apenas uma categoria e sair do sistema, retornando posteriormente para avaliar as demais categorias em um outro momento), nesta avaliação os usuários utilizaram um período contínuo, de aproximadamente duas horas, para realizar as avaliações dos 43 indicadores. Portanto, o cansaço associado ao tempo disponível para a conclusão da avaliação do módulo pode ter contribuído para o baixo índice de propostas.

O Quadro 8.5 também permite visualizar as escolhas de cada avaliador, ou seja, os indicadores que obtiveram um maior número de avaliações neste módulo. Pode-se notar que, com relação aos indicadores relacionados ao Tema Energia, por exemplo, 75\% (6) dos avaliadores escolheram o indicador E1, enquanto que 25\% (2) escolheram o indicador E2. Para o Tema Impacto Ambiental: 55,5\% I1 e 44,5\% I2. Há um equilíbrio nas escolhas dos indicadores deste tema, que pode estar relacionado com a identificação do avaliador com o indicador na cidade, ou seja, os dois indicadores deste tema são de fácil reconhecimento dos problemas a ele associados no município. Com relação aos indicadores do Tema Qualidade do Ar, os índices foram: 25\% - Q2, 12,5\% - Q3, e 62,5\% - Q4. E para o Tema Ruído há um equilíbrio na escolha dos indicadores: 50\% - R1 e 50\% - R2 (ver Figura 8.2). 


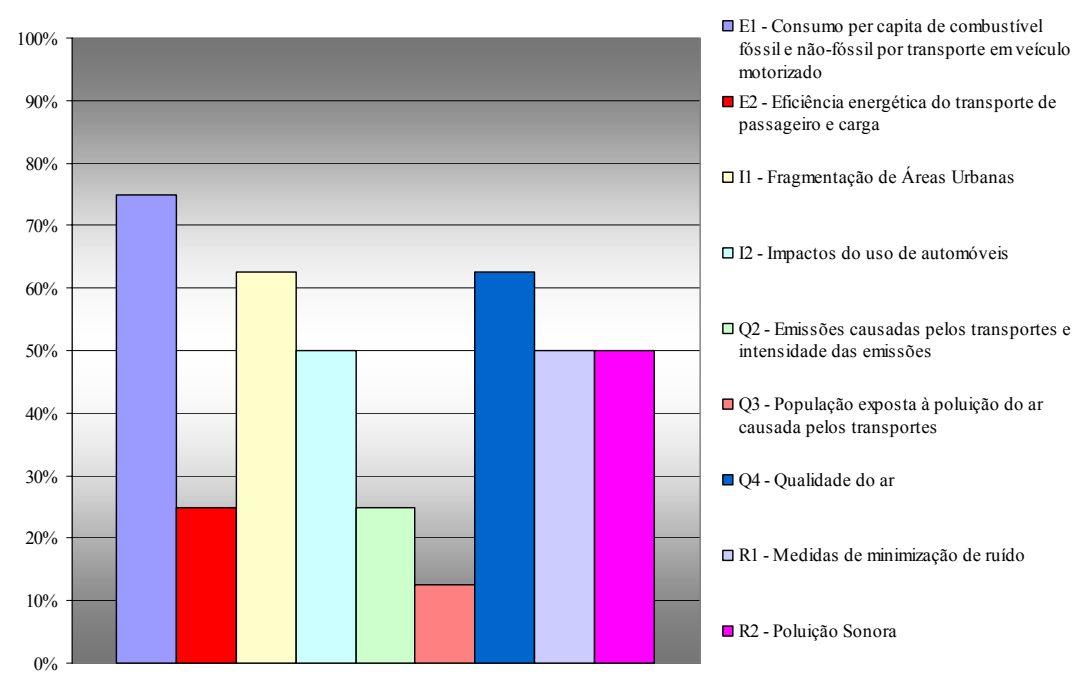

Figura 8.2 - Categoria Meio Ambiente e Transportes

Os mesmos tipos de distribuição, para os demais temas, encontram-se representados nas Figuras 8.3 a 8.6.

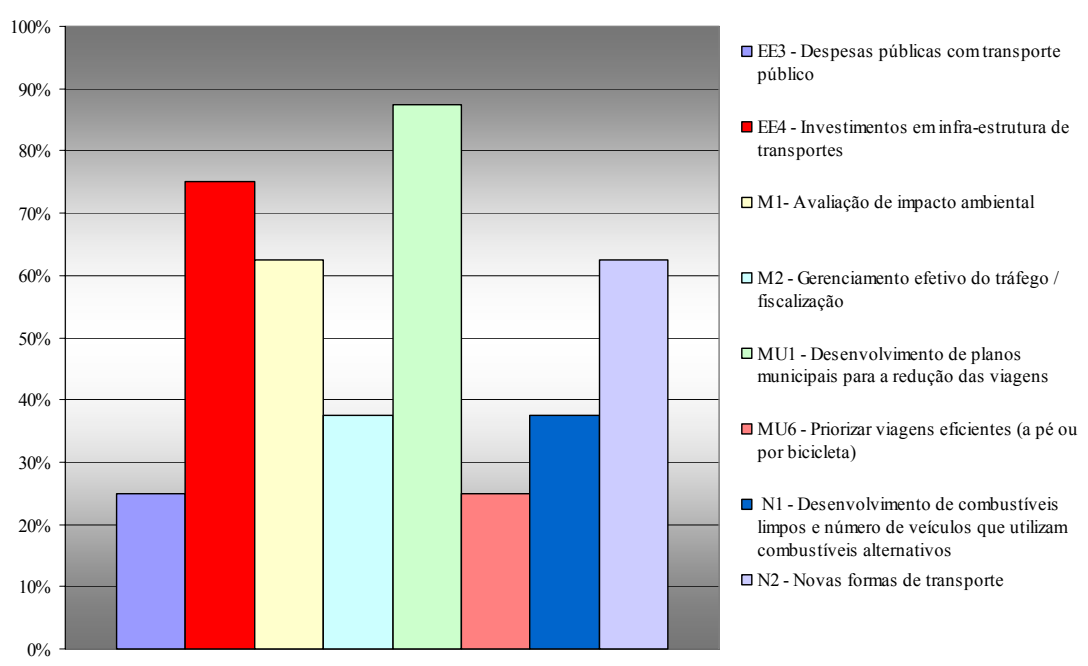

Figura 8.3 - Categoria Gestão dos Transportes 


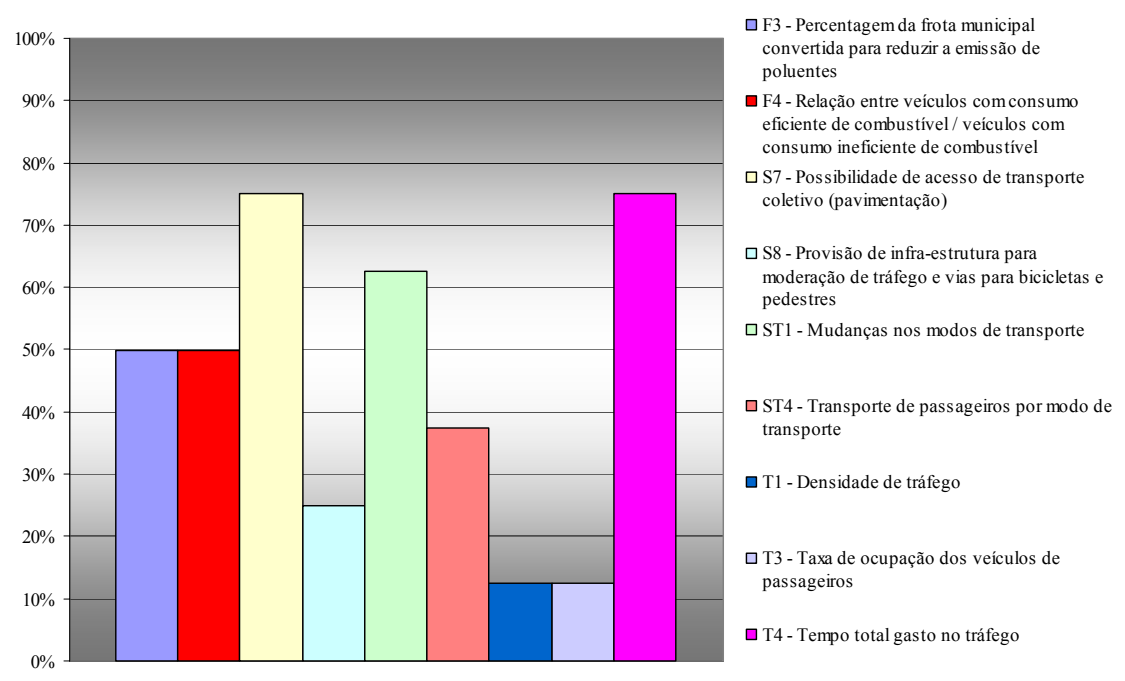

Figura 8.4 - Categoria Infra-estrutura dos Transportes

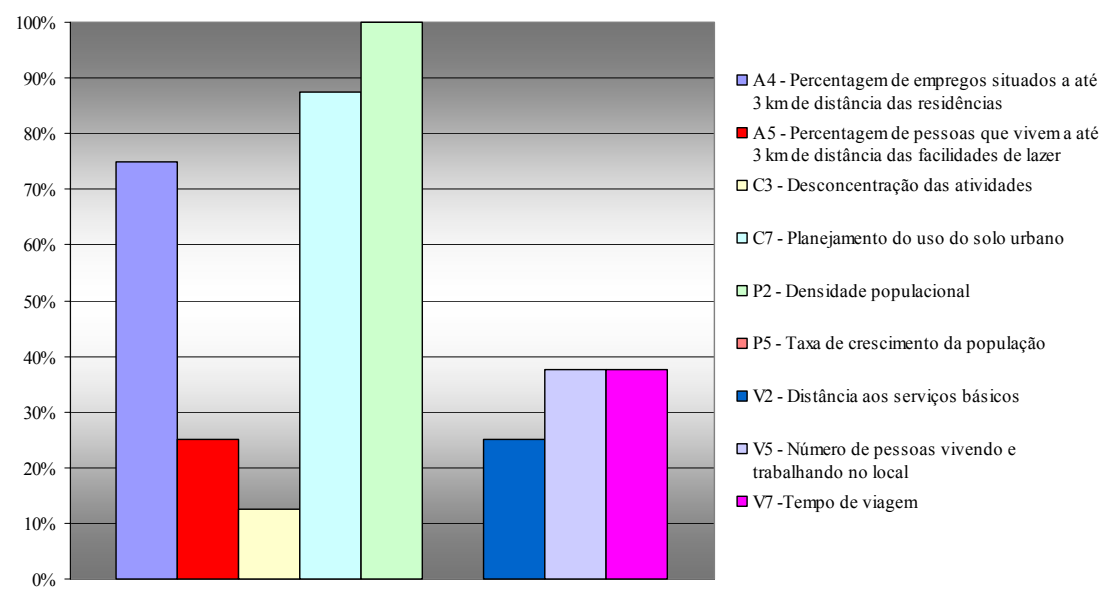

Figura 8.5 - Categoria Planejamento dos Transportes

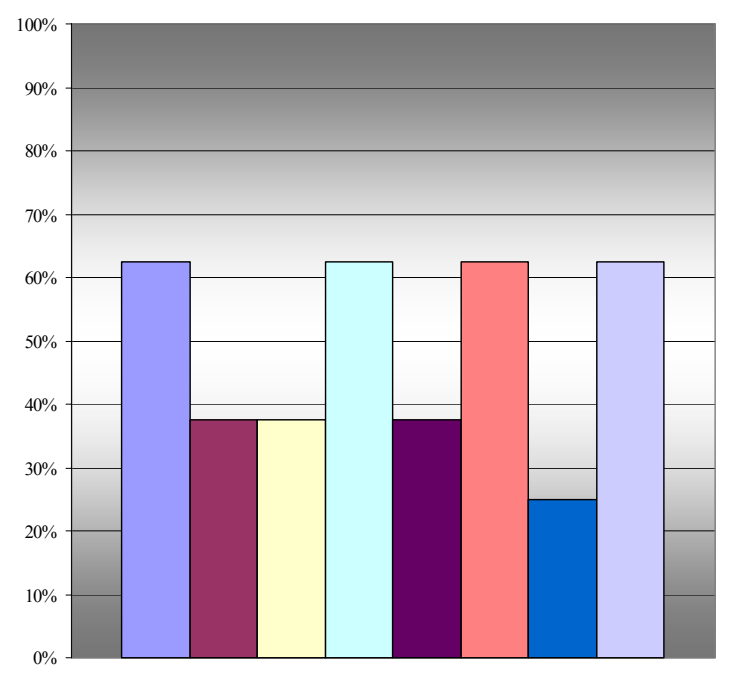

CT1 - Custo por passageiro transportado corrigido pela inflação

曰 СТ3 - Preço dos combustíveis e taxas

口IS1 - Benefícios dos usuários de transportes 口 IS3 - Custos sociais dos transportes

GV1 - Acidentes fatais de transporte

口 SV2 - Feridos por acidentes de tráfego

QTP1 - Demanda por transporte de

passageiros

$\square$ TP2 - Disponibilidade de transporte público

Figura 8.6 - Categoria Aspectos Socioeconômicos dos Transportes 
De acordo com o Quadro 8.5 e as Figuras 8.2 a 8.6 pode-se afirmar que os indicadores mais escolhidos pelos participantes possuem significado para cada avaliador, seja pela associação a algum problema enfrentado em seu cotidiano ou por seu significado ser de fácil compreensão e apreensão, o que permite visualizá-lo como importante para o planejamento da mobilidade urbana.

O Quadro 8.6 e o Anexo 9 apresentam respectivamente, os problemas e soluções por avaliador para o Tema Energia, e uma síntese geral de todos os problemas e soluções inseridos no sistema.

Quadro 8.6 - Relação dos problemas e soluções apresentados para os Indicadores relacionados ao Tema Energia

\begin{tabular}{|c|c|c|c|c|c|}
\hline \multicolumn{6}{|c|}{ TEMA: ENERGIA } \\
\hline & & \multicolumn{2}{|c|}{$\begin{array}{l}\text { E1 - Consumo per capita de combustível fóssil e } \\
\text { não-fóssil por transporte em veículo motorizado }\end{array}$} & \multicolumn{2}{|c|}{$\begin{array}{c}\text { E2 - Eficiência energética do transporte de } \\
\text { passageiro e carga }\end{array}$} \\
\hline & & Problemas & Soluções & Problemas & Soluções \\
\hline \multirow{3}{*}{\multicolumn{2}{|c|}{$\begin{array}{l}\text { Informações } \\
\text { fornecidas } \\
\text { pelo Sistema }\end{array}$}} & $\begin{array}{l}\text { Aumento na poluição do } \\
\text { ar. }\end{array}$ & $\begin{array}{l}\text { Incentivo a utilização de } \\
\text { combustíveis não } \\
\text { poluentes. }\end{array}$ & $\begin{array}{l}\text { Aumento no consumo de } \\
\text { combustível. }\end{array}$ & $\begin{array}{l}\text { Utilização de Transporte } \\
\text { Público. }\end{array}$ \\
\hline & & $\begin{array}{l}\text { Consumo excessivo de } \\
\text { energia não renovável. }\end{array}$ & $\begin{array}{l}\text { Redução do número de } \\
\text { viagens por transporte } \\
\text { individual. }\end{array}$ & $\begin{array}{l}\text { Alteração no clima da } \\
\text { cidade. }\end{array}$ & Renovação da frota. \\
\hline & & & $\begin{array}{l}\text { Pesquisas sobre novas } \\
\text { formas de transportes } \\
\text { "limpos". }\end{array}$ & & $\begin{array}{l}\text { Redução do número de } \\
\text { viagens por transporte } \\
\text { individual. }\end{array}$ \\
\hline \multirow{6}{*}{ 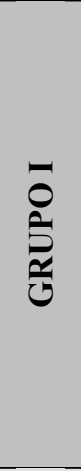 } & 2 & $\begin{array}{l}\text { Aumento/diminuição dos } \\
\text { gastos pessoais em } \\
\text { função da variação do } \\
\text { preço do combustível. }\end{array}$ & $\begin{array}{l}\text { Incentivar a população a } \\
\text { utilizar transporte } \\
\text { público. }\end{array}$ & \multirow[t]{2}{*}{ Não respondeu. } & \multirow[t]{2}{*}{ Não respondeu. } \\
\hline & & $\begin{array}{l}\text { Variação do preço do } \\
\text { combustível em função } \\
\text { do consumo. }\end{array}$ & $\begin{array}{l}\text { Tomar medidas para } \\
\text { reduzir o valor da tarifa } \\
\text { do transporte público. }\end{array}$ & & \\
\hline & 3 & Não respondeu. & Não respondeu. & $\begin{array}{l}\text { Aumento do nível de } \\
\text { ruído. }\end{array}$ & $\begin{array}{l}\text { Aumentar quantidade de } \\
\text { ciclovias e viagens a pé. }\end{array}$ \\
\hline & 4 & Não respondeu. & Não respondeu. & Não respondeu. & Não respondeu. \\
\hline & 5 & Não respondeu. & Não respondeu. & Não respondeu. & Não respondeu. \\
\hline & 6 & Não respondeu. & $\begin{array}{l}\text { Priorização do transporte } \\
\text { coletivo. }\end{array}$ & Não respondeu. & Não respondeu. \\
\hline \multirow[b]{3}{*}{$\begin{array}{l}= \\
0 \\
\vdots \\
0 \\
0\end{array}$} & 9 & Não respondeu. & Não respondeu. & Não respondeu. & Não respondeu. \\
\hline & 10 & Não respondeu. & Não respondeu. & Não respondeu. & Não respondeu. \\
\hline & 11 & $\begin{array}{l}\text { Comprometimento do } \\
\text { orçamento familiar. }\end{array}$ & $\begin{array}{l}\text { Medidas de planejamento } \\
\text { urbano, visando a } \\
\text { redução de distâncias de } \\
\text { transporte (por exemplo, } \\
\text { entre residência e } \\
\text { trabalho). }\end{array}$ & Não respondeu. & Não respondeu. \\
\hline
\end{tabular}

Analisando os resultados do Quadro 8.6 pode-se observar que, embora o banco de dados tenha registrado três respostas para os problemas relacionados ao indicador $\mathbf{E 1}$ (Consumo per capita de combustivel fóssil e não-fóssil por transporte em veículo motorizado), todas as respostas têm como fundamentação a questão do custo do combustível. Com relação às soluções deste mesmo indicador, foram apresentadas duas 
propostas: i) a primeira solução (três "votos”) enfoca a questão da utilização do transporte público (ou transporte coletivo); e ii) a segunda proposta insere a questão do planejamento urbano como uma das alternativas para solucionar (ou reduzir) o consumo de combustível fóssil.

Para o indicador E2 (Eficiência energética do transporte de passageiro e carga), apenas um avaliador avaliou este indicador. Foi definido como problema o aumento no nível de ruído e como solução a proposta foi aumentar a quantidade de ciclovias e viagens a pé.

Com relação às demais soluções elencadas pelos participantes, referentes aos demais temas avaliados destacam-se: aumentar os trechos de ciclovias; incentivar a utilização de transporte coletivo; incentivar à utilização de meios não motorizados; utilizar transporte coletivo movido a energia elétrica; implantar novas vias de interligação de bairros para transposição das barreiras físicas; legislação de uso e ocupação do solo adequadas; educação para o trânsito; diminuir o consumo de combustíveis; diminuir o número de viagens motorizadas; promover a interação entre os modos de transportes; promover o uso de combustível limpo no transporte coletivo; aumentar o número de ciclovias; melhorar integração dos transportes; realizar pesquisa de origem-destino para definição de melhores rotas; incentivar o transporte solidário (carona/rodízio); integração modal; melhorar a distribuição das atividades urbanas; criar zonas mistas; limitar o perímetro urbano; incentivar a ocupação de vazios urbanos e zonas com baixa densidade populacional; pavimentação e manutenção das vias de transporte público; restringir loteamentos distantes do centro.

A maioria dos problemas e soluções listados pelos participantes neste item foram também inseridos nas respostas do Questionário 2 (ver Anexo 14).

\section{- Outras análises - Análises de Suporte à Tomada de Decisão}

Ainda neste item os avaliadores puderam estabelecer alguns prazos para a solução dos problemas de Mobilidade identificados no item anterior, definir qual a esfera governamental que é responsável pelo envio de verbas para a solução dos problemas relacionados a cada indicador avaliado e definir qual o tipo de solução deveria ser adotada para resolver o(s) problema(s) relacionados ao indicador avaliado. O Quadro 8.7 apresenta as respostas (em percentagem) para estas avaliações e o número de avaliadores por indicador para a Categoria Meio Ambiente e Transportes. Os demais resultados encontramse no Anexo 10, divididos por Categoria. 
Quadro 8.7 - Análises de Suporte à Tomada de Decisão em relação aos Problemas avaliados no Módulo III

\begin{tabular}{|c|c|c|c|c|c|c|}
\hline \multicolumn{7}{|c|}{ TOMADA DE DECISÃO } \\
\hline CATEG. & TEMA & IND & Prazo Médio & Responsável & Solução & $\mathbf{N}^{0}$ AVAL. \\
\hline \multirow{9}{*}{ 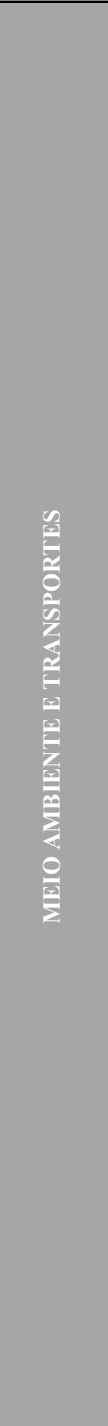 } & \multirow{2}{*}{ 产 } & $\begin{array}{c}\text { E1 } \\
\text { Consumo per capita de } \\
\text { combustível fóssil e não- } \\
\text { fóssil por transporte em } \\
\text { veículo motorizado }\end{array}$ & $\begin{array}{l}16,6 \% \text { Menos de } 6 \\
\text { meses } \\
16,6 \% \text { Até } 1 \text { ano } \\
16,6 \% \text { Até } 2 \text { anos } \\
50,0 \% \text { Mais de } 2 \text { anos }\end{array}$ & $\begin{array}{l}\text { 66,6\% Governo } \\
\text { Municipal } \\
\text { Governo Estadual } \\
\text { Governo Federal } \\
\text { 33,4\% Não definido }\end{array}$ & $\begin{array}{l}\text { 50,0\% Estudo Técnico } \\
\text { Manutenção } \\
\text { Construção } \\
50 \% \text { Não definido }\end{array}$ & 6 \\
\hline & & $\begin{array}{c}\text { E2 } \\
\text { Eficiência energética do } \\
\text { transporte de passageiro e } \\
\text { carga }\end{array}$ & $\begin{array}{l}\text { Menos de } 6 \text { meses } \\
\text { Até } 1 \text { ano } \\
50 \% \text { Até } 2 \text { anos } \\
50 \% \text { Mais de } 2 \text { anos }\end{array}$ & $\begin{array}{l}50 \% \text { Governo } \\
\text { Municipal } \\
\text { Governo Estadual } \\
50 \% \text { Governo Federal } \\
\text { Não definido } \\
\end{array}$ & $\begin{array}{l}50 \% \text { Estudo Técnico } \\
50 \% \text { Manutenção } \\
\text { Construção } \\
\text { Não definido }\end{array}$ & 2 \\
\hline & \multirow{2}{*}{ 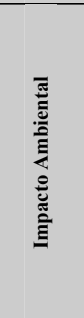 } & $\begin{array}{l}\text { I1 } \\
\begin{array}{c}\text { Fragmentação de Áreas } \\
\text { Urbanas }\end{array}\end{array}$ & $\begin{array}{l}\text { Menos de } 6 \text { meses } \\
\text { Até } 1 \text { ano } \\
20 \% \text { Até } 2 \text { anos } \\
80 \% \text { Mais de } 2 \text { anos }\end{array}$ & $\begin{array}{l}100 \% \text { Governo } \\
\text { Municipal } \\
\text { Governo Estadual } \\
\text { Governo Federal } \\
\text { Não definido }\end{array}$ & $\begin{array}{l}60 \% \text { Estudo Técnico } \\
\text { Manutenção } \\
20 \% \text { Construção } \\
20 \% \text { Não definido }\end{array}$ & 5 \\
\hline & & $\begin{array}{l}\text { I2 } \\
\text { Impactos do uso de } \\
\text { automóveis }\end{array}$ & $\begin{array}{l}25 \% \text { Menos de } 6 \text { meses } \\
\text { Até } 1 \text { ano } \\
\text { Até } 2 \text { anos } \\
75 \% \text { Mais de } 2 \text { anos }\end{array}$ & $\begin{array}{l}50 \% \text { Governo } \\
\text { Municipal } \\
\text { Governo Estadual } \\
25 \% \text { Governo Federal } \\
25 \% \text { Não definido }\end{array}$ & $\begin{array}{l}50 \% \text { Estudo Técnico } \\
25 \% \text { Manutenção } \\
\text { Construção } \\
25 \% \text { Não definido }\end{array}$ & 4 \\
\hline & \multirow{3}{*}{ 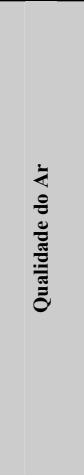 } & $\begin{array}{c}\text { Q2 } \\
\text { Emissões causadas pelos } \\
\text { transportes e intensidade das } \\
\text { emissões }\end{array}$ & $\begin{array}{l}50 \% \text { Menos de } 6 \text { meses } \\
\text { Até } 1 \text { ano } \\
50 \% \text { Até } 2 \text { anos } \\
\text { Mais de } 2 \text { anos }\end{array}$ & $\begin{array}{l}100 \% \text { Governo } \\
\text { Municipal } \\
\text { Governo Estadual } \\
\text { Governo Federal } \\
\text { Não definido }\end{array}$ & $\begin{array}{l}50 \% \text { Estudo Técnico } \\
\text { Manutenção } \\
\text { Construção } \\
50 \% \text { Não definido }\end{array}$ & 2 \\
\hline & & $\begin{array}{c}\text { Q3 } \\
\text { População exposta à } \\
\text { poluição do ar causada pelos } \\
\text { transportes }\end{array}$ & $\begin{array}{l}\text { Menos de } 6 \text { meses } \\
\text { Até } 1 \text { ano } \\
\text { Até } 2 \text { anos } \\
100 \% \text { Mais de } 2 \text { anos }\end{array}$ & $\begin{array}{l}100 \% \text { Governo } \\
\text { Municipal } \\
\text { Governo Estadual } \\
\text { Governo Federal } \\
\text { Não definido }\end{array}$ & $\begin{array}{l}100 \% \text { Estudo Técnico } \\
\text { Manutenção } \\
\text { Construção } \\
\text { Não definido }\end{array}$ & 1 \\
\hline & & $\begin{array}{c}\text { Q4 } \\
\text { Qualidade do ar }\end{array}$ & $\begin{array}{l}\text { Menos de } 6 \text { meses } \\
\text { Até } 1 \text { ano } \\
40 \% \text { Até } 2 \text { anos } \\
60 \% \text { Mais de } 2 \text { anos }\end{array}$ & $\begin{array}{l}60 \% \text { Governo } \\
\text { Municipal } \\
\text { Governo Estadual } \\
40 \% \text { Governo Federal } \\
\text { Não definido }\end{array}$ & $\begin{array}{l}60 \% \text { Estudo Técnico } \\
40 \% \text { Manutenção } \\
\text { Construção } \\
\text { Não definido }\end{array}$ & 5 \\
\hline & \multirow{2}{*}{$\stackrel{\overbrace{}}{\cong}$} & $\begin{array}{l}\text { R1 } \\
\text { Medidas de minimização de } \\
\text { ruído }\end{array}$ & $\begin{array}{l}25 \% \text { Menos de } 6 \text { meses } \\
25 \% \text { Até } 1 \text { ano } \\
\text { Até } 2 \text { anos } \\
50 \% \text { Mais de } 2 \text { anos }\end{array}$ & $\begin{array}{l}25 \% \text { Governo } \\
\text { Municipal } \\
\text { Governo Estadual } \\
25 \% \text { Governo Federal } \\
50 \% \text { Não definido } \\
\end{array}$ & $\begin{array}{l}50 \% \text { Estudo Técnico } \\
25 \% \text { Manutenção } \\
\text { Construção } \\
25 \% \text { Não definido }\end{array}$ & 4 \\
\hline & & $\begin{array}{c}\mathbf{R 2} \\
\text { Poluição Sonora }\end{array}$ & $\begin{array}{l}\text { Menos de } 6 \text { meses } \\
\text { Até } 1 \text { ano } \\
50 \% \text { Até } 2 \text { anos } \\
50 \% \text { Mais de } 2 \text { anos }\end{array}$ & $\begin{array}{l}50 \% \text { Governo } \\
\text { Municipal } \\
\text { Governo Estadual } \\
25 \% \text { Governo Federal } \\
25 \% \text { Não definido }\end{array}$ & $\begin{array}{l}25 \% \text { Estudo Técnico } \\
25 \% \text { Manutenção } \\
25 \% \text { Construção } \\
25 \% \text { Não definido }\end{array}$ & 4 \\
\hline
\end{tabular}

Os resultados obtidos nesta avaliação mostraram que nem todos os avaliadores tem uma opinião formada (embora vários sejam especialistas) a respeito dos prazos mínimos para a solução de um problema relacionado a um determinado indicador.

Com relação a avaliação "Responsável pela Solução do Problema", a maioria definiu que a solução para quase todos os problemas é de responsabilidade municipal.

O último item permitiu verificar se os avaliadores tem algum conhecimento sobre os aspectos que estão diretamente relacionados com a solução de cada indicador apresentado, ou seja, se a solução depende de estudo técnico, se é falta de manutenção ou se está associada à construção. 


\subsubsection{Análise do Grau de Importância dos Indicadores}

O segundo item avaliado no Módulo III referiu-se a análise do Grau de Importância de cada Indicador. Para esta análise o procedimento adotado foi: i) definição dos pesos por avaliador e por grupo; ii) definição do peso médio de cada indicador por grupo e iii) ordenamento dos indicadores.

Inicialmente foram calculados os pesos por avaliador e por indicador, a média de cada indicador e seu respectivo desvio padrão. As tabelas que mostram os pesos de cada indicador por avaliador são apresentadas no Anexo 11.

A Tabela 8.10 apresenta o peso médio de cada indicador por grupo de avaliação, seu correspondente peso final e o ranking final. As células coloridas mostram os indicadores que obtiveram as dez primeiras colocações (através do cálculo do ranking) para cada um dos grupos; e as células com borda em destaque mostram os indicadores que obtiveram o mesmo peso final nos Grupos I e II e o mesmo ordenamento final.

Tabela 8.10 - Cálculo do peso médio por grupo e o respectivo ordenamento na avaliação do Grau de importância dos indicadores

\begin{tabular}{|c|c|c|c|c|c|c|c|c|}
\hline \multirow{2}{*}{ CATEG. } & \multirow[t]{2}{*}{ TEMA } & \multirow[t]{2}{*}{ IND } & \multicolumn{2}{|c|}{$\begin{array}{c}\text { PESO PARCIAL } \\
\text { (peso médlio por grupo) }\end{array}$} & \multicolumn{2}{|c|}{ PESO FINAL } & \multicolumn{2}{|c|}{$\begin{array}{l}\text { RANKING } \\
\text { FINAL } \\
\end{array}$} \\
\hline & & & GRUPO I & GRUPO II & GRUPO I & GRUPO II & GRUPO I & GRUPO II \\
\hline \multirow{9}{*}{ 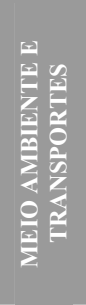 } & \multirow{2}{*}{ Energia } & E1 & 0,211 & 0,171 & 0,010 & 0,010 & 10 & 9 \\
\hline & & E2 & 0,050 & 0,063 & 0,002 & 0,004 & 34 & 27 \\
\hline & \multirow{2}{*}{ Impacto Ambiental } & I1 & 0,186 & 0,197 & 0,011 & 0,011 & 7 & 8 \\
\hline & & 12 & 0,121 & 0,151 & 0,007 & 0,008 & 16 & 11 \\
\hline & \multirow{3}{*}{ Qualidade do Ar } & Q2 & 0,044 & 0,119 & 0,002 & 0,005 & 36 & 22 \\
\hline & & Q3 & 0,000 & 0,063 & 0,000 & 0,003 & 40 & 32 \\
\hline & & Q4 & 0,181 & 0,067 & 0,008 & 0,003 & 12 & 31 \\
\hline & \multirow{2}{*}{ Ruído } & R1 & 0,090 & 0,135 & 0,003 & 0,005 & 29 & 24 \\
\hline & & R2 & 0,116 & 0,033 & 0,004 & 0,001 & 25 & 35 \\
\hline \multirow{8}{*}{$\begin{array}{l}0 \\
8 \\
8 \\
0 \\
0 \\
0 \\
0 \\
0 \\
0 \\
0 \\
0 \\
0 \\
0 \\
0 \\
0\end{array}$} & \multirow{2}{*}{ Estratégias Econômicas } & EE3 & 0,096 & 0,000 & 0,005 & 0,000 & 21 & 36 \\
\hline & & EE4 & 0,175 & 0,227 & 0,009 & 0,012 & 11 & 6 \\
\hline & \multirow{2}{*}{ Monitoramento } & M1 & 0,165 & 0,128 & 0,008 & 0,005 & 15 & 23 \\
\hline & & M2 & 0,044 & 0,169 & 0,002 & 0,007 & 37 & 15 \\
\hline & \multirow{2}{*}{ Mobilidade Urbana } & MU1 & 0,209 & 0,294 & 0,012 & 0,017 & 4 & 1 \\
\hline & & MU6 & 0,083 & 0,000 & 0,005 & 0,000 & 20 & 36 \\
\hline & \multirow{2}{*}{ Novas Tecnologias } & N1 & 0,072 & 0,059 & 0,002 & 0,002 & 33 & 34 \\
\hline & & N2 & 0,155 & 0,123 & 0,005 & 0,005 & 19 & 25 \\
\hline \multirow{9}{*}{ 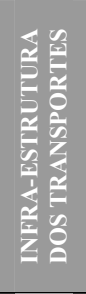 } & \multirow{2}{*}{ Frota } & F3 & 0,101 & 0,195 & 0,004 & 0,007 & 27 & 16 \\
\hline & & F4 & 0,089 & 0,153 & 0,004 & 0,005 & 28 & 21 \\
\hline & \multirow{2}{*}{ Sistema Viário } & $\mathbf{S 7}$ & 0,203 & 0,146 & 0,011 & 0,008 & 9 & 13 \\
\hline & & S8 & 0,056 & 0,152 & 0,003 & 0,008 & 32 & 12 \\
\hline & \multirow{2}{*}{ Serviços de Transportes } & ST1 & 0,159 & 0,121 & 0,008 & 0,005 & 13 & 19 \\
\hline & & ST4 & 0,128 & 0,056 & 0,007 & 0,003 & 17 & 33 \\
\hline & \multirow{3}{*}{ Tráfego } & T1 & 0,000 & 0,061 & 0,000 & 0,003 & 40 & 30 \\
\hline & & T3 & 0,033 & 0,000 & 0,002 & 0,000 & 39 & 36 \\
\hline & & T4 & 0,231 & 0,116 & 0,012 & 0,006 & 5 & 18 \\
\hline \multirow{9}{*}{ 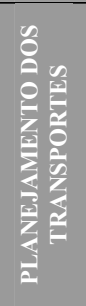 } & \multirow{2}{*}{ Acessibilidade Urbana } & A4 & 0,215 & 0,239 & 0,014 & 0,014 & 1 & 5 \\
\hline & & A5 & 0,033 & 0,000 & 0,002 & 0,000 & 35 & 36 \\
\hline & \multirow{2}{*}{ Crescimento Urbano } & $\mathrm{C3}$ & 0,059 & 0,000 & 0,003 & 0,000 & 30 & 36 \\
\hline & & C7 & 0,231 & 0,200 & 0,013 & 0,011 & 2 & 7 \\
\hline & \multirow{2}{*}{ População Urbana } & P2 & 0,217 & 0,317 & 0,013 & 0,015 & 3 & 3 \\
\hline & & P5 & 0,000 & 0,000 & 0,000 & 0,000 & 40 & 36 \\
\hline & \multirow{3}{*}{ Viagens } & $\mathbf{V} 2$ & 0,040 & 0,067 & 0,002 & 0,003 & 38 & 28 \\
\hline & & V5 & 0,091 & 0,067 & 0,005 & 0,003 & 23 & 28 \\
\hline & & V7 & 0,114 & 0,111 & 0,006 & 0,005 & 18 & 20 \\
\hline
\end{tabular}


Tabela 8.10 - Cálculo do peso médio por grupo e o respectivo ordenamento na avaliação do Grau de importância dos indicadores (continuação)

\begin{tabular}{|c|c|c|c|c|c|c|c|c|}
\hline \multirow{8}{*}{ 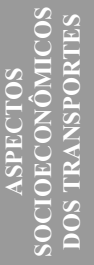 } & \multirow{2}{*}{ Custos } & CT1 & 0,274 & $\mathbf{0 , 0 0 0}$ & 0,012 & $\mathbf{0 , 0 0 0}$ & 6 & 36 \\
\hline & & CT3 & $\mathbf{0 , 0 0 0}$ & 0,259 & 0,000 & 0,016 & 40 & 2 \\
\hline & \multirow{2}{*}{$\begin{array}{c}\text { Impactos } \\
\text { Socioeconômicos }\end{array}$} & IS1 & 0,093 & 0,071 & 0,004 & 0,004 & 26 & 26 \\
\hline & & IS3 & 0,102 & 0,271 & 0,005 & 0,014 & 22 & 4 \\
\hline & \multirow{2}{*}{ Segurança Viária } & SV1 & 0,090 & 0,000 & 0,004 & 0,000 & 24 & 36 \\
\hline & & SV2 & 0,156 & 0,199 & 0,008 & 0,009 & 14 & 10 \\
\hline & \multirow{2}{*}{ Transporte Público } & TP1 & 0,063 & 0,104 & 0,003 & $\mathbf{0 , 0 0 7}$ & 31 & 14 \\
\hline & & TP2 & 0,224 & 0,095 & 0,011 & 0,006 & 8 & 17 \\
\hline
\end{tabular}

Analisando os dados referente aos pesos finais, apresentados na Tabela 8.10, pode-se verificar que, dos 43 indicadores, apenas 7 obtiveram o mesmo peso final nos dois grupos de avaliadores (células com borda em destaque). Estes indicadores são: E1 (Consumo per capita de combustível fóssil e não-fóssil por transporte em veículo motorizado), I1 (Fragmentação de Áreas Urbanas), N1 (Desenvolvimento de combustíveis limpos e número de veículos que utilizam combustíveis alternativos), $\mathbf{N 2}$ (Novas formas de transporte), A4 (Percentagem de empregos situados a até $3 \mathrm{~km}$ de distância das residências), P5 (Taxa de crescimento da população) e IS1 (Benefícios dos usuários de transportes) cujos pesos são respectivamente: 0,$010 ; 0,011 ; 0,002 ; 0,005 ; 0,014 ; 0,000$ e 0,004. É importante ressaltar que durante o processo de avaliação deste módulo foi solicitado aos participantes que escolhessem apenas um Indicador de cada Tema, embora o sistema permita a escolha de até dois indicadores para avaliação. Esta é a justificativa para que alguns indicadores não tenham sido escolhidos, obtendo, portanto, peso igual a zero.

Outro aspecto relevante, apresentado na Tabela 8.10, refere-se ao ordenamento final dos indicadores. Nas colunas 8 e 9, pode-se localizar os indicadores que obtiveram o mesmo ranking final (células com borda em destaque); são eles: P2 (Densidade populacional) e IS1 (Beneficios dos usuários de transportes) que ficaram respectivamente na $3^{\mathrm{a}}$ e $26^{\mathrm{a}}$ posição.

A partir das informações apresentadas no Tabela 8.10, é possível analisar o ordenamento dos indicadores. Para facilitar esta análise foi construído o Quadro 8.8 que permite analisar os indicadores que pertencem às dez primeiras colocações em cada grupo. 
Quadro 8.8 - Relação dos 10 primeiros indicadores Mais Importantes por grupo de avaliação

\begin{tabular}{|c|c|c|c|c|}
\hline & TEMA & INDICADOR & DESCRIÇÃO & $\overline{\text { ORDEM }}$ \\
\hline \multirow{10}{*}{$\begin{array}{l}\overrightarrow{0} \\
\tilde{b} \\
\underline{0}\end{array}$} & Acessibilidade Urbana & A4 & $\begin{array}{l}\text { Percentagem de empregos situados a até } 3 \mathrm{~km} \text { de distância das } \\
\text { residências }\end{array}$ & 1 \\
\hline & Crescimento Urbano & C7 & Planejamento do uso do solo urbano & 2 \\
\hline & População Urbana & $\mathbf{P 2}$ & Densidade populacional & 3 \\
\hline & Mobilidade Urbana & MU1 & Desenvolvimento de planos municipais para a redução das viagens & 4 \\
\hline & Tráfego & T4 & Tempo total gasto no tráfego & 5 \\
\hline & Custos & CT1 & Custo por passageiro transportado corrigido pela inflação & 6 \\
\hline & Impacto Ambiental & I1 & Fragmentação de Áreas Urbanas & 7 \\
\hline & Transporte Público & TP2 & Disponibilidade de transporte público & 8 \\
\hline & Sistema Viário & S7 & Possibilidade de acesso de transporte coletivo (pavimentação) & 9 \\
\hline & Energia & E1 & $\begin{array}{l}\text { Consumo per capita de combustível fóssil e não-fóssil por transporte } \\
\text { em veículo motorizado }\end{array}$ & 10 \\
\hline \multirow{10}{*}{$\begin{array}{l}\equiv \\
0 \\
\hat{0} \\
\frac{0}{0}\end{array}$} & Mobilidade Urbana & MU1 & Desenvolvimento de planos municipais para a redução das viagens & 1 \\
\hline & Custos & CT3 & Preço dos combustíveis e taxas & 2 \\
\hline & População Urbana & $\mathbf{P 2}$ & Densidade populacional & 3 \\
\hline & Impactos Socioeconômicos & IS3 & Custos sociais dos transportes & 4 \\
\hline & Acessibilidade Urbana & A4 & $\begin{array}{l}\text { Percentagem de empregos situados a até } 3 \mathrm{~km} \text { de distância das } \\
\text { residências }\end{array}$ & 5 \\
\hline & Estratégias Econômicas & EE4 & Investimentos em infra-estrutura de transportes & 6 \\
\hline & Crescimento Urbano & C7 & Planejamento do uso do solo urbano & 7 \\
\hline & Impacto Ambiental & I1 & Fragmentação de Áreas Urbanas & 8 \\
\hline & Energia & E1 & $\begin{array}{l}\text { Consumo per capita de combustível fóssil e não-fóssil por transporte } \\
\text { em veículo motorizado }\end{array}$ & 9 \\
\hline & Segurança Viária & SV2 & Feridos por acidentes de tráfego & 10 \\
\hline
\end{tabular}

Ao analisar o Quadro 8.8 pode-se observar que 30\% dos Temas (e seus respectivos indicadores) são diferentes nas avaliações dos Grupos I e II. No Grupo I (especialistas) esta diferença pode ser observada através dos seguintes indicadores: T4 (Tempo total gasto no tráfego), TP2 (Disponibilidade de Transporte Público) e CT1 (Custo por passageiro transportado corrigido pela inflação). Enquanto que no Grupo II (nãoespecialistas) há uma outra abordagem (preocupação) com relação a Mobilidade Urbana, que pode ser identificada nos seguintes indicadores: IS3 (Custos sociais dos transportes); EE4 (Investimentos em infra-estrutura de transportes); SV2 (Feridos por acidentes de tráfego).

Por outro lado, a análise das avaliações presentes no Quadro 8.8 permitiu verificar que há um consenso na escolha dos 70\% dos indicadores relativos à Mobilidade Urbana. Embora os grupos sejam heterogêneos pôde-se perceber que ambos possuem a mesma preocupação com relação aos problemas mais importantes para o município de Bauru.

A questão do crescimento espacial desordenado na cidade gerando grandes vazios urbanos, a falta de um planejamento integrado entre a questão do uso do solo e do transporte no município estão representadas na escolha dos seguintes indicadores: A4 (Percentagem de empregos situados a até $3 \mathrm{~km}$ de distância das residências); C7 (Planejamento do uso do solo urbano); P2 (Densidade populacional); MU1 
(Desenvolvimento de planos municipais para a redução das viagens); e I1 (Fragmentação de Áreas Urbanas).

\subsubsection{Comparação entre a avaliação dos Temas e dos Indicadores}

Com os resultados obtidos na avaliação das Categorias e Temas (Módulo I) associados à avaliação dos Indicadores (Módulo III) foi possível comparar estes resultados e verificar se houve uma correspondência entre os ordenamentos nos dois módulos, ou seja, verificar se os avaliadores atribuíram o mesmo "grau de importância" para Temas e Indicadores.

O Quadro 8.9 foi construído a partir dos resultados apresentados nos Quadros 8.3 e 8.8. Ele apresenta o resultado da avaliação dos Temas (avaliação do Módulo I) e dos Indicadores (avaliação Módulo III) entre os grupos de especialistas (Grupo I) e nãoespecialistas (Grupo II). As células com um asterisco correspondem àqueles Temas encontrados entre as 10 primeiras posições, por grupo de avaliação, e as células com a borda em destaque correspondem àquelas que permaneceram com o mesmo ordenamento nas duas avaliações (avaliações dos Temas e Indicadores) (ver Quadros 8.3 e 8.8).

Quadro 8.9 - Resultado das avaliações dos Módulos I e III - Ordenamento dos Temas e Indicadores por grupo de avaliação

\begin{tabular}{|c|c|c|c|c|c|}
\hline & \multicolumn{2}{|l|}{ GRUPO I } & \multicolumn{2}{|l|}{ GRUPO II } & ORDEM \\
\hline \multirow{10}{*}{$\sum_{i=1}^{\infty}$} & \multicolumn{2}{|l|}{ Acessibilidade Urbana * } & \multicolumn{2}{|l|}{ Transporte Público } & 1 \\
\hline & \multicolumn{2}{|l|}{ Impacto Ambiental * } & \multicolumn{2}{|l|}{ Custos * } & 2 \\
\hline & \multicolumn{2}{|l|}{ Mobilidade Urbana * } & \multicolumn{2}{|l|}{ Mobilidade Urbana * } & 3 \\
\hline & \multicolumn{2}{|l|}{ População Urbana * } & \multicolumn{2}{|l|}{ Energia * } & 4 \\
\hline & \multicolumn{2}{|l|}{ Crescimento Urbano * } & \multicolumn{2}{|l|}{ Acessibilidade Urbana * } & 5 \\
\hline & \multicolumn{2}{|l|}{ Sistema Viário * } & \multicolumn{2}{|l|}{ Impacto Ambiental * } & 6 \\
\hline & \multicolumn{2}{|l|}{ Serviços de Transportes } & \multicolumn{2}{|l|}{ Crescimento Urbano * } & 7 \\
\hline & \multicolumn{2}{|l|}{ Tráfego * } & \multicolumn{2}{|l|}{ Sistema Viário } & 8 \\
\hline & \multicolumn{2}{|l|}{ Estratégias Econômicas } & \multicolumn{2}{|l|}{ Impactos Socioeconômicos * } & 9 \\
\hline & \multicolumn{2}{|l|}{ Viagens } & \multicolumn{2}{|l|}{ Estratégias Econômicas } & 10 \\
\hline \multirow{10}{*}{ 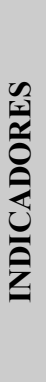 } & Acessibilidade Urbana * & A4 & Mobilidade Urbana * & MU1 & 1 \\
\hline & Crescimento Urbano * & C7 & Custos * & CT3 & 2 \\
\hline & População Urbana * & P2 & População Urbana & P2 & 3 \\
\hline & Mobilidade Urbana * & MU1 & Impactos Socioeconômicos * & IS3 & 4 \\
\hline & Tráfego * & T4 & Acessibilidade Urbana * & A4 & 5 \\
\hline & Custos & CT1 & Estratégias Econômicas & EE4 & 6 \\
\hline & Impacto Ambiental * & I1 & Crescimento Urbano * & C7 & 7 \\
\hline & Transporte Público & TP2 & Impacto Ambiental * & I1 & 8 \\
\hline & Sistema Viário * & S7 & Energia * & E1 & 9 \\
\hline & Energia & E1 & Segurança Viária & SV2 & 10 \\
\hline
\end{tabular}

Na comparação dos resultados dos Temas e Indicadores, avaliando cada grupo independentemente pode-se observar que, tanto para o Grupo I quanto para o Grupo II, o índice de correspondência dos temas foi de 70\% (células com asterisco) o que permite indicar que embora as avaliações para os Temas e Indicadores tenham ocorrido em períodos 
distintos, a definição dos temas mais importantes para a avaliação da Mobilidade Urbana para Bauru permaneceu, na maioria dos casos, sem alteração.

Com os resultados apresentados no Quadro 8.9, pode-se afirmar que os Temas em comum na avaliação dos Módulo I e III não devem ser excluídos do Sistema de Indicadores de Mobilidade Urbana.

Ainda com relação a avaliação do Grau de Importância dos Indicadores foi analisada a existência de uma correspondência (correlação) nos resultados de cada grupo e entre os resultados dos dois grupos. Foram calculados o Coeficiente de Correlação de Concordância de Kendall (w) e o Coeficiente de Correlação de Postos de Kendall $(\tau)$.

\section{- Cálculo do coeficiente de correlação de concordância de Kendall (w)}

Após a realização do cálculo dos pesos dos indicadores por avaliador foi calculado o respectivo ranking por Categoria para posteriormente calcular o coeficiente de Correlação de Kendall (w) por grupo de avaliação e por Categoria.

A Tabela 8.11 apresenta os resultados obtidos no cálculo do índice de correlação de Kendall (w) com relação à avaliação do "grau de importância" de cada indicador para os Grupos I e II.

Tabela 8.11 - Cálculo do Coeficiente de Correlação de Kendall (w) para os indicadores através da avaliação do Grau de importância de cada indicador

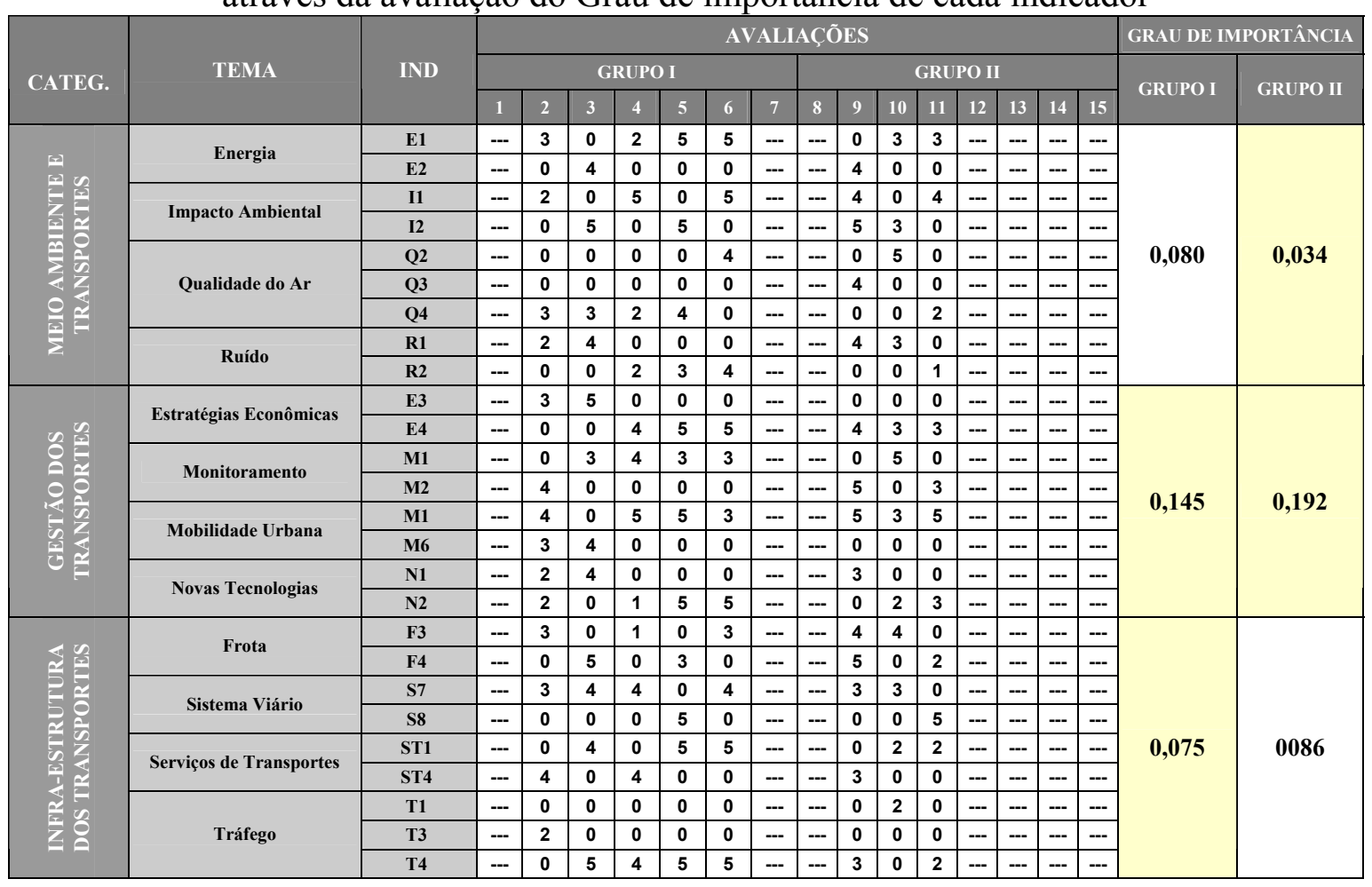


Tabela 8.11 - Cálculo do Coeficiente de Correlação de Kendall (w) para os indicadores através da avaliação do Grau de importância de cada indicador (continuação)

\begin{tabular}{|c|c|c|c|c|c|c|c|c|c|c|c|c|c|c|c|c|c|c|c|}
\hline \multirow{9}{*}{ 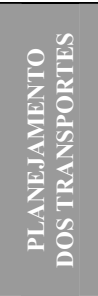 } & \multirow{2}{*}{ Acessibilidade Urbana } & A4 & -- & 0 & 5 & 4 & 4 & 5 & --- & --- & 3 & 3 & 4 & -- & --- & --- & -- & \multirow{9}{*}{0,123} & \multirow{9}{*}{0,119} \\
\hline & & A5 & -- & 2 & 0 & 0 & 0 & 0 & -- & --- & 0 & 0 & 0 & -- & --- & --- & -- & & \\
\hline & \multirow{2}{*}{ Crescimento Urbano } & C3 & --- & 0 & 0 & 5 & 0 & 0 & --- & --- & 0 & 0 & 0 & --- & --- & --- & --- & & \\
\hline & & C7 & \begin{tabular}{ll|}
-- \\
\end{tabular} & 3 & 5 & 0 & 5 & 5 & --- & --- & 0 & 5 & 4 & --- & --- & --- & --- & & \\
\hline & \multirow{2}{*}{ População Urbana } & P2 & -- & 3 & 4 & 4 & 3 & 3 & -- & $--\cdot$ & 5 & 4 & 4 & -- & $--\cdot$ & --- & -- & & \\
\hline & & P5 & -- & 0 & 0 & 0 & 0 & 0 & $-\cdots$ & $\cdots$ & 0 & 0 & 0 & -- & $-\cdots$ & $-\cdots$ & $--\cdot$ & & \\
\hline & \multirow{3}{*}{ Viagens } & V2 & $-\cdots$ & 0 & 0 & 0 & 3 & 0 & $-\cdots$ & $-\cdots$ & 0 & 0 & 3 & -- & $-\cdots$ & $-\cdots$ & $-\cdots$ & & \\
\hline & & V5 & -- & 0 & 3 & 0 & 0 & 5 & $-\cdots$ & --- & 0 & 3 & 0 & -- & -- & --- & --- & & \\
\hline & & V7 & --- & 4 & 0 & 4 & 0 & 0 & -- & --- & 4 & 0 & 0 & -- & $-\cdots$ & --- & $--\cdot$ & & \\
\hline \multirow{8}{*}{ 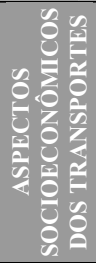 } & \multirow{2}{*}{ Custos } & CT1 & --- & 3 & 4 & 4 & 5 & 5 & $--\cdot$ & --- & 0 & 0 & 0 & -- & $-\cdots$ & --- & $--\cdot$ & \multirow{8}{*}{0,120} & \multirow{8}{*}{0,157} \\
\hline & & CT3 & --- & 0 & 0 & 0 & 0 & 0 & $--\cdot$ & --- & 5 & 3 & 1 & -- & --- & --- & --- & & \\
\hline & \multirow{2}{*}{ Impactos Socioeconômicos } & IS1 & -- & 0 & 5 & 3 & 0 & 0 & -- & --- & 0 & 3 & 0 & -- & -- & --- & --- & & \\
\hline & & IS3 & -- & 3 & 0 & 0 & 2 & 2 & $--\cdot$ & $-\cdots$ & 5 & 0 & 5 & -- & $--\cdot$ & $-\cdots$ & -- & & \\
\hline & \multirow{2}{*}{ Segurança Viária } & SV1 & -- & 3 & 0 & 0 & 0 & 3 & -- & -- & 0 & 0 & 0 & -- & --- & -- & -- & & \\
\hline & & SV2 & -- & 0 & 5 & 4 & 4 & 0 & -- & --- & 0 & 4 & 5 & -- & $--\cdot$ & --- & $--\cdot$ & & \\
\hline & \multirow{2}{*}{ Transporte Público } & TP1 & $-\cdots$ & 0 & 0 & 5 & 0 & 0 & -- & --- & 0 & 0 & 5 & -- & $--\cdot$ & --- & $--\cdot$ & & \\
\hline & & TP2 & $-\cdots$ & 3 & 4 & 0 & 5 & 5 & -- & --- & 0 & 4 & 0 & -- & --- & --- & $--\cdot$ & & \\
\hline
\end{tabular}

Os resultados do índice de correlação de Kendall (w) obtidos por grupo de avaliação mostram que o Grupo II apresentou o maior e o menor índice geral de correlação na comparação entre os dois grupos; sendo que a categoria Gestão dos Transportes obteve o maior índice $(\mathrm{w}=0,192)$, enquanto que a categoria Meio Ambiente e Transportes obteve o menor índice geral $(\mathrm{w}=0,034)$. Com relação ao Grupo I pode-se observar que o maior índice de correlação também foi encontrado na categoria Gestão dos Transportes (w = 0,145). Com relação a categoria que obteve o menor índice neste grupo, a categoria Infraestrutura dos Transportes, obteve o índice $\mathrm{w}=0,075$.

Os resultados dos índices de correlação de concordância de Kendall obtidos nos dois grupos indicam baixas correlações positivas. Este índice pode ser ratificado através do ordenamento de cada categoria, que mostrou que não há um consenso entre os grupos. Ao observar o ordenamento de cada categoria nos dois grupos de avaliação tem-se o seguinte resultado: Gestão dos Transportes ( $1^{\mathrm{a}}$ e $1^{\mathrm{a}}$ ordem), Planejamento dos Transportes ( $2^{\mathrm{a}}$ e $3^{\mathrm{a}}$ ordem), Aspectos Socioeconômicos dos Transportes ( $3^{\mathrm{a}}$ e $2^{\mathrm{a}}$ ordem), Meio ambiente e Transportes ( $4^{\mathrm{a}}$ e $5^{\mathrm{a}}$ ordem) e Infra-estrutura dos Transportes ( $5^{\mathrm{a}}$ e $4^{\mathrm{a}}$ ordem).

\section{- Cálculo do coeficiente de correlação de postos de Kendall $(\tau)$}

Posteriormente foi calculado o Índice de Correlação de Postos de Kendall $(\tau)$ que permitiu identificar uma correspondência na determinação do "grau de importância" de cada Indicador para os Grupos I e II (especialistas e não-especialistas).

A Tabela 8.12 apresenta o peso médio de cada indicador por grupo de avaliação, seu correspondente peso final, o ranking final e o índice de postos de Kendall, respectivamente. As células com borda em destaque mostram os Indicadores que obtiveram o mesmo peso final e mesmo ordenamento nos Grupos I e II. 
Tabela 8.12 - Cálculo do Coefíciente de Correlação de Postos de Kendall $(\tau)$ para os indicadores através da avaliação do Grau de Importância de cada indicador

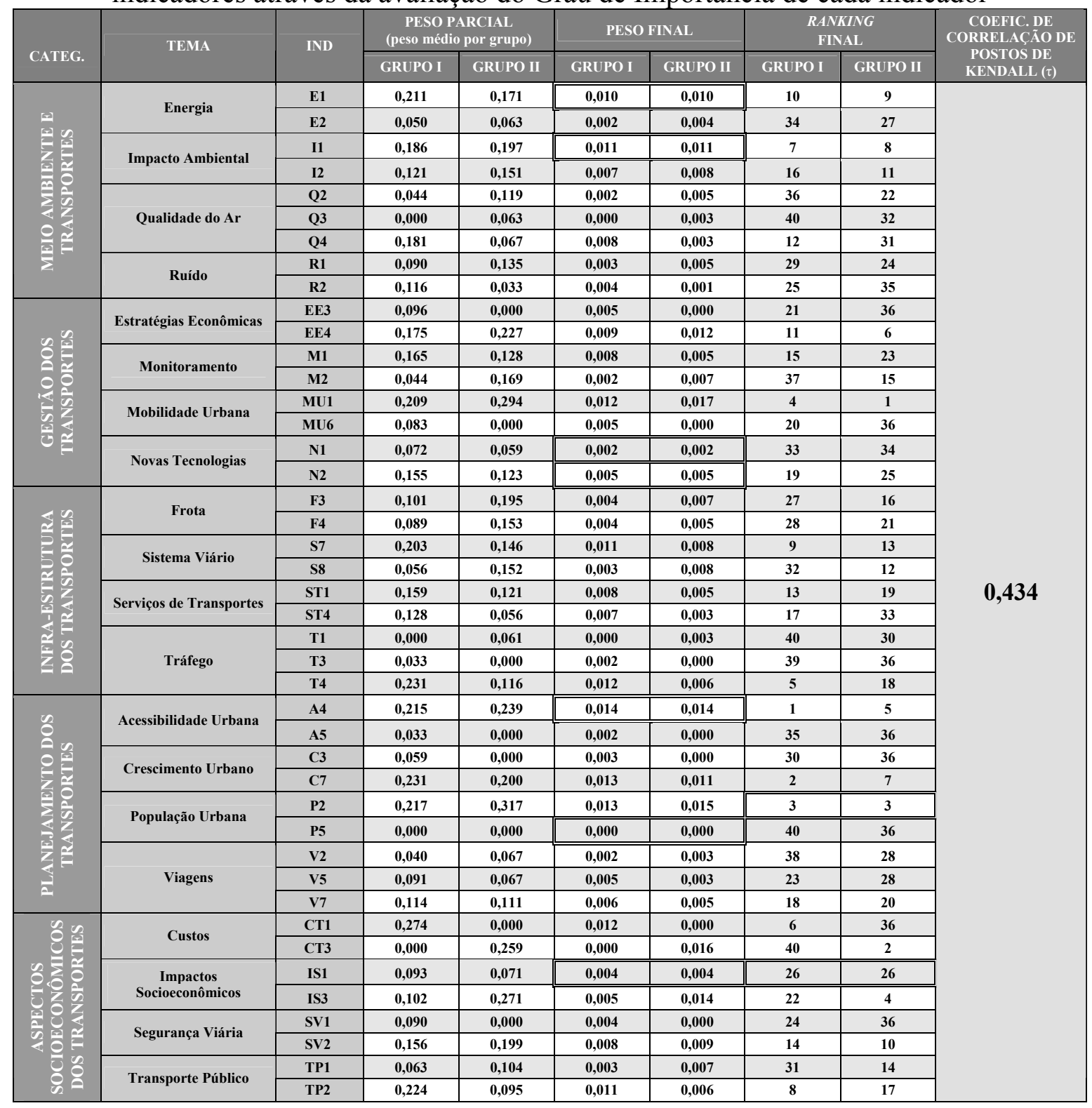

O resultado obtido através do cálculo do coeficiente de correlação de postos de Kendall $(\tau)$ vem confirmar os dados apresentados anteriormente, mostrando uma razoável correlação positiva entre os avaliadores.

\subsubsection{Análise do Grau de Urgência dos Indicadores}

Após a análise do "Grau de Importância” realizou-se a análise do "Grau de Urgência" dos Indicadores para os dois grupos de avaliação. Os procedimentos utilizados foram análogos ao cálculo do Grau de Importância. Inicialmente definiu-se os pesos para cada indicador; foi calculado o peso médio por indicador e por grupo, para posteriormente 
calcular o índice de Correlação de Concordância de Kendall (w) por grupo de avaliação e por Categoria.

A Tabela 8.13 apresenta os pesos por avaliador, a média entre os dois grupos e os respectivos desvios padrões.

Tabela 8.13 - Avaliação do Grau de Urgência dos Indicadores - Definição dos pesos por avaliador, média global e desvio padrão

\begin{tabular}{|c|c|c|c|c|c|c|c|c|c|c|c|c|c|c|c|c|c|c|c|}
\hline \multirow[b]{2}{*}{ CATEG. } & \multirow{2}{*}{ TEMA } & \multirow{2}{*}{ IND } & \multicolumn{7}{|c|}{$\overline{\text { GRUPO I }}$} & \multicolumn{8}{|c|}{$\overline{\text { GRUPO II }}$} & \multirow{2}{*}{ MÉD } & \multirow{2}{*}{$\begin{array}{l}\text { DESV. } \\
\text { PAD. }\end{array}$} \\
\hline & & & 1 & 2 & 3 & $\overline{4}$ & 5 & $\overline{6}$ & 7 & 8 & 9 & 10 & 11 & 12 & 13 & 14 & 15 & & \\
\hline \multirow{9}{*}{ 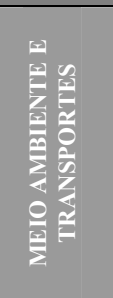 } & \multirow{2}{*}{ Energia } & E1 & -- & 0,333 & & 0,100 & 0,267 & 0,278 & -- & -- & & 0,200 & 0,333 & -- & -- & -- & - & 0,189 & 0,139 \\
\hline & & E2 & --- & & 0,250 & & & & --- & --- & 0,174 & & & -- & --- & -- & -- & 0,053 & 0,100 \\
\hline & \multirow{2}{*}{ Impacto Ambiental } & I1 & --- & 0,250 & & 0,500 & & 0,278 & --- & --- & 0,174 & & 0,417 & --- & -- & -- & -- & 0,202 & 0,195 \\
\hline & & 12 & --- & & 0,313 & & 0,333 & & -- & $--\cdot$ & 0,217 & 0,267 & & -- & -- & -- & -- & 0,141 & 0,155 \\
\hline & \multirow{3}{*}{ Qualidade do Ar } & Q2 & --- & & & & & 0,222 & --- & --- & & 0,333 & & --- & -- & -- & -- & 0,069 & 0,132 \\
\hline & & Q3 & --- & & & & & & --- & --- & 0,217 & & & --- & -- & $--\cdot$ & -- & 0,027 & 0,077 \\
\hline & & Q4 & --- & 0,250 & 0,188 & 0,200 & 0,200 & & -- & --- & & & \begin{tabular}{|l|}
0,167 \\
\end{tabular} & -- & -- & --- & -- & 0,126 & 0,106 \\
\hline & \multirow{2}{*}{ Ruído } & R1 & --- & 0,167 & 0,250 & & & & -- & -- & 0,217 & 0,200 & & -- & -- & -- & -- & 0,104 & 0,114 \\
\hline & & $\mathbf{R 2}$ & --- & & & 0,200 & 0,200 & 0,222 & --- & -- & & & 0,083 & -- & -- & -- & -- & 0,088 & 0,103 \\
\hline \multirow{8}{*}{$\begin{array}{l}0 \\
8 \\
8 \\
0 \\
0 \\
0 \\
0\end{array}$} & \multirow{2}{*}{$\begin{array}{l}\text { Estratégias } \\
\text { Econômicas }\end{array}$} & E3 & --- & 0,200 & 0,313 & & & & -- & --- & & & & --- & --- & --- & -- & 0,064 & 0,122 \\
\hline & & $\mathbf{E 4}$ & --- & & & 0,267 & 0,278 & 0,313 & -- & -- & 0,235 & 0,200 & 0,267 & --- & --- & --- & -- & 0,195 & 0,125 \\
\hline & \multirow{2}{*}{ Monitoramento } & M1 & -- & & 0,188 & 0,333 & 0,167 & 0,188 & -- & -- & & 0,500 & & -- & --- & -- & -- & 0,172 & 0,178 \\
\hline & & M2 & -- & 0,200 & & & & & -- & -- & 0,294 & & 0,200 & -- & -- & -- & -- & 0,087 & 0,123 \\
\hline & \multirow{2}{*}{ Mobilidade Urbana } & M1 & -- & 0,267 & & 0,333 & 0,278 & 0,188 & -- & -- & 0,294 & 0,200 & 0,333 & -- & -- & -- & -- & 0,237 & 0,110 \\
\hline & & M6 & -- & 0,133 & 0,250 & & & & -- & --- & & & & -- & -- & -- & -- & 0,048 & 0,094 \\
\hline & \multirow{2}{*}{ Novas Tecnologias } & N1 & --- & 0,067 & 0,250 & & & & -- & --- & 0,176 & & & -- & -- & -- & -- & 0,062 & 0,098 \\
\hline & & N2 & --- & 0,133 & & 0,067 & 0,278 & 0,313 & -- & --- & & 0,100 & 0,200 & --- & -- & -- & $-\ldots$ & 0,136 & 0,119 \\
\hline & & F3 & -- & 0,250 & & 0,077 & & 0,235 & -- & -- & 0,190 & 0,500 & & -- & -- & -- & -- & 0,157 & 0,175 \\
\hline 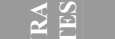 & Frota & F4 & --- & & 0,278 & & 0,167 & & --- & --- & 0,238 & & 0,182 & --- & -- & --- & -- & 0,108 & 0,120 \\
\hline 를 & Sistema Viário & S7 & --- & 0,333 & 0,222 & 0,308 & & 0,176 & -- & --- & 0,190 & 0,300 & & -- & -- & --- & -- & 0,191 & 0,131 \\
\hline 20 & Sistema Vıarıo & $\begin{array}{l}\mathbf{S 8} \\
\end{array}$ & --- & & & & 0,278 & & -- & --- & & & 0,455 & -- & -- & -- & -- & 0,092 & 0,176 \\
\hline$\frac{1}{5}$ & Serviços de & ST1 & --- & & 0,222 & & 0,278 & 0,294 & -- & --- & & 0,100 & 0,182 & --- & --- & --- & -- & 0,134 & 0,126 \\
\hline 2 & Transportes & ST4 & --- & 0,167 & & 0,308 & & & -- & --- & 0,238 & & & -- & -- & -- & -- & 0,089 & 0,129 \\
\hline$\frac{1}{0}$ & & T1 & --- & & & & & & -- & -- & & 0,100 & & -- & --- & -- & -- & 0,013 & 0,035 \\
\hline 留 & Tráfego & T3 & -- & 0,250 & & & & & -- & --- & & & & -- & -- & -- & -- & 0,031 & 0,088 \\
\hline & & T4 & -- & & 0,278 & 0,308 & 0,278 & 0,294 & -- & -- & 0,143 & & 0,182 & -- & -- & -- & -- & 0,185 & 0,128 \\
\hline & Acessibilidade & A4 & -- & & 0,294 & 0,235 & 0,267 & 0,278 & -- & --- & 0,167 & 0,231 & 0,176 & -- & -- & -- & -- & 0,206 & 0,095 \\
\hline & Urbana & A5 & --- & 0,222 & & & & & -- & --- & & & & --- & -- & -- & -- & 0,028 & 0,079 \\
\hline $\bar{z}_{x=}^{\circ}$ & Crescimento & $\mathrm{C3}$ & -- & & & 0,294 & & & -- & -- & & & & -- & -- & -- & -- & 0,037 & 0,104 \\
\hline$\frac{1}{2}$ & Urbano & C7 & -- & 0,222 & 0,294 & & 0,333 & 0,278 & -- & --- & 0,278 & 0,385 & 0,294 & -- & -- & -- & -- & 0,260 & 0,115 \\
\hline$\frac{n}{3}$ & Populacão Urbana & P2 & -- & \begin{tabular}{|l|}
0,333 \\
\end{tabular} & 0,235 & 0,235 & 0,200 & 0,167 & -- & --- & 0,278 & 0,231 & \begin{tabular}{|l|}
0,294 \\
\end{tabular} & -- & -- & -- & -- & 0,247 & 0,053 \\
\hline$\frac{\sqrt{n}}{2} \simeq$ & Populaçao Urbana & P5 & --- & & & & & & -- & --- & & & & -- & -- & -- & -- & 0,000 & 0,000 \\
\hline$=$ & & V2 & --- & & & & 0,200 & & -- & --- & & & 0,235 & -- & -- & -- & -- & 0,054 & 0,101 \\
\hline 용 & Viagens & V5 & --- & & 0,176 & & & 0,278 & -- & --- & & 0,154 & & -- & -- & -- & -- & 0,076 & 0,111 \\
\hline & & V7 & --- & 0,222 & & 0,235 & & & -- & --- & 0,278 & & & --- & -- & -- & -- & 0,092 & 0,128 \\
\hline & Custos & CT1 & --- & 0,200 & 0,222 & 0,200 & 0,313 & 0,333 & -- & -- & & & & -- & -- & -- & -- & 0,159 & 0,140 \\
\hline 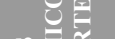 & Custos & CT3 & --- & & & & & & -- & -- & 0,500 & 0,250 & 0,182 & -- & -- & -- & -- & 0,116 & 0,184 \\
\hline 8ह ह & Impactos & IS1 & -- & & 0,278 & 0,200 & & & - & -- & & 0,250 & & -- & -- & -- & -- & 0,091 & 0,127 \\
\hline 记玄言 & Socioeconômicos & IS3 & -- & 0,200 & & & 0,125 & 0,133 & -- & -- & 0,500 & & 0,273 & -- & -- & -- & -- & 0,154 & 0,173 \\
\hline 정 & Seguranca Viária & SV1 & -- & 0,300 & & & & 0,200 & -- & -- & & & & -- & -- & -- & -- & 0,063 & 0,119 \\
\hline 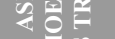 & Segurança viaria & SV2 & --- & & 0,278 & 0,267 & 0,250 & & -- & --- & & 0,313 & 0,273 & -- & -- & -- & -- & 0,172 & 0,144 \\
\hline & & TP1 & --- & & & 0,333 & & & -- & --- & & & 0,273 & --- & -- & -- & -- & 0,076 & 0,141 \\
\hline & Transporte Público & TP2 & -- & 0,300 & 0,222 & & 0,313 & 0,333 & -- & --- & & 0,188 & & -- & -- & -- & -- & 0,169 & 0,148 \\
\hline
\end{tabular}

Com os dados apresentados na Tabela 8.13, pode-se verificar se há algum grau de concordância nas avaliações realizadas pelos Grupos I e II, ou seja, se os dois grupos possuem o mesmo entendimento (consenso) quanto à prioridade na resolução dos problemas de mobilidade relacionados a cada indicador avaliado.

Cabe observar que nesta avaliação (determinação do Grau de Urgência) não foi possível realizar a comparação entre o ordenamento das avaliações do Grau de 
Importância com o Grau de Urgência, pois esta última avaliação só está presente no Módulo III. Esta comparação permitiria verificar se há uma correspondência na definição dos Indicadores mais importantes e mais urgentes para o município.

A Tabela 8.14 apresenta o cálculo do peso médio de cada Indicador por grupo e seu respectivo ranking. As células em amarelo apresentam os indicadores que obtiveram um ordenamento classificado entre as dez primeiras posições.

Tabela 8.14 - Cálculo do peso médio por grupo e o respectivo ordenamento na avaliação do Grau de Urgência dos indicadores

\begin{tabular}{|c|c|c|c|c|c|c|}
\hline \multirow[b]{2}{*}{ CATEG. } & \multirow{2}{*}{ TEMA } & \multirow{2}{*}{ IND } & \multicolumn{2}{|c|}{ PESO PARCIAL } & \multicolumn{2}{|c|}{ RANKING FINAL } \\
\hline & & & GRUPO I & GRUPO II & GRUPO I & GRUPO II \\
\hline \multirow{9}{*}{ 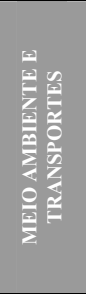 } & \multirow{2}{*}{ Energia } & E1 & 0,211 & 0,171 & 7 & 11 \\
\hline & & E2 & 0,050 & 0,063 & 34 & 30 \\
\hline & \multirow{2}{*}{ Impacto Ambiental } & I1 & $\mathbf{0 , 1 8 6}$ & $\mathbf{0 , 1 9 7}$ & 10 & 9 \\
\hline & & I2 & 0,121 & 0,151 & 18 & 15 \\
\hline & \multirow{3}{*}{ Qualidade do Ar } & Q2 & 0,044 & 0,119 & 35 & 21 \\
\hline & & Q3 & 0,000 & 0,063 & 40 & 30 \\
\hline & & Q4 & 0,181 & 0,067 & 11 & 27 \\
\hline & \multirow{2}{*}{ Ruído } & R1 & 0,090 & 0,135 & 26 & 17 \\
\hline & & R2 & 0,116 & $\begin{array}{c}0,033 \\
\end{array}$ & 19 & 35 \\
\hline \multirow{8}{*}{ 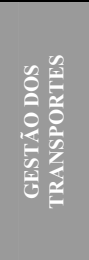 } & \multirow{2}{*}{ Estratégias Econômicas } & EE3 & 0,096 & 0,000 & 23 & 36 \\
\hline & & EE4 & 0,175 & $\mathbf{0 , 2 2 7}$ & 12 & 6 \\
\hline & \multirow{2}{*}{ Monitoramento } & M1 & 0,165 & 0,128 & 13 & 18 \\
\hline & & M2 & 0,044 & 0,169 & 35 & 12 \\
\hline & \multirow{2}{*}{ Mobilidade Urbana } & MU1 & 0,209 & 0,294 & 8 & 2 \\
\hline & & MU6 & 0,083 & 0,000 & 29 & 36 \\
\hline & \multirow{2}{*}{ Novas Tecnologias } & N1 & 0,072 & 0,059 & 30 & 33 \\
\hline & & N2 & 0,155 & 0,123 & 16 & 19 \\
\hline \multirow{9}{*}{ 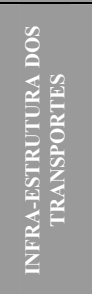 } & \multirow{2}{*}{ Frota } & F3 & 0,101 & 0,195 & 22 & 10 \\
\hline & & F4 & 0,089 & 0,153 & 28 & 13 \\
\hline & \multirow{2}{*}{ Sistema Viário } & S7 & 0,203 & 0,146 & 9 & 16 \\
\hline & & S8 & 0,056 & 0,152 & 33 & 14 \\
\hline & \multirow{2}{*}{ Serviços de Transportes } & ST1 & 0,159 & 0,121 & 14 & 20 \\
\hline & & ST4 & 0,128 & 0,056 & 17 & 34 \\
\hline & \multirow{3}{*}{ Tráfego } & T1 & 0,000 & 0,061 & 40 & 32 \\
\hline & & T3 & $\mathbf{0 , 0 3 3}$ & $\mathbf{0 , 0 0 0}$ & 38 & 36 \\
\hline & & T4 & 0,231 & 0,116 & 2 & 22 \\
\hline \multirow{9}{*}{ 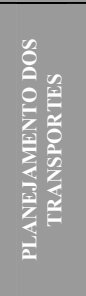 } & \multirow{2}{*}{ Acessibilidade Urbana } & A4 & 0,215 & 0,239 & 6 & 5 \\
\hline & & A5 & $\mathbf{0 , 0 3 3}$ & 0,000 & 38 & 36 \\
\hline & \multirow{2}{*}{ Crescimento Urbano } & $\mathrm{C} 3$ & 0,059 & 0,000 & 32 & 36 \\
\hline & & $\mathrm{C} 7$ & 0,231 & 0,200 & 2 & 7 \\
\hline & Populacõo Urbang & $\mathbf{P 2}$ & 0,217 & 0,317 & 5 & 1 \\
\hline & 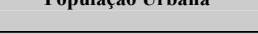 & P5 & 0,000 & 0,000 & 40 & 36 \\
\hline & & V2 & 0,040 & 0,067 & 37 & 27 \\
\hline & Viagens & V5 & 0,091 & 0,067 & 25 & 27 \\
\hline & & V7 & 0,114 & 0,111 & 20 & 23 \\
\hline & Custos & CT1 & 0,274 & 0,000 & 1 & 36 \\
\hline 8 & Custos & CT3 & 0,000 & 0,259 & 40 & 4 \\
\hline $8 \equiv$ & Imnactos STciecon̂tmicos & IS1 & 0,093 & 0,071 & 24 & 26 \\
\hline 늠 & & IS3 & 0,102 & 0,271 & 21 & 3 \\
\hline 원 & Sosuranca Viária & SV1 & 0,090 & 0,000 & 26 & 36 \\
\hline$<0$ & segurainça viáta & SV2 & 0,156 & 0,199 & 15 & 8 \\
\hline 80 & Transnorte Públice & TP1 & 0,063 & 0,104 & 31 & 24 \\
\hline & Transporte Pubico & TP2 & 0,224 & 0,095 & 4 & 25 \\
\hline
\end{tabular}

Com base na Tabela 8.14 foi possível verificar uma comparação entre os resultados do ordenamento das dez primeiras posições entre os dois grupos de avaliação. $\mathrm{O}$ Quadro 8.10 apresenta esta comparação. As células com asterisco mostram os temas encontrados nos Grupos I e II e as células com a borda em destaque mostram os indicadores que foram escolhidos pelos dois grupos. 
Quadro 8.10 - Relação dos 10 primeiros indicadores Mais Urgentes por grupo de avaliação

\begin{tabular}{|c|c|c|c|c|}
\hline & TEMA & INDICADOR & DESCRIÇÃO & ORDEM \\
\hline \multirow{10}{*}{ 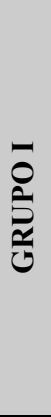 } & Custos * & CT1 & Custo por passageiro transportado corrigido pela inflação & 1 \\
\hline & Tráfego & T4 & Tempo total gasto no tráfego & 2 \\
\hline & Crescimento Urbano * & C7 & Planejamento do uso do solo urbano & 2 \\
\hline & Transporte Público & TP2 & Disponibilidade de transporte público & 4 \\
\hline & População Urbana * & P2 & Densidade populacional & 5 \\
\hline & Acessibilidade Urbana * & A4 & Percentagem de empregos situados a até $3 \mathrm{~km}$ de distância das residências & 6 \\
\hline & Energia & E1 & $\begin{array}{l}\text { Consumo per capita de combustivel fóssil e não-fóssil por transporte em veículo } \\
\text { motorizado }\end{array}$ & 7 \\
\hline & Mobilidade Urbana * & MU1 & Desenvolvimento de planos municipais para a redução das viagens & 8 \\
\hline & Sistema Viário & S7 & Possibilidade de acesso de transporte coletivo (pavimentação) & 9 \\
\hline & Impacto Ambiental * & I1 & Fragmentação de Áreas Urbanas & 10 \\
\hline \multirow{10}{*}{ 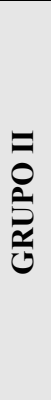 } & População Urbana * & P2 & Densidade populacional & 1 \\
\hline & Mobilidade Urbana * & MU1 & Desenvolvimento de planos municipais para a redução das viagens & 2 \\
\hline & Impactos Socioeconômicos & IS3 & Custos sociais dos transportes & 3 \\
\hline & Custos * & CT3 & Preço dos combustíveis e taxas & 4 \\
\hline & Acessibilidade Urbana * & A4 & Percentagem de empregos situados a até $3 \mathrm{~km}$ de distância das residências & 5 \\
\hline & Estratégias Econômicas & EE4 & Investimentos em infra-estrutura de transportes & 6 \\
\hline & Crescimento Urbano * & C7 & Planejamento do uso do solo urbano & 7 \\
\hline & Segurança Viária & SV2 & Feridos por acidentes de tráfego & 8 \\
\hline & Impacto Ambiental * & I1 & Fragmentação de Áreas Urbanas & 9 \\
\hline & Frota & F3 & Percentagem da frota municipal convertida para reduzir a emissão de poluentes & 10 \\
\hline
\end{tabular}

Embora não tenha sido encontrada uma correlação direta entre as escolhas dos Indicadores para os dois grupos, de acordo com os resultados apresentados no Quadro 8.10, pode-se verificar que 60\% dos Temas e 50\% dos Indicadores são comuns para estes avaliadores. Este resultado significa que os indicadores: C7 - Planejamento do uso do solo urbano; P2 - Densidade populacional; $A 4$ - Percentagem de empregos situados a até $3 \mathrm{~km}$ de distância das residências; MU1 - Desenvolvimento de planos municipais para a redução das viagens; I1 - Fragmentação de Áreas Urbanas), segundo a avaliação dos especialistas e não-especialistas, devem ter prioridade na implantação de medidas para minimizar os problemas de mobilidade urbana no município.

Segundo o Quadro 8.10 os temas considerados "mais urgentes" para os Grupos I e II (Crescimento Urbano, População Urbana, Acessibilidade Urbana, Mobilidade Urbana e Impacto Ambiental) vêm ratificar as respostas obtidas no Questionário 2 - que permitiu realizar um diagnóstico sobre dos principais problemas de Mobilidade Urbana do município de Bauru.

\section{- Cálculo do Coeficiente de Correlação de Concordância de Kendall (w)}

A Tabela 8.15 apresenta as avaliações de cada participante e o Índice de Correlação de Concordância de Kendall para os Indicadores.

Os resultados obtidos por grupo de avaliação na determinação do índice de correlação de Kendall (w) mostram que o Grupo II apresentou o maior e o menor índice de correlação na comparação entre os dois grupos. A categoria Gestão dos Transportes obteve 
o maior índice $(\mathrm{w}=0,180)$ enquanto que a categoria Meio Ambiente e Transportes obteve o menor índice $(\mathrm{w}=0,039)$. Com relação ao Grupo I pode-se observar que o maior índice de correlação refere-se a categoria Aspectos Socioeconômicos dos Transportes (w $=0,150)$ enquanto que o menor índice está associado à categoria Infra-estrutura dos Transportes (w $=0,066)$.

Tabela 8.15 - Cálculo do Coeficiente de Correlação de Kendall (w) para os indicadores através da avaliação do Grau de Urgência de cada indicador

\begin{tabular}{|c|c|c|c|c|c|c|c|c|c|c|c|c|c|c|c|c|c|c|c|}
\hline \multirow{3}{*}{ CATEG. } & \multirow{3}{*}{ TEMA } & \multirow{3}{*}{ IND } & \multicolumn{15}{|c|}{ AVALIAÇÕES } & \multicolumn{2}{|c|}{$\begin{array}{l}\text { COEF. CORRELAÇÃO DE } \\
\text { KENDALL (w) }\end{array}$} \\
\hline & & & \multicolumn{7}{|c|}{ GRUPO I } & \multicolumn{8}{|c|}{ GRUPO II } & \multirow{2}{*}{ GRUPO I } & \multirow{2}{*}{ GRUPO II } \\
\hline & & & 1 & 2 & 3 & 4 & 5 & 6 & 7 & 8 & 9 & 10 & 11 & 12 & 13 & 14 & 15 & & \\
\hline \multirow{9}{*}{ 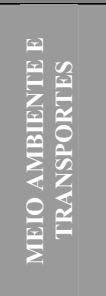 } & \multirow{2}{*}{ Energia } & E1 & -- & 4 & 0 & 1 & 4 & 5 & --- & -- & 0 & 3 & 4 & -- & -- & -- & -- & \multirow{9}{*}{0,088} & \multirow{9}{*}{$\mathbf{0 , 0 3 9}$} \\
\hline & & E2 & -- & 0 & 4 & 0 & 0 & 0 & --- & --- & 4 & 0 & 0 & -- & --- & -- & -- & & \\
\hline & \multirow{2}{*}{ Impacto Ambiental } & I1 & -- & 3 & 0 & 5 & 0 & 5 & --- & --- & 4 & 0 & 5 & -- & --- & -- & --- & & \\
\hline & & 12 & -- & 0 & 5 & 0 & 5 & 0 & --- & -- & 5 & 4 & 0 & -- & -- & -- & -- & & \\
\hline & \multirow{3}{*}{ Qualidade do Ar } & Q2 & -- & 0 & 0 & 0 & 0 & 4 & --- & -- & 0 & 5 & 0 & -- & --- & -- & -- & & \\
\hline & & Q3 & -- & 0 & 0 & 0 & 0 & 0 & -- & -- & 5 & 0 & 0 & -- & -- & -- & -- & & \\
\hline & & Q4 & -- & 3 & 3 & 2 & 3 & 0 & --- & -- & 0 & 0 & 2 & -- & --- & -- & --- & & \\
\hline & \multirow{2}{*}{ Ruído } & R1 & -- & 2 & 4 & 0 & 0 & 0 & --- & -- & 5 & 3 & 0 & --- & --- & -- & --- & & \\
\hline & & R2 & --- & 0 & 0 & 2 & 3 & 4 & --- & --- & 0 & 0 & 1 & --- & --- & -- & --- & & \\
\hline & Fstratégias Fconômicas & E3 & -- & 3 & 5 & 0 & 0 & 0 & --- & -- & 0 & 0 & 0 & -- & --- & -- & --- & & \\
\hline & Estratégias Econômicas & E4 & -- & 0 & 0 & 4 & 5 & 5 & -- & --- & 4 & 2 & 4 & -- & -- & -- & -- & & \\
\hline 远 & Monitoramento & M1 & -- & 0 & 3 & 5 & 3 & 3 & --- & --- & 0 & 5 & 0 & -- & --- & -- & --- & & \\
\hline 0 & Monitoramento & M2 & -- & 3 & 0 & 0 & 0 & 0 & --- & -- & 5 & 0 & 3 & -- & --- & -- & -- & 0002 & 0180 \\
\hline$\leqslant 5$ & & M1 & -- & 4 & 0 & 5 & 5 & 3 & -- & -- & 5 & 2 & 5 & -- & -- & -- & -- & 0,092 & 0,180 \\
\hline 5 & Mobilidade Urbana & M6 & -- & 2 & 4 & 0 & 0 & 0 & -- & -- & 0 & 0 & 0 & -- & -- & -- & -- & & \\
\hline & Noxas Tecnologias & N1 & -- & 1 & 4 & 0 & 0 & 0 & -- & -- & 3 & 0 & 0 & -- & -- & -- & -- & & \\
\hline & Novas Tecnologias & N2 & -- & 2 & 0 & 1 & 5 & 5 & -- & -- & 0 & 1 & 3 & -- & --- & -- & -- & & \\
\hline & Frata & F3 & -- & 3 & 0 & 1 & 0 & 4 & --- & --- & 4 & 5 & 0 & -- & -- & -- & --- & & \\
\hline 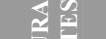 & Frota & F4 & -- & 0 & 5 & 0 & 3 & 0 & -- & -- & 5 & 0 & 2 & -- & -- & -- & -- & & \\
\hline 를 & Sistema Viário & S7 & -- & 4 & 4 & 4 & 0 & 3 & --- & --- & 4 & 3 & 0 & --- & --- & -- & --- & & \\
\hline 28 & Sistema viario & 58 & -- & 0 & 0 & 0 & 5 & 0 & --- & --- & 0 & 0 & 5 & -- & --- & -- & --- & & \\
\hline$\frac{n}{2}$ & & ST1 & -- & 0 & 4 & 0 & 5 & 5 & -- & $-\cdots$ & 0 & 1 & 2 & -- & --- & -- & --- & 0,066 & 0,106 \\
\hline$\frac{1}{2} \cong$ & Serviços de Transportes & ST4 & -- & 2 & 0 & 4 & 0 & 0 & -- & -- & 5 & 0 & 0 & -- & -- & -- & -- & & \\
\hline$\approx 0$ & & T1 & -- & 0 & 0 & 0 & 0 & 0 & --- & -- & 0 & 1 & 0 & -- & -- & -- & -- & & \\
\hline z & Tráfego & T3 & -- & 3 & 0 & 0 & 0 & 0 & --- & --- & 0 & 0 & 0 & -- & --- & -- & --- & & \\
\hline & & T4 & -- & 0 & 5 & 4 & 5 & 5 & --- & --- & 3 & 0 & 2 & -- & --- & -- & --- & & \\
\hline & Acessibilidade Urbana & A4 & -- & 0 & 5 & 4 & 4 & 5 & --- & --- & 3 & 3 & 3 & -- & --- & -- & -- & & \\
\hline 을 졸 & Acessibindade Urbana & A5 & -- & 2 & 0 & 0 & 0 & 0 & -- & -- & 0 & 0 & 0 & -- & -- & -- & -- & & \\
\hline $\bar{z} \bar{z}$ & Crescimento Urbano & $\mathrm{C3}$ & -- & 0 & 0 & 5 & 0 & 0 & -- & -- & 0 & 0 & 0 & -- & --- & -- & -- & & \\
\hline$\frac{1}{2} \stackrel{0}{2}$ & Crescimento Urbano & C7 & -- & 2 & 5 & 0 & 5 & 5 & -- & -- & 5 & 5 & 5 & -- & -- & -- & -- & & \\
\hline$\leq \frac{n}{2}$ & Ponulacão Urbana & P2 & -- & 3 & 4 & 4 & 3 & 3 & -- & -- & 5 & 3 & 5 & -- & -- & -- & -- & 0,106 & 0,154 \\
\hline$\frac{F}{2} \cong$ & Populaçao Urbana & P5 & -- & 0 & 0 & 0 & 0 & 0 & --- & -- & 0 & 0 & 0 & -- & -- & -- & --- & & \\
\hline & & V2 & -- & 0 & 0 & 0 & 3 & 0 & --- & --- & 0 & 0 & 4 & -- & -- & -- & --- & & \\
\hline 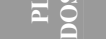 & Viagens & V5 & -- & 0 & 3 & 0 & 0 & 5 & -- & -- & 0 & 2 & 0 & -- & --- & -- & -- & & \\
\hline & & V7 & -- & 2 & 0 & 4 & 0 & 0 & -- & -- & 5 & 0 & 0 & -- & --- & -- & --- & & \\
\hline & Custos & CT1 & -- & 2 & 4 & 3 & 5 & 5 & --- & --- & 0 & 0 & 0 & -- & --- & -- & --- & & \\
\hline 을 죌 & Custos & CT3 & -- & 0 & 0 & 0 & 0 & 0 & --- & -- & 5 & 4 & 2 & -- & -- & -- & -- & & \\
\hline ชุ $\sum_{0}^{\overline{0}}$ & Imnactos Secipeconêmicos & IS1 & -- & 0 & 5 & 3 & 0 & 0 & --- & -- & 0 & 4 & 0 & -- & -- & -- & -- & & \\
\hline 븐흠 & Impactos socioeconomicos & IS3 & -- & 2 & 0 & 0 & 2 & 2 & --- & --- & 5 & 0 & 3 & -- & --- & -- & -- & 0.150 & 0123 \\
\hline 언 & Seouranca Viária & SV1 & -- & 3 & 0 & 0 & 0 & 3 & --- & -- & 0 & 0 & 0 & -- & -- & -- & -- & 0,150 & 0,123 \\
\hline 2 동 을 & & SV2 & -- & 0 & 5 & 4 & 4 & 0 & --- & -- & 0 & 5 & 3 & -- & -- & -- & --- & & \\
\hline 르 & Transporte Público & TP1 & -- & 0 & 0 & 5 & 0 & 0 & --- & -- & 0 & 0 & 3 & -- & --- & -- & -- & & \\
\hline $0=$ & Transporte Público & TP2 & -- & 3 & 4 & 0 & 5 & 5 & --- & -- & 0 & 3 & 0 & -- & -- & -- & --- & & \\
\hline
\end{tabular}

Os resultados dos índices de correlação de concordância de Kendall obtidos nos dois grupos indicam uma baixa correlação positiva. Este resultado pode ser analisado visualizando o ordenamento de cada categoria, que confirma que não há um consenso na avaliação entre os dois grupos. 


\subsubsection{Comparação entre os resultados do ordenamento da Avaliação do Grau de Importância e Grau de Urgência para as Categorias}

Realizando-se uma comparação entre o ordenamento das categorias por grau de importância e grau de urgência entre os Grupos I e II (especialistas e não-especialistas) pode-se observar que os resultados obtidos foram diferentes. (ver Tabela 8.16).

Tabela 8.16 - Comparação entre o ranking das avaliações referentes ao Grau de Importância e ao Grau de Urgência por Categoria

\begin{tabular}{|c|c|c|c|c|c|c|c|c|}
\hline \multirow{3}{*}{ CATEGORIA } & \multicolumn{4}{|c|}{ GRAU DE IMPORTÂNCIA } & \multicolumn{4}{|c|}{ GRAU DE URGÊNCIA } \\
\hline & \multicolumn{2}{|c|}{$\begin{array}{c}\text { COEF. CORRELAÇÃO } \\
\text { KENDALL }(w)\end{array}$} & \multicolumn{2}{|c|}{ ORDEM } & \multicolumn{2}{|c|}{$\begin{array}{l}\text { COEF. CORRELAÇÃO } \\
\text { KENDALL (w) }\end{array}$} & \multicolumn{2}{|c|}{ ORDEM } \\
\hline & GRUPO I & GRUPO II & GRUPO I & GRUPO II & GRUPO I & GRUPO II & GRUPO I & GRUPO II \\
\hline Meio ambiente e Transportes & 0,080 & $\mathbf{0 , 0 3 4}$ & 4 & 5 & 0,088 & 0,039 & 4 & 5 \\
\hline Gestão dos Transportes & 0,145 & 0,192 & 1 & 2 & 0,092 & 0,180 & 3 & 1 \\
\hline Infra-estrutura dos Transportes & 0,075 & 0,086 & 5 & 1 & 0,066 & 0,106 & 5 & 4 \\
\hline Aspectos socioeconômicos dos Transportes & 0,120 & 0,157 & 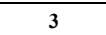 & 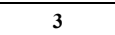 & 0,150 & 0,123 & 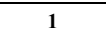 & 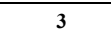 \\
\hline
\end{tabular}

Analisando os dados apresentados na Tabela 8.16, por grupo de avaliação, pode-se verificar que, no Grupo I, os avaliadores definiram valores muito semelhantes para a avaliação dos Indicadores para os aspectos "mais importante" e "mais urgente" para o município de Bauru (ver células com borda em destaque); este resultado é confirmado na coluna referente ao ranking destes critérios. As categorias que obtiveram o mesmo ordenamento nas duas avaliações foram: Planejamento dos Transportes, Meio Ambiente e Transportes e Infra-estrutura dos Transportes.

No Grupo II foram identificadas apenas duas categorias que permaneceram com o mesmo ordenamento nas duas avaliações: Aspectos Socioeconômicos dos Transportes e Meio Ambiente e Transportes.

A comparação entre a avaliação do indicador por Grau de Importância e por Grau de Urgência é importante para que o avaliador possa identificar que, embora um problema de mobilidade detectado no município seja importante (relevante) nem sempre ele é o mais urgente. Os resultados acima apresentados confirmam a diferença que existe entre as avaliações do grupo dos especialistas em relação ao grupo dos não-especialistas.

\subsubsection{Análise da localização dos problemas de Mobilidade por indicador e por região na cidade}

A última etapa de avaliação do Módulo III permitiu verificar a espacialização dos problemas definidos no sistema, para cada indicador, entre todos os 
participantes da avaliação. A Tabela 8.17 apresenta o percentual de cada avaliação de cada indicador para as cinco regiões da cidade e o número de avaliadores por indicador.

Tabela 8.17 - Identificação dos problemas relacionados a cada indicador nas cinco regiões do município de Bauru

\begin{tabular}{|c|c|c|c|c|c|c|c|c|c|}
\hline CATEG. & TEMA & IND & DEFINIÇÃO DO INDICADOR & CENTRO & NORTE & SUL & LESTE & OESTE & $\begin{array}{l}\mathbf{N}^{0} \\
\text { AVAL. }\end{array}$ \\
\hline \multirow{9}{*}{ 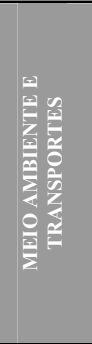 } & \multirow[t]{2}{*}{ Energia } & E1 & $\begin{array}{l}\text { Consumo per capita de combustível fóssil e não-fóssil por } \\
\text { transporte em veículo motorizado }\end{array}$ & $100,0 \%$ & $66,7 \%$ & $66,7 \%$ & $50,0 \%$ & $50,0 \%$ & 6 \\
\hline & & E2 & Eficiência energética do transporte de passageiro e carga & $50,0 \%$ & $50,0 \%$ & $50,0 \%$ & $50,0 \%$ & $50,0 \%$ & 2 \\
\hline & \multirow{2}{*}{$\begin{array}{c}\text { Impacto } \\
\text { Ambiental }\end{array}$} & I1 & Fragmentação de Áreas Urbanas & $20,0 \%$ & $80,0 \%$ & $20,0 \%$ & $80,0 \%$ & $60,0 \%$ & 5 \\
\hline & & $\mathbf{I 2}$ & Impactos do uso de automóveis & $100,0 \%$ & $75,0 \%$ & $75,0 \%$ & $75,0 \%$ & $75,0 \%$ & 4 \\
\hline & \multirow{3}{*}{ Qualidade do Ar } & Q2 & $\begin{array}{l}\text { Emissões causadas pelos transportes e intensidade das } \\
\text { emissões }\end{array}$ & $100,0 \%$ & $100,0 \%$ & $100,0 \%$ & $100,0 \%$ & $100,0 \%$ & 2 \\
\hline & & Q3 & População exposta à poluição do ar causada pelos transportes & $100,0 \%$ & ---- & ---- & ---- & ---- & 1 \\
\hline & & Q4 & Qualidade do ar & $60,0 \%$ & $20,0 \%$ & $20,0 \%$ & ---- & ---- & 5 \\
\hline & \multirow{2}{*}{ Ruído } & R1 & Medidas de minimização de ruído & $75,0 \%$ & $50,0 \%$ & $25,0 \%$ & $25,0 \%$ & $25,0 \%$ & 4 \\
\hline & & R2 & Poluição Sonora & $100,0 \%$ & ---- & 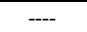 & ---- & ---- & 4 \\
\hline \multirow{8}{*}{ 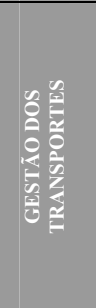 } & \multirow{2}{*}{$\begin{array}{l}\text { Estratégias } \\
\text { Econômicas }\end{array}$} & EE3 & Despesas públicas com transporte público & $100,0 \%$ & $100,0 \%$ & $50,0 \%$ & $50,0 \%$ & $50,0 \%$ & 2 \\
\hline & & EE4 & Investimentos em infra-estrutura de transportes & $66,7 \%$ & $83,3 \%$ & $66,7 \%$ & $83,3 \%$ & $83,3 \%$ & 6 \\
\hline & \multirow{2}{*}{ Monitoramento } & M1 & Avaliação de impacto ambiental & $80,0 \%$ & $20,0 \%$ & $80,0 \%$ & $40,0 \%$ & $20,0 \%$ & 5 \\
\hline & & M2 & Gerenciamento efetivo do tráfego / fiscalização & $66,7 \%$ & $33,3 \%$ & $33,3 \%$ & $33,3 \%$ & $33,3 \%$ & 3 \\
\hline & \multirow{2}{*}{$\begin{array}{l}\text { Mobilidade } \\
\text { Urbana }\end{array}$} & MU1 & $\begin{array}{l}\text { Desenvolvimento de planos municipais para a redução das } \\
\text { viagens }\end{array}$ & $28,6 \%$ & $71,4 \%$ & $42,9 \%$ & $71,4 \%$ & $71,4 \%$ & 7 \\
\hline & & MU6 & Priorizar viagens eficientes (a pé ou por bicicleta) & $100,0 \%$ & $100,0 \%$ & $50,0 \%$ & $50,0 \%$ & $50,0 \%$ & 2 \\
\hline & \multirow[t]{2}{*}{ Novas Tecnologias } & N1 & $\begin{array}{l}\text { Desenvolvimento de combustíveis limpos e número de } \\
\text { veículos que utilizam combustíveis alternativos }\end{array}$ & $66,7 \%$ & $66,7 \%$ & $66,7 \%$ & $66,7 \%$ & $66,7 \%$ & 3 \\
\hline & & N2 & Novas formas de transporte & $50,0 \%$ & $50,0 \%$ & $0,0 \%$ & $50,0 \%$ & $50,0 \%$ & 6 \\
\hline \multirow{9}{*}{ 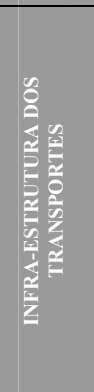 } & \multirow[b]{2}{*}{ Frota } & F3 & $\begin{array}{l}\text { Percentagem da frota municipal convertida para reduzir a } \\
\text { emissão de poluentes }\end{array}$ & $80,0 \%$ & $60,0 \%$ & $60,0 \%$ & $60,0 \%$ & $60,0 \%$ & 5 \\
\hline & & F4 & $\begin{array}{l}\text { Relação entre veículos com consumo eficiente de } \\
\text { combustivel / veículos com consumo ineficiente de } \\
\text { combustivel }\end{array}$ & $25,0 \%$ & --- & $25,0 \%$ & --- & --- & 4 \\
\hline & \multirow[b]{2}{*}{ Sistema Viário } & S7 & Possibilidade de acesso de transporte coletivo (pavimentação) & $100,0 \%$ & $33,3 \%$ & $66,7 \%$ & $33,3 \%$ & $33,3 \%$ & 6 \\
\hline & & S8 & $\begin{array}{l}\text { Provisão de infra-estrutura para moderação de tráfego e vias } \\
\text { para bicicletas e pedestres }\end{array}$ & --- & --- & --- & --- & --- & 2 \\
\hline & \multirow{2}{*}{$\begin{array}{l}\text { Serviços de } \\
\text { Transportes }\end{array}$} & ST1 & Mudanças nos modos de transporte & $80,0 \%$ & $80,0 \%$ & $80,0 \%$ & $80,0 \%$ & $80,0 \%$ & 5 \\
\hline & & ST4 & Transporte de passageiros por modo de transporte & $33,3 \%$ & $66,7 \%$ & $33,3 \%$ & $66,7 \%$ & $66,7 \%$ & 3 \\
\hline & \multirow{3}{*}{ Tráfego } & T1 & Densidade de tráfego & $100,0 \%$ & --- & --- & -+-- & -+- & 1 \\
\hline & & T3 & Taxa de ocupação dos veículos de passageiros & $100,0 \%$ & ---- & ---- & $100,0 \%$ & $100,0 \%$ & 1 \\
\hline & & T4 & Tempo total gasto no tráfego & $50,0 \%$ & $33,3 \%$ & $50,0 \%$ & $33,3 \%$ & $33,3 \%$ & 6 \\
\hline \multirow{9}{*}{ 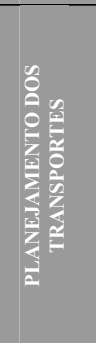 } & \multirow{2}{*}{$\begin{array}{l}\text { Acessibilidade } \\
\text { Urbana }\end{array}$} & A4 & $\begin{array}{l}\text { Percentagem de empregos situados a até } 3 \mathrm{~km} \text { de distância } \\
\text { das residências }\end{array}$ & $14,3 \%$ & $57,1 \%$ & $28,6 \%$ & $57,1 \%$ & $57,1 \%$ & 7 \\
\hline & & A5 & $\begin{array}{l}\text { Percentagem de pessoas que vivem a até } 3 \mathrm{~km} \text { de distância } \\
\text { das facilidades de lazer }\end{array}$ & $50,0 \%$ & $50,0 \%$ & $50,0 \%$ & $50,0 \%$ & $50,0 \%$ & 2 \\
\hline & \multirow{2}{*}{$\begin{array}{l}\text { Crescimento } \\
\text { Urbano }\end{array}$} & $\mathrm{C3}$ & Desconcentração das atividades & --- & $\begin{array}{c}--- \\
-\end{array}$ & $100,0 \%$ & $100,0 \%$ & $100,0 \%$ & 1 \\
\hline & & C7 & Planejamento do uso do solo urbano & $57,1 \%$ & $57,1 \%$ & $42,9 \%$ & $42,9 \%$ & $42,9 \%$ & 7 \\
\hline & \multirow{2}{*}{ População Urbana } & $\mathbf{P 2}$ & Densidade populacional & $12,5 \%$ & $50,0 \%$ & $50,0 \%$ & $37,5 \%$ & $37,5 \%$ & 8 \\
\hline & & P5 & Taxa de crescimento da população & ---- & ---- & ---- & -+-- & ---- & $\mathbf{0}$ \\
\hline & \multirow{3}{*}{ Viagens } & $\mathbf{V 2}$ & Distância aos serviços básicos & $-\cdots-$ & --- & --- & --- & ---- & 2 \\
\hline & & $\mathbf{V 5}$ & Número de pessoas vivendo e trabalhando no local & $100,0 \%$ & $66,7 \%$ & $66,7 \%$ & $66,7 \%$ & $66,7 \%$ & 3 \\
\hline & & V7 & Tempo de viagem & $33,3 \%$ & $66,7 \%$ & ---- & $66,7 \%$ & $33,3 \%$ & 3 \\
\hline \multirow{8}{*}{ 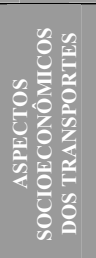 } & \multirow{2}{*}{ Custos } & CT1 & Custo por passageiro transportado corrigido pela inflação & $40,0 \%$ & $60,0 \%$ & $40,0 \%$ & $60,0 \%$ & $60,0 \%$ & 5 \\
\hline & & CT3 & Preço dos combustiveis e taxas & $33,3 \%$ & $33,3 \%$ & $33,3 \%$ & $33,3 \%$ & $33,3 \%$ & 3 \\
\hline & Impactos & IS1 & Benefícios dos usuários de transportes & $100,0 \%$ & $66,7 \%$ & $66,7 \%$ & $66,7 \%$ & $66,7 \%$ & 3 \\
\hline & Socioeconômicos & IS3 & Custos sociais dos transportes & $40,0 \%$ & $20,0 \%$ & $20,0 \%$ & $20,0 \%$ & $20,0 \%$ & 5 \\
\hline & Seouranca Viária & SV1 & Acidentes fatais de transporte & $66,7 \%$ & $33,3 \%$ & $33,3 \%$ & $33,3 \%$ & $33,3 \%$ & 3 \\
\hline & Segurança Viária & SV2 & Feridos por acidentes de tráfego & $60,0 \%$ & $20,0 \%$ & $40,0 \%$ & $20,0 \%$ & $20,0 \%$ & 5 \\
\hline & & TP1 & Demanda por transporte de passageiros & $50,0 \%$ & $50,0 \%$ & $50,0 \%$ & $50,0 \%$ & $50,0 \%$ & 2 \\
\hline & Público & TP2 & Disponibilidade de transporte público & -.-- & $60,0 \%$ & $40,0 \%$ & $80,0 \%$ & $80,0 \%$ & 5 \\
\hline
\end{tabular}

O Quadro 8.11 apresenta os gráficos comparativos (Figuras 8.7 a 8.11) dos Indicadores agrupados por Categoria e por região da cidade e suas respectivas análises. Estes resultados permitiram caracterizar, nas cinco regiões da cidade os principais problemas de mobilidade associados a cada uma delas, facilitando um diagnóstico das regiões por Categoria. 
Quadro 8.11 - Análise da distribuição dos problemas de Mobilidade por Categoria (Região da Cidade com Problema relacionado ao indicador avaliado)

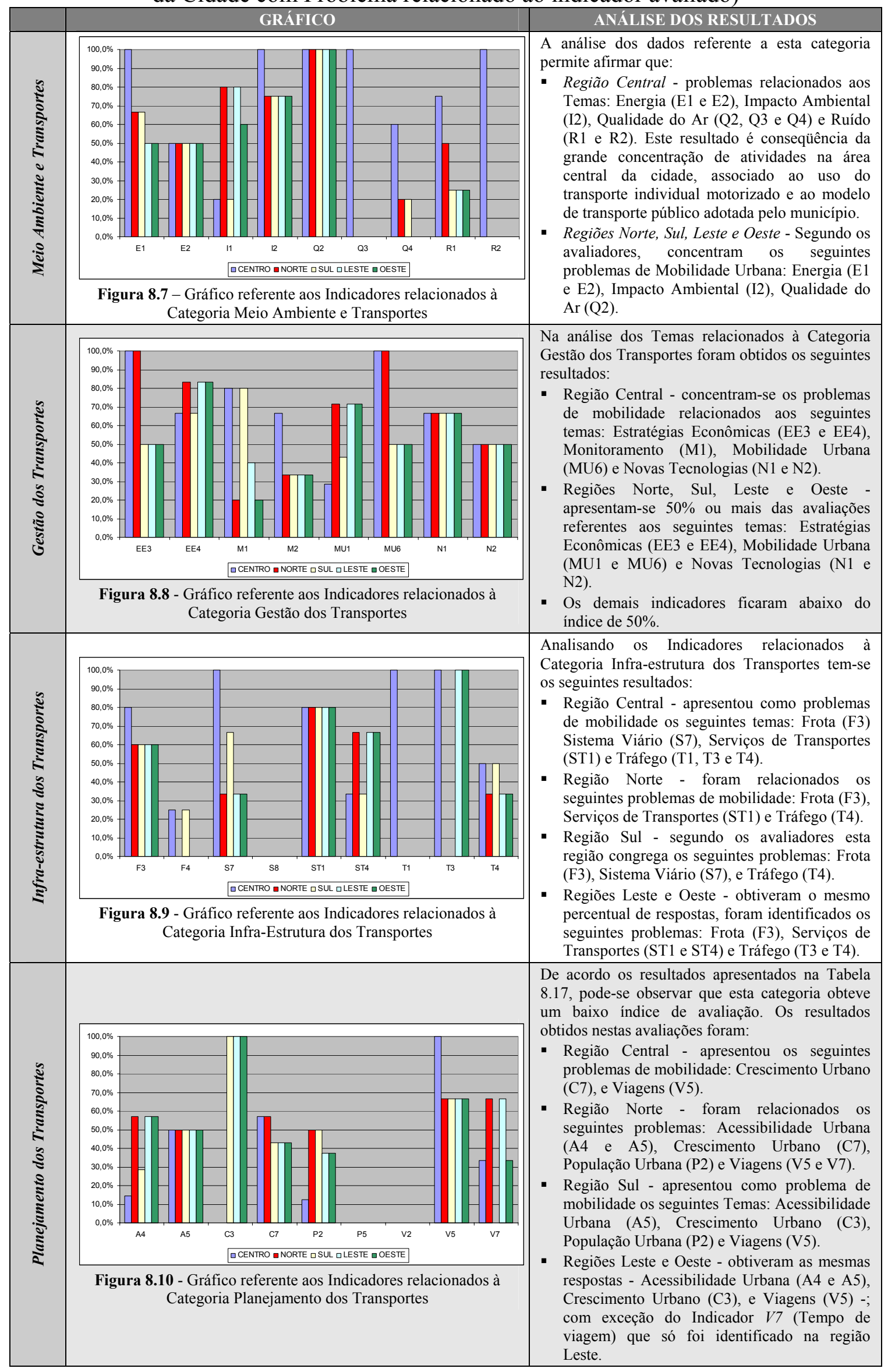


Quadro 8.11 - Análise da distribuição dos problemas de Mobilidade por Categoria (Região da Cidade com Problema relacionado ao indicador avaliado) (continuação)

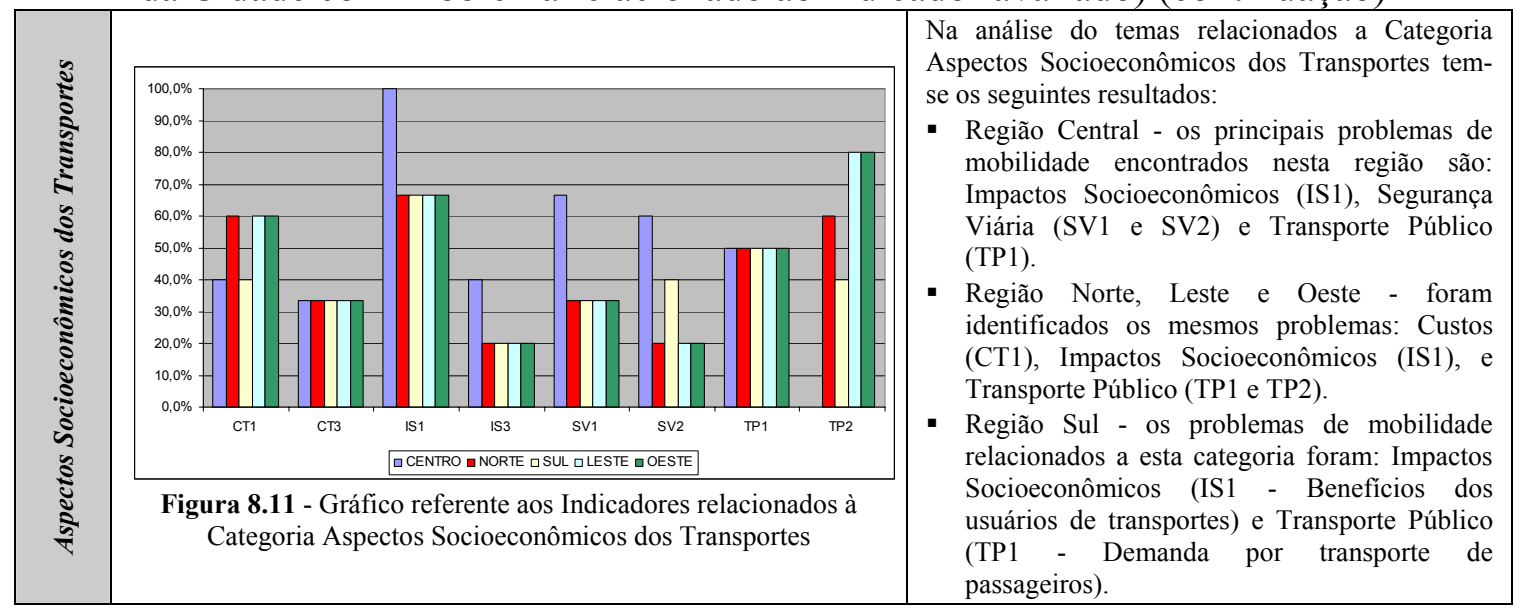

\section{- Outras Informações - Definição dos problemas mais importantes por Sub-região}

Este Módulo ainda permite que os avaliadores visualizem os problemas de Mobilidade Urbana apresentados ou inseridos no sistema por sub-região da cidade; entretanto, como foi obtido um baixo nível de avaliação deste item, suas avaliações não foram representativas para serem analisadas nesta pesquisa.

O próximo item deste capítulo apresenta a avaliação dos Questionários aplicados no Curso de Capacitação que permitirá verificar se houve alteração na percepção dos avaliadores com relação ao Tema Mobilidade Urbana.

\subsection{Avaliação dos Questionários}

Com o intuito de verificar se o Sistema PLANUTS pode interferir no grau de percepção de cada usuário sobre as questões que envolvem a Mobilidade Urbana, foram aplicados dois questionários: i) o Questionário 1 ( $A$ e $B$ ) no primeiro dia do curso de capacitação e ii) o Questionário 2 no último dia do curso. Nas duas fases os questionários continham perguntas abertas, fechadas e/ou de múltipla escolha.

As perguntas abertas permitiram identificar o grau de conhecimento e a incorporação (no atual repertório de cada participante) de outros aspectos que estão associados intrinsecamente à questão da mobilidade urbana; enquanto que as respostas fechadas permitiram quantificar alguns dados e assim gerar um diagnóstico da mobilidade na cidade de Bauru.

$\mathrm{Na}$ primeira fase foram desenvolvidos 2 tipos de questionários: um para os técnicos ligados à Prefeitura Municipal (com 30 questões) e outro para os demais 
participantes (contendo 13 questões); conforme apresentado no Capítulo 5 - Quadros 5.4 e 5.5 .

Ao todo 15 pessoas participaram desta primeira fase, sendo que 9 participantes responderam ao questionário técnico (denominado de Questionário 1A) e 6 participantes ao questionário não-técnico (Questionário 1B).

Das 30 questões propostas para avaliação no Questionário 1A, 13 foram abertas e 17 fechadas e/ou de múltipla escolha. Para a análise das questões abertas utilizouse o seguinte procedimento: primeiro realizou-se a transcrição das respostas de cada avaliador; posteriormente o conjunto de idéias extraídas das respostas foi organizado por afinidade (procurou-se idéias análogas que pudessem ser agrupadas) obtendo-se desta forma uma resposta mais consensual sobre cada tema em cada pergunta (ver Anexo 12). O método adotado é denominado de análise de conteúdo e foi descrito por Bardin (1977).

Das 30 questões elaboradas para o Questionário 1A, foi obtido um índice médio de 10,7 questões não respondidas. O Quadro 8.12 apresenta as questões em branco por avaliador.

De acordo com o Quadro 8.12 é possível afirmar que as questões que obtiveram um alto índice de respostas em branco (onde 5 ou mais avaliadores não responderam a questão) foram aquelas onde os participantes deveriam responder sobre as questões de mobilidade e transportes referente ao município de Bauru (questões 6, 15 e 19).

Embora este questionário tenha sido elaborado para o corpo técnico, as avaliações mostraram que os participantes possuem uma visão setorizada (fragmentada), ou seja, conhecem apenas dos problemas que envolvem diretamente seu campo de atuação; não possuem um conhecimento mais amplo de todas as questões que envolvem o planejamento municipal. 
Quadro 8.12 - Questões em branco por avaliador - Questionário 1A

\begin{tabular}{|c|c|c|c|c|c|c|c|c|c|c|}
\hline \multirow{2}{*}{ QUESTÕES } & \multicolumn{9}{|c|}{ AVALIADORES - GRUPO I } & \multirow[b]{2}{*}{ Total } \\
\hline & 1 & 2 & 3 & 4 & 5 & 6 & 7 & 8 & 9 & \\
\hline 1. Definição de Mobilidade Urbana & & & & & & & & & & 0 \\
\hline 2. O que você entende por Planejamento de Transportes? & & & & & & & & & & 0 \\
\hline 3. O município possui algum Plano de Transporte? & $\checkmark$ & & & & & & $\checkmark$ & & & 2 \\
\hline $\begin{array}{l}\text { 4. Quando ele foi elaborado (ano)? Décadas } 1970 \text { / } 1980 \text { / } 1990 \text { / } \\
\text { após } 2000 .\end{array}$ & $\checkmark$ & $\checkmark$ & & & $\checkmark$ & & $\checkmark$ & & & 4 \\
\hline $\begin{array}{l}\text { 5. Este Plano foi elaborado para minimizar quais problemas da } \\
\text { cidade? }\end{array}$ & $\checkmark$ & & & $\checkmark$ & $\checkmark$ & & $\checkmark$ & & & 4 \\
\hline $\begin{array}{l}\text { 6. Quais os problemas da cidade que não estão inseridos neste } \\
\text { Plano? }\end{array}$ & $\checkmark$ & & & $\checkmark$ & $\checkmark$ & $\checkmark$ & $\checkmark$ & $\checkmark$ & & 6 \\
\hline $\begin{array}{l}\text { 7. O município tem previsão para realizar um novo Plano de } \\
\text { Transporte ou Mobilidade Urbana para a cidade? Qual o prazo } \\
\text { (ano)? }\end{array}$ & $\checkmark$ & $\checkmark$ & & & & $\checkmark$ & $\checkmark$ & & & 4 \\
\hline $\begin{array}{l}\text { 8.Existe alguma medida para promover (incentivar) a melhoria da } \\
\text { mobilidade urbana no município? }\end{array}$ & & & & & & & & & & 0 \\
\hline 9. Qual (quais) medida(s) foi (foram) adotada(s)? & & & & $\checkmark$ & & $\checkmark$ & & & & 2 \\
\hline $\begin{array}{l}\text { 10. Qual (quais) o(s) setor(es) que atualmente estão envolvidos numa } \\
\text { alteração do Plano de Transporte para o município? }\end{array}$ & & & & & $\checkmark$ & & & & & 1 \\
\hline $\begin{array}{l}\text { 11. Qual (quais) a(s) secretaria(s) que atualmente estão envolvidas } \\
\text { quando se elabora alguma modificação no Plano de Transporte? }\end{array}$ & & & & & & & & & & 0 \\
\hline $\begin{array}{l}\text { 12. Quais são os principais TEMAS da política de transportes do } \\
\text { município? }\end{array}$ & $\checkmark$ & & & & & $\checkmark$ & $\checkmark$ & $\checkmark$ & & 4 \\
\hline $\begin{array}{l}\text { 13. Quais os principais objetivos da política de } \\
\text { ESTACIONAMENTOS para o município? }\end{array}$ & $\checkmark$ & & & & & & $\checkmark$ & $\checkmark$ & & 3 \\
\hline $\begin{array}{l}\text { 14. Quais os principais objetivos da política de TRANSPORTE } \\
\text { PÚBLICO para o município? }\end{array}$ & & & & & & & $\checkmark$ & $\checkmark$ & & 2 \\
\hline $\begin{array}{l}\text { 15. Quais os principais objetivos da política de CIRCULAÇÃO para } \\
\text { o município? }\end{array}$ & $\checkmark$ & & $\checkmark$ & & $\checkmark$ & & $\checkmark$ & $\checkmark$ & & 5 \\
\hline $\begin{array}{l}\text { 16. O município tem algum plano para diminuir a POLUIÇÃO } \\
\text { causada pelos meios de transportes na cidade (por ex. o controle da } \\
\text { qualidade do ar)? }\end{array}$ & $\checkmark$ & & & & & $\checkmark$ & & $\checkmark$ & & 3 \\
\hline $\begin{array}{l}\text { 17. Cite as medidas adotadas para reduzir os NÍVEIS DE } \\
\text { POLUIÇÃO causados pelos meios de transportes na cidade. }\end{array}$ & $\checkmark$ & $\checkmark$ & & & & $\checkmark$ & & $\checkmark$ & & 4 \\
\hline $\begin{array}{l}\text { 18. O município tem algum plano para diminuir o RUÍDO causado } \\
\text { pelos meios de transportes na cidade? }\end{array}$ & $\checkmark$ & & & & $\checkmark$ & $\checkmark$ & $\checkmark$ & & & 4 \\
\hline $\begin{array}{l}\text { 19. Quais das medidas abaixo foram adotadas para reduzir os } \\
\text { NÍVEIS DE RUÍDO causados pelos meios de transportes na cidade? } \\
\text { Cite as outras medidas adotadas? }\end{array}$ & $\checkmark$ & $\checkmark$ & $\checkmark$ & $\checkmark$ & & & $\checkmark$ & & & 5 \\
\hline $\begin{array}{l}\text { 20. O município tem algum plano para reduzir alguns pontos de } \\
\text { CONGESTIONAMENTOS na cidade? }\end{array}$ & $\checkmark$ & & & & & & $\checkmark$ & & & 2 \\
\hline $\begin{array}{l}\text { 21. Cite as medidas adotadas para reduzir os } \\
\text { CONGESTIONAMENTOS na cidade. }\end{array}$ & $\checkmark$ & & & $\checkmark$ & & & $\checkmark$ & & & 3 \\
\hline 22. O município tem algum plano de ACESSIBILIDADE? & $\checkmark$ & $\checkmark$ & $\checkmark$ & & & $\checkmark$ & & & & 4 \\
\hline $\begin{array}{l}\text { 23. Quais os principais projetos relacionados com a atual política de } \\
\text { ACESSIBILIDADE do município? }\end{array}$ & $\checkmark$ & & $\checkmark$ & & & & & & & 2 \\
\hline $\begin{array}{l}\text { 24. O atual Plano de Transportes prevê a adaptação dos pontos de } \\
\text { ônibus para torná-los mais acessíveis para todos os cidadãos? }\end{array}$ & & $\checkmark$ & & & & $\checkmark$ & $\checkmark$ & $\checkmark$ & & 4 \\
\hline 25. Quais os principais projetos deste Plano? & & $\checkmark$ & & & & $\checkmark$ & $\checkmark$ & $\checkmark$ & & 4 \\
\hline $\begin{array}{l}\text { 26. Qual a secretaria, setor ou órgão municipal que trabalha com os } \\
\text { temas e políticas de acessibilidade para as pessoas com deficiência? }\end{array}$ & & & & & & & & & & 0 \\
\hline $\begin{array}{l}\text { 27. Quais os principais problemas de infra-estrutura de transportes } \\
\text { que o município possui, identifique-os por região da cidade. }\end{array}$ & & & & & & & & & & 0 \\
\hline $\begin{array}{l}\text { 28. Existe alguma política municipal para incentivar as VIAGENS a } \\
\text { PÉ ou por BICICLETA? }\end{array}$ & & & & & & $\checkmark$ & & & & 1 \\
\hline $\begin{array}{l}\text { 29. Existe alguma política municipal para reduzir o NÚMERO DE } \\
\text { ACIDENTES DE TRÂNSITO no município? }\end{array}$ & & & & & & & & $\checkmark$ & & 1 \\
\hline $\begin{array}{l}\text { 30. Quais as regiões da cidade que possuem um maior ÍNDICE DE } \\
\text { ACIDENTES DE TRÂNSITO? }\end{array}$ & & & $\checkmark$ & & $\checkmark$ & & & $\checkmark$ & & 3 \\
\hline
\end{tabular}

No Anexo 12 encontram-se as questões apresentadas para o grupo técnico (9 avaliadores), as respectivas respostas (que foram transcritas em função da metodologia de análise adotada - ver Capítulo 5) e avaliação contendo uma análise geral dos dados coletados referente ao Questionário 1A. 
Para a avaliação dos participantes não-especialistas foram elaboradas 13 questões para o Questionário 1B, sendo 3 para serem respondidas de forma aberta. As demais eram questões fechadas ou de múltipla escolha. Para a análise das questões abertas foi utilizado o mesmo procedimento adotado para o Questionário 1A. O Anexo 13 apresenta os resultados e a avaliação de cada questão.

O Quadro 8.13 apresenta as questões em branco por avaliador. De acordo com as respostas apresentadas neste quadro, é possível afirmar que não foi encontrado um alto índice de respostas em branco.

Quadro 8.13 - Questões em branco por avaliador - Questionário 1B

\begin{tabular}{|c|c|c|c|c|c|c|c|}
\hline \multirow{2}{*}{ QUESTÕES } & \multicolumn{7}{|c|}{ AVALIADORES - GRUPO II } \\
\hline & 10 & 11 & 12 & 13 & 14 & 15 & Total \\
\hline $\begin{array}{l}\text { 1. Você tem o conhecimento se em sua cidade existe algum Plano de } \\
\text { Transporte? }\end{array}$ & & & & & & & 0 \\
\hline 2. Você sabe para que "serve" um Plano de Transporte? & & & & & & & 0 \\
\hline 3. Você acha importante a elaboração deste plano para sua cidade? Por quê? & & & & & & & 0 \\
\hline 4. Você sabe qual é o objetivo de um Plano Diretor de Mobilidade Urbana? & & & & & & $\checkmark$ & 1 \\
\hline 5. Quais dos problemas abaixo você encontra em sua CIDADE? & & & & & & & 0 \\
\hline 6. Quais dos problemas abaixo você encontra em seu BAIRRO? & & & & & & & 0 \\
\hline $\begin{array}{l}\text { 7. Qual o meio de transporte que você utiliza para ir: ao trabalho / à escola/ } \\
\text { ao centro da cidade? }\end{array}$ & & & & & & & 0 \\
\hline $\begin{array}{l}\text { 8. Você tem alguma dificuldade em utilizar o Transporte Coletivo (ônibus) } \\
\text { em sua cidade? }\end{array}$ & & & & & & & 0 \\
\hline $\begin{array}{l}\text { 9. Assinale com um } \mathbf{X} \text { o(s) problema(s) relacionados à utilização do } \\
\text { Transporte Coletivo (ônibus) que você encontra na cidade? }\end{array}$ & $\checkmark$ & & $\checkmark$ & & & & 2 \\
\hline $\begin{array}{l}\text { 10. Em seu BAIRRO, você tem algum problema com o excesso de barulho } \\
\text { provocado por veículos (carro, moto, ônibus, caminhão)? }\end{array}$ & & & & & & & 0 \\
\hline $\begin{array}{l}\text { 11. Em seu BAIRRO há muitos veículos que lançam fumaça no ar? } \\
\text { (presença de veículos lançando produtos tóxicos) }\end{array}$ & & & $\checkmark$ & & & & 1 \\
\hline 12. Há ligação de ruas - direta, entre seu bairro e os bairros vizinhos? & & & & & & & 0 \\
\hline $\begin{array}{l}\text { 13. Você já perdeu a concentração ao desenvolver qualquer atividade em } \\
\text { sua casa ou seu trabalho em função do excesso de barulho provocado por } \\
\text { qualquer meio de transporte (ônibus, caminhão, carro, moto, etc.)? }\end{array}$ & & & & & & & 0 \\
\hline
\end{tabular}

Comparando os resultados dos Questionários 1A e 1B, de forma geral pôdese perceber que a maioria dos participantes não possui um conhecimento das questões de mobilidade de seu município e que a própria definição do que é mobilidade é muito diversificada, sendo muito associada ao planejamento e ou construção de infra-estrutura viária.

$\mathrm{Na}$ segunda fase, os questionários foram iguais para todos os participantes, pois todos participaram das etapas de atualização teórica e de avaliação dos três módulos. $\mathrm{O}$ objetivo desta etapa foi determinar o grau de percepção das questões relacionadas à mobilidade após a realização do curso de capacitação e da utilização da ferramenta PLANUTS. 
Participaram desta fase 7 pessoas (especialistas e não-especialistas) que responderam ao Questionário 2. Este possuía 20 questões, sendo 10 abertas e 10 de múltipla escolha e/ou fechada; conforme mostra o Anexo 14.

Para a elaboração do Questionário 2, utilizou-se como referência os Questionários 1A e 1B; entretanto, para que fosse possível realizar uma comparação entre os dois períodos de aplicação do questionários aos participantes, algumas perguntas foram re-elaboradas para permitir a identificação de elementos que possibilitassem uma comparação e assim pudesse ser verificada uma eventual mudança no grau de conhecimento dos participantes em relação a alguns aspectos que envolvem o planejamento da Mobilidade Urbana.

Para realizar a análise comparativa das respostas dos questionários aplicados antes e após a utilização do Sistema PLANUTS, em função das respostas obtidas nos três questionários, adotou-se uma integração entre as seguintes metodologias de análise: i) Análise de Conteúdo e ii) Mapas Cognitivos (Mapas de Causa).

A análise de conteúdo foi utilizada para identificar nas respostas dos três questionários (tendo como referência de comparação o Questionário 2), algumas palavraschave que pudessem servir de elementos de comparação, permitindo realizar a identificação na diferenciação do grau de conhecimento do grupo em relação a Mobilidade Urbana.

Os Mapas Cognitivos (Mapas de Causa) foram utilizados como meio de representação dos elementos decodificados pela técnica de análise de conteúdo. Entretanto ao invés da utilização de frases, como o método estabelece, foi utilizada a representação através de palavras-chave, uma vez que as respostas, na maioria das vezes, eram compostas de elementos muito sintéticos. Em alguns casos as respostas eram compreendidas por uma série de palavras-chave (ver Anexo 14).

O Quadro 8.14 apresenta as questões que serviram de base para as análises comparativas entre os três questionários e a respectiva forma de análise. 
Quadro 8.14 - Comparação entre as avaliações dos Questionários 1A, 1B e 2

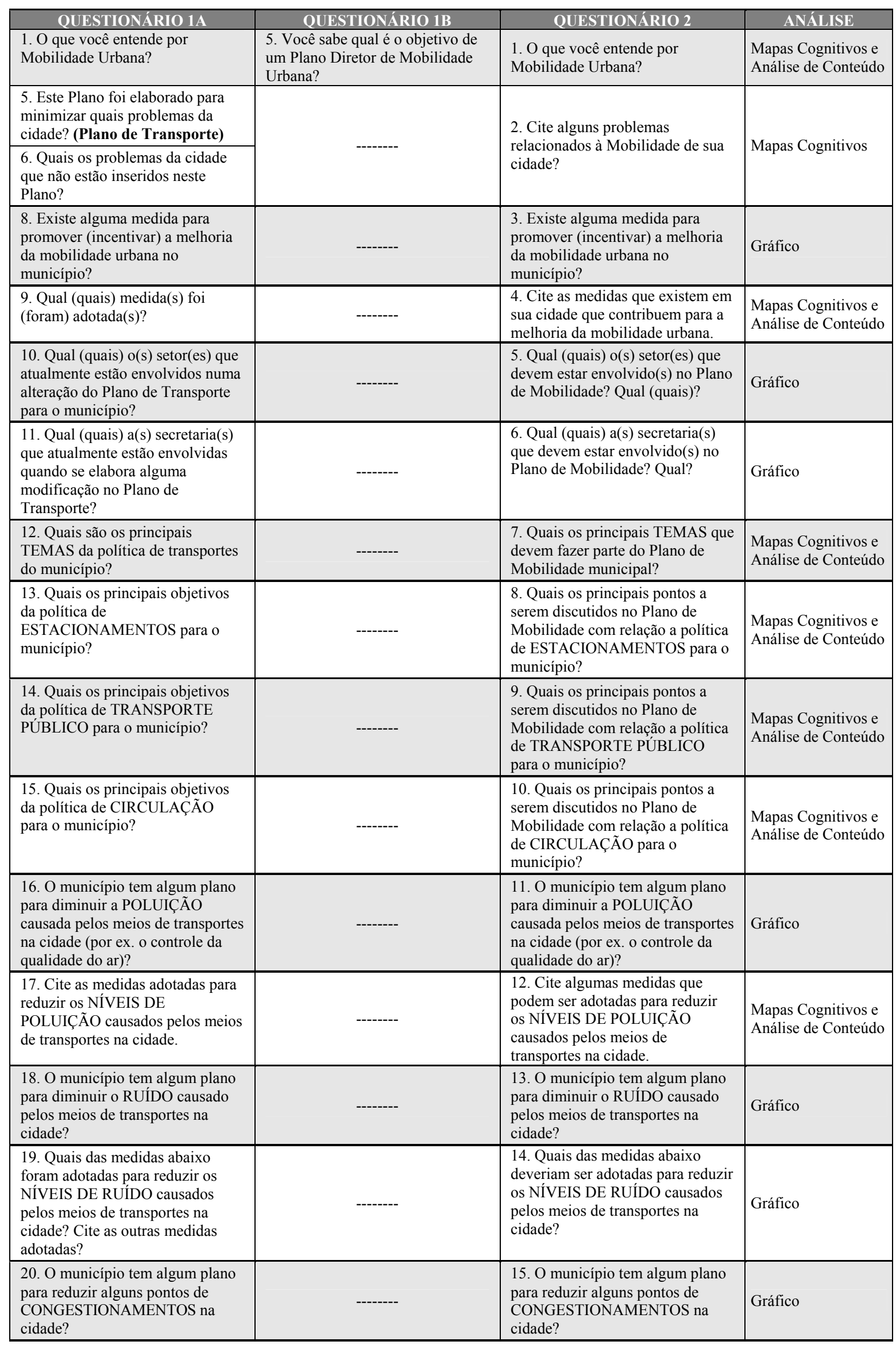


Quadro 8.14 - Comparação entre as avaliações dos Questionários 1A, 1B e 2 (continuação)

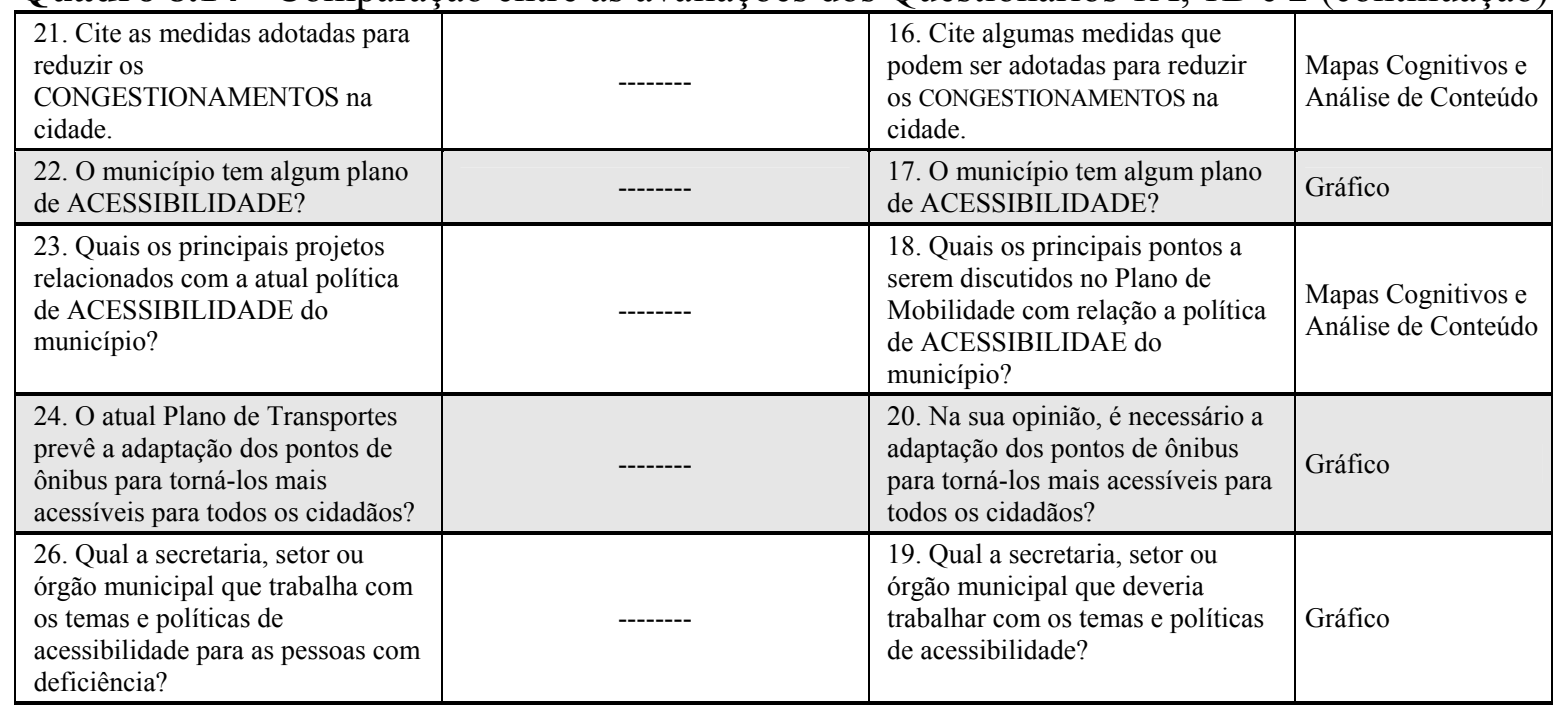

O processo de análise dos resultados foi iniciado com a definição das palavras-chave em cada questionário. Na seqüência foi realizada a construção dos Mapas Cognitivos (Mapas de Causa) para cada cenário, ou seja, para cada um dos questionários comparados foi construído um mapa cognitivo.

A referência para a análise comparativa foi estabelecida a partir dos mapas construídos com base nos Questionários 1A e 1B e sua comparação com o mapa construído a partir das respostas obtidas no Questionário 2. Foram identificados no segundo Mapa Cognitivo (denominado de Mapa 2, construído a partir do Questionário 2) os elementos (palavras-chave) que estavam presentes no Mapa Cognitivo denominado de Mapa 1. Para auxiliar neste diagnóstico foram definidas cores diferenciadas para que as células pudessem representar elementos distintos no Mapa 2, isto é, foi adotada a cor vermelho escuro para as células que apresentaram "novas definições" e a cor azul para aquelas definições que não estavam diretamente associadas ao termo Mobilidade Urbana. A cor branco referiu-se aos elementos identificados no Questionário $1 \mathrm{~A}$ e B.

$\mathrm{Na}$ seqüência são apresentados os resultados destas análises através de Quadros (que mostram as palavras-chave identificadas) e dos Mapas Cognitivos ${ }^{1}$.

\footnotetext{
${ }^{1}$ As respostas dos participantes com relação ao Questionário 2 e ao Módulo III (Problemas e Soluções do Módulo III - Anexo 9) são muito semelhantes e na maioria das vezes muito diferentes das apresentadas no Questionário I.
} 


\section{- Definição de Mobilidade Urbana}

Quadro 8.15 - Transcrição e análise das respostas dos especialistas para a questão que trata da definição de Mobilidade Urbana nos Questionários 1A, 1B e 2

\begin{tabular}{|c|c|c|c|}
\hline QUESTÃO & QUESTIONÁRIO 1A & QUESTIONÁRIO 1B & QUESTIONÁRIO 2 \\
\hline $\begin{array}{l}\text { O que você entende por } \\
\text { Mobilidade Urbana? } \\
\text { (Questionários 1A / 2) } \\
\text { Você sabe qual é o } \\
\text { objetivo de um Plano } \\
\text { Diretor de Mobilidade } \\
\text { Urbana? (Questionário } \\
\text { 1B) } \\
\text { Objetivo - Identificar se } \\
\text { houve um avanço no grau de } \\
\text { conhecimento dos } \\
\text { participantes com relação a } \\
\text { questão da mobilidade e do } \\
\text { planejamento dos } \\
\text { transportes. }\end{array}$ & 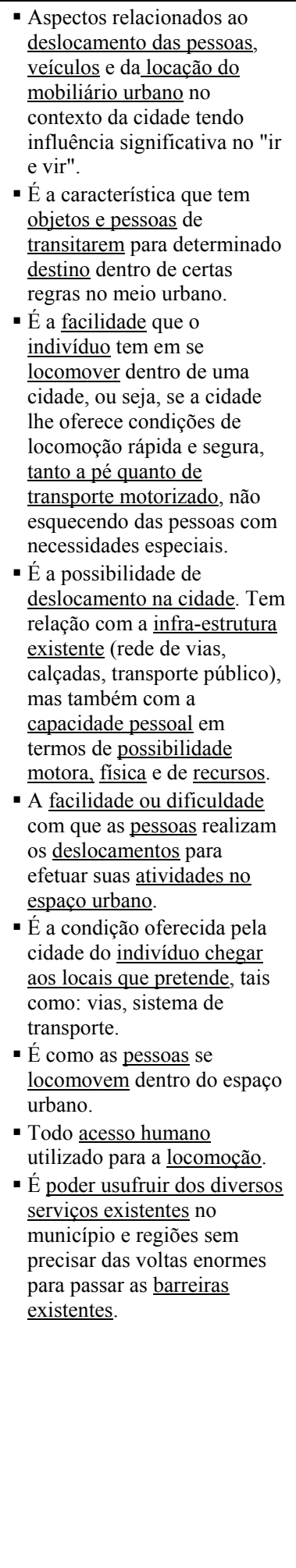 & $\begin{array}{l}\text { - Facilitar acessos. } \\
\text { - Sim. } \\
\text { - Humanizar e organizar os } \\
\text { fluxos das pessoas entre seus } \\
\text { percursos diários com a } \\
\text { otimizacão dos diversos } \\
\text { meios de transportes: a pé, de } \\
\text { auto, transporte coletivo, } \\
\text { acessibilidade, etc. } \\
\text { - Descentralizar e criar novas } \\
\underline{\text { rotas para evitar o colapso }} \\
\text { viário. } \\
\text { - Adequar e qualificar } \\
\text { qualquer tipo de mobilidade } \\
\text { inserindo ainda os portadores } \\
\text { de deficiência no seu direito } \\
\text { de ir e vir. }\end{array}$ & $\begin{array}{l}\text { - Mobilidade urbana é o meio } \\
\text { pelo qual podemos estudar e } \\
\text { planejar o transporte e a } \\
\text { locomocão de bens e pessoas } \\
\text { visando a otimização dos } \\
\text { recursos e preservação dos } \\
\text { mesmos. } \\
\text { - É a possibilidade de todas as } \\
\text { pessoas se locomoverem } \\
\text { dentro das cidades, sem } \\
\text { obstáculos as quais estas não } \\
\text { possam transpor. Ainda, } \\
\text { acessarem os meios de } \\
\underline{\text { transporte e as edificações, }} \\
\text { sem que encontrem } \\
\text { obstáculos intransponíveis. } \\
\text { - É a capacidade (ou } \\
\text { possibilidade) das pessoas e } \\
\text { bens circularem pela cidade. } \\
\text { Entendemos que esse termo } \\
\text { deva ser ampliado para } \\
\text { contemplar a zona rural, onde } \\
\text { moram pessoas que tem } \\
\text { necessidades de educação, } \\
\text { saúde, consumo em geral, } \\
\text { além das cargas (produção } \\
\text { agrícola, pecuária, etc.). A } \\
\text { mobilidade depende da } \\
\text { estrutura física (vias, } \\
\text { calçadas) mas também da } \\
\text { condição física e financeira } \\
\text { das pessoas, além do sistema } \\
\text { de transporte disponível. } \\
\text { - Meio pelo qual as pessoas e } \\
\text { bens se locomovem ns } \\
\text { cidades. } \\
\text { - A mobilidade urbana é o que } \\
\text { rege a vida dos cidadãos, no } \\
\text { que se refere ao transporte, } \\
\text { circulação de bens, no } \\
\text { cotidiano da cidade. } \\
\text { - É o meio de locomoção de } \\
\text { pessoas e bens, incluindo } \\
\text { transporte e acessibilidade } \\
\text { em geral, com preocupação } \\
\text { ambiental. } \\
\text { - Ainda não tenho uma } \\
\text { definição elaborada, mas } \\
\text { entendo que tem relação com } \\
\text { as condições que a cidade } \\
\text { oferece a seus habitantes, } \\
\text { visando garantir que os } \\
\text { mesmos satisfaçam suas } \\
\text { necessidades de } \\
\text { deslocamento, sejam eles } \\
\text { com finalidade de trabalho, } \\
\text { de lazer, de cultura, } \\
\text { educação, etc., } \\
\text { preferencialmente } \\
\text { consumindo o mínimo de } \\
\text { recursos, com o mínimo de } \\
\text { agressão ao ambiente. }\end{array}$ \\
\hline
\end{tabular}


Quadro 8.15 - Transcrição e análise das respostas dos especialistas para a questão que trata da definição de Mobilidade Urbana nos Questionários 1A, 1B e 2 (continuação)

\begin{tabular}{|l|l|}
\hline AVALIAÇÃO & $\begin{array}{l}\text { No Mapa Cognitivo } 1 \text { a definição de Mobilidade Urbana é dada pelos participantes através da } \\
\text { associação dos seguintes elementos: infra-estrutura, ao deslocamento de pessoas e veículos, a } \\
\text { eliminação de barreiras físicas (mobiliário urbano), utilização de meios de transporte motorizado e } \\
\text { não-motorizado. } \\
\text { O Mapa Cognitivo } 2 \text { apresenta uma visão sobre o conceito de mobilidade muito similar à definição } \\
\text { apresentada pelo Grupo I (especialistas) (ver Mapas 1 e 2). As palavras-chave identificadas neste } \\
\text { mapa foram: facilidade de acesso, fluxo de pessoas, otimização dos meios de transporte, criação de } \\
\text { novas rotas. }\end{array}$ \\
$\begin{array}{l}\text { No terceiro Mapa Cognitivo, pode-se observar uma ampliação desta definição através da inclusão } \\
\text { dos seguintes itens: acessibilidade, mobilidade na área urbana e rural, circulação de bens (além das } \\
\text { pessoas), facilitar o desenvolvimento de atividades (trabalho, lazer, cultura e educação), } \\
\text { planejamento, preservação e otimizar os recursos, e a preocupação ambiental. } \\
\text { No sistema PLANUTS a definição de mobilidade está contemplada na avaliação do Módulo I, } \\
\text { através da definição das } 5 \text { Categorias e 20 Temas relacionados à Mobilidade. Os participantes } \\
\text { associaram à definição de Mobilidade os seguintes: Meio Ambiente, Gestão, Infra-estrutura, } \\
\text { Planejamento e Aspectos Socioeconômicos. }\end{array}$ \\
\hline
\end{tabular}

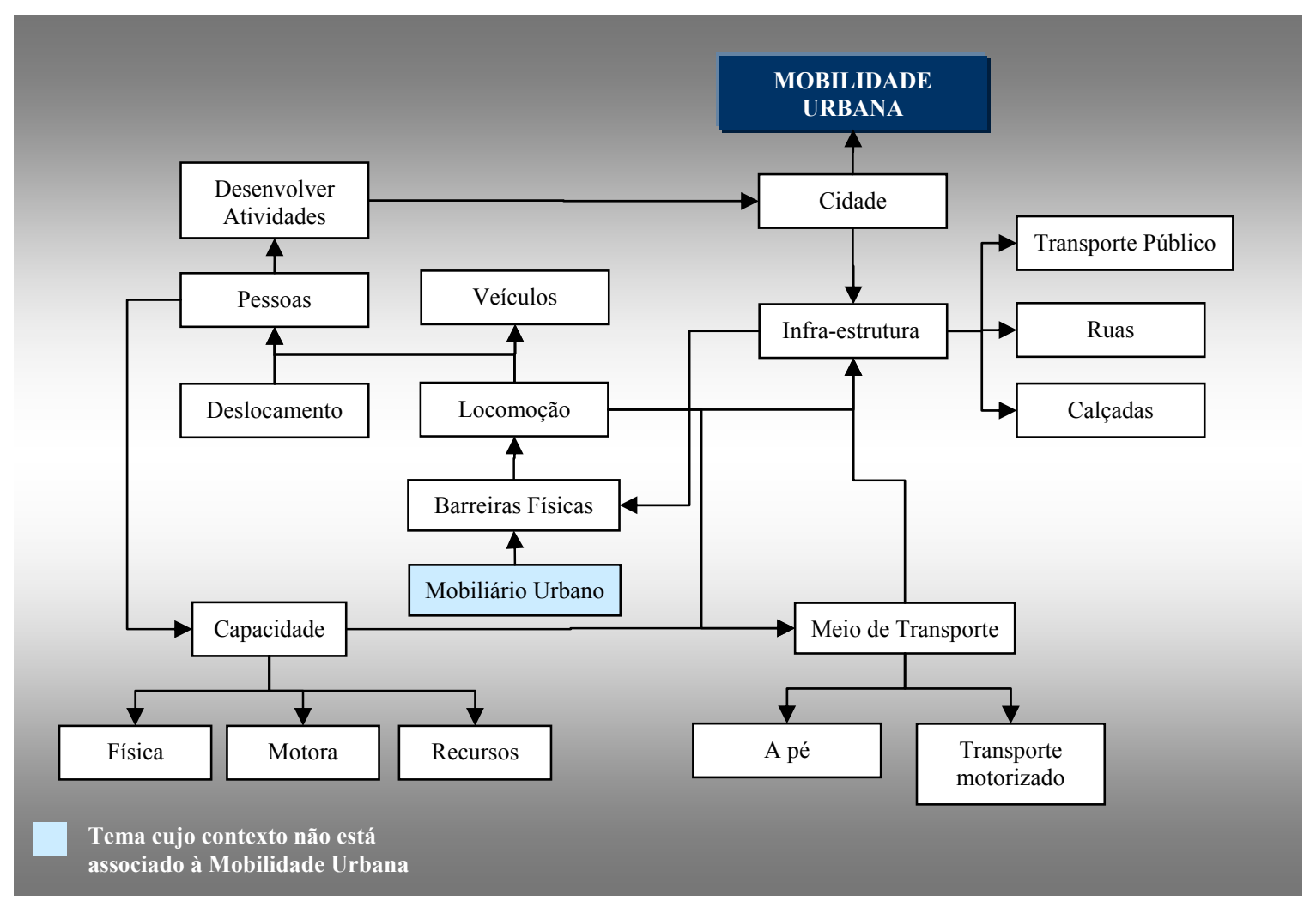

Figura 8.12 - Mapa Cognitivo 1 - Definição de Mobilidade Urbana extraída do Questionário 1A 


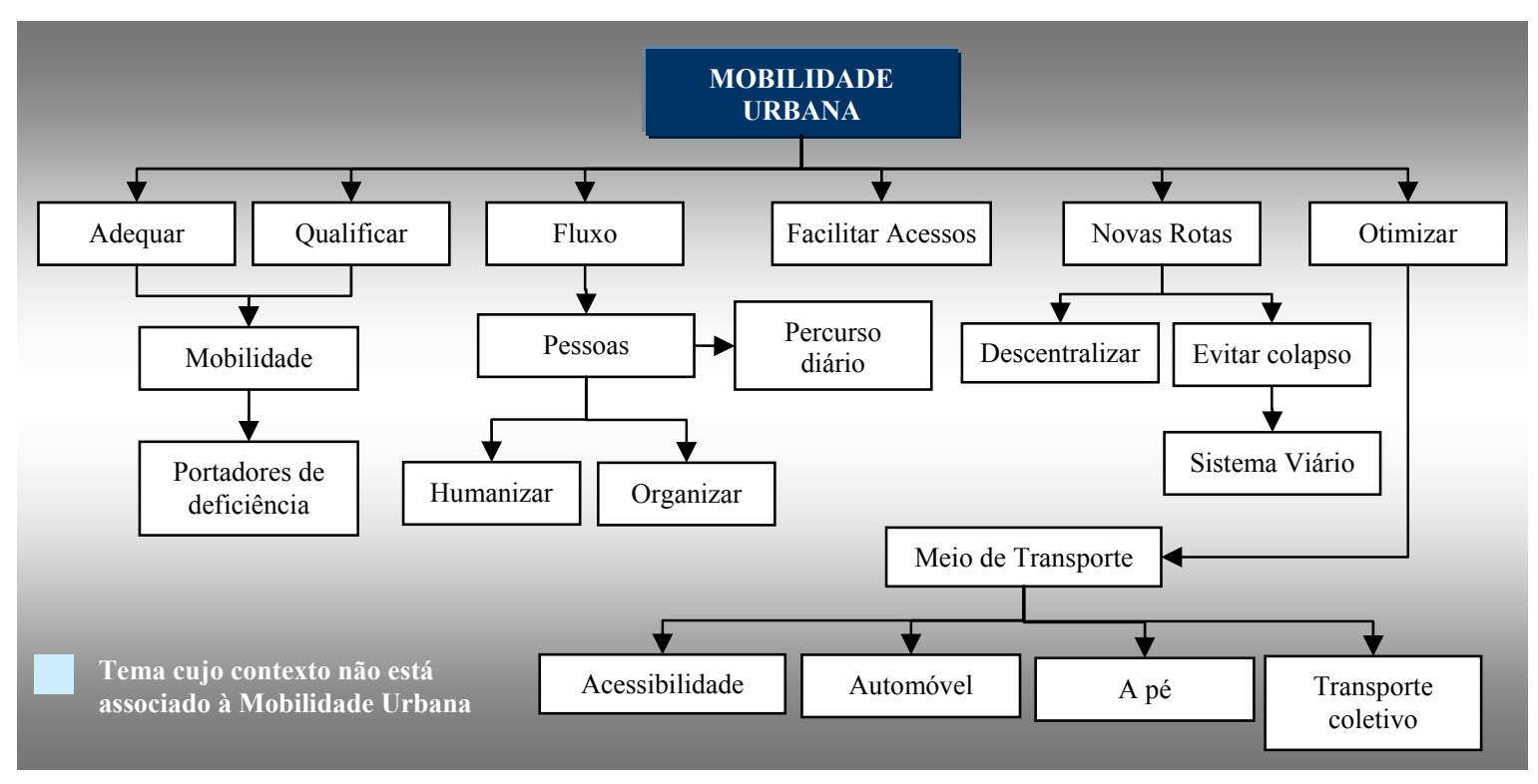

Figura 8.13 - Mapa Cognitivo 2 - Definição de Mobilidade Urbana extraída do Questionário 1B 


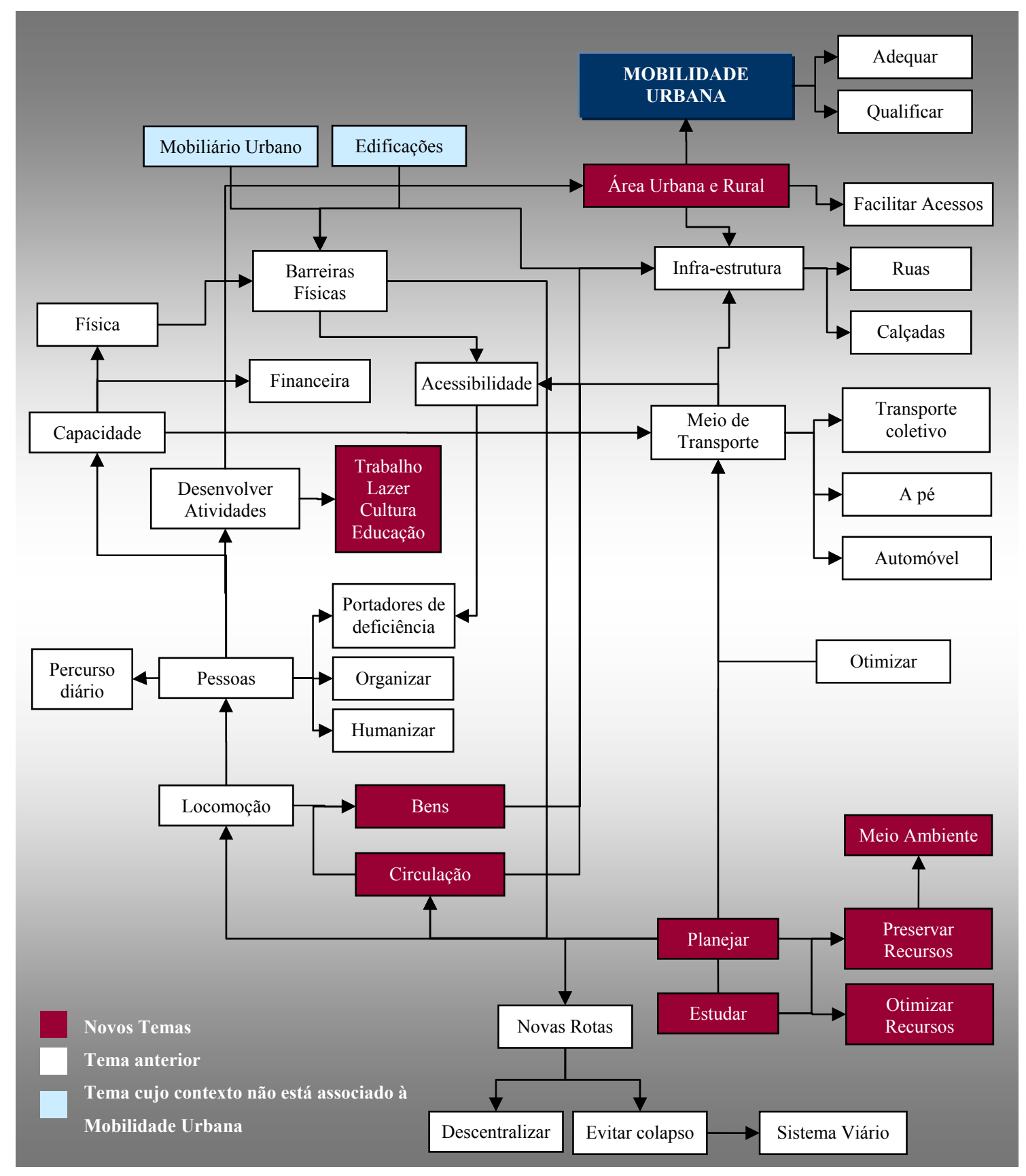

Figura 8.14 - Mapa Cognitivo 3 - Definição de Mobilidade Urbana extraídas do Questionário 2 


\section{- Identificação de problemas de Mobilidade Urbana}

Quadro 8.16 - Transcrição e análise das respostas dos avaliadores para a questão que trata da identificação dos problemas de Mobilidade Urbana nos Questionários 1A e 2

\begin{tabular}{|c|c|c|}
\hline$\overline{\text { QUESTÃO }}$ & QUESTIONÁRIO 1A & QUESTIONÁRIO 2 \\
\hline 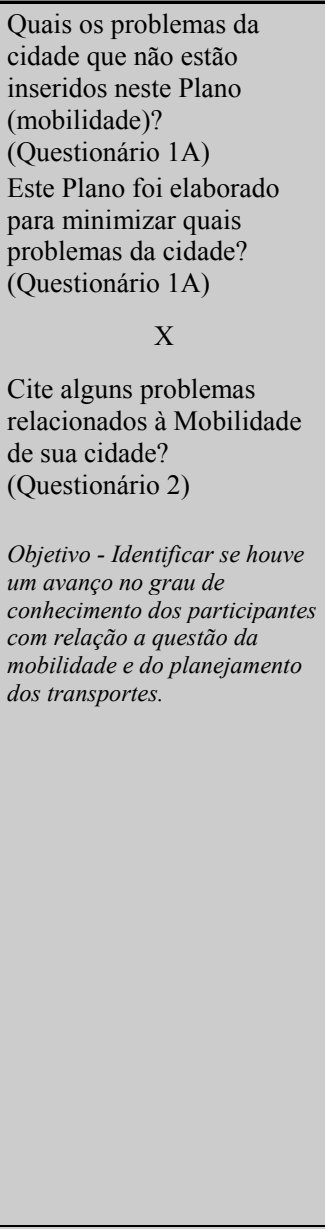 & 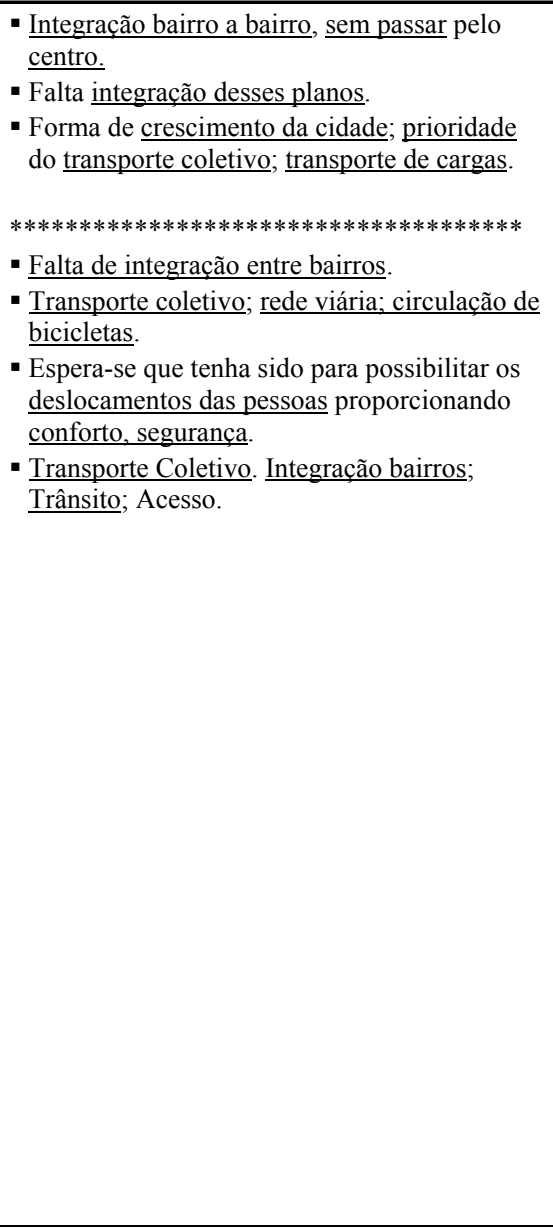 & 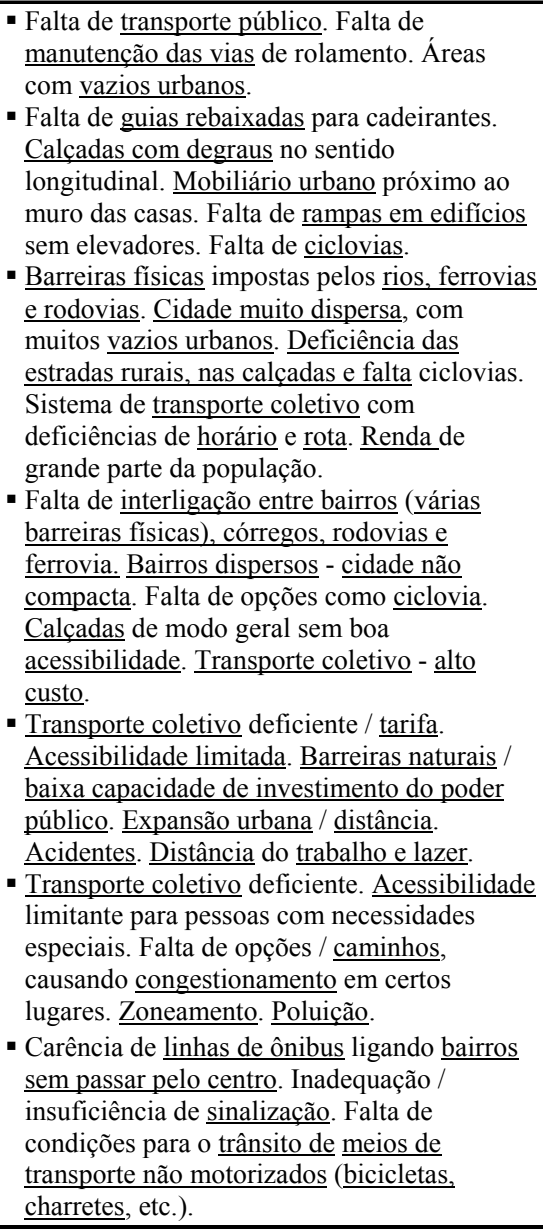 \\
\hline AVALIAÇÃO & \multicolumn{2}{|c|}{$\begin{array}{l}\text { Observando os dois Mapas Cognitivos pode-se afirmar que no Mapa } 1 \text { (Figura 8.15) os problemas } \\
\text { de mobilidade identificados no primeiro questionário representavam problemas que estavam } \\
\text { diretamente associados a questão do Planejamento de Transporte associado as questões de } \\
\text { planejamento e de infra-estrutura viária e também a questão do planejamento urbano associado ao } \\
\text { planejamento de transportes. } \\
\text { No Mapa } 2 \text { (Figura 8.16) pode-se observar uma ampliação no elenco de Temas elencados pelos } \\
\text { inquiridos (entrevistados). Muitas das palavras-chave identificadas nas respostas deste questionário } \\
\text { representam os Temas considerados mais importantes na avaliação dos participantes no Módulo I } \\
\text { (Crescimento Urbano, Sistema Viário, Acessibilidade Urbana, Impacto Ambiental, Mobilidade } \\
\text { Urbana e Estratégias Econômicas) e considerados os mais urgentes para o município, } \\
\text { identificados nas avaliações do Módulo III (Crescimento Urbano, População Urbana, } \\
\text { Acessibilidade Urbana, Mobilidade Urbana e Impacto Ambiental). }\end{array}$} \\
\hline
\end{tabular}




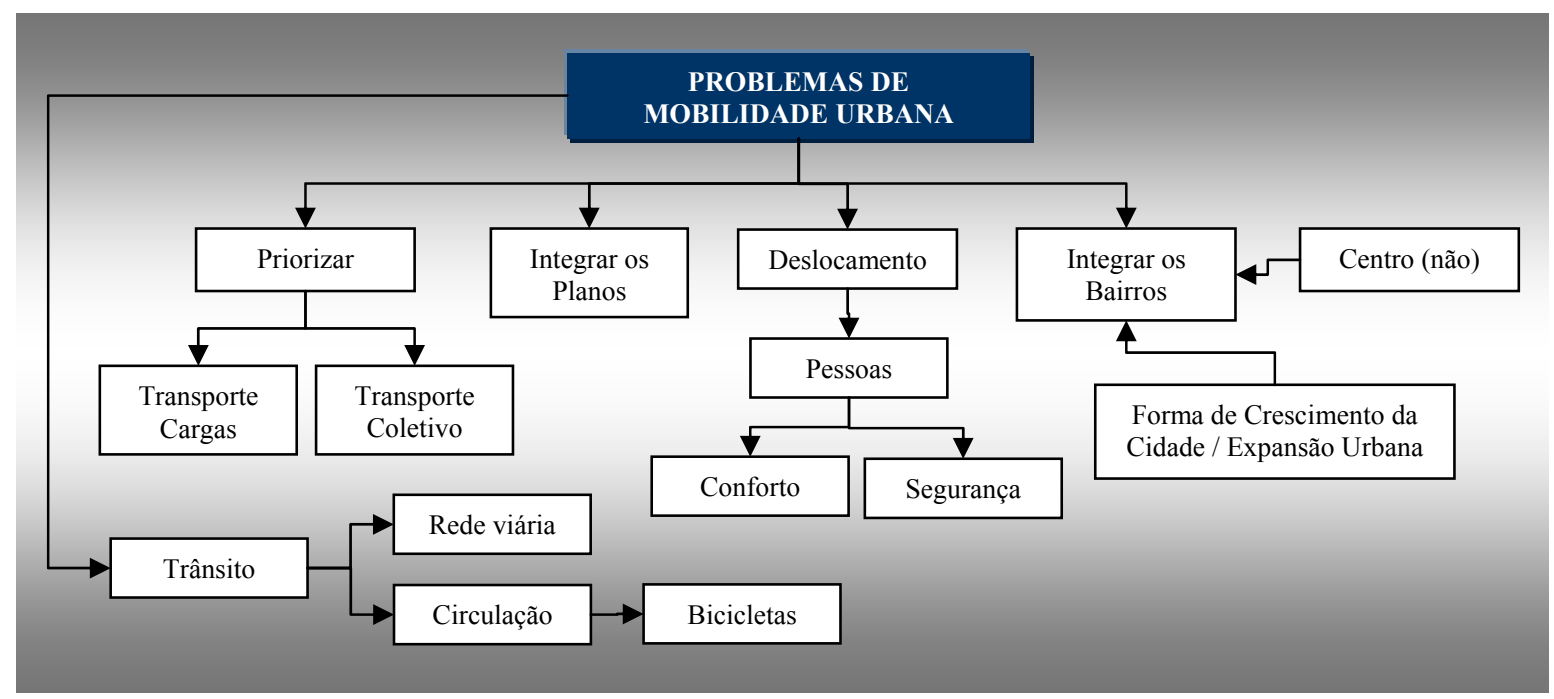

Figura 8.15 - Mapa Cognitivo 1 - Identificação dos problemas de Mobilidade Urbana extraídos do Questionário 1A

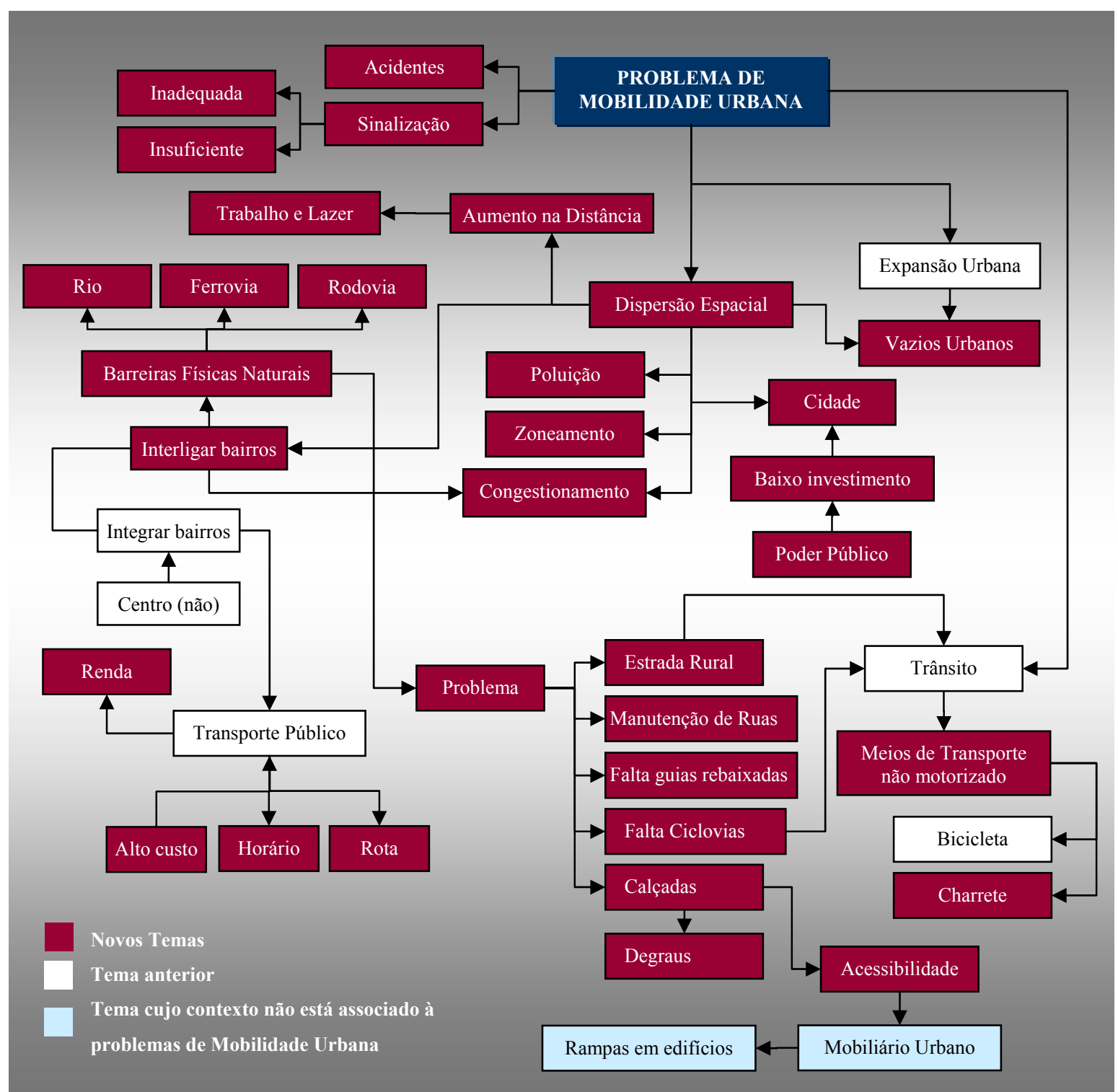

Figura 8.16 - Mapa Cognitivo 2 - Identificação dos problemas de Mobilidade Urbana extraídos do Questionário 2 


\section{- Medidas para incentivar a mobilidade}

Quadro 8.17 - Transcrição e análise das respostas dos avaliadores para a questão que trata da identificação da existência de medidas para promover a melhoria da Mobilidade Urbana no município nos Questionários 1A e 2

\begin{tabular}{|c|c|c|}
\hline QUESTÃO & QUESTIONÁRIO 1 & QUESTIONÁRIO 2 \\
\hline $\begin{array}{l}\text { Existe alguma medida para } \\
\text { promover (incentivar) a } \\
\text { melhoria da mobilidade } \\
\text { urbana no município? } \\
\text { (Questionários 1A e 2) } \\
\text { Objetivo - Verificar se os } \\
\text { avaliadores conseguem } \\
\text { identificar se existem algumas } \\
\text { medidas de incentivo a } \\
\text { mobilidade no municipio após a } \\
\text { utilização do Sistema } \\
\text { PLANUTS. }\end{array}$ & $\begin{array}{l}8 \mathrm{Sim} \\
1 \text { Não }\end{array}$ & 6 Sim \\
\hline AVALIAÇÃO & \multicolumn{2}{|c|}{$\begin{array}{l}\text { Detectou-se um consenso entre as avaliações dos dois questionários, ou seja, aproximadamente } \\
90 \% \text { dos participantes afirmaram que o município possui alguma medida para a melhoria na } \\
\text { mobilidade urbana na cidade. }\end{array}$} \\
\hline $11 \%$ & $\begin{array}{l}\square \operatorname{Sim} \\
\square \text { Não }\end{array}$ & $\begin{array}{l}\square \text { Sim } \\
\square \text { Não }\end{array}$ \\
\hline Figuras 8.1 & $\begin{array}{l}\text { mparativo mostrando o grau d } \\
\text { melhorar a mobilid }\end{array}$ & $\begin{array}{l}\text { participantes sobre a existência de medidas para } \\
\text { ípio }\end{array}$ \\
\hline
\end{tabular}




\section{- Definição das medidas adotadas no município para incentivar a mobilidade}

Quadro 8.18 - Transcrição e análise das respostas dos avaliadores para a questão que trata da identificação das medidas adotadas para promover a melhoria da Mobilidade Urbana no município nos Questionários 1A e 2

\begin{tabular}{|c|c|c|}
\hline QUESTÃO & QUESTIONÁRIO 1A & QUESTIONÁRIO 2 \\
\hline $\begin{array}{l}\text { Qual (quais) medida(s) foi } \\
\text { (foram) adotada(s)? } \\
\text { (Questionário 1A) } \\
\qquad \mathrm{X} \\
\text { Cite as medidas que } \\
\text { existem em sua cidade que } \\
\text { contribuem para a melhoria } \\
\text { da mobilidade urbana. } \\
\text { (Questionário 2) } \\
\\
\text { Objetivo - Verificar se os } \\
\text { avaliadores conseguem } \\
\text { identificar se existem algumas } \\
\text { medidas de incentivo a } \\
\text { mobilidade no municipio após a } \\
\text { utilização do Sistema } \\
\text { PLANUTS. }\end{array}$ & $\begin{array}{l}\text { - Melhoria das estruturas - infra-estrutura. } \\
\text { - Criação de um grupo de análise de } \\
\text { empreendimentos, que avalia os projetos } \\
\text { encaminhados, contemplando sistema viário e } \\
\text { transporte. } \\
\text { - Projeto de obras de interligação de bairros, } \\
\text { muito segmentados pelas rodovias, ferrovias e } \\
\text { córregos, através de passarelas ou viadutos; } \\
\text { fiscalização da execução de calçadas. } \\
\text { - Mudança de conceito está prevista no Plano } \\
\text { Diretor, assim como a exigência da } \\
\text { elaboração do Plano de Mobilidade. } \\
\text { - A previsão de um Plano de Mobilidade } \\
\text { Urbana conforme o Projeto de Lei do Plano } \\
\text { Diretor. } \\
\text { - Plano Diretor Participativo de Bauru. } \\
\text { - Previsão e prazo no PDP. }\end{array}$ & $\begin{array}{l}\text { - Gerenciamento e monitoração do transporte } \\
\text { coletivo. Agendamento de vans para } \\
\text { transporte de deficientes / cadeirantes. } \\
\text { - Estacionamento rotativo na área central. } \\
\text { uma diretrizes dos novos loteamentos, existe } \\
\text { umaiancia de implantação de rampas nas } \\
\text { guias para acesso de deficientes, bem como, } \\
\text { onde existe possibilidade, implantação de } \\
\text { ciclovias. } \\
\text { - Proposta de não expansão do perímetro } \\
\text { urbano, contida no Plano Diretor. IPTU } \\
\text { progressivo e parcelamento compulsório para } \\
\text { glebas ociosas, proposta do Plano Diretor. } \\
\text { Implantação de novas vias, travessias e } \\
\text { transposições de barreiras físicas. } \\
\underline{\text { Implantação de rampas de acesso de }} \\
\text { deficientes nas esquinas, conforme prioridade } \\
\text { apresentada pelo Conselho de Portadores de } \\
\text { Necessidades Especiais, e exigência de } \\
\text { implantação pelo loteador nos novos } \\
\text { empreendimentos. } \\
\text { - Previsão no Plano Diretor Participativo do } \\
\text { Plano de Mobilidade sob uma nova ótica a da } \\
\text { sustentabilidade econômica, social e } \\
\text { - Ombiental. } \\
\text { O curso que fizemos com você é um início. O } \\
\text { Plano Diretor Participativo. Não expansão do } \\
\text { perímetro urbano. } \\
\text { - Existem previsões dentro do novo plano } \\
\text { diretor. Curso para técnicos de Prefeitura. } \\
\text { - Desconheço as medidas / políticas públicas } \\
\text { voltadas à mobilidade urbana. }\end{array}$ \\
\hline AVALIAÇÃO & \multicolumn{2}{|c|}{$\begin{array}{l}\text { Na abordagem do Questionário 1A (Mapa 1) os participantes relacionaram as ações de mobilidade } \\
\text { implantadas na cidade sob o enfoque da infra-estrutura de transportes (implantação de obras). Em } \\
50 \% \text { das respostas obtidas, os participantes relacionaram as ações de mobilidade com a inclusão } \\
\text { deste Tema no Plano Diretor Participativo. } \\
\text { No Questionário } 2 \text { (Mapa 2) pode-se verificar uma ampliação das abordagens dos participantes; } \\
\text { outras questões importantes foram pontuadas como: a questão da acessibilidade, a necessidade da } \\
\text { integração das políticas de planejamento urbano e de transportes, o controle da expansão urbana, o } \\
\text { enfoque do Plano Diretor de Transportes e Mobilidade a ser elaborado pelo município sob a ótica } \\
\text { da sustentabilidade (econômica, social e ambiental). Todos estes temas fazem parte dos três } \\
\text { Módulos de Avaliação do Sistema PLANUTS, através das avaliações das Categorias, Temas e } \\
\text { Indicadores. } \\
\text { Observação: Embora o sistema não tenha enfocado, em suas avaliações, diretamente a questão da } \\
\text { capacitação técnica, este item foi mencionado no segundo questionário, pois os participantes } \\
\text { sentiram a necessidade da realização de outros cursos para que eles possam elaborar o Plano } \\
\text { Diretor de Transportes e Mobilidade no município de Bauru. }\end{array}$} \\
\hline
\end{tabular}




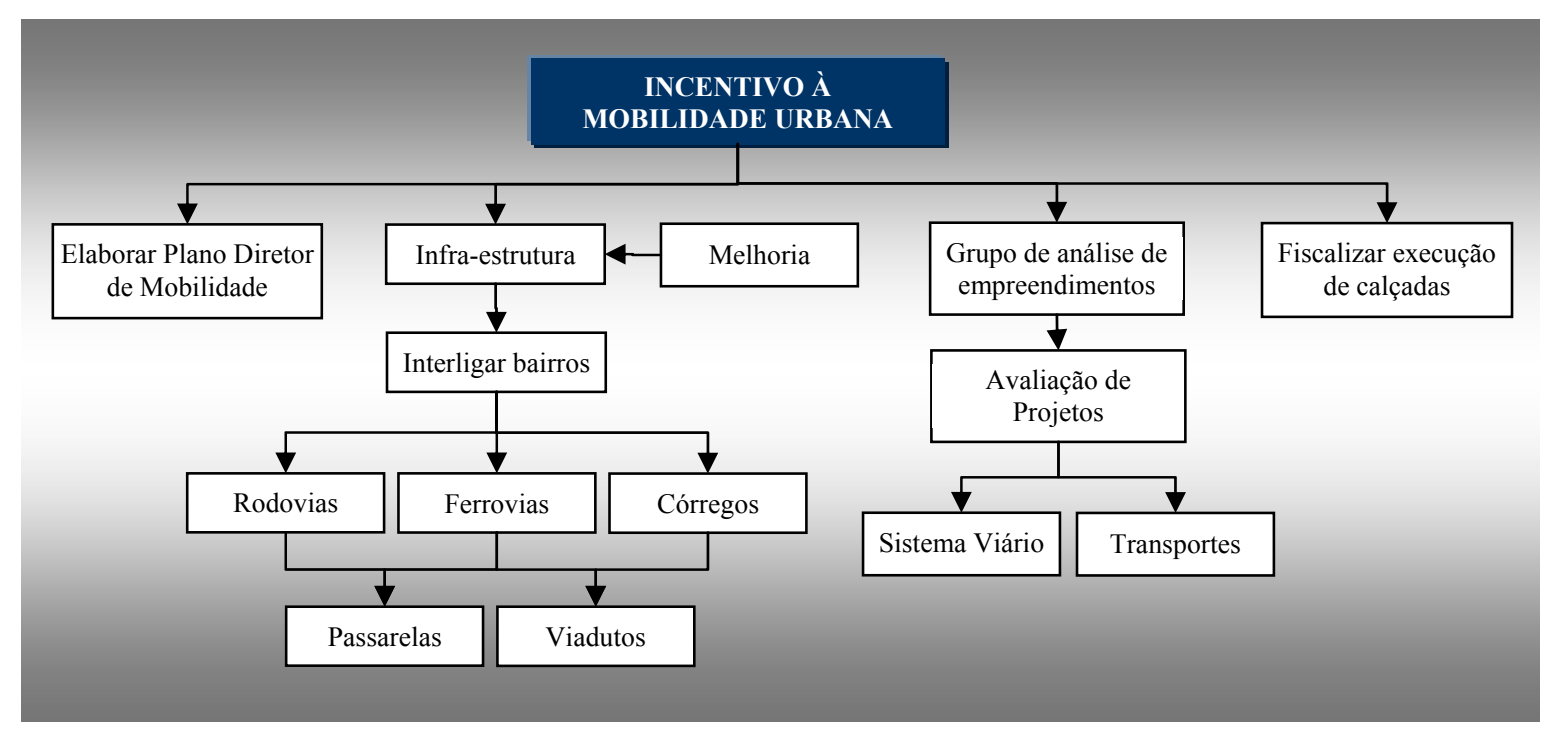

Figura 8.19 - Mapa Cognitivo 1 - Medidas adotadas no município para incentivar a mobilidade extraídos do Questionário 1A

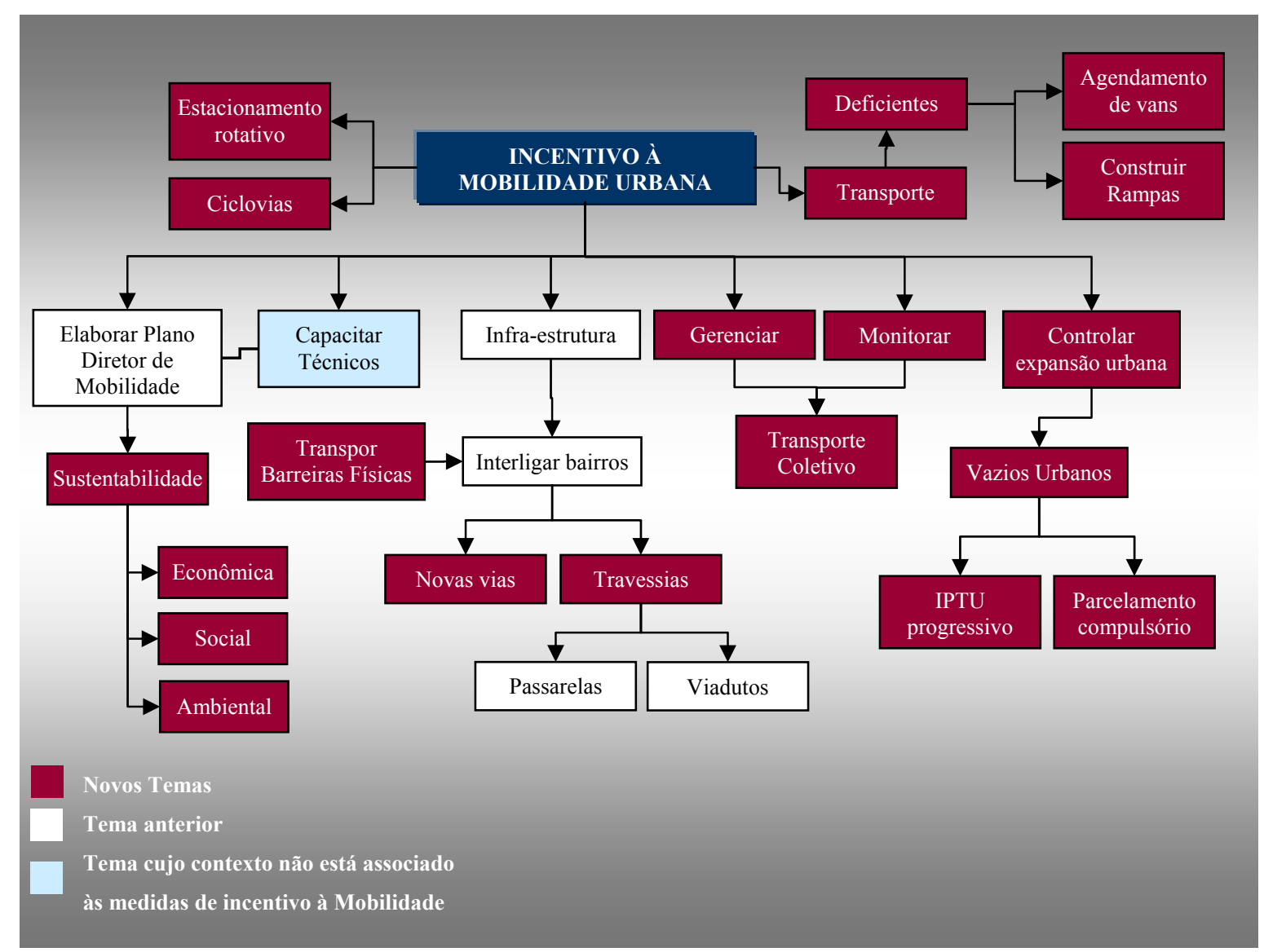

Figura 8.20 - Mapa Cognitivo 2 - Medidas adotadas no município para incentivar a mobilidade extraídos do Questionário 2 


\section{- Setores envolvidos no Plano de Transporte / Mobilidade}

Quadro 8.19 - Transcrição e análise das respostas dos avaliadores para a questão que trata da identificação dos setores envolvidos com o Plano de Transporte e Mobilidade no município nos Questionários 1A e 2

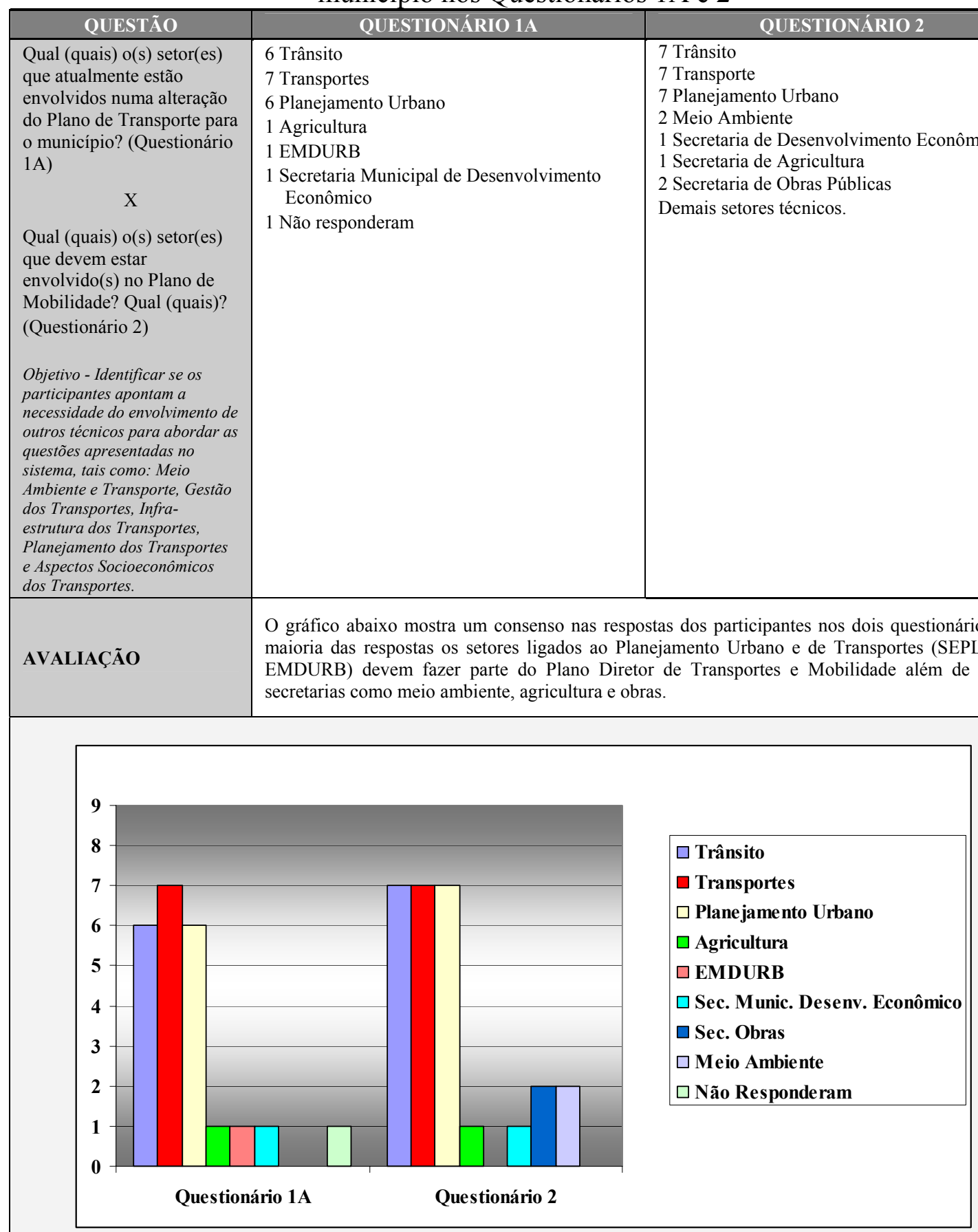

Figura 8.21 - Gráfico comparativo mostrando os setores municipais estão envolvidos com o com o Plano de Transporte e Mobilidade 


\section{- Secretarias envolvidas no Plano Diretor de Transportes e Mobilidade}

Quadro 8.20 - Transcrição e análise das respostas dos avaliadores para a questão que trata da identificação das secretarias envolvidas com o Plano de Transporte e Mobilidade no município nos Questionários 1A e 2

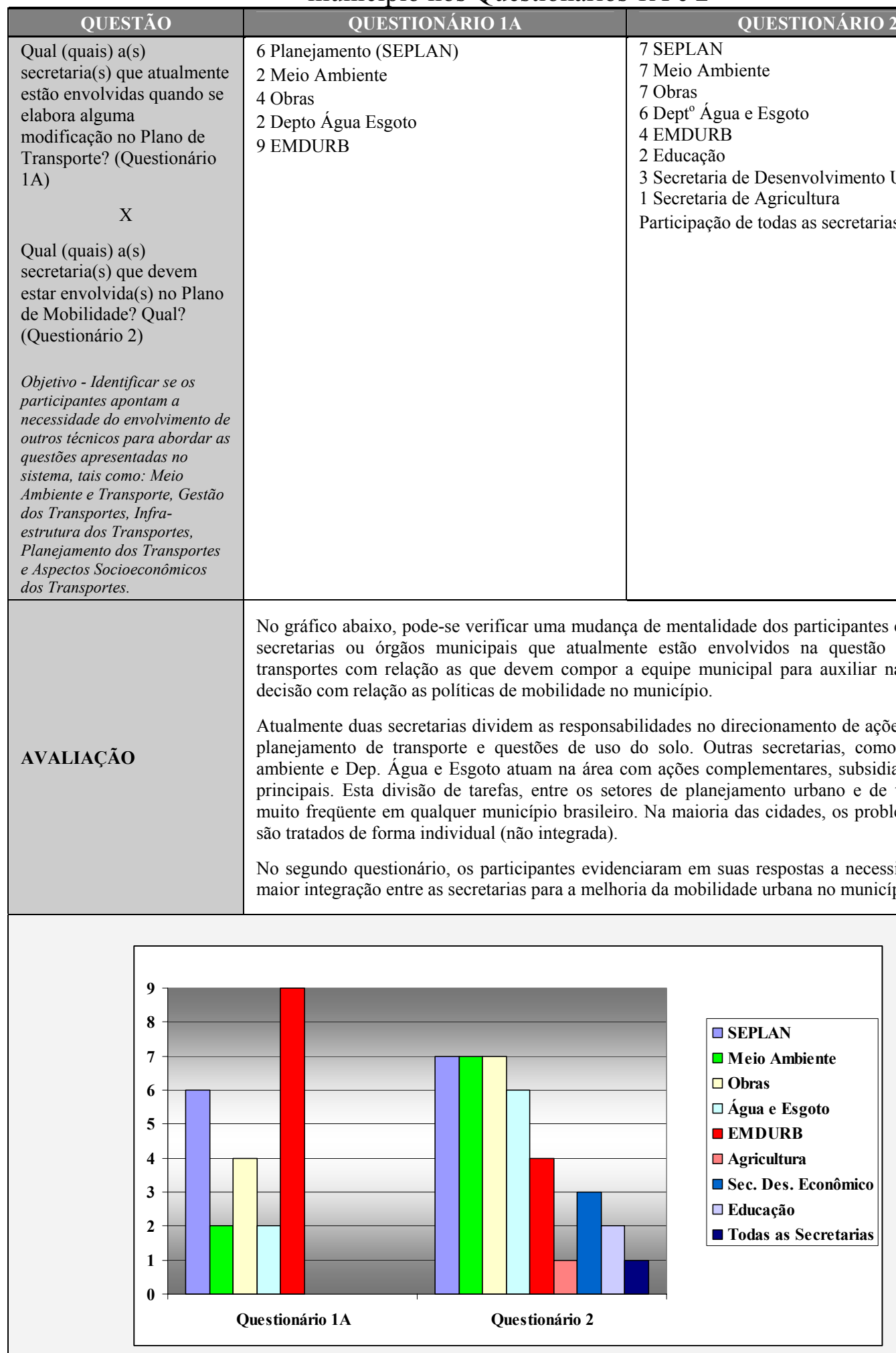

Figura 8.22 - Gráfico comparativo mostrando as secretarias municipais envolvidas com o Plano de Transporte e Mobilidade 


\section{- Definição dos principais Temas relacionados à Mobilidade}

Quadro 8.21 - Transcrição e análise das respostas dos avaliadores para a questão que trata da identificação dos principais Temas relacionados à política de Transporte e Mobilidade no município nos Questionários $1 \mathrm{~A}$ e 2

\begin{tabular}{|c|c|c|}
\hline QUESTÃO & QUESTIONÁRIO 1A & QUESTIONÁRIO 2 \\
\hline 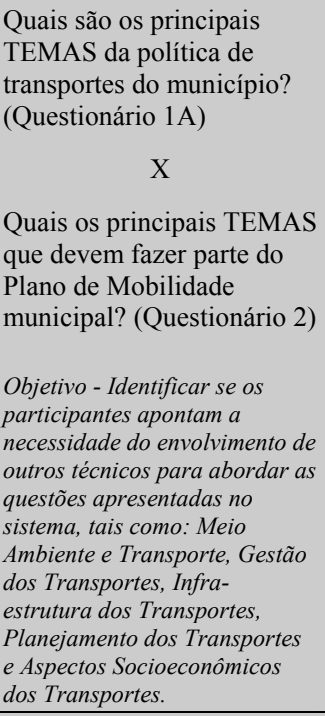 & $\begin{array}{l}\text { - Mobilidade Urbana. } \\
\text { - Na proposta contida no PDP deverão ser } \\
\text { envolvidos todos os meios de transportes } \\
\text { individuais e coletivos, público e privados. } \\
\text { - Transporte coletivo / Trânsito. } \\
\text { - } \underline{\text { Sistema Viário / Transporte coletivo. }}\end{array}$ & 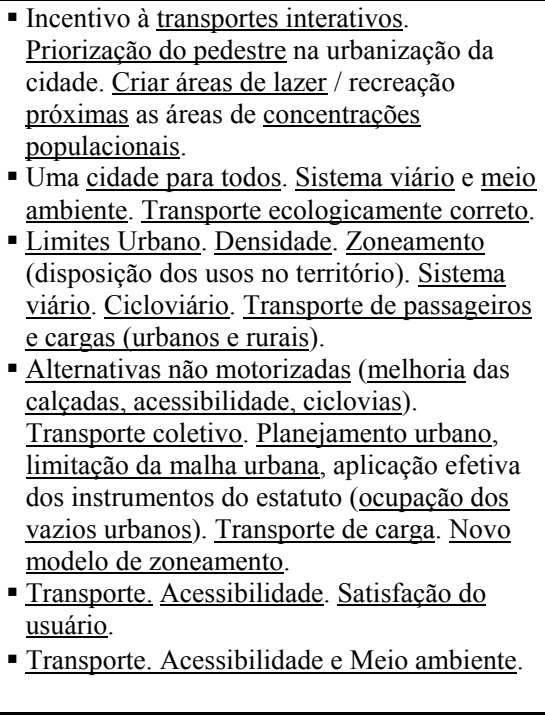 \\
\hline AVALIAÇÃo & \multicolumn{2}{|c|}{$\begin{array}{l}\text { O Mapa Cognitivo } 1 \text { mostra um cenário que retrata o pensamento da maioria dos cidadãos quando } \\
\text { se aborda a questão do transporte no município. A política de transporte está associada sempre com } \\
\text { a questão da infra-estrutura (sistema viário), e o gerenciamento do trânsito na cidade com ações } \\
\text { setoriais. } \\
\text { O Mapa Cognitivo } 2 \text { apresenta uma ampliação no antigo conceito relacionado ao Planejamento de } \\
\text { Transportes. Comparando-se os Mapas } 1 \text { e } 2 \text { pode-se perceber claramente a inserção de novos } \\
\text { temas relacionados à política de Mobilidade Urbana preconizada pelo Ministério das Cidades e } \\
\text { abordadas no Curso de Capacitação e no Sistema PLANUTS, como por exemplo: prioridade ao } \\
\text { pedestre, sistema viário, meio ambiente, limite urbanos, densidades, zoneamento, acessibilidade, } \\
\text { transporte coletivo, transporte de carga, modos não motorizados. } \\
\text { Os temas inseridos no segundo questionário (Mapa 2) fazem parte das } 5 \text { categorias propostas para } \\
\text { avaliação no sistema PLANUTS: Meio Ambiente e Transportes; Gestão dos Transportes; Infra- } \\
\text { estrutura dos Transportes; Planejamento dos Transportes e Aspectos Socioeconômicos dos } \\
\text { Transportes. } \\
\text { Ver Quadro } 8.3 \text { (avaliação das Categorias e Temas - análise dos Temas que pertencem às dez } \\
\text { primeiras colocações em cada grupo). }\end{array}$} \\
\hline
\end{tabular}

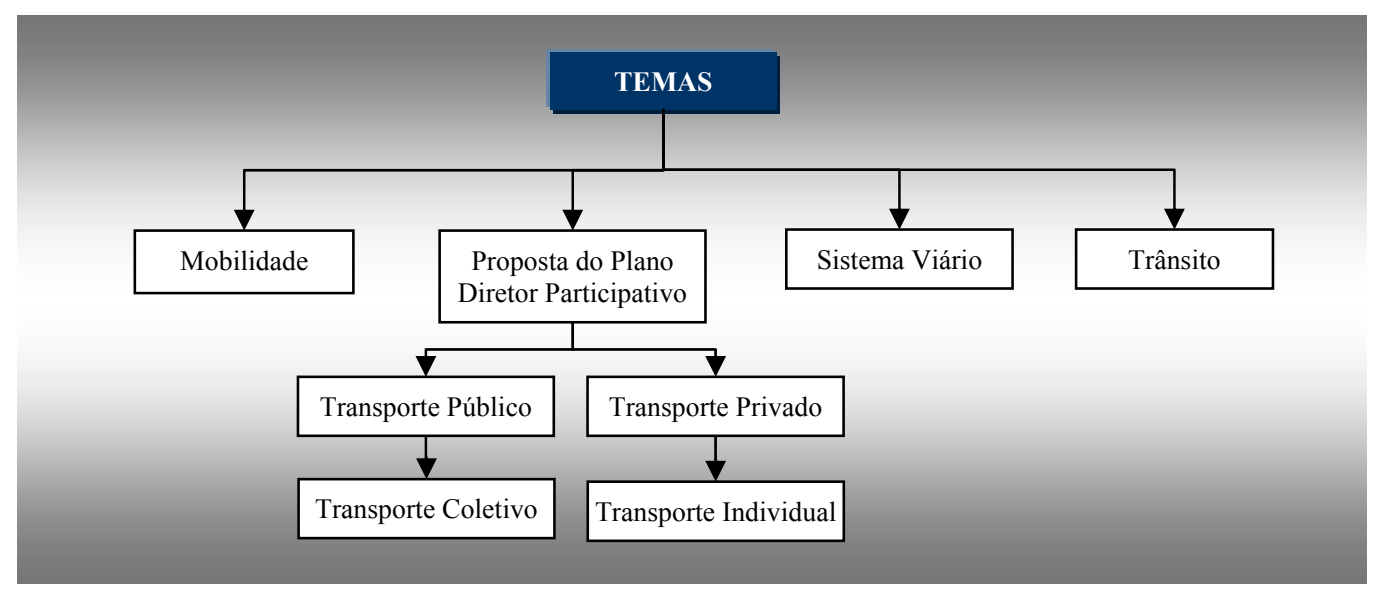

Figura 8.23 - Mapa Cognitivo 1 - Identificação dos Temas de Mobilidade Urbana extraídos do Questionário 1A 


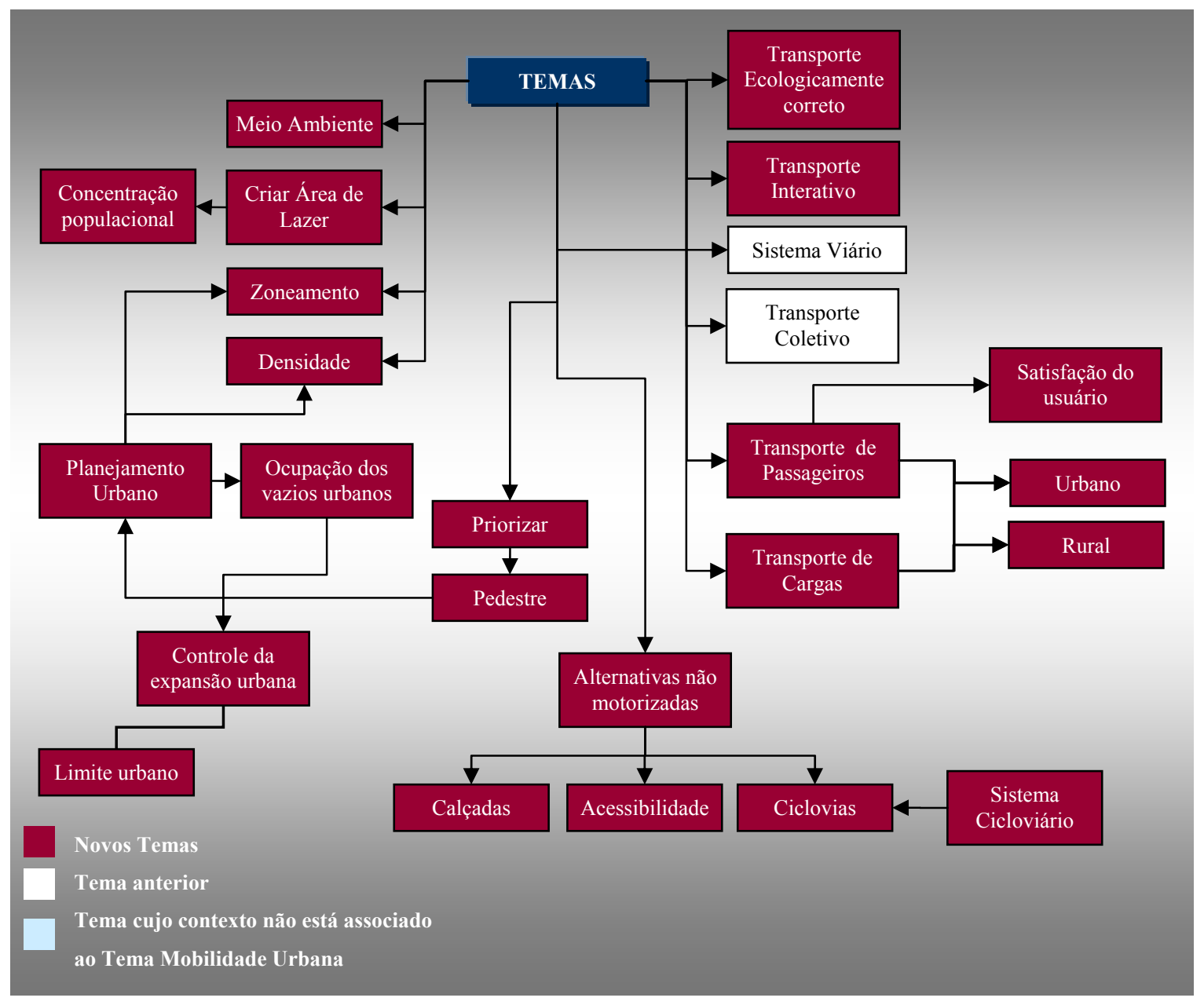

Figura 8.24 - Mapa Cognitivo 2 - Identificação dos Temas de Mobilidade Urbana extraídos do Questionário 2 


\section{- Política de Estacionamentos}

Quadro 8.22 - Transcrição e análise das respostas dos avaliadores para a questão que trata da identificação da política municipal de Estacionamentos nos Questionários $1 \mathrm{~A} \mathrm{e} 2$

\begin{tabular}{|c|c|c|}
\hline QUESTÃO & QUESTIONÁRIO 1A & QUESTIONÁRIO 2 \\
\hline $\begin{array}{l}\text { Quais os principais } \\
\text { objetivos da política de } \\
\text { ESTACIONAMENTOS } \\
\text { para o município? } \\
\text { (Questionário 1A) } \\
\qquad \text { X } \\
\text { Quais os principais pontos a } \\
\text { serem discutidos no Plano } \\
\text { de Mobilidade com relação } \\
\text { a política de } \\
\text { ESTACIONAMENTOS } \\
\text { para o município? } \\
\text { (Questionário 2) }\end{array}$ & $\begin{array}{l}\text { - Incentivar a criação de estacionamentos } \\
\text { internos, retirar veículos dos estacionamentos } \\
\text { públicos junto as vias e priorizar o fluxo de } \\
\text { veículos. } \\
\text { - Existe uma tendência de aumentar a exigência } \\
\text { para estacionamento interno aos } \\
\text { estabelecimentos que precisa ser revista. } \\
\text { - Momento ainda é priorizar o transporte } \\
\text { individual. } \\
\text { - Dar condições de estacionamento para quem } \\
\text { usa o automóvel em determinada área, onde o } \\
\text { número de vagas é menor do que a demanda. } \\
\text { - Elaborar novos parâmetros para prover } \\
\text { estacionamentos em novas construções de } \\
\text { acordo com a metragem quadrada e uso. }\end{array}$ & 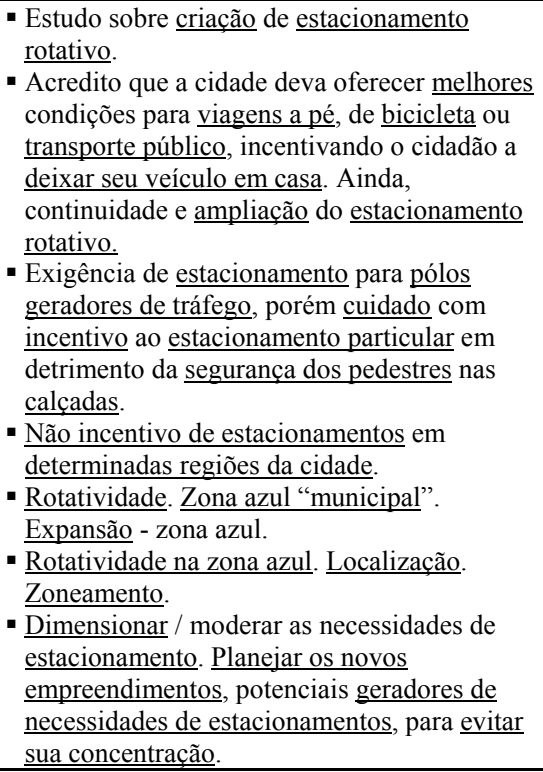 \\
\hline AVALIAÇ & \multicolumn{2}{|c|}{$\begin{array}{l}\text { O Mapa Cognitivo } 1 \text { retrata a atual política de transportes, não só do município de Bauru, como } \\
\text { também de muitas cidades do Brasil e do exterior, onde a prioridade é incentivar o uso do } \\
\text { automóvel em detrimento do transporte coletivo. As palavras-chaves identificadas nas respostas } \\
\text { obtidas no Questionário } 1 \text { mostram a necessidade pela criação de mais vagas de estacionamentos } \\
\text { no município para suprir a demanda. Conforme foi apresentado anteriormente neste capítulo, } \\
\text { Bauru possui uma média de aproximadamente } 2,27 \text { habitantes/veículos (dados obtidos até o mês de } \\
\text { agosto de 2007) isso gera um déficit na infra-estrutura viária do município. } \\
\text { As respostas obtidas no Questionário } 2 \text { (ver Mapa Cognitivo 2) mostram que apesar da atual } \\
\text { política de transporte priorizar o transporte individual motorizado, os participantes assimilaram a } \\
\text { necessidade de reverter este cenário através do incentivo de outros meios de transporte. A adoção } \\
\text { de outros meios de transporte tem um impacto direto na política de estacionamento municipal, ou } \\
\text { seja, a mudança do uso do automóvel pela utilização do transporte coletivo tem como } \\
\text { conseqüência a diminuição da necessidade de implantação de novas áreas de estacionamento. } \\
\text { No Sistema PLANUTS, as respostas obtidas no segundo questionário podem ser associadas a } \\
\text { avaliação dos seguintes Temas e Indicadores: Mobilidade Urbana (Priorizar viagens eficientes - a } \\
\text { pé ou por bicicleta), Sistema Viário (Número de estacionamentos para carros na cidade, Provisão } \\
\text { de infra-estrutura para moderação de tráfego e vias para bicicletas e pedestres), Serviços de } \\
\text { Transportes (Mudanças nos modos de transporte), Crescimento Urbano (Políticas de uso do solo } \\
\text { para pedestres, ciclistas e transporte público). }\end{array}$} \\
\hline
\end{tabular}




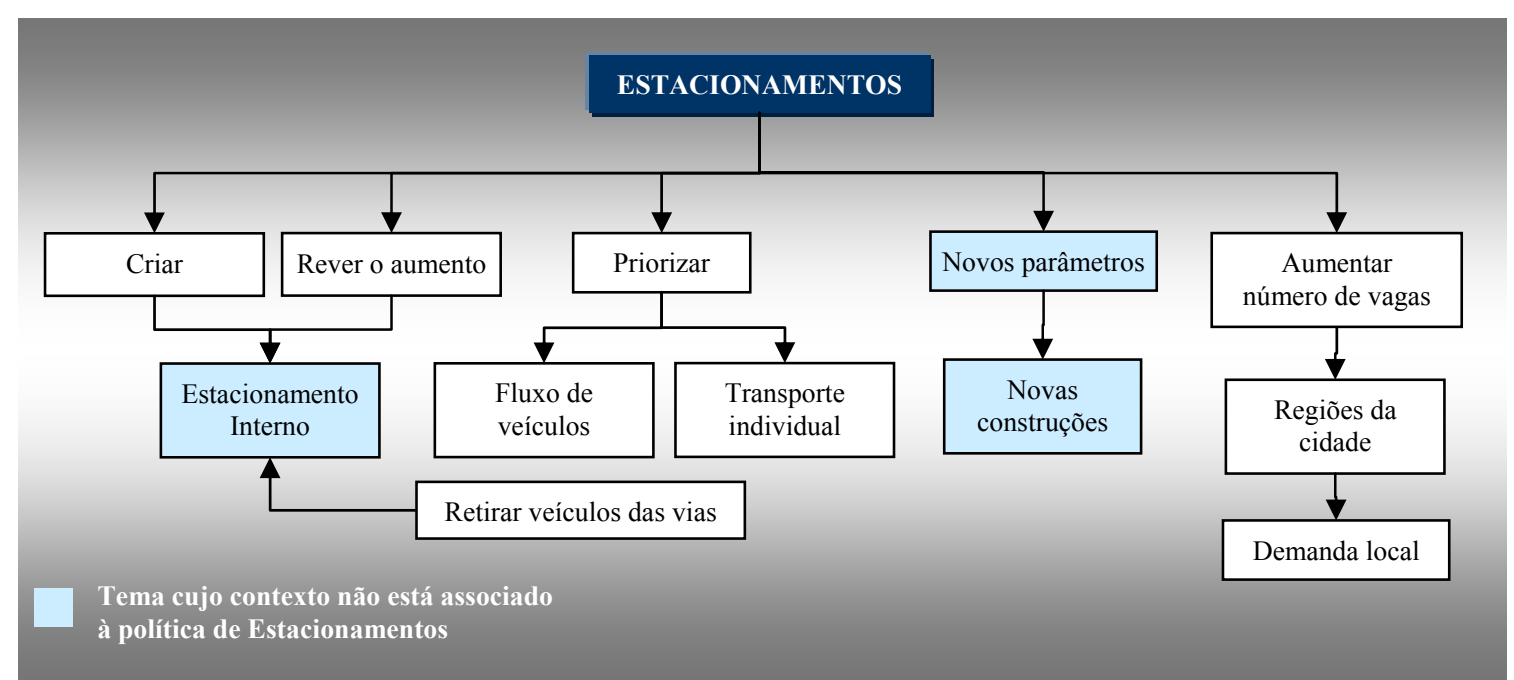

Figura 8.25 - Mapa Cognitivo 1 - Identificação da política de Estacionamentos extraídos do Questionário 1A

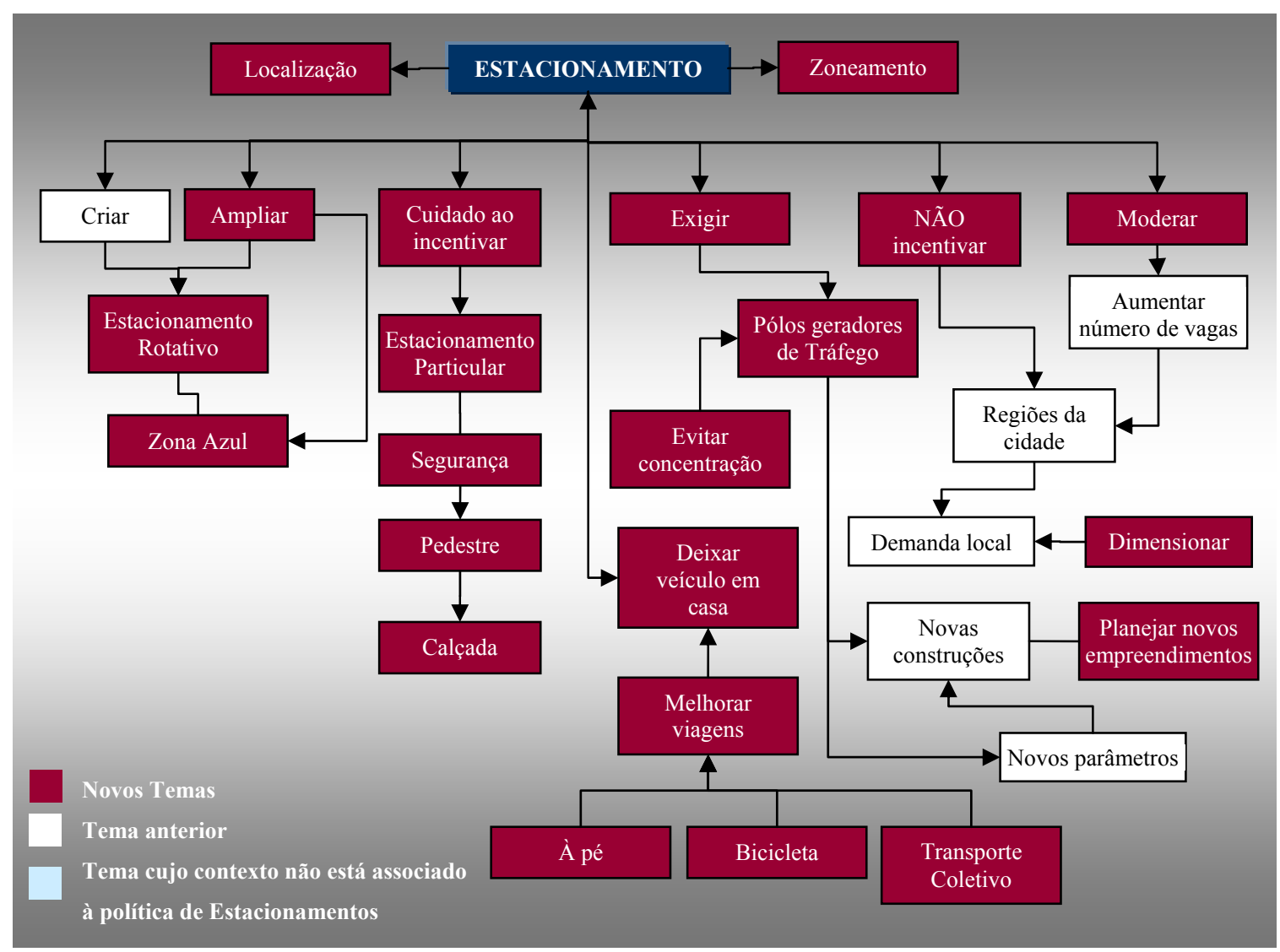

Figura 8.26 - Mapa Cognitivo 2 - Identificação da política de Estacionamentos extraídos do Questionário 2 


\section{- Política de Transporte Público}

Quadro 8.23 - Transcrição e análise das respostas dos avaliadores para a questão que trata da identificação da política municipal de Transporte Público nos Questionários 1A e 2

\begin{tabular}{|c|c|c|}
\hline QUESTÃO & QUESTIONÁRIO 1A & QUESTIONÁRIO 2 \\
\hline $\begin{array}{l}\text { Quais os principais } \\
\text { objetivos da política de } \\
\text { TRANSPORTE PÚBLICO } \\
\text { para o município? } \\
\text { (Questionário 1A) } \\
\qquad \text { X } \\
\text { Quais os principais pontos a } \\
\text { serem discutidos no Plano } \\
\text { de Mobilidade com relação } \\
\text { a política de } \\
\text { TRANSPORTE PÚBLICO } \\
\text { para o município? } \\
\text { (Questionário 2) } \\
\text { Objetivo - Identificar alguns } \\
\text { problemas (chave) de } \\
\text { mobilidade no municipio a } \\
\text { partir das definições das } \\
\text { Categorias, Temas e } \\
\text { Indicadores. }\end{array}$ & $\begin{array}{l}\text { - Realizar o transporte de forma segura, } \\
\text { eficiente e economicamente viável. } \\
\text { - Acredito que seja a oferta de transporte que } \\
\text { comporte a demanda, com possibilidade de se } \\
\text { chegar ao destino de forma confortável e } \\
\text { - Integura. } \\
\text { - Easse integração. } \\
\text { - Essa política hoje se restringe a EMDURB, } \\
\text { não sendo do nosso conhecimento. } \\
\text { - Transporte eficiente de passageiros nos } \\
\text { - Esterários e locais que são necessários. }\end{array}$ & 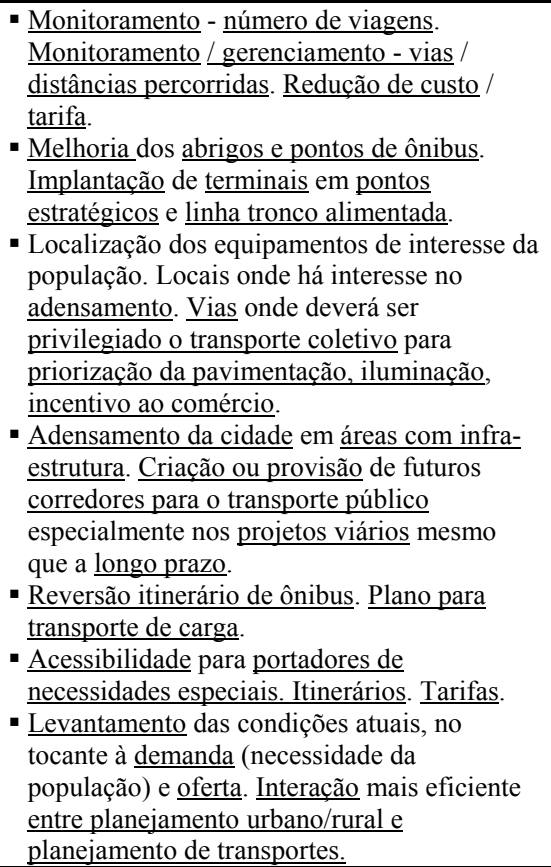 \\
\hline AVALIAÇÃO & \multicolumn{2}{|c|}{$\begin{array}{l}\text { Analisando os Mapas Cognitivos I e II pode-se notar uma diferença na abordagem com relação aos } \\
\text { objetivos da política de Transporte Público e a definição dos principais temas a serem discutidos } \\
\text { num Plano Diretor de Transportes e Mobilidade sobre a mesma questão. } \\
\text { No Mapa Cognitivo I o enfoque sobre o tema foi pautado sobre questões de planejamento e } \\
\text { operação do Transporte Público, ou seja, foram relacionados os seguintes aspectos: oferta e } \\
\text { demanda, integração de linhas, eficiência econômica, freqüência, conforto, segurança e órgão } \\
\text { gestor. } \\
\text { No Mapa Cognitivo II as respostas incluíram outras abordagens tais como: integração entre o } \\
\text { planejamento urbano e de transportes, viagens, percurso, redução de custos e tarifas, melhoria dos } \\
\text { pontos de ônibus, corredores para transporte público, itinerários, demanda, oferta e acessibilidade } \\
\text { para portadores de necessidades especiais. Além da proposição de algumas soluções como, por } \\
\text { exemplo, a adoção de linha tronco-alimentada, criação de corredores para o transporte coletivo e } \\
\text { implantação de terminais. } \\
\text { No Sistema PLANUTS este item é abordado através do Tema Transporte Público que engloba os } \\
\text { seguintes Indicadores: Demanda por transporte de passageiros, Disponibilidade de transporte } \\
\text { público, Necessidade de sistemas de transporte, Nivel de serviço do transporte público e } \\
\text { modalidades lentas. }\end{array}$} \\
\hline
\end{tabular}




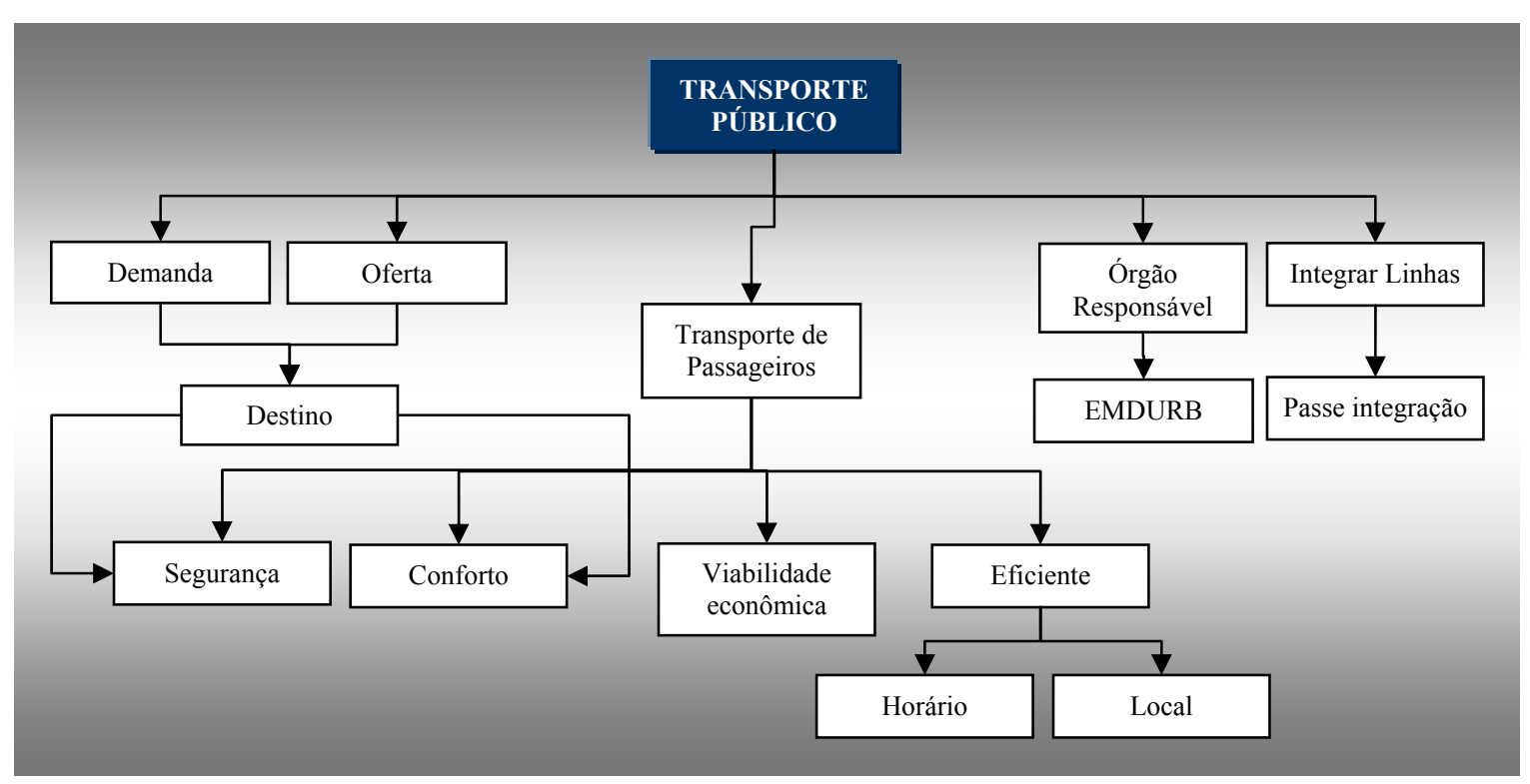

Figura 8.27 - Mapa Cognitivo 1 - Identificação da política de Transporte Público extraídos do Questionário 1A

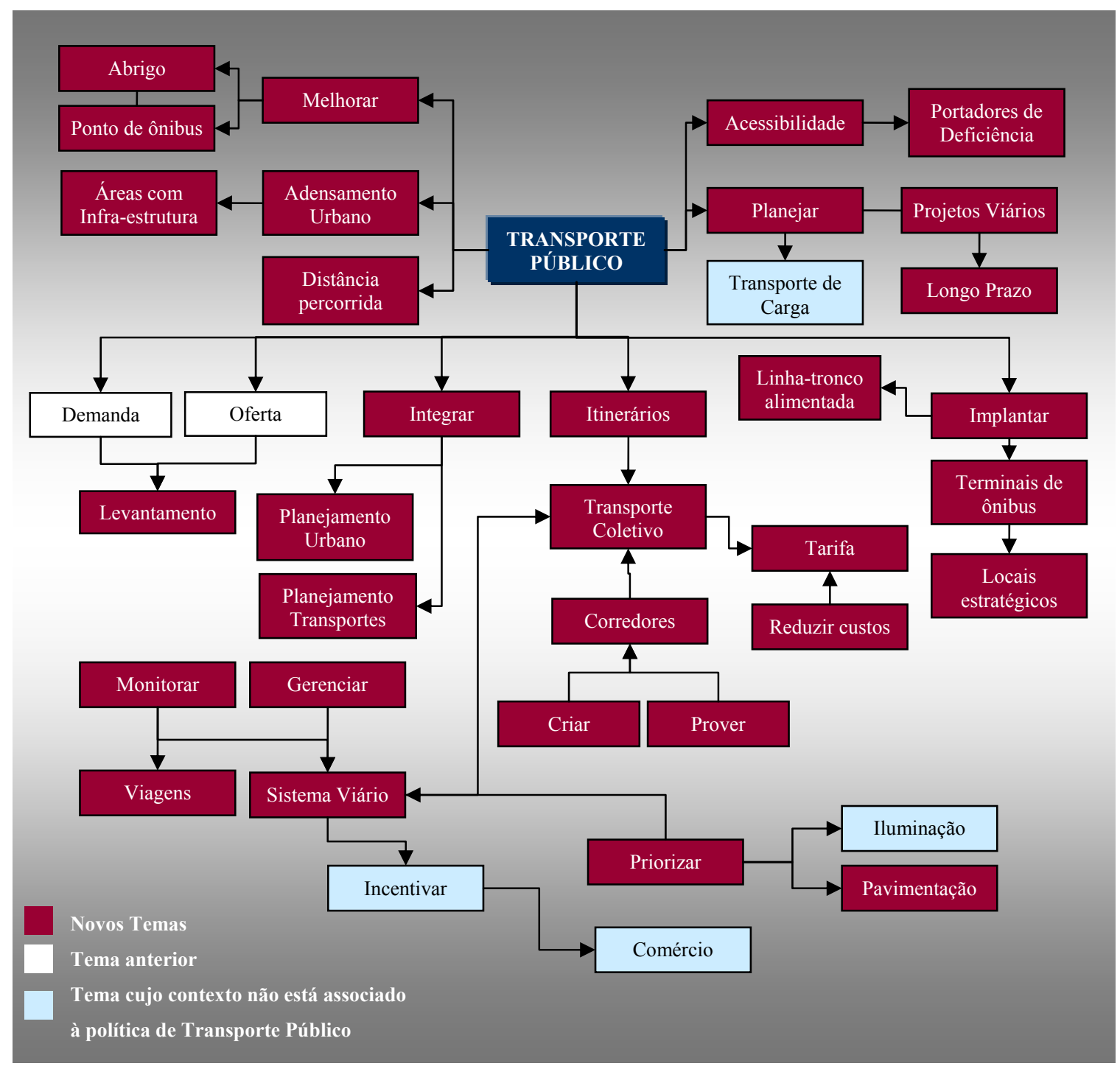

Figura 8.28 - Mapa Cognitivo 2 - Identificação da política de Transporte Público extraídos do Questionário 2 


\section{- Política de Circulação}

Quadro 8.24 - Transcrição e análise das respostas dos avaliadores para a questão que trata da identificação da política municipal de Circulação nos Questionários 1A e 2

\begin{tabular}{|c|c|c|}
\hline QUESTÃO & QUESTIONÁRIO 1A & QUESTIONÁRIO 2 \\
\hline 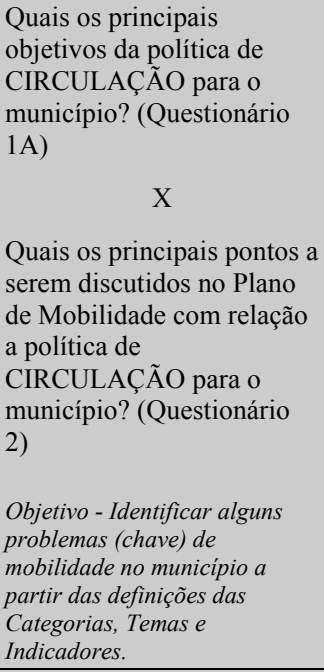 & $\begin{array}{l}\text { - Propiciar deslocamentos rápidos e } \\
\text { confortáveis evitando a saturação da via, } \\
\text { implicando em poluição (atmosférica, visual, } \\
\text {...). } \\
\text { - Ter um sistema viário adequado, com vias } \\
\text { que comportem o fluxo de veículos, calçadas } \\
\underline{\text { adequadas ao trânsito de pedestres e }} \\
\underline{\text { deficientes físicos, não nos esquecendo de }} \\
\text { - } \underline{\text { ciclovias. }} \text { Transporte individual - pouco com relação a } \\
\text { pedestre, ciclista e transporte coletivo. } \\
\text { - Organizar o sistema viário de forma a criar os } \\
\underline{\text { corredores que facilitem a locomoção das }} \\
\text { pessoas em toda a cidade. }\end{array}$ & 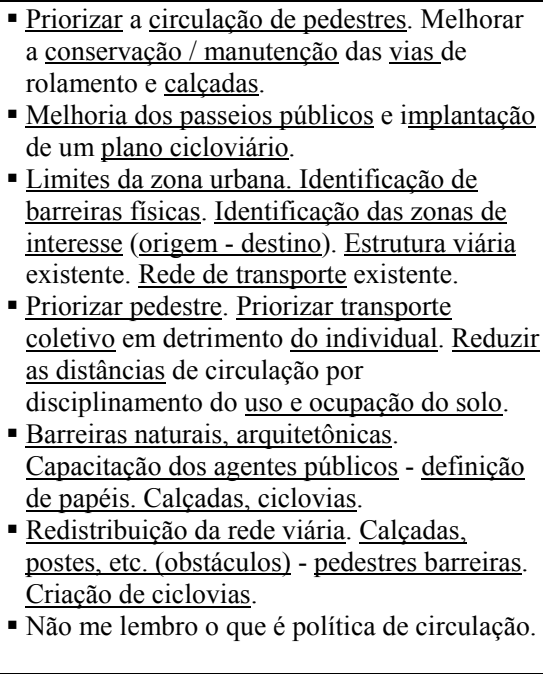 \\
\hline AVALIAÇÃO & \multicolumn{2}{|c|}{$\begin{array}{l}\text { Os Mapas Cognitivos I e II apresentam uma complementação nas respostas dos dois questionários. } \\
\text { A questão da infra-estrutura é presente nos dois mapas. A atual política municipal privilegia o } \\
\text { transporte individual motorizado; entretanto, os entrevistados mostraram a importância do } \\
\text { município investir em políticas de circulação mais sustentáveis através do incentivo a utilização de } \\
\text { modos não-motorizados, como o modo à pé e bicicleta, mas para isto é necessária uma infra- } \\
\text { estrutura de apoio. } \\
\text { Com relação aos modos motorizados as respostas mostram a necessidade de incentivar a utilização } \\
\text { do transporte coletivo e principalmente a adoção de uma nova política de adensamento urbano e } \\
\text { gerenciamento do uso do solo municipal. }\end{array}$} \\
\hline
\end{tabular}




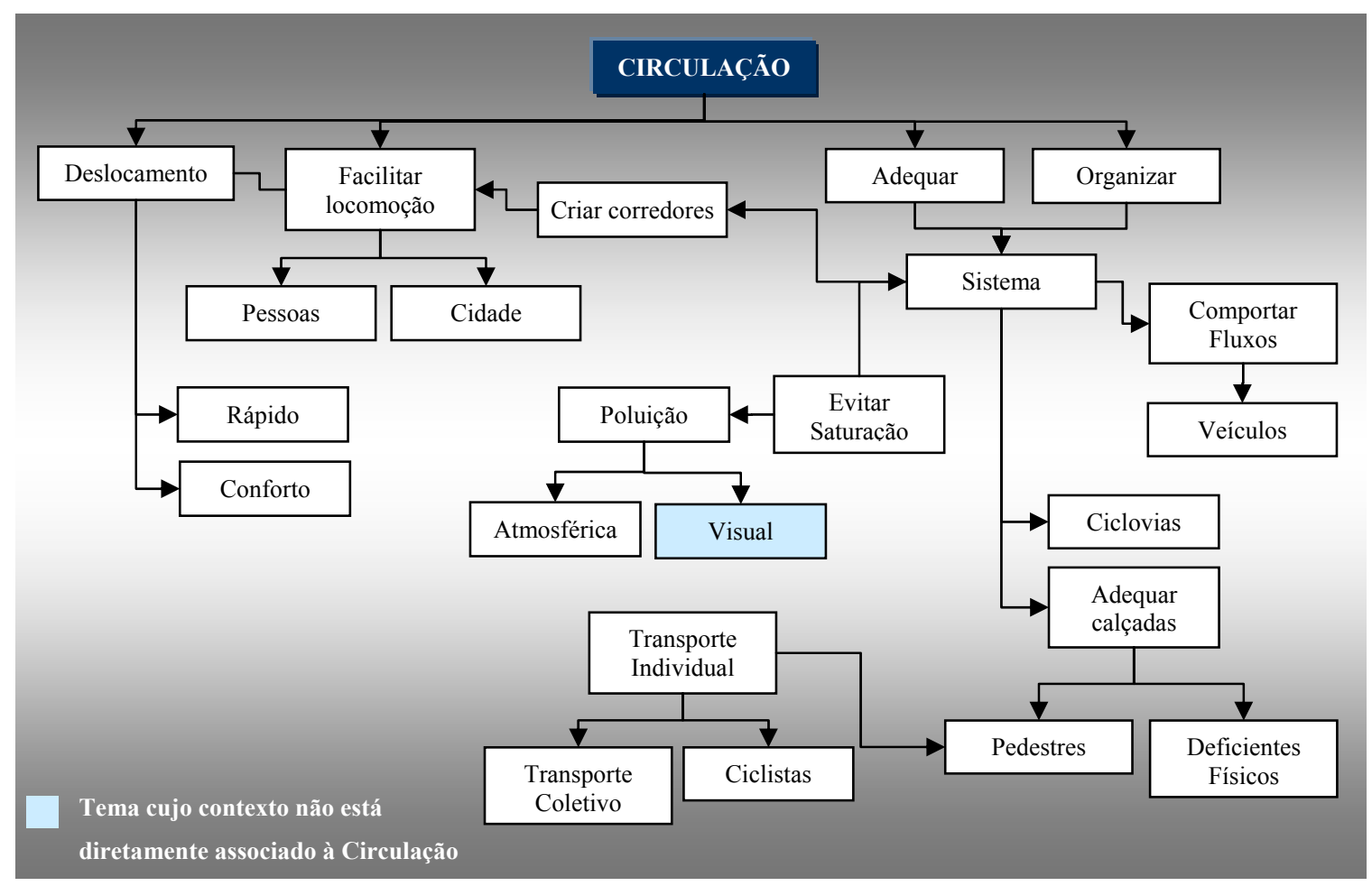

Figura 8.29 - Mapa Cognitivo 1 - Identificação da política de Circulação extraídos do Questionário 1A

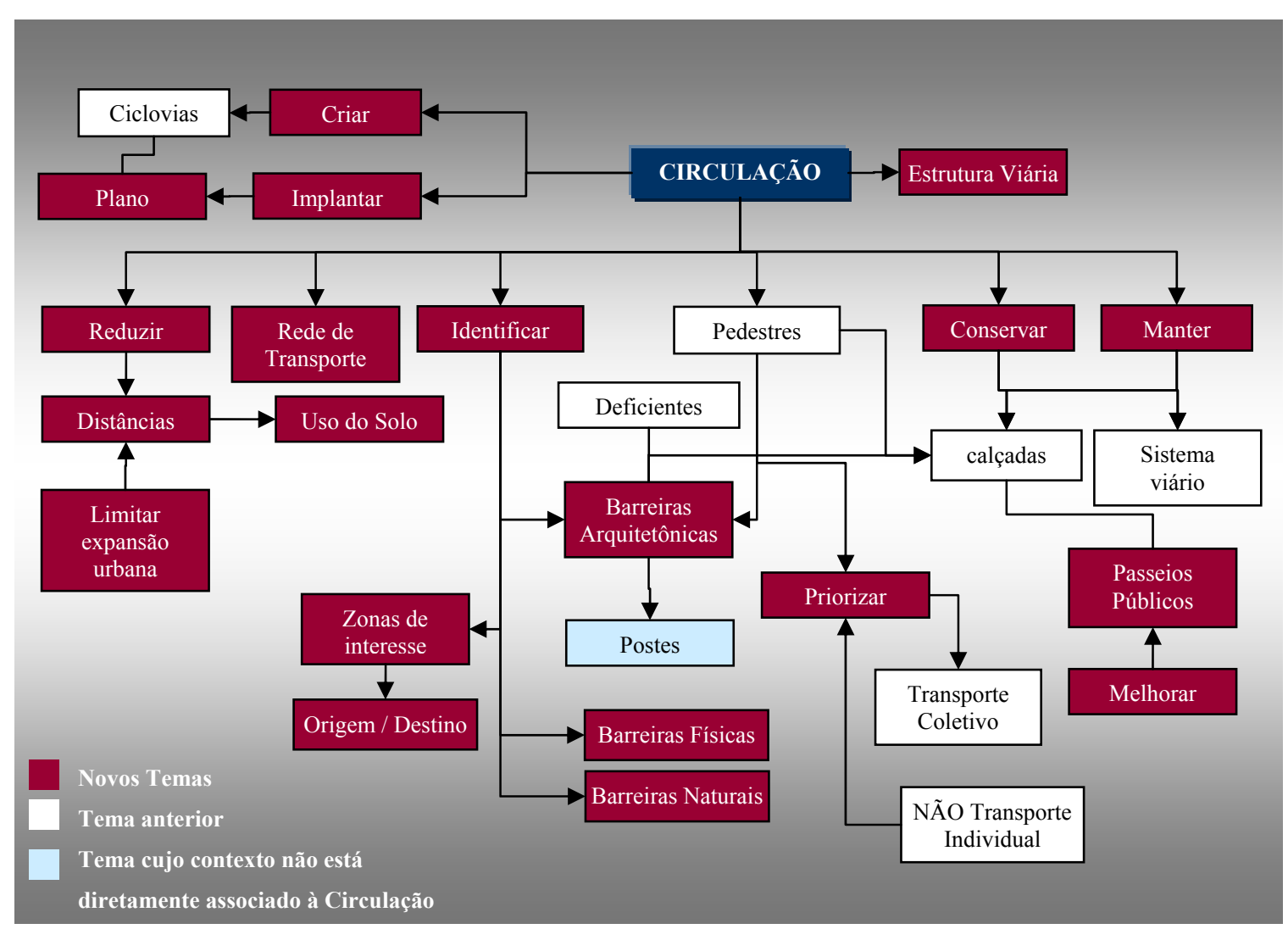

Figura 8.30 - Mapa Cognitivo 2 - Identificação da política de Circulação extraídos do Questionário 2 


\section{- Política de redução da Poluição}

Quadro 8.25 - Transcrição e análise das respostas dos avaliadores para a questão que trata da identificação da existência de um plano para a diminuição da poluição provocada pelos transportes no município nos Questionários $1 \mathrm{~A}$ e 2

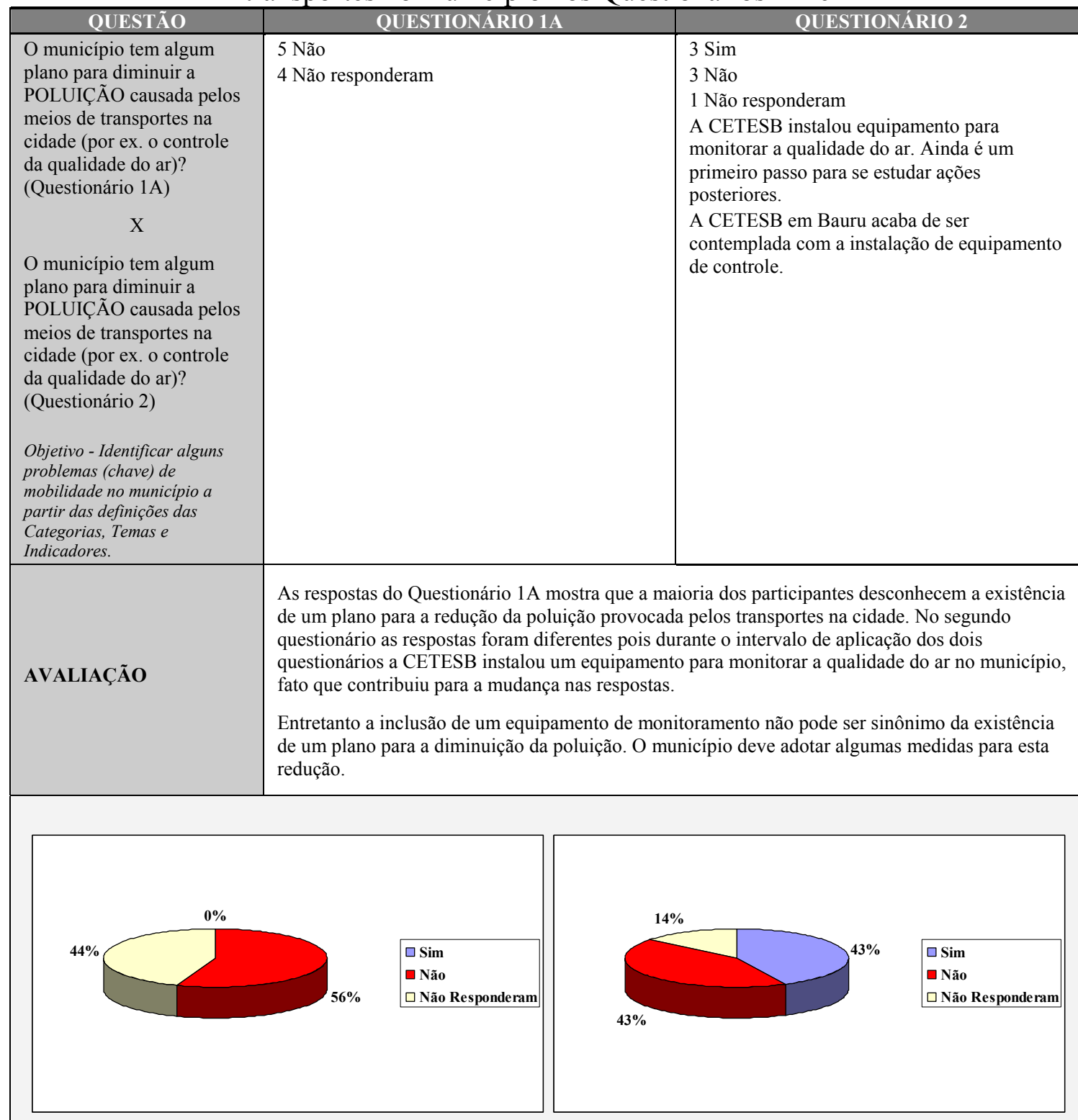

Figuras 8.31 e 8.32 - Gráfico comparativo mostrando o grau de conhecimento dos participantes sobre a existência de um plano para a diminuição da poluição provocada pelos transportes 


\section{- Medidas para a redução dos Níveis de Poluição}

Quadro 8.26 - Transcrição e análise das respostas dos avaliadores para a questão que trata da identificação da existência de uma política de redução dos Níveis de Poluição nos

Questionários 1A e 2

\begin{tabular}{|c|c|c|}
\hline QUESTÃO & QUESTIONÁRIO 1A & QUESTIONÁRIO 2 \\
\hline 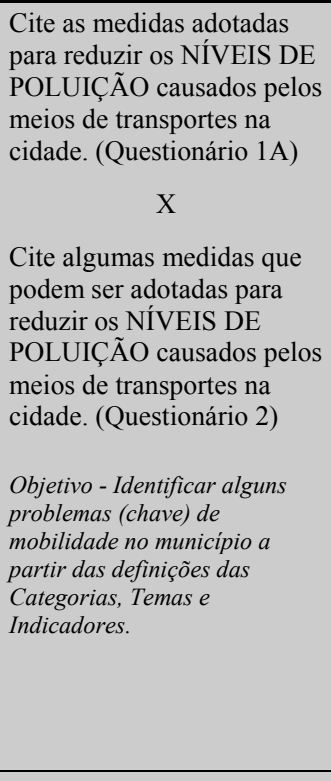 & $\begin{array}{l}4 \text { Não tem } \\
5 \text { Não responderam }\end{array}$ & $\begin{array}{l}\text { - Incentivar o uso do transporte coletivo. } \\
\text { Incentivar o uso de meios de transporte que } \\
\text { utilizam energia limpa. } \\
\text { Implantação de ônibus movido a energia } \\
\text { elétrica e inclusão de biodiesel. } \\
\text { Incentivo ao transporte coletivo (com } \\
\text { melhoria do mesmo); uso de bicicleta; } \\
\text { melhoria das calçadas. } \\
\text { - Incentivar o uso do transporte coletivo a partir } \\
\text { de sua melhoria. Investir em meios } \\
\text { alternativos, ciclovia, segurança e qualidade } \\
\text { para os pedestres. Evitar modelos de fluidez } \\
\text { do transporte individual. } \\
\text { Investimento em frotas. Construção de } \\
\text { ciclovias. Incentivo a carona amiga. } \\
\text { Incentivar o uso de meios de transporte não } \\
\text { poluente. Incentivar o transporte em veículos } \\
\text { públicos. } \\
\text { - Renovação e manutenção da frota de ônibus } \\
\text { urbanos. Instituir medidas de controle de } \\
\text { qualidade do ar em pontos estratégicos da } \\
\text { cidade, visando a elaboração de diagnóstico } \\
\text { dos principais poluidores, para definir a } \\
\text { política de redução dos níveis de poluição. }\end{array}$ \\
\hline AVALIAÇÃOO & \multicolumn{2}{|c|}{$\begin{array}{l}\text { Não foi possível construir o Mapa Cognitivo } 1 \text { em função das respostas dos avaliadores. } \\
\text { As respostas do Questionário 2, apresentadas no Mapa Cognitivo } 2 \text { mostram que os participantes } \\
\text { relacionaram a redução dos níveis de poluição com diversos Temas e Indicadores apresentados nos } \\
\text { Módulos I e II do Sistema PLANUTS. } \\
\text { Os itens elencados pelos participantes podem ser agrupados nos seguintes Temas: Impacto } \\
\text { Ambiental (Impactos do uso de automóveis), Qualidade do Ar (Qualidade do ar), Mobilidade } \\
\text { Urbana (Implementação de estratégias ambientais para o setor de transportes, Medidas: operação } \\
\text { eficiente da frota de veículos, Priorizar viagens eficientes - a pé ou por bicicleta), Novas } \\
\text { Tecnologias (Desenvolvimento de combustíveis limpos e número de veículos que utilizam } \\
\text { combustíveis alternativos e Novas formas de transporte). }\end{array}$} \\
\hline
\end{tabular}

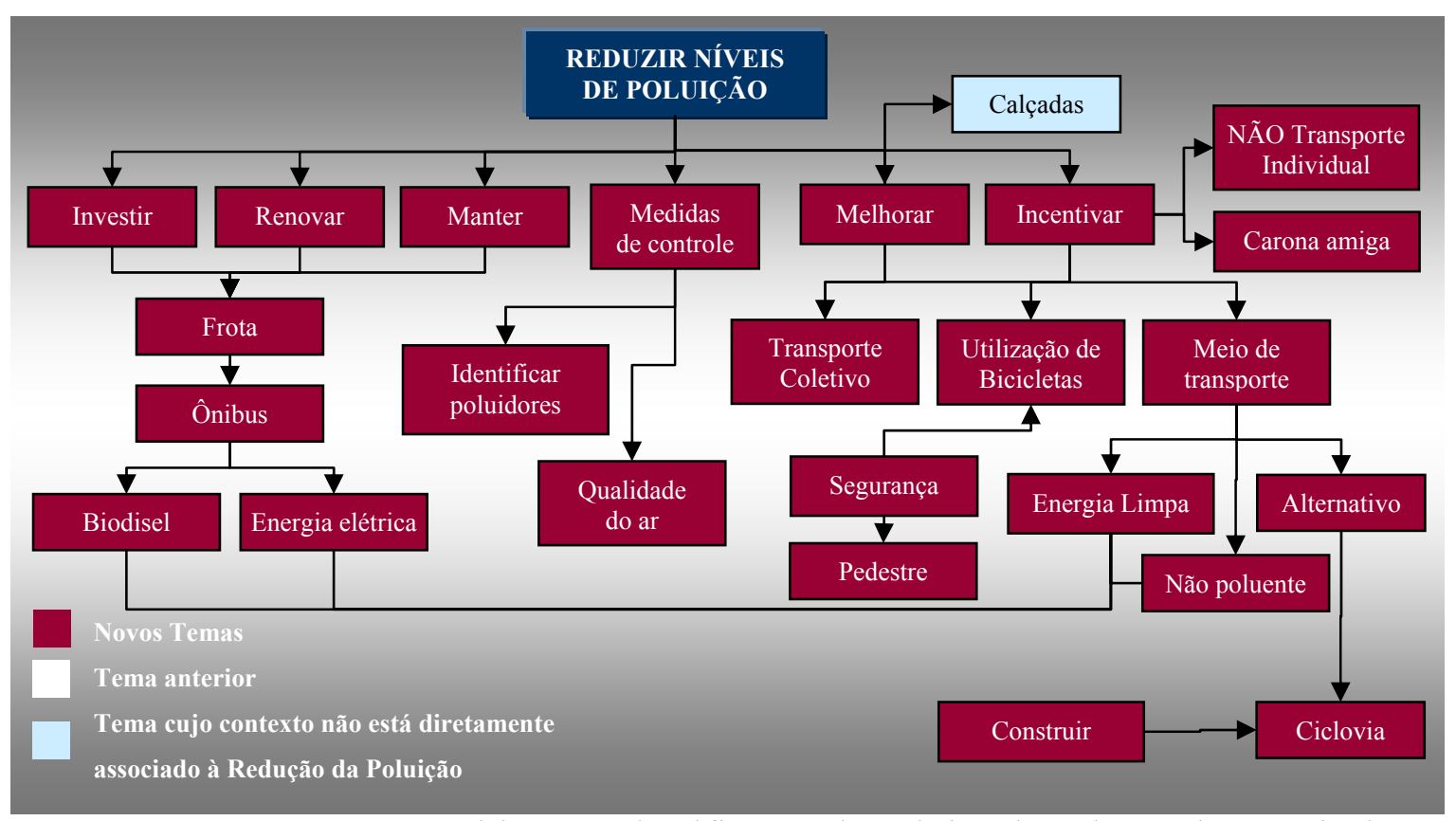

Figura 8.33 - Mapa Cognitivo 2 - Identificação da política de redução dos níveis de poluição extraídos do Questionário 2 


\section{- Diminuição do Ruído}

Quadro 8.27 - Transcrição e análise das respostas dos avaliadores para a questão que trata da identificação da existência de um plano para a diminuição dos níveis de ruído provocados pelos transportes no município nos Questionários $1 \mathrm{~A}$ e 2

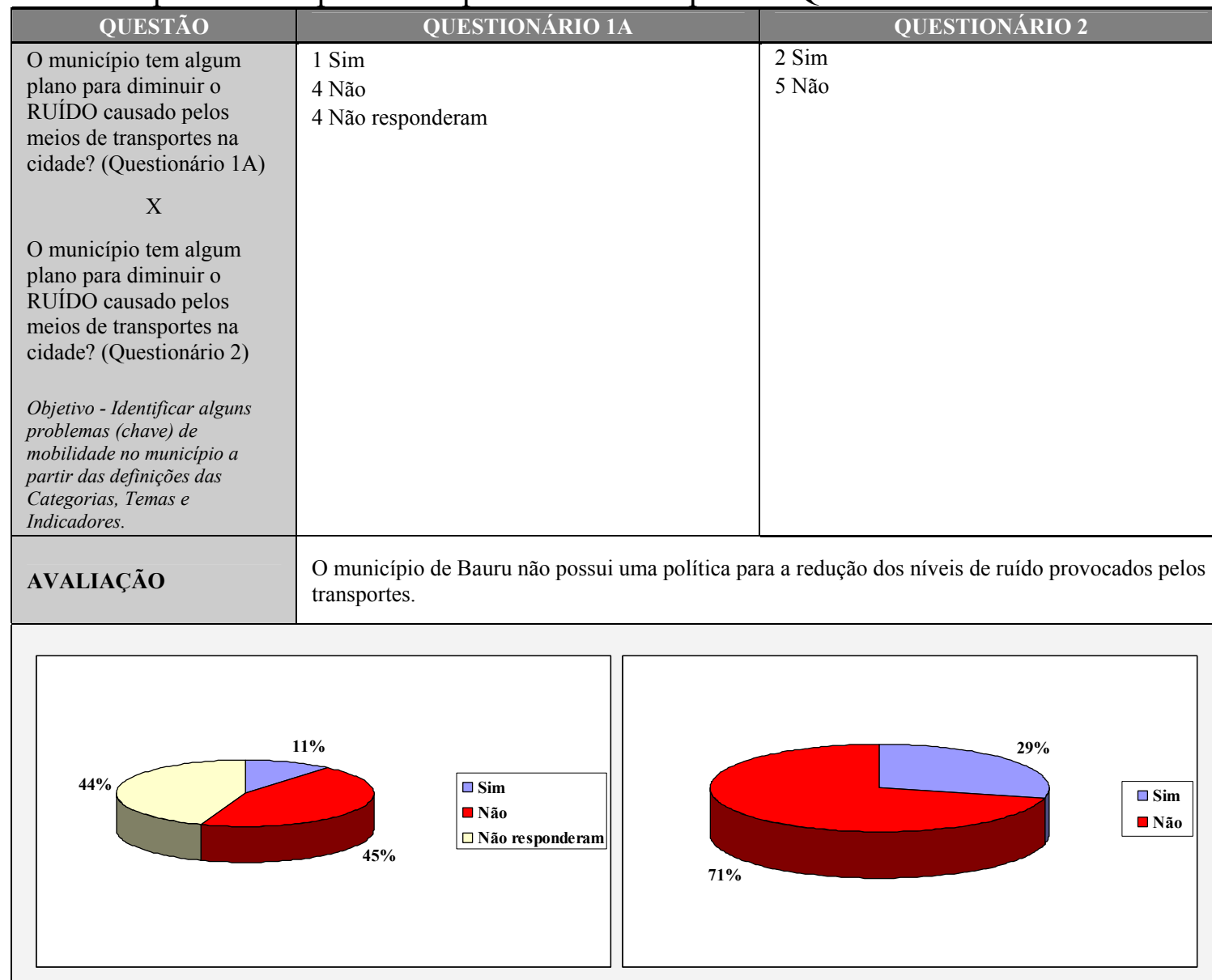

Figuras 8.34 e 8.35 - Gráfico comparativo mostrando o grau de conhecimento dos participantes sobre a existência de um plano para a redução dos níveis de ruído provocados pelos transportes 


\section{- Medidas de redução dos Níveis de Ruído}

Quadro 8.28 - Transcrição e análise das respostas dos avaliadores para a questão que trata da identificação de medidas para a redução dos níveis de Ruído no município nos

Questionários 1A e 2

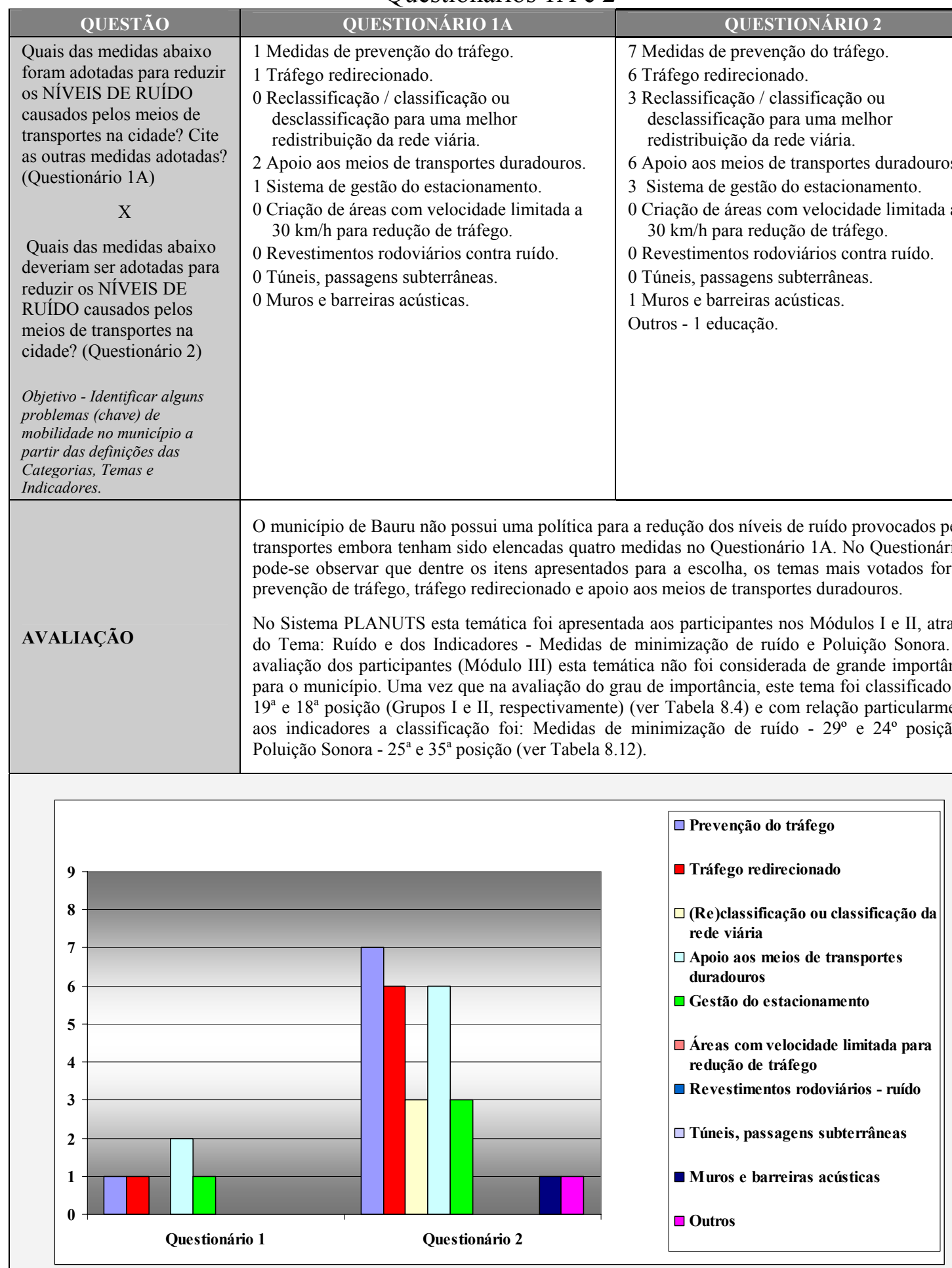

Figura 8.36 - Gráfico comparativo mostrando as medidas a serem adotadas para a redução dos Níveis de Ruído 


\section{- Plano para a redução de pontos de Congestionamentos}

Quadro 8.29 - Transcrição e análise das respostas dos avaliadores para a questão que trata da identificação da existência de um plano para a redução dos pontos de Congestionamento no município nos Questionários 1A e 2

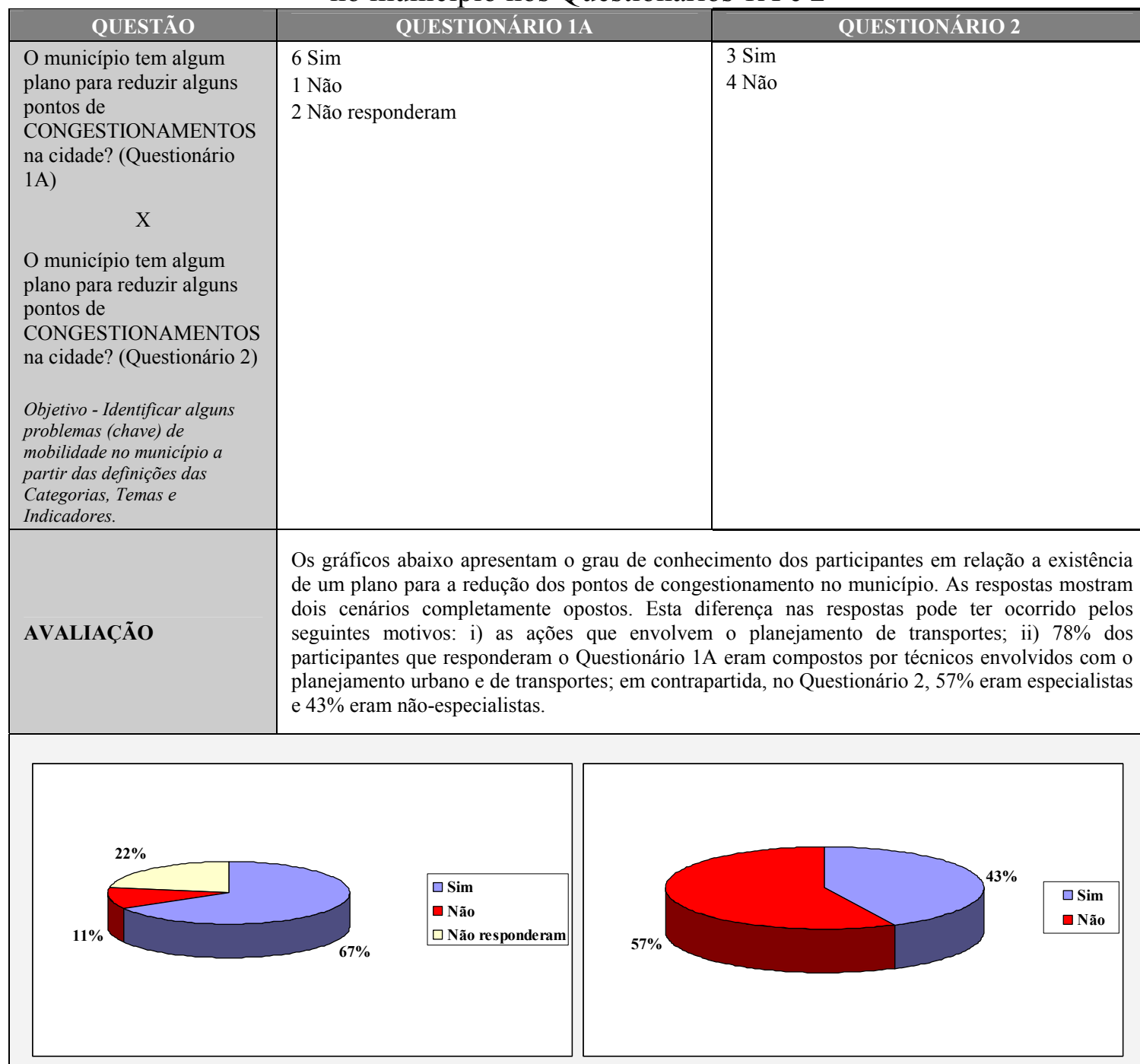

Figuras 8.37 e 8.38 - Gráfico comparativo que permite identificar o grau de conhecimento dos participantes sobre a existência de um plano para a redução dos pontos de congestionamento no município de Bauru 


\section{- Medida para a redução de pontos de Congestionamentos}

Quadro 8.30 - Transcrição e análise das respostas dos avaliadores para a questão que trata da identificação de medidas para a redução dos pontos de Congestionamento no município nos Questionários 1A e 2

\begin{tabular}{|c|c|c|}
\hline QUESTÃO & QUESTIONÁRIO 1A & QUESTIONÁRIO 2 \\
\hline $\begin{array}{l}\text { Cite as medidas adotadas } \\
\text { para reduzir os } \\
\text { CONGESTIONAMENTOS } \\
\text { na cidade. (Questionário } \\
\text { 1A) } \\
\qquad \text { X } \\
\text { Cite algumas medidas que } \\
\text { podem ser adotadas para } \\
\text { reduzir os } \\
\text { CONGESTIONAMENTOS na } \\
\text { cidade. (Questionário 2) }\end{array}$ & 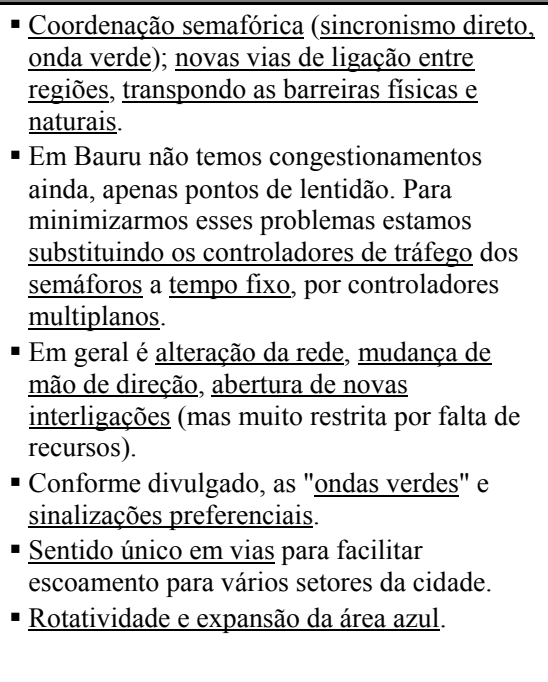 & 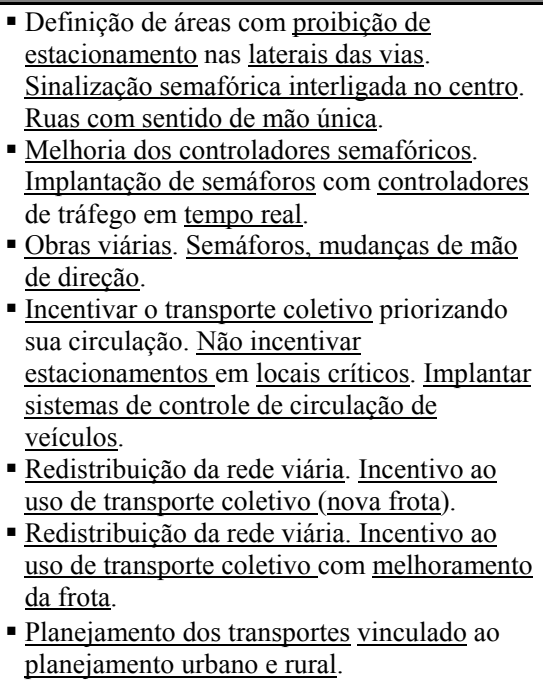 \\
\hline $\mathbf{A}$ & \multicolumn{2}{|c|}{$\begin{array}{l}\text { O Mapa Cognitivo } 1 \text { mostra as atuais medidas adotadas pelo município para a redução dos pontos } \\
\text { de congestionamento, identificadas no Questionário } 1 \text { A. Destacam-se dois temas: i) implantação de } \\
\text { infra-estrutura de transportes (construção de sistema viário, alteração de sentido de vias), e ii) } \\
\text { instrumentos para monitorar monitorar o trânsito (semáforos). } \\
\text { No Mapa Cognitivo } 2 \text { os participantes elencaram, além dos dois temas listados no Mapa 1, as } \\
\text { seguintes questões: Medidas para controle de circulação (pode estar associado a outros } \\
\text { instrumentos para monitorar o trânsito), integração entre o Planejamento Urbano e de Transportes, } \\
\text { incentivo a utilização de Transporte Coletivo, e proibição de estacionamentos em vias de grande } \\
\text { fluxo viário. Neste mapa, os participantes relacionaram os temas acima mencionados com as } \\
\text { seguintes Categorias, Temas e Indicadores apresentados no Sistema PLANUTS (Módulos I e II): } \\
\text { Gestão dos Transportes (Monitoramento - Gerenciamento efetivo do tráfego / fiscalização) e Infra- } \\
\text { estrutura dos Transportes (Sistema Viário - Capacidade das redes de infra-estrutura de transportes, } \\
\text { Desenvolvimento de vias para otimizar o fluxo de tráfego, e Tráfego - Densidade de tráfego, } \\
\text { Tempo total gasto no tráfego, Velocidade de tráfego). }\end{array}$} \\
\hline
\end{tabular}




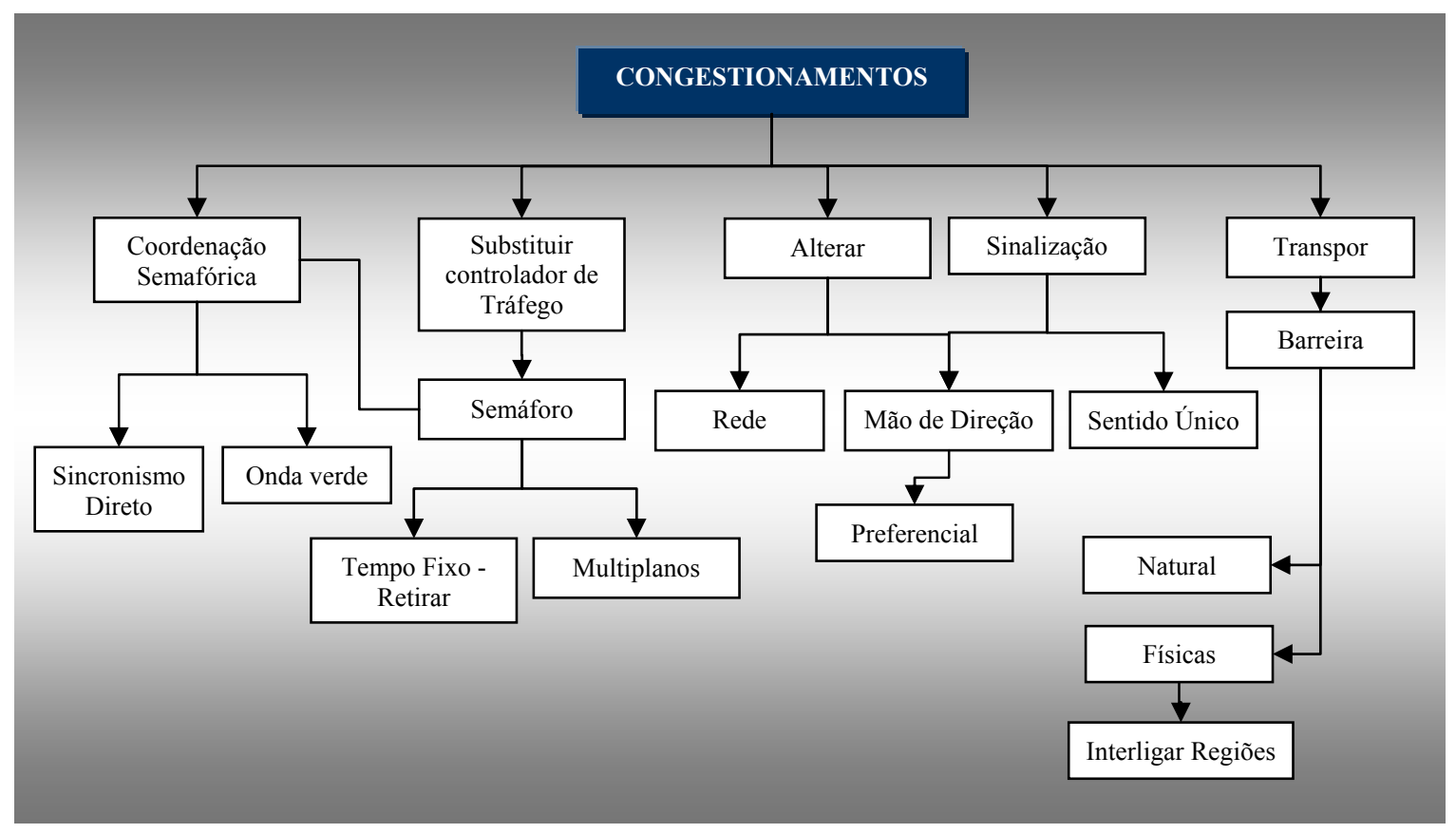

Figura 8.39 - Mapa Cognitivo 1 - Identificação da política de Congestionamentos extraídos do Questionário 1A

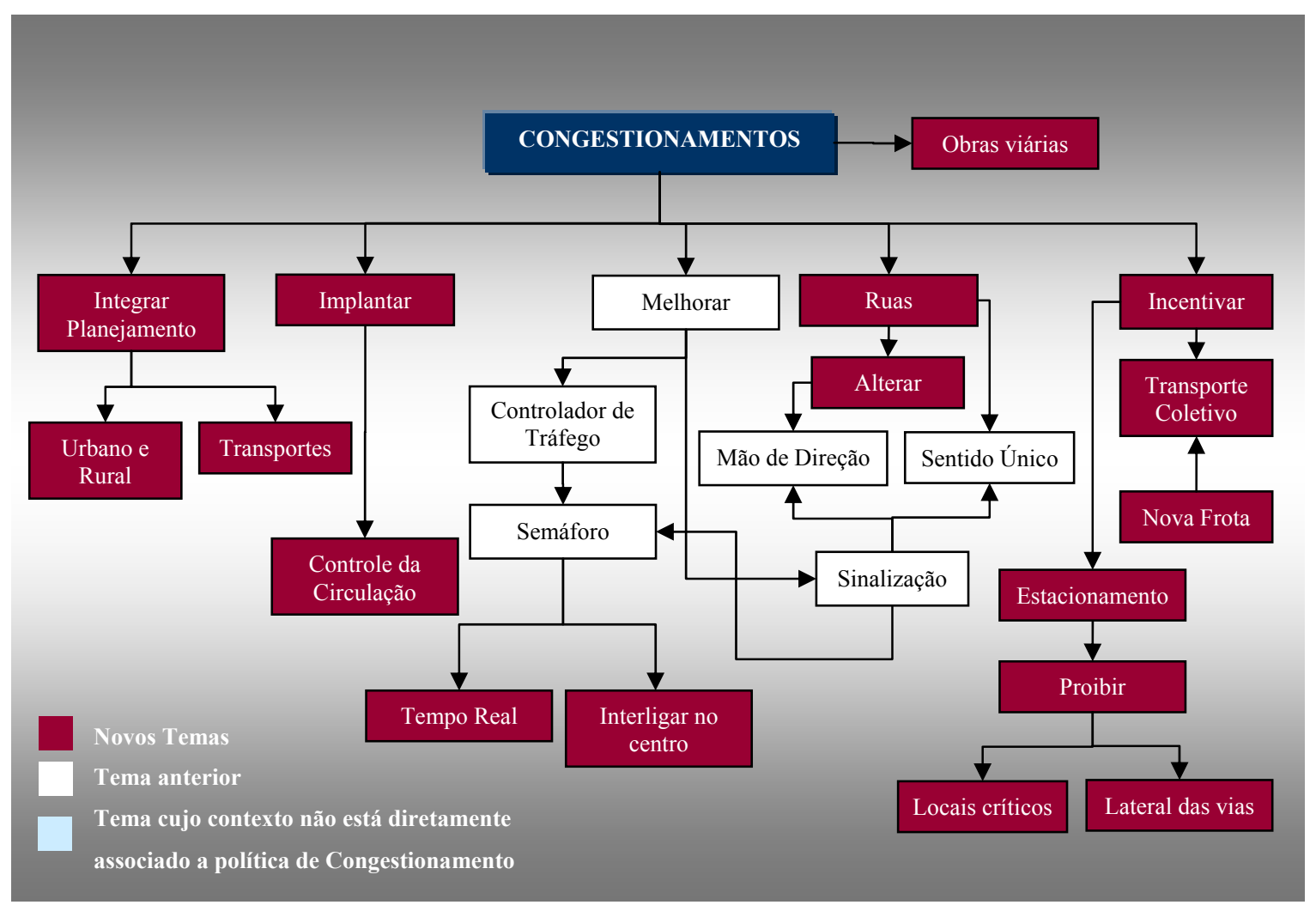

Figura 8.40 - Mapa Cognitivo 2 - Identificação da política de Congestionamentos extraídos do Questionário 2 


\section{- Existência de Plano de Acessibilidade}

Quadro 8.31 - Transcrição e análise das respostas dos avaliadores para a questão que trata da identificação do grau de conhecimento dos participantes sobre a existência de um Plano de Acessibilidade Municipal nos Questionários 1A e 2

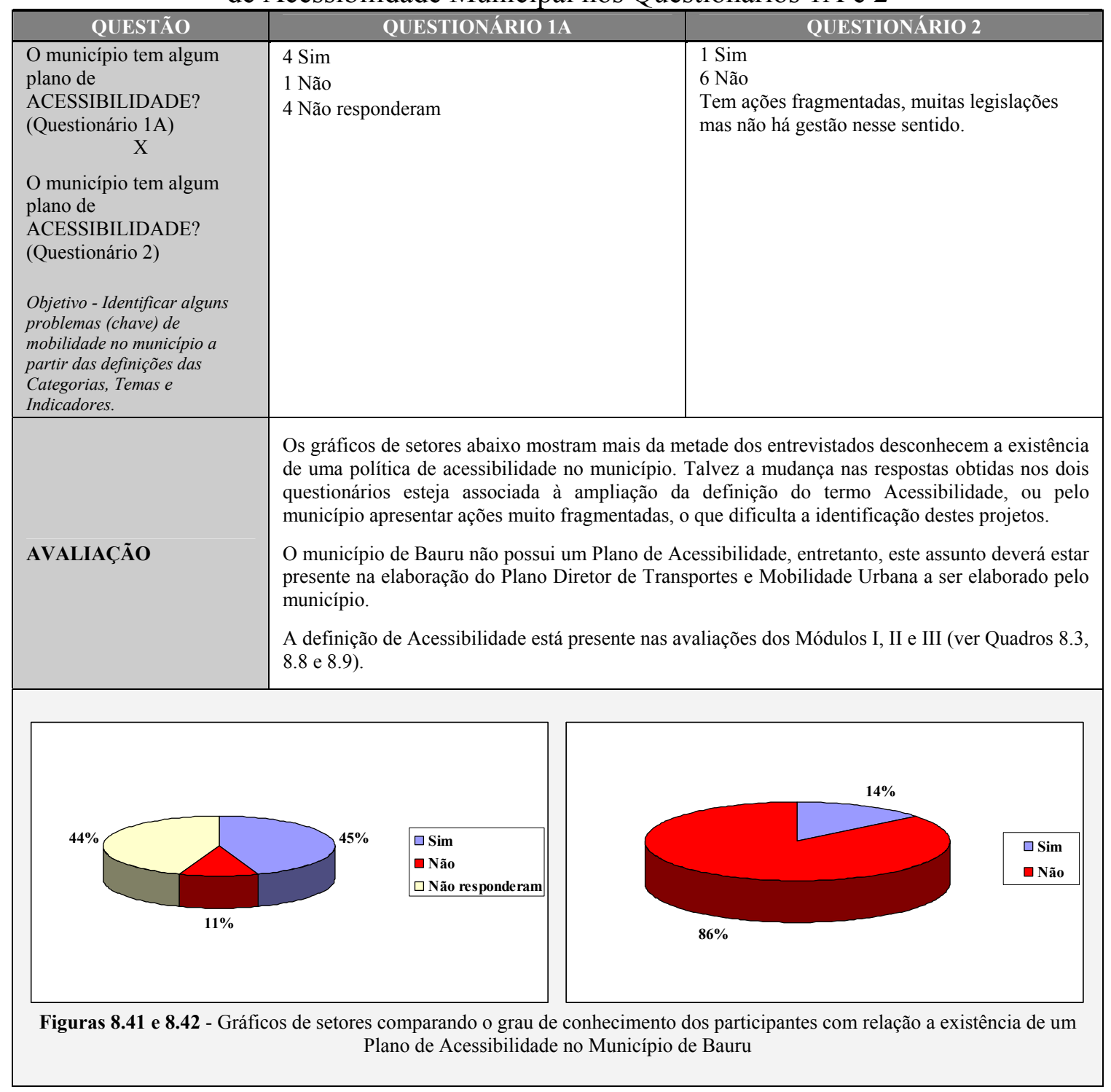




\section{- Identificação da Política de Acessibilidade no município}

Quadro 8.32 - Transcrição e análise das respostas dos avaliadores para a questão que trata da identificação da política de Acessibilidade no município nos Questionários $1 \mathrm{~A}$ e 2

\begin{tabular}{|c|c|c|}
\hline QUESTÃO & QUESTIONÁRIO 1A & QUESTIONÁRIO 2 \\
\hline 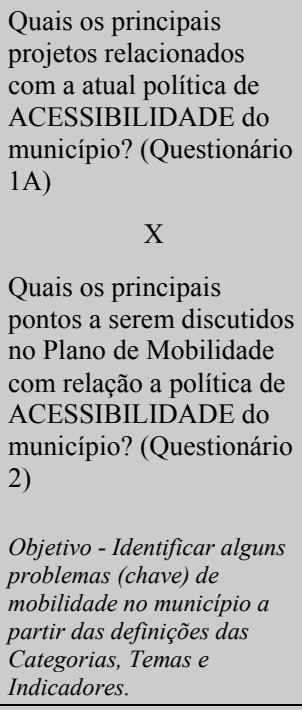 & $\begin{array}{l}\text { - Implantação de semáforos com fase exclusiva } \\
\text { para pedestre. } \\
\text { - Adaptação de ônibus / aprovação de projeto } \\
\text { obra pública e particular. } \\
\text { - O atendimento à NBR 9050, aplicados aos } \\
\text { projetos em aprovação. } \\
\text { - Implantação de rampas nas esquinas no } \\
\text { passeio público, adequação e exigência nos } \\
\text { projetos de construção à NBR 9050. } \\
\text { - O município tem uma comissão que cuida } \\
\text { desses assuntos. } \\
\text { - Construção de binários; ciclovia. }\end{array}$ & 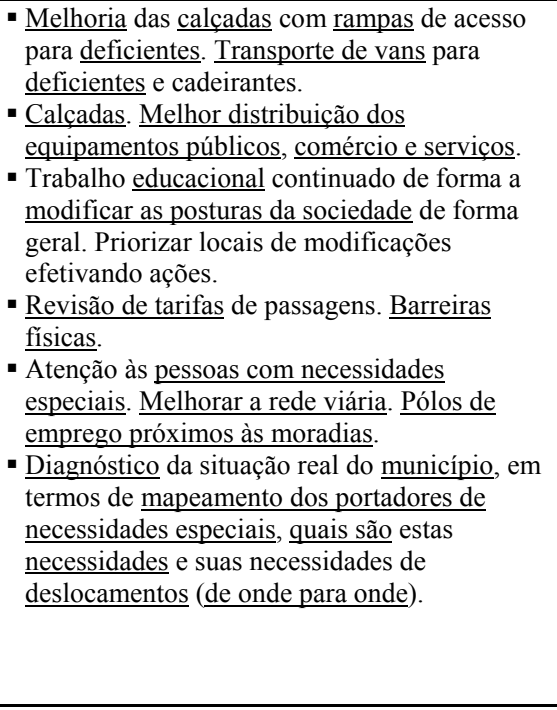 \\
\hline AVALIAÇÃO & \multicolumn{2}{|c|}{$\begin{array}{l}\text { A questão da Acessibilidade foi apresentada inicialmente no Módulo I através da definição do Tema } \\
\text { Acessibilidade Urbana e posteriormente no Módulo II com a definição dos Indicadores relacionados } \\
\text { a este tema (Acessibilidade ao bairro, Acessibilidade ao centro, Acesso aos serviços de transportes, } \\
\text { Percentagem de empregos situados a até } 3 \text { quilometros de distância das residências, Percentagem } \\
\text { de pessoas que vivem a até } 3 \text { quilometros de distância das facilidades de lazer); sendo estes dois } \\
\text { últimos Indicadores os mais votados par a avaliação no Módulo III. } \\
\text { O Mapa Cognitivo } 1 \text { (Figura } 8.43 \text { ) mostra que a maioria das respostas associam a questão da } \\
\text { acessibilidade com os projetos e ações relacionadas a eliminação de barreiras físicas para os } \\
\text { portadores de necessidades especiais. } \\
\text { Esta definição ainda está presente no Mapa Cognitivo } 2 \text { (Figura 8.44), entretanto, pode-se identificar } \\
\text { a associação do termo acessibilidade como a facilidade (melhoria) de acesso na cidade. Dentre as } \\
\text { respostas obtidas no Questionário } 2 \text { pode-se identificar a presença do Indicador - Percentagem de } \\
\text { empregos situados a até } 3 \text { quilometros de distância das residências em uma das respostas; ver célula } \\
\text { em destaque. Outro destaque neste mapa refere-se a revisão de tarifas, este tema não está diretamente } \\
\text { associado à questão da acessibilidade urbana no município. }\end{array}$} \\
\hline
\end{tabular}

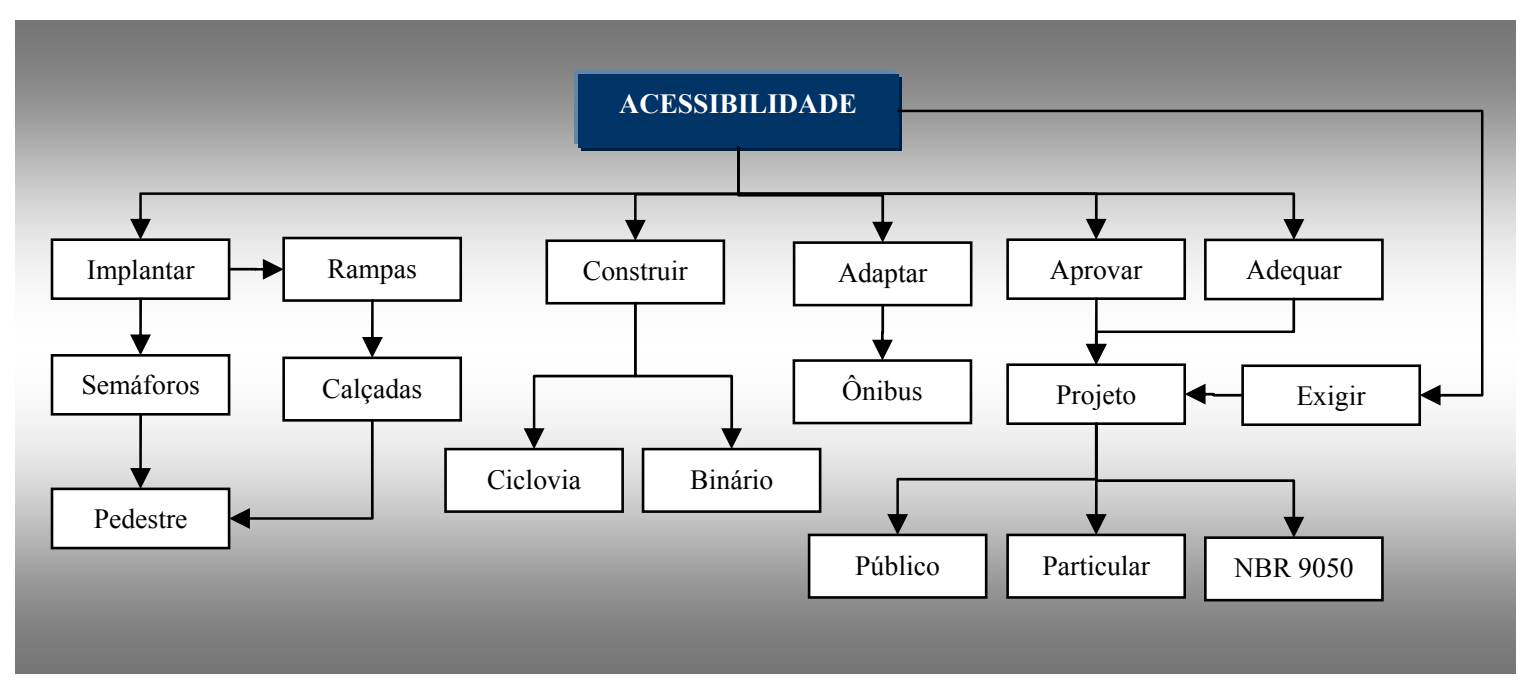

Figura 8.43 - Mapa Cognitivo 1 - Identificação da política de Acessibilidade extraídos do Questionário 1A 


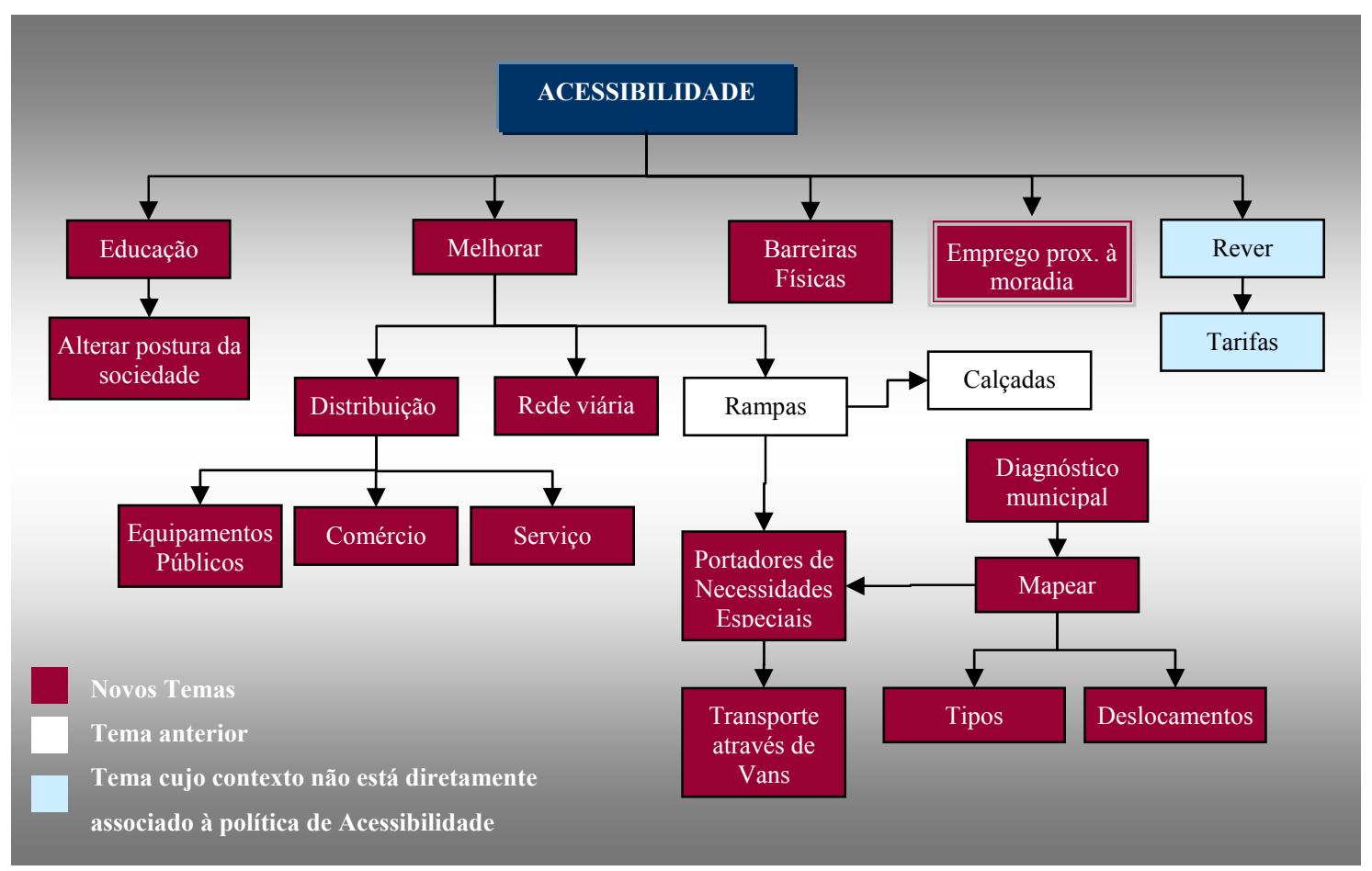

Figura 8.44 - Mapa Cognitivo 2 - Identificação da política de Acessibilidade extraídos do Questionário 2 


\section{- Adaptação dos Pontos de Ônibus}

Quadro 8.33 - Transcrição e análise das respostas dos avaliadores para a questão que trata da adaptação de Pontos de ônibus nos Questionários 1A e 2

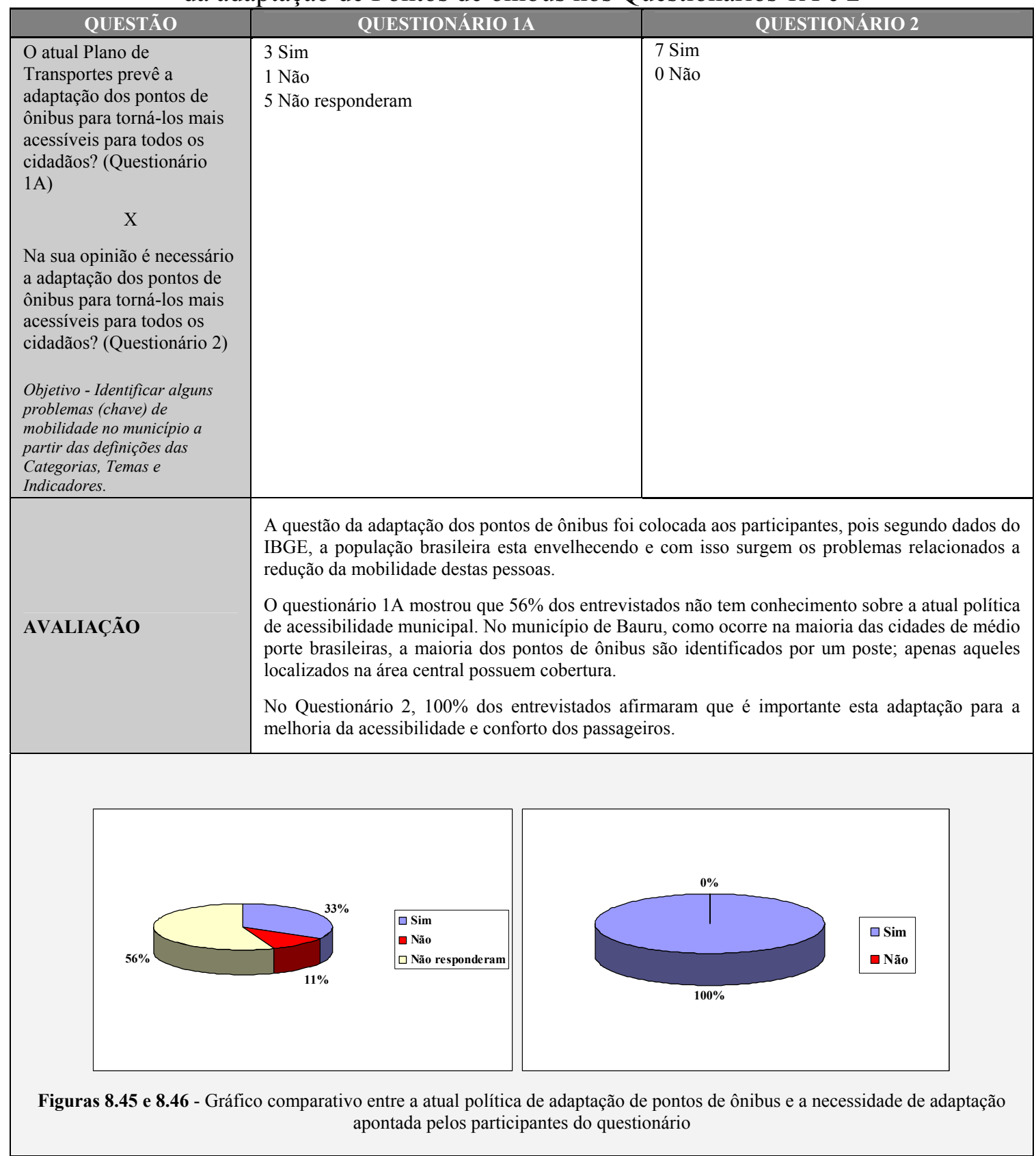




\section{- Envolvimento das secretarias municipais na política de Acessibilidade}

Quadro 8.34 - Transcrição e análise das respostas dos avaliadores para a questão que trata do envolvimento das secretarias municipais na política de Acessibilidade nos Questionários

$1 \mathrm{~A}$ e 2

\begin{tabular}{|c|c|c|}
\hline QUESTÃO & QUESTIONÁRIO 1A & QUESTIONÁRIO 2 \\
\hline $\begin{array}{l}\text { Qual a secretaria, setor ou } \\
\text { orgão municipal que } \\
\text { trabalha com os temas e } \\
\text { políticas de acessibilidade } \\
\text { para as pessoas com } \\
\text { deficiência? (Questionário } \\
\text { 1A) } \\
\qquad \mathrm{X} \\
\text { Qual a secretaria, setor ou } \\
\text { órgão municipal que } \\
\text { deveria trabalhar com os } \\
\text { temas e políticas de } \\
\text { acessibilidade? } \\
\text { (Questionário 2) } \\
\text { Objetivo - Verificar o grau de } \\
\text { conhecimentos dos técnicos } \\
\text { sobre as inter-relaçóes que } \\
\text { devem existir entre os diversos } \\
\text { setores da prefeitura para a } \\
\text { melhoria da mobilidade no } \\
\text { municipio. }\end{array}$ & $\begin{array}{l}8 \text { SEPLAN } \\
6 \text { EMDURB } \\
2 \text { BEM ESTAR SOCIAL } \\
2 \text { OUTROS (COMUDE, CPA) }\end{array}$ & $\begin{array}{l}6 \text { Trânsito (EMDURB) } \\
6 \text { Transportes (EMDURB) } \\
6 \text { Planejamento Urbano (SEPLAN) } \\
3 \text { Secretaria de Obras } \\
2 \text { Secretaria do bem estar social } \\
1 \text { Agricultura } \\
1 \text { Desenvolvimento econômico } \\
1 \text { Educação } \\
1 \text { Secretaria de saúde. }\end{array}$ \\
\hline AVALIAÇÃO & \multicolumn{2}{|c|}{$\begin{array}{l}\text { Na comparação entre as respostas do Questionário } 1 \mathrm{~A} \text { e Questionário 2, (ver Figura 8.47) pode-se } \\
\text { observar que no primeiro questionário as respostas listaram apenas as secretarias ligadas ao } \\
\text { Planejamento Urbano e de Transportes (SEPLAN e EMDURB), que no município são } \\
\text { responsáveis por projetos e ações ligadas a acessibilidade; entretanto as ações são específicas a } \\
\text { cada secretaria, ou seja, aspectos relacionados ao transporte de passageiros (deficientes) está } \\
\text { ligado, à EMDURB e as políticas de melhoria urbana (eliminação de barreiras físicas, por } \\
\text { exemplo) estão ligadas à SEPLAN. } \\
\text { No segundo questionário pode-se verificar que parte dos participantes assimilaram a importância } \\
\text { de uma integração entre as secretarias ou órgãos municipais para o desenvolvimento de políticas } \\
\text { públicas referente a questão da acessibilidade. Embora os órgãos ligados ao planejamento urbano e } \\
\text { de transportes tenham um peso maior no desenvolvimento de ações relacionadas à acessibilidade } \\
\text { municipal, outras secretarias devem (e podem) contribuir para a melhoria da acessibilidade tanto na } \\
\text { área urbana quanto na área rural. } \\
\text { OBS: Dentre as secretarias listadas no Questionário } 2 \text { foi inserida a Secretaria de Agricultura, em } \\
\text { função de gerenciar as políticas públicas referentes a área rural no município de Bauru. }\end{array}$} \\
\hline
\end{tabular}

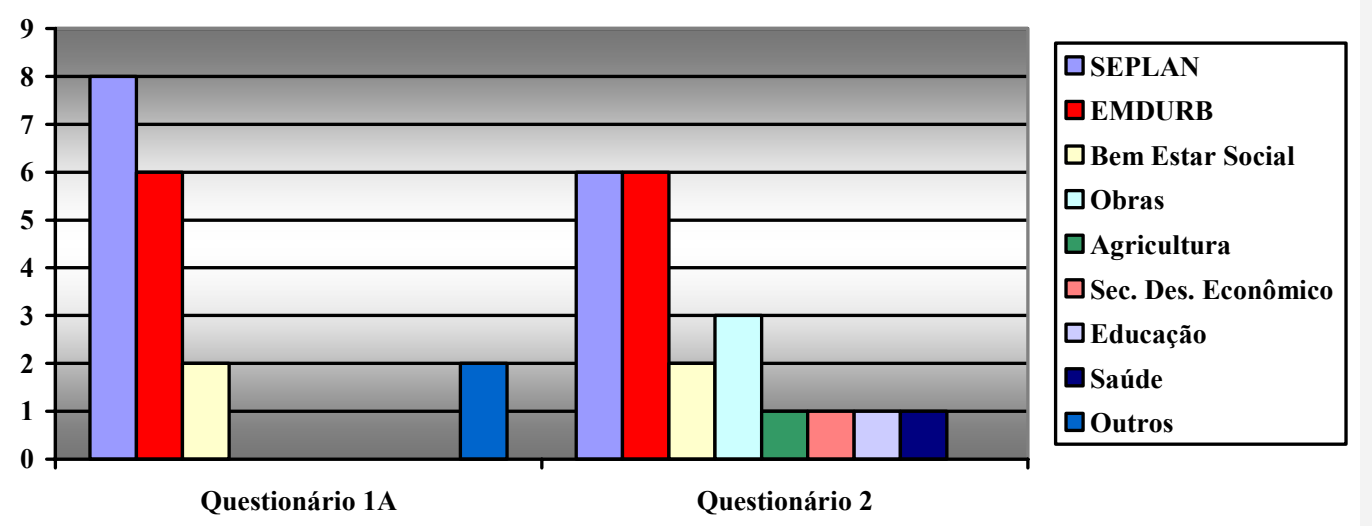

Figura 8.47 - Gráfico comparativo entre as secretarias envolvidas na atual política de acessibilidade e aquelas que poderiam integrar-se ao atual conjunto de secretarias 
Algumas respostas, apresentadas através de "palavras-chave" nos mapas cognitivos, são recorrentes, ou seja, são importantes para a definição ou contribuem para a melhoria de diferentes Temas. Como exemplo, tem-se: criação de ciclovias (identificada nos temas: problemas de mobilidade, incentivo à mobilidade, temas relacionados à Mobilidade Urbana, Política de Circulação,) e incentivo ao Transporte Coletivo (identificada nos temas: incentivo à mobilidade, temas relacionados à Mobilidade Urbana, política de estacionamentos, política de Transporte Público, política de Circulação, política de Redução da Poluição, política de Congestionamento), entre outros.

Algumas das palavras-chave definidas pelos especialistas e não-especialistas podem ser encontradas inclusive em outros trabalhos, como o de Steg e Gifford (2005), pelo fato de que elas representam alguns dos problemas urbanos advindos da utilização dos meios de transporte motorizados individuais (utilização do automóvel) e que têm afetado de maneira negativa a qualidade de vida da população urbana.

A maioria das palavras-chave identificadas nos mapas cognitivos foram inseridas no Módulo III (item problemas e soluções) pelos participantes, conforme apresenta o Anexo 9.

As soluções elencadas pelos avaliadores no Módulo III podem ser agrupadas em dois grupos: i) Políticas para um deslocamento eficiente e sustentável, representado por temas associados às questões de infra-estrutura, meio ambiente, gestão e segurança viária; e ii) Políticas de uso do solo, representado por ações relacionadas ao planejamento urbano municipal.

- Políticas para um deslocamento eficiente e sustentável - aumentar os trechos (números) de ciclovias; incentivar a utilização de transporte coletivo; incentivar viagens à pé; redução de tarifas; incentivar a utilização de meios não motorizados; utilizar transporte coletivo movido a energia elétrica; implantar novas vias de interligação de bairros para transposição das barreiras físicas; diminuir o consumo de combustíveis; diminuir o número de viagens motorizadas; promover a interação entre os modos de transportes; promover o uso de combustível limpo no transporte coletivo; melhorar integração dos transportes; realizar pesquisa de origem-destino para definição de melhores rotas; incentivar o transporte solidário (carona/rodízio); integração modal; pavimentação e manutenção das vias de transporte público; realizar campanhas de conscientização da população; realizar campanhas de educação para o trânsito; incentivar a utilização de combustíveis alternativos; implementar medidas de 
fiscalização e controle da velocidade; implantar pedágios urbanos para automóveis; criar um sistema de rodízio; aumentar a punição aos motoristas infratores; fiscalizar mais efetivamente condutores e veículos; investir em planejamento de transportes.

- Políticas de uso do solo - implantar legislação de uso e ocupação do solo adequadas; melhorar a distribuição das atividades urbanas; criar zonas de uso misto; limitar o perímetro urbano; incentivar a ocupação de vazios urbanos e zonas com baixa densidade populacional; restringir loteamentos distantes do centro; realizar um planejamento contínuo, independente dos governantes.

A partir das ações acima listadas pode-se concluir que, embora o sistema possibilite a identificação dos problemas e soluções associados à mobilidade, agrupadas em Categorias, Temas e Indicadores, o que possibilitaria uma visão mais integrada do conceito de Planejamento da Mobilidade, as respostas apresentadas pelos avaliadores (especialistas e não-especialistas) refletem, num primeiro momento, o antigo formato de planejamento adotado no Brasil, onde os aspectos relacionados ao planejamento de transportes estavam desvinculados do planejamento urbano. Entretanto, ao avaliar os temas relacionados ao primeiro grupo (Políticas para um deslocamento eficiente e sustentável) são encontrados elementos que não pertenciam a antiga política de transporte brasileira, como a questão da sustentabilidade (identificada através dos seguintes itens: incentivar a utilização de transporte coletivo; incentivar viagens à pé; redução de tarifas; incentivar à utilização de meios não motorizados; utilizar transporte coletivo movido a energia elétrica; incentivar o transporte solidário (carona/rodízio); incentivar a utilização de combustíveis alternativos).

Em síntese, através da análise comparativa das respostas dos participantes (apresentadas através de gráficos e dos mapas cognitivos e da avaliação dos Módulos I, II e III), pôde-se concluir que a utilização dos três Módulos de Avaliação da Mobilidade Urbana contribuiu significativamente para ampliar as definições que cada especialista e não-especialista tinha a respeito dos principais Temas que envolvem a Mobilidade Urbana. 


\section{CONCLUSÕES E CONSIDERAÇÕES FINAIS}

Atualmente, no Brasil, o processo de planejamento tem envolvido a participação de técnicos e de representantes da sociedade, predominantemente através de reuniões presenciais. A nova política urbana brasileira tem incentivado a participação popular no processo de planejamento das cidades. No entanto, para que o processo leve a cidades mais igualitárias é necessário que uma parcela significativa da população possa participar destas discussões.

As questões relacionadas à mobilidade urbana começam a ser discutidas em alguns grandes centros urbanos. Entretanto, os problemas urbanos que estão direta ou indiretamente relacionados a esta definição ainda não estão muito claros para a maioria da população. De acordo com dados coletados antes da utilização do sistema PLANUTS, a mobilidade ainda é entendida como sinônimo de planejamento de infra-estrutura (sistema viário), ou seja, ainda está muito presente a definição do planejamento de transportes através da visão tradicional.

Esta pesquisa partiu de dois pontos principais: i) desenvolver uma ferramenta computacional voltada à internet (denominada PLANUTS), que possibilitasse auxiliar planejadores e decisores locais no processo de elaboração de Planos Diretores de Transportes e Mobilidade para cidades de pequeno e médio porte brasileiras, através de uma maior participação popular no processo de tomada de decisão; ii) avaliar se a utilização do Sistema PLANUTS, através da inserção de recursos computacionais (multimídia e hipermídia) no processo de discussão dos problemas de Mobilidade Urbana, pode produzir alterações significativas no conhecimento de cada avaliador (especialista ou não-especialista); e iii) definir um elenco de Indicadores de Mobilidade Urbana que pudessem compor um Sistema de Indicadores de Mobilidade Municipal para auxiliar os decisores locais nas etapas de planejamento e monitoramento do Plano Diretor de Transportes e Mobilidade. 
Para demonstrar os objetivos acima mencionados, o sistema desenvolvido foi aplicado junto a um grupo de especialistas e não-especialistas no município de Bauru, localizado no Estado de São Paulo, Brasil.

O desenvolvimento do Sistema PLANUTS foi embasado em experiências nacionais e internacionais sobre modelos e sistemas que permitem a participação popular nos formatos tradicionais e pela internet, como mostra a revisão bibliográfica. Entretanto, contribuíram de forma significativa os trabalhos desenvolvidos por: Yigitcanlar (2001); Lautso et al. (2002); Gayda et al. (2003); bem como o processo participativo adotado pelo Município de Bauru no desenvolvimento do Plano Diretor Municipal.

A construção e implantação do Sistema PLANUTS possibilitou comprovar que esta ferramenta é um instrumento que pode ser adotado no processo de elaboração do Plano Diretor de Transportes e Mobilidade. Ela permitiu a incorporação de uma nova visão de construção do conhecimento sobre a realidade da cidade, através da identificação e ordenamento dos problemas de mobilidade (advindos das avaliações dos participantes) e a geração de alguns produtos que podem auxiliar os decisores neste processo de tomada de decisão.

De acordo com o resultado obtido no processo de avaliação da mobilidade no município de Bauru, pode-se afirmar que a ferramenta computacional proposta é um instrumento que permite a sistematização de algumas etapas no processo de elaboração do Plano de Mobilidade, como as etapas de diagnóstico e análise urbana.

Os produtos que podem ser gerados pelo sistema PLANUTS, e que permitem instrumentalizar o processo de avaliação da mobilidade de forma participativa são:

- Definição de uma lista contendo os indicadores mais importantes - através da avaliação do Módulo II, os avaliadores especialistas e não-especialistas puderam definir os indicadores mais importantes para o município e assim determinar os principais problemas associados à mobilidade da cidade.

- Ordenamento dos Temas e Indicadores mais importantes - através das avaliações dos Módulos I e III foi possível determinar, através de rankings, os Temas e Indicadores mais importantes para compor um Sistema de Indicadores de Mobilidade municipal. Este ordenamento permite que os técnicos possam priorizar as ações para os temas e indicadores que estão associados aos maiores problemas de mobilidade do município e assim propor soluções em função desta prioridade. 
- Definição dos indicadores mais urgentes para o município - associado ao ordenamento anterior, uma outra definição (produto) gerada pelo sistema consiste na definição dos problemas de mobilidade mais urgentes, ou seja, aqueles que têm prioridade em sua resolução segundo a avaliação da maioria dos participantes.

- Identificação de problemas e soluções para os Indicadores - após o processo de avaliação do Módulo III é possível definir uma lista de problemas e soluções para cada indicador avaliado. Este recurso é importante, pois permite uma maior compreensão dos aspectos que podem envolver a solução de cada indicador ou tema relacionado à mobilidade. Esta ferramenta foi desenvolvida para sistematizar a etapa de diagnóstico e proposição de soluções realizadas de forma presencial num processo de participação tradicional.

- Identificação dos problemas de mobilidade por região e por bairro (subregiões) do município - esta identificação facilitará a espacialização dos principais problemas de mobilidade do município diagnosticados por todos os participantes. Esta ferramenta foi projetada para sistematizar a etapa de elaboração de mapas de diagnóstico, auxiliando posteriormente os decisores na visualização dos problemas de mobilidade do município que poderão ser acessados através da internet subsidiando as seguintes etapas do plano diretor: Análise das propostas, Geração de cenários e Audiências sobre as propostas.

O método de Análise Multicritério adotado para sistematizar e analisar os resultados coletados pelo sistema mostrou-se de fácil compreensão e utilização, facilitando as análises das Categorias, Temas e Indicadores relacionados à Mobilidade, bem como na geração dos produtos acima descritos.

A interface construída para o Sistema PLANUTS possibilitou que os avaliadores não tivessem dificuldade para votar e visualizar os resultados em cada módulo de avaliação. Este sistema foi considerado de fácil utilização, mas muitos participantes apontaram a necessidade da realização de um curso de capacitação para tirar eventuais dúvidas que os usuários possam apresentar.

Com os resultados obtidos é possível comprovar que o sistema permite a participação de diferentes segmentos da sociedade na avaliação dos dois primeiros módulos de avaliação. Dentre os participantes havia uma heterogeneidade de faixa etária, de grau de familiaridade com as ferramentas computacionais (hardware e software) e de conhecimento 
técnico na área de planejamento urbano e de transportes, mesmo assim, não foi encontrada dificuldade no processo de avaliação do sistema.

Os recursos de multimídia e hipermídia (texto, som e imagens) possibilitaram essa diversidade de participantes, uma vez que estes recursos permitiram a realização do processo de avaliação das Categorias, Temas e Indicadores de forma bastante intuitiva.

A possibilidade de realizar a avaliação dos Módulos I, II e III através da internet foi outro fator de destaque na avaliação dos participantes. Embora as avaliações tenham sido realizadas, pela maioria deles, no Laboratório de Informática da UNESPBauru, dois participantes testaram a utilização do sistema em local e horário diferenciados. Utilizaram, portanto, a flexibilidade de acesso que o sistema possui para concluir seu processo de participação.

A utilização da internet como meio de participação no processo de tomada de decisão para a definição de Indicadores de Mobilidade permitiu que cada avaliador pudesse participar das avaliações sem receio de expor seus pontos de vista e avaliar o sistema de forma independente, pois em alguns casos as respostas obtidas nos módulos foram divergentes dentro de cada grupo de avaliação (especialistas e não-especialistas). Embora esta pesquisa não tenha apresentado estes resultados explicitamente por sub-grupos de avaliação, esta divergência de opiniões ocorreu em função da própria composição dos participantes destes grupos, que foi muito diversificada (participaram da avaliação técnicos representantes da secretaria de planejamento, da secretaria de transportes, de outros órgãos municipais e representantes de diferentes segmentos da sociedade).

A utilização do sistema PLANUTS num processo mais amplo, quando a implantação do sistema vier a envolver um número maior de participantes, a avaliação individual possibilitará uma minimização dos conflitos por parte dos representantes de cada segmento representado no Plano Diretor de Transportes e Mobilidade Urbana. Neste sentido, a utilização de metodologias que incentivem a participação popular sem uma exposição direta de determinados grupos minoritários de avaliadores (por exemplo, através da internet) poderá proporcionar um aumento não só no número de participantes, mas principalmente no processo de discussão dos problemas de mobilidade.

A concepção do sistema PLANUTS permite sua interação com qualquer outro DSS ou SIG. Neste sistema a ferramenta SIG está desvinculada dos quatro módulos de Avaliação, o que permite uma flexibilidade na escolha do software a ser adotado em função das necessidades locais, do nível de conhecimento e familiaridade dos recursos 
computacionais da população bem como da situação econômica e tecnológica do município que estiver implantando o sistema.

Uma vez realizadas as alterações internas específicas, o sistema poderá ser implantado em qualquer cidade brasileira de pequeno e médio porte. A sua estrutura modular permite que seja adaptado à realidade de cada cidade em que venha a ser aplicado. Assim, os técnicos da cidade em questão poderão alterar algumas informações internas do sistema, tais como a etapa de coleta de informações que se encontra nos Módulos I e III (Questionário e Mapas).

Adicionalmente, o sistema permitiu identificar o grau de homogeneidade observado no resultado final do processo de avaliação da mobilidade entre os especialistas e não-especialistas da área nos três módulos de avaliação do sistema.

É importante destacar que os resultados obtidos nesta pesquisa refletem apenas as avaliações deste grupo de participantes. Para a implantação do sistema dentro de um processo de elaboração do Plano de Mobilidade é necessário que todos os envolvidos neste processo, técnicos (especialistas) e demais representantes dos diversos segmentos da sociedade possam participar da avaliação do sistema e assim definir os temas e indicadores mais importantes para o município, ou seja, definir um Sistema de Indicadores de Mobilidade Urbana Sustentável.

A hipótese principal desta pesquisa, de que a utilização do Sistema PLANUTS pode produzir alterações significativas no grau de conhecimento de cada avaliador (especialista ou não-especialista) sobre o tema mobilidade, foi comprovada através das análises dos mapas cognitivos elaborados a partir dos questionários aplicados antes e após a utilização dos três Módulos de Avaliação da Mobilidade Urbana.

A identificação de "novas palavras-chave" na comparação dos mapas cognitivos permitiu verificar a mudança de paradigma (através da ampliação do conhecimento) sobre as questões que envolvem o planejamento da mobilidade no município. Esta alteração pôde ser detectada nos dois grupos que participaram da avaliação do sistema proposto.

De acordo com as palavras-chaves identificadas nos Mapas Cognitivos resultantes dos questionários 1A, 1B e 2, apresentados no Capítulo 8, pode-se afirmar que inicialmente as avaliações (ações e problemas de mobilidade identificados pelos avaliadores nos questionários 1A e 1B) estavam associadas principalmente a impactos diretos do planejamento de transporte em relação às questões de uso do solo no município (Litman; 2004 e 2006b); conforme apresentada o Quadro 9.1. 


\section{Quadro 9.1 - Problemas de Mobilidade apresentados nos Questionários 1A e 1}

$$
\text { Palavras-chave identificadas nos Mapas Cognitivos 1A e 1B }
$$

deslocamentos de pessoas e veículos; facilidade na locomoção (relacionado à acessibilidade); segurança e rapidez na locomoção; facilidade de acessos; organização dos fluxos; falta de integração entre bairros; falta de integração entre planos (transporte e uso do solo); problemas associados ao crescimento da cidade; priorizar o transporte coletivo; transporte de carga; melhorar a infra-estrutura; implantar projeto para interligar bairros; fiscalizar execução de calçadas; exigir a elaboração do Plano de Mobilidade; priorizar o fluxo de veículos; criar estacionamentos internos; integrar linhas de ônibus; definir a oferta de transporte público em função da demanda local; transporte de passageiros de forma eficiente; coordenação semafórica; alterar a rede viária; implantar o sentido único em vias; implantar a rotatividade e ampliar da área azul; implantar semáforos para pedestres; adaptar ônibus; aplicar a NBR9050 (norma sobre acessibilidade a portadores de deficiência) nos projetos.

Posteriormente, pode-se verificar uma ampliação, principalmente na identificação dos problemas de mobilidade no município, com a incorporação de elementos associados à sustentabilidade (ambiental, econômica e social) abordados no processo de avaliação do sistema PLANUTS. Estes elementos podem ser observados no Quadro 9.2.

Quadro 9.2 - Problemas de Mobilidade apresentados no Questionário 2 Palavras-chave identificadas no Mapa Cognitivo 2

locomoção de bens e pessoas; eliminar obstáculos; acessibilidade; preocupação ambiental; acesso aos meios de transportes; locomoção visando a otimização e preservação de recursos; vazios urbanos; falta de ciclovias; dispersão da cidade (ou dispersão espacial); problemas de acessibilidade (rebaixamento de guias, degraus em calçadas; rampas para acesso a edificações); tarifa (custo do transporte público); acidentes; distância do trabalho e lazer (acessibilidade); pontos de congestionamento; falta de linhas de ônibus para ligar bairros; sinalização viária insuficiente; falta de condições para os transportes nãomotorizados; gerenciar e monitorar o transporte coletivo; estacionamento rotativo; implantar ciclovias; implantar o IPTU progressivo e parcelamento compulsório; ampliar o sistema viário (construção de ruas e pontes); capacitação técnica; elaborar o Plano Diretor de Mobilidade sob o enfoque da sustentabilidade econômica, social e ambiental; incentivar transportes interativos; priorizar o pedestre; transporte ecologicamente correto; densidade; zoneamento (novo modelo); transporte de carga e passageiros (urbano e rural); ocupação dos vazios urbanos; satisfação do usuário, meio ambiente; criar estacionamentos rotativos; melhorar viagens a pé, bicicleta e transporte público; melhorar a segurança de pedestres nas calçadas; dimensionar novas áreas de estacionamentos; monitorar o número de viagens; gerenciar e monitorar vias; melhorar os abrigos de ônibus; implantar terminais; implantar linhas troncoalimentada; priorizar pavimentação adequada em vias que utilizam o transporte coletivo; implantar um plano para o transporte de carga; realizar um levantamento da demanda e oferta; definir a interação entre planejamento urbano/rural e de transportes; implantar um plano cicloviário; incentivar o uso de meios de transporte que utilizem energia limpa; implantar ônibus movido a energia elétrica e biodisel; investir em novas frotas; incentivar carona amiga, incentivar a utilização de meios de transporte não poluentes; renovar e manter a frota de ônibus; adotar medidas de controle da qualidade do ar; diagnosticar os principais poluidores; definir uma política de redução dos níveis de poluição; proibir estacionamentos nas laterais de algumas vias; adotar ruas com sentido de mão única; melhorar controladores semafóricos; melhorar a distribuição de equipamentos públicos; comércio e serviços (acessibilidade); implantar um trabalho educacional continuado para modificar a postura da sociedade; rever tarifas; realizar um diagnóstico do município sobre as necessidades dos portadores de necessidades especiais; realizar um diagnóstico do município sobre os deslocamentos.

Outro elemento que reforça a hipótese refere-se a inclusão de alguns dos Temas apresentados no processo de avaliação no sistema PLANUTS (Módulos I, II e III). Muitos deles passaram a fazer parte das respostas do questionário final, como sendo 
importantes para comporem as discussões do Plano de Mobilidade participativo para o município. Os Temas mencionados no questionário final foram: incentivo a utilização de meios de transporte não motorizados, transporte público, questão ambiental associada aos transportes, zoneamento, densidade urbana, acessibilidade, utilização de meios de transporte que utilizam energia limpa, medidas de controle de qualidade do ar, entre outros.

Diante das respostas obtidas nos Módulos I, II e III e nos Questionários 1A, 1B e 2, ficou evidente que houve uma ampliação no conhecimento dos participantes principalmente com relação às questões relacionadas ao planejamento do uso do solo e transportes, incorporando a elas a visão da sustentabilidade.

Embora a visão dos participantes tenha se ampliado, através da incorporação de outros elementos associados à mobilidade até então desconhecidos para a maioria dos participantes, é importante ressaltar que a mudança do tradicional planejamento urbano e de transportes para o novo conceito de planejamento da mobilidade não se dará de forma imediata. Ela só se efetivará a partir do momento que o município adotar medidas que contribuam para diminuir a excessiva dependência ao transporte individual motorizado e a dispersão espacial, através do incentivo a utilização de outras formas de transportes mais sustentáveis e a ocupação dos vazios urbanos, que em grande parte contribuem para agravar os problemas de mobilidade nos municípios.

Como em todo processo participativo, a definição e participação de representantes dos diversos segmentos da sociedade possibilitará uma participação mais igualitária. No caso da utilização do sistema PLANUTS esta igualdade de participação no processo de escolha dos Indicadores de Mobilidade Urbana [representada por uma definição de um percentual que represente efetivamente os diferentes grupos envolvidos por segmento da sociedade; sendo que para a escolha dos representantes de cada grupo de delegados (avaliadores) deve-se adotar critérios particulares que expressem cada setor] proporcionará um resultado que reflete uma visão mais realista dos principais problemas de Mobilidade do município que estiver adotando o sistema. Caso contrário, os resultados (a definição dos indicadores) poderão mostrar apenas a visão de um segmento, o que poderá invalidar todo o processo de escolha dos Indicadores de forma participativa.

Com base nos resultados do processo de aprovação de alguns Planos Diretores Municipais sugere-se a obrigatoriedade da participação efetiva da Câmara Municipal local, através dos vereadores municipais, no processo de discussão do Plano Diretor de Transportes e Mobilidade, incluindo a definiç̧ão dos Indicadores de Mobilidade, 
para que eventuais problemas possam ser discutidos durante o processo de elaboração do plano com toda a sociedade; diminuindo assim o tempo de aprovação da Minuta do Projeto de Lei que institucionalizará o Plano Diretor de Transportes e Mobilidade no município.

Em síntese, o desenvolvimento da pesquisa (e do sistema PLANUTS) pode contribuir para o processo de discussão da Mobilidade Urbana, na elaboração e/ou avaliação do Plano Diretor de Transportes e Mobilidade para os municípios. O sistema pode inclusive vir a representar importante alternativa para ampliar a participação popular no processo de tomada de decisão e aprimorar o processo de planejamento urbano e de transportes tradicionalmente utilizado nas cidades médias brasileiras.

A implantação do sistema mostrou que é possível construir uma ferramenta computacional para o planejamento da mobilidade urbana (que aqui recebeu o nome PLANUTS) que seja capaz de incorporar a visão e a participação de múltiplos agentes, sejam eles especialistas ou não.

Com relação a ampliação do grau de conhecimento dos participantes, através da análise comparativa entre os questionários aplicados antes e após a utilização do sistema PLANUTS pode-se afirmar que houve uma alteração significativa na definição dos Temas que envolvem a mobilidade urbana.

Portanto, a construção do Sistema PLANUTS e sua aplicação no município de Bauru permitiram definir um elenco de indicadores de mobilidade urbana, considerados mais importantes, que poderão compor um Sistema de Indicadores de Mobilidade para o Plano Diretor de Transportes e Mobilidade Municipal. Além destes resultados, a aplicação do sistema permitiu identificar os indicadores mais urgentes, ou seja, problemas que necessitam de um menor prazo para a sua solução.

\subsection{Trabalhos Futuros}

Uma recomendação para futuros trabalhos refere-se ao aprimoramento interno de alguns módulos do sistema PLANUTS tais como: alterar o layout do Módulo I para diferenciar a avaliação das Categorias e Temas; alterar o tempo de salvamento das informações e alterar a permissão para avaliar os Módulos I e II, de modo que o usuário possa sair do sistema e continuar o processo de votação em outro dia e horário prédeterminado por ele. E, a alteração na flexibilidade (voltar a visualizar um elemento já votado) de utilização das páginas referentes às Categorias, Temas e Indicadores (Módulos I e III). 
Para a continuidade desta pesquisa recomenda-se o desenvolvimento do Módulo IV e de uma metodologia que possa sintetizar os indicadores utilizados neste sistema. Esta definição permitirá que cada município que venha a utilizar o sistema possa estabelecer suas metas e propostas de ações para melhorar o desempenho dos indicadores selecionados (identificados como mais importantes).

Os resultados apresentados nesta pesquisa ainda podem ser analisados sob outros aspectos, ou seja, podem ser realizadas análises agrupadas por representantes de cada setor (representes da secretaria de planejamento, de transportes e demais segmentos da sociedade). Através desta subdivisão pode ser detectado se há uma homogeneidade, ou não, entre as avaliações dos membros de cada grupo (especialistas da área de planejamento urbano, especialistas da área de planejamento de transportes e não-especialistas) e entre as avaliações dos diferentes grupos.

Outro desdobramento desta pesquisa refere-se à elaboração de uma ferramenta computacional ou jogo (virtual ou presencial, ex. Quiz, Game Honoloko ${ }^{1}$, entre outros) que possibilite a participação de adultos de forma interativa, possibilitando com isso que mesmo não-especialistas entrem em contato com os problemas de mobilidade que possam estar ocorrendo em seu município.

Uma outra sugestão para dar continuidade ao desenvolvimento desta pesquisa refere-se ao desenvolvimento de jogos virtuais interativos voltados para o público infantil, com o objetivo de iniciar as discussões sobre os temas ligados à mobilidade sustentável e suas conseqüências no ordenamento do território; contribuindo assim para a construção de cidadãos mais conscientes e comprometidos com o desenvolvimento sustentável de seu município.

\footnotetext{
${ }^{1}$ Honoloko é um jogo desenvolvido para crianças (com idade entre 8 a 12 anos) que possibilita a avaliação de questões relacionadas à saúde e meio ambiente. Este jogo mostra os impactos das escolhas diárias relacionadas à saúde e ao meio ambiente; associando a estes temas questões como: transporte, utilização de energia, poluição da água, mudanças climáticas, consumo sustentável, utilização de recursos naturais e desperdício. Site: http://www.honoloko.com/Honoloko.html
} 


\section{REFERÊNCIAS BIBLIOGRÁFICAS}

Abdi, H. The Kendall Rank Correlation Coefficient. Disponível em: http://www.utdallas.edu/ herve/Abdi-KendallCorrelation2007-pretty.pdf

Allen, W.; Kilvington, M.; and Horn, C. (2002) Using participatory and learning-based approaches for environmental management to help achieve constructive behavior change. Landcare Research Contract Report LC0102/057, Lincoln, New Zealand. Disponível

em:

http://www.landcareresearch.co.nz/research/sustainablesoc/social/par_rep.asp

Arruda, F.S. (2005) Aplicação de um modelo baseado em atividades para análise da relação uso do solo e transportes no contexto brasileiro. Tese (Doutorado). Escola de Engenharia de São Carlos, Universidade de São Paulo, São Carlos.

Associação Nacional de Transportes Públicos - ANTP (2003) Secretaria diz como trabalhará pela mobilidade sustentável. Informativo ANTP, São Paulo, n 101, maio.

Banister, D. The sustainable mobility paradigm. Transport Policy 15 (2008) 73-80.

Bardin, L. (1977) Análise de Conteúdo. Edições 70. Lisboa.

Batty, M. e Densham, P.J. (1996) Decision Support, GIS, and Urban Planning. Disponível http://www.acturban.org/biennial/doc_planners/decission_gis_planning.htm

Bergman, L.; Rabi, N. I. A. de. (2005) Mobilidade e política urbana: subsídios para uma gestão integrada. Rio de Janeiro: IBAM; Ministério das Cidades.

Beynon, M.; Rasmequan, S. \& Russ, S. A new paradigm for computer-based decision support. Decision Support Systems. Elsevier. Volume 33, Issue 2, June 2002, Pages 111-126.

Biesterfeld, J. \& Jobmann, K. (s/d) Evaluating different Mobility Management Methods. Disponível em: http://www.ant.uni-annover.de/Forschung/Public/Kn/1998/BJ1998a.pdf

Black, J.A., Paez, A. e Suthanaya, P.A. (2002) Sustainable urban transportation: performance indicators and some analytical approaches. Journal of Urban Planning and Development, vol. 128, p. 184-209.

Bossel, H. (1997) Finding a comprehensive set of indicators of sustainable development by application of the orientation theory. Em: MOLDAN, B. et al (ed.) Sustainability indicators: a report on the project on indicators of sustainable development. New York: Wiley. Cap.1, p. 101-109. 
Brail, R. K. and Klosterman, R. E. (2001) Planning Support Systems: Integrating Geographic Information Systems, Models, and Visualization Tools, ESRI Press. California.

Câmara, G.; Souza, R.C.M.; Freitas, U.M. \& Garrido, J. (1996) SPRING: Integrating remote sensing and GIS by object-oriented data modelling. Computers \& Graphics, 20: 395-403.

Carvalho, R. P. (s/d) Instrumentos da Gestão da Mobilidade. Disponível em: http://www.cm-porto.pt/document/449218/466845.pdf

Carver, S; Evans, A.; Kingston, R. e Turton, I. (s/d) Virtual Slaithwaite: A Web Based Public Participation Planning for Real ${ }^{\circledR}$ System. Disponível em: http://www.geog.leeds.ac.uk/papers/99-8/

COMMUNITYVIZ. Disponível em: http://www.communityviz.com/ e http://www.simcenter.org/Projects/CommunityViz/communityviz.html

Connor D. M. (s/d) Preventing and Resolving Public Controversy. Disponível em: http://www.connor.bc.ca/connor/preventing.html

Costa, M. S.; Silva, A. N. R .e Ramos, R. A. R. (2005) Sustainable urban mobility: a comparative study and the basis for a management system in Brazil and Portugal. Em: Brebbia, C. A. \& Wadhwa, L. C. (eds.) Urban transport and the environment in the $21^{\text {th }}$ century. WIT Press, Southampton, UK, 2005. p. 323-332.

Costa, M.S. (2003) Mobilidade urbana sustentável: um estudo comparativo e as bases de um sistema de gestão para Brasil e Portugal. Dissertação (Mestrado) - Escola de Engenharia de São Carlos, Universidade de São Paulo, São Carlos.

Costa, M.S.; Silva, A.N.R.; Magagnin, R.C. e Souza, L.C.L. (2003) Em busca de um sistema de indicadores visando a mobilidade sustentável em cidades brasileiras de médio porte: o que revelam os sítios eletrônicos dos governos locais Em: III ENECS III Encontro Nacional sobre Edificações e Comunidades Sustentáveis. São Carlos. Anais em CD.

Craig, J.W.; Harris, T.M. e Weiner, D. (2002) Community participation and Geographic Information Systems. Taylor and Francis. London and New York.

Cybernetica, P. (1999) The Decision Theory. Disponível em: http://pespmc1.vub.ac.be/asc/DECISI THEOR.html

Deakin, E. (1998) Land use for sustainable urban transport: an assessment of problems and options. European Conference of the Ministers of Transport. Paris. OECD-ECMT workshop on Land-Use for Sustainable Urban Transport: Implementing. Change 23-24 September 1998. Linz. Austria. Disponível em: http://www.cemt.org/UrbTrav/Workshops/LandUse/Deakin.pdf

DENATRAN - Departamento Nacional de Trânsito. Disponível em: http://www.denatran.gov.br/

DENATRAN - Departamento Nacional de Trânsito. Registro Nacional de Acidentes e Estatísticas de Trânsito - RENAEST. Disponível em: http://www.infoseg.gov.br/renaest/detalheNoticia.do?noticia.codigo=121

Dickey, J. (2001) New conceptual modeling using QCQ: Hall's "Future Cities". Em: International Conference On Computers In Urban Planning And Urban Management On The Edge Of The Millennium, 7, 2001, Honolulu, Hawaii. Proceedings (in CD-ROM). 
Direção Geral do Ambiente (2000) Proposta para um Sistema de Indicadores de Desenvolvimento Sustentável. Direção de Serviços de Informação e Creditação, Lisboa, Portugal. Disponível em: http://www.iambiente.pt/sids/sids.pdf

Drogendijk, A e Kuijn, M. (1999) Interactive Support Systems for Participatory Planning. Em: Planning Support Systems in Practice. Edit. S. Geertman and J. Stillwell, Springer, New York

European Commission's DG Environment. (s/d) Disponível em: http://ec.europa.eu/environment/index_en.htm

European Environment Agency (2000) Are We Moving in the Right Direction? Indicators on transport and environment integration in the EU. Copenhagen, Denmark. EEA. Disponível em: http://reports.eea.europa.eu/ENVISSUENo12/en

European Environment Agency (EEA). Indicators of transport and environment integration (TERM). Copenhagen, Denmark. Disponível em: http://themes.eea.eu.int/Sectors_and_activities/transport/indicators

European mobility week. Disponível em: http://www.mobilityweek.eu/

Findlay, A.; Morris, A.; Rogerson, R. (1988) Where to live in Britain in 1988: Quality of life in British Cities. Cities, v. 5, n. 3, p. 268-276.

Gaunt, C. e Jackson, L. (2003) Models for assessing the effects of community change on land use patterns. Em: Planning Support Systems in Practice. Edit. S. Geertman and J. Stillwell, Springer, New York.

Gayda, S.; Boon, K; Schaillée, N.; Batty, M.; Besussi, E.; Chin, N.; Haag, G.; Binder, J.; Martino, A.; Lautso, K.; Noël, C. e Dormois, R. (2003) The SCATTER project sprawling cities and transport: from evaluation to recommendations. Disponível em: http://www.stratec.be/Articles/ETC03-SG.pdf

Geertman, S. and Stillwell, J. (2003) Planning Support Systems in Practice, Springer, New York.

Geurs, K.T. e Wee, B.V. (2004) Land-use/transport Interaction Models as Tools for Sustainability Impact Assessment of Transport Investments: Review and Research Perspectives. Disponível em: http://ejtir.tudelft.nl/issues/2004_03/pdf/2004_03_05.pdf

Gonçalves, M.F.; Brandão, C.A. e Galvão, A.C. (2003) Regiões e cidades, cidades nas regiões: o desafio urbano-regional. M.F. Gonçalves; C.A. Brandão \& A.C. Galvão organizadores. Editora Unesp - ANPUR. São Paulo.

Gorham, R. (1998) Land-Use Planning and Sustainable Urban Travel. European Conference of the Ministers of Transport. Paris. OECD-ECMT workshop on LandUse for Sustainable Urban Transport: Implementing. Change 23-24 September 1998. Linz. Austria. Disponível em: http://www.cemt.org/UrbTrav/Workshops/LandUse/LiGorham.pdf

Graeml, Felipe Reis (2000) Indicadores Estratégicos: uma ferramenta de auxílio na administração municipal. Dissertação (Mestrado). UFSC. Santa Catarina.

Gudmundsson, H (2001) Indicators and performance measures for Transportation, Environment and Sustainability in North America. Report from a German Marshall Fund Fellowship 2000. Individual study tour October 2000. Research Notes No. 148. Disponível

$\mathrm{em}:$ http://www2.dmu.dk/1_viden/2_Publikationer/3_arbrapporter/rapporter/AR148.pdf 
Gudmundsson, H (2004) Sustainable transport and performance indicators. Em R.E. Hester and R.M. Harrison (ed.) Transport and Environment, Issues in Environmental Science and Technology. The Royal Society of Chemistry, p. 35-64, Cambridge, U.K.

GUIDEMAPS Handbook (2004) Successful Transport Decision-Making Handbook. A project management and stakeholder engagement handbook. Disponível em: http://www.eltis.org/docs/GUIDEMAPSHandbook web.pdf

Harris, B. (1998) Planning Support Systems: An Introduction. Em: Planning Support Systems in Practice. Edit. S. Geertman and J. Stillwell, Springer, New York.

Harris, B. (2001). Sketch Planning: Systematic Methods in Planning and Its Support. Em: Planning Support Systems: Integrating Geographic Information Systems, Models, and Visualization Tools, Edit. R. K. Brail e R.E. Klosterman, ESRI Press, 59-80.

Huxhold, W. E. (1991) An Introduction to Urban Geographic Information Systems. Oxford University Press, Oxford.

IBAM - Instituto Brasileiro de Administração Municipal. Disponível em: http://thor.ibam.org.br/

IBGE - Instituto Brasileiro de Geografia e Estatística. (2007) Censo 2007. Disponível em: http://www.ibge.gov.br/

Innes, J.E. e Booher, D. E. (2000) Public Participation in Planning: new strategies for 21st Century. Annual Conference of the Association of Collegiate Schools of Planning. Disponível em: http://www-iurd.ced.berkeley.edu/pub/WP-2000-07.pdf

Instituto da Mobilidade Sustentável. Rua viva. Disponível em: http://www.ruaviva.org.br/menu.html

Instituto do Ambiente (2000) SIDS - Proposta para um Sistema de Indicadores de Desenvolvimento Sustentável. Disponível em: http://www.iambiente.pt/sids/sids.pdf

Jankowski, P. e Nyerges, T. (2001) Geographic Information Systems for Group Decision Making. Taylor and Francis. London and New York.

Johnston, R.A. e La Barra, T. de (1998) Modelistica - Comprehensive Regional Modeling for Long-range Planning: Linking Integrated Urban Models to Geographic Information Systems. Disponível em: http://www.modelistica.com/

Kersten, G.E.; Mikolajuk, Z. e Gar-on Yeh, A. (1999) Decision Support Systems for Sustainable Development: a resource book of methods and aplications. Edit. G. E. Kersten; Z. Mikolajuk, and A.Gar-on Yeh. Klumer Academic Publishers. Boston. Dordrecht. London.

Ketele, J. de e Roegiers, X. (1993) Metodologia da Recolha de dados: Fundamentos dos métodos de observações, de questionários, de entrevistas e de estudos de documentos. Instituto Piaget. Lisboa.

Kingston, R.; Carver, S.; Evans, A. e Turton, I. Virtual Decision Making in Spatial Planning: Web-Based Geographical Information Systems for Public Participation in Environmental Decision Making. Disponível em: http://www.geog.leeds.ac.uk/papers/99-9/index.html

Kingston, R.; Evans, A. e Carver, S. (2003) Public Participation via On-line Democracy. Em Planning Support Systems in Practice. Edit. S. Geertman and J. Stillwell, Springer, New York. 
Klosterman, R. E. (2001). Planning Support Systems: a New Perspective on ComputerAided Planning. Em: Planning Support Systems: Integrating Geographic Information Systems, Models, and Visualization Tools, Edit. R. K. Brail e R.E. Klosterman, ESRI Press, 1-23.

Lacaze, J.P. (2001) Os métodos do urbanismo. 2 ed. Papirus, Campinas.

Laurini, R. (2001) Information Systems for Urban Planning - A hipermidia cooperative approach. Taylor and Francis. London and New York.

Lautso, K. (1998) The SPARTACUS approach to assessing urban sustainability. Em: DONALD BOYD \& TJEERD DEELSTRA (eds.) Indicators for sustainable development. Proceedings of the advanced study course. Patrocinado por Directorate - General XII/D Environment and Climate RTD Programme, European Comission. Delft, The Netherlands: The International Institute for the Urban Environment.

Lautso, K.; Spiekermann, K. e Wegener, M (2002) Modelling Policies for Urban Sustainability. Disponível em: http://www.raumplanung.unidortmund.de/rwp/ersa2002/cd-rom/papers/384.pdf

Lima, R.S. (2003) Bases para uma metodologia de apoio à decisão para serviços de educação e saúde sob a ótica dos transportes. Tese (Doutorado). Escola de Engenharia de São Carlos. Universidade de São Paulo, São Carlos.

Litman, T (2004) Evaluating Transportation Land Use Impacts. Victoria Transport Policy Institute. GTZ Transport and Mobility Group. Disponível em: http://www.vtpi.org

Litman, T (2006a) Planning Principles and Practices. Victoria Transport Policy Institute. GTZ Transport and Mobility Group. Disponível em: http://www.vtpi.org

Litman, T (2006b) Evaluating Transportation Land Use Impacts. Victoria Transport Policy Institute. GTZ Transport and Mobility Group. Disponível em: http://www.vtpi.org

Litman, T. (2003) Mobility Management. Sustainable Transport: A Sourcebook for Policy-makers in Developing Cities Module 2b. Victoria Transport Policy Institute. GTZ Transport and Mobility Group. Disponível em: http://www.vtpi.org

Lopes, R. (1998) A cidade intencional: o planejamento estratégico de cidades. Mauad. 2 ed. Rio de Janeiro.

Loukopoulos, P. e Scholz, R.W. (2004) Sustainable future urban mobility: using area development negotiations for scenario assessment and participatory strategic planning. Environment and Planning A, vol. 36, p. 2203-2226.

Machado, J.A.R. (2000) A emergência dos sistemas de Informação Geográfica na análise e organização do espaço. Fundação Calouste Gulbenkian.

Magagnin, R.C.; Rodrigues, D.S.; Ramos, R.A.R. e Silva, A.N.R. da. (2005) A Spatial Decision Support System for Participative Planning. Em: CUPUM 05 - Computers in Urban Planning and Urban Management. Londres: CASA - Centre of Advanced Spatial Analysis - University College London.

Magagnin, R.C.; Silva, A.N.R. da e Ramos, R.A.R. (2007) An assessment of evaluation methods applied in decision support systems for sustainable urban mobility planning. Em: CUPUM 2007 - Computers in Urban Planning and Urban Management. Foz do Iguaçu. São Carlos: School of Engineering of São Carlos - University of São Paulo. 
Magagnin, R.C.; Silva, A.N.R. da; Ramos, R.A.R. e Rodrigues, D.S. (2005) Explorando recursos de software livre para a construção de um sistema de suporte à decisão espacial na web. Em: PLURIS 2005 - $\mathbf{1}^{\circ}$ Congresso Luso Brasileiro para o Planejamento Urbano, Regional, Integrado e Sustentável. São Carlos.

Magagnin, R.C.; Silva, AN.R. e Costa, M.S. (2004) Planejamento Participativo e Internet (www): um breve histórico, tendências e perspectivas no Brasil e em Portugal. Em: Contribuições para o desenvolvimento sustentável em cidades portuguesas e brasileiras, Almedina, Coimbra, Portugal. p. 163-177.

Malczewski, J. (1999) Gis and Multicriteria Decison Analysis. John Wiley \& Sons. New York, NY, EUA.

Matos, M.A.C.N et al. (s/d) Modelo de demanda para planejamento estratégico de transporte urbano. IPT. 2. Modelos Urbanos, Regionais e de Transportes.

Mendes, J. F. G.; Silva, J.; Rametta, F. e Giordano, S. (1999) Mapping Urban Quality of Life in Portugal: A GIS Approach. Em: Bento, J.; Arantes e Oliveira, E.; Pereira, E. (eds.) Proceedings of the EPMESC VII: Computational Methods in Engineering and Science, vol. 2, p. 1107-1115. Elsevier, Macao.

Meurs, H. e Wee, B.V. (2003) Land use and Mobility: a synthesis of findings and policy implications. $\quad$ Disponível http://www.ejtir.tbm.tudelft.nl/issues/2003 02/pdf/2003_02_06.pdf

Ministério das Cidades (2004) Plano Diretor Participativo: guia para a elaboração pelos municípios e cidadãos. Disponível em: www.cidades.gov.br/

Ministério das Cidades (2005) Pesquisa Nacional sobre Transporte Acessível. Secretaria Nacional de Transporte e da Mobilidade Urbana. Disponível em: http://www.cidades.gov.br

Ministério das Cidades (2006a). Curso Gestão Integrada da Mobilidade Urbana. Módulo I: Política Nacional de Mobilidade Urbana. Ministério das Cidades, Programa Nacional de Capacitação das Cidades, Brasília, Março, 2006. Disponível em: http://www.cidades.gov.br/CursoSemob/modulos.html

Ministério das Cidades (2006b). Curso Gestão Integrada da Mobilidade Urbana. Módulo II: Política Nacional de Mobilidade Urbana. Ministério das Cidades, Programa Nacional de Capacitação das Cidades, Brasília, Março, 2006. Disponível em: http://www.cidades.gov.br/CursoSemob/modulos.html

Ministério das Cidades (2006c). Curso Gestão Integrada da Mobilidade Urbana. Módulo III: Política Nacional de Mobilidade Urbana. Ministério das Cidades, Programa Nacional de Capacitação das Cidades, Brasília, Março, 2006. Disponível em: http://www.cidades.gov.br/CursoSemob/modulos.html

Ministério das Cidades (2007). PlanMob - Construindo a cidade sustentável. Caderno de referência para Elaboração de Plano de Mobilidade Urbana. Disponível em: http://www.cidades.gov.br/media/LivroPlanoMobilidade05092007.pdf

Ministério das Cidades e IBAM (2004) Mobilidade e Política urbana: Subsídios para uma Gestão Integrada. Disponível em: http://www.cidades.gov.br/media/MobilidadeePoliticaUrbana.pdf

Modelistica - TRANUS. Disponível em: http://www.modelistica.com/

Monteiro, Y.D.P. (1990) Subsídios para a elaboração do Plano Diretor. vol 1 e 2. CEPAM. São Paulo. 
Nicolas, J.-P.; Pochet, P. e Poimboeuf H. (2003) Towards sustainable mobility indicators: application to the Lyons conurbation. Transport Policy 10, p. 197-208.

Nyerges, T.; Brooks, T.; Drew, C.; Jankowski, P.; Rutherford, G.S. e Young, R. (2003). An Internet Platform to Support Public Participation in Transportation Decision Making project description revised based on project award. Disponível em: http://depts.washington.edu/pgist/doc/2003 NSF transportation decision proj descrip.pdf

Organization for Economic Co-operation and Development (OECD). Working Group on the State of the Environment. Indicators for the integration of environmental concerns into transport policies. Disponível em: http://www.olis.oecd.org/olis/1998doc.nsf/LinkTo/ENV-EPOC-SE(98)1-FINAL

Parra Filho, D. e Santos, J.A. (1998) Metodologia Científica. Futura. São Paulo.

Peneau, J.P. (1990) Nuevos instrumientos de gestion y de concepcion del espacio urbano. Em: Nuevas tecnologias en urbanismo. Ciudad y Territorio. N 84, Madrid.

Pereira, J.C.R. (2001) Análise de dados qualitativos: estratégias metodológicas para as ciências da saúde, humanas e sociais. EDUSP. 3 ed. São Paulo.

Pidd, M. (2003) Tools for Thinking. Modelling in Management Science. John Wiley \& Sons. $2^{\text {nd }}$ ed, England, UK.

Prefeitura Municipal de Bauru. Plano Diretor Participativo. Disponível em: http://www.bauru.sp.gov.br/prefeitura/site/planejamento/

Prefeitura Municipal de Bauru. Projeto de Lei - Plano Diretor Participativo. Disponível em:

http://www.bauru.sp.gov.br/prefeitura/conteudo/gabinete/imprensa/PDP Projeto de_Le i 75-06.pdf

Prefeitura Municipal de São Paulo. (2004) Plano Diretor Estratégico do Município de São Paulo - 2002-2012. Secretaria Municipal de Planejamento Urbano do Município de São Paulo (SEMPLA) - organização. Editora Senac. São Paulo.

PROPOLIS. Disponível em: http://www.wspgroup.fi/lt/propolis/index.htm

Richardson B.C. (2005) Sustainable transport: analysis frameworks. Journal of Transport Geography, vol. 13, p. 29-39.

Rieg e Araújo Filho (2002) O uso das metodologias "planejamento estratégico situacional" e "mapeamento cognitivo" em uma situação concreta: o caso da pró-reitoria de extensão da UFSCar. Gestão\& Produção. v.9, n.2, p.163-179.

Rieg e Araújo Filho (2003) Mapas cognitivos como ferramenta de estrututação e resolução de problemas: o caso da pró-reitoria de extensão da UFSCar. Gestão\& Produção. vol.10, no.2, p.145-162.

Rinner, C. Web-based Spatial Decision Support: Status and Research Directions. Disponível em: http://individual.utoronto.ca/rinner/pubs/Rinner_published_GIDA-012003.pdf

Saboya, R.T. (2000) Análises espaciais em planejamento urbano: novas tendências. Revista Brasileira de Estudos Urbanos e Regionais, n.3, p.61-79.

Saboya, R.T. (2007) Construção de um sistema de suporte à elaboração de planos diretores participativos. Tese (Doutorado). Universidade Federal de Santa Catarina, Florianópolis. 
Sant'Anna, R.M. de (2007) O ambiente viário na percepção de pedestres idosos: uma contribuição da psicologia social. Em: XXI Congresso de Pesquisa e Ensino em Transportes. Rio de Janeiro - RJ. Anais em CD.

SEADE - Fundação Sistema Estadual de Análise de Dados. (2007) Perfil Municipal de Bauru. Disponível em: http://www.seade.gov.br/produtos/perfil/perfil.php

Senado Federal (2001) Estatuto das Cidades. Disponível em: http://www.interlegis.gov.br/processo_legislativo/copy_of_20020308104014/view?page $=$ HTTOC.HTM

Shiffer, M.J. (1992) Towards a Collaborative Planning Systems. Massachusetts Institute of Technology. Disponível em: http://gis.mit.edu/people/mshiffer/collab.html

Shiffer, M.J. (1995) Interactive multimedia planning support: moving from stand-alone systems to the World Wide Web. Environment and Planning B. Planning and design. v. 22, n6, november, p. 649-664.

Shim, J.P.; Warkentin, M.; Courtney, J.F.; Power, D.J.; Sharda, R. e Carlsson, C. (2002) Past, present, and future of decision support technology. Decision Support Systems. Elsevier. Volume 33, Issue 2, June 2002, Pages 111-126.

Silva, A.N.; Ramos, R.A.R.; Souza, L.C.L.; Rodrigues, D.S. e Mendes, J.F.G. (2004) SIG: Uma plataforma para introdução de técnicas emergentes no planejamento urbano, regional e de transportes: uma ferramenta $3 D$ para análise ambiental urbana, avaliação multicritério, redes neurais artificiais. São Carlos, SP. Ed. dos autores.

Silva, A.N.R. da; Magagnin, R.C. e Souza, L.C.L. de. (2007) Should Planning-Support Tools rely on Public Participation or on Expert's Judgments? Em: REAL CORP 007. Vienna - Austria. REAL CORP 007 Proceedings. Viena: Editors: Manfred SCHRENK, Vasily V. POPOVICH, Josef BENEDIKT, 2007. p. 899-903.

Silva, A.N.R.; Costa, M.S. e Macedo, M.H. (2007b) Multiple Views of Sustainable Urban Mobility in a Developing Country - The Case of Brazil. Proceedings of 11th World Conference on Transport Research, WCTR, Berkeley. Anais em CD.

SMILE - Sustainable Mobility Initiatives for Local Environment. SMILE Project. Disponível em: http://www.smile-europe.org/index.html

SNIU (2002) Sistema Nacional de Indicadores Urbanos. Programa de Gestão da Política de Desenvolvimento Urbano, Governo Federal. Disponível em: www.planalto.gov.br. Acessado em 2003.

Sobek, A.D. and Miller, H.J. U-Access: A Web-Based Spatial Decision Support System Routing Pedestrians of Differing Abilities. Disponível em: http://www.ucgis.org/summer2005/studentpapers/sobek.pdf

Spiekermann, K. e Wegener, M. (2004) Evaluating urban sustainability using land-use transport interaction models. Disponível em: http://ejtir.tudelft.nl/issues/2004_03/pdf/2004_03_01.pdf

Steg, L. e Gifford, R. (2005) Sustainable transportation and quality of life. Journal of Transport Geography, vol. 13, p. 59-69.

Sugumaran, V. e Sugumaran, R. (2005) Web-based Spatial Decision Support Systems (WebSDSS): Evolution, Architecture, and Challenges. Third Annual SIGDSS PreICIS Workshop Designing Complex Decision Support: Discovery and Presentation of Information and Knowledge. Las Vegas, Nevada. Disponível em: http://mis.temple.edu/sigdss/icis05/proceedings/DSSWorkshop05-Sugumaran.pdf 
Sustainable Seattle (1998) Summary of Indicators. Disponível em: http://sustainableseattle.org

SUTRA. Disponível em: http://www.ess.co.at/SUTRA/

Timmermans, H. (1997) Decision Support Systems in Urban Planning. Edit. H. Timmermans. Department of Architecture. University of Eindhoven, The Netherlands. E \& FN Spon. London, UK.

TRANSPLUS - TRANSport Planning Land-Use and Sustentability. Disponível em: Www.transplus.net

TRANSPLUS (2003) Achieving sustainable transport and land use with integrated policies. Disponível em: http://www.isis-it.com/transplus/TrDoc/T inglese.pdf

UITP (2004) Ticket to the Future 3 stops to Sustainable Mobility. Disponível em: http://www.uitp.org/Project/pics/susdev/Brochure-EN.pdf

UITP. Better Mobility in Urban Areas. Disponível em: http://www.uitp.org/mos/brochures/33-en.pdf

UITP. Better urban mobility in developing countries. Disponível em: http://www.uitp.org/mos/brochures/34-en.pdf

UNCED (1992) Agenda 21. United Nations Conference on Environment and Development. Disponível em: http://www.um.org/esa/sustdev/agenda21.htm

UNCHS (1996) Urban Indicators. Disponível em: http://www.unhabitat.org/programmes/guo/guo indicators.asp

Vuchic, V.R. (1981) Urban Public Transportation Systems and Tecnology. Prentice Hall New Jersey.

WCED (1987) Our Common Future (The Brundtland Report). World Comission on Environment and Development. Oxford. Oxford University Press.

What-if? Disponível em: http://www.what-if-pss.com/index.html

Yigitcanlar, T. \& Stimson, R. (2003) Evaluating the Potential of Australia for Online Public Participatory Planning. 27 ${ }^{\text {th }}$ ANZRSAI Annual Conference. Fremantle, Western Australia. Disponível em: http://www.urbanizm.org/pdf/publication perth.pdf

Yigitcanlar, T. (2001) A methodology for Geographical Information Systems based participatory decision making approach. Tese (Doutorado), Izmir Institute of Technology, Turkey. Disponível em: http://www.urbanizm.org/pdf/thesis gisbpdm.pdf

Yigitcanlar, T. (2003) Building the E-Democracy bridge to support citizen involvement in decision making process. $2^{\text {nd }}$ Annual International Conference: E-governance: Regions, Devolution, Participation, Formation. Churchill, Victoria, Australia. Disponível em: http://www.urbanizm.org/pdf/publication_monash.pdf 


\section{ANEXOS}


ANEXO 1 - Indicadores de Mobilidade Sustentável propostos por Costa (2003)

\begin{tabular}{|c|c|c|c|}
\hline Cate & TEMA & \multicolumn{2}{|l|}{ INDICADOR } \\
\hline \multirow{20}{*}{ 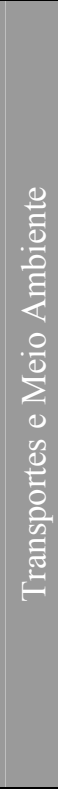 } & \multirow[t]{5}{*}{ Energia / Combustível } & Consumo per capita de combustível fóssil por transporte em veículo motorizado & 01. \\
\hline & & Eficiência energética do transporte de passageiro e carga & 02. \\
\hline & & Energia final consumida pelo setor de transportes & 03. \\
\hline & & Intensidade do uso de energia: Transporte & 04. \\
\hline & & Proporção de energia originada de fontes de combustível fóssil e não-fóssil. & 05 . \\
\hline & \multirow[t]{5}{*}{ Impacto Ambiental } & Descargas acidentais de óleo no mar por navios. & 06. \\
\hline & & Fragmentação de terras e florestas & 07. \\
\hline & & Impactos do uso de automóveis & 08. \\
\hline & & Proximidade de infra-estrutura de transportes a áreas protegidas & 09. \\
\hline & & Resíduos gerados por veículos rodoviários & 10. \\
\hline & \multirow[t]{6}{*}{ Qualidade do Ar } & Dias por ano em que os padrões de qualidade do ar não são atendidos & 11. \\
\hline & & Emissão de gases acidificantes pelos transportes & 12. \\
\hline & & Emissão de gases que geram o efeito estufa pelos transportes & 13. \\
\hline & & Emissões causadas pelos transportes e intensidade das emissões & 14. \\
\hline & & População exposta à poluição do ar causada pelos transportes & 15. \\
\hline & & Qualidade do ar & 16. \\
\hline & \multirow[t]{4}{*}{ Ruído de Tráfego } & Medidas de minimização de ruído & 17. \\
\hline & & Poluição Sonora & 18. \\
\hline & & População exposta ao ruído acima de $65 \mathrm{~dB}$ (A) causado pelos transportes & 19. \\
\hline & & Ruído de tráfego: exposição e incômodo & 20. \\
\hline \multirow{22}{*}{ 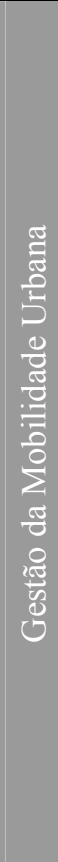 } & \multirow{6}{*}{$\begin{array}{l}\text { Despesas / Investimentos } \\
\text { / Estratégias Econômicas }\end{array}$} & Capital investido por modo & 21. \\
\hline & & Despesas públicas com transporte privado & 22. \\
\hline & & Despesas públicas com transporte público & 23. \\
\hline & & Investimentos em infra-estrutura de transportes & 24. \\
\hline & & Subsídios diretos aos transportes & 25. \\
\hline & & Taxação relativa de veículos e utilização de veículos & 26. \\
\hline & \multirow{3}{*}{$\begin{array}{l}\text { Gerenciamento / } \\
\text { Monitoração }\end{array}$} & Avaliação de impacto ambiental & 27. \\
\hline & & Gerenciamento efetivo do tráfego / fiscalização & 28. \\
\hline & & Sistema nacional para monitoração dos transportes e meios ambiente & 29. \\
\hline & \multirow{6}{*}{$\begin{array}{l}\text { Medidas para incremento } \\
\text { da mobilidade urbana }\end{array}$} & Desenvolvimento de planos municipais para a redução das viagens & 30. \\
\hline & & Estabelecimento de regulamentação para densidades mínimas na cidade & 31. \\
\hline & & Implementação de estratégias ambientais para o setor de transportes & 32. \\
\hline & & Medidas: operação eficiente da frota de veículos & 33. \\
\hline & & Melhoria dos transportes & 34. \\
\hline & & Priorizar viagens eficientes (a pé ou por bicicleta) & 35. \\
\hline & \multirow[t]{7}{*}{ Novas tecnologias } & Desenvolvimento de combustíveis limpos e número de veículos que utilizam combustíveis & 36. \\
\hline & & Gastos com Pesquisa e Desenvolvimento de "combustíveis limpos" & 37. \\
\hline & & Gastos com Pesquisa e Desenvolvimento de "veículos ecológicos" & 38. \\
\hline & & Novas formas de transporte & 39. \\
\hline & & Possível custo inicial de veículos ecológicos & 40. \\
\hline & & Uso de tecnologia de cartões inteligentes & 41. \\
\hline & & Vida útil dos veículos ecológicos & 42. \\
\hline
\end{tabular}


ANEXO 1 - Indicadores de Mobilidade Sustentável propostos por Costa (2003) (continuação)

\begin{tabular}{|c|c|c|c|}
\hline Categorias & TEMA & INDICADOR & \\
\hline \multirow{14}{*}{ 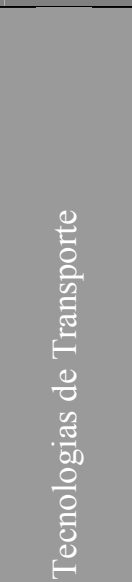 } & \multirow{6}{*}{ Frota } & Estrutura da frota de veículos rodoviários & 43. \\
\hline & & Idade média dos veículos & 44. \\
\hline & & Percentagem da frota municipal convertida para reduzir a emissão de poluentes & 45 . \\
\hline & & Propriedade de automóveis privados & 46. \\
\hline & & $\begin{array}{l}\text { Relação entre veículos com consumo eficiente de combustível/veículos com consumo } \\
\text { ineficiente de combustível. }\end{array}$ & 47. \\
\hline & & Veículos em circulação & 48. \\
\hline & \multirow{8}{*}{$\begin{array}{l}\text { Infra-estrutura / Sistema } \\
\text { Viário }\end{array}$} & Capacidade das redes de infra-estrutura de transportes & 49. \\
\hline & & Comprimento total das vias para ciclistas & 50 . \\
\hline & & Desenvolvimento de vias para otimizar o fluxo de tráfego & 51. \\
\hline & & Estrutura da rede viária & 52. \\
\hline & & Extensão total das vias designadas para pedestres & 53. \\
\hline & & Número de estacionamentos para carros na cidade & 54. \\
\hline & & Possibilidade de acesso de transporte coletivo (pavimentação) & 55 . \\
\hline & & Provisão de infra-estrutura para traffic calming e vias para bicicletas e pedestres & 56. \\
\hline \multirow{11}{*}{ 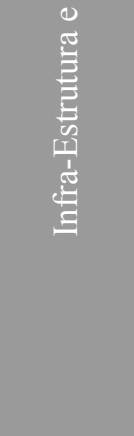 } & \multirow{5}{*}{$\begin{array}{l}\text { Tecnologias e Serviços de } \\
\text { Transporte }\end{array}$} & Aquisição de bicicletas em cidades menos desenvolvidas & 57. \\
\hline & & Mudanças nos modos de transporte & 58. \\
\hline & & Tendências do tráfego rodoviário e densidades & 59 . \\
\hline & & Transporte de carga por modo & 60. \\
\hline & & Transporte de passageiros por modo de transporte & 61. \\
\hline & \multirow{6}{*}{ Tráfego } & Congestionamento de tráfego & 62. \\
\hline & & Densidade de tráfego & 63. \\
\hline & & Geração de volume de tráfego e tipo & 64. \\
\hline & & Taxa de ocupação dos veículos de passageiros & 65 . \\
\hline & & Tempo total gasto no tráfego & 66. \\
\hline & & Velocidade de tráfego & 67. \\
\hline \multirow{14}{*}{ 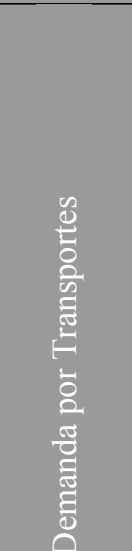 } & \multirow{6}{*}{$\begin{array}{l}\text { Acesso aos Serviços e } \\
\text { Atividades Urbanas }\end{array}$} & Acessibilidade ao bairro & 68. \\
\hline & & Acessibilidade ao centro & 69. \\
\hline & & Acesso aos serviços básicos & 70. \\
\hline & & Acesso aos serviços de transportes & 71. \\
\hline & & Percentagem de empregos situados a até 3 quilômetros de distância das residências & 72 . \\
\hline & & Percentagem de pessoas que vivem a até 3 quilômetros de distância das facilidades de lazer & 73. \\
\hline & \multirow{8}{*}{$\begin{array}{l}\text { Desenvolvimento Urbano } \\
\text { / Uso do Solo }\end{array}$} & Área total em categorias significativas de uso do solo & 74. \\
\hline & & Áreas verdes versus áreas destinadas ao automóvel privado & 75 . \\
\hline & & Desconcentração das atividades & 76. \\
\hline & & Forma urbana & 77. \\
\hline & & Incentivo ao uso misto/alta densidade & 78. \\
\hline & & Mudanças no uso do solo devido à infra-estrutura de transportes & 79. \\
\hline & & Planejamento do uso do solo urbano & 80. \\
\hline & & Políticas de uso do solo para pedestres, ciclistas e transporte público & 81. \\
\hline 0 & \multirow[t]{5}{*}{ População Urbana } & Crescimento do número de unidades unifamiliares comparado ao crescimento da população & 82. \\
\hline.$\frac{\sqrt{5}}{5}$ & & Densidade populacional & 83. \\
\hline 胥 & & Estrutura etária da população & 84. \\
\hline [-1 & & Rendimento familiar per capita & 85. \\
\hline \multirow{9}{*}{ 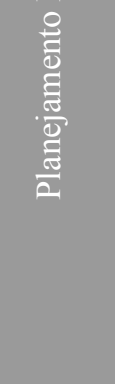 } & & Taxa de crescimento da população & 86. \\
\hline & \multirow{8}{*}{ Viagens / Deslocamentos } & Deslocamento de crianças para a escola & 87. \\
\hline & & Distância aos serviços básicos & 88. \\
\hline & & Distância média entre os moradores e os demais membros de sua família & 89. \\
\hline & & Distância percorrida a pé ou por bicicleta per capita por dia & 90. \\
\hline & & Mobilidade local e passageiros transportados & 91. \\
\hline & & Número de pessoas vivendo e trabalhando no local & 92. \\
\hline & & $\begin{array}{l}\text { Percentagem de pessoas que utilizam o automóvel para viagens com distância inferior a } 3 \\
\text { quilômetros }\end{array}$ & 93. \\
\hline & & Tempo de viagem & 94. \\
\hline
\end{tabular}


ANEXO 1 - Indicadores de Mobilidade Sustentável propostos por Costa (2003) (continuação)

\begin{tabular}{|c|c|c|c|}
\hline Categorias & TEMA & \multicolumn{2}{|l|}{ INDICADOR } \\
\hline \multirow{7}{*}{ 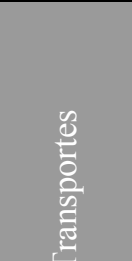 } & \multirow[t]{5}{*}{ Custos / Preços / Tarifas } & Custo por passageiro transportado, corrigido pela inflação & 95. \\
\hline & & Evolução dos preços dos diferentes tipos de combustíveis e eletricidade & 96. \\
\hline & & Mudanças reais nos preços de transporte por modo & 97. \\
\hline & & Preço dos combustíveis e taxas & 98. \\
\hline & & Tendências dos preços do transporte público & 99. \\
\hline & \multirow{4}{*}{$\begin{array}{l}\text { Impactos } \\
\text { Socioeconômicos dos } \\
\text { Transportes }\end{array}$} & Benefícios dos usuários de transportes & 100. \\
\hline & & Custos do congestionamento & 101. \\
\hline \multirow{8}{*}{ 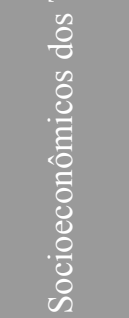 } & & Custos sociais dos transportes & 102. \\
\hline & & Rendimentos dos operadores de transportes & 103. \\
\hline & \multirow[t]{5}{*}{ Segurança } & Acidentes fatais de transportes & 104. \\
\hline & & Feridos por acidentes de tráfego & 105 . \\
\hline & & Número de crimes violentos ocorridos no trânsito & 106. \\
\hline & & Pedestres e ciclistas feridos em acidentes de trânsito & 107. \\
\hline & & Segurança e proteção para as vias residenciais & 108. \\
\hline & \multirow[t]{7}{*}{ Transporte Público } & Demanda por transporte de passageiros & 109. \\
\hline 8 & & Disponibilidade de transporte público & 110. \\
\hline 8 & & Fator de diversidade para serviços de transporte & 111. \\
\hline \multirow{4}{*}{$\sum_{4}^{\infty}$} & & Necessidade de sistemas de transporte & 112 . \\
\hline & & Nível de serviço do transporte público e modalidades lentas & 113. \\
\hline & & Percentagem de pessoas que consideram o transporte público inseguro & 114. \\
\hline & & Percentagem de pessoas que escolhem o transporte público em detrimento ao carro & 115 . \\
\hline
\end{tabular}


ANEXO 2 - Indicadores de Mobilidade Sustentável implantados no PLANUTS

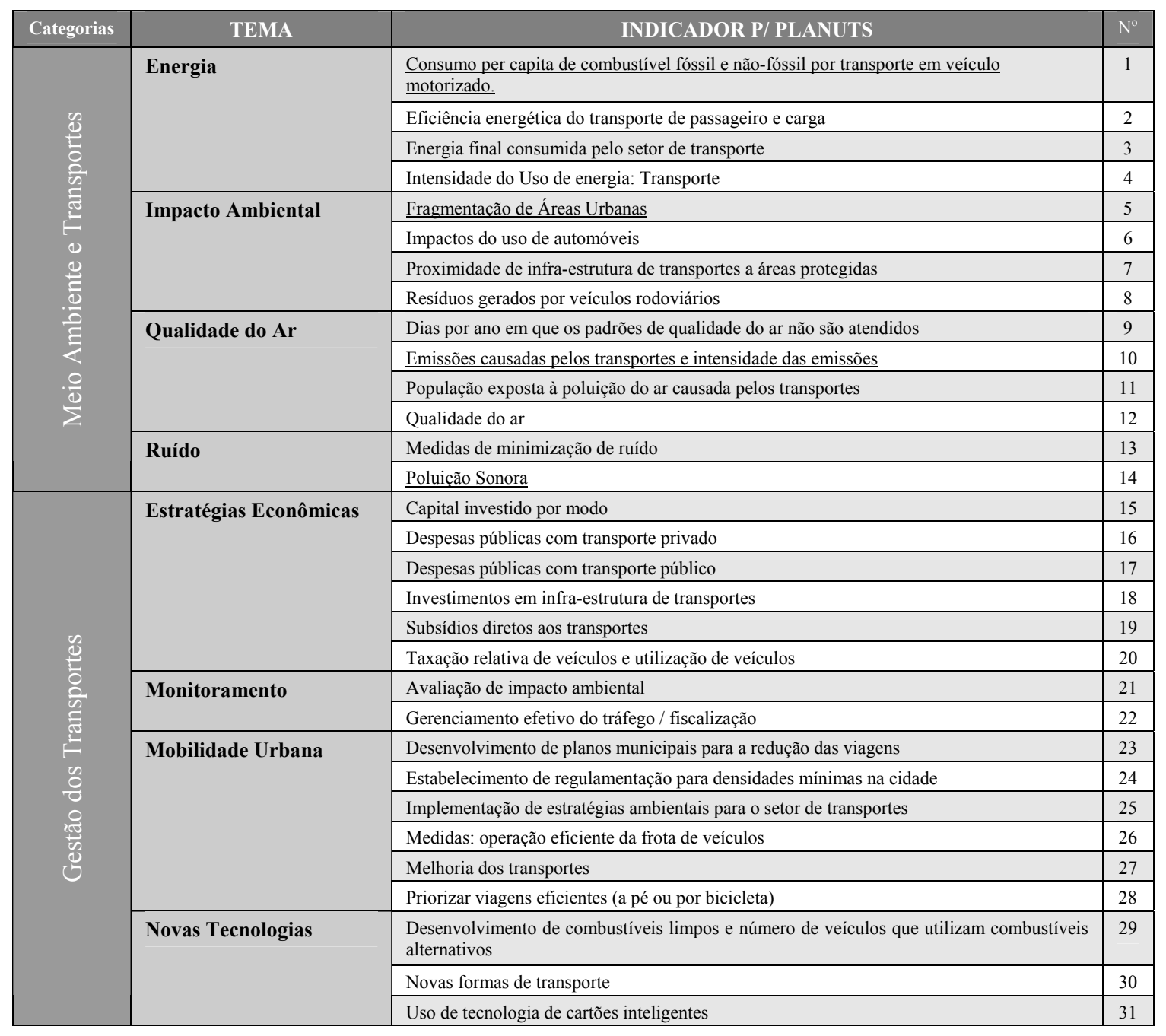




\section{ANEXO 2 - Indicadores de Mobilidade Sustentável implantados no PLANUTS} (continuação)

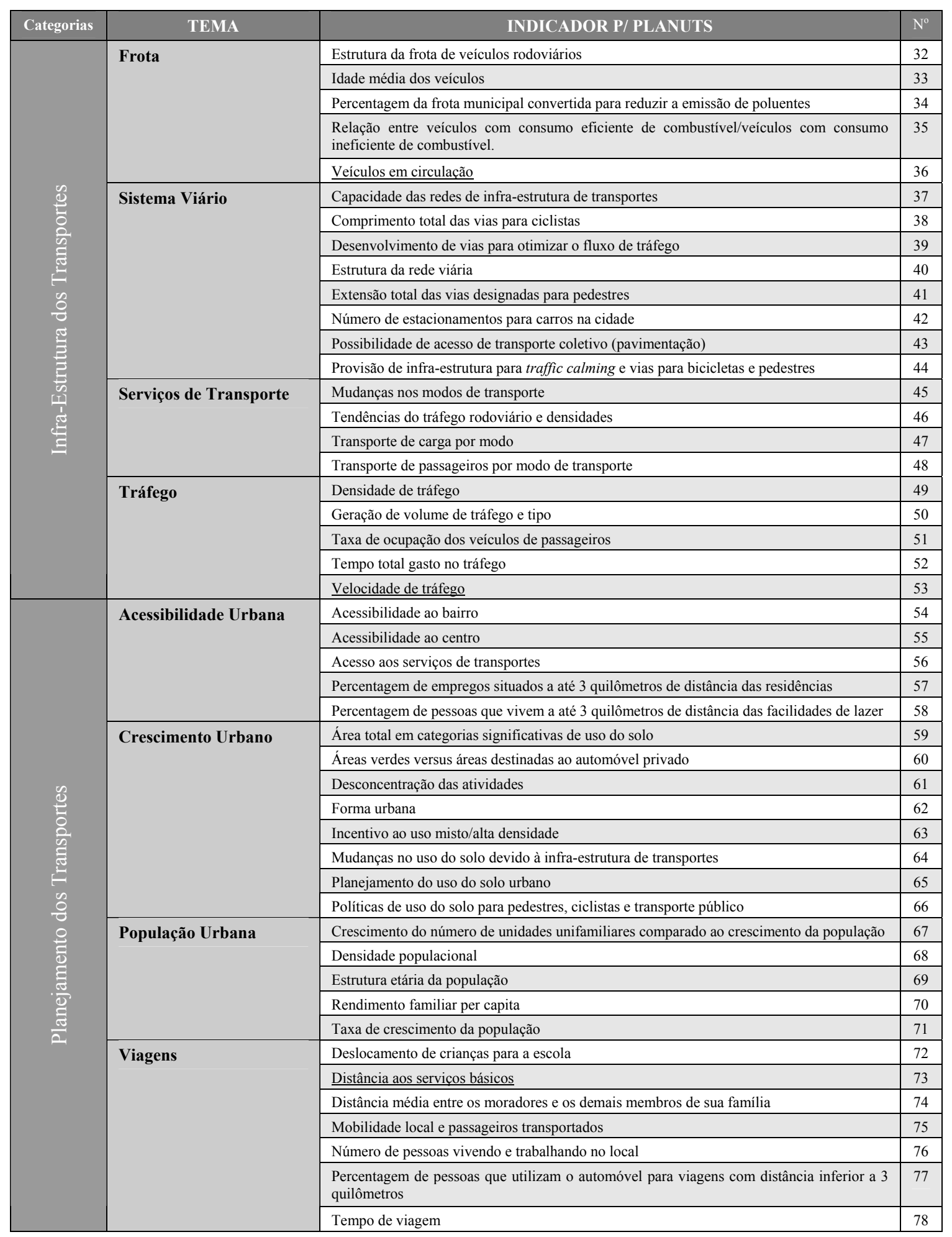


ANEXO 2 - Indicadores de Mobilidade Sustentável implantados no PLANUTS (continuação)

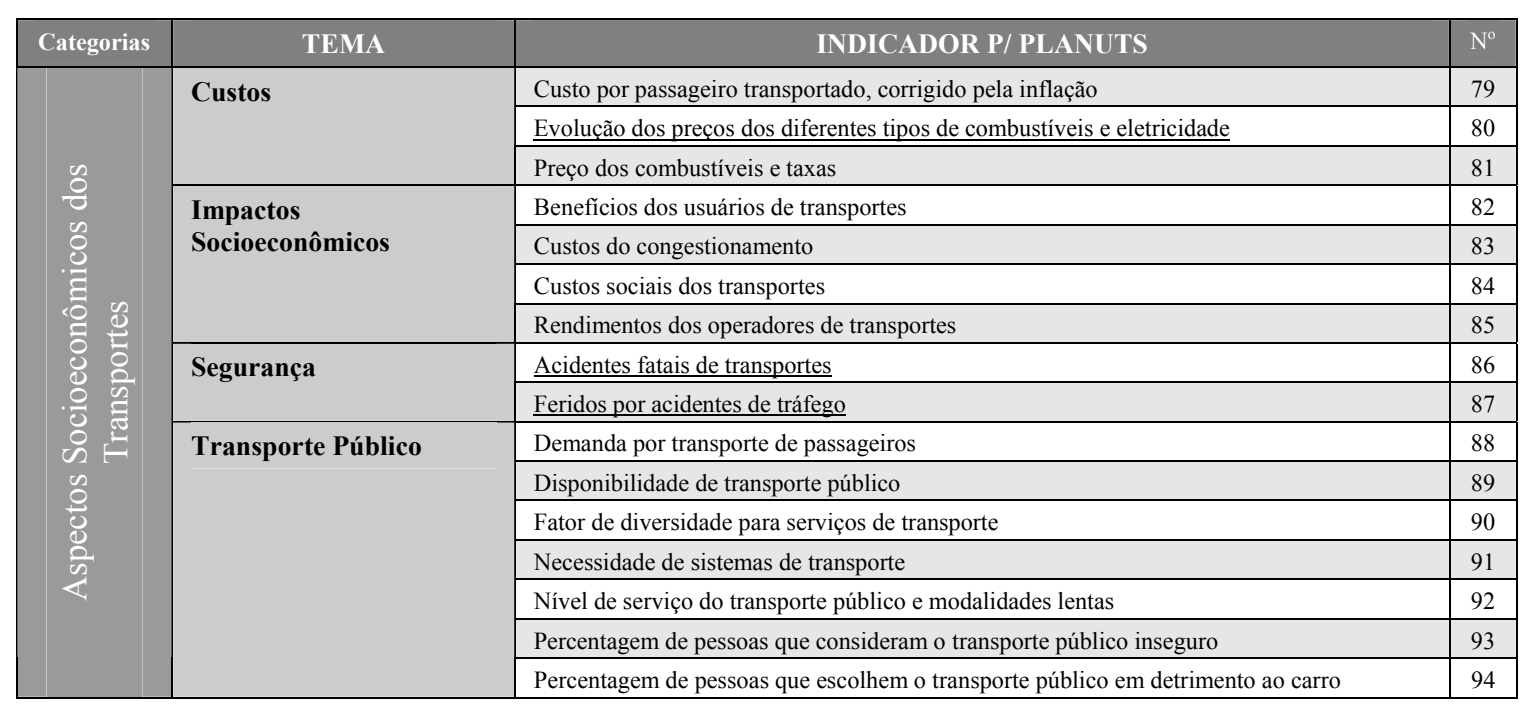




\section{ANEXO 3 - Definição das Categorias e Temas avaliados no Módulo I}

\begin{tabular}{|c|c|}
\hline CATEGORIAS & TEMAS \\
\hline \multirow{4}{*}{$\begin{array}{l}\text { Meio Ambiente e Transportes } \\
\text { Categoria que inclui indicadores } \\
\text { destinados a monitorar as interaçoses entre } \\
\text { os transportes e o meio ambiente, tais } \\
\text { como consumo de combustível e impactos } \\
\text { ambientais, ou seja, a interferência dos } \\
\text { transportes no meio ambiente, qualidade } \\
\text { do ar e ruído. }\end{array}$} & $\begin{array}{l}\text { Energia - Tema que inclui indicadores para medir e monitorar o consumo de } \\
\text { combustível não-renovável (gasolina, óleo diesel, gás natural) e combustível renovável } \\
\text { (eletricidade, álcool, etc.); por pessoa e por meio de transporte (automóvel, motocicleta, } \\
\text { caminhão, ônibus, entre outros) na cidade. }\end{array}$ \\
\hline & $\begin{array}{l}\text { Impacto Ambiental - Tema que inclui indicadores que medem a interferência do Sistema } \\
\text { de Transporte no meio ambiente urbano ou rural como, por exemplo, a construção de } \\
\text { novas ruas, avenidas e rodovias em áreas de proteção ambiental; o uso excessivo de } \\
\text { meios de transportes (automóveis, motos, ônibus) que causam poluição (atmosférica e } \\
\text { sonora) ou gerem resíduos poluentes (como pneus e óleos lubrificantes) na cidade. }\end{array}$ \\
\hline & $\begin{array}{l}\text { Qualidade do } A r-\text { Tema que inclui indicadores para monitorar e medir o nível de } \\
\text { poluição do ar (gases tóxicos) nos diferentes bairros da cidade, provocado pelo sistema } \\
\text { de transporte. }\end{array}$ \\
\hline & $\begin{array}{l}\text { Ruido - Tema que inclui indicadores para medir e monitorar o nível de ruído (poluição } \\
\text { sonora), a que a população está exposta nos diversos bairros da cidade provocado pelo } \\
\text { sistema de transporte. }\end{array}$ \\
\hline \multirow{4}{*}{$\begin{array}{l}\text { Gestão dos Transportes } \\
\text { yoria que inclui indicadores } \\
\text { onados no gerenciamento, } \\
\text { toração e avaliação dos sistemas de } \\
\text { oortes e desenvolvimento de dados e } \\
\text { sticas para o setor. }\end{array}$} & $\begin{array}{l}\text { Estratégias Econômicas - Tema que inclui indicadores para medir, monitorar e gerenciar } \\
\text { o capital investido no setor de transporte público e privado da cidade; como a construção } \\
\text { e manutenção de infra-estrutura (ruas, avenidas, estradas, ciclovias e calçadas), medidas } \\
\text { para controle e incentivo ao transporte público e a meios de transportes não poluentes. }\end{array}$ \\
\hline & $\begin{array}{l}\text { Monitoramento - Tema que inclui indicadores para medir a existência de instrumentos } \\
\text { que permitem fiscalizar o tráfego urbano e as políticas municipais de transporte } \\
\text { implantadas na cidade. }\end{array}$ \\
\hline & $\begin{array}{l}\text { Mobilidade Urbana - Tema que inclui indicadores para medir o incentivo à utilização } \\
\text { dos meios de transportes "saudáveis ou sustentáveis" (ônibus "limpo", metrô, trem, } \\
\text { bicicleta, a pé), bem como a adoção de políticas urbanas de adensamento espacial em } \\
\text { certas regiões da cidade, que podem causar problemas no setor de transporte da cidade. }\end{array}$ \\
\hline & $\begin{array}{l}\text { Novas Tecnologias - Tema que inclui indicadores para medir o incentivo a utilização de } \\
\text { novas formas de transporte na cidade, tais como a utilização de cartões inteligentes no } \\
\text { transporte público. }\end{array}$ \\
\hline \multirow{4}{*}{$\begin{array}{l}\text { Infra-estrutura dos Transportes } \\
\text { Categoria que inclui indicadores para } \\
\text { monitorar as características de infra- } \\
\text { estrutura (dimensionamento do sistema } \\
\text { viário, tamanho da frota e tráfego) e } \\
\text { tecnologia para o transporte de carga e } \\
\text { passageiros. Inclui tecnologias que não são } \\
\text { empregadas diretamente no transporte } \\
\text { urbano, mas que podem influenciar de } \\
\text { maneira direta no dia-a-dia das cidades, } \\
\text { tanto pela infra-estrutura que necessitam } \\
\text { como pelos impactos que ocasionam. }\end{array}$} & $\begin{array}{l}\text { Frota - Tema que inclui indicadores para medir o número de veículos que circulam na } \\
\text { cidade (por tipo, ano e tipo de combustível utilizado). }\end{array}$ \\
\hline & $\begin{array}{l}\text { Sistema Viário - Tema que inclui indicadores para medir o comprimento da rede viária } \\
\text { destinada a veículos automotores, bicicletas, transporte público e pedestre (calçadas). } \\
\text { Inclui indicadores para medir a segurança viária, a segurança do pedestre e dos ciclistas } \\
\text { na cidade. }\end{array}$ \\
\hline & $\begin{array}{l}\text { Serviços de Transportes - Tema que inclui indicadores para medir a distribuição, } \\
\text { utilização e preferência pelos diversos modos de transporte (automóvel, ônibus, metrô, } \\
\text { trem, bicicleta, a pé) pela população. }\end{array}$ \\
\hline & $\begin{array}{l}\text { Tráfego - Tema que inclui indicadores para medir as distâncias e o tempo gasto pela } \\
\text { população utilizando os diversos modos de transporte para ir ao trabalho, a escola, aos } \\
\text { serviços de saúde, às áreas de lazer, visitar parentes, entre outros. }\end{array}$ \\
\hline \multirow{4}{*}{$\begin{array}{l}\text { Planejamento dos Transportes } \\
\text { Categoria que inclui indicadores para } \\
\text { monitorar a relação entre forma urbana (ou } \\
\text { o crescimento urbano das cidades), com os } \\
\text { padrões de uso do solo (localização de } \\
\text { áreas residenciais, comerciais e industriais } \\
\text { na cidade) e o crescimento da população } \\
\text { com a demanda por transportes e a } \\
\text { necessidade de viagens (ou os } \\
\text { deslocamentos entre os bairros). }\end{array}$} & $\begin{array}{l}\text { Acessibilidade Urbana - Tema que inclui indicadores para medir a facilidade (ou } \\
\text { dificuldade) no acesso aos serviços de saúde, à escola, ao trabalho, ao centro da cidade e } \\
\text { a outros bairros da cidade, através da utilização de algum meio de transporte (automóvel, } \\
\text { onibus, trem, metrô, bicicleta, a pé). }\end{array}$ \\
\hline & $\begin{array}{l}\text { Crescimento Urbano - Tema que inclui indicadores para medir as áreas de expansão da } \\
\text { cidade; os bairros considerados residenciais, comerciais, industriais; a falta de infra- } \\
\text { estrutura de transportes, como a insuficiência do transporte público para a população } \\
\text { local; o excesso de equipamentos em relação ás áreas verdes e de lazer para a população, } \\
\text { como por exemplo, o excesso de áreas de estacionamento em relação a áreas verdes. }\end{array}$ \\
\hline & $\begin{array}{l}\text { População Urbana - Tema que inclui indicadores para medir a distribuição e o } \\
\text { crescimento da população na cidade. Estes indicadores permitirão avaliar as } \\
\text { necessidades de cada faixa etária da população em relação ao acesso aos diferentes } \\
\text { meios de transporte. }\end{array}$ \\
\hline & $\begin{array}{l}\text { Viagens - Tema que inclui indicadores para medir as distâncias percorridas pelas } \\
\text { mercadorias e pela população através dos diferentes meios de transporte na cidade. }\end{array}$ \\
\hline
\end{tabular}


ANEXO 3 - Definição das Categorias e Temas avaliados no Módulo I (continuação)

\begin{tabular}{|c|c|}
\hline $\begin{array}{c}\text { Aspectos Socioeconômicos dos } \\
\text { Transportes }\end{array}$ & $\begin{array}{l}\text { Custos - Tema que inclui indicadores para medir e monitorar o custo do transporte } \\
\text { público para a população e para os empresários. }\end{array}$ \\
\hline $\begin{array}{l}\text { Categoria que inclui indicadores para } \\
\text { medir e monitorar os custos dos } \\
\text { transportes na cidade e as interações entre } \\
\text { os transportes, a economia e a sociedade. } \\
\text { Inclui impactos (prejuízos e benefícios) }\end{array}$ & $\begin{array}{l}\text { Impactos Socioeconômicos - Tema que inclui indicadores para medir os investimentos } \\
\text { no setor de transporte para diminuir os problemas causados pelo congestionamento, } \\
\text { prevenção de acidentes, segurança no transporte público, prevenção à poluição e } \\
\text { implantação de infra-estrutura urbana necessária ao deslocamento da população na } \\
\text { cidade. }\end{array}$ \\
\hline $\begin{array}{l}\text { transportes (como a diminuição dos } \\
\text { congestionamentos, prevenção de } \\
\text { acidentes, segurança no transporte público, }\end{array}$ & $\begin{array}{l}\text { Segurança Viária - Tema que inclui indicadores para medir e monitorar o número de } \\
\text { acidentes de trânsito ocorridos na cidade e verificar as medidas implantadas para } \\
\text { diminuir estes acidentes. }\end{array}$ \\
\hline $\begin{array}{l}\text { monitoram as ações implementadas pelo } \\
\text { poder público para diminuir o número de } \\
\text { acidentes no trânsito e melhorar a } \\
\text { qualidade do transporte público da cidade. }\end{array}$ & $\begin{array}{l}\text { Transporte Público - Tema que inclui indicadores para medir o número de passageiros } \\
\text { transportados pelo transporte público na cidade e para identificar quais os bairros ou } \\
\text { regiões da cidade que estão mal servidas por este sistema. }\end{array}$ \\
\hline
\end{tabular}


ANEXO 4 - Módulo I - Seqüência de Imagens referente às Categorias

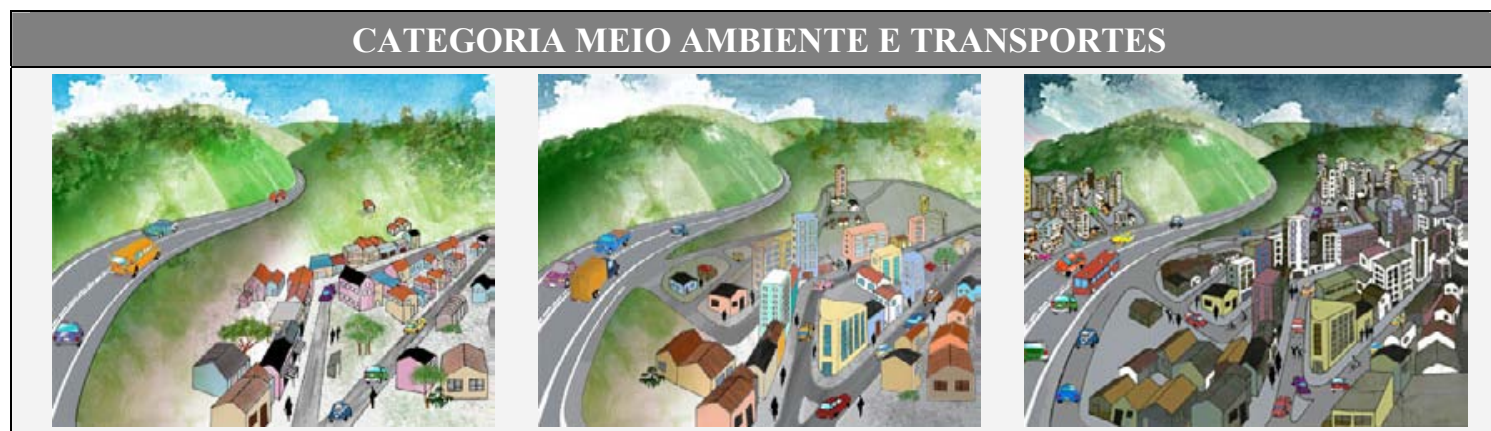

CATEGORIA GESTÃO DOS TRANSPORTES
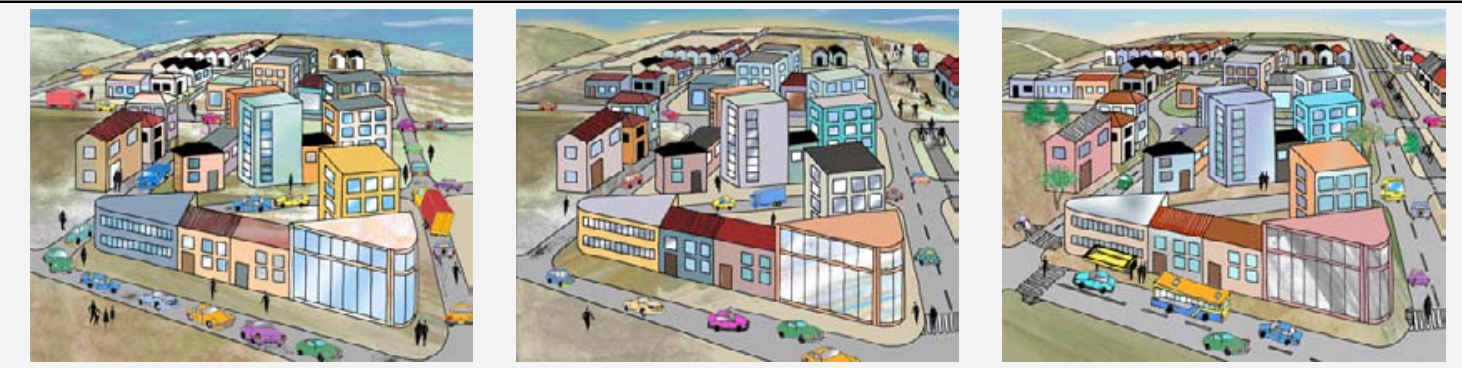

CATEGORIA INFRA-ESTRUTURA DOS TRANSPORTES
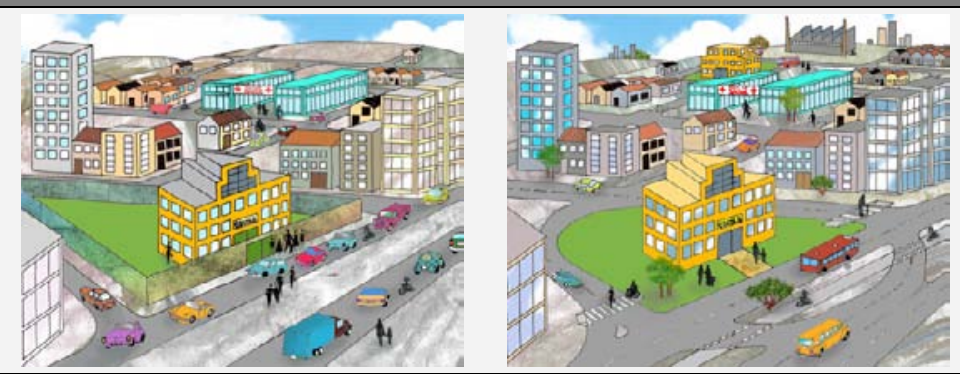

\section{CATEGORIA PLANEJAMIENTO DOS TRANSPORTES}
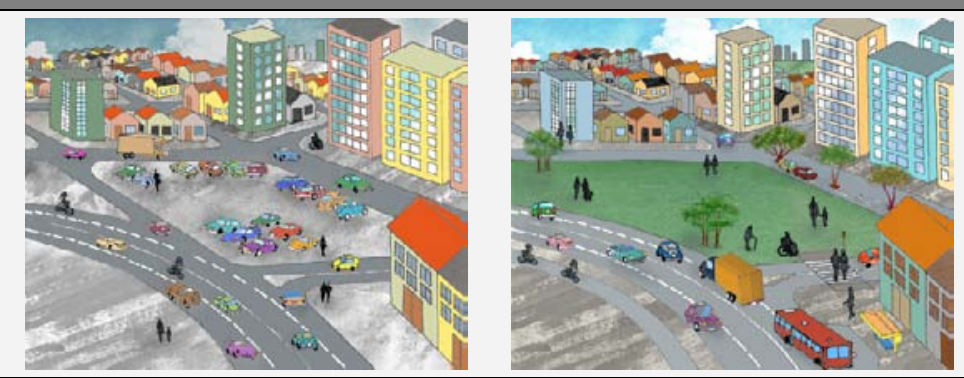

CATEGORIA ASPECTOS SOCIOECONÔMICOS DOS TRANSPORTES
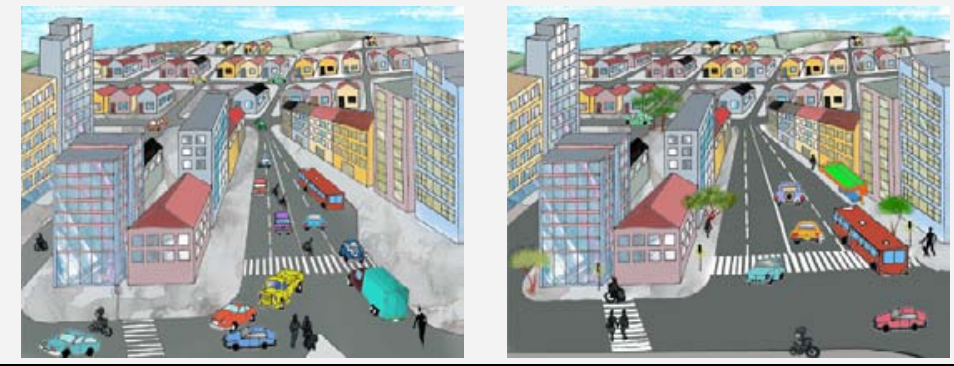
ANEXO 5 - Definição dos Indicadores avaliados no Módulo II

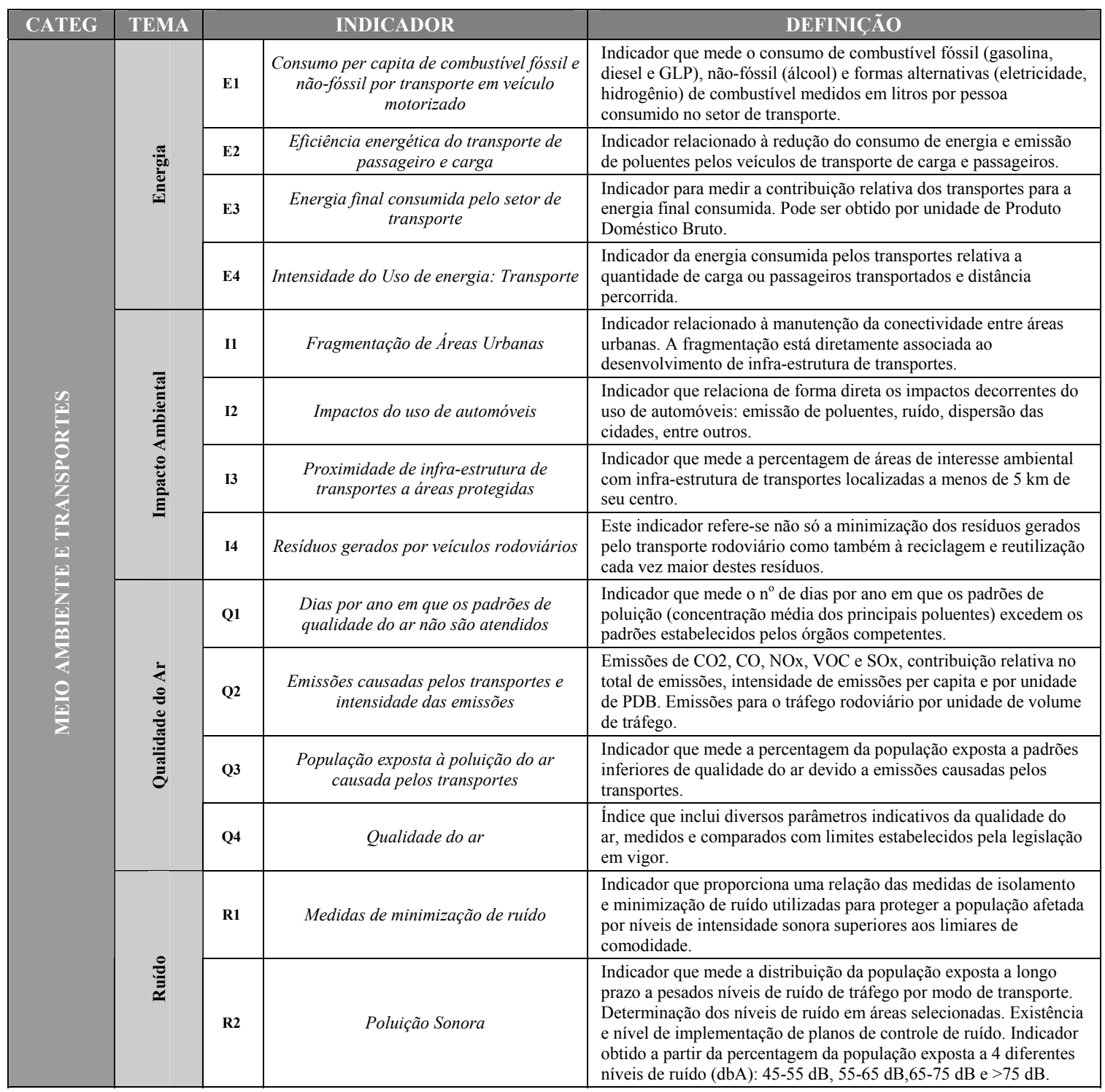




\section{ANEXO 5 - Definição dos Indicadores avaliados no Módulo II (continuação)}

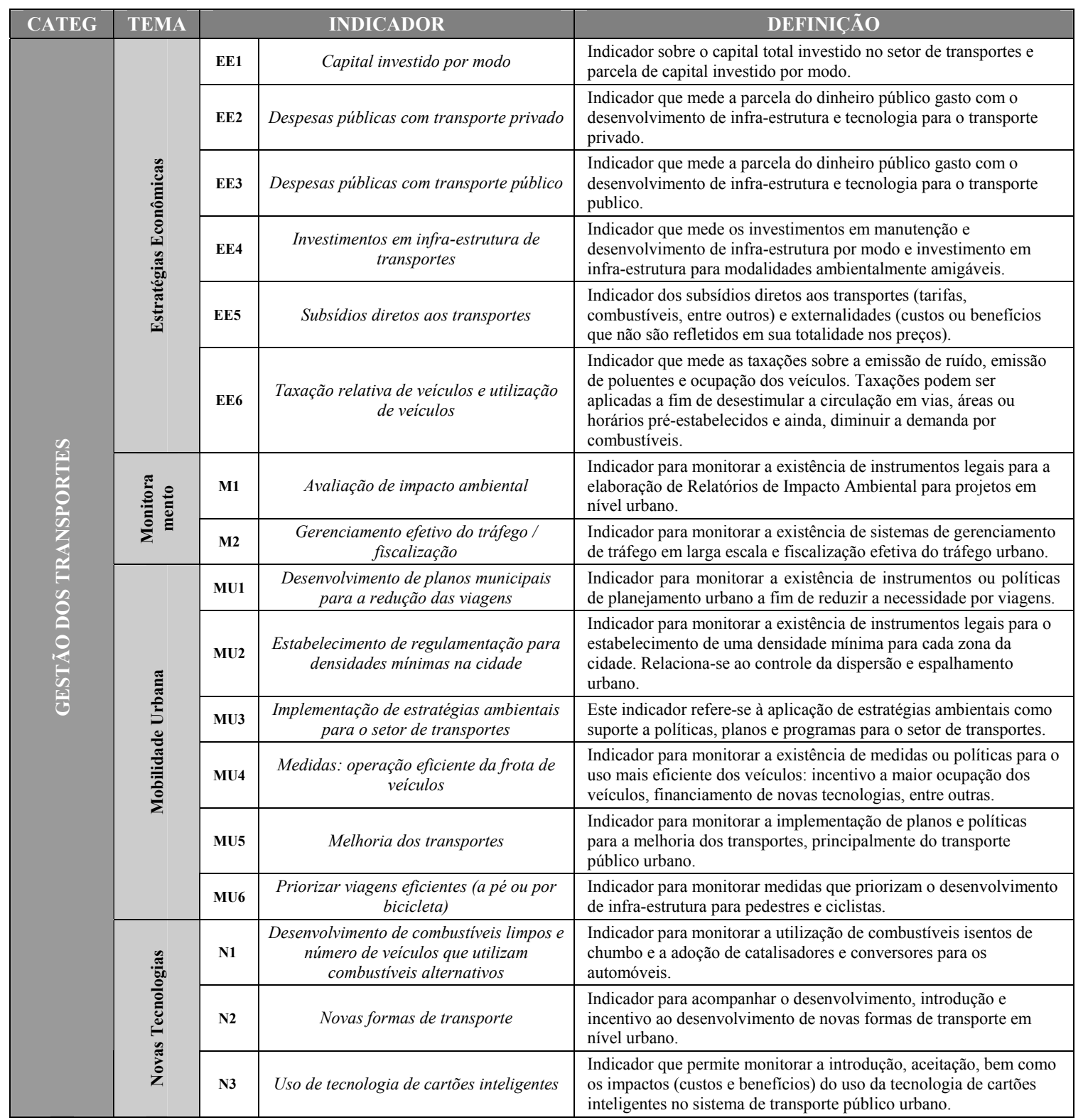




\section{ANEXO 5 - Definição dos Indicadores avaliados no Módulo II (continuação)}

\begin{tabular}{|c|c|c|c|c|}
\hline CATEG & TEMA & \multicolumn{2}{|r|}{ INDICADOR } & DEFINIÇÃO \\
\hline \multirow{22}{*}{ 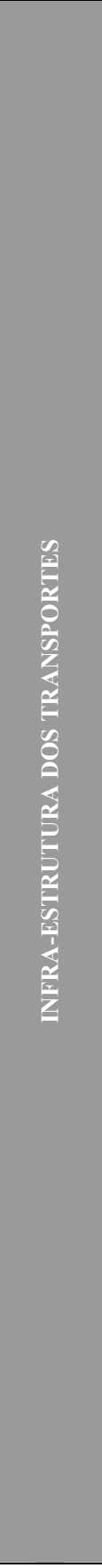 } & \multirow{5}{*}{ 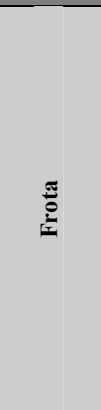 } & F1 & Estrutura da frota de veículos rodoviários & $\begin{array}{l}\text { Indicador que revela a estrutura da frota de veículos por tipo de } \\
\text { veículo (cargas e passageiros) e por tipo de combustível. }\end{array}$ \\
\hline & & F2 & Idade média dos veículos & $\begin{array}{l}\text { Indicador do número médio em anos dos veículos em circulação, } \\
\text { uma vez que a idade dos veículos pode ser indicativa da tecnologia } \\
\text { empregada em sua fabricação. }\end{array}$ \\
\hline & & F3 & $\begin{array}{c}\text { Percentagem da frota municipal } \\
\text { convertida para reduzir a emissão de } \\
\text { poluentes }\end{array}$ & $\begin{array}{l}\text { Indicador medido através da percentagem de veículos convertidos } \\
\text { para a utilização de gás natural, eletricidade ou outra forma } \\
\text { alternativa de energia não poluente. }\end{array}$ \\
\hline & & F4 & $\begin{array}{l}\text { Relação entre veículos com consumo } \\
\text { eficiente de combustivel / veículos com } \\
\text { consumo ineficiente de combustivel }\end{array}$ & $\begin{array}{l}\text { Para o desenvolvimento deste indicador são necessárias } \\
\text { informações sobre a economia de combustíveis e emissões de } \mathrm{CO} 2 \\
\text { por tipo de veículo. }\end{array}$ \\
\hline & & F5 & Veículos em circulação & $\begin{array}{l}\text { Indicador que fornece o número de veículos em circulação na área } \\
\text { urbana. }\end{array}$ \\
\hline & \multirow{8}{*}{ 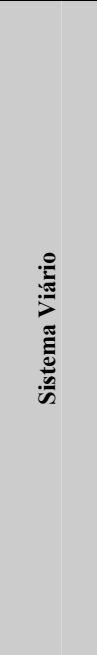 } & S1 & $\begin{array}{c}\text { Capacidade das redes de infra-estrutura } \\
\text { de transportes }\end{array}$ & $\begin{array}{l}\text { Indicador que permite acompanhar a evolução da infra-estrutura de } \\
\text { transporte (para cada modo) em um período determinado. }\end{array}$ \\
\hline & & S2 & Comprimento total das vias para ciclistas & $\begin{array}{l}\text { Este indicador pode ser expresso também como proporção do total } \\
\text { de vias urbanas destinadas aos ciclistas. Constitui uma medida do } \\
\text { incentivo à adoção deste modo de transporte. }\end{array}$ \\
\hline & & S3 & $\begin{array}{l}\text { Desenvolvimento de vias para otimizar o } \\
\text { fluxo de tráfego }\end{array}$ & $\begin{array}{l}\text { Indicador para monitorar o desenvolvimento de novas vias na área } \\
\text { urbana (extensão, tipo, capacidade, volume de tráfego, entre } \\
\text { outros). }\end{array}$ \\
\hline & & S4 & Estrutura da rede viária & Indicador sobre a evolução da rede viária, por tipo de via. \\
\hline & & S5 & $\begin{array}{l}\text { Extensão total das vias designadas para } \\
\text { pedestres }\end{array}$ & $\begin{array}{l}\text { Este indicador pode ser expresso também como proporção do total } \\
\text { de vias urbanas. Relaciona-se à exclusão social, segurança e } \\
\text { conforto dos deslocamentos feitos a pé. }\end{array}$ \\
\hline & & S6 & $\begin{array}{l}\text { Número de estacionamentos para carros } \\
\text { na cidade }\end{array}$ & $\begin{array}{l}\text { Este indicador pode ser expresso também como área de } \\
\text { estacionamento por habitante. }\end{array}$ \\
\hline & & S7 & $\begin{array}{l}\text { Possibilidade de acesso de transporte } \\
\text { coletivo (pavimentação) }\end{array}$ & $\begin{array}{l}\text { Indicador que mede a percentagem ou extensão de vias com } \\
\text { pavimentação adequada para o acesso de veículos de transporte } \\
\text { coletivo. }\end{array}$ \\
\hline & & S8 & $\begin{array}{l}\text { Provisão de infra-estrutura para } \\
\text { moderação de tráfego e vias para } \\
\quad \text { bicicletas e pedestres }\end{array}$ & $\begin{array}{l}\text { Indicador para acompanhar a implementação de medidas de } \\
\text { moderação de tráfego. Estas medidas visam, de um modo geral, à } \\
\text { redução da velocidade dos veículos em vias urbanas, garantindo } \\
\text { maior segurança para pedestres e ciclistas. }\end{array}$ \\
\hline & \multirow{4}{*}{ 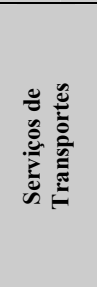 } & ST1 & Mudanças nos modos de transporte & $\begin{array}{l}\text { Indicador relacionado à introdução e utilização de novas formas de } \\
\text { transporte em nível urbano. }\end{array}$ \\
\hline & & ST2 & $\begin{array}{l}\text { Tendências do tráfego rodoviário e } \\
\text { densidades }\end{array}$ & $\begin{array}{l}\text { Indicador que fornece medidas do volume de passageiros e carga } \\
\text { transportados pelo modo rodoviário, densidades e impactos } \\
\text { ambientais. }\end{array}$ \\
\hline & & ST3 & Transporte de carga por modo & $\begin{array}{l}\text { Este indicador permite avaliar se há equilíbrio na divisão modal do } \\
\text { transporte de cargas. }\end{array}$ \\
\hline & & ST4 & $\begin{array}{l}\text { Transporte de passageiros por modo de } \\
\text { transporte }\end{array}$ & $\begin{array}{l}\text { Indicador que mede a intensidade de utilização do transporte de } \\
\text { passageiros por modo de transporte. }\end{array}$ \\
\hline & \multirow{5}{*}{ 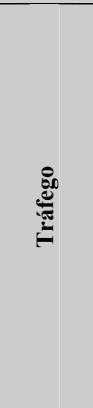 } & T1 & Densidade de tráfego & $\begin{array}{l}\text { Indicador que fornece o número de veículos que ocupam um trecho } \\
\text { de via ou uma via em um instante determinado. }\end{array}$ \\
\hline & & $\mathbf{T} 2$ & Geração de volume de tráfego e tipo & $\begin{array}{l}\text { Indicador para monitorar o volume de tráfego por tipo de veículo na } \\
\text { área urbana. Volume de tráfego é definido como o número de } \\
\text { veículos passando por uma seção de controle durante um intervalo } \\
\text { de tempo. }\end{array}$ \\
\hline & & T3 & $\begin{array}{c}\text { Taxa de ocupação dos veículos de } \\
\text { passageiros }\end{array}$ & $\begin{array}{l}\text { Este indicador permite acompanhar a evolução da taxa de ocupação } \\
\text { dos veículos na área urbana ao longo do tempo. }\end{array}$ \\
\hline & & T4 & Tempo total gasto no tráfego & $\begin{array}{l}\text { Indicador obtido a partir da soma de todos os tempos de viagem } \\
\text { (anuais) dividido por mil habitantes. }\end{array}$ \\
\hline & & T5 & Velocidade de tráfego & $\begin{array}{l}\text { Este indicador pode ser definido pela média aritmética das } \\
\text { velocidades dos veículos individuais ou baseado no tempo } \\
\text { necessário para um veículo percorrer determinada distância. }\end{array}$ \\
\hline
\end{tabular}




\section{ANEXO 5 - Definição dos Indicadores avaliados no Módulo II (continuação)}

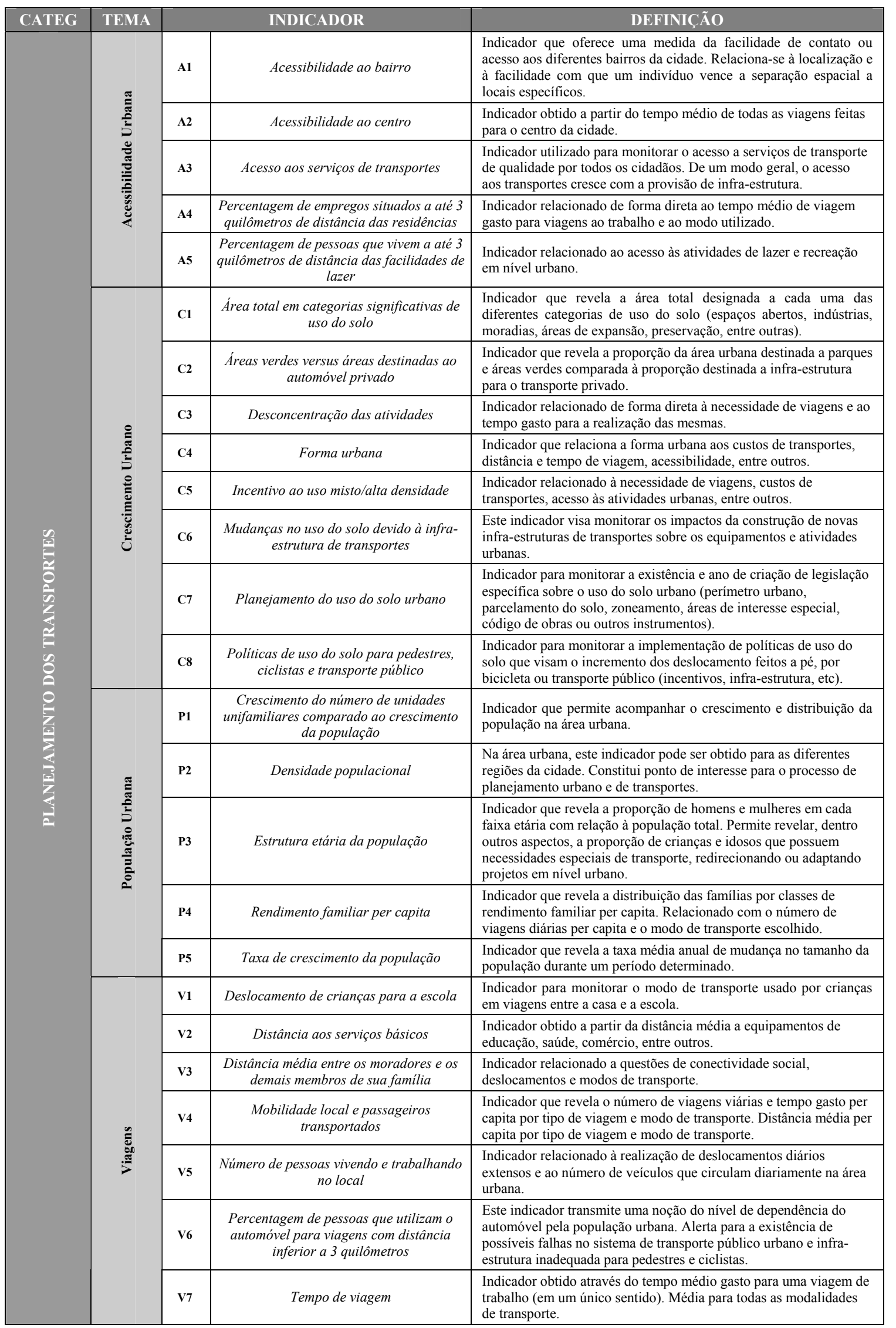


ANEXO 5 - Definição dos Indicadores avaliados no Módulo II (continuação)

\begin{tabular}{|c|c|c|c|c|}
\hline CATEG & TEMA & \multicolumn{2}{|r|}{ INDICADOR } & DEFINIÇÃO \\
\hline \multirow{12}{*}{ 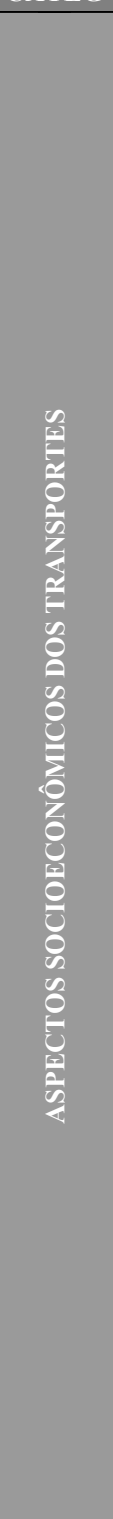 } & \multirow{2}{*}{$\stackrel{气}{\tilde{s}}$} & CT1 & $\begin{array}{l}\text { Custo por passageiro transportado, } \\
\text { corrigido pela inflação }\end{array}$ & $\begin{array}{l}\text { Indicador relacionado à viabilidade econômica e à eficiência dos } \\
\text { diferentes modos de transporte, à qualidade do serviço ofertado, } \\
\text { além dos insumos que compõem os custos de transporte. }\end{array}$ \\
\hline & & CT3 & Preço dos combustiveis e taxas & $\begin{array}{l}\text { O preço dos combustíveis constitui um misto entre preços de } \\
\text { mercado e taxas ditadas pelo governo. Este indicador permite } \\
\text { visualizar a parcela do preço dos combustíveis determinada por } \\
\text { cada um destes fatores. Indicador para monitorar as variações nos } \\
\text { custos do transporte público e privado em um período determinado. }\end{array}$ \\
\hline & & IS1 & Beneficios dos usuários de transportes & $\begin{array}{l}\text { Índice econômico que agrega fatores como custos dos recursos, } \\
\text { externalidades (ruído, emissões, acidentes) além de benefícios } \\
\text { generalizados aos usuários de transportes. }\end{array}$ \\
\hline & $\stackrel{\varrho}{\ddot{\Xi}}$ & IS2 & Custos do congestionamento & $\begin{array}{l}\text { Indicador que revela os prejuízos ambientais, econômicos e sociais } \\
\text { causados pelos congestionamentos de tráfego. }\end{array}$ \\
\hline & & IS4 & $\begin{array}{l}\text { Rendimentos dos operadores de } \\
\text { transportes }\end{array}$ & $\begin{array}{l}\text { Indicador dos benefícios econômicos dos operadores de transporte } \\
\text { urbano. }\end{array}$ \\
\hline & 离 & SV1 & Acidentes fatais de transporte & $\begin{array}{l}\text { Este indicador alerta para a implementação de medidas para a } \\
\text { educação no trânsito, mudanças na legislação, manutenção na rede } \\
\text { viária, entre outros. Ele oferece uma medida da segurança no } \\
\text { trânsito relacionada ao comportamento de motoristas, ciclistas e } \\
\text { pedestres; está relacionado com a segurança e proteção de pedestres } \\
\text { e ciclistas, o que pode revelar uma carência de infra-estrutura para } \\
\text { os deslocamentos feitos a pé ou por bicicleta. }\end{array}$ \\
\hline & $\ddot{\omega}$ & SV2 & Feridos por acidentes de tráfego & $\begin{array}{l}\text { Indicador que fornece o número de indivíduos que tenham sofrido } \\
\text { lesões corporais em acidentes ocorridos na área urbana. }\end{array}$ \\
\hline & & TP1 & Demanda por transporte de passageiros & $\begin{array}{l}\text { Indicador relacionado ao número de passageiros transportados por } \\
\text { quilômetro pelos diferentes modos de transporte (incluindo } \\
\text { automóvel privado) ao Produto Doméstico Bruto. Pode revelar } \\
\text { ligações entre o crescimento econômico e o crescimento no } \\
\text { transporte de passageiros. }\end{array}$ \\
\hline & 产 & TP4 & Necessidade de sistemas de transporte & $\begin{array}{l}\text { Indicador que revela a percentagem de domicílios que não possuem } \\
\text { meios de transporte próprios. }\end{array}$ \\
\hline & 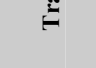 & TP5 & $\begin{array}{l}\text { Nivel de serviço do transporte público e } \\
\text { modalidades lentas }\end{array}$ & $\begin{array}{l}\text { Indicador relacionado à freqüência de atendimento do transporte } \\
\text { público e ao tempo de viagem. }\end{array}$ \\
\hline & & TP6 & $\begin{array}{l}\text { Percentagem de pessoas que consideram o } \\
\text { transporte público inseguro }\end{array}$ & $\begin{array}{l}\text { Indicador que fornece uma medida da segurança e confiabilidade, } \\
\text { que pode estar intimamente ligada à demanda por transporte } \\
\text { público. }\end{array}$ \\
\hline & & TP7 & $\begin{array}{l}\text { Percentagem de pessoas que escolhem o } \\
\text { transporte público em detrimento ao carro }\end{array}$ & $\begin{array}{l}\text { Indicador associado ao conforto, segurança e disponibilidade de } \\
\text { transporte público de passageiros. }\end{array}$ \\
\hline
\end{tabular}




\section{Proposta de Lei referente à Mobilidade inserida no PDM}

Art. 251. O Plano Diretor de Transporte e de Mobilidade deverá contemplar os seguintes princípios:

I - acessibilidade urbana como um direito universal;

II - garantia de acesso dos cidadãos ao transporte coletivo urbano;

III - desenvolvimento sustentável do município;

IV - eficiência e eficácia na prestação dos serviços de transporte urbano;

V - transparência e participação social no planejamento, controle e avaliação da política de mobilidade urbana;

VI - justa distribuição dos benefícios e ônus decorrentes do uso dos diferentes modos de transporte urbano;

VII - equidade no uso do espaço público de circulação, vias e logradouros;

VIII - garantir a diversidade das modalidades de transporte, respeitando as características dos setores, priorizando o transporte coletivo, que é estruturante, sobre o individual, os modos não-motorizados, em especial as ciclovias e a valorização, conforto e segurança do pedestre;

IX - garantir a mobilidade inclusiva, como direito básico de todo cidadão;

$\mathrm{X}$ - implantar a gestão de Mobilidade, de forma sistêmica entre transporte, planejamento urbano de uso e ocupação do solo e sistema viário. A gestão deve ser integrada ao Plano Diretor Municipal e aos Planos de Setoriais;

$\mathrm{XI}$ - contemplar a mobilidade e transporte regional, desenvolvendo as características logísticas existentes;

XII - garantir o controle da expansão urbana, a universalização do acesso à cidade, a melhoria da qualidade ambiental, e o controle dos impactos no sistema de mobilidade gerados pela ordenação do uso do solo; XIII- proteger e preservar o meio ambiente com políticas redutoras dos níveis de poluição do ar e sonora;

Art. 253. O município elaborará o Plano Diretor de Transporte e de Mobilidade Urbana-com visão de futuro, que proporcione qualidade de vida a população e seja sustentável ambiental e economicamente.

$\S 1^{\circ}$. O prazo para elaboração do Plano será de 1 ano a partir da aprovação desta Lei, com o objetivo de integrar o planejamento de uso e ocupação do solo, sistema viário e transporte coletivo, respeitando o princípio da gestão participativa.

$\S 2^{\circ}$. O Plano Diretor de Transporte e Mobilidade Urbana deverá ser realizado através da participação da comunidade, com a supervisão e gerenciamento de uma equipe multidisciplinar que envolvam técnicos do Poder Público e Universidade.

Art. 254. O Plano de Transporte e de Mobilidade Urbana deverá contemplar no mínimo:

I - o transporte coletivo urbano;

II - a circulação viária e de orientação de tráfego, priorizando o transporte coletivo e o não-motorizado;

III - a circulação de pedestres e ciclistas;

IV - elaboração de um plano de acessibilidade para o Município que inclua diretrizes para eliminação de barreiras arquitetônicas na cidade.

$\mathrm{V}$ - as infra-estruturas de integração de duas ou mais modalidades de transporte;

VI - justa distribuição dos benefícios e ônus decorrentes do uso dos diferentes modos de transporte urbano; VII - equidade no uso do espaço público de circulação, vias e logradouros.

Art.255. Deverá ser elaborado Plano de Mobilidade e Acessibilidade para a zona rural que leve em conta suas características.

\section{Fonte: Projeto de Lei do Plano Diretor Municipal - Bauru.}


ANEXO 7 - Coeficiente de correlação de concordância de Kendall para as Categorias Módulo I

- Etapa 1 - Cálculo dos pesos por avaliador

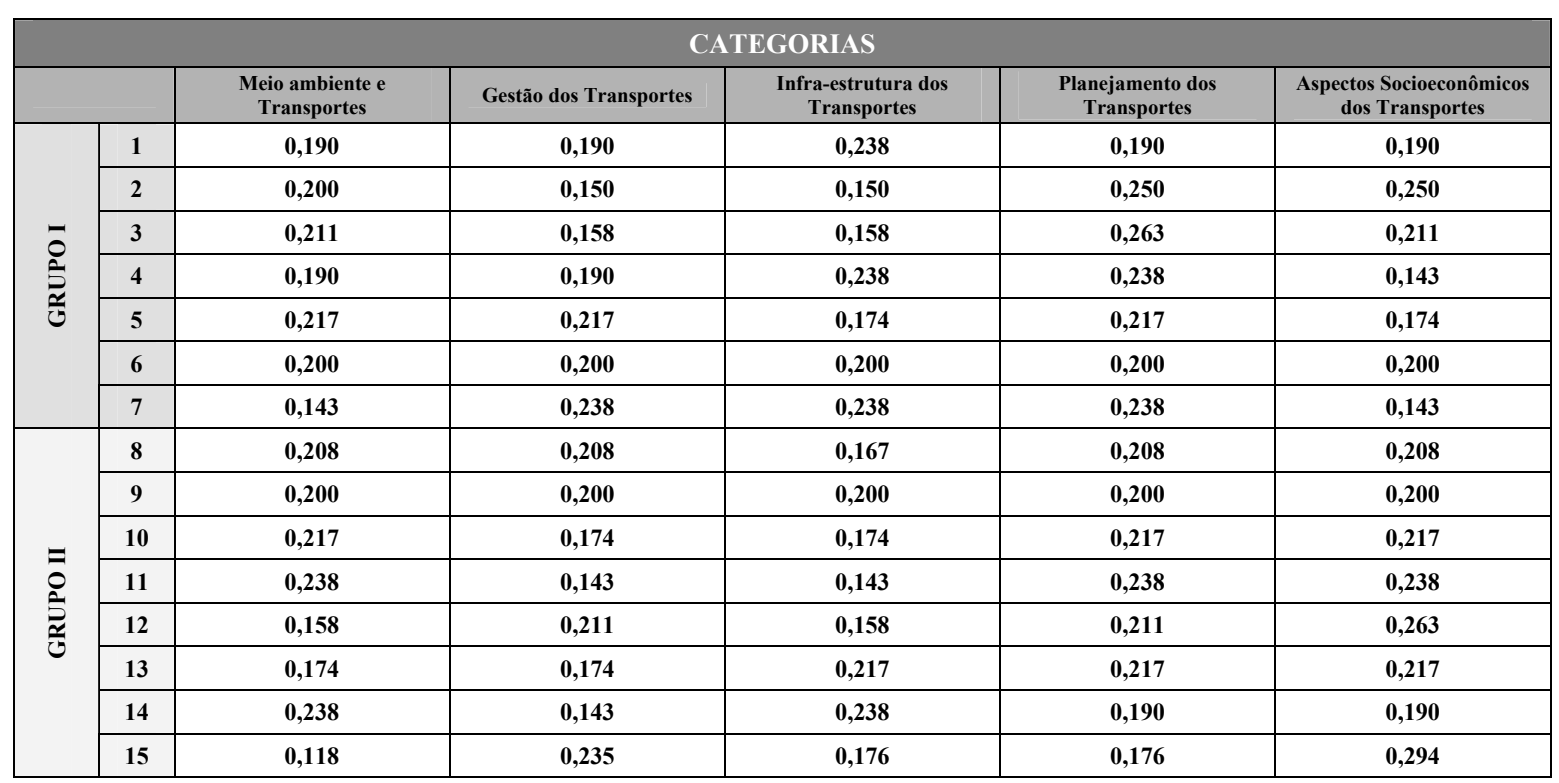

- Etapa 2 - Cálculo do ordenamento dos pesos por avaliador

\begin{tabular}{|c|c|c|c|c|c|c|}
\hline \multicolumn{7}{|c|}{ CATEGORIAS } \\
\hline & & $\begin{array}{l}\text { Meio ambiente e } \\
\text { Transportes }\end{array}$ & Gestão dos Transportes & $\begin{array}{l}\text { Infra-estrutura dos } \\
\text { Transportes }\end{array}$ & $\begin{array}{l}\text { Planejamento dos } \\
\text { Transportes }\end{array}$ & $\begin{array}{l}\text { Aspectos Socioeconômicos } \\
\text { dos Transportes }\end{array}$ \\
\hline \multirow{7}{*}{$\begin{array}{l}\overline{0} \\
\text { S: } \\
\text { ثئ }\end{array}$} & 1 & 1 & 1 & 5 & 1 & 1 \\
\hline & 2 & 3 & 1 & 1 & 4 & 4 \\
\hline & 3 & 3 & 2 & 1 & 5 & 3 \\
\hline & 4 & 2 & 2 & 4 & 4 & 1 \\
\hline & 5 & 3 & 4 & 1 & 4 & 1 \\
\hline & 6 & 1 & 1 & 1 & 1 & 1 \\
\hline & 7 & 1 & 3 & 3 & 3 & 1 \\
\hline \multirow{8}{*}{$\begin{array}{l}\text { = } \\
\text { 岇 } \\
\text { 원 }\end{array}$} & 8 & 2 & 2 & 1 & 2 & 2 \\
\hline & 9 & 1 & 1 & 1 & 1 & 1 \\
\hline & 10 & 3 & 1 & 1 & 3 & 3 \\
\hline & 11 & 3 & 1 & 1 & 3 & 3 \\
\hline & 12 & 1 & 3 & 1 & 3 & 5 \\
\hline & 13 & 1 & 1 & 3 & 3 & 3 \\
\hline & 14 & 4 & 1 & 4 & 2 & 2 \\
\hline & 15 & 1 & 4 & 2 & 2 & 5 \\
\hline \multicolumn{7}{|c|}{ Coeficiente de Correlação de Kendall (w) } \\
\hline & & Meio ambiente e Transportes & Gestão dos Transportes & $\begin{array}{l}\text { Infra-estrutura dos } \\
\text { Transportes }\end{array}$ & $\begin{array}{l}\text { Planejamento dos } \\
\text { Transportes }\end{array}$ & $\begin{array}{l}\text { Aspectos Socioeconômicos } \\
\text { dos Transportes }\end{array}$ \\
\hline \multicolumn{2}{|c|}{ GRUPO I } & \multicolumn{5}{|c|}{0,203} \\
\hline \multicolumn{2}{|c|}{ GRUPO II } & \multicolumn{5}{|c|}{0,264} \\
\hline
\end{tabular}


- Etapa 3 - Cálculo dos empates dos ordenamentos dos pesos por avaliador e cálculo do Índice de Correlação de Concordância de Kendall (w)

\begin{tabular}{|c|c|c|c|c|c|c|}
\hline \multicolumn{7}{|c|}{$\overline{\text { CATEGORIAS }}$} \\
\hline & & $\begin{array}{l}\text { Meio ambiente e } \\
\text { Transportes }\end{array}$ & Gestão dos Transportes & $\begin{array}{l}\text { Infra-estrutura dos } \\
\text { Transportes }\end{array}$ & $\begin{array}{l}\text { Planejamento dos } \\
\text { Transportes }\end{array}$ & $\begin{array}{c}\text { Aspectos Socioeconômicos } \\
\text { dos Transportes }\end{array}$ \\
\hline \multirow{7}{*}{ 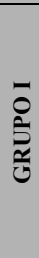 } & 1 & 2,5 & 2,5 & 5 & 2,5 & 2,5 \\
\hline & 2 & 3 & 1,5 & 1,5 & 4,5 & 4,5 \\
\hline & 3 & 3,5 & 2 & 1 & 5 & 3,5 \\
\hline & 4 & 2 & 2 & 4,5 & 4,5 & 1 \\
\hline & 5 & 3 & 4,5 & 1,5 & 4,5 & 1,5 \\
\hline & 6 & 3 & 3 & 3 & 3 & 3 \\
\hline & 7 & 1,5 & 4 & 4 & 4 & 1,5 \\
\hline \multicolumn{2}{|c|}{ RJ } & 18,500 & 19,500 & 20,500 & 28,000 & 17,500 \\
\hline \multicolumn{2}{|c|}{ ordem } & 3,7 & 3,9 & 4,1 & 5,6 & 3,5 \\
\hline \multicolumn{2}{|c|}{ Média } & 20,800 & & & & \\
\hline \multicolumn{2}{|c|}{$\mathbf{S}$} & 69,800 & & & & \\
\hline \multicolumn{2}{|c|}{$\overline{\mathbf{w}}$} & 0,203 & & & & \\
\hline
\end{tabular}

- Etapa 4 - Cálculo dos fatores de correção para os empates referentes ao ordenamento dos especialistas - Grupo I

\begin{tabular}{|c|c|c|}
\hline $\mathrm{T}$ & \multicolumn{2}{|c|}{ Empates } \\
\hline $\mathrm{T} 1$ & $1(4)$ & 5,0 \\
\hline $\mathrm{T} 2$ & $2(2)$ & 1,0 \\
\hline $\mathrm{T} 3$ & 1(1) & 0,5 \\
\hline $\mathrm{T} 4$ & $2(2)$ & 1,0 \\
\hline T5 & $2(2)$ & 1,0 \\
\hline T6 & $1(5)$ & 10,0 \\
\hline $\mathrm{T} 7$ & $1(2)+1(3)$ & 2,5 \\
\hline \multicolumn{2}{|c|}{ Soma $(\mathrm{T})$} & 21,00 \\
\hline
\end{tabular}

\section{- Equação referente ao fator de Correção para cada avaliador}

$$
\mathbf{T}=\left(\mathbf{t}^{\wedge} \mathbf{3 - t}\right) / \mathbf{1 2}
$$

(Equação 7.1)

Sendo: $\mathrm{t}$ - número de empates 
ANEXO 8 - Coeficiente de Correlação de Kendall para as Categorias

- Etapa 1 - Cálculo dos pesos por grupo de avaliação.

\begin{tabular}{|c|c|c|c|c|c|}
\hline \multicolumn{7}{|c|}{ MÉTODO DE CORRELAÇÃO DE POSTOS DE KENDALL - CATEGORIAS } \\
\hline & $\begin{array}{c}\text { Meio Ambiente e } \\
\text { Transportes }\end{array}$ & $\begin{array}{c}\text { Gestão dos } \\
\text { Transportes }\end{array}$ & $\begin{array}{c}\text { Infra-estrutura dos } \\
\text { Transportes }\end{array}$ & $\begin{array}{c}\text { Planejamento dos } \\
\text { Transportes }\end{array}$ & $\begin{array}{c}\text { Aspectos } \\
\text { Socioeconômicos dos } \\
\text { Transportes }\end{array}$ \\
\hline ORDEM GRUPO I & $\mathbf{0 , 1 9 3}$ & $\mathbf{0 , 1 9 2}$ & $\mathbf{0 , 1 9 9}$ & $\mathbf{0 , 2 2 8}$ & $\mathbf{0 , 1 8 7}$ \\
\hline ORDEM GRUPO II & $\mathbf{0 , 1 9 4}$ & $\mathbf{0 , 1 8 6}$ & $\mathbf{0 , 1 8 4}$ & $\mathbf{0 , 2 0 7}$ & $\mathbf{0 , 2 2 9}$ \\
\hline
\end{tabular}

- Etapa 2 - Ordenamento dos critérios em função dos pesos finais.

\begin{tabular}{|c|c|c|c|c|c|}
\hline & $\begin{array}{c}\text { MÉTODO DE CORRELAÇÃO DE POSTOS DE KENDALL - CATEGORIAS } \\
\text { Meio Ambiente e } \\
\text { Transportes }\end{array}$ & $\begin{array}{c}\text { Gestão dos } \\
\text { Transportes }\end{array}$ & $\begin{array}{c}\text { Infra-estrutura dos } \\
\text { Transportes }\end{array}$ & $\begin{array}{c}\text { Planejamento dos } \\
\text { Transportes }\end{array}$ & $\begin{array}{c}\text { Aspectos } \\
\text { Socioeconômicos dos } \\
\text { Transportes }\end{array}$ \\
\hline ORDEM GRUPO I & $\mathbf{3}$ & $\mathbf{4}$ & $\mathbf{2}$ & $\mathbf{1}$ & $\mathbf{5}$ \\
\hline ORDEM GRUPO II & $\mathbf{3}$ & $\mathbf{4}$ & $\mathbf{5}$ & $\mathbf{2}$ & $\mathbf{1}$ \\
\hline
\end{tabular}

- Etapa 3 - Ordenamento do Grupo I - ordem crescente.

\begin{tabular}{|c|c|c|c|c|c|}
\hline \multirow{2}{*}{} & A & B & C & D & E \\
\cline { 2 - 6 } & $\begin{array}{c}\text { Planejamento dos } \\
\text { Transportes }\end{array}$ & $\begin{array}{c}\text { Infra-estrutura } \\
\text { dos Transportes }\end{array}$ & $\begin{array}{c}\text { Meio Ambiente e } \\
\text { Transportes }\end{array}$ & $\begin{array}{c}\text { Gestão dos } \\
\text { Transportes }\end{array}$ & $\begin{array}{c}\text { Aspectos } \\
\text { Socioeconômicos } \\
\text { dos Transportes }\end{array}$ \\
\hline ORDEM GRUPO I & $\mathbf{1}$ & $\mathbf{2}$ & $\mathbf{3}$ & $\mathbf{4}$ & $\mathbf{5}$ \\
\hline ORDEM GRUPO II & $\mathbf{2}$ & $\mathbf{5}$ & $\mathbf{3}$ & $\mathbf{4}$ & $\mathbf{1}$ \\
\hline
\end{tabular}

- Etapa 4 - Cálculo dos pares para cada Grupo segundo as condições a seguir:

- Condição I (X) - se “A” for maior que "B" o resultado é negativo (-1), caso contrário o valor é positivo.

- Condição II (Y) - se "A" for maior que "B" o resultado é negativo (-1), caso contrário o valor é positivo.

- Cálculo do produto entre os dois grupos

\begin{tabular}{|c|c|c|c|c|c|}
\hline & $(\mathrm{A}, \mathrm{B})$ & $(\mathrm{A}, \mathrm{C})$ & $(\mathbf{A}, \mathbf{D})$ & $(\mathbf{A}, \mathbf{E})$ & \\
\hline $\mathbf{X}$ & 1 & 1 & 1 & 1 & \\
\hline $\mathbf{Y}$ & 1 & 1 & 1 & -1 & \\
\hline Produtos & 1 & 1 & 1 & -1 & $\Sigma S_{A}=2$ \\
\hline
\end{tabular}

- Observação: A Tabela apresenta a combinação somente para os pares de A. Posteriormente, foram realizadas as combinações para os pares: B (B,C; B,D e B,E), C (C,D; C,E) e D (D,E). 
- Etapa 5 - Cálculo do "S"

- Sendo: $\mathrm{S}=$ Somatória dos produtos em relação a todos os pares de critérios.

- $\mathrm{S}=\Sigma \mathbf{S}_{\mathrm{A}}+\mathrm{S}_{\mathrm{B}}+\mathrm{S}_{\mathrm{C}}+\mathrm{S}_{\mathrm{D}}$

- $\mathbf{S}=\mathbf{- 2}$

- Etapa 6 - Cálculo dos empates referentes aos Grupos I e II
- $T \mathbf{x}_{(\text {GRUPO I })}=1 / 2 * t(t-1)$
(Equação 8.1)
- $\mathrm{Ty}_{(\text {GRUPO II })}=1 / 2 * \mathrm{t}(\mathrm{t}-1)$
(Equação 8.2)

Sendo: $\mathrm{t}$ (Tx) - número de observações empatadas na variável X (técnicos).

$\mathrm{t}$ (Ty) - número de observações empatadas na variável Y (comunidade).

OBS: Como não há empates no ordenamento entre cada grupo individualmente, $\mathbf{T} \mathbf{x}=\mathbf{0}$ e $\mathbf{T y}=\mathbf{0}$.

- Etapa 7 - Cálculo do índice de correlação de Postos de Kendall

- $\tau=2 \mathrm{~S} / \mathrm{n} *(\mathrm{n}-1)$

(Equação 8.3)

- Sendo: $\mathrm{n}=$ número total de critérios (técnico e comunidade)

- $\boldsymbol{\tau}=\mathbf{- 0 , 2 0 0}$ - Correlação negativa

\begin{tabular}{|c|c|c|c|c|c|}
\hline \multirow[t]{2}{*}{ CATEGORIAS } & \multicolumn{2}{|c|}{$\begin{array}{c}\text { PESOS } \\
\text { (peso médio por } \\
\text { grupo) }\end{array}$} & \multicolumn{2}{|c|}{$\begin{array}{l}\text { RANKING } \\
\text { (Ordenamento) }\end{array}$} & \multirow[t]{2}{*}{$\begin{array}{l}\text { COEFICIENTE DE } \\
\text { KENDALL }(\tau)\end{array}$} \\
\hline & GRUPO I & GRUPO II & GRUPO I & GRUPO II & \\
\hline Meio ambiente e Transportes & 0,193 & 0,194 & 3 & 3 & \multirow{5}{*}{ - 0,200 } \\
\hline Gestão dos Transportes & 0,192 & 0,186 & 4 & 4 & \\
\hline Infra-estrutura dos Transportes & 0,199 & 0,184 & 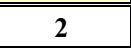 & 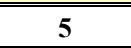 & \\
\hline Planejamento dos Transportes & 0,228 & $\mathbf{0 , 2 0 7}$ & 1 & 2 & \\
\hline Aspectos Socioeconômicos dos Transportes & 0,187 & 0,229 & 5 & 1 & \\
\hline
\end{tabular}


ANEXO 9 - Relação dos Problemas e Soluções avaliados no Módulo III

\begin{tabular}{|c|c|c|c|c|c|c|}
\hline \multicolumn{7}{|c|}{ PROBLEMAS E SOLUÇÕES } \\
\hline \multirow[b]{2}{*}{ CATEG. } & \multirow{2}{*}{ TEMA } & \multirow{2}{*}{ IND } & \multicolumn{2}{|c|}{ FORNECIDO PELO SISTEMA } & \multicolumn{2}{|c|}{ INSERIDO PELO USUÁRIO } \\
\hline & & & PROBLEMAS & SOLUÇÕES & PROBLEMAS & SOLUÇÕES \\
\hline \multirow{9}{*}{ 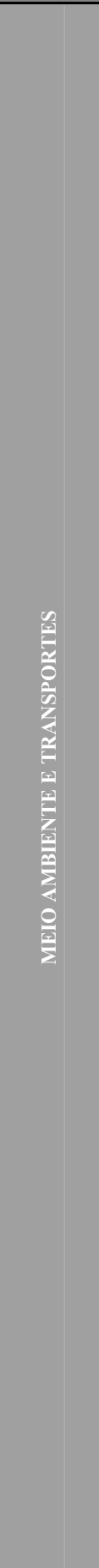 } & \multirow[t]{2}{*}{ Energia } & E1 & $\begin{array}{l}\text { - Aumento na poluição do ar. } \\
\text { - Consumo excessivo de } \\
\text { energia não renovável. }\end{array}$ & $\begin{array}{l}\text { - Incentivo a utilização de } \\
\text { combustiveis não poluentes. } \\
\text { - Redução do número de } \\
\text { viagens por transporte } \\
\text { individual. } \\
\text { - Pesquisas sobre novas } \\
\text { formas de transportes } \\
\text { "limpos". }\end{array}$ & $\begin{array}{l}\text { - Aumento/diminuição dos } \\
\text { gastos pessoais em função da } \\
\text { variação do preço do } \\
\text { combustivel. } \\
\text { - Variação do preço do } \\
\text { combustivel em função do } \\
\text { consumo. } \\
\text { - Comprometimento do } \\
\text { orçamento familiar. }\end{array}$ & $\begin{array}{l}\text { - Incentivar a população a } \\
\text { utilizar transporte público. } \\
\text { - Tomar medidas para reduzir } \\
\text { o valor da tarifa do transporte } \\
\text { público. } \\
\text { - Priorização do transporte } \\
\text { coletivo. } \\
\text { - Medidas de planejamento } \\
\text { urbano, visando a redução de } \\
\text { distâncias de transporte (por } \\
\text { exemplo, entre residência e } \\
\text { trabalho). }\end{array}$ \\
\hline & & $\mathbf{E 2}$ & $\begin{array}{l}\text { - Aumento no consumo de } \\
\text { combustível. } \\
\text { - Alteração no clima da } \\
\text { cidade. }\end{array}$ & $\begin{array}{l}\text { - Utilização de Transporte } \\
\text { Público. } \\
\text { - Renovação da frota. } \\
\text { - Redução do número de } \\
\text { viagens por transporte } \\
\text { individual. }\end{array}$ & - Aumento do nível de ruído. & $\begin{array}{l}\text { - Aumentar quantidade de } \\
\text { ciclovias e viagens a pé. }\end{array}$ \\
\hline & \multirow[t]{2}{*}{$\begin{array}{c}\text { Impacto } \\
\text { Ambiental }\end{array}$} & I1 & \begin{tabular}{|l|} 
- Aumento nas distâncias \\
percorridas por falta de \\
conexão das áreas urbanas. \\
- Aumento nos gastos com a \\
infra-estrutura de transportes. \\
- Aumento nos gastos com \\
transporte público. \\
Barreira física entre a \\
população da cidade. \\
(segregação espacial) \\
\end{tabular} & $\begin{array}{l}\text { - Cidades compactas. } \\
\text { - Urbanizacão de vazios } \\
\text { urbanos na cidade. }\end{array}$ & - & 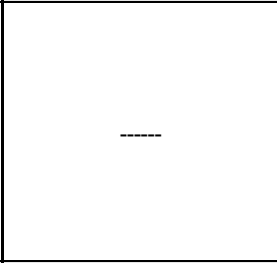 \\
\hline & & 12 & $\begin{array}{l}\text { - Aumento na poluição do ar. } \\
\text { - Aumento na poluição sonora. } \\
\text { - Aumento no custo dos } \\
\text { combustíveis. } \\
\text { - Aumento no gasto com infra- } \\
\text { estrutura de transportes } \\
\text { associadas ao transporte } \\
\text { individual (automóvel). }\end{array}$ & $\begin{array}{l}\text { - Incentivo a utilização de } \\
\text { transportes coletivos. } \\
\text { - Incentivo ao uso de outros } \\
\text { meios de transporte não } \\
\text { poluentes como a pé e } \\
\text { bicicleta. }\end{array}$ & - Congestionamentos. & $\begin{array}{l}\text { - Aumentar os trechos de } \\
\text { ciclovias. }\end{array}$ \\
\hline & \multirow{3}{*}{ Qualidade do Ar } & Q2 & $\begin{array}{l}\text { - Aumento na poluição do ar. } \\
\text { - Problemas de saúde. } \\
\text { - Corrosão de edificações e } \\
\text { estruturas. } \\
\text { Aumento da temperatura da } \\
\text { Terra. }\end{array}$ & $\begin{array}{l}\text { - Redução da emissão de } \\
\text { poluentes pelos automóveis. } \\
\text { - Utilização de catalisadores. } \\
\text { - Incentivo a troca de } \\
\text { automóveis mais novos. } \\
\text { Redução da \% de enxofre nos } \\
\text { combustíveis. }\end{array}$ & -.-- & $\begin{array}{l}\text { Incentivo a utilização de } \\
\text { transporte coletivo }\end{array}$ \\
\hline & & Q3 & $\begin{array}{l}\text { Problemas de saúde. } \\
\text { Alta concentração de } \\
\text { poluentes como CO2, CO, } \\
\text { NOx, VOC e SOx. }\end{array}$ & $\begin{array}{l}\text { - Redução da emissão de } \\
\text { poluentes pelos automóveis. } \\
\text { - Utilização da catalisadores. } \\
\text { - Incentivo a troca de } \\
\text { automóveis mais novos. } \\
\text { - Monitoração da poluição do } \\
\text { ar em pontos estratégicos na } \\
\text { cidade. }\end{array}$ & -ב-ב- & --- \\
\hline & & Q4 & $\begin{array}{l}\text { - Problemas de saúde - } \\
\text { problemas respiratórios. } \\
\text { - Problemas ambientais. }\end{array}$ & $\begin{array}{l}\text { - Redução da emissão de } \\
\text { poluentes pelos automóveis. } \\
\text { - Utilização da catalisadores. } \\
\text { - Incentivo a troca de } \\
\text { automóveis mais novos. } \\
\text { - Monitoração da poluição do } \\
\text { ar em pontos estratégicos na } \\
\text { cidade. }\end{array}$ & $\begin{array}{l}\text { - Consumo de energia com } \\
\text { purificação do ar, por } \\
\text { exemplo, em sistemas de } \\
\text { condicionamento de ar. } \\
\text { - Aumento de queimadas nos } \\
\text { vazios urbanos. }\end{array}$ & $\begin{array}{l}\text { - Incentivo à utilização de } \\
\text { meios não motorizados. } \\
\text { - Campanhas de } \\
\text { conscientização da } \\
\text { população. }\end{array}$ \\
\hline & \multirow{2}{*}{ Ruído } & R1 & \begin{tabular}{|l|} 
- Problemas de audição. \\
- Irritabilidade. \\
- Problemas de saúde. \\
- Prejuízo ao desenvolvimento \\
de atividades humanas.
\end{tabular} & $\begin{array}{l}\text { - Incentivo a troca de veículos } \\
\text { mais novos. } \\
\text { - Educação no trânsito. } \\
\text { Criação de barreiras sonoras } \\
\text { em vias de tráfego intenso. }\end{array}$ & --- & $\begin{array}{l}\text { - Utilização de transporte } \\
\text { coletivo movido a energia } \\
\text { elétrica. }\end{array}$ \\
\hline & & $\mathbf{R 2}$ & $\begin{array}{l}\text { - Problemas de audição. } \\
\text { - Irritabilidade. } \\
\text { - Perda de concentração. } \\
\text { - Prejuízo ao desenvolvimento } \\
\text { de atividades humanas. }\end{array}$ & $\begin{array}{l}\text { - Monitoramento e controle } \\
\text { dos ruídos gerados pelo } \\
\text { sistema de transporte. } \\
\text { - Programa para compra de } \\
\text { veículos mais novos. }\end{array}$ & $\begin{array}{l}\text { - Aumento de despesa com } \\
\text { isolamento acústico dos } \\
\text { ambientes. }\end{array}$ & ---- \\
\hline
\end{tabular}


ANEXO 9 - Relação dos Problemas e Soluções avaliados no Módulo III (continuação)

\begin{tabular}{|c|c|c|c|c|c|c|}
\hline \multicolumn{7}{|c|}{ PROBLEMAS E SOLUÇÕES } \\
\hline \multirow[b]{2}{*}{ CATEG. } & \multirow{2}{*}{ TEMA } & \multirow{2}{*}{ IND } & \multicolumn{2}{|c|}{ FORNECIDO PELO SISTEMA } & \multicolumn{2}{|c|}{ INSERIDO PELO USUÁRIO } \\
\hline & & & PROBLEMAS & SOLUÇÕES & PROBLEMAS & SOLUÇÕES \\
\hline \multirow{8}{*}{ 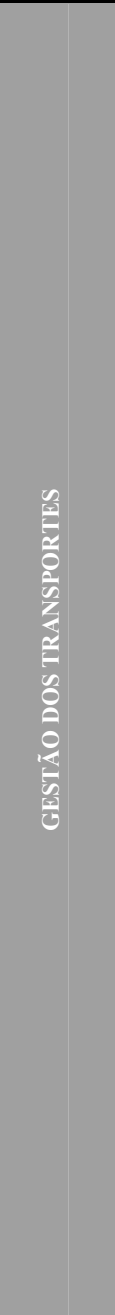 } & \multirow[b]{2}{*}{$\begin{array}{l}\text { Estratégias } \\
\text { Econômicas }\end{array}$} & EE3 & $\begin{array}{l}\text { - Falta de investimento } \\
\text { público. }\end{array}$ & ----- & $\begin{array}{l}\text { - Descontinuidade entre } \\
\text { gestôes de governo. } \\
\text { - Existência de vazios urbanos. }\end{array}$ & $\begin{array}{l}\text { Planejamento contínuo } \\
\text { independente de governo. }\end{array}$ \\
\hline & & EE4 & $\begin{array}{l}\text { - Falta de manutenção do } \\
\text { sistema viário. } \\
\text { - Falta de vias urbanas em } \\
\text { determinados bairros da } \\
\text { cidade. } \\
\text { - Falta de ciclovias. } \\
\text { - Falta de calçadas. }\end{array}$ & $\begin{array}{l}\text { - Implantar uma política de } \\
\text { manutenção da infra- } \\
\text { estrutura atual (sistema } \\
\text { viário, calçadas e ciclovias). } \\
\text { - Construção de ciclovias e } \\
\text { calçadas de acordo com as } \\
\text { normas de acessibilidade. }\end{array}$ & - & $\begin{array}{l}\text { Priorização de vias para } \\
\text { transporte coletivo. } \\
\text { Implantar política de } \\
\text { investimento em outros } \\
\text { modos de transportes } \\
\text { coletivos. } \\
\text { - Implantar novas vias de } \\
\text { interligação de bairros para } \\
\text { transposição das barreiras } \\
\text { fisicas. } \\
\text { - Investimentos em } \\
\text { planejamento de transportes. }\end{array}$ \\
\hline & \multirow[t]{2}{*}{ Monitoramento } & M1 & $\begin{array}{l}\text { - Comprometimento com o } \\
\text { meio ambiente. } \\
\text { - Aumento do ruído. } \\
\text { Aumento da poluição do ar. }\end{array}$ & \begin{tabular}{|l} 
- Criação de legislação que \\
institua a obrigação de \\
elaboração de Relatório de \\
Impacto Ambiental para \\
projetos urbanos.
\end{tabular} & --- & - Lei de zoneamento adequada. \\
\hline & & M2 & $\begin{array}{l}\text { Acidentes de trânsito. } \\
\text { Congestionamento urbano. }\end{array}$ & $\begin{array}{l}\text { - Criação de normas para } \\
\text { gerenciamento do tráfego na } \\
\text { cidade. }\end{array}$ & $\begin{array}{l}\text { - Deficiência na mobilidade } \\
\text { urbana, causando } \\
\text { insatisfação da população. }\end{array}$ & --- \\
\hline & \multirow[b]{2}{*}{$\begin{array}{c}\text { Mobilidade } \\
\text { Urbana }\end{array}$} & MU1 & $\begin{array}{l}\text { - Falta de comunicação } \\
\text { (ligação) entre as diversas } \\
\text { regiôes (bairros) da cidade. } \\
\text { - Falta de transporte público } \\
\text { integrado com outros } \\
\text { sistemas. }\end{array}$ & $\begin{array}{l}\text { - Re-organização das linhas de } \\
\text { transporte público. } \\
\text { - Definição de uma política de } \\
\text { uso do solo urbano. }\end{array}$ & --.- & $\begin{array}{l}\text { - Legislação de uso e ocupação } \\
\text { do dolo adequadas. } \\
\text { - Implantação de obras de } \\
\text { interligação de bairros. }\end{array}$ \\
\hline & & MU6 & $\begin{array}{l}\text { - Calçadas fora de padrões de } \\
\text { acessibilidade. } \\
\text { - Falta de vias para ciclistas. } \\
\text { - Aumento no número de } \\
\text { ciclistas no trânsito. } \\
\text { - Aumento no número de } \\
\text { acidentes de trânsito. }\end{array}$ & --- & --- & $\begin{array}{l}\text { - Educação para o transito. } \\
\text { - Diminuição do consumo de } \\
\text { combustiveis. } \\
\text { - Diminuição do número de } \\
\text { viagens motorizadas. }\end{array}$ \\
\hline & \multirow[b]{2}{*}{$\begin{array}{l}\text { Novas } \\
\text { Tecnologias }\end{array}$} & N1 & - Aumento na poluição do ar. & - & $\begin{array}{l}\text { - Contaminação do meio } \\
\text { ambiente }\end{array}$ & $\begin{array}{l}\text { - Utilização de combustíveis } \\
\text { limpos / renováveis. }\end{array}$ \\
\hline & & N2 & - & - & $\begin{array}{l}\text { - A existência de somente um } \\
\text { modo de transporte coletivo. } \\
\text { - A priorização do transporte } \\
\text { individual. } \\
\text { - As alternativas de transporte } \\
\text { são muito limitadas, } \\
\text { reduzindo as possibilidades } \\
\text { de escolha disponíveis aos } \\
\text { habitantes. }\end{array}$ & $\begin{array}{l}\text { - Incentivar o transporte não } \\
\text { motorizado. } \\
\text { - Incentivar o uso do } \\
\text { transporte coletivo. } \\
\text { - Promover a interação entre } \\
\text { os modos de transportes. } \\
\text { Estabelecer parcerias com } \\
\text { instituições de pesquisa e } \\
\text { desenvolvimento nesta área. } \\
\text { - Incentivar as iniciativas de } \\
\text { implantação de novas formas } \\
\text { de transporte. }\end{array}$ \\
\hline
\end{tabular}


ANEXO 9 - Relação dos Problemas e Soluções avaliados no Módulo III (continuação)

\begin{tabular}{|c|c|c|c|c|c|c|}
\hline \multicolumn{7}{|c|}{ PROBLEMAS E SOLUÇÕES } \\
\hline \multirow[b]{2}{*}{ CATEG. } & \multirow{2}{*}{ TEMA } & \multirow{2}{*}{ IND } & \multicolumn{2}{|c|}{ FORNECIDO PELO SISTEMA } & \multicolumn{2}{|c|}{ INSERIDO PELO USUÁRIO } \\
\hline & & & PROBLEMAS & SOLUÇÕES & PROBLEMAS & SOLUÇÕES \\
\hline \multirow{9}{*}{ 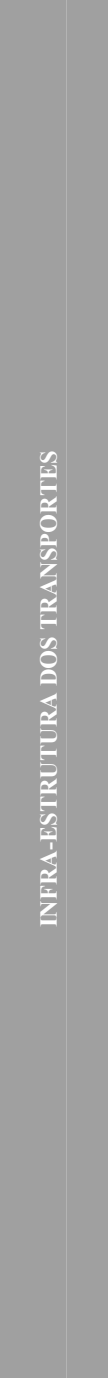 } & \multirow{2}{*}{ Frota } & F3 & $\begin{array}{l}\text { - Aumento na poluição } \\
\text { ambiental. } \\
\text { - Consumo de combustível. }\end{array}$ & - Renovação da frota. & ---- & $\begin{array}{l}\text { - Promover o uso de } \\
\text { combustivel limpo no } \\
\text { transporte coletivo } \\
\text { - Incentivo a utilização de } \\
\text { combustiveis alternativos. } \\
\end{array}$ \\
\hline & & F4 & - Idade da frota. & --- & $\begin{array}{l}\text { - Comprometimento da } \\
\text { qualidade do ar. } \\
\text { - Ausência de vistoria veicular } \\
\text { obrigatória. }\end{array}$ & $\begin{array}{l}\text { - Incentivar (por exemplo, } \\
\text { incentivos fiscais) a } \\
\text { substituição da frota por } \\
\text { veículos mais eficientes ou } \\
\text { mais novos. } \\
\end{array}$ \\
\hline & \multirow{2}{*}{ Sistema Viário } & S7 & ----- & ---- & $\begin{array}{l}\text { - Aumento da emissão de } \\
\text { poluentes. }\end{array}$ & $\begin{array}{l}\text { - Implementar medidas de } \\
\text { fiscalização e controle de } \\
\text { velocidade } \\
\text { - Monitorar o trânsito. } \\
\text { - Eliminar obstáculos naturais. } \\
\text { - Aumentar número de } \\
\text { ciclovias. }\end{array}$ \\
\hline & & S8 & --- & --- & $\begin{array}{l}\text { Deficiências no acesso ao } \\
\text { transporte coletivo. } \\
\text { - Depreciação da frota de } \\
\text { veículos utilizados no } \\
\text { transporte coletivo. } \\
\text { - Desestímulo ao aumento da } \\
\text { oferta de transporte coletivo. }\end{array}$ & ------ \\
\hline & \multirow{2}{*}{$\begin{array}{l}\text { Serviços de } \\
\text { Transportes }\end{array}$} & ST1 & --- & --- & $\begin{array}{l}\text { - Ausência de ciclovias. } \\
\text { - Passeios públicos } \\
\text { danificados. }\end{array}$ & $\begin{array}{l}\text { - Incentivos a utilização do } \\
\text { transporte não motorizado. } \\
\text { - Legislação de uso e ocupação } \\
\text { do solo. } \\
\text { - Políticas de incentivo ao } \\
\text { desenvolvimento de novos } \\
\text { modos de transporte. } \\
\text { - Melhorar integração dos } \\
\text { transportes. } \\
\end{array}$ \\
\hline & & ST4 & - & 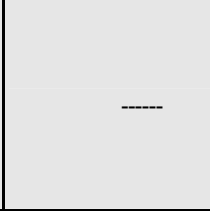 & $\begin{array}{l}\text { - Trajetos inadequados. } \\
\text { - Alto custo. } \\
\text { - Aumento do número de } \\
\text { viagens. }\end{array}$ & $\begin{array}{l}\text { - Mais opções de horários. } \\
\text { - Realização de pesquisa de } \\
\text { origem-destino para } \\
\text { definição de melhores rotas. } \\
\text { - Incentivo a utilização do } \\
\text { transporte público. } \\
\text { - Incentivo ao transporte } \\
\text { solidário (carona/rodízio). }\end{array}$ \\
\hline & \multirow[b]{3}{*}{ Tráfego } & T1 & ----- & ---- & ----- & ----- \\
\hline & & T3 & -+- & +-- & ----- & $\begin{array}{ll}---- \\
\end{array}$ \\
\hline & & T4 & ----- & - & $\begin{array}{l}\text { - Desestímulo à utilização de } \\
\text { transporte coletivo. } \\
\text { - Problemas de saúde } \\
\text { relacionados ao estresse }\end{array}$ & $\begin{array}{l}\text { - Legislação de uso e ocupação } \\
\text { de solo que propicie uma } \\
\text { redução no tempo de viagens } \\
\text { (trabalho/residência). } \\
\text { - Integração modal. } \\
\text { - Pedágios urbanos para } \\
\text { automóveis. } \\
\text { - Criação de sistema de } \\
\text { rodizio. }\end{array}$ \\
\hline
\end{tabular}


ANEXO 9 - Relação dos Problemas e Soluções avaliados no Módulo III (continuação)

\begin{tabular}{|c|c|c|c|c|c|c|}
\hline \multicolumn{7}{|c|}{ PROBLEMAS E SOLUÇÕES } \\
\hline \multirow[b]{2}{*}{ CATEG. } & \multirow{2}{*}{ TEMA } & \multirow{2}{*}{ IND } & \multicolumn{2}{|c|}{ FORNECIDO PELO SISTEMA } & \multicolumn{2}{|c|}{ INSERIDO PELO USUÁRIO } \\
\hline & & & $\overline{\text { PROBLEMAS }}$ & SOLUÇÕES & $\overline{\text { PROBLEMAS }}$ & SOLUÇÕES \\
\hline \multirow{9}{*}{ 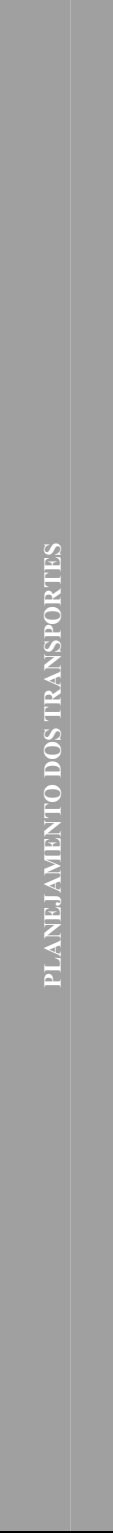 } & \multirow[t]{2}{*}{$\begin{array}{l}\text { Acessibilidade } \\
\text { Urbana }\end{array}$} & A4 & ---- & ---- & $\begin{array}{l}\text { - Tempo gasto de } \\
\text { deslocamento para trabalho } \\
\text { e/ou estudo. } \\
\text { - Distritos industriais distantes } \\
\text { das zonas residenciais. } \\
\text { - Muitos vazios urbanos. } \\
\end{array}$ & $\begin{array}{l}\text { - Melhor distribuição das } \\
\text { atividades urbanas. } \\
\text { - Criação de zonas mistas } \\
\text { - Mudança na lei de } \\
\text { zoneamento e ocupação do } \\
\text { solo. }\end{array}$ \\
\hline & & A5 & --- & --- & $\begin{array}{l}\text { - Falta de áreas de lazer nas } \\
\text { proximidades. }\end{array}$ & $\begin{array}{l}\text { - Criação de novas áreas de } \\
\text { lazer e recreação. } \\
\text { - Manutenção e conservação } \\
\text { das áreas de lazer existentes. }\end{array}$ \\
\hline & \multirow{2}{*}{$\begin{array}{l}\text { Crescimento } \\
\text { Urbano }\end{array}$} & C3 & $\begin{array}{l}\text { - Espalhamento urbano. } \\
\text { - Gasto com infra-estrutura de } \\
\text { transportes. }\end{array}$ & \begin{tabular}{|l|} 
- Implantação de uso misto na \\
cidade. \\
- Incentivo ao uso de \\
transporte coletivo. \\
- Descentralização das \\
atividades para os bairros.
\end{tabular} & ----- & ----- \\
\hline & & C7 & $\begin{array}{l}\text { - Espalhamento urbano. } \\
\text { - Vazios urbanos. } \\
\text { Alta densidade em } \\
\text { determinados bairros. }\end{array}$ & \begin{tabular}{|l|} 
- Criação de legislação para \\
orientação do uso do solo \\
urbano. \\
- Fiscalização do cumprimento \\
da legislação.
\end{tabular} & $\begin{array}{l}\text { - Altas densidades em } \\
\text { determinados horários. } \\
\text { - Crescimento urbano } \\
\text { desordenado. }\end{array}$ & $\begin{array}{l}\text { - Incentivo através da redução } \\
\text { de taxas por área de } \\
\text { zoneamento. } \\
\text { - Limitar perímetro urbano. } \\
\text { - Aumentar impostos de } \\
\text { terrenos sem construção. }\end{array}$ \\
\hline & \multirow[t]{2}{*}{$\begin{array}{l}\text { População } \\
\text { Urbana }\end{array}$} & $\mathbf{P 2}$ & $\begin{array}{l}\text { - Falta de infra-estrutura de } \\
\text { transporte. } \\
\text { - Aumento na demanda por } \\
\text { transporte público. }\end{array}$ & $\begin{array}{l}\text { - Criação de legislação que } \\
\text { determine a densidade em } \\
\text { diferentes bairros da cidade. }\end{array}$ & $\begin{array}{l}\text { - Diminuição de } \\
\text { estacionamento público nas } \\
\text { vias. }\end{array}$ & \begin{tabular}{|l} 
- Incentivo a ocupação de \\
determinadas áreas por \\
aumento do coeficiente de \\
aproveitamento e dispensa de \\
outorga onerosa. \\
- Construção de escolas e \\
postos de saúde próximos as \\
grandes concentrações \\
urbanas. \\
- Incentivo a ocupação de \\
vazios urbanos e zonas com \\
baixa densidade \\
populacional. \\
\end{tabular} \\
\hline & & P5 & $\begin{array}{l}\text { Impacto direto na demanda } \\
\text { por transporte público. } \\
\text { Demanda por infra-estrutura } \\
\text { de transporte. }\end{array}$ & $\begin{array}{l}\text { - Desenvolvimento de projetos } \\
\text { para suprir a demanda de } \\
\text { infra-estrutura. }\end{array}$ & ----- & ------ \\
\hline & \multirow{3}{*}{ Viagens } & $\mathrm{V} 2$ & $\begin{array}{ll}---- \\
\end{array}$ & $\begin{array}{ll}---- \\
\end{array}$ & $\begin{array}{ll}---- \\
\end{array}$ & $\begin{array}{ll}----- \\
\end{array}$ \\
\hline & & v5 & $\begin{array}{l}\text { - Aumento no } \\
\text { congestionamento. } \\
\text { - Aumento no número de } \\
\text { viagens intra-urbana. } \\
\text { - Aumento na poluição } \\
\text { ambiental. } \\
\text { - Aumento na demanda por } \\
\text { transporte. } \\
\text { - Aumento no gasto com } \\
\text { tarifas de transportes. } \\
\text { (passagens) }\end{array}$ & $\begin{array}{l}\text { - Re-organização espacial. } \\
\text { Criação de zonas mistas } \\
\text { urbanas. } \\
\text { - Diminuição no gasto com } \\
\text { transporte. } \\
\text { - Diminuição do número de } \\
\text { viagens na cidade. }\end{array}$ & ------ & ------ \\
\hline & & V7 & $\begin{array}{l}\text { - Aumento no tempo de } \\
\text { viagem. } \\
\text { - Congestionamento. } \\
\text { - Problemas no pavimento das } \\
\text { principais vias de transporte } \\
\text { público (buracos). }\end{array}$ & $\begin{array}{l}\text { - Re-organização das linhas de } \\
\text { transporte público. } \\
\text { - Diminuição no tempo de } \\
\text { viagem. } \\
\text { - Aumento da frota. } \\
\text { - Pavimentação das principais } \\
\text { vias. }\end{array}$ & ------ & $\begin{array}{l}\text { - Incentivo a transportes } \\
\text { alternativos. }\end{array}$ \\
\hline
\end{tabular}


ANEXO 9 - Relação dos Problemas e Soluções avaliados no Módulo III (continuação)

\begin{tabular}{|c|c|c|c|c|c|c|}
\hline \multicolumn{7}{|c|}{ PROBLEMAS E SOLUÇÕES } \\
\hline \multirow[b]{2}{*}{ CATEG. } & \multirow{2}{*}{ TEMA } & \multirow{2}{*}{ IND } & \multicolumn{2}{|c|}{ FORNECIDO PELO SISTEMA } & \multicolumn{2}{|c|}{ INSERIDO PELO USUÁRIO } \\
\hline & & & PROBLEMAS & SOLUÇÕES & PROBLEMAS & SOLUÇÕES \\
\hline \multirow{8}{*}{ 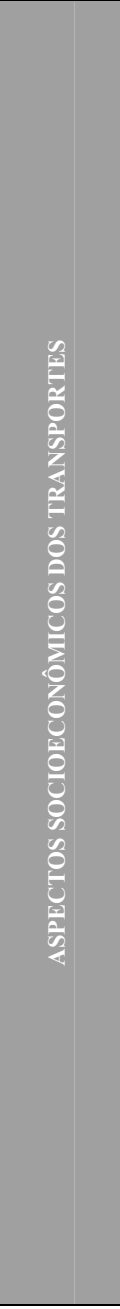 } & \multirow[b]{2}{*}{ Custos } & CT1 & $\begin{array}{l}\text { - Baixa demanda de } \\
\text { passageiros por determinados } \\
\text { modos de transporte. } \\
\text { - Aumento das tarifas de } \\
\text { transporte público. }\end{array}$ & $\begin{array}{l}\text { - Incentivo ao uso de } \\
\text { transporte público. } \\
\text { - Revisão das tarifas de } \\
\text { transporte. }\end{array}$ & $\begin{array}{l}\text { - Falta de terminais de } \\
\text { integração. }\end{array}$ & $\begin{array}{l}\text { - Criação de tarifas de } \\
\text { integração. } \\
\text { - Subsídio ao transporte } \\
\text { público. }\end{array}$ \\
\hline & & CT3 & $\begin{array}{l}\text { - Aumento das tarifas do } \\
\text { transporte público. } \\
\text { - Diminuição da demanda de } \\
\text { passageiros no transporte } \\
\text { público. } \\
\text { - Aumento da poluição do ar. }\end{array}$ & $\begin{array}{l}\text { - Incentivar a utilização de } \\
\text { combustíveis "limpos". } \\
\text { - Revisão das tarifas de } \\
\text { transporte. }\end{array}$ & ----- & ------ \\
\hline & \multirow{2}{*}{$\begin{array}{c}\text { Impactos } \\
\text { Socioeconômicos }\end{array}$} & IS1 & $\begin{array}{l}\text { - Frota antiga. } \\
\text { - Aumento da poluição } \\
\text { ambiental. } \\
\text { - Aumento nos } \\
\text { congestionamentos. }\end{array}$ & $\begin{array}{l}\text { - Redução do tempo de } \\
\text { viagem. } \\
\text { - Redução dos } \\
\text { congestionamentos. } \\
\text { - Diminuição da poluição } \\
\text { ambiental. }\end{array}$ & $\begin{array}{l}\text { - Aumento do consumo de } \\
\text { combustiveis não } \\
\text { renováveis. }\end{array}$ & $\begin{array}{l}\text { - Redução de custos com } \\
\text { sistema viário. }\end{array}$ \\
\hline & & IS3 & $\begin{array}{l}\text { - Desapropriação de terrenos e } \\
\text { imóveis para a construção de } \\
\text { equipamentos de transportes. } \\
\text { - Re-alocação de famílias e } \\
\text { atividades. }\end{array}$ & $\begin{array}{l}\text { - Redução do tempo de } \\
\text { viagem. } \\
\text { - Melhoria da infra-estrutura } \\
\text { de transportes. }\end{array}$ & ----- & ----- \\
\hline & \multirow{2}{*}{ Segurança Viária } & SV1 & $\begin{array}{l}\text { - Aumento no número de } \\
\text { vitimas fatais no trânsito. } \\
\text { - Falta de sinalização viária } \\
\text { adequada. } \\
\text { - Aumento na velocidade das } \\
\text { vias. } \\
\text { - Falta de ciclovias e calçadas } \\
\text { adequadas. }\end{array}$ & $\begin{array}{l}\text { - Diminuição na velocidade } \\
\text { das vias. } \\
\text { - Adequação das calçadas e } \\
\text { ciclovias de acordo com as } \\
\text { normas técnicas. } \\
\text { - Construção de calçadas e } \\
\text { ciclovias para segurança de } \\
\text { ciclistas e pedestres. }\end{array}$ & ----- & - Monitoramento do trânsito. \\
\hline & & SV2 & $\begin{array}{l}\text { - Falta de sinalização viária } \\
\text { adequada. } \\
\text { - Aumento na velocidade das } \\
\text { vias. }\end{array}$ & $\begin{array}{l}\text { - Diminuição na velocidade } \\
\text { das vias. }\end{array}$ & $\begin{array}{l}\text { - Falta de rigor na fiscalização } \\
\text { dos veículos } \\
\text { - Despreparo dos motoristas } \\
\text { - Desrespeito às regras de } \\
\text { trânsito. } \\
\text { - Incentivo ao consumo de } \\
\text { bebidas alcoólicas pelas } \\
\text { propagandas. }\end{array}$ & $\begin{array}{l}\text { - Educação no trânsito. } \\
\text { - Fiscalização mais efetiva de } \\
\text { condutores e veículos } \\
\text { - Maior rigor na emissão das } \\
\text { carteiras de habilitação } \\
\text { - Aumentar a punição aos } \\
\text { motoristas infratores. }\end{array}$ \\
\hline & \multirow{2}{*}{$\begin{array}{l}\text { Transporte } \\
\text { Público }\end{array}$} & TP1 & $\begin{array}{l}\text { - Excesso de passageiros no } \\
\text { modo privado. } \\
\text { - Falta de linhas de transporte } \\
\text { público em alguns bairros. } \\
\text { - Falta de transportes público. } \\
\text { - Custo da passagem (tarifa). }\end{array}$ & $\begin{array}{l}\text { - Incentivo ao uso do } \\
\text { transporte público. } \\
\text { - Reorganização das linhas de } \\
\text { transporte público. } \\
\text { - Aumento da frota. }\end{array}$ & ---- & ----- \\
\hline & & TP2 & $\begin{array}{l}\text { - Falta de linhas de transporte } \\
\text { público em alguns bairros. } \\
\text { - Falta de transportes público. }\end{array}$ & $\begin{array}{l}\text { - Reorganização das linhas de } \\
\text { transporte público. } \\
\text { - Aumento da frota. }\end{array}$ & $\begin{array}{l}\text { - Falta de pavimentação em } \\
\text { alguns bairros. } \\
\text { - Expansão desordenada da } \\
\text { cidade. }\end{array}$ & $\begin{array}{l}\text { - Pavimentação e manutenção } \\
\text { das vias de transporte } \\
\text { público. } \\
\text { - Restrição aos loteamentos } \\
\text { distantes do centro. }\end{array}$ \\
\hline
\end{tabular}


ANEXO 10 - Análises de suporte à tomada de decisão em relação aos problemas avaliados no Módulo III

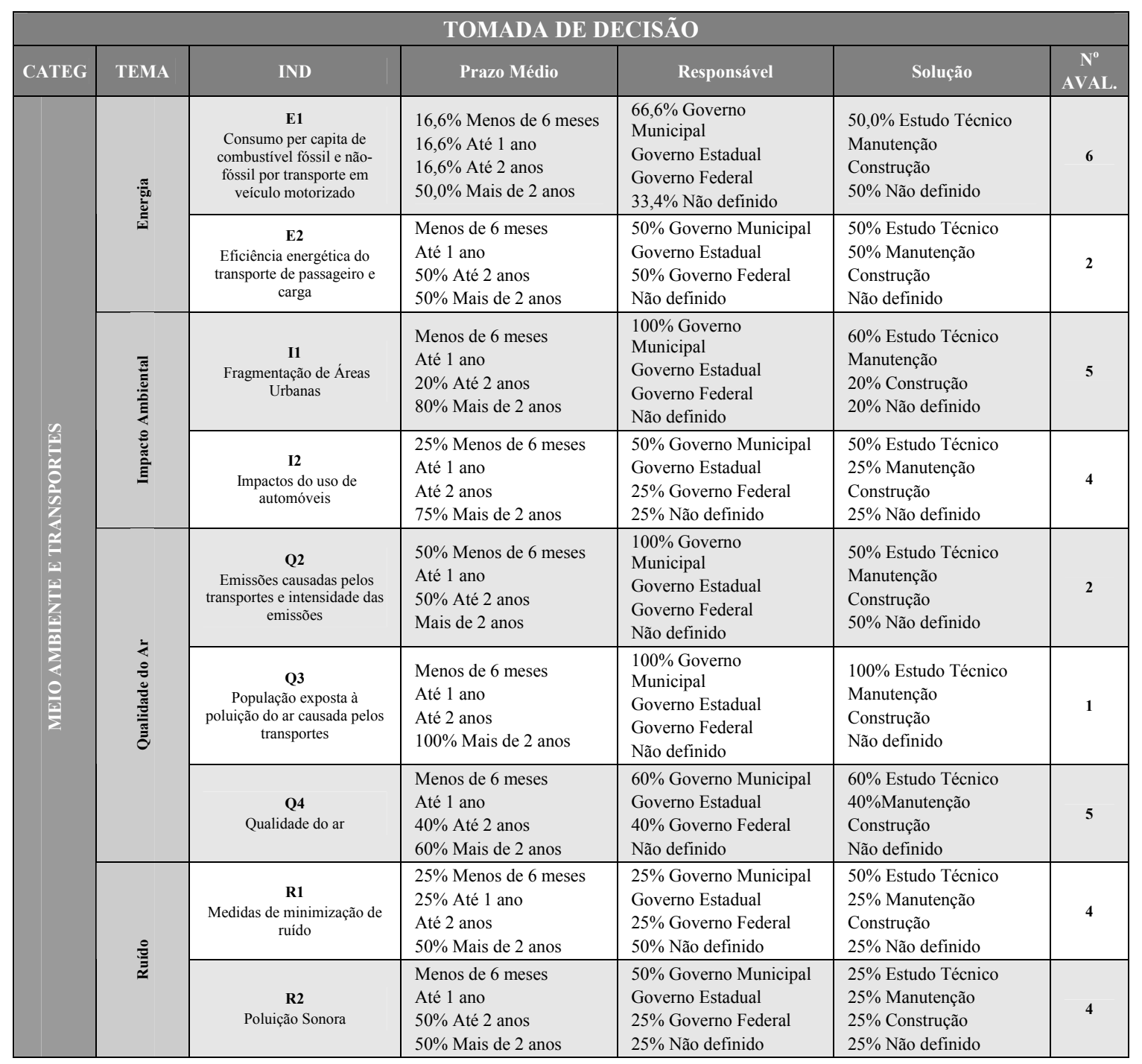


ANEXO 10 - Análises de suporte à tomada de decisão em relação aos problemas avaliados no Módulo III (continuação)

\begin{tabular}{|c|c|c|c|c|c|c|}
\hline \multicolumn{7}{|c|}{ TOMADA DE DECISÃO } \\
\hline CATEG & TEMA & IND & Prazo Médio & Responsável & Solução & $\begin{array}{c}\mathbf{N}^{0} \\
\text { AVAL. }\end{array}$ \\
\hline \multirow{8}{*}{ 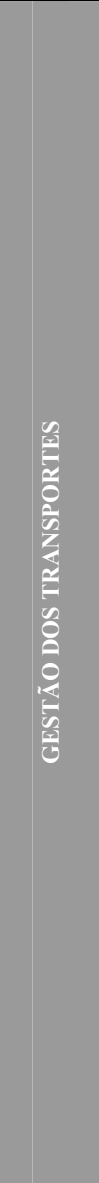 } & \multirow{2}{*}{ 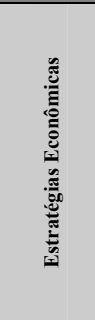 } & $\begin{array}{c}\text { EE3 } \\
\text { Despesas públicas com } \\
\text { transporte público }\end{array}$ & $\begin{array}{l}\text { Menos de } 6 \text { meses } \\
\text { Até } 1 \text { ano } \\
\text { Até } 2 \text { anos } \\
100 \% \text { Mais de } 2 \text { anos }\end{array}$ & $\begin{array}{l}100 \% \text { Governo } \\
\text { Municipal } \\
\text { Governo Estadual } \\
\text { Governo Federal } \\
\text { Não definido }\end{array}$ & $\begin{array}{l}50 \% \text { Estudo Técnico } \\
50 \% \text { Manutenção } \\
\text { Construção } \\
\text { Não definido }\end{array}$ & 2 \\
\hline & & $\begin{array}{l}\text { EE4 } \\
\text { Investimentos em infra- } \\
\text { estrutura de transportes }\end{array}$ & $\begin{array}{l}16,6 \% \text { Menos de } 6 \text { meses } \\
\text { Até } 1 \text { ano } \\
33,2 \% \text { Até } 2 \text { anos } \\
50,2 \% \text { Mais de } 2 \text { anos }\end{array}$ & $\begin{array}{l}100 \% \text { Governo } \\
\text { Municipal } \\
\text { Governo Estadual } \\
\text { Governo Federal } \\
\text { Não definido } \\
\end{array}$ & $\begin{array}{l}50 \% \text { Estudo Técnico } \\
\text { Manutenção } \\
50 \% \text { Construção } \\
\text { Não definido }\end{array}$ & 6 \\
\hline & \multirow{2}{*}{ 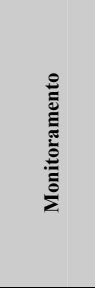 } & $\begin{array}{c}\text { M1 } \\
\text { Avaliação de impacto } \\
\text { ambiental }\end{array}$ & $\begin{array}{l}40 \% \text { Menos de } 6 \text { meses } \\
40 \% \text { Até } 1 \text { ano } \\
20 \% \text { Até } 2 \text { anos } \\
\text { Mais de } 2 \text { anos }\end{array}$ & $\begin{array}{l}80 \% \text { Governo Municipal } \\
\text { Governo Estadual } \\
\text { Governo Federal } \\
20 \% \text { Não definido }\end{array}$ & $\begin{array}{l}60 \% \text { Estudo Técnico } \\
20 \% \text { Manutenção } \\
\text { Construção } \\
20 \% \text { Não definido }\end{array}$ & 5 \\
\hline & & $\begin{array}{c}\text { M2 } \\
\text { Gerenciamento efetivo do } \\
\text { tráfego / fiscalização }\end{array}$ & $\begin{array}{l}33,3 \% \text { Menos de } 6 \text { meses } \\
\text { Até } 1 \text { ano } \\
\text { Até } 2 \text { anos } \\
66,7 \% \text { Mais de } 2 \text { anos }\end{array}$ & $\begin{array}{l}33,3 \% \text { Governo } \\
\text { Municipal } \\
\text { Governo Estadual } \\
\text { Governo Federal } \\
\text { 66,7\% Não definido }\end{array}$ & $\begin{array}{l}\text { 33,3\% Estudo Técnico } \\
\text { Manutenção } \\
\text { Construção } \\
66,7 \% \text { Não definido }\end{array}$ & 3 \\
\hline & \multirow{2}{*}{ 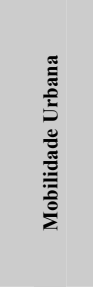 } & $\begin{array}{c}\text { MU1 } \\
\text { Desenvolvimento de planos } \\
\text { municipais para a redução } \\
\text { das viagens }\end{array}$ & $\begin{array}{l}14,25 \% \text { Menos de } 6 \\
\text { meses } \\
14,25 \% \text { Até } 1 \text { ano } \\
28,5 \% \text { Até } 2 \text { anos } \\
43 \% \text { Mais de } 2 \text { anos } \\
\end{array}$ & $\begin{array}{l}85,75 \% \text { Governo } \\
\text { Municipal } \\
\text { Governo Estadual } \\
14,25 \% \text { Governo Federal } \\
\text { Não definido }\end{array}$ & $\begin{array}{l}\text { 71,5\% Estudo Técnico } \\
\text { Manutenção } \\
\text { 14,25\% Construção } \\
\text { 14,25\% Não definido }\end{array}$ & 7 \\
\hline & & $\begin{array}{c}\text { MU6 } \\
\text { Priorizar viagens eficientes } \\
\text { (a pé ou por bicicleta) }\end{array}$ & $\begin{array}{l}\text { Menos de } 6 \text { meses } \\
\text { Até } 1 \text { ano } \\
50 \% \text { Até } 2 \text { anos } \\
50 \% \text { Mais de } 2 \text { anos } \\
\end{array}$ & $\begin{array}{l}50 \% \text { Governo Municipal } \\
\text { Governo Estadual } \\
50 \% \text { Governo Federal } \\
\text { Não definido }\end{array}$ & $\begin{array}{l}\text { 100\% Estudo Técnico } \\
\text { Manutenção } \\
\text { Construção } \\
\text { Não definido }\end{array}$ & 2 \\
\hline & \multirow{2}{*}{ 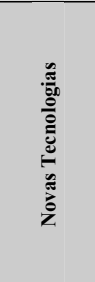 } & $\begin{array}{c}\mathbf{N 1} \\
\text { Desenvolvimento de } \\
\text { combustiveis limpos e } \\
\text { número de veículos que } \\
\text { utilizam combustiveis } \\
\text { alternativos } \\
\end{array}$ & $\begin{array}{l}33 \% \text { Menos de } 6 \text { meses } \\
\text { Até } 1 \text { ano } \\
\text { Até } 2 \text { anos } \\
67 \% \text { Mais de } 2 \text { anos }\end{array}$ & $\begin{array}{l}\text { Governo Municipal } \\
\text { Governo Estadual } \\
100 \% \text { Governo Federal } \\
\text { Não definido }\end{array}$ & $\begin{array}{l}67 \% \text { Estudo Técnico } \\
33 \% \text { Manutenção } \\
\text { Construção } \\
\text { Não definido }\end{array}$ & 3 \\
\hline & & $\begin{array}{c}\mathbf{N} 2 \\
\text { Novas formas de transporte }\end{array}$ & $\begin{array}{l}67 \% \text { Menos de } 6 \text { meses } \\
\text { Até } 1 \text { ano } \\
\text { Até } 2 \text { anos } \\
33 \% \text { Mais de } 2 \text { anos }\end{array}$ & $\begin{array}{l}33 \% \text { Governo Municipal } \\
\text { Governo Estadual } \\
17 \% \text { Governo Federal } \\
50 \% \text { Não definido }\end{array}$ & $\begin{array}{l}33 \% \text { Estudo Técnico } \\
\text { Manutenção } \\
\text { Construção } \\
67 \% \text { Não definido }\end{array}$ & 6 \\
\hline
\end{tabular}


ANEXO 10 - Análises de suporte à tomada de decisão em relação aos problemas avaliados no Módulo III (continuação)

\begin{tabular}{|c|c|c|c|c|c|c|}
\hline \multicolumn{7}{|c|}{ TOMADA DE DECISÃO } \\
\hline CATEG & TEMA & IND & Prazo Médio & Responsável & Solução & $\begin{array}{c}\mathbf{N}^{0} \\
\text { AVAL. }\end{array}$ \\
\hline \multirow{9}{*}{ 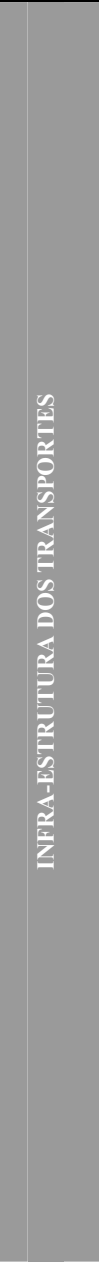 } & \multirow{2}{*}{ 劳 } & $\begin{array}{c}\text { F3 } \\
\text { Percentagem da frota } \\
\text { municipal convertida para } \\
\text { reduzir a emissão de } \\
\text { poluentes }\end{array}$ & $\begin{array}{l}20 \% \text { Menos de } 6 \text { meses } \\
\text { Até } 1 \text { ano } \\
20 \% \text { Até } 2 \text { anos } \\
60 \% \text { Mais de } 2 \text { anos }\end{array}$ & $\begin{array}{l}40 \% \text { Governo Municipal } \\
\text { Governo Estadual } \\
40 \% \text { Governo Federal } \\
20 \% \text { Não definido }\end{array}$ & $\begin{array}{l}20 \% \text { Estudo Técnico } \\
20 \% \text { Manutenção } \\
20 \% \text { Construção } \\
40 \% \text { Não definido }\end{array}$ & 5 \\
\hline & & $\begin{array}{c}\text { F4 } \\
\text { Relação entre veículos com } \\
\text { consumo eficiente de } \\
\text { combustível/ veículos com } \\
\text { consumo ineficiente de } \\
\text { combustível } \\
\end{array}$ & $\begin{array}{l}\text { Menos de } 6 \text { meses } \\
\text { Até } 1 \text { ano } \\
\text { Até } 2 \text { anos } \\
100 \% \text { Mais de } 2 \text { anos }\end{array}$ & $\begin{array}{l}50 \% \text { Governo Municipal } \\
\text { Governo Estadual } \\
50 \% \text { Governo Federal } \\
\text { Não definido }\end{array}$ & $\begin{array}{l}75 \% \text { Estudo Técnico } \\
\text { Manutenção } \\
\text { Construção } \\
25 \% \text { Não definido }\end{array}$ & 4 \\
\hline & \multirow{2}{*}{ } & $\begin{array}{c}\text { S7 } \\
\text { Possibilidade de acesso de } \\
\text { transporte coletivo } \\
\text { (pavimentação) }\end{array}$ & $\begin{array}{l}33 \% \text { Menos de } 6 \text { meses } \\
17 \% \text { Até } 1 \text { ano } \\
33 \% \text { Até } 2 \text { anos } \\
17 \% \text { Mais de } 2 \text { anos }\end{array}$ & $\begin{array}{l}67 \% \text { Governo Municipal } \\
\text { Governo Estadual } \\
17 \% \text { Governo Federal } \\
17 \% \text { Não definido }\end{array}$ & $\begin{array}{l}50 \% \text { Estudo Técnico } \\
33 \% \text { Manutenção } \\
17 \% \text { Construção } \\
\text { Não definido } \\
\end{array}$ & 6 \\
\hline & & $\begin{array}{c}\mathbf{S 8} \\
\text { Provisão de infra-estrutura } \\
\text { para moderação de tráfego e } \\
\text { vias para bicicletas e } \\
\text { pedestres } \\
\end{array}$ & $\begin{array}{l}\text { Menos de } 6 \text { meses } \\
\text { Até } 1 \text { ano } \\
\text { Até } 2 \text { anos } \\
100 \% \text { Mais de } 2 \text { anos }\end{array}$ & $\begin{array}{l}\text { 50\% Governo Municipal } \\
\text { Governo Estadual } \\
\text { Governo Federal } \\
50 \% \text { Não definido }\end{array}$ & $\begin{array}{l}50 \% \text { Estudo Técnico } \\
\text { Manutenção } \\
50 \% \text { Construção } \\
\text { Não definido } \\
\end{array}$ & 2 \\
\hline & \multirow{2}{*}{ 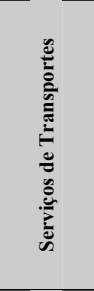 } & $\begin{array}{c}\text { ST1 } \\
\begin{array}{c}\text { Mudanças nos modos de } \\
\text { transporte }\end{array}\end{array}$ & $\begin{array}{l}20 \% \text { Menos de } 6 \text { meses } \\
\text { Até } 1 \text { ano } \\
20 \% \text { Até } 2 \text { anos } \\
60 \% \text { Mais de } 2 \text { anos }\end{array}$ & $\begin{array}{l}100 \% \text { Governo } \\
\text { Municipal } \\
\text { Governo Estadual } \\
\text { Governo Federal } \\
\text { Não definido } \\
\end{array}$ & $\begin{array}{l}80 \% \text { Estudo Técnico } \\
20 \% \text { Manutenção } \\
\text { Construção } \\
\text { Não definido }\end{array}$ & 5 \\
\hline & & $\begin{array}{c}\text { ST4 } \\
\text { Transporte de passageiros } \\
\text { por modo de transporte }\end{array}$ & $\begin{array}{l}33 \% \text { Menos de } 6 \text { meses } \\
67 \% \text { Até } 1 \text { ano } \\
\text { Até } 2 \text { anos } \\
\text { Mais de } 2 \text { anos }\end{array}$ & $\begin{array}{l}67 \% \text { Governo Municipal } \\
\text { Governo Estadual } \\
\text { Governo Federal } \\
33 \% \text { Não definido }\end{array}$ & $\begin{array}{l}67 \% \text { Estudo Técnico } \\
\text { Manutenção } \\
\text { Construção } \\
33 \% \text { Não definido }\end{array}$ & 3 \\
\hline & \multirow{3}{*}{ 密 } & $\begin{array}{c}\text { T1 } \\
\text { Densidade de tráfego }\end{array}$ & $\begin{array}{l}\text { Menos de } 6 \text { meses } \\
\text { Até } 1 \text { ano } \\
\text { Até } 2 \text { anos } \\
100 \% \text { Mais de } 2 \text { anos }\end{array}$ & $\begin{array}{l}100 \% \text { Governo } \\
\text { Municipal } \\
\text { Governo Estadual } \\
\text { Governo Federal } \\
\text { Não definido }\end{array}$ & $\begin{array}{l}100 \% \text { Estudo Técnico } \\
\text { Manutenção } \\
\text { Construção } \\
\text { Não definido }\end{array}$ & 1 \\
\hline & & $\begin{array}{c}\text { T3 } \\
\text { Taxa de ocupaçãao dos } \\
\text { veículos de passageiros }\end{array}$ & $\begin{array}{l}100 \% \text { Menos de } 6 \text { meses } \\
\text { Até } 1 \text { ano } \\
\text { Até } 2 \text { anos } \\
\text { Mais de } 2 \text { anos }\end{array}$ & $\begin{array}{l}\text { Governo Municipal } \\
\text { Governo Estadual } \\
\text { Governo Federal } \\
100 \% \text { Não definido }\end{array}$ & $\begin{array}{l}\text { Estudo Técnico } \\
\text { Manutenção } \\
\text { Construção } \\
100 \% \text { Não definido }\end{array}$ & 1 \\
\hline & & $\begin{array}{c}\text { T4 } \\
\text { Tempo total gasto no tráfego }\end{array}$ & $\begin{array}{l}33 \% \text { Menos de } 6 \text { meses } \\
17 \% \text { Até } 1 \text { ano } \\
\text { Até } 2 \text { anos } \\
50 \% \text { Mais de } 2 \text { anos }\end{array}$ & $\begin{array}{l}67 \% \text { Governo Municipal } \\
\text { Governo Estadual } \\
\text { Governo Federal } \\
33 \% \text { Não definido }\end{array}$ & $\begin{array}{l}\text { 33\% Estudo Técnico } \\
33 \% \text { Manutenção } \\
\text { 17\% Construção } \\
17 \% \text { Não definido }\end{array}$ & 6 \\
\hline
\end{tabular}


ANEXO 10 - Análises de suporte à tomada de decisão em relação aos problemas avaliados no Módulo III (continuação)

\begin{tabular}{|c|c|c|c|c|c|c|}
\hline \multicolumn{7}{|c|}{ TOMADA DE DECISÃO } \\
\hline CATEG & TEMA & IND & Prazo Médio & Responsável & Solução & $\begin{array}{c}\mathbf{N}^{0} \\
\text { AVAL. }\end{array}$ \\
\hline \multirow{9}{*}{ 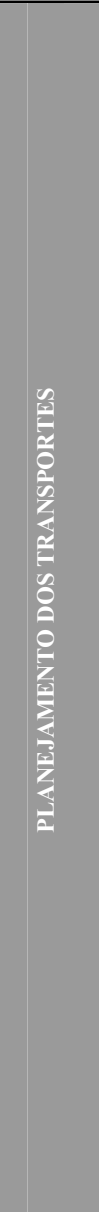 } & \multirow{2}{*}{ 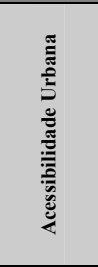 } & $\begin{array}{c}\text { A4 } \\
\text { Percentagem de empregos } \\
\text { situados a até } 3 \mathrm{~km} \text { de } \\
\text { distância das residências }\end{array}$ & $\begin{array}{l}29 \% \text { Menos de } 6 \text { meses } \\
14 \% \text { Até } 1 \text { ano } \\
29 \% \text { Até } 2 \text { anos } \\
29 \% \text { Mais de } 2 \text { anos }\end{array}$ & $\begin{array}{l}71 \% \text { Governo Municipal } \\
\text { Governo Estadual } \\
\text { Governo Federal } \\
29 \% \text { Não definido }\end{array}$ & $\begin{array}{l}43 \% \text { Estudo Técnico } \\
14 \% \text { Manutenção } \\
14 \% \text { Construção } \\
29 \% \text { Não definido } \\
\end{array}$ & 7 \\
\hline & & $\begin{array}{c}\text { A5 } \\
\text { Percentagem de pessoas que } \\
\text { vivem a até } 3 \mathrm{~km} \text { de } \\
\text { distância das facilidades de } \\
\text { lazer } \\
\end{array}$ & $\begin{array}{l}50 \% \text { Menos de } 6 \text { meses } \\
\text { Até } 1 \text { ano } \\
\text { Até } 2 \text { anos } \\
\text { Mais de } 2 \text { anos }\end{array}$ & $\begin{array}{l}\text { Governo Municipal } \\
\text { Governo Estadual } \\
\text { Governo Federal } \\
50 \% \text { Não definido }\end{array}$ & $\begin{array}{l}\text { Estudo Técnico } \\
\text { Manutenção } \\
\text { Construção } \\
50 \% \text { Não definido }\end{array}$ & 2 \\
\hline & \multirow{2}{*}{ 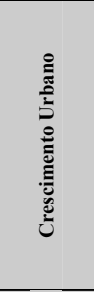 } & $\begin{array}{c}\mathbf{C 3} \\
\begin{array}{c}\text { Desconcentração das } \\
\text { atividades }\end{array}\end{array}$ & $\begin{array}{l}\text { Menos de } 6 \text { meses } \\
100 \% \text { Até } 1 \text { ano } \\
\text { Até } 2 \text { anos } \\
\text { Mais de } 2 \text { anos }\end{array}$ & $\begin{array}{l}100 \% \text { Governo } \\
\text { Municipal } \\
\text { Governo Estadual } \\
\text { Governo Federal } \\
\text { Não definido } \\
\end{array}$ & $\begin{array}{l}100 \% \text { Estudo Técnico } \\
\text { Manutenção } \\
\text { Construção } \\
\text { Não definido }\end{array}$ & 1 \\
\hline & & $\begin{array}{c}\text { C7 } \\
\begin{array}{c}\text { Planejamento do uso do solo } \\
\text { urbano }\end{array}\end{array}$ & $\begin{array}{l}57 \% \text { Menos de } 6 \text { meses } \\
14 \% \text { Até } 1 \text { ano } \\
14 \% \text { Até } 2 \text { anos } \\
14 \% \text { Mais de } 2 \text { anos }\end{array}$ & $\begin{array}{l}57 \% \text { Governo Municipal } \\
\text { Governo Estadual } \\
\text { Governo Federal } \\
29 \% \text { Não definido }\end{array}$ & $\begin{array}{l}57 \% \text { Estudo Técnico } \\
\text { Manutenção } \\
\text { Construção } \\
43 \% \text { Não definido } \\
\end{array}$ & 7 \\
\hline & \multirow{2}{*}{ 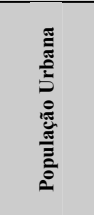 } & $\begin{array}{c}\text { P2 } \\
\text { Densidade populacional }\end{array}$ & $\begin{array}{l}13 \% \text { Menos de } 6 \text { meses } \\
25 \% \text { Até } 1 \text { ano } \\
25 \% \text { Até } 2 \text { anos } \\
38 \% \text { Mais de } 2 \text { anos }\end{array}$ & $\begin{array}{l}75 \% \text { Governo Municipal } \\
\text { Governo Estadual } \\
\text { Governo Federal } \\
25 \% \text { Não definido }\end{array}$ & $\begin{array}{l}50 \% \text { Estudo Técnico } \\
25 \% \text { Manutenção } \\
13 \% \text { Construção } \\
13 \% \text { Não definido } \\
\end{array}$ & 8 \\
\hline & & $\begin{array}{c}\mathbf{P 5} \\
\text { Taxa de crescimento da } \\
\text { população }\end{array}$ & ------ & ------ & ------ & $\mathbf{0}$ \\
\hline & \multirow{3}{*}{ 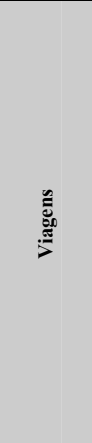 } & $\begin{array}{c}\mathbf{V 2} \\
\text { Distância aos serviços } \\
\text { básicos }\end{array}$ & $\begin{array}{l}\text { Menos de } 6 \text { meses } \\
\text { Até } 1 \text { ano } \\
100 \% \text { Até } 2 \text { anos } \\
\text { Mais de } 2 \text { anos }\end{array}$ & $\begin{array}{l}100 \% \text { Governo } \\
\text { Municipal } \\
\text { Governo Estadual } \\
\text { Governo Federal } \\
\text { Não definido }\end{array}$ & $\begin{array}{l}100 \% \text { Estudo Técnico } \\
\text { Manutenção } \\
\text { Construção } \\
\text { Não definido }\end{array}$ & 2 \\
\hline & & $\begin{array}{l}\text { V5 } \\
\text { Número de pessoas vivendo } \\
\text { e trabalhando no local }\end{array}$ & $\begin{array}{l}33 \% \text { Menos de } 6 \text { meses } \\
\text { Até } 1 \text { ano } \\
\text { Até } 2 \text { anos } \\
67 \% \text { Mais de } 2 \text { anos }\end{array}$ & $\begin{array}{l}100 \% \text { Governo } \\
\text { Municipal } \\
\text { Governo Estadual } \\
\text { Governo Federal } \\
\text { Não definido }\end{array}$ & $\begin{array}{l}\text { 67\% Estudo Técnico } \\
33 \% \text { Manutenção } \\
\text { Construção } \\
\text { Não definido }\end{array}$ & 3 \\
\hline & & $\begin{array}{c}\text { V7 } \\
\text { Tempo de viagem }\end{array}$ & $\begin{array}{l}33 \% \text { Menos de } 6 \text { meses } \\
\text { Até } 1 \text { ano } \\
33 \% \text { Até } 2 \text { anos } \\
33 \% \text { Mais de } 2 \text { anos }\end{array}$ & $\begin{array}{l}\text { 67\% Governo Municipal } \\
\text { Governo Estadual } \\
\text { Governo Federal } \\
33 \% \text { Não definido }\end{array}$ & $\begin{array}{l}\text { 33\% Estudo Técnico } \\
\text { 33\% Manutenção } \\
\text { Construção } \\
33 \% \text { Não definido }\end{array}$ & 3 \\
\hline
\end{tabular}


ANEXO 10 - Análises de suporte à tomada de decisão em relação aos problemas avaliados no Módulo III (continuação)

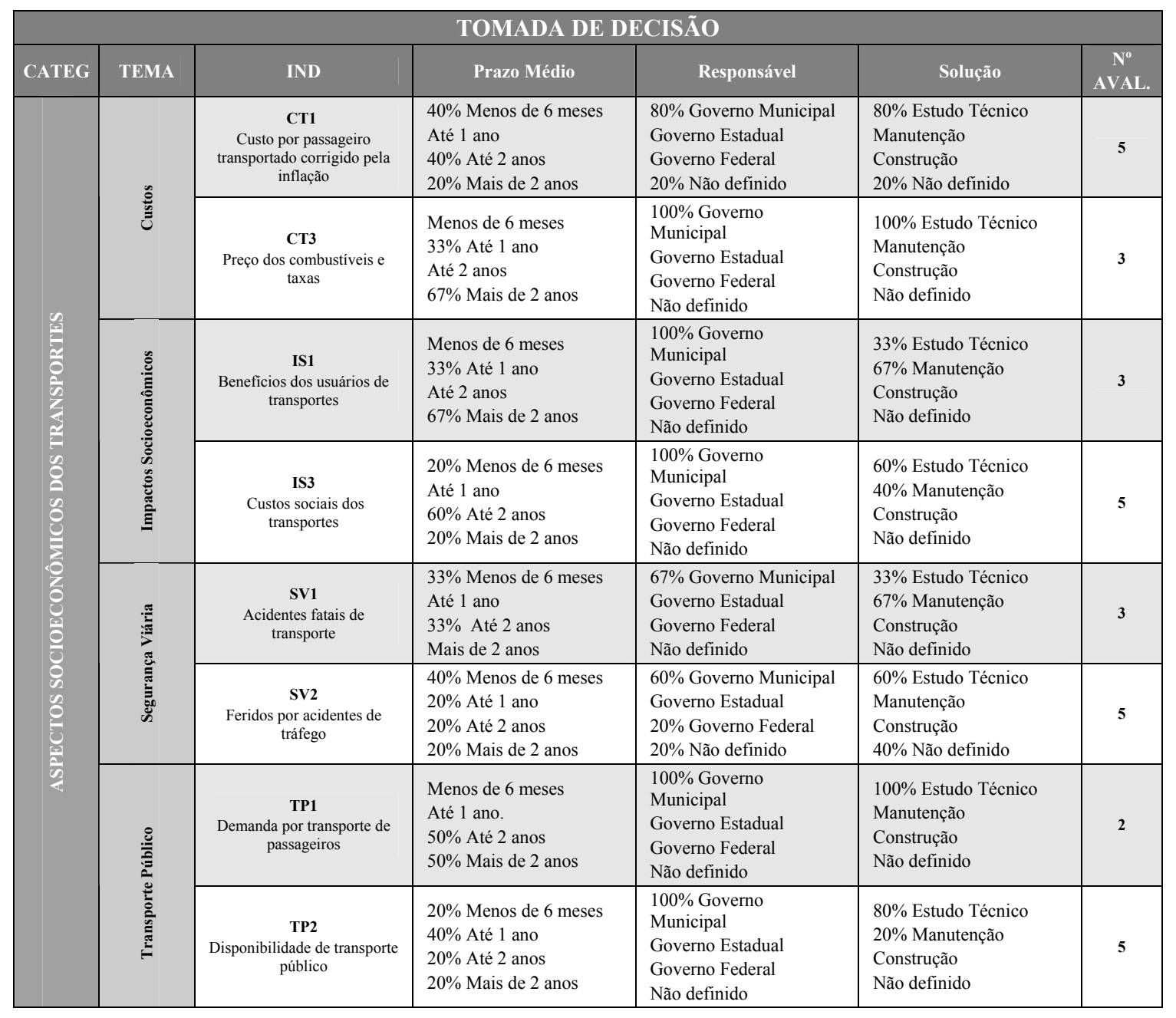


ANEXO 11 - Cálculo dos pesos dos indicadores por avaliador e por Indicador - Grau de Urgência (Módulo III)

- Etapa 1 - Cálculo dos pesos por indicador e por grupo de avaliação para a Categoria Meio Ambiente e Transportes

\begin{tabular}{|c|c|c|c|c|c|c|c|c|c|c|}
\hline \multirow{2}{*}{\multicolumn{2}{|c|}{ AVALIADORES }} & \multicolumn{2}{|c|}{ Energia } & \multicolumn{2}{|c|}{ Impacto Ambiental } & \multicolumn{3}{|c|}{ Qualidade do Ar } & \multicolumn{2}{|c|}{ Ruído } \\
\hline & & E1 & E2 & I5 & I6 & Q3 & Q3 & Q4 & $\mathbf{R} 1$ & $\mathbf{R 2}$ \\
\hline \multirow{7}{*}{ 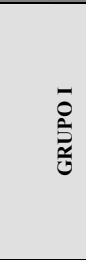 } & 1 & --- & --- & --- & --- & --- & --- & --- & --- & --- \\
\hline & 2 & 0,300 & 0,000 & 0,200 & 0,000 & 0,000 & 0,000 & 0,300 & 0,200 & 0,000 \\
\hline & 3 & 0,000 & 0,250 & 0,000 & 0,313 & 0,000 & 0,000 & 0,188 & 0,250 & 0,000 \\
\hline & 4 & 0,182 & 0,000 & 0,455 & 0,000 & 0,000 & 0,000 & 0,182 & 0,000 & 0,182 \\
\hline & 5 & 0,294 & 0,000 & 0,000 & 0,294 & 0,000 & 0,000 & 0,235 & 0,000 & 0,176 \\
\hline & 6 & 0,278 & 0,000 & 0,278 & 0,000 & 0,222 & 0,000 & 0,000 & 0,000 & 0,222 \\
\hline & 7 & --- & --- & --- & --- & --- & -- & --- & --- & --- \\
\hline \multirow{8}{*}{$\begin{array}{l}= \\
\text { : } \\
\text { 잉 }\end{array}$} & 8 & --- & --- & --- & --- & --- & --- & --- & --- & --- \\
\hline & 9 & 0,000 & 0,190 & 0,190 & 0,238 & 0,000 & 0,190 & 0,000 & 0,190 & 0,000 \\
\hline & 10 & 0,214 & 0,000 & 0,000 & 0,214 & 0,357 & 0,000 & 0,000 & 0,214 & 0,000 \\
\hline & 11 & 0,300 & 0,000 & 0,400 & 0,000 & 0,000 & 0,000 & 0,200 & 0,000 & 0,100 \\
\hline & 12 & --- & --- & --- & --- & --- & -- & --- & --- & --- \\
\hline & 13 & --- & --- & --- & --- & --- & --- & --- & --- & --- \\
\hline & 14 & --- & --- & --- & --- & --- & -- & --- & --- & --- \\
\hline & 15 & --- & --- & --- & --- & --- & --- & --- & --- & --- \\
\hline \multicolumn{2}{|l|}{ MÉDIA } & 0,196 & 0,055 & 0,190 & 0,132 & 0,072 & 0,024 & 0,138 & 0,107 & 0,085 \\
\hline \multicolumn{2}{|c|}{ DESVIO PADRÃO } & 0,128 & 0,103 & 0,181 & 0,145 & 0,139 & 0,067 & 0,120 & 0,115 & 0,097 \\
\hline
\end{tabular}

- Etapa 2 - Cálculo dos pesos por indicador e por grupo de avaliação para a Categoria Gestão dos Transportes

\begin{tabular}{|c|c|c|c|c|c|c|c|c|c|}
\hline \multirow{2}{*}{\multicolumn{2}{|c|}{ AVALIADORES }} & \multicolumn{2}{|c|}{$\begin{array}{l}\text { Estratégias } \\
\text { Econômicas }\end{array}$} & \multicolumn{2}{|c|}{ Monitoramento } & \multicolumn{2}{|c|}{ Mobilidade Urbana } & \multicolumn{2}{|c|}{ Novas Tecnologias } \\
\hline & & EE3 & EE4 & M1 & M2 & MU1 & MU6 & N1 & $\mathbf{N 2}$ \\
\hline \multirow{7}{*}{ 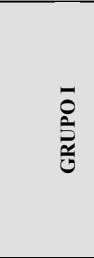 } & 1 & --- & --- & --- & --- & --- & --- & --- & --- \\
\hline & 2 & 0,167 & 0,000 & 0,000 & 0,222 & 0,222 & 0,167 & 0,111 & 0,111 \\
\hline & 3 & 0,313 & 0,000 & 0,188 & 0,000 & 0,000 & 0,250 & 0,250 & 0,000 \\
\hline & 4 & 0,000 & 0,286 & 0,286 & 0,000 & 0,357 & 0,000 & 0,000 & 0,071 \\
\hline & 5 & 0,000 & 0,278 & 0,167 & 0,000 & 0,278 & 0,000 & 0,000 & 0,278 \\
\hline & 6 & 0,000 & 0,313 & 0,188 & 0,000 & 0,188 & 0,000 & 0,000 & 0,313 \\
\hline & 7 & --- & --- & --- & --- & --- & --- & --- & --- \\
\hline \multirow{8}{*}{ 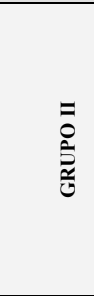 } & 8 & --- & --- & --- & $\begin{array}{ll}-- \\
\end{array}$ & --- & --- & --- & --- \\
\hline & 9 & 0,000 & 0,235 & 0,000 & 0,294 & 0,294 & 0,000 & 0,176 & 0,000 \\
\hline & 10 & 0,000 & 0,231 & 0,385 & 0,000 & 0,231 & 0,000 & 0,000 & 0,154 \\
\hline & 11 & 0,000 & 0,214 & 0,000 & 0,214 & 0,357 & 0,000 & 0,000 & 0,214 \\
\hline & 12 & --- & --- & --- & --- & --- & --- & --- & --- \\
\hline & 13 & --- & --- & --- & $\begin{array}{ll}-- \\
\end{array}$ & --- & --- & $\begin{array}{ll}-- \\
\end{array}$ & $\begin{array}{ll}-- \\
\end{array}$ \\
\hline & 14 & --- & --- & $\begin{array}{l}-- \\
\end{array}$ & $\begin{array}{l}-- \\
\end{array}$ & --- & --- & $\begin{array}{l}-- \\
\end{array}$ & --- \\
\hline & 15 & --- & --- & --- & --- & --- & --- & --- & --- \\
\hline \multicolumn{2}{|l|}{ MÉDIA } & 0,06 & 0,19 & 0,15 & 0,09 & 0,24 & 0,05 & 0,07 & 0,14 \\
\hline \multicolumn{2}{|c|}{ DESVIO PADRÃO } & 0,12 & 0,12 & 0,14 & 0,13 & 0,11 & 0,10 & 0,10 & 0,12 \\
\hline
\end{tabular}


- Etapa 3 - Cálculo dos pesos por indicador e por grupo de avaliação para a Categoria Infra-estrutura dos Transportes

\begin{tabular}{|c|c|c|c|c|c|c|c|c|c|c|}
\hline \multirow{2}{*}{\multicolumn{2}{|c|}{ AVALIADORES }} & \multicolumn{2}{|c|}{ Frota } & \multicolumn{2}{|c|}{ Sistema Viário } & \multicolumn{3}{|c|}{ Serviços de Transportes } & \multicolumn{2}{|c|}{ Tráfego } \\
\hline & & $\mathrm{F3}$ & F4 & S7 & 58 & ST1 & ST4 & $\mathrm{T} 1$ & $\mathrm{T3}$ & $\mathrm{T} 4$ \\
\hline \multirow{7}{*}{$\begin{array}{l}\overline{0} \\
\text { S: } \\
\text { 웝 }\end{array}$} & 1 & --- & --- & --- & --- & --- & --- & --- & --- & --- \\
\hline & 2 & 0,250 & 0,000 & 0,250 & 0,000 & 0,000 & 0,333 & 0,000 & 0,167 & 0,000 \\
\hline & 3 & 0,000 & 0,278 & 0,222 & 0,000 & 0,222 & 0,000 & 0,000 & 0,000 & 0,278 \\
\hline & 4 & 0,077 & 0,000 & 0,308 & 0,000 & 0,000 & 0,308 & 0,000 & 0,000 & 0,308 \\
\hline & 5 & 0,000 & 0,167 & 0,000 & 0,278 & 0,278 & 0,000 & 0,000 & 0,000 & 0,278 \\
\hline & 6 & 0,176 & 0,000 & 0,235 & 0,000 & 0,294 & 0,000 & 0,000 & 0,000 & 0,294 \\
\hline & 7 & --- & --- & --- & $\begin{array}{c}-- \\
\end{array}$ & --- & --- & --- & --- & --- \\
\hline \multirow{8}{*}{ 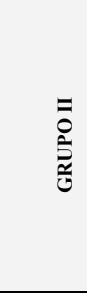 } & 8 & --- & --- & --- & --- & --- & --- & --- & --- & --- \\
\hline & 9 & 0,222 & 0,278 & 0,167 & 0,000 & 0,000 & 0,167 & 0,000 & 0,000 & 0,167 \\
\hline & 10 & 0,364 & 0,000 & 0,273 & 0,000 & 0,182 & 0,000 & 0,182 & 0,000 & 0,000 \\
\hline & 11 & 0,000 & 0,182 & 0,000 & 0,455 & 0,182 & 0,000 & 0,000 & 0,000 & 0,182 \\
\hline & 12 & --- & --- & --- & --- & --- & --- & --- & --- & \\
\hline & 13 & --- & --- & --- & --- & --- & --- & --- & --- & --- \\
\hline & 14 & --- & --- & --- & --- & --- & --- & --- & --- & --- \\
\hline & 15 & --- & --- & --- & --- & --- & --- & --- & --- & --- \\
\hline \multicolumn{2}{|l|}{ MÉDIA } & 0,14 & 0,11 & 0,18 & 0,09 & 0,14 & 0,10 & 0,02 & 0,02 & 0,19 \\
\hline \multicolumn{2}{|c|}{ DESVIO PADRÃO } & 0,14 & 0,13 & 0,12 & 0,18 & 0,13 & 0,15 & 0,06 & 0,06 & 0,13 \\
\hline
\end{tabular}

- Etapa 4 - Cálculo dos pesos por indicador e por grupo de avaliação para a Categoria Planejamento dos Transportes

\begin{tabular}{|c|c|c|c|c|c|c|c|c|c|c|}
\hline \multirow{2}{*}{\multicolumn{2}{|c|}{ AVALIADORES }} & \multicolumn{2}{|c|}{$\begin{array}{c}\text { Acessibilidade } \\
\text { Urbana } \\
\end{array}$} & \multicolumn{2}{|c|}{ Crescimento Urbano } & \multicolumn{2}{|c|}{ População Urbana } & \multicolumn{3}{|c|}{ Viagens } \\
\hline & & $\overline{\mathbf{A 4}}$ & $\mathbf{A 5}$ & $\mathrm{C} 3$ & $\mathrm{C7}$ & P2 & $\overline{\mathrm{P} 5}$ & $\sqrt{2}$ & $\sqrt{5}$ & $\sqrt{7}$ \\
\hline \multirow{7}{*}{ 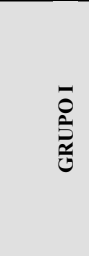 } & 1 & --- & --- & --- & --- & --- & --- & --- & --- & --- \\
\hline & 2 & 0,000 & 0,167 & 0,000 & 0,250 & 0,250 & 0,000 & 0,000 & 0,000 & 0,333 \\
\hline & 3 & 0,294 & 0,000 & 0,000 & 0,294 & 0,235 & 0,000 & 0,000 & 0,176 & 0,000 \\
\hline & 4 & 0,235 & 0,000 & 0,294 & 0,000 & 0,235 & 0,000 & 0,000 & 0,000 & 0,235 \\
\hline & 5 & 0,267 & 0,000 & 0,000 & 0,333 & 0,200 & 0,000 & 0,200 & 0,000 & 0,000 \\
\hline & 6 & 0,278 & 0,000 & 0,000 & 0,278 & 0,167 & 0,000 & 0,000 & 0,278 & 0,000 \\
\hline & 7 & --- & --- & $\begin{array}{l}-- \\
-\end{array}$ & $\begin{array}{ll}-- \\
\end{array}$ & $\begin{array}{ll}-- \\
-\end{array}$ & $\begin{array}{l}-- \\
-\end{array}$ & --- & $\begin{array}{c}-- \\
--\end{array}$ & --- \\
\hline \multirow{8}{*}{ 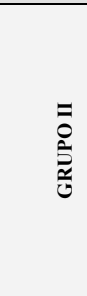 } & 8 & --- & --- & --- & --- & --- & --- & --- & --- & --- \\
\hline & 9 & 0,250 & 0,000 & 0,000 & 0,000 & 0,417 & 0,000 & 0,000 & 0,000 & 0,333 \\
\hline & 10 & 0,200 & 0,000 & 0,000 & 0,333 & 0,267 & 0,000 & 0,000 & 0,200 & 0,000 \\
\hline & 11 & 0,267 & 0,000 & 0,000 & 0,267 & 0,267 & 0,000 & 0,200 & 0,000 & 0,000 \\
\hline & 12 & --- & --- & --- & --- & --- & --- & --- & --- & \\
\hline & 13 & $\begin{array}{ll}-- \\
--\end{array}$ & $\begin{array}{ll}-- \\
\end{array}$ & --- & --- & $\begin{array}{ll}-- \\
--\end{array}$ & --- & $\begin{array}{ll}-- \\
\end{array}$ & --- & --- \\
\hline & 14 & --- & --- & --- & --- & --- & --- & --- & --- & --- \\
\hline & 15 & --- & --- & --- & --- & --- & --- & --- & --- & --- \\
\hline \multicolumn{2}{|l|}{ MÉDIA } & 0,22 & 0,02 & 0,04 & 0,22 & 0,25 & 0,00 & 0,05 & 0,08 & 0,11 \\
\hline \multicolumn{2}{|c|}{ DESVIO PADRÃO } & 0,09 & 0,06 & 0,10 & 0,14 & 0,07 & 0,00 & 0,09 & 0,12 & 0,16 \\
\hline
\end{tabular}


- Etapa 5 - Cálculo dos pesos por indicador e por grupo de avaliação para a Categoria Aspectos Socioeconômicos dos Transportes

\begin{tabular}{|c|c|c|c|c|c|c|c|c|c|}
\hline \multirow{2}{*}{\multicolumn{2}{|c|}{ AVALIADORES }} & \multicolumn{2}{|c|}{ Custos } & \multicolumn{2}{|c|}{$\begin{array}{c}\text { Impactos } \\
\text { Socioeconômicos }\end{array}$} & \multicolumn{2}{|c|}{ Segurança Viária } & \multicolumn{2}{|c|}{ Transporte Público } \\
\hline & & CT1 & CT3 & IS1 & IS3 & SV1 & SV2 & TP1 & TP2 \\
\hline \multirow{7}{*}{ 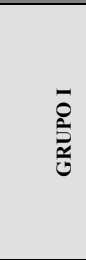 } & 1 & --- & --- & --- & --- & --- & --- & --- & --- \\
\hline & 2 & 0,250 & 0,000 & 0,000 & 0,250 & 0,250 & 0,000 & 0,000 & 0,250 \\
\hline & 3 & 0,222 & 0,000 & 0,278 & 0,000 & 0,000 & 0,278 & 0,000 & 0,222 \\
\hline & 4 & 0,250 & 0,000 & 0,188 & 0,000 & 0,000 & 0,250 & 0,313 & 0,000 \\
\hline & 5 & 0,313 & 0,000 & 0,000 & 0,125 & 0,000 & 0,250 & 0,000 & 0,313 \\
\hline & 6 & 0,333 & 0,000 & 0,000 & 0,133 & 0,200 & 0,000 & 0,000 & 0,333 \\
\hline & 7 & --- & --- & --- & --- & --- & --- & --- & --- \\
\hline \multirow{8}{*}{ 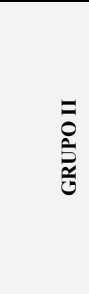 } & 8 & --- & --- & --- & --- & --- & --- & --- & --- \\
\hline & 9 & 0,000 & 0,500 & 0,000 & 0,500 & 0,000 & 0,000 & 0,000 & 0,000 \\
\hline & 10 & 0,000 & 0,214 & 0,214 & 0,000 & 0,000 & 0,286 & 0,000 & 0,286 \\
\hline & 11 & 0,000 & 0,063 & 0,000 & 0,313 & 0,000 & 0,313 & 0,313 & 0,000 \\
\hline & 12 & --- & --- & --- & --- & --- & --- & --- & \\
\hline & 13 & --- & --- & --- & --- & --- & --- & --- & --- \\
\hline & 14 & -- & --- & --- & --- & --- & --- & $\begin{array}{ll}-- \\
--\end{array}$ & $\begin{array}{ll}-- \\
-\end{array}$ \\
\hline & 15 & --- & --- & --- & --- & --- & --- & --- & --- \\
\hline \multicolumn{2}{|l|}{ MÉDIA } & 0,17 & 0,10 & 0,08 & 0,17 & 0,06 & 0,17 & 0,08 & 0,18 \\
\hline \multicolumn{2}{|c|}{ DESVIO PADRÃO } & 0,15 & 0,18 & 0,12 & 0,18 & 0,11 & 0,14 & 0,14 & 0,15 \\
\hline
\end{tabular}


ANEXO 12 - Questionário 1A

\begin{tabular}{|c|c|c|}
\hline QUESTÕES & RESPOSTAS & AVALIAÇÃO \\
\hline $\begin{array}{l}\text { 1. O que você entende por } \\
\text { Mobilidade Urbana? }\end{array}$ & $\begin{array}{l}\text { - Aspectos relacionados ao deslocamento das } \\
\text { pessoas, veículos e da locação do mobiliário } \\
\text { urbano no contexto da cidade tendo influência } \\
\text { significativa no "ir e vir". } \\
\text { - É a característica que tem objetos e pessoas de } \\
\text { transitarem para determinado destino dentro de } \\
\text { certas regras no meio urbano. } \\
\text { - É a facilidade que o indivíduo tem em se } \\
\text { locomover dentro de uma cidade, ou seja, se a } \\
\text { cidade lhe oferece condições de locomoção } \\
\text { rápida e segura, tanto a pé quanto de transporte } \\
\text { motorizado, não esquecendo das pessoas com } \\
\text { necessidades especiais. } \\
\text { - É a possibilidade de deslocamento na cidade. } \\
\text { Tem relação com a infra-estrutura existente } \\
\text { (rede de vias, calçadas, transporte público), mas } \\
\text { também com a capacidade pessoal em termos de } \\
\text { possibilidade motora, física e de recursos. } \\
\text { - A facilidade ou dificuldade com que as pessoas } \\
\text { realizam os deslocamentos para efetuar suas } \\
\text { atividades no espaço urbano. } \\
\text { - É a condição oferecida pela cidade do indivíduo } \\
\text { chegar aos locais que pretende, tais como: vias, } \\
\text { sistema de transporte. } \\
\text { - É como as pessoas se locomovem dentro do } \\
\text { espaço urbano. } \\
\text { - Todo acesso humano utilizado para a } \\
\text { locomoção. } \\
\text { É poder usufruir dos diversos serviços existentes } \\
\text { enormes para passar as barreiras existentes". }\end{array}$ & $\begin{array}{l}\text { Todos os avaliadores transcreveram em } \\
\text { suas respostas que a mobilidade urbana } \\
\text { está relacionada ao deslocamento de } \\
\text { pessoas na cidade e que este deslocamento } \\
\text { está intimamente associado com a infra- } \\
\text { estrutura local. Em apenas } 1 \text { resposta } \\
(11,1 \%) \text { o participante associou a questão } \\
\text { do deslocamento de bens (serviço) como } \\
\text { um item da mobilidade. } \\
\text { De uma forma geral todos os participantes } \\
\text { possuem alguma definição do que é o } \\
\text { termo mobilidade, ou por conhecimento } \\
\text { técnico na área ou por associação dos } \\
\text { termos. }\end{array}$ \\
\hline $\begin{array}{l}\text { 2. O que você entende por } \\
\text { Planejamento de Transportes? }\end{array}$ & $\begin{array}{l}\text { - Uma adequada rede para o deslocamento de } \\
\text { pessoas e cargas dentro do sistema viário. } \\
\text { - É estruturar da melhor forma possível os meios } \\
\text { para que o transporte e a locomoção de pessoas } \\
\text { e objetos sejam feitos de maneira segura e } \\
\text { eficiente. } \\
\text { - Planejar o transporte de modo que ele seja } \\
\text { eficiente e eficaz, atendendo a toda a população } \\
\text { no menor intervalo de tempo, com tarifas } \\
\text { acessíveis. } \\
\text { - O Planejamento integrado dos diversos meios de } \\
\text { locomoção: a pé, bicicleta, veículo próprio, } \\
\text { transporte público através da infra-estrutura } \\
\text { necessária para cada um deles. } \\
\text { - Planejamento do transporte público, individual, } \\
\text { de carga e descarga de forma integrada com o } \\
\text { planejamento urbano que deve ter por objetivo } \\
\text { priorizar o transporte coletivo e outros modos de } \\
\text { transporte em detrimento do individual. } \\
\text { - É um dos aspectos a ser abordado no Plano de } \\
\text { Mobilidade Urbana. } \\
\text { - É o estudo de como as pessoas se locomovem } \\
\text { utilizando o sistema viário existente e os meios } \\
\text { de transportes utilizados, como também prever e } \\
\text { elaborar projetos para futuras soluções. } \\
\text { - Planejamento de transporte para o município. } \\
\text { - É pensar tecnicamente a cidade, contemplando } \\
\text { em primeiro lugar o ser humano para que ocorra } \\
\text { a acessibilidade com segurança. }\end{array}$ & $\begin{array}{l}\text { Com relação a esta questão pode-se } \\
\text { observar que a maioria das respostas } \\
(89 \% \text { ) associa o Planejamento de } \\
\text { Transportes com a estruturação } \\
\text { (organização) e utilização do sistema } \\
\text { viário na cidade. } \\
\text { Estas respostas permitem afirmar que a } \\
\text { maioria dos participantes possuem um } \\
\text { conhecimento técnico desta questão como } \\
\text { sendo o sinônimo do planejamento do } \\
\text { sistema viário e dos meios de transportes. }\end{array}$ \\
\hline
\end{tabular}


ANEXO 12 - Questionário 1A (continuação)

\begin{tabular}{|c|c|c|}
\hline $\begin{array}{l}\text { 3. O município possui algum } \\
\text { Plano de Transporte? }\end{array}$ & $\begin{array}{l}3 \text { Sim } \\
2 \text { Não } \\
4 \text { Não responderam }\end{array}$ & \multirow{2}{*}{$\begin{array}{l}\text { As respostas às perguntas } 3 \text { e } 4 \text { são } \\
\text { complementares. } \\
33 \% \text { das respostas afirmaram que foi } \\
\text { realizado um Plano de Transporte Coletivo } \\
\text { (ou modelagem). } \\
\text { Para } 22,2 \% \text { dos participantes este plano foi } \\
\text { realizado na década de } 90 \text { e para outro } \\
\text { grupo ( } 22,2 \% \text { ) ele foi realizado após } 2000 \text {, } \\
\text { sendo que este último grupo associou a } \\
\text { elaboração do Plano de Transporte com a } \\
\text { inclusão da questão da Mobilidade Urbana } \\
\text { na elaboração do Plano Diretor } \\
\text { Participativo ocorrida em } 2006 \text {. }\end{array}$} \\
\hline $\begin{array}{l}\text { 4. Quando ele foi elaborado } \\
\text { (ano)? Décadas } 1970 \text { / } 1980 \text { / } \\
1990 \text { / após } 2000 .\end{array}$ & $\begin{array}{l}2 \text { Década de } 1990 \\
2 \text { Após } 2000 \\
5 \text { Não responderam }\end{array}$ & \\
\hline $\begin{array}{l}\text { 5. Este Plano foi elaborado } \\
\text { para minimizar quais } \\
\text { problemas da cidade? }\end{array}$ & $\begin{array}{l}\text { - Falta de integração entre bairros. } \\
\text { - Transporte coletivo; rede viária; circulação de } \\
\text { bicicletas. } \\
\text { - Espera-se que tenha sido para possibilitar os } \\
\text { deslocamentos das pessoas proporcionando } \\
\text { conforto, segurança. } \\
\text { - Transporte Coletivo. } \\
\text { - Integração bairros; Trânsito; Acesso. }\end{array}$ & $\begin{array}{l}\text { Embora os participantes não tenham um } \\
\text { conhecimento exato da existência de um } \\
\text { Plano de Transportes para o município de } \\
\text { Bauru, 55,5\% dos avaliadores elencaram } \\
\text { uma série de problemas que ainda hoje } \\
\text { podem ser encontrados no município. }\end{array}$ \\
\hline $\begin{array}{l}\text { 6. Quais os problemas da } \\
\text { cidade que não estão inseridos } \\
\text { neste Plano? }\end{array}$ & $\begin{array}{l}\text { - Integração bairro a bairro, sem passar pelo } \\
\text { centro. } \\
\text { - Falta integração desses planos. } \\
\text { - Forma de crescimento da cidade; prioridade do } \\
\text { transporte coletivo; transporte de cargas. }\end{array}$ & $\begin{array}{l}\text { Em função do que já foi comentado } \\
\text { anteriormente, da falta de conhecimento de } \\
\text { um plano de transporte municipal, as } \\
\text { respostas também deste item referiram-se } \\
\text { aos atuais problemas municipais } \\
\text { relacionados ao transporte. } \\
\text { Nesta questão apenas } 33 \% \text { dos } \\
\text { participantes deram uma resposta; sendo } \\
\text { que o foco principal refere-se às questões } \\
\text { de infra-estrutura e transporte público } \\
\text { (ônibus). }\end{array}$ \\
\hline \multirow[b]{2}{*}{$\begin{array}{l}\text { 7. O município tem previsão } \\
\text { para realizar um novo Plano } \\
\text { de Transporte ou Mobilidade } \\
\text { Urbana para a cidade? } \\
\text { 7.1Qual o prazo (ano)? }\end{array}$} & $\begin{array}{l}7 \mathrm{Sim} \\
2 \text { Não responderam }\end{array}$ & \multirow{2}{*}{$\begin{array}{l}\text { Como todos os participantes que } \\
\text { responderam a este questionário fizeram } \\
\text { parte de forma direta ou indireta na } \\
\text { elaboração do novo Plano Diretor } \\
\text { Municipal em 2006, as respostas deveriam } \\
\text { ser unânimes; entretanto, não foi o que se } \\
\text { verificou. } \\
\text { Embora a maioria ( } 77,7 \% \text { ) dos } \\
\text { participantes tenham respondido que tem } \\
\text { conhecimento sobre a elaboração deste } \\
\text { plano, metade deles não sabe do prazo } \\
\text { estabelecido por lei. } \\
\text { No Plano Diretor Participativo há um } \\
\text { capítulo referente a Mobilidade. Nele são } \\
\text { descritas entre outras informações a } \\
\text { exigência da elaboração do Plano Diretor } \\
\text { de Mobilidade Participativo para Bauru, } \\
\text { estabelecendo um prazo de } 1 \text { ano após a } \\
\text { aprovação na Câmara. }\end{array}$} \\
\hline & $\begin{array}{l}4 \text { Após aprovação do PD } \\
5 \text { Não responderam }\end{array}$ & \\
\hline
\end{tabular}


ANEXO 12 - Questionário 1A (continuação)

\begin{tabular}{|c|c|c|}
\hline $\begin{array}{l}\text { 8. Existe alguma medida para } \\
\text { promover (incentivar) a } \\
\text { melhoria da mobilidade } \\
\text { urbana no município? }\end{array}$ & $\begin{array}{l}8 \text { Sim } \\
1 \text { Não }\end{array}$ & \multirow{2}{*}{$\begin{array}{l}\text { Embora } 88,8 \% \text { dos participantes (técnicos } \\
\text { municipais) afirmem que o município } \\
\text { possui alguma medida para incentivar a } \\
\text { melhoria da mobilidade urbana no } \\
\text { município (questão } 8 \text { ), estes avaliadores } \\
\text { possuem uma vaga compreensão dessas } \\
\text { medidas, conforme mostram as respostas } \\
\text { da questão } 9 \text {. } \\
\text { Mais da metade das respostas enfatiza } \\
\text { apenas o aspecto infra-estrutura; o que } \\
\text { pode indicar um desconhecimento de todas } \\
\text { as questões que envolvem o planejamento } \\
\text { da mobilidade urbana em um município. } \\
\text { As outras respostas (44,4\%), por não terem } \\
\text { o conhecimento efetivo destas medidas no } \\
\text { município, apenas mencionam (associam) } \\
\text { a existência desta temática no Plano } \\
\text { Diretor Participativo, elaborado em } 2006 \text {. }\end{array}$} \\
\hline $\begin{array}{l}\text { 9. Qual (quais) medida(s) foi } \\
\text { (foram) adotada(s)? }\end{array}$ & $\begin{array}{l}\text { - Melhoria das estruturas - infra-estrutura. } \\
\text { - Criação de um grupo de análise de } \\
\text { empreendimentos, que avalia os projetos } \\
\text { encaminhados, contemplando sistema viário e } \\
\text { transporte. } \\
\text { - Projeto de obras de interligação de bairros, } \\
\text { muito segmentados pelas rodovias, ferrovias e } \\
\text { córregos, através de passarelas ou viadutos; } \\
\text { fiscalização da execução de calçadas. } \\
\text { - Mudança de conceito está prevista no Plano } \\
\text { Diretor, assim como a exigência da elaboração } \\
\text { do Plano de Mobilidade. } \\
\text { - A previsão de um Plano de Mobilidade Urbana } \\
\text { conforme o Projeto de Lei do Plano Diretor. } \\
\text { - Plano Diretor Participativo de Bauru. } \\
\text { - Previsão e prazo no PDP. }\end{array}$ & \\
\hline $\begin{array}{l}\text { 10. Qual (quais) o(s) setor(es) } \\
\text { que atualmente estão } \\
\text { envolvidos em uma alteração } \\
\text { do Plano de Transporte para o } \\
\text { município? }\end{array}$ & $\begin{array}{l}6 \text { Trânsito } \\
7 \text { Transportes } \\
6 \text { Planejamento Urbano } \\
1 \text { Agricultura } \\
1 \text { EMDURB } \\
1 \text { Secretaria Municipal de Desenvolvimento } \\
\text { Econômico } \\
1 \text { Não respondeu }\end{array}$ & $\begin{array}{l}\text { As respostas apresentadas pelos } \\
\text { participantes mostram que, embora ainda } \\
\text { não conheçam a atuação exata de cada } \\
\text { setor da prefeitura, há um consenso em } \\
\text { associar as questões relacionadas ao plano } \\
\text { de transporte municipal com duas } \\
\text { secretarias ou órgãos: a EMDURB } \\
\text { (responsável pelas áreas de trânsito e } \\
\text { transporte urbano) e a SEPLAN } \\
\text { (responsável pelo planejamento do uso do } \\
\text { solo). } \\
\text { As exceções neste consenso referiram-se: } \\
\text { i) a inclusão da Secretaria de Agricultura } \\
\text { (que atualmente está envolvida com as } \\
\text { questões da área rural inclusive as } \\
\text { relacionadas ao transporte e ii) a inclusão } \\
\text { da Secretaria Municipal de } \\
\text { Desenvolvimento Econômico, que não } \\
\text { possui uma ação direta no planejamento } \\
\text { espacial do município. }\end{array}$ \\
\hline $\begin{array}{l}\text { 11. Qual (quais) a(s) } \\
\text { secretaria(s) que atualmente } \\
\text { estão envolvidas quando se } \\
\text { elabora alguma modificação } \\
\text { no Plano de Transporte? }\end{array}$ & $\begin{array}{l}6 \text { Planejamento } \\
2 \text { Meio Ambiente } \\
4 \text { Obras } \\
2 \text { Depto Água Esgoto } \\
9 \text { EMDURB }\end{array}$ & $\begin{array}{l}\text { Todos os participantes associam o termo } \\
\text { Planejamento de Transporte com a questão } \\
\text { da infra-estrutura, como foi visto nas } \\
\text { questões } 2 \text { e } 10 \text {. As respostas para este } \\
\text { item complementam o item anterior. }\end{array}$ \\
\hline $\begin{array}{l}\text { 12. Quais são os principais } \\
\text { TEMAS da política de } \\
\text { transportes do município? }\end{array}$ & $\begin{array}{l}\text { - Mobilidade Urbana. } \\
\text { - Na proposta contida no PDP deverão ser } \\
\text { envolvidos todos os meios de transportes } \\
\text { individuais e coletivos, público e privados. } \\
\text { - Transporte coletivo / Trânsito. } \\
\text { - Sistema Viário / Transporte coletivo. }\end{array}$ & $\begin{array}{l}55,5 \% \text { dos participantes não responderam } \\
\text { a esta questão. As demais respostas } \\
\text { abordaram apenas os temas referentes ao } \\
\text { transporte público, sistema viário (infra- } \\
\text { estrutura). } \\
\text { Não ficou muito claro para a avaliação a } \\
\text { inserção da resposta "Mobilidade Urbana" } \\
\text { uma vez que ela define a política de } \\
\text { transporte para o município. }\end{array}$ \\
\hline
\end{tabular}


13. Quais os principais objetivos da política de ESTACIONAMENTOS para o município?

o municipio?

14. Quais os principais objetivos da política de TRANSPORTE PÚBLICO para o município?
- Incentivar a criação de estacionamentos internos, retirar veículos dos estacionamentos públicos junto as vias e priorizar o fluxo de veículos.

- Existe uma tendência de aumentar a exigência para estacionamento interno aos estabelecimentos que precisa ser revista.

- Momento ainda é priorizar o transporte individual.

- Dar condições de estacionamento para quem usa o automóvel em determinada área, onde o número de vagas é menor do que a demanda.

- Elaborar novos parâmetros para prover estacionamentos em novas construções de acordo com a metragem quadrada e uso.

- Realizar o transporte de forma segura, eficiente e economicamente viável.

- Acredito que seja a oferta de transporte que comporte a demanda, com possibilidade de se chegar ao destino de forma confortável e segura.

- Integração das linhas ofertadas através do passe integração.

- Essa política hoje se restringe a EMDURB, não sendo do nosso conhecimento.

- Transporte eficiente de passageiros nos horários e locais que são necessários.

- Este é um trabalho elaborado pela EMDURB.

- Propiciar deslocamentos rápidos e confortáveis evitando a saturação da via, implicando em poluição (atmosférica, visual, ...).

- Ter um sistema viário adequado, com vias que comportem o fluxo de veículos, calçadas adequadas ao trânsito de pedestres e deficientes físicos, não nos esquecendo de ciclovias.

- Transporte individual - pouco com relação a pedestre, ciclista e transporte coletivo.

- Organizar o sistema viário de forma a criar os corredores que facilitem a locomoção das pessoas em toda a cidade.

16. O município tem algum plano para diminuir a

POLUIÇÃO causada pelos meios de transportes na cidade (por ex. o controle da qualidade do ar)?

17. Cite as medidas adotadas para reduzir os NÍVEIS DE POLUIÇÃO causados pelos meios de transportes na cidade.

18. O município tem algum plano para diminuir o RUÍDO causado pelos meios de transportes na cidade?

19. Quais das medidas abaixo foram adotadas para reduzir os NÍVEIS DE RUÍDO causados pelos meios de transportes na cidade? Cite as outras medidas adotadas?
5 Não

4 Não responderam

4 Não tem

5 Não responderam

$1 \mathrm{Sim}$

4 Não

4 Não responderam

1 Prevenção do tráfego

1 Tráfego redirecionado.

0 Reclassificação / classificação ou

desclassificação para uma melhor redistribuição da rede viária.

2 Apoio aos meios de transportes duradouros.

1 Sistema de gestão do estacionamento.

$\mathrm{km} / \mathrm{h}$ para redução de tráfego.

0 Revestimentos rodoviários contra ruído.

0 Túneis, passagens subterrâneas.

0 Muros e barreiras acústicas.
0 Criação de áreas com velocidade limitada a 30
$44,4 \%$ dos avaliadores não responderam esta questão; entretanto as demais respostas mostram que o município têm adotado uma política de incentivo ao uso do transporte motorizado individual, e, em função desta política, há a necessidade de se expandir as áreas de estacionamento para facilitar ainda mais a utilização do carro no município.

$44,4 \%$ das respostas associam a política do transporte público com as questões de oferta, demanda, segurança e preço da tarifa.

$22,2 \%$ desconhecem o assunto, pois não está ligado ao órgão que gerencia estas questões. Os demais não responderam.

A metade das respostas apresentadas ao lado, evidenciam a atual política de transportes adotada pelo município que está associada à utilização do transporte individual motorizado.

$\mathrm{O}$ alto índice de respostas em branco $(55 \%)$ evidencia o desconhecimento do tema ou as ações a ele relacionadas.

Há um desconhecimento geral dos participantes sobre esta questão. Uma hipótese para este alto índice de respostas em branco pode estar relacionada à setorização das funções nos órgãos municipais e pelo fato que os temas Poluição e Ruído são tratados no âmbito da secretaria de Meio Ambiente ou em outra secretaria municipal.

$88 \%$ dos entrevistados não sabem ou afirmam que o município não possui um plano para a diminuição do ruído causado pelos transportes.

\section{7,7\% Não responderam.}

Em função das respostas acima, pode-se afirmar que embora alguns itens desta pergunta tenham sido respondidos, não é possível afirmar que os avaliadores tenham um conhecimento real das medidas para a redução dos Níveis de Ruído causados pelos transportes no município. 
ANEXO 12 - Questionário 1A (continuação)

\begin{tabular}{|c|c|c|}
\hline $\begin{array}{l}\text { 20. O município tem algum } \\
\text { plano para reduzir alguns } \\
\text { pontos de } \\
\text { CONGESTIONAMENTOS } \\
\text { na cidade? }\end{array}$ & $\begin{array}{l}6 \text { Sim } \\
1 \text { Não } \\
2 \text { Não responderam }\end{array}$ & \multirow{2}{*}{$\begin{array}{l}67 \% \text { dos avaliadores afirmam que Bauru } \\
\text { possui algum Plano para a redução de } \\
\text { pontos de congestionamentos na cidade. } \\
\text { Dentre as medidas existentes no município } \\
\text { destacam: implantação de novas vias para } \\
\text { a ligação de bairros ou regiões da cidade; } \\
\text { coordenação semafórica; e definição de } \\
\text { sentido único em determinadas vias. }\end{array}$} \\
\hline $\begin{array}{l}\text { 21. Cite as medidas adotadas } \\
\text { para reduzir os } \\
\text { CONGESTIONAMENTOS } \\
\text { na cidade. }\end{array}$ & $\begin{array}{l}\text { - Coordenação semafórica (sincronismo direto, } \\
\text { onda verde); novas vias de ligação entre regiões, } \\
\text { transpondo as barreiras físicas e naturais. } \\
\text { - Em Bauru não temos congestionamentos ainda, } \\
\text { apenas pontos de lentidão. Para minimizarmos } \\
\text { esses problemas estamos substituindo os } \\
\text { controladores de tráfego dos semáforos a tempo } \\
\text { fixo, por controladores multiplanos. } \\
\text { - Em geral é alteração da rede, mudança de mão } \\
\text { de direção, abertura de novas interligações (mas } \\
\text { muito restrita por falta de recursos). } \\
\text { - Conforme divulgado, as "ondas verdes" e } \\
\text { sinalizações preferenciais. } \\
\text { - Sentido único em vias para facilitar escoamento } \\
\text { para vários setores da cidade. } \\
\text { - Rotatividade e expansão da área azul. }\end{array}$ & \\
\hline $\begin{array}{l}\text { 22. O município tem algum } \\
\text { plano de } \\
\text { ACESSIBILIDADE? }\end{array}$ & $\begin{array}{l}4 \text { Sim } \\
1 \text { Não } \\
4 \text { Não responderam }\end{array}$ & $\begin{array}{l}44 \% \text { dos entrevistados afirmam que o } \\
\text { município possui algum Plano de } \\
\text { Acessibilidade. }\end{array}$ \\
\hline $\begin{array}{l}\text { 23. Quais os principais } \\
\text { projetos relacionados com a } \\
\text { atual política de } \\
\text { ACESSIBILIDADE do } \\
\text { município? }\end{array}$ & $\begin{array}{l}\text { - Implantação de semáforos com fase exclusiva } \\
\text { para pedestre. } \\
\text { - Adaptação de ônibus / aprovação de projeto } \\
\text { obra pública e particular. } \\
\text { - O atendimento à NBR 9050, aplicados aos } \\
\text { projetos em aprovação. } \\
\text { - Implantação de rampas nas esquinas no passeio } \\
\text { público, adequação e exigência nos projetos de } \\
\text { construção à NBR 9050. } \\
\text { - O município tem uma comissão que cuida } \\
\text { desses assuntos. } \\
\text { - Construção de binários; ciclovia. }\end{array}$ & $\begin{array}{l}\text { Nesta questão } 67 \% \text { dos entrevistados } \\
\text { conhecem algum projeto municipal } \\
\text { relacionado à política de acessibilidade. } \\
\text { Dentre estas respostas destacam-se: } \\
\text { adaptação de ônibus, aplicação da norma } \\
\text { de acessibilidade (NBR 9050) na } \\
\text { aprovação dos projetos e em novas } \\
\text { construções no município. }\end{array}$ \\
\hline $\begin{array}{l}\text { 24. O atual Plano de } \\
\text { Transportes prevê a adaptação } \\
\text { dos pontos de ônibus para } \\
\text { torná-los mais acessíveis para } \\
\text { todos os cidadãos? }\end{array}$ & $\begin{array}{l}3 \text { Sim } \\
1 \text { Não } \\
5 \text { Não responderam }\end{array}$ & $\begin{array}{l}56 \% \text { dos entrevistados não responderam a } \\
\text { esta questão; apenas } 33 \% \text { das respostas } \\
\text { indicam que o município possui alguma } \\
\text { legislação que prevê a adaptação dos } \\
\text { pontos de ônibus para torná-los mais } \\
\text { acessíveis a todos os cidadãos. }\end{array}$ \\
\hline $\begin{array}{l}\text { 25. Quais os principais } \\
\text { projetos deste Plano? }\end{array}$ & $\begin{array}{l}\text { - Facilitar o acesso do cidadão ao transporte } \\
\text { público através de melhor distribuição das linhas } \\
\text { de ônibus. Pontos e alocação de carros especiais } \\
\text { para portadores de necessidades especiais. } \\
\text { - Apesar de não ter Plano de Transporte, existe } \\
\text { uma preocupação com a melhoria dos pontos de } \\
\text { ônibus. } \\
\text { - Não sabe. Específico da EMDURB. } \\
\text { - Ônibus adaptado; alteração dos pontos. }\end{array}$ & $\begin{array}{l}56 \% \text { dos participantes não responderam a } \\
\text { esta questão, talvez por desconhecimento } \\
\text { do assunto ou pela falta de divulgação } \\
\text { deste tema para a comunidade. As } \\
\text { respostas obtidas elencaram os seguintes } \\
\text { itens: facilidade na utilização do transporte } \\
\text { público, e a adaptação de alguns ônibus e } \\
\text { pontos de ônibus para portadores de } \\
\text { necessidades especiais. }\end{array}$ \\
\hline $\begin{array}{l}\text { 26. Qual a secretaria, setor ou } \\
\text { órgão municipal que trabalha } \\
\text { com os temas e políticas de } \\
\text { acessibilidade para as pessoas } \\
\text { com deficiência? }\end{array}$ & $\begin{array}{l}8 \text { SEPLAN } \\
6 \text { EMDURB } \\
2 \text { BEM ESTAR SOCIAL } \\
2 \text { OUTROS }\end{array}$ & $\begin{array}{l}89 \% \text { das respostas indicam a Secretaria de } \\
\text { Planejamento (SEPLAN) como a } \\
\text { responsável pelos temas e políticas } \\
\text { relacionados à acessibilidade, enquanto } \\
\text { que } 67 \% \text { das respostas apontam para a } \\
\text { EMDURB (responsável pelo setor de } \\
\text { trânsito e transportes). Estas respostas } \\
\text { refletem a falta de conhecimento que a } \\
\text { maioria dos participantes têm em relação à } \\
\text { definição do órgão ou setor municipal } \\
\text { responsável pelo planejamento e execução } \\
\text { da política de acessibilidade do município. }\end{array}$ \\
\hline
\end{tabular}


ANEXO 12 - Questionário 1A (continuação)

27. Quais os principais problemas de infra-estrutura de transportes que o município possui, identifiqueos por região da cidade.

Construção/região da cidade Calçadas

Passarelas

Ciclovias

Terminal Ônibus

Ponto ônibus

Estacionamento

Pistas (sistema viário)

Viaduto

Manutenção/região da cidade

Calçadas

Passarelas

Ciclovias

Terminal Ônibus

Ponto ônibus

Estacionamento

Pistas (sistema viário)

Viaduto

\section{Tabela 1 - Problemas de Construção}

\begin{tabular}{|l|l|l|l|l|l|}
\hline \multicolumn{6}{|l|}{ CONSTRUÇÃO } \\
\hline & Norte & Centro & Leste & Oeste & Sul \\
\hline Calçadas & 8 & 2 & 7 & 8 & 6 \\
\hline Passarelas & 5 & 0 & 3 & 3 & 0 \\
\hline Ciclovias & 9 & 8 & 9 & 9 & 8 \\
\hline Terminal ônibus & 3 & 5 & 5 & 4 & 3 \\
\hline Ponto ônibus & 6 & 4 & 5 & 4 & 3 \\
\hline Estacionamento & 2 & 4 & 4 & 2 & 4 \\
\hline Pistas (ruas) & 7 & 1 & 5 & 6 & 3 \\
\hline Viaduto & 2 & 2 & 2 & 3 & 1 \\
\hline
\end{tabular}

Tabela 2 - Problemas de Manutenção

\begin{tabular}{|l|l|l|l|l|l|}
\hline \multicolumn{2}{|l|}{ MANUTENÇÃO } \\
\hline & Norte & Centro & Leste & Oeste & Sul \\
\hline Calçadas & 9 & 9 & 9 & 8 & 7 \\
\hline Passarelas & 2 & 0 & 1 & 0 & 0 \\
\hline Ciclovias & 0 & 0 & 2 & 0 & 0 \\
\hline Terminal ônibus & 0 & 2 & 1 & 0 & 0 \\
\hline Ponto ônibus & 7 & 5 & 7 & 5 & 5 \\
\hline Estacionamento & 1 & 2 & 2 & 1 & 1 \\
\hline Pistas (ruas) & 6 & 5 & 7 & 6 & 6 \\
\hline Viaduto & 1 & 1 & 0 & 1 & 0 \\
\hline
\end{tabular}

$0 \% \mathrm{Sim}$

$77,7 \%$ Não

$22,3 \%$ Não responderam

VIAGENS a PÉ ou por BICICLETA?

Segundo os resultados apresentados nas tabelas, pode-se observar que o principal problema de infra-estrutura do município refere-se a construção de ciclovias e a manutenção das calçadas.

A região Norte, segundo os avaliadores é aquela que mais necessita de construção de equipamentos (infra-estrutura) poderão melhorar a mobilidade urbana no município; enquanto que a região Leste foi eleita como necessitando de maiores investimentos para a manutenção da infraestrutura de transportes.

Analisando a distribuição dos problemas de infra-estrutura (construção) por região da cidade tem-se o seguinte resultado:

- Região Norte - os principais problemas desta região são: calçadas, passarelas, ciclovias, ponto de ônibus e ruas.

- Região central - os principais problemas são: a construção de ciclovias e terminal de ônibus.

- Região Leste - foram identificados os seguintes problemas: calçadas, ciclovias, terminal de ônibus, ponto de ônibus e ruas.

- Região Oeste - foram identificados os seguintes problemas: calçadas, ciclovias e ruas.

- Região Sul - foram identificados os seguintes problemas: calçadas e ciclovias.

Analisando a distribuição dos problemas de infra-estrutura (manutenção) por região da cidade tem-se o seguinte resultado:

- Regiões Norte, Central, Leste, Oeste e $\mathrm{Sul}$ - os principais problemas encontrados nestas regiões referem-se a manutenção: de calçadas, ponto de ônibus e ruas.

As respostas refletem a falta de uma política municipal que incentive os modos de transportes não motorizados. Embora a cidade possua muitas pessoas que utilizem estes meios para sua locomoção são encontradas calçadas com pouca acessibilidade e apenas duas ciclovias sendo que elas fazem a ligação de dois bairros, pontualmente.

$77 \%$ dos participantes afirmam que o município possui alguma política para reduzir o número de acidentes de trânsito.

municipal para reduzir NÚMERO DE ACIDENTES

DE TRÂNSITO no município?

30. Quais as regiões da cidade que possuem um maior ÍNDICE DE ACIDENTES DE TRÂNSITO?

\section{$77,7 \% \mathrm{Sim}$}

$0 \%$ Não

$22,3 \%$ Não responderam

\section{$55,5 \%$ Centro}

$0 \%$ Norte

$55,5 \% \mathrm{Sul}$

$11,1 \%$ Leste

$0 \%$ Oeste
A maioria dos avaliadores não avaliou esta questão por desconhecimento destas informações. O registro destes dados é realizado pela polícia de trânsito e os resultados são pouco divulgados pela imprensa local. 
ANEXO 13 - Questionário 1B

\begin{tabular}{|c|c|c|}
\hline QUESTÕES & RESPOSTAS & AVALIAÇÃO \\
\hline $\begin{array}{l}\text { 1. Você tem o conhecimento } \\
\text { se em sua cidade existe algum } \\
\text { Plano de Transporte? }\end{array}$ & $\begin{array}{l}5 \text { Sim } \\
1 \text { Não }\end{array}$ & $\begin{array}{l}\text { Dos } 6 \text { avaliadores que preencheram este } \\
\text { questionário, } 83 \% \text { afirmam que a cidade } \\
\text { de Bauru possui um Plano de Transporte. }\end{array}$ \\
\hline $\begin{array}{l}\text { 2. Você sabe para que "serve" } \\
\text { um Plano de Transporte? }\end{array}$ & $\begin{array}{l}\text { - Para que os usuários do transporte público } \\
\text { tenham mais facilidade de deslocamento, } \\
\text { atingindo / chegando com mais rapidez a seu } \\
\text { destino. } \\
\text { - Tenho alguma idéia. } \\
\text { - Facilitar o fluxo das pessoas entre seus destinos: } \\
\text { moradia, escola, trabalho, lazer, etc. Orienta o } \\
\text { desenvolvimento urbano em um sentido de } \\
\text { descentralização e equilíbrio do } \\
\text { desenvolvimento. Humanizar a vida urbana, } \\
\text { diminuindo tempos. Permitir maior relação com } \\
\text { a paisagem e entorno, etc. Acessibilidade. } \\
\text { - Para facilitar o deslocamento das pessoas pela } \\
\text { cidade. } \\
\text { - Para a adequação, organização do sistema } \\
\text { viário. Organização do transporte público. } \\
\text { - Para melhorar o fluxo e organizar melhor o } \\
\text { tráfego. }\end{array}$ & $\begin{array}{l}\text { Das respostas obtidas para esta questão } \\
\text { pode-se concluir que os avaliadores } \\
\text { entendem a definição do "Plano de } \\
\text { Transporte" como sinônimo de } \\
\text { planejamento do transporte público e } \\
\text { sistema viário na cidade. }\end{array}$ \\
\hline \multirow[b]{2}{*}{$\begin{array}{l}\text { 3. Você acha importante a } \\
\text { elaboração deste plano para } \\
\text { sua cidade? Por quê? }\end{array}$} & $\begin{array}{l}6 \text { Sim } \\
0 \text { Não }\end{array}$ & \multirow{2}{*}{$\begin{array}{l}100 \% \text { dos avaliadores reconhecem que a } \\
\text { elaboração de um Plano de Transporte é } \\
\text { importante para o município; pois este } \\
\text { plano pode melhorar o tráfego, o } \\
\text { deslocamento de pessoas e da produção, e } \\
\text { o transporte coletivo. }\end{array}$} \\
\hline & $\begin{array}{l}\text { - Porque, pessoalmente, tenho dificuldade para } \\
\text { utilizar o transporte público e, pelo que tenho } \\
\text { notado isso é geral. } \\
\text { - Imagino que seja importante para todas as } \\
\text { cidades, com maior ou menor complexidade, } \\
\text { dependendo das dimensões da cidade. } \\
\text { - O Plano de transporte, no que diz respeito à } \\
\text { estrutura viária principal está orientado para } \\
\text { uma centralização do destino das pessoas, o que } \\
\text { não permite à médio e longo prazos enxergar o } \\
\text { sistema em um sentido de re-orientação do } \\
\text { desenvolvimento urbano em um sentido amplo. } \\
\text { - Através dele pode-se planejar o melhor } \\
\text { deslocamento do tráfego e da produção. } \\
\text { - Pois é cada vez maior a frota de carros além da } \\
\text { demanda de usuários seja frota privada ou } \\
\text { coletiva. E hoje em dia é necessário que as } \\
\text { pessoas se locomovam com mais rapidez e } \\
\text { eficiência. } \\
\text { - Melhorar o tráfego. }\end{array}$ & \\
\hline $\begin{array}{l}\text { 4. Você sabe qual é o objetivo } \\
\text { de um Plano Diretor de } \\
\text { Mobilidade Urbana? }\end{array}$ & $\begin{array}{l}\text { - Facilitar acessos. } \\
\text { - Sim. } \\
\text { - Humanizar e organizar os fluxos das pessoas } \\
\text { entre seus percursos diários com a otimização } \\
\text { dos diversos meios de transportes: a pé, de auto, } \\
\text { transporte coletivo, acessibilidade, etc. } \\
\text { - Descentralizar e criar novas rotas para evitar o } \\
\text { colapso viário. } \\
\text { - Adequar e qualificar qualquer tipo de } \\
\text { mobilidade inserindo ainda os portadores de } \\
\text { deficiência no seu direito de ir e vir. }\end{array}$ & $\begin{array}{l}\text { Em função das respostas obtidas pode-se } \\
\text { verificar que este grupo de avaliadores } \\
\text { associa o Plano Diretor de Mobilidade } \\
\text { Urbana com a facilidade de acessos na } \\
\text { cidade, ou seja, com a questão dos fluxos } \\
\text { tanto de pessoas quanto de veículos no } \\
\text { município. }\end{array}$ \\
\hline $\begin{array}{l}\text { 5. Quais dos problemas abaixo } \\
\text { você encontra em sua } \\
\text { CIDADE? }\end{array}$ & $\begin{array}{l}5 \text { Sinalização de ruas. } \\
6 \text { Estado de conservação das calçadas. } \\
6 \text { Estado de conservação das ruas. } \\
5 \text { Ausência de ciclovias. } \\
5 \text { Construção de ruas ligando alguns bairros da } \\
\text { cidade. } \\
\text { - Necessidade de re-orientação do sistema viário } \\
\text { que permita a descentralização do } \\
\text { desenvolvimento. } \\
\text { - Humanização do sistema, com maior atenção ao } \\
\text { pedestre, deficientes físicos, ciclistas. } \\
\text { - Iluminação precária. }\end{array}$ & $\begin{array}{l}\text { Dentre os problemas apresentados aos } \\
\text { avaliadores, } 100 \% \text { das respostas } \\
\text { apontaram como problemas encontrados } \\
\text { no município de Bauru: o "estado de } \\
\text { conservação das ruas e calçadas", } \\
\text { "sinalização das ruas, ausência de } \\
\text { ciclovias e interligação de bairros". }\end{array}$ \\
\hline
\end{tabular}




\section{ANEXO 13 - Questionário 1B (continuação)}

\begin{tabular}{|c|c|c|c|c|c|}
\hline $\begin{array}{l}\text { 6. Quais dos problemas abaixo } \\
\text { você encontra em seu } \\
\text { BAIRRO? }\end{array}$ & \multicolumn{4}{|c|}{$\begin{array}{l}5 \text { Sinalização de ruas. } \\
5 \text { Estado de conservação das calçadas. } \\
6 \text { Estado de conservação das ruas. } \\
4 \text { Ausência de ciclovias. } \\
4 \text { Construção de ruas ligando alguns bairros da } \\
\text { cidade. }\end{array}$} & $\begin{array}{l}\text { Dentre os problemas elencados pelos } \\
\text { participantes } 100 \% \text { das respostas elegeram } \\
\text { o item "estado de conservação das ruas" } \\
\text { como o principal problema dos bairros, } \\
\text { bem como de todo o município de Bauru. } \\
\text { Na seqüência, } 83 \% \text { das respostas } \\
\text { indicaram a "sinalização das ruas e a } \\
\text { conservação das calçadas" e } 67 \% \text { "a } \\
\text { ausência de ciclovias e a ligação entre } \\
\text { bairros". }\end{array}$ \\
\hline \multirow{8}{*}{$\begin{array}{l}\text { 7. Qual o meio de transporte } \\
\text { que você utiliza para ir: ao } \\
\text { trabalho / à escola / ao centro } \\
\text { da cidade? }\end{array}$} & \multicolumn{4}{|c|}{ Tabela 1 - Meio de Transporte } & \multirow{8}{*}{$\begin{array}{l}\text { Segundo os resultados apresentados na } \\
\text { tabela ao lado, pode-se observar que o } \\
\text { meio de transporte mais utilizado para ir } \\
\text { ao trabalho e ao centro da cidade é o } \\
\text { automóvel. As demais opções de } \\
\text { transporte, que representam apenas } 17 \% \text {, } \\
\text { utilizam a moto para ir tanto ao trabalho } \\
\text { como à escola e ao centro da cidade. Como } \\
\text { apenas } 1 \text { participante era estudante, esta } \\
\text { coluna não foi preenchida pela maioria dos } \\
\text { entrevistados. }\end{array}$} \\
\hline & & Trabalho & Escola & Centro & \\
\hline & Carro & 4 & 1 & 4 & \\
\hline & Moto & 1 & 1 & 1 & \\
\hline & A pé & 1 & 0 & 0 & \\
\hline & Bicicleta & 0 & 0 & 0 & \\
\hline & Ônibus & 0 & 0 & 1 & \\
\hline & & & & & \\
\hline $\begin{array}{l}\text { 8. Você tem alguma } \\
\text { dificuldade em utilizar o } \\
\text { Transporte Coletivo (ônibus) } \\
\text { em sua cidade? }\end{array}$ & \multicolumn{4}{|l|}{$\begin{array}{l}4 \text { Sim } \\
2 \text { Não }\end{array}$} & $\begin{array}{l}67 \% \text { dos entrevistados têm algum } \\
\text { problema para utilizar o transporte coletivo } \\
\text { na cidade de Bauru. Sendo que alguns } \\
\text { destes motivos encontram-se destacados } \\
\text { na próxima questão. }\end{array}$ \\
\hline $\begin{array}{l}\text { 9. Assinale com um } \mathbf{X} \text { o(s) } \\
\text { problema(s) relacionados à } \\
\text { utilização do Transporte } \\
\text { Coletivo (ônibus) que você } \\
\text { encontra na cidade? }\end{array}$ & \multicolumn{4}{|c|}{$\begin{array}{l}1 \text { Entrar no ônibus } \\
0 \text { Descer do ônibus } \\
2 \text { Degrau muito alto } \\
2 \text { Altura da calçada em relação ao degrau do } \\
\text { ônibus } \\
4 \text { Falta de cobertura nos pontos de ônibus } \\
4 \text { Falta de informação sobre o trajeto dos ônibus } \\
\text { nos pontos de ônibus } \\
\text { - Outros: } \\
1 \text { Falta de placa indicando o percurso na lateral } \\
\text { do ônibus. }\end{array}$} & $\begin{array}{l}\text { Das opções apresentadas para seleção, } \\
67 \% \text { dos avaliadores elegeram a "falta de } \\
\text { cobertura e a falta de informação sobre o } \\
\text { trajeto dos ônibus nos pontos de ônibus" } \\
\text { como um dos problemas que dificultam a } \\
\text { utilização do transporte coletivo na cidade. } \\
\text { Na seqüência ( } 33 \% \text { das respostas) indicam } \\
\text { que a "altura do degrau da calçada e do } \\
\text { onibus" dificultam uma maior utilização } \\
\text { deste sistema de transporte. }\end{array}$ \\
\hline $\begin{array}{l}\text { 10. Em seu BAIRRO, você } \\
\text { tem algum problema com o } \\
\text { excesso de barulho provocado } \\
\text { por veículos (carro, moto, } \\
\text { ônibus, caminhão)? }\end{array}$ & \multicolumn{4}{|l|}{$\begin{array}{l}1 \text { Sim } \\
4 \text { Não }\end{array}$} & $\begin{array}{l}\text { A maioria dos entrevistados ( } 67 \% \text { das } \\
\text { respostas) não tem problema com o } \\
\text { excesso de barulho provocado por veículos } \\
\text { (carro, moto, ônibus, caminhão) em seus } \\
\text { respectivos bairros. }\end{array}$ \\
\hline $\begin{array}{l}\text { 11. Em seu BAIRRO há } \\
\text { muitos veículos que lançam } \\
\text { fumaça no ar? (presença de } \\
\text { veículos lançando produtos } \\
\text { tóxicos) }\end{array}$ & \multicolumn{4}{|l|}{$\begin{array}{l}3 \text { Sim } \\
2 \text { Não }\end{array}$} & $\begin{array}{l}\text { Em } 50 \% \text { das respostas os avaliadores } \\
\text { percebem que em seu bairro há problemas } \\
\text { com a poluição do ar provocada pela } \\
\text { emissão de gases originadas do sistema de } \\
\text { transporte. }\end{array}$ \\
\hline $\begin{array}{l}\text { 12. Há ligação de ruas - direta, } \\
\text { entre seu bairro e os bairros } \\
\text { vizinhos? }\end{array}$ & \multicolumn{4}{|l|}{$\begin{array}{l}4 \text { Sim } \\
2 \text { Não }\end{array}$} & $\begin{array}{l}\text { Para a maioria dos entrevistados o bairro } \\
\text { onde reside não tem problema de } \\
\text { interligação viária com os demais bairros } \\
\text { do entorno. }\end{array}$ \\
\hline $\begin{array}{l}\text { 13. Você já perdeu a } \\
\text { concentração ao desenvolver } \\
\text { qualquer atividade em sua casa } \\
\text { ou seu trabalho em função do } \\
\text { excesso de barulho provocado } \\
\text { por qualquer meio de } \\
\text { transporte (ônibus, caminhão, } \\
\text { carro, moto, etc.)? }\end{array}$ & \multicolumn{4}{|l|}{$\begin{array}{l}2 \text { Sim } \\
4 \text { Não }\end{array}$} & $\begin{array}{l}\text { Na maioria dos bairros dos avaliadores, } \\
\text { talvez por serem bairros residenciais, não } \\
\text { foram detectados problemas significativos } \\
\text { de ruído provocados pelos meios de } \\
\text { transportes. }\end{array}$ \\
\hline
\end{tabular}


ANEXO 14 - Questionário 2

\begin{tabular}{|c|c|c|}
\hline QUESTÕES & RESPOSTAS & AVALIAÇÃ̃O \\
\hline $\begin{array}{l}\text { 1. O que você entende por } \\
\text { Mobilidade Urbana? }\end{array}$ & $\begin{array}{l}\text { - Mobilidade urbana é o meio pelo qual } \\
\text { podemos estudar e planejar o transporte e a } \\
\text { locomoção de bens e pessoas visando a } \\
\text { otimização dos recursos e preservação dos } \\
\text { mesmos. } \\
\text { - É a possibilidade de todas as pessoas se } \\
\text { locomoverem dentro das cidades, sem } \\
\text { obstáculos as quais estas não possam } \\
\text { transpor. Ainda, acessarem os meios de } \\
\text { transporte e as edificações, sem que } \\
\text { encontrem obstáculos intransponíveis. } \\
\text { - É a capacidade (ou possibilidade) das } \\
\text { pessoas e bens circularem pela cidade. } \\
\text { Entendemos que esse termo deva ser } \\
\text { ampliado para contemplar a zona rural, onde } \\
\text { moram pessoas que tem necessidades de } \\
\text { educação, saúde, consumo em geral, além } \\
\text { das cargas (produção agrícola, pecuária, } \\
\text { etc.). A mobilidade depende da estrutura } \\
\text { fisica (vias, calçadas) mas também da } \\
\text { condição física e financeira das pessoas, } \\
\text { além do sistema de transporte disponível. } \\
\text { - Meio pelo qual as pessoas e bens se } \\
\text { locomovem ns cidades. } \\
\text { - A mobilidade urbana é o que rege a vida dos } \\
\text { cidadãos, no que se refere ao transporte, } \\
\text { circulação de bens, no cotidiano da cidade. } \\
\text { - É o meio de locomoção de pessoas e bens, } \\
\text { incluindo transporte e acessibilidade em } \\
\text { geral, com preocupação ambiental. } \\
\text { - Ainda não tenho uma definição elaborada, } \\
\text { mas entendo que tem relação com as } \\
\text { condições que a cidade oferece a seus } \\
\text { habitantes, visando garantir que os mesmos } \\
\text { satisfaçam suas necessidades de } \\
\text { deslocamento, sejam eles com finalidade de } \\
\text { trabalho, de lazer, de cultura, educação, etc., } \\
\text { preferencialmente consumindo o mínimo de } \\
\text { recursos, com o mínimo de agressão ao } \\
\text { ambiente. }\end{array}$ & $\begin{array}{l}\text { Há um consenso nas respostas de todos os } \\
\text { participantes em associar a definição de } \\
\text { Mobilidade Urbana com a palavra } \\
\text { "deslocamento", tanto de bens quanto de } \\
\text { pessoas na cidade. }\end{array}$ \\
\hline
\end{tabular}


ANEXO 14 - Questionário 2 (continuação)

\begin{tabular}{|c|c|c|}
\hline $\begin{array}{l}\text { 2. Cite alguns problemas } \\
\text { relacionados à Mobilidade de } \\
\text { sua cidade? }\end{array}$ & $\begin{array}{l}\text { - Falta de transporte público. Falta de } \\
\text { manutenção das vias de rolamento. Áreas } \\
\text { com vazios urbanos. } \\
\text { - Falta de guias rebaixadas para cadeirantes. } \\
\text { Calçadas com degraus no sentido } \\
\text { longitudinal. Mobiliário urbano próximo ao } \\
\text { muro das casas. Falta de rampas em } \\
\text { edifícios sem elevadores. Falta de ciclovias. } \\
\text { - Barreiras físicas impostas pelos rios, } \\
\text { ferrovias e rodovias. Cidade muito dispersa, } \\
\text { com muitos vazios urbanos. Deficiência das } \\
\text { estradas rurais, nas calçadas e falta ciclovias. } \\
\text { Sistema de transporte coletivo com } \\
\text { deficiências de horário e rota. Renda de } \\
\text { grande parte da população. } \\
\text { Falta de interligação entre bairros (várias } \\
\text { barreiras físicas), córregos, rodovias e } \\
\text { ferrovia. Bairros dispersos - cidade não } \\
\text { compacta. Falta de opções como ciclovia. } \\
\text { Calçadas de modo geral sem boa } \\
\text { acessibilidade. Transporte coletivo - alto } \\
\text { custo. } \\
\text { - Transporte coletivo deficiente / tarifa. } \\
\text { Acessibilidade limitada. Barreiras naturais / } \\
\text { baixa capacidade de investimento do poder } \\
\text { público. Expansão urbana / distância. } \\
\text { Acidentes. Distância do trabalho e lazer. } \\
\text { - Transporte coletivo deficiente. } \\
\text { Acessibilidade limitante para pessoas com } \\
\text { necessidades especiais. Falta de opções / } \\
\text { caminhos, causando congestionamento em } \\
\text { certos lugares. Zoneamento. Poluição. } \\
\text { - Carência de linhas de ônibus ligando bairros } \\
\text { sem passar pelo centro. Inadequação / } \\
\text { insuficiência de sinalização. Falta de } \\
\text { condições para o trânsito de meios de } \\
\text { transporte não motorizados (bicicletas, } \\
\text { charretes, etc.). }\end{array}$ & $\begin{array}{l}\text { Dentre os problemas elencados pelos } \\
\text { participantes inserem-se a questão da infra- } \\
\text { estrutura (sistema viário, calçadas - } \\
\text { acessibilidade); deficiências no transporte } \\
\text { coletivo; expansão urbana, entre outros. } \\
\text { Grande parte destes problemas foram também } \\
\text { listados pelos participantes como sendo mais } \\
\text { importantes ou mais urgentes nos Módulos I e } \\
\text { III do Sistema PLANUTS, conforme os itens } \\
\text { a seguir: } \\
\text { - Temas mais Importantes (Módulo I) - } \\
\text { Crescimento Urbano, Sistema Viário, } \\
\text { Acessibilidade Urbana, Impacto Ambiental, } \\
\text { Mobilidade Urbana e Estratégias } \\
\text { Economicas. } \\
\text { - Temas mais Urgentes (Módulo III) - } \\
\text { Crescimento Urbano, População Urbana, } \\
\text { Acessibilidade Urbana, Mobilidade Urbana } \\
\text { e Impacto Ambiental. }\end{array}$ \\
\hline $\begin{array}{l}\text { 3. Existe alguma medida para } \\
\text { promover (incentivar) a } \\
\text { melhoria da mobilidade } \\
\text { urbana no município? }\end{array}$ & $\begin{array}{l}6 \mathrm{Sim} \\
1 \mathrm{Não}\end{array}$ & $\begin{array}{l}86 \% \text { dos avaliadores acreditam que o } \\
\text { município de Bauru possui alguma medida } \\
\text { para melhorar a Mobilidade Urbana do } \\
\text { Município. }\end{array}$ \\
\hline
\end{tabular}




\section{ANEXO 14 - Questionário 2 (continuação)}

\begin{tabular}{|c|c|c|}
\hline $\begin{array}{l}\text { 4. Cite as medidas que } \\
\text { existem em sua cidade que } \\
\text { contribuem para a melhoria da } \\
\text { Mobilidade Urbana. }\end{array}$ & $\begin{array}{l}\text { - Gerenciamento e monitoração do transporte } \\
\text { coletivo. Agendamento de vans para } \\
\text { transporte de deficientes / cadeirantes. } \\
\text { Estacionamento rotativo na área central. } \\
\text { - Nas diretrizes dos novos loteamentos, existe } \\
\text { uma exigência de implantação de rampas } \\
\text { nas guias para acesso de deficientes, bem } \\
\text { como, onde existe possibilidade, } \\
\text { implantação de ciclovias. } \\
\text { - Proposta de não expansão do perímetro } \\
\text { urbano, contida no Plano Diretor. IPTU } \\
\text { progressivo e parcelamento compulsório } \\
\text { para glebas ociosas, proposta do Plano } \\
\text { Diretor. Implantação de novas vias, } \\
\text { travessias e transposições de barreiras } \\
\text { físicas. Implantação de rampas de acesso de } \\
\text { deficientes nas esquinas, conforme } \\
\text { prioridade apresentada pelo Conselho de } \\
\text { Portadores de Necessidades Especiais, e } \\
\text { exigência de implantação pelo loteador nos } \\
\text { novos empreendimentos. } \\
\text { - Previsão no Plano Diretor Participativo do } \\
\text { Plano de Mobilidade sob uma nova ótica a } \\
\text { da sustentabilidade econômica, social e } \\
\text { ambiental. } \\
\text { - O curso que fizemos com você é um início. } \\
\text { O Plano Diretor Participativo. Não expansão } \\
\text { do perímetro urbano. } \\
\text { - Existem previsões dentro do novo plano } \\
\text { diretor. Curso para técnicos de Prefeitura. } \\
\text { - Desconheço as medidas / políticas públicas } \\
\text { voltadas à mobilidade urbana. }\end{array}$ & $\begin{array}{l}\text { No que se refere às medidas existentes no } \\
\text { município de Bauru para a melhoria da } \\
\text { Mobilidade Urbana, os participantes } \\
\text { destacaram: o transporte de portadores de } \\
\text { necessidades especiais; as diretrizes para a } \\
\text { execução de rampas nas calçadas; a revisão da } \\
\text { expansão urbana com ocupação dos vazios } \\
\text { urbanos existentes no município; e a } \\
\text { construção de sistema viário interligando } \\
\text { bairros ou determinadas regiões da cidade. }\end{array}$ \\
\hline $\begin{array}{l}\text { 5. Qual (quais) o(s) setor(es) } \\
\text { que devem estar envolvido(s) } \\
\text { no Plano de Mobilidade? Qual } \\
\text { (quais)? }\end{array}$ & $\begin{array}{l}7 \text { Trânsito } \\
7 \text { Transporte } \\
7 \text { Planejamento Urbano } \\
\text { - } 2 \text { Meio Ambiente } \\
\text { - } 1 \text { Secretaria de Desenvolvimento } \\
\text { Econômico } \\
\text { - } 1 \text { Secretaria de Agricultura } \\
\text { - } 2 \text { Secretaria de Obras Públicas } \\
\text { Demais setores técnicos. }\end{array}$ & $\begin{array}{l}\text { Há um consenso nas respostas de que o setor } \\
\text { responsável pelo Trânsito, Transporte e } \\
\text { Planejamento Urbano devem efetivamente } \\
\text { fazer parte das discussões, de forma integrada, } \\
\text { do Plano de Mobilidade Municipal. Outros } \\
\text { setores também foram mencionados como } \\
\text { sendo importantes nesta discussão. }\end{array}$ \\
\hline $\begin{array}{l}\text { 6. Qual (quais) a(s) } \\
\text { secretaria(s) que devem estar } \\
\text { envolvido(s) no Plano de } \\
\text { Mobilidade? Qual? }\end{array}$ & $\begin{array}{l}7 \text { SEPLAN } \\
7 \text { Meio Ambiente } \\
7 \text { Obras }^{\circ} \\
6 \text { Dept }^{\circ} \text { Água e Esgoto } \\
\text { - } 4 \text { EMDURB } \text { - } 2 \text { Educação } \\
\text { - } 3 \text { Secretaria de Desenvolvimento Urbano } \\
\text { - } 1 \text { Secretaria de Agricultura } \\
\text { Participação de todas as secretarias. }\end{array}$ & $\begin{array}{l}\text { Há um consenso nas respostas na definição } \\
\text { das secretarias envolvidas na discussão do } \\
\text { Plano Diretor de Transporte e Mobilidade } \\
\text { (SEPLAN, Meio Ambiente, Obras). Também } \\
\text { foram mencionadas a participação de outras } \\
\text { secretarias ou órgãos municipais neste } \\
\text { processo, tais como: EMDURB, Secretaria de } \\
\text { Desenvolvimento Urbano, Educação e } \\
\text { Agricultura. }\end{array}$ \\
\hline
\end{tabular}




\section{ANEXO 14 - Questionário 2 (continuação)}

\begin{tabular}{|c|c|c|}
\hline $\begin{array}{l}\text { 7. Quais os principais TEMAS } \\
\text { que devem fazer parte do } \\
\text { Plano de Mobilidade } \\
\text { municipal? }\end{array}$ & $\begin{array}{l}\text { - Incentivo à transportes interativos. } \\
\text { Priorização do pedestre na urbanização da } \\
\text { cidade. Criar áreas de lazer / recreação } \\
\text { próximas as áreas de concentrações } \\
\text { populacionais. } \\
\text { - Uma cidade para todos. Sistema viário e } \\
\text { meio ambiente. Transporte ecologicamente } \\
\text { correto. } \\
\text { - Limites Urbano. Densidade. Zoneamento } \\
\text { (disposição dos usos no território). Sistema } \\
\text { viário. Cicloviário. Transporte de } \\
\text { passageiros e cargas (urbanos e rurais). } \\
\text { - Alternativas não motorizadas (melhoria das } \\
\text { calçadas, acessibilidade, ciclovias). } \\
\text { Transporte coletivo. Planejamento urbano, } \\
\text { limitação da malha urbana, aplicação efetiva } \\
\text { dos instrumentos do estatuto (ocupação dos } \\
\text { vazios urbanos). Transporte de carga. Novo } \\
\text { modelo de zoneamento. } \\
\text { - Transporte. Acessibilidade. Satisfação do } \\
\text { usuário. } \\
\text { - Transporte. Acessibilidade e Meio ambiente. }\end{array}$ & $\begin{array}{l}\text { De acordo com as respostas obtidas pode-se } \\
\text { perceber a inserção de novos temas, como por } \\
\text { exemplo: prioridade ao pedestre, sistema } \\
\text { viário, meio ambiente, limite urbanos, } \\
\text { densidades, zoneamento, acessibilidade, } \\
\text { transporte coletivo, transporte de carga, } \\
\text { modos não motorizados. } \\
\text { Os temas descritos neste questionário fazem } \\
\text { parte das } 5 \text { categorias propostas para } \\
\text { avaliação no sistema PLANUTS: Meio } \\
\text { Ambiente e Transportes; Gestão dos } \\
\text { Transportes; Infra-estrutura dos Transportes; } \\
\text { Planejamento dos Transportes e Aspectos } \\
\text { Socioeconômicos dos Transportes. }\end{array}$ \\
\hline $\begin{array}{l}\text { 8. Quais os principais pontos a } \\
\text { serem discutidos no Plano de } \\
\text { Mobilidade com relação a } \\
\text { política de } \\
\text { ESTACIONAMENTOS para } \\
\text { o município? }\end{array}$ & $\begin{array}{l}\text { - Estudo sobre criação de estacionamento } \\
\text { rotativo. } \\
\text { - Acredito que a cidade deva oferecer } \\
\text { melhores condições para viagens a pé, de } \\
\text { bicicleta ou transporte público, incentivando } \\
\text { o cidadão a deixar seu veículo em casa. } \\
\text { Ainda, continuidade e ampliação do } \\
\text { estacionamento rotativo. } \\
\text { - Exigência de estacionamento para pólos } \\
\text { geradores de tráfego, porém cuidado com } \\
\text { incentivo ao estacionamento particular em } \\
\text { detrimento da segurança dos pedestres nas } \\
\text { calçadas. } \\
\text { - Não incentivo de estacionamentos em } \\
\text { determinadas regiões da cidade. } \\
\text { - Rotatividade. Zona azul "municipal". } \\
\text { Expansão - zona azul. } \\
\text { - Rotatividade na zona azul. Localização. } \\
\text { Zoneamento. } \\
\text { - Dimensionar / moderar as necessidades de } \\
\text { estacionamento. Planejar os novos } \\
\text { empreendimentos, potenciais geradores de } \\
\text { necessidades de estacionamentos, para evitar } \\
\text { sua concentração. }\end{array}$ & $\begin{array}{l}\text { Os principais pontos elencados pelos } \\
\text { participantes sobre a política de } \\
\text { estacionamentos foram: incentivo à utilização } \\
\text { de meios de transporte não motorizado } \\
\text { (bicicleta e a pé) ou à utilização de transporte } \\
\text { coletivo, o que diminuiria a necessidade da } \\
\text { ampliação de novas vagas de estacionamentos } \\
\text { no município; a implantação de } \\
\text { estacionamentos rotativos para algumas } \\
\text { regiões da cidade; e o planejamento da } \\
\text { implantação de vagas em novos } \\
\text { empreendimentos considerados pólos } \\
\text { geradores de tráfego. }\end{array}$ \\
\hline
\end{tabular}


ANEXO 14 - Questionário 2 (continuação)

\begin{tabular}{|c|c|c|}
\hline $\begin{array}{l}\text { 9. Quais os principais pontos a } \\
\text { serem discutidos no Plano de } \\
\text { Mobilidade com relação a } \\
\text { política de TRANSPORTE } \\
\text { PÚBLICO para o município? }\end{array}$ & $\begin{array}{l}\text { - Monitoramento - número de viagens. } \\
\text { Monitoramento / gerenciamento - vias / } \\
\text { distâncias percorridas. Redução de custo / } \\
\text { tarifa. } \\
\text { - Melhoria dos abrigos e pontos de ônibus. } \\
\text { Implantação de terminais em pontos } \\
\text { estratégicos e linha tronco alimentada. } \\
\text { - Localização dos equipamentos de interesse } \\
\text { da população. Locais onde há interesse no } \\
\text { adensamento. Vias onde deverá ser } \\
\text { privilegiado o transporte coletivo para } \\
\text { priorização da pavimentação, iluminação, } \\
\text { incentivo ao comércio. } \\
\text { - Adensamento da cidade em áreas com infra- } \\
\text { estrutura. Criação ou provisão de futuros } \\
\text { corredores para o transporte público } \\
\text { especialmente nos projetos viários mesmo } \\
\text { que a longo prazo. } \\
\text { - Reversão itinerário de ônibus. Plano para } \\
\text { transporte de carga. } \\
\text { - Acessibilidade para portadores de } \\
\text { necessidades especiais. Itinerários. Tarifas. } \\
\text { - Levantamento das condições atuais, no } \\
\text { tocante à demanda (necessidade da } \\
\text { população) e oferta. Interação mais eficiente } \\
\text { entre planejamento urbano/rural e } \\
\text { planejamento de transportes. }\end{array}$ & $\begin{array}{l}\text { Com relação ao tema Transporte Público } \\
\text { pode-se perceber nas respostas que os } \\
\text { participantes incluíram outras abordagens, tais } \\
\text { como: viagens, percurso, redução de custos e } \\
\text { tarifas, melhoria dos pontos de ônibus, } \\
\text { corredores para transporte público, itinerários, } \\
\text { demanda, oferta e acessibilidade para } \\
\text { portadores de necessidades especiais. }\end{array}$ \\
\hline $\begin{array}{l}\text { 10. Quais os principais pontos } \\
\text { a serem discutidos no Plano de } \\
\text { Mobilidade com relação a } \\
\text { política de CIRCULAÇÃO } \\
\text { para o município? }\end{array}$ & $\begin{array}{l}\text { - Priorizar a circulação de pedestres. Melhorar } \\
\text { a conservação / manutenção das vias de } \\
\text { rolamento e calçadas. } \\
\text { - Melhoria dos passeios públicos e } \\
\text { implantação de um plano cicloviário. } \\
\text { - Limites da zona urbana. Identificação de } \\
\text { barreiras físicas. Identificação das zonas de } \\
\text { interesse (origem - destino). Estrutura viária } \\
\text { existente. Rede de transporte existente. } \\
\text { - Priorizar pedestre. Priorizar transporte } \\
\text { coletivo em detrimento do individual. } \\
\text { Reduzir as distâncias de circulação por } \\
\text { disciplinamento do uso e ocupação do solo. } \\
\text { - Barreiras naturais, arquitetônicas. } \\
\text { Capacitação dos agentes públicos - } \\
\text { definição de papéis. Calçadas, ciclovias. } \\
\text { - Redistribuição da rede viária. Calçadas, } \\
\text { postes, etc. (obstáculos) - pedestres } \\
\text { barreiras. Criação de ciclovias. } \\
\text { - Não me lembro o que é política de } \\
\text { circulação. }\end{array}$ & $\begin{array}{l}\text { Embora a atual política municipal privilegie o } \\
\text { transporte individual motorizado; os } \\
\text { entrevistados têm a consciência da } \\
\text { importância do município investir em políticas } \\
\text { de circulação mais sustentáveis através do } \\
\text { incentivo à utilização de modos não- } \\
\text { motorizados como o modo a pé e bicicleta, } \\
\text { mas para isto é necessário uma infra-estrutura } \\
\text { de apoio. } \\
\text { Com relação aos modos motorizados, as } \\
\text { respostas mostram a necessidade de incentivar } \\
\text { a utilização do transporte coletivo e } \\
\text { principalmente a adoção de uma nova política } \\
\text { de adensamento urbano e gerenciamento do } \\
\text { uso do solo municipal. }\end{array}$ \\
\hline $\begin{array}{l}\text { 11. O município tem algum } \\
\text { plano para diminuir a } \\
\text { POLUIÇÃO causada pelos } \\
\text { meios de transportes na cidade } \\
\text { (por ex. o controle da } \\
\text { qualidade do ar)? }\end{array}$ & $\begin{array}{l}3 \text { Sim } \\
3 \text { Não } \\
1 \text { Não respondeu } \\
\text { A CETESB instalou equipamento para } \\
\text { monitorar a qualidade do ar. Ainda é um } \\
\text { primeiro passo para se estudar ações } \\
\text { posteriores. } \\
\text { A CETESB em Bauru acaba de ser } \\
\text { contemplada com a instalação de equipamento } \\
\text { de controle. }\end{array}$ & $\begin{array}{l}43 \% \text { dos participantes têm o conhecimento de } \\
\text { alguma medida municipal para diminuir a } \\
\text { poluição causada pelos meios de transportes, } \\
\text { enquanto que outros } 43 \% \text { desconhecem estas } \\
\text { medidas. } \\
14 \% \text { dos participantes não responderam a esta } \\
\text { questão, talvez por desconhecimento destas } \\
\text { medidas. }\end{array}$ \\
\hline
\end{tabular}


ANEXO 14 - Questionário 2 (continuação)

\begin{tabular}{|c|c|c|}
\hline $\begin{array}{l}\text { 12. Cite algumas medidas que } \\
\text { podem ser adotadas para } \\
\text { reduzir os NÍVEIS DE } \\
\text { POLUIÇÃO causados pelos } \\
\text { meios de transportes na } \\
\text { cidade. }\end{array}$ & $\begin{array}{l}\text { - Incentivar o uso do transporte coletivo. } \\
\text { Incentivar o uso de meios de transporte que } \\
\text { utilizam energia limpa. } \\
\text { - Implantação de ônibus movido a energia } \\
\text { elétrica e inclusão de biodisel. } \\
\text { - Incentivo ao transporte coletivo (com } \\
\text { melhoria do mesmo); uso de bicicleta; } \\
\text { melhoria das calçadas. } \\
\text { - Incentivar o uso do transporte coletivo a } \\
\text { partir de sua melhoria. Investir em meios } \\
\text { alternativos, ciclovia, segurança e qualidade } \\
\text { para os pedestres. Evitar modelos de fluidez } \\
\text { do transporte individual. } \\
\text { - Investimento em frotas. Construção de } \\
\text { ciclovias. Incentivo a carona amiga. } \\
\text { - Incentivar o uso de meios de transporte não } \\
\text { poluente. Incentivar o transporte em } \\
\text { veículos públicos. } \\
\text { - Renovação e manutenção da frota de ônibus } \\
\text { urbanos. Instituir medidas de controle de } \\
\text { qualidade do ar em pontos estratégicos da } \\
\text { cidade, visando a elaboração de diagnóstico } \\
\text { dos principais poluidores, para definir a } \\
\text { política de redução dos níveis de poluição. }\end{array}$ & $\begin{array}{l}\text { Dentre as medidas citadas para reduzir o nível } \\
\text { de poluição destacam-se: o incentivo à } \\
\text { utilização de meios de transporte que utilizem } \\
\text { energia "mais limpa"; utilização de transporte } \\
\text { coletivo; e incentivo à utilização de meios de } \\
\text { transporte não motorizado (bicicleta e andar a } \\
\text { pé). }\end{array}$ \\
\hline $\begin{array}{l}\text { 13. O município tem algum } \\
\text { plano para diminuir o RUÍDO } \\
\text { causado pelos meios de } \\
\text { transportes na cidade? }\end{array}$ & $\begin{array}{l}2 \text { Sim } \\
5 \text { Não }\end{array}$ & $\begin{array}{l}29 \% \text { das respostas indicam que o município } \\
\text { possui medidas para a redução do ruído } \\
\text { provocado pelos meios de transportes, } \\
\text { enquanto que } 71 \% \text { desconhecem estas } \\
\text { medidas. }\end{array}$ \\
\hline $\begin{array}{l}\text { 14. Quais das medidas abaixo } \\
\text { deveriam ser adotadas para } \\
\text { reduzir os NÍVEIS DE } \\
\text { RUÍDO causados pelos meios } \\
\text { de transportes na cidade? }\end{array}$ & $\begin{array}{l}7 \text { Prevenção do tráfego } \\
6 \text { Tráfego redirecionado. } \\
3 \text { Reclassificação / classificação ou } \\
\text { desclassificação para uma melhor } \\
\text { redistribuição da rede viária. } \\
6 \text { Apoio aos meios de transportes duradouros. } \\
3 \text { Sistema de gestão do estacionamento. } \\
0 \text { Criação de áreas com velocidade limitada a } \\
30 \mathrm{~km} / \mathrm{h} \text { para redução de tráfego. } \\
\text { 0 Revestimentos rodoviários contra ruído. } \\
\text { 0 Túneis, passagens subterrâneas. } \\
1 \text { Muros e barreiras acústicas. } \\
\text { Outros. } 1 \text { educação. }\end{array}$ & $\begin{array}{l}\text { 100\% dos participantes escolheram como a } \\
\text { principal medida para solucionar os problemas } \\
\text { de ruído causados pelos meios de transportes a } \\
\text { "prevenção do tráfego"; na seqüência foram } \\
\text { selecionados "o apoio aos meios de } \\
\text { transportes duradouros" e "o tráfego } \\
\text { redirecionado" ( } 86 \% \text { dos participantes); e } \\
43 \% \text { das respostas elegeram "Reclassificação / } \\
\text { classificação ou desclassificação para uma } \\
\text { melhor redistribuição da rede viária" e } \\
\text { "Sistema de gestão do estacionamento". }\end{array}$ \\
\hline $\begin{array}{l}\text { 15. O município tem algum } \\
\text { plano para reduzir alguns } \\
\text { pontos de } \\
\text { CONGESTIONAMENTOS } \\
\text { na cidade? }\end{array}$ & $\begin{array}{l}3 \text { Sim } \\
4 \text { Não }\end{array}$ & $\begin{array}{l}57 \% \text { dos participantes desconhecem as } \\
\text { medidas para a redução dos pontos de } \\
\text { congestionamento que existem em } \\
\text { determinados lugares da cidade. Por outro } \\
\text { lado, } 43 \% \text { deles conhecem estas medidas, } \\
\text { talvez por trabalharem em setores municipais } \\
\text { que planejam ações para minimizar este } \\
\text { problema. }\end{array}$ \\
\hline $\begin{array}{l}\text { 16. Cite algumas medidas que } \\
\text { podem ser adotadas para } \\
\text { reduzir os } \\
\text { CONGESTIONAMENTOS na } \\
\text { cidade. }\end{array}$ & $\begin{array}{l}\text { - Definição de área com proibição de } \\
\text { estacionamento em laterais das vias. } \\
\text { Sinalização semafórica interligada no } \\
\text { centro. Ruas com sentido de mão única. } \\
\text { - Melhoria dos controladores semafóricos. } \\
\text { Implantação de semáforos com } \\
\text { controladores de tráfego em tempo real. } \\
\text { - Obras viárias. Semáforos, mudanças de mão } \\
\text { de direção. } \\
\text { - Incentivar o transporte coletivo priorizando } \\
\text { sua circulação. Não incentivar } \\
\text { estacionamentos em locais críticos. } \\
\text { Implantar sistemas de controle de circulação } \\
\text { de veículos. } \\
\text { - Redistribuição da rede viária. Incentivo ao } \\
\text { uso de transporte coletivo (nova frota). } \\
\text { - Redistribuição da rede viária. Incentivar ao } \\
\text { uso do transporte coletivo com } \\
\text { melhoramento da frota. } \\
\text { - Planejamento dos transportes vinculado ao } \\
\text { planejamento urbano e rural. }\end{array}$ & $\begin{array}{l}\text { Embora na questão anterior a maioria tenha } \\
\text { respondido que não conhecia as medidas } \\
\text { adotadas no município de Bauru, todos os } \\
\text { participantes têm o conhecimento de algumas } \\
\text { soluções que podem ser adotadas para } \\
\text { minimizar este problema, como por exemplo: } \\
\text { planejamento viário (rever o estacionamento } \\
\text { nas vias, coordenação semafórica, etc.), } \\
\text { incentivo ao transporte não motorizado, e } \\
\text { incentivo ao transporte público. }\end{array}$ \\
\hline
\end{tabular}




\section{ANEXO 14 - Questionário 2 (continuação)}

\begin{tabular}{|c|c|c|}
\hline $\begin{array}{l}\text { 17. O município tem algum } \\
\text { plano de ACESSIBILIDADE? }\end{array}$ & $\begin{array}{l}\text { 1 Sim } \\
6 \text { Não } \\
\text { Tem ações fragmentadas, muitas legislações, } \\
\text { mas não há gestão nesse sentido. }\end{array}$ & $\begin{array}{l}86 \% \text { dos participantes afirmam que o } \\
\text { município não possui um Plano de } \\
\text { Acessibilidade. }\end{array}$ \\
\hline $\begin{array}{l}\text { 18. Quais os principais pontos } \\
\text { a serem discutidos no Plano de } \\
\text { Mobilidade com relação a } \\
\text { política de ACESSIBILIDAE } \\
\text { do município? }\end{array}$ & $\begin{array}{l}\text { - Melhoria das calçadas com rampas de } \\
\text { acesso para deficientes. Transporte de vans } \\
\text { para deficientes e cadeirantes. } \\
\text { - Calçadas. Melhor distribuição dos } \\
\text { equipamentos públicos, comércio e serviços. } \\
\text { - Trabalho educacional continuado de forma a } \\
\text { modificar as posturas da sociedade de forma } \\
\text { geral. Priorizar locais de modificações } \\
\text { efetivando ações. } \\
\text { - Revisão de tarifas de passagens. Barreiras } \\
\text { físicas. } \\
\text { - Atenção às pessoas com necessidades } \\
\text { especiais. Melhorar a rede viária. Pólos de } \\
\text { emprego próximos às moradias. } \\
\text { - Diagnóstico da situação real do município, } \\
\text { em termos de mapeamento dos portadores } \\
\text { de necessidades especiais, quais são estas } \\
\text { necessidades e suas necessidades de } \\
\text { deslocamentos (de onde para onde). }\end{array}$ & $\begin{array}{l}\text { Dentre os pontos para serem discutidos num } \\
\text { Plano de Acessibilidade para Bauru, os } \\
\text { participantes destacaram a melhoria da infra- } \\
\text { estrutura (calçadas, rampas) e a distribuição } \\
\text { (concentração) de comércio e serviços em } \\
\text { determinadas regiões da cidade como pontos } \\
\text { principais para a discussão da acessibilidade } \\
\text { no município. }\end{array}$ \\
\hline $\begin{array}{l}\text { 19. Qual a secretaria, setor ou } \\
\text { órgão municipal que deveria } \\
\text { trabalhar com os temas e } \\
\text { políticas de acessibilidade? }\end{array}$ & $\begin{array}{l}6 \text { Trânsito (EMDURB) } \\
6 \text { Transportes (EMDURB) } \\
6 \text { Planejamento Urbano (SEPLAN) } \\
3 \text { Secretaria de Obras } \\
2 \text { Secretaria do Bem Estar Social } \\
1 \text { Agricultura } \\
1 \text { Desenvolvimento econômico } \\
1 \text { Educação } \\
1 \text { Secretaria de saúde. } \\
\end{array}$ & $\begin{array}{l}\text { Para } 86 \% \text { dos que responderam a esta questão, } \\
\text { tanto a EMDURB quanto a SEPLAN devem } \\
\text { trabalhar em conjunto no desenvolvimento de } \\
\text { políticas municipais de acessibilidade. Outras } \\
\text { secretarias ou órgão municipais também } \\
\text { foram mencionados nas respostas dos } \\
\text { participantes, mas numa baixa percentagem. }\end{array}$ \\
\hline $\begin{array}{l}\text { 20. Na sua opinião é } \\
\text { necessário a adaptação dos } \\
\text { pontos de ônibus para torná- } \\
\text { los mais acessíveis para todos } \\
\text { os cidadãos? }\end{array}$ & $\begin{array}{l}7 \text { Sim } \\
0 \text { Não }\end{array}$ & $\begin{array}{l}100 \% \text { dos participantes apontam a } \\
\text { necessidade do município adaptar os pontos } \\
\text { de ônibus para torná-los mais acessíveis à toda } \\
\text { população bauruense. }\end{array}$ \\
\hline
\end{tabular}

